DFPARTMENT OF TIE INTERIOR

UNITEL STATES GEOLOGICAL SURVEY

GEORGE OTIS SMITH, IIRECTOP

Professional Paper 60

\title{
THE INTERPRETATION OF TOPOGRAPHIC MAPS
}

BY

\author{
ROLLIN D. SALISBURY
}

AND

WALLACE W. ATWOOD

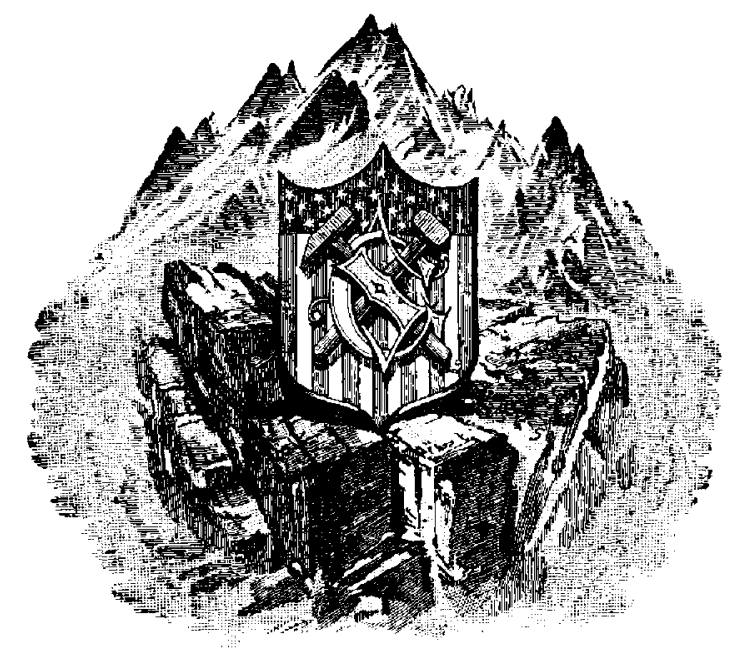

WASHINGTON

GOVERNMENT PRINTING OFFICE 


\section{CONTENTS.}

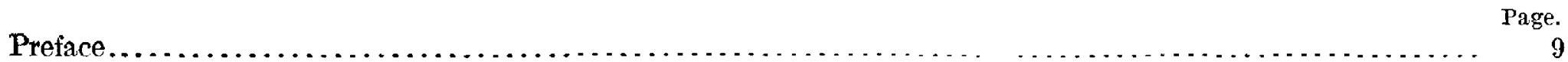

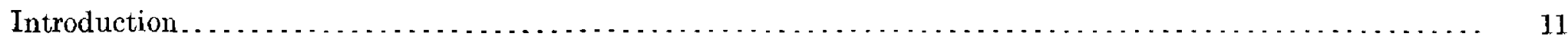

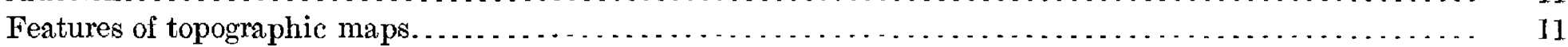

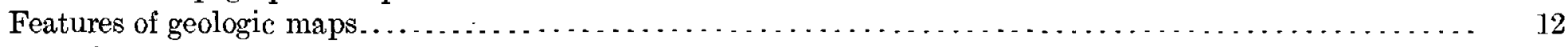

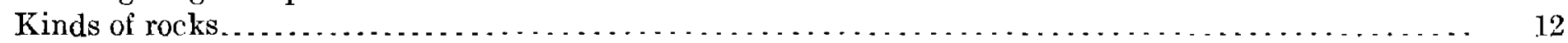

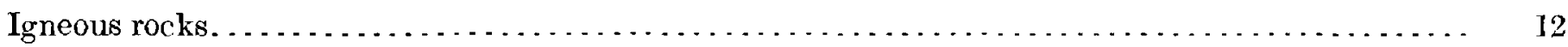

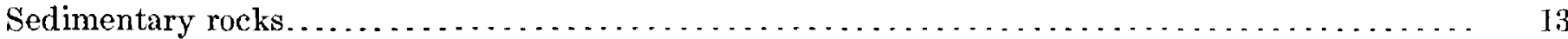

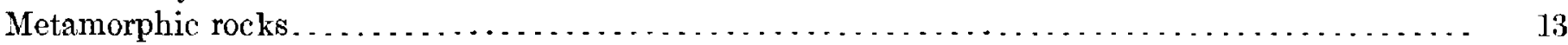

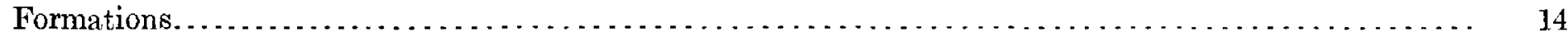

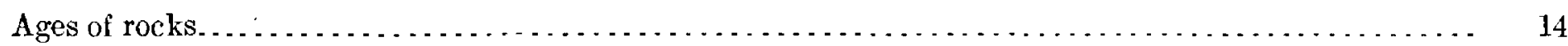

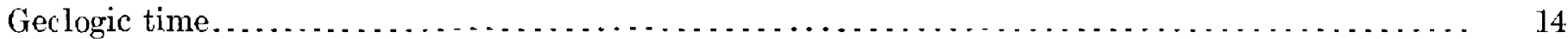

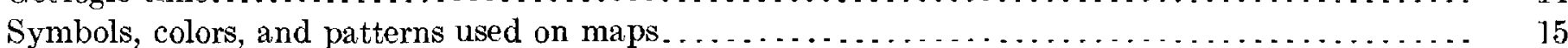

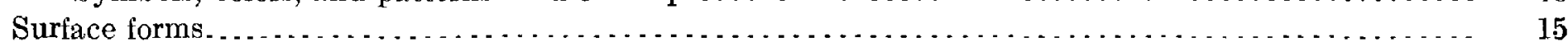

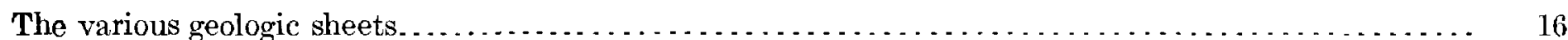

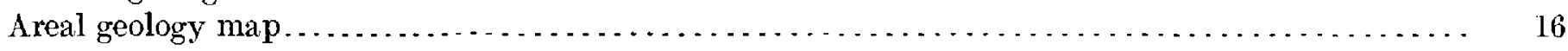

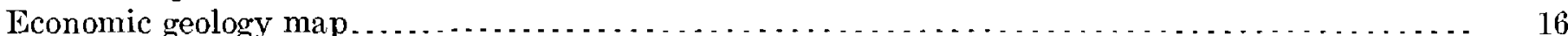

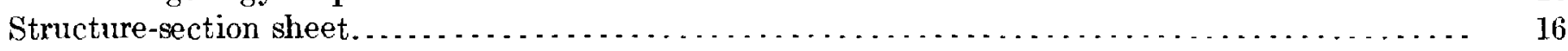

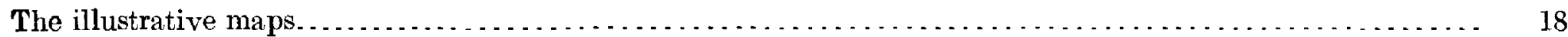

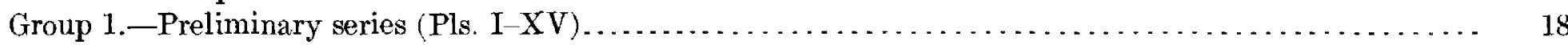

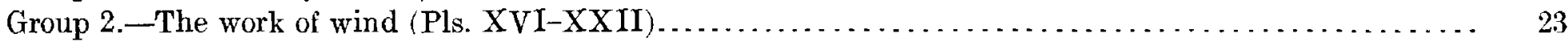

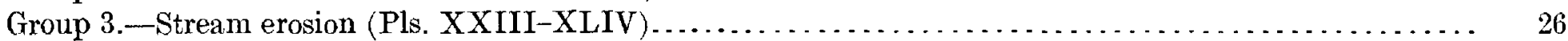

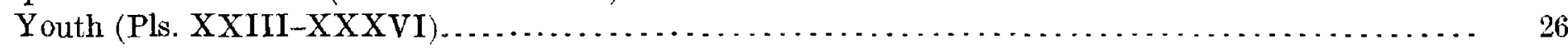

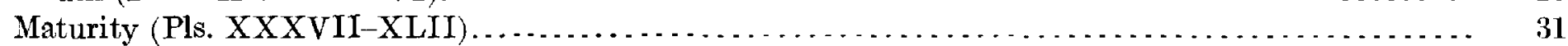

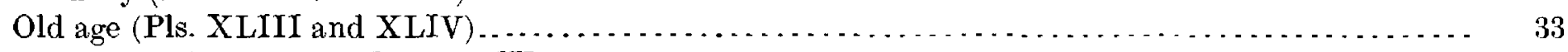

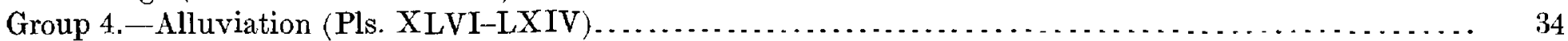

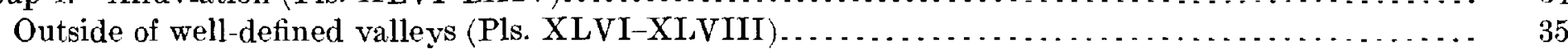

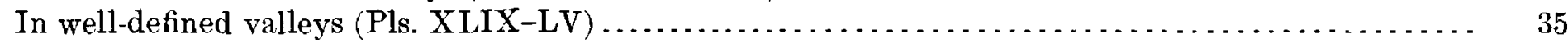

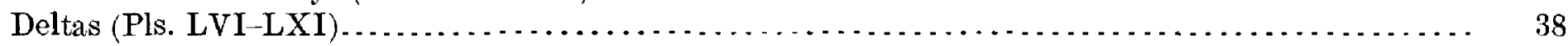

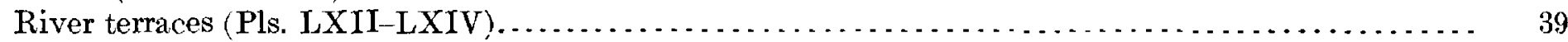

Group 5.-Topographic effects resulting from unequal hardness of rocks $(\mathrm{Pls}$. LXV-LXXI) . . . . . . . 40

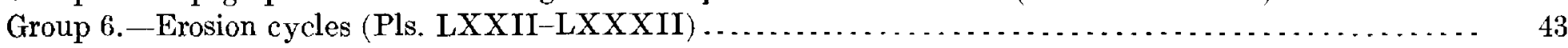

Group 7.-Stream piracy and adjustment (Pls. LXXXIII-LXXXIX) $\ldots \ldots \ldots \ldots \ldots$

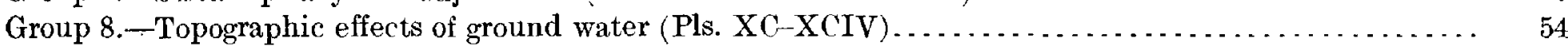

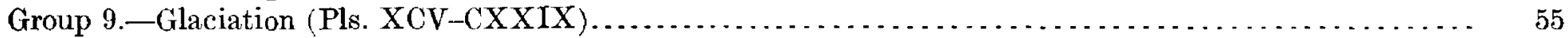

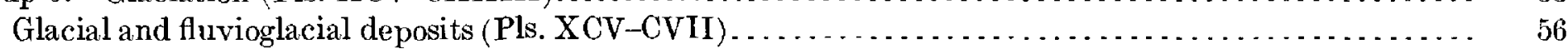

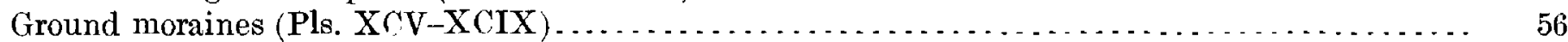

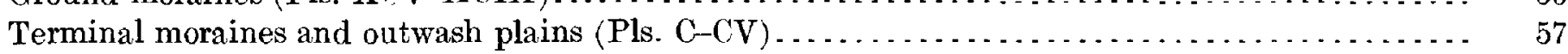

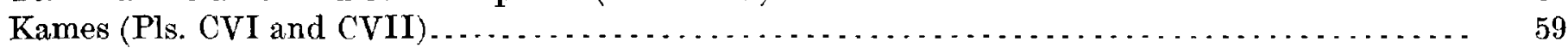

Derangement of drainage effected by glaciation (Pls. CVIII-CXX) $\ldots \ldots \ldots \ldots$

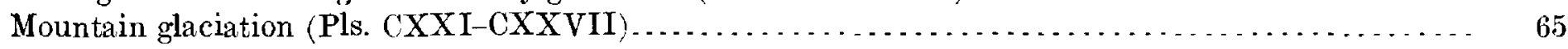

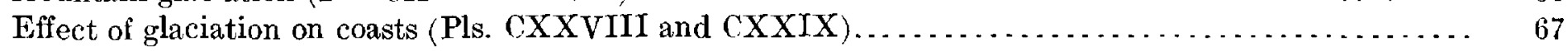

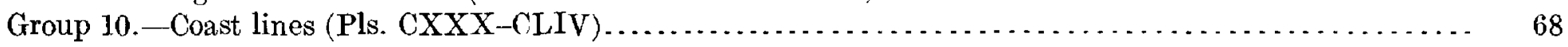

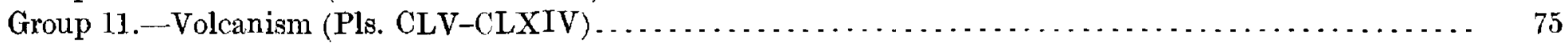

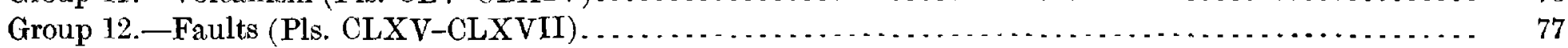

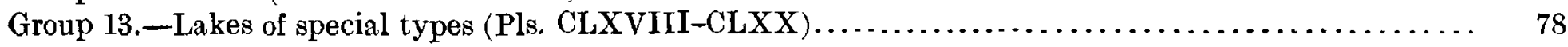




\title{
ILLÚSTRATIONS.
}

\author{
PIATES. a
}

Plate I. Progress map.

II. Conventional signs.

III. Part of Montross (Va.-Md.) sheet: $A$, Contours only; $B$, Drainage only.

IV. Part of Montross (Va.-Md.) sheet: $A$, Contours and drainage; $B$, Contours, drainage, and culture.

V. Part of Frostburg (Md.-W. Va.-Pa.) sheet.

VI. Part of Tipton (Iowa) sheet: $A$, Scale $1: 62,500 ; B$, Scale $1: 125,000$.

VII. Part of Cottonwood Falls (Kans.) sheet: $A$, Contour interval 20 feet; $B$, Contour interval 100 feet.

VIII. $A$, Part of Mesa de Maya (Colo.) sheet; $B$, Mesa Verde, Colorado.

IX. $A$, Part of Shasta (Cal.) sheet; $B$, View of Mount Shasta.

X. Part of Hamilton (Mont.-Idaho) sheet.

XI. Part of Everett ( $\mathrm{Pa}$.$) sheet.$

XII. Relief map of northern Appalachians.

XIII. $A$, Part of Dennisville (N. J.) sheet; $B$, Part of Tamalpais (Cal.) sheet.

XIV. $A$, Arctic coast; $B$, Cape Blanco, Oregon.

XV. A, Part of Minneapolis (Minn.) sheet: $B$, Moraine topography.

$$
\text { GroUP 2.-THE WORK OF WINI. }
$$

XVI. Part of Norfolk (Va.-N. C.) geologic sheet.

XVII. A, Part of Toleston (Ind.) sheet; B, Part of Ocean ('ity (Mil.-Del.) sheet.

XVIII. Views of dunes.

XIX. Part of Lakin (Kans.) sheet.

XX. Views of dunes.

XXI. Parts of Camp Clarke (Nebr.) geologic sheet.

XXII. Views showing topographic effects of wind erosion.

$$
\text { (iroup 3.- Strraan libosion. }
$$

XXIII. Part of Highwood (Ill.) sheet.

XXIV. $A$, Part of Rochester (N. Y.) sheet; $B$, Part of Dunlap (Ill.) sheet.

XXV. Part of Bisuka (Idaho) sheet.

XXVI. Parts of Gallatin and Canyon (Yellowstone National Park) sheets.

XXVII. $A$, View of young valley; $B$, View of Lower Falls of the Yellowstone.

XXVIII. Part of Bright Angel (Ariz.) sheet.

XXIX. Views of Grand Canyon of the Colorado.

XXX. A, Part of Yosemite (Cal.) sheet; $B$, View of upper Tuolumne Canyon.

XXXI Part of Yosemite Valley (Cal.) map.

XXXII. Part of Oak Orchard (N. Y.) sheet.

XXXIII. Part of Parmele (N. C.) sheet.

XXXIV. View illustrating youthful topography and drainage.

XXXV. $A$, Part of Anson (Tex.) sheet; $B$, Part of Fargo (N. Dak.-Minn.) sheet.

XXXVI. Part of Oberlin (Ohio) sheet.

XXXVII. Part of Wartburg (Tenn.) shect.

XXXVIII. Part of Charleston (W. Va.) sheet.

XXXIX. A, Part of Medicine Lodge (Kans.) sheet; $B$, Part of Mount Mitchell ( N. C.) sheet.

XL. Part of Monterey (Va.-W. Va.) sheet.

XLI. Part of Monterey (Va.-W. Va.) geologic sheet.

XLII. Part of Tell City (Ky.-Ind.) sheet.

XLIII. Part of Princeton (Ind.-Ill.) sheet.

XLIV. A, Part of Butler (Mo.) sheet; $B$, Part of Morrillton (Ark.) sheet.

XLV. Part of St. Croix Dalles (Wis.-Minn.) sheet. 
Plate XLVI. Part of Cucamonga (Cal.) sheet.

XLVII. View of alluvial fan.

XI.VIII. Part of Sierraville (Cal.) sheet.

XLIX. Part of Three Forks (Mont.) sheet: $A$, Topography; $B$, Geology.

L. $A$, Part of St. Louis (Mo.) sheet; $B$, Part of Paxton (Nebr.) sheet.

LI. A, Part of Marshall (Mo.) sheet; $B$, Part of Morrillton (Ark.) sheet.

LII. Part of Waukon (Iowa-Wis.) sheet.

LIII. Part of St. Louis (Ill.-Mo.) sheet.

LIV. Part of Williamston (N. C.) sheet.

LV. Part of Hahnville (La.) sheet.

LVI. Part of Watkins (N. Y.) sheet.

LVII. Views of Watkins Glen.

LVIII. Part of Tacoma (Wash.) geologic sheet.

LIX. Part of Portland (Oreg.-Wash.) sheet.

LX. Delta of the Mississippi.

LXI. Part of East Delta (La.) sheet.

LXII. $A$, Part of Marseilles (Ill.) sheet; $B$, Part of Hartford (Conn.) sheet.

LXIII. Part of Cohoes (N. Y.) sheet.

LXIV. Parts of Mountain Home and Camas Prairie (Idaho) sheets.

Group 5.-Topographic Effects Resulting from Unequal Hardness of Rocks.

LXV. A, Part of Holyoke (Mass.-Conn.) sheet; B, Part of High Bridge (N. J.) sheet.

LXVI. Part of Denver (Colo.) geologic sheet.

LXVII. Part of Saypo (Mont.) sheet.

LXVIII. Part of Uvalde (Tex.) geologic sheet.

LXIX. Part of Hollidaysburg (Pa.) sheet.

LXX. Part of Rome (Ga.) sheet.

LXXI. Part of Rome (Ga.) geologic sheet.

$$
\text { Group 6.-Erosion Cyches. }
$$

LXXII. Parts of Winchester (W. Va.-Va.) and Harpers Ferry (Va.-W. Va.-Md.) sheets. LXXIII. A, Part of Batesville (Ark.) sheet; B, Part of Mountain View (Ark.) sheet.

LXXIV. Part of Palo Pinto (Tex.) sheet.

LXXV. Part of Watrous (N. Mex.) sheet.

LXXVI. Part of Harrisburg (Pa.) sheet.

LXXVII. Part of Huntingdon (Pa.) sheet.

LXXVIII. Part of Wausau (Wis.) sheet.

LXXIX. Part of Ditney (Ind.) sheet: $A$, Topography; $B$, Geology.

LXXX. Part of Delaware Water Gap (Pa.-N. J.) sheet.

LXXXI. View of Delaware Water Gap.

LXXXII. Part of Tusayan ( $\Lambda$ riz.) sheet.

$$
\text { Grole 7.-Stream Piracy and Adjtstment. }
$$

LXXXIII. Part of Kaaterskill (N. Y.) sheet.

LXXXIV. Parts of Lake (Yellowstone National Park) sheet.

LXXXV. Part of Lancaster (Wis.-Iowa-Ill.) sheet.

LXXXVI. Part of Harpers Ferry (Va.-W. Va.-Md.) sheet.

LXXXVII. Part of Chattanooga (Tenn.) geologic sheet.

LXXXVIII. Parts of Piedmont (Md.-W. Va.) and Franklin (W. Va.-Va.) geologic sheets.

- LXXXIX. Parts of Stevenson (Ala.-Ga.-Tenn.) and Ringgold (Tenn.-Ga.) geologic sheets.

$$
\text { Group 8.-Topographic Effects of Ground Water. }
$$

XC. Part of Standingstone (Tenn.) sheet.

XCI. Part of Standingstone (Tenn.) geologic sheet.

XCII. View of sinkhole.

XCIII. Part of Bristol (Va.) sheet: $A$, Topography; $B$, Geology.

XCIV. Part of Kingston (Tenn.) geologic sheet. 
Group 9.-GLaciation.

Plate XCV. Part of Muskego (Wis.) sheet.

XCVI. $A$, Part of Tower (N. Dak.) sheet; $B$, Part of Durant (Iowa) sheet.

XCVII. Parts of Niagara Falls and Tonawanda (N. Y.) sheets.

XCVIII. Part of Waterloo (Wis.) sheet.

XCIX. Part of Weedsport (N. Y.) sheet.

C. Map of moraine.

CI. Parts of Harlem (N. Y.-N. J.) and Brooklyn (N. Y.) geologic sheets.

CII. A, Part of Briggsville (Wis.) sheet; $B$, Part of Whitewater (Wis.) sheet.

CIrT. Geologic map of moraine.

CrV. Part of Lake Geneva (Wis.) sheet.

CV. Parts of Denzer and Baraboo (Wis.) sheets.

CVI. $A$, Part of Rochester (N. Y.) sheet; $B$, Part of Plainfield (N. J.-N. Y.) sheet.

CVII. Geologic map showing kames.

CVIII. Part of Green wood Lake (N. Y.-N. J.) sheet.

CIX. Part of Snoqualmie (Wash.) sheet.

CX. Parts of Methow and Chelan (Wash.) sheets.

CXI. View of the slope above Lake Chelan, Wash.

CXII. Parts of Penn Yan and Hammondsport (N. Y.) sheets.

CXIII. Part of Pingree (N. Dak.) sheet.

CXIV. Part of Syracuse (N. Y.) sheet.

CXV. Part of Elmira (N. Y.-Pa.) sheet.

CXVI. Part of Little Falls (N. Y.) sheet.

CXVIr. Part of Rosendale (N. Y.) sheet.

CXVIII. Part of Cincinnati (Ohio-Ky.) sheet.

CXIX. Part of Masontown (Pa.) geologic sheet.

CXX. Parts of The Dells, Denzer, Briggsville, and Baraboo (Wis.) sheets.

CXXI. Parts of Glacier Peak (Wash.) sheet.

CXXIr. Views of glaciers.

CXXIII. A, Part of Shasta (Cal.) special sheet; $B$, Part of Colfax (Cal.) sheet.

CXXIV. Part of Chief Mountain (Mont.) sheet.

CXXV. Part of Cloud Peak (Wyo.) sheet.

CXXVI. Part of Hayden Peak (Utah-Wyo.) sheet.

CXXVII. Part of Paradox Lake (N. Y.) sheet.

CXXVIII. Part of Boothbay (Me.) sheet.

CXXIX. Part of Deer Isle (Me.) sheet.

Group 10.-Coast Lines.

CXXX. A, Part of Fairview (Pa.) sheet; $B$, View of lake cliff.

CXXXI. Part of Cayucos (Cal.) sheet.

CXXXII. Views on Pacific coast.

CXXXIII. Part of Marthas Vineyard (Mass.) sheet.

CXXXIV. Parts of Babylon and Fire Island (N. Y.) sheets.

CXXXV. Part of Atlantic City (N. J.) sheet.

CXXXVI. Part of Sandy Hook (N. J.-N. Y.) sheet.

CXXXVII. Part of Erie (Pa.) sheet.

CXXXVIII. Parts of Provincetown and Wellfleet (Mass.) sheets.

CXXXIX. Part of Nantucket (Mass.) sheet.

CXL. A, Part of Boston Bay (Mass.) sheet; $B$, View showing island tying.

CXLI. Part of Haywards (Cal.) sheet.

CXLIr. Part of Tamalpais (Cal.) sheet.

CXLIII. Views on Pacific coast.

CXLIV. Parts of Sodus Bay and Clyde (N. Y.) sheets.

CXLV. Parts of San Francisco and San Mateo (Cal.) sheets.

CXLVI. Part of Euclid (Ohio) sheet.

CXLVII. Part of Port Orford (Oreg.) geologic sheet.

CXLVIII. Map of shore bars and terraces at Wellsville, Utah.

CXLIX. Map of shore terraces near Dove Creek, Utah.

CL. Map of deltas formed in Lake Bonneville by Logan River.

CLI. Part of Oceanside (Cal.) sheet.

CLII. Views on California coast.

CLIII. Part of Tolchester (Md.) sheet.

CLIV. Part of Falmouth (Mass.) sheet. 
Grotr 11.--Totchism.

Plate ClV. Part of Marysville (Cal.) geologic sheet.

CLVI. Geologic map of Mount Mazama and Crater Lake, Oreg.

CLVII. View of Crater Lake, Oreg.

CLVIII. Part of Lassen Peak (Cal.) sheet.

CLIX. Views of Cinder Cone, Cal.

CLX. Part of Mount Lyell (Cal.) sheet.

CLXI. Geologic map of northwestern New Mexico.

CLXII. Part of San Francisco Mountains (Ariz.) sheet.

CLXIII. Part of Henry Mountain ( $\mathbf{C}^{\mathrm{t}}$ tah) sheet.

CLXIV. View of relief model of Henry Mountains, Utah.

Grolp 12.-Faults.

CLXV. Part of Mount Trumbull (Ariz.) sheet.

CLXVI. Parts of Mount Trumbull and Diamond Creek (Ariz.) sheets.

CLXVII. Part of Honey Lake (Cal.) sheet.

Group 13.-Lakes of Spegtal Types.

CLXVIII. Part of Williston (Fla.) sheet.

CLXIX. Parts of Arredondo and Williston (Fla.) sheets.

CLXX. A, Part of Granada (Colo.-Kans.) sheet; $B$, Part of Laramie (Wyo.) sheet.

\section{FIGURES.}

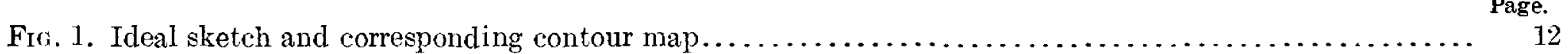

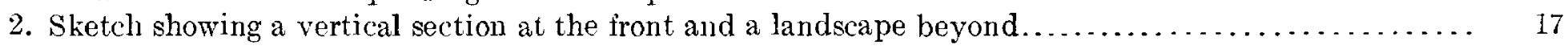

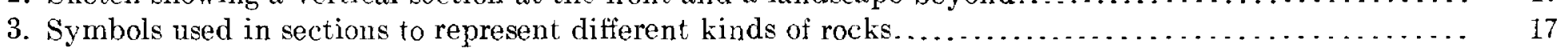

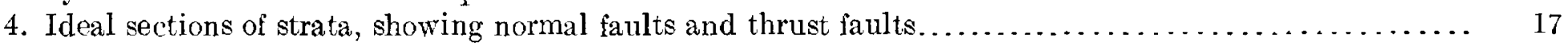

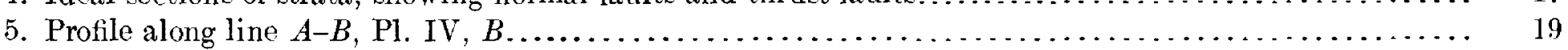

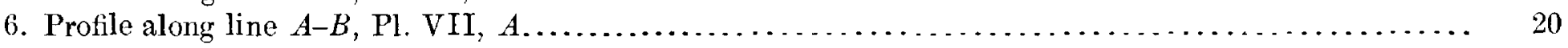

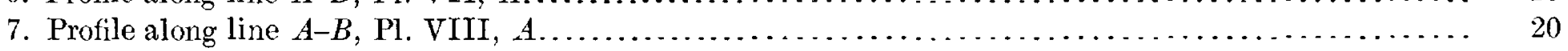

8. Contour map to illustrate the method adopted in the dropping of contours...................... 21

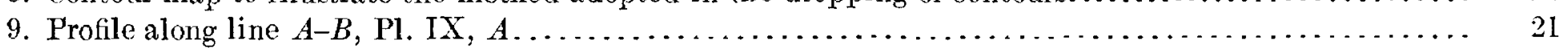

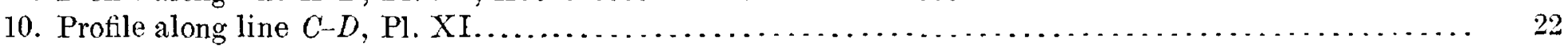

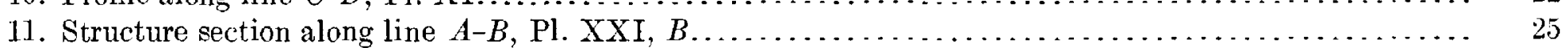

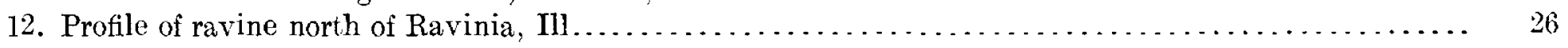

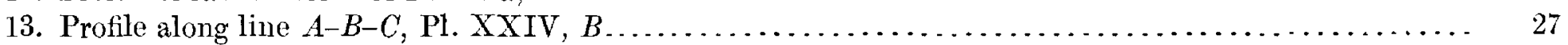

14. Diagram showing the type of surface represented on PI. XXXVIII-an area of mature topography..... 32

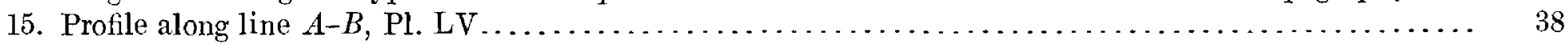

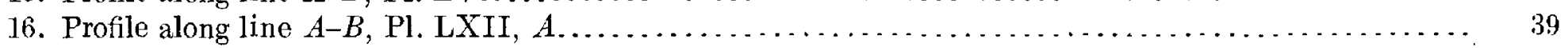

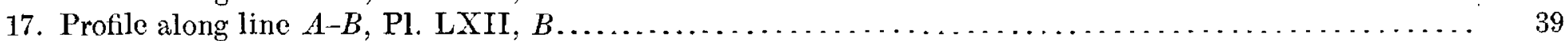

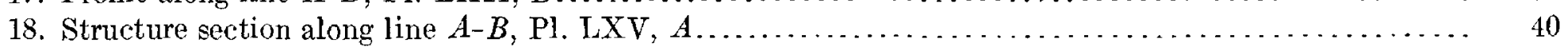

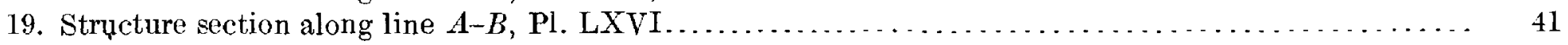

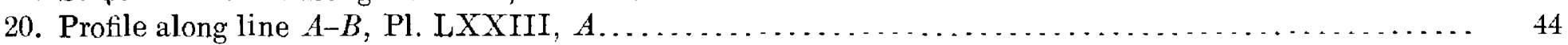

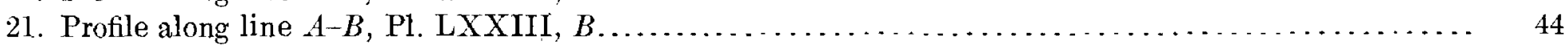

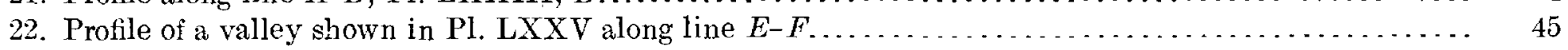

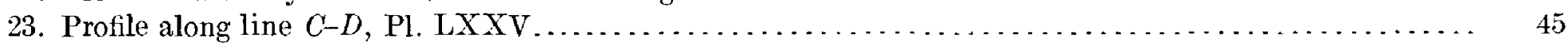

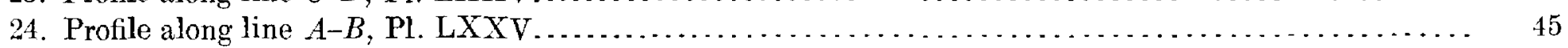

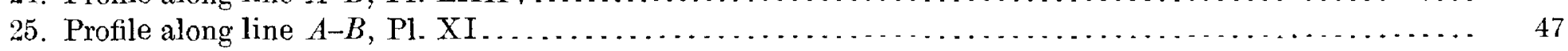

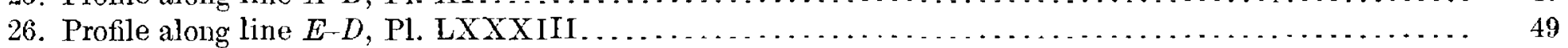

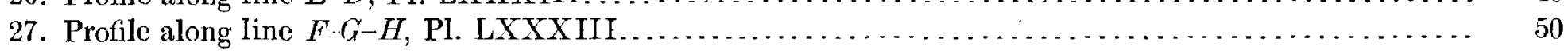

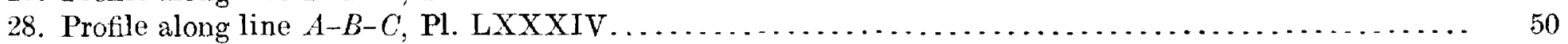

29 and 30. Sketch maps to illustrate the capture of the head of Beaverdam Creek by the Shenandoal, Vir-

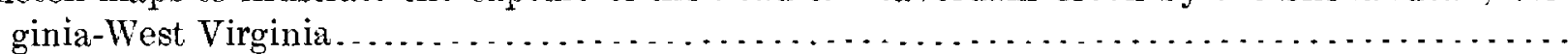

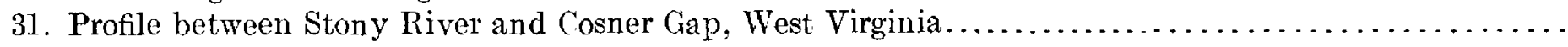

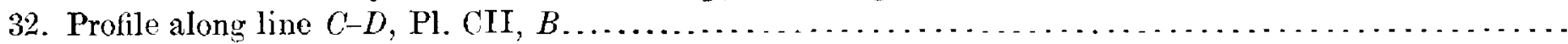

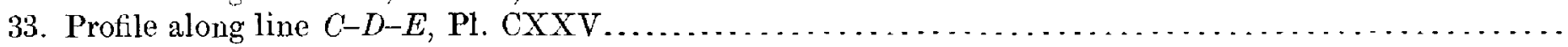

34. Cross section of Mount Hillers, Utah, with ideal representation of the underground structure...... 


\section{PREFACE.}

For nearly twenty-five years the United States Geological Survey has been preparing a topographic map of the United States. This map is issued in sheets of convenient size, each representing a rectangular area called a quadrangle. The areas already mapped are widely scattered, nearly every State being represented, as shown on Pl. I, which exhibits the progress of the work up to the present time. The sheets already published number about 1,800 .

In making these maps three scales are used, the largest scale being $1: 62,500$, or very nearly 1 mile to $1 \mathrm{inch}$; that is, 1 linear mile on the ground is represented by 1 linear inch on the map. This scale is used for maps of those parts of the country that are thickly settled or industrially important. For maps of the greater part of the country a scale of $1: 125,000$, or about 2 miles to 1 inch, is employed. A third and still smaller scale, $1: 250,000$, or about 4 miles to 1 inch, has been used in maps of the desert regions of the Far West. The sheets on the largest of the three scales defined above cover 15 minutes of latitude by 15 minutes of longitude, those on the intermediate scale 30 minutes of latitude by 30 minutes of longitude, and those on the smallest scale 1 degree of latitude by 1 degree of longitude. $\Lambda$ few special maps of small areas in mining districts are made on larger scales.

The United States Geological Survey is also preparing a geologic map of the United States. The topographic map is the base on which the geology and the mineral resources are represented. The topographic and geologic maps of a quadrangle are finally bound together, with a description of the district, to form a folio of the Geologic Atlas of the United States. The preparation of the geologic map is less advanced than that of the topographic map. The number of folios published to date (1908) is about 160. Although the areas described in these folios comprise but a small fraction of the total area of the country, they are so widely distributed that nearly every type of surface and most of the important types of geologic structure find representation among them.

The value of the maps has become fully appreciated in many quarters, but they are less widely used for educational purposes than they should be. They form the best basis, and for many regions the only basis, for careful geographic and geologic study. It is with the purpose of bringing these maps before teachers of geography and geology, as well as before laymen, that the present paper has been prepared. The plates that make up the bulk of this volume have been selected chiefly from the various maps and folios of the United States Geological Survey. Some of them are accompanied by reproductions of photographs and sketehes of the same features, or the same sort of features, that the maps show by contours. Each map has been selected to illustrate some special feature, and the maps as a whole have been selected with a view to illustrating all the more important and more common phases of topography. They have been so arranged as to exhibit, group by group, certain classes of features; and within each group the maps have been arranged with the idea of showing, so far as practicable, the history of the types of surface represented.

Group 1, Pls. I to XV, is designed to illustrate primarily the various types of surface represented on a topographic map and the ways in which the various features are shown.

Group 2, Pls. XVI to XXII, is intended to illustrate primarily the work of wind.

Group 3, Pls. XXIII to XLIV, illustrates especially the commoner phases of river erosion. (See p. 34 for explanation of Pl. XLV.) 
Group 4, Pls. XLVI to LXIV, represents especially alluviation, or the types of topography brought about through the deposition of sediment by running water.

Group 5, Pls. LXV to LXXI, illustrates the effects of inequality of hardness on the topography developed by river erosion.

Group 6, Pls. LXXII to LXXXII, illustrates erosion cycles.

Group 7, Pls. LXXXIII to LXXXIX, exhibits certain phases of piracy and adjustment. Group 8, Pls. XC to XCIV, represents the topographic effects produced by ground water.

Group 9, Pls. XCV to CXXIX, shows various topographic effects brought about by glaciation.

Group 10, Pls. CXXX to CLIV, exhibits various phases of coast lines.

Group 11, Pls. CLV to CLXIV, represents various topographic effects of volcanism. faulting.

Group 12, Pls. CLXV to CLXVII, represents certain topographic effects produced by

Group 13, Pls. CLXVIII to CLXX, embraces a few maps showing lakes in relations and positions that have not been distinctly brought out in the preceding groups.

The range of the area from which maps have been selected is very great, nearly every State and Territory being represented.

The brief notes accompanying each map are meant to supplement the maps and to increase their effectiveness in illustrating the history of the several phases of topography represented. These notes are simple, and to the geographer and geologist skilled in the interpretation of topographic and geologic maps they would be unnecessary; they have been prepared for the use of persons who are not thoroughly familiar with such maps, but who understand the meaning of the technical terms found in modern text-books on geology and physiography. It is believed that the notes are sufficiently full to enable anyone with such a knowledge to understand the maps, and it is believed further that a study of the whole series will enable the student to understand and interpret other maps. The paper may be looked on as a sort of laboratory map manual for the use of students. College students taking thorough courses in geology may wish to use all the maps and illustrations. The skillful teacher of briefer courses will know how to select helpful material.

The explanations of the maps are very unequal in respect to fullness of statement. In general, the early maps of a group are more fully explained than the later ones, especially if several maps within one group illustrate the same phenomena. It follows that the maps will be most clearly understood if they and the accompanying explanations are studied seriatim.

When interpretations have been suggested which are not known, from information now in hand, to be the true ones, the attempt has been made to designate them as possible explanations, and to indicate that the interpretation is not based on a knowledge of the field itself, but only on the features of the map. Such interpretations are to be regarded as tentative only.

Many references are made to other maps which illustrate points under discussion equally well; and in some connections, especially in the earlier parts of the volume, suggestions are made for students.

It will of course be possible for the intelligent teacher, or for the advanced student who is not a teacher, to use the maps in ways other than those indicated by the general plan of this volume. 


\title{
THE INTERPRETATION OF TOPOGRAPHIC MAPS.
}

\author{
By Rollin D. Salisbury and Wallace W. Atwood. \\ INTRODUCTION. \\ FEATURES OF TOPOGRAPHIC MAPS. $a$
}

The features shown on topographic maps may, for convenience, be classed in three groups: (1) Water, including seas, lakes, ponds, rivers and other streams, canals, swamps, etc.; (2) relief, including mountains, hills, valleys, cliffs, etc.; (3) culture, i. e., works of man, such as towns, cities, roads, railroads, boundaries, etc. The conventional signs used for these features are grouped on Pl. II. Variations appear in some maps of early dates.

All water features are shown in blue, the smaller streams and canals in full blue lines, and the larger streams, lakes, and the sea by blue water lining. Certain streams, however, which flow during only a part of the year, their beds being dry at other times, are shown, not by full lines, but by lines of dots and dashes. Ponds which are dry during a part of the year are shown by oblique parallel lines. Salt-water marshes are shown by horizontal ruling interspersed with tufts of blue, and fresh-water marshes and swamps by blue tufts with broken horizontal lines.

Relief is shown by contour lines in brown. Each contour passes through points which have the same altitude. One who follows a contour on the ground will go neither uphill nor downhill, but on a level. By the use of contours not only are the shapes of the plains, hills, and mountains shown, but also their elevations. The line of the seacoast itself is a contour line, the datum or zero of elevation being mean sea level. The contour line at, say, 20 feet above sea level is the line that would be the seacoast if the sea were to rise or the land to sink 20 feet. Such a line runs back up the valleys and forward around the points of hills and spurs. On a gentle slope this contour line is far from the present coast line; on a steep slope it is near the coast. Thus a succession of these contour lines far apart on the map indicates a gentle slope; if close together, a steep slope; and if the contours run together in one line, as if each were vertically under the one above it, they indicate a cliff. In many parts of the country are depressions or hollows with no outlets. The contours, of course, surround these, just as they surround hills. The small hollows known as sinks are usually indicated by hachures, or short dashes, on the inside of the curve.

The manner in which contours express elevation, form, and grade is shown in the accompanying sketch and corresponding contour map (fig. 1). The sketch represents a river valley between two hills. In the foreground is the sea, with a bay which is partly closed by a hooked sand bar. On each side of the valley is a terrace. From the terrace on the right a hill rises

a This description of the topographic maps is taken partly from the text which accompanies the published map sheets of the United States Geological survey and partly from the folios. 
gradually; from that on the left the ground ascends steeply in a precipice. Contrasted with this precipice is the gentle descent of the slope at the left. In the map each of these features is indicated, directly beneath its position in the sketch, by contours.

The contour interval, or the vertical distance in feet between one contour and the next, is stated at the bottom of each map. This interval varies according to the character of the area mapped; in a flat country it may be as small as 10 feet; in a mountainous region it may be 200 feet. Certain contours, usually every fifth one, are commonly accentuated and accompanied by
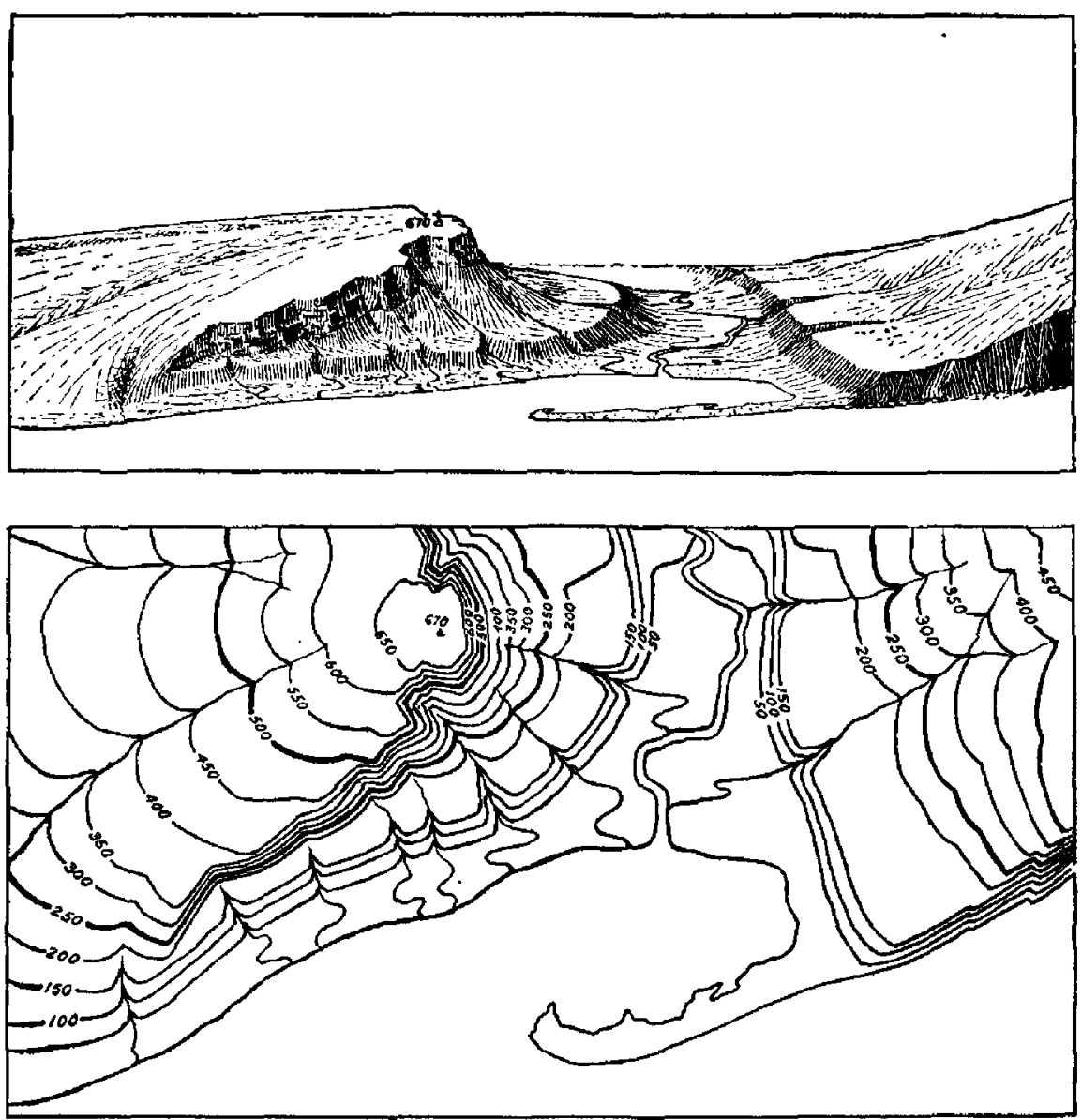

FIG. 1.-Ideal sketch and corresponding contour map. figures stating elevation above sea level. The heights of many definite points, such as road cormers, railroad crossings, railroad stations, summits, water surfaces, triangulation stations, and bench marks, are also given. The figures in each case are placed close to the point to which they apply, and express the elevation to the nearest whole number of feet only. The exact elevations of bench marks and their descriptions, as well as the descriptions and gcodetic coordinates of triangulation stations, are published in the annual reports and bulletins of the Survey.

The works of man are shown in black, in which color all lettering also is printed. Boundaries, such as State, county, city, land-grant, reservation, etc., are shown by broken lines of different kinds and weights. Cities are indicated by black blocks, representing the built-up portions, and country houses by small black squares. Roads are shown by fine double lines (full for the better roads, dotted for the inferior ones), trails by single dotted lines, and railroads by full black lines with cross lines. Other cultural features are represented by conventions which are easily understood.

Each sheet of the topographic atlas is designated by the name of a principal town or of some prominent natural feature within the district, and the names of adjoining published sheets are printed on the margins.

\section{FEATURES OF GEOLOGIC MAPS.}

The maps representing the geology show, by colors and conventional signs printed on the topographic base map, the distribution of rock masses on the surface of the land; and the structure sections show their underground relations, as far as known and in such detail as the scale permits.

\section{KINDS OF ROCKS.}

Rocks are of many kinds. On the geologic map they are distinguished as igneous, sedimentary, and metamorphic.

Igneous rocks.-Rocks that have cooled and consolidated from a liquid state are called igneous. Through rocks of all ages molten material has from time to time been forced upward in fissures or channels of various shapes and sizes to or nearly to the surface. Rocks formed by

This description of the geologic maps is taken from the text of the folios of the Ceologic Atlas of the United States published by the United States deological Survey. 
the consolidation of the molten mass within these channels--that is, below the surface-are called intrusive. When the rock occupies a fissure with approximately parallel walls the mass is called a dike; when it fills a large and irregular conduit the mass is termed a stock. When the conduits for molten magmas traverse stratified rocks they often send off branches parallel to the bedding planes; the rock masses filling such fissures are called sills or sheets if comparatively thin, and laccoliths if occupying larger chambers produced by the force propelling the magmas upward. Within rock inclosures molten material cools slowly, with the result that intrusive rocks are generally of crystalline texture. When the channels reach the surface the liquid material poured out through them is called lava, and lavas often build up volcanic mountains. Igneous rocks thus formed upon the surface are called extrusive. Lavas cool rapidly in the air, and acquire a glassy or, more commonly, a partially crystalline condition in their outer parts, but are more fully crystalline in their inner portions. The outer parts of lava flows are usually more or less porous. Explosive action often accompanies volcanic eruptions, causing ejections of dust, ash, and larger fragments. These materials, when consolidated, constitute breccias, agglomerates, and tuffs. Volcanic ejecta may fall in bodies of water or may be carried into lakes or seas and form sedimentary rocks.

Sedimentary rocks.-Rocks composed of the materials of older rocks which have been broken up and the fragments of which have been carried to a different place and deposited are called sedimentary.

The chief agent of transportation of rock débris is water in motion, including rain, streams, and the water of lakes and of the sea. The materials are in large part carried as solid particles, and the deposits are then said to be mechanical. Such are gravel, sand, and clay, which are later consolidated into conglomerate, sandstone, and shale. In smaller portion the materials are carried in solution, and the deposits are then called organic if formed with the aid of life, or chemical if formed without the aid of life. The more important rocks of chemical and organic origin are limestone, chert, gypsum, salt, iron ore, peat, lignite, and coal. Any one of the deposits may be separately formed, or the different materials may be intermingled in many ways, producing a great variety of rocks.

Another transporting agent is air in motion, or wind; and a third is ice in motion, or glaciers. The most characteristic of the wind-borne or eolian deposits are sand and loess, a fine-grained earth; the most characteristic of the glacial deposits is till, a heterogeneous mixture of bowlders and pebbles with clay or sand.

Sedimentary rocks are usually made up of layers or beds which can be easily separated. These layers are called strata. Rocks deposited in layers are sajd to be stratified.

The surface of the earth is not fixed, as it seems to be; it very slowly rises or sinks, with reference to the sea, over wide expanses; and as it rises or subsides the shore lines of the ocean are changed. As a result of the rising of the surface, marine sedimentary rocks may become part of the land, and extensive land areas are in fact occupied by such rocks.

Rocks exposed at the surface of the land are acted on by air, water, ice, animals, and plants. They are gradually broken into fragments, and the more soluble parts are leached out, leaving the less soluble as a residual layer. Water washes residual material down the slopes, and it is eventually carried by rivers to the ocean or other bodies of standing water. Usually its journey is not continuous, but it is temporarily built into river bars and flood plains, where it is called alluvium. Alluvial deposits, glacial deposits (collectively known as drift), and eolian deposits belong to the surficial class, and the residual layer is commonly included with them. Their upper parts, occupied by the roots of plants, constitute soils and subsoils, the soils being usually distinguished by a notable admixture of organic matter.

Metamorphic rocks. - In the course of time, and by a variety of processes, rocks may become greatly changed in composition and in texture. When the newly acquired characteristics are more pronounced than the old ones the rocks are called metamorphic. In the process of metamorphism the substances of which a rock is composed may enter into new combinations, certain substances may be lost, or new substances may be added. There is often a complete 
gradation from the primary to the metamorphic form within a single rock mass. Such changes transform sandstone into quartzite and limestone into marble and modify other rocks in various ways.

From time to time in geologic history igneous and sedimentary rocks have been deeply buried and later have been raised to such elevations that erosion has removed their covering and left them again at the surface. During this process, through the agencies of pressure, movement, and chemical action, their original structure may be entirely lost and new structures appear. Often a system of division planes along which the rocks split easily is developed, and these planes may cross the strata at any angle. This structure is called cleavage. Sometimes crystals of mica or other foliaceous minerals are developed with their laminæ approximately parallel; in such rocks the structure is said to be schistose or characterized by schistosity.

As a rule the oldest rocks are most altered and the younger formations have escaped metamorphism, but to this rule there are important exceptions.

\section{FORMATIONS.}

For purposes of geologic mapping rocks of all the kinds described above are divided into formations. A sedimentary formation contains between its upper and lower limits either rocks of uniform character or rocks more or less uniformly varied in character, as, for example, an alternation of shale and limestone. Where the passage from one kind of rocks to another is gradual it may be necessary to separate two contiguous formations by an arbitrary plane, and in some cases the distinction depends almost entirely on the contained fossils. An igneous formation is constituted of one or more bodies either containing the same kind of igneous rock or having the same mode of occurrence. A metamorphic formation may consist of rock of uniform character or of several rocks having common characteristics.

When for scientific or economic reasons it is desirable to recognize and map one or more specially developed parts of a varied formation, such parts are called members, or by some other appropriate term, as lentils.

\section{AGES OF ROCKS.}

Geologic time.-The time during which the rocks were made is divided into several periods. Smaller time divisions are called epochs, and still smaller ones stages. The age of a rock is expressed by naming the time interval in which it was formed, when known.

The sedimentary formations deposited during a period are grouped together into a system. The principal divisions of a system are called series. Any aggregate of formations less than a series is called a group.

As sedimentary deposits or strata accumulate, the younger rest upon those that are older, and the relative ages of the deposits may be determined by observing their positions. This relationship holds except in regions of intense disturbance; in such regions sometimes the beds have been reversed, and it is often difficult to determine their relative ages from their positions; then fossils, or the remains and imprints of plants and animals, indicate which of two or more formations is the oldest.

Many stratified rocks contain the remains or imprints of plants and animals which, at the time the strata were deposited, lived in the sea or were washed from the land into lakes or seas, or were buried in surficial deposits on the land. Such rocks are called fossiliferous. By studying fossils it has been found that the life of each period of the earth's history was to a great extent different from that of other periods. Only the simpler kinds of marine life existed when the oldest fossiliferous rocks were deposited. In course of time more complex kinds developed, and as the simpler ones lived on in modified forms life became more varied. But during each period there lived peculiar forms, which did not exist in earlier times and have not existed since; these are characteristic types, and they define the age of any bed of rock in which they are found. Other types passed on from period to period, and thus linked the systems together, forming a chain of life from the time of the oldest fossiliferous rocks to the present. Where two sedimentary formations are remote from each other and it is impossible to observe their 
relative positions, the characteristic fossil types found in them may determine which was deposited first. Fossil remains found in the strata of different areas, provinces, and continents afford the most important means for combining local histories into a general earth history.

It is often difficult or impossible to determine the age of an igneous formation, but the relative age of such a formation can sometimes be ascertained by observing whether an associated sedimentary formation of known age is cut by the igneous mass or is deposited upon it.

Similarly, the time at which metamorphic rocks were formed from the original masses may be shown by their relations to adjacent formations of known age; but the age recorded on the map is that of the original masses and not that of their metamorphism.

Symbols, colors, and patterns used on maps.-Each formation is shown on the map by a distinctive combination of color and pattern and is labeled by a special letter symbol.

Symbols and colors assigned to the rock systems.

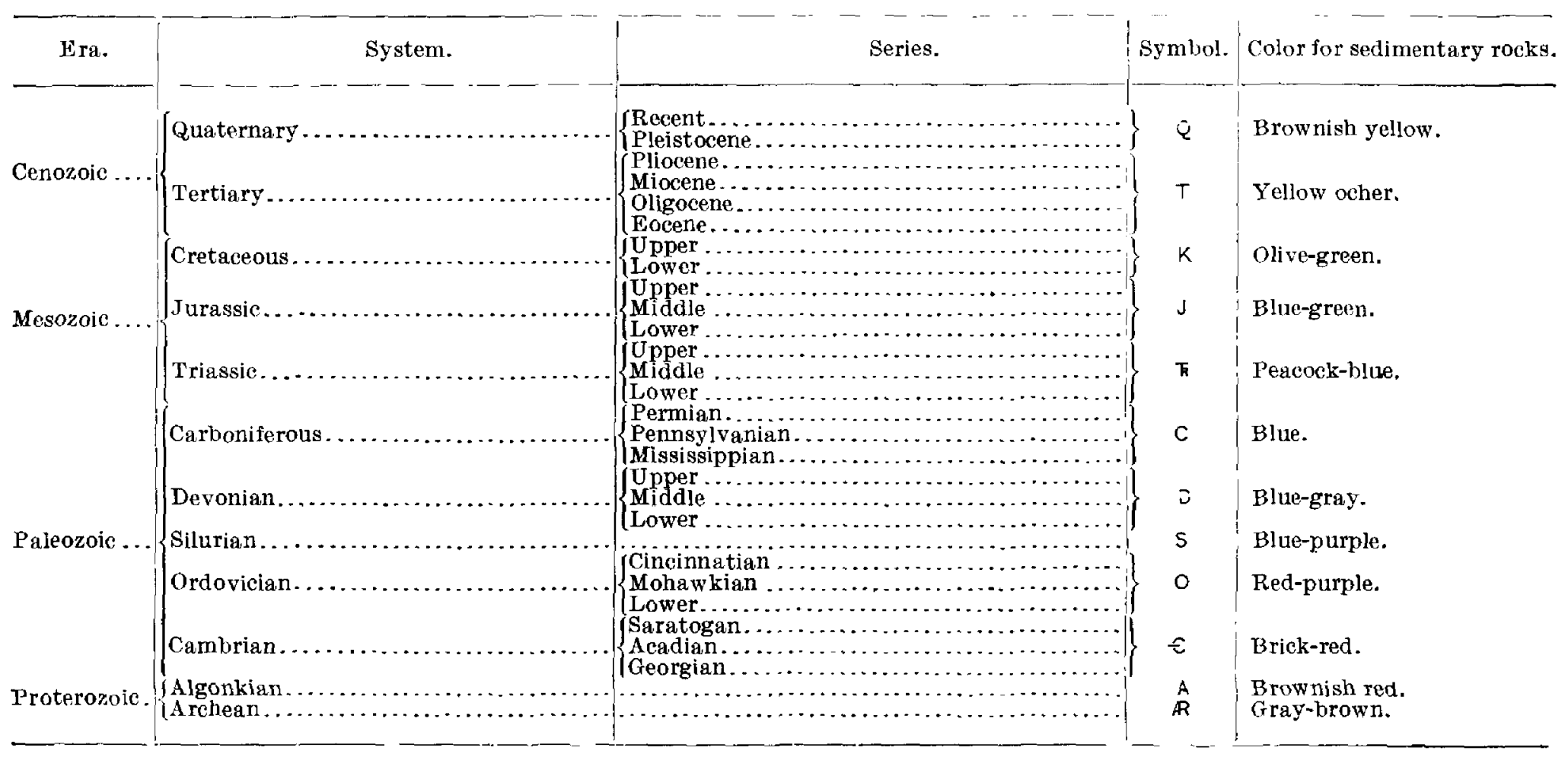

Patterns composed of parallel straight lines are used to represent sedimentary formations deposited in the sea or in lakes. Patterns of dots and circles represent alluvial, glacial, and eolian formations. Patterns of triangles and rhombs are used for igneous formations. Metamorphic rocks of unknown origin are represented by short dashes irregularly placed; if the rock is schist the dashes may be arranged in wavy lines parallel to the structure planes. Suitable combination patterns are used for metamorphic formations known to be of sedimentary or of igneous origin.

The patterns of each class are printed in various colors. With the patterns of parallel lines, colors are used to indicate age, a particular color being assigned to each system. The symbols by which formations are labeled consist each of two or more letters. If the age of a formation is known the symbol includes the system symbol, which is a capital letter or monogram; otherwise the symbols are composed of small letters. The names of the systems and recognized series, in proper order (from new to old), with the color and symbol assigned to each system, are given in the preceding table.

\section{SURFACE FORMS.}

Hills and valleys and all other surface forms have been produced by geologic processes. For example, most valleys are the result of erosion by the streams that flow through them (see fig. 1), and the alluvial plains bordering many streams were built up by the streams; sea cliffs are made by the eroding action of waves, and sand spits are built up by waves. Topographic forms thus constitute part of the record of the history of the earth. 
Some forms are produced in the making of deposits and are inseparably connected with them. The hooked spit shown in fig. 1 is an illustration. To this class belong beaches, alluvial plains, lava streams, drumlins (smooth oval hills of till), and moraines (uneven ridges of drift made at the edges of glaciers). Other forms are produced by erosion, and these are, in origin, independent of the associated material. The sea cliff is an illustration; it may be carved from any rock. To this class belong abandoned river channels, glacial furrows, and peneplains. In the making of a stream terrace an alluvial plain is first built and afterward partly eroded away. The shaping of a marine or lacustrine plain is usually a double process, hills being worn away (degraded) and valleys being filled up (aggraded).

All parts of the land surface are subject to the action of air, water, and ice, which slowly wear them down, and streams carry the waste material to the sea. As the process depends on the flow of water to the sea, it can not be carried below sea level, and the sea is therefore called the base-level of erosion. When a large tract is for a long time undisturbed by uplift or subsidence it is degraded nearly to base-level, and the even surface thus produced is called a peneplain. If the tract is afterward uplifted the peneplain at the top is a record of the former relation of the tract to sea level.

\section{THE VARIOUS GEOLOGIC SHEETS.}

Areal geology map.-The map showing the areas occupied by the various formations is called an areal geology map. On the margin is a legend, which is the key to the map. To ascertain the meaning of any colored pattern and its letter symbol the reader should look for that color, pattern, and symbol in the legend, where he will find the name and description of the formation. If it is desired to find any given formation, its name should be sought in the legend and its color and pattern noted, when the areas on the map corresponding in color and pattern may be traced out. As a rule each formation has a distinct color or pattern, its boundaries being also indicated by fine black lines. In some of the plates in this volume, where it is not important to discriminate closely between several formations belonging to the same system, only one color is used for a group of such formations; but their limits can usually be traced by means of the fine boundary lines and the letter symbols.

The legend is also a partial statement of the geologic history. In it the formations are arranged in columnar form, grouped primarily according to origin-sedimentary, igneous, and crystalline of unknown origin - and within each group they are placed in the order of age, so far as known, the youngest at the top.

Economic geology map.--The map representing the distribution of useful minerals and rocks, showing their relations to the topographic features and to the geologic formations, is called an economic geology map. The formations that appear on the areal geology map are usually shown on the economic geology map by fainter color patterns, which afford a subdued background upon which the areas of productive formations may be emphasized by strong colors. A mine symbol is printed at each mine or quarry, accompanied by the name of the principal mineral mined or stone quarried. For regions where there are important mining industries or where artesian basins exist special maps are prepared to show these additional economic features.

Structure-section sheet.- The sheet that exhibits the relations of the formations beneath the surface is called a structure-section sheet. In cliffs, canyons, shafts, and other natural and artificial cuttings, the relations of different beds to one another may be seen. Any cutting which exhibits those relations is called a section, and the same term is applied to a diagram representing the relations. The arrangement of rocks in the earth is the earth's structure, and a section exhibiting this arrangement is called a structure section.

The geologist is not limited, however, to the natural and artificial cuttings for his information concerning the earth's structure. Knowing the manner of formation of rocks, and having traced out the relations among the beds on the surface, he can infer their relative positions after they pass beneath the surface, and can draw sections representing the structure of the earth to a considerable deptl. Such a section exhibits what would be seen in the side of a cutting many miles long and several thousand feet deep. This is illustrated in fig. 2. 
The figure represents a landscape which is cut off sharply in the foreground on a vertical plane, so as to show the underground relations of the rocks. The kinds of rock are indicated by appropriate symbols of lines, dots, and dashes. These symbols admit of much variation, but those shown in fig. 3 are generally used in sections to represent the commoner kinds of rock.

The plateau shown in fig. 2 presents toward the lower land an escarpment, or front, which is made up of sandstones, forming the cliffs, and shales, constituting the slopes, as shown at the 'extreme left of the section. The broad belt of lower land is traversed by several ridges, which are seen in the section to correspond to the outcrops of a bed of

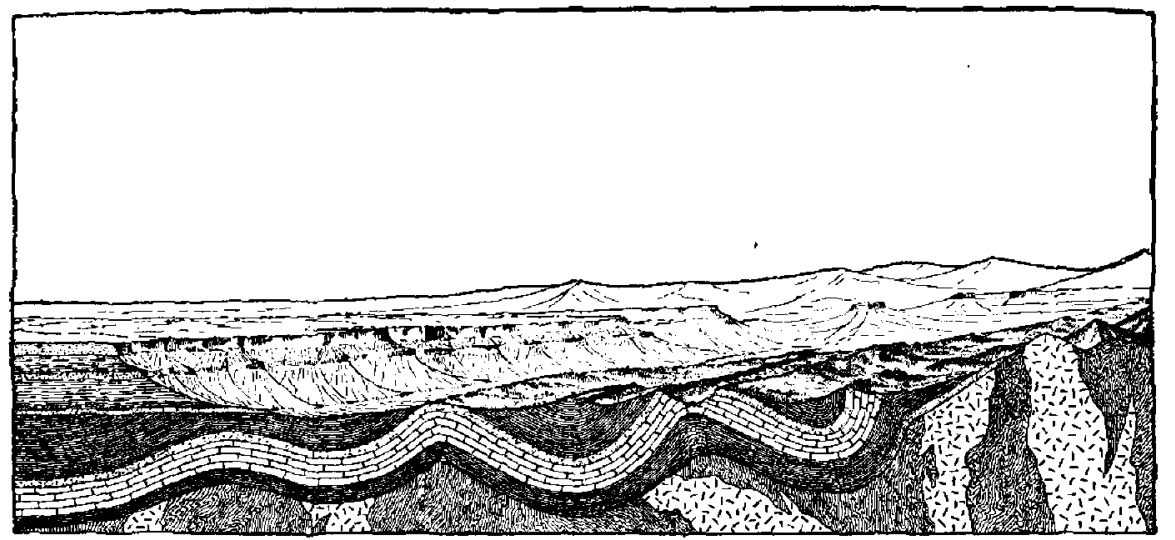

Fig. 2.-Sketch showing a vertical section at the iront and a landscape heyond. sandstone that rises to the surface. The upturned edges of this bed form the ridges, and the intermediate valleys follow the outcrops of limestone and calcareous shale.

Where the edges of the strata appear at the surface their thickness can be measured

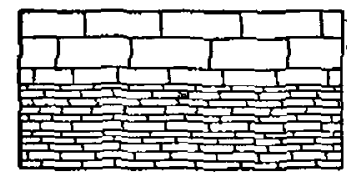

Limestones.

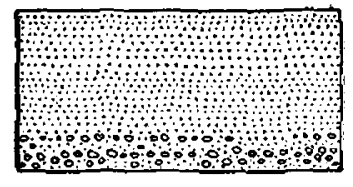

Sandstones and conglomerates.

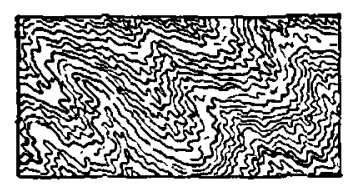

Schists.

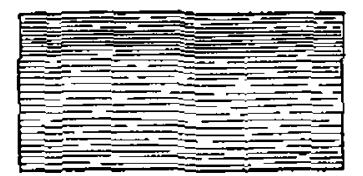

Shales.

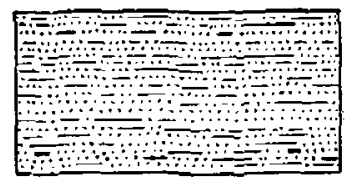

Shaly sandstones.

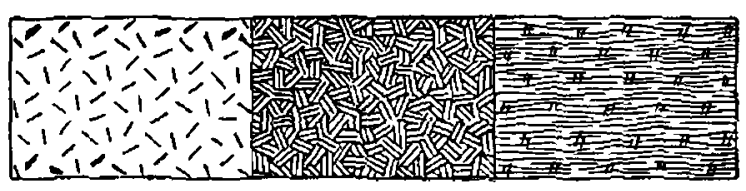

Massive and bedded igneous rocks.

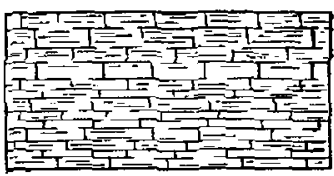

Shaly limestones.

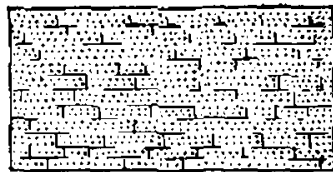

Calcareous sandstones. and the angles at which they dip below the surface can be observed. Thus their positions underground can be inferred. The direction that the intersection of a bed with a horizontal plane will take is called the strike. The inclination of the bed to the horizontal plane, measured at right angles to the strike, is called the dip.

In many places strata are curved in troughs and arches, such as are seen in fig. 2 . The arches are called anticlines and the troughs synelines. But the sandstones, shales, and limestones were deposited beneath the sea in nearly flat sheets; that they are now bent and folded is proof that forces have from time to time caused the earth's surface to wrinkle along certain zones. In places the strata are broken across and the parts have slipped past each other. Such breaks are termed faults. Two kinds of faults are shown in fig. 4 .

On the right of fig. 2 the section is composed of schists which are traversed by masses of igneous rock. The schists are much contorted, and their arrangement underground can not be inferred. Hence that portion of the section delineates what is probably true but is not known by observation or wellfounded inference.

The section in fig. 2 shows three

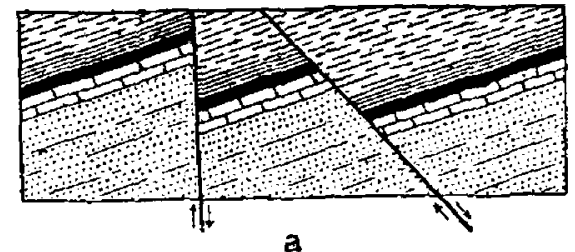

Fig. 4.-Ideal sections of strata, showing (a) normal faults and (b) a thrust fault. sets of formations, distinguished by their underground relations. The uppermost of these, seen at the left of the section, is a set of sandstones and shales, which lie in a horizontal position. These sedimentary strata are now high above the sea, forming a plateau, and their change of elevation shows that a portion of the earth's mass has been raised from a lower to a higher level. The strata of this set are parallel, a relation which is called conformable.

$$
\text { 1710-08-2 }
$$


The second set of formations consists of strata which form arches and troughs. These strata were once continuous, but the crests of the arches have been removed by degradation. The beds, like those of the first set, are conformable.

The horizontal strata of the plateau rest upon the upturned, eroded edges of the beds of the second set at the left of the section. The overlying deposits are, from their positions, evidently younger than the underlying formations, and the bending and degradation of the older strata must have occurred between the deposition of the older beds and the accumulation of the younger. When younger rocks thus rest upon an eroded surface of older rocks the relation between the two is an unconformable one, and their surface of contact is an unconformity.

The third set of formations consists of crystalline schists and igneous rocks. At some period of their history the schists were plicated by pressure and traversed by eruptions of molten rock. But the pressure and intrusion of igneous rocks have not affected the overlying strata of the second set. Thus it is evident that a considerable interval elapsed between the formation of the schists and the beginning of deposition of the strata of the second set. During this interval the schists suffered metamorphism, they were the scene of eruptive activity, and they were deeply eroded. The contact between the second and third sets is another unconformity; it marks a time interval between two periods of rock formation.

The section and landscape in fig. 2 are ideal, but they illustrate relations which actually occur. The sections on the structure-section sheet are related to the maps as the section in the figure is related to the landscape. The profile of the surface in the section corresponds to the actual slopes of the ground along the section line, and the depth below the surface of any mineralproducing or water-bearing stratum which appears in the section may be measured by using the scale of the map.

The geologic map may be accompanied by a columnar section, drawn to scale, showing the succession and thicknesses of the formations and the character of the rocks composing them. In this section the intervals of time which correspond to events of uplift and degradation and constitute interruptions of deposition are indicated graphically and by the word "unconformity."

\section{THE ILLUSTRATIVE MAPS.}

\section{GROUP 1.-PRELIMINARY SERIES.}

This preliminary group of maps (Pls. I-XV) is designed to familiarize the reader with topographic maps and to bring into contrast various common types of topography. The first maps are analyzed for the double purpose of showing (1) how topographic maps are made and (2) the relations between drainage and relief on the one hand and relief and culture on the other. It is assumed throughout that the reader understands the principles of the topographic map. (See pp. 11-12.)

In the study of contour maps the scale of the map and the contour interval should be noted at the outset. It is also well to note the location of the area which the map represents. These data are given on each map.

PLATES I AND II.

The titles of PIs. I and II sufficiently indicate their character and purpose.

PLATES III AND IV.

Pl. III, $A$, includes contour lines only. The highest points shown on the map are but little more than 180 feet above sea level, which is represented by the blank area at the north. The crowding of the contours along the north edge indicates a steep slope, or cliff, on that side. Steep slopes are also indicated at various other points, especially at the east side. South of the cliff at the north there is no considerable area free from contour lines. This means that no large tracts are level. The slopes over much of the area are such that rain water would run off readily, and the territory is therefore well drained. Pl. III, $B$, shows the drainage of the area represented by $A$.

Pl. IV, $A$, combines $A$ and $B$ of Pl. III, and brings out the intimate relations between topography and drainage. Every stream occupies a depression, one end of which is lower 
than the other, and the inference may readily be drawn that the streams have been concerned in the development of the depressions.

Pl. IV, $B$, adds the culture conventions (see Pl. II) to the data represented on Pl. III and shows that the position of certain cultural features, such as roads, is influenced by topography. Most of the roads occupy the divides between the valleys, though some of them cross the valleys. The points where there are steep grades along the roads may be readily seen. Thus the road between Stratford and Shaws Mount and the road north from Shaws Mount have little grade, but that between Stratford and Chilton crosses a considerable valley. In general, the steepness of slope at any point may be determined by means of the contour interval and the horizontal scale of the map. Thus, along the north edge of the land area eight contours are crowded into one-sixteenth of an inch. As one-sixteenth of an inch represents approximately the same fraction of a mile, and as the contour interval is 20 feet, it follows that the surface declines about 160 feet in 110 yards ( 20 rods) if the map accurately represents the slope.

The region covered by Pls. III and IV is sparsely settled, hardly more than a dozen houses being shown on the map. The slopes of some parts of the surface are so steep that the land could not well be cultivated, but the topography of the area as a whole is not such as to account for the apparent meagerness of the population.

Whoever wishes to familiarize himself thoroughly with topographic maps will do well to draw sections showing the profile of the surface along selected lines. For this purpose profile or cross-section paper should be

used. It is usually convenient to make the horizontal scale of the profile the same as the horizontal

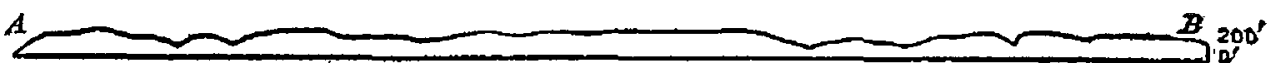

FIG. 5.-Profile along line $A-B, \mathrm{Pl}$. IV $B$. The base line represents sea level. Vertical scale a little more than five times the horizontal. scale of the map. The vertical

scale is often exaggerated. One space on the profile paper should be taken to represent a definite number of contour intervals. The amount of vertical exaggeration in the profile should always be noted. Fig. 5 is a profile along the line $A-B$ of $\mathrm{Pl}$. IV, $B$. The vertical scale is about five times the horizontal.

\section{PLATE V}

Pl. V represents an area of much greater relief than that shown on the preceding plate, the elevations constituting low mountains. The country is notably rough, as is indicated by the crowding of the contour lines (considered in relation to the scale and contour interval) at many points and along many belts. The disposition of these lines shows that the elevations are in the form of interrupted ridges (Piney Mountain, Wills Mountain, Shriver Ridge, etc.) having a general northeast-southwest trend. The high points along the several ridges approach a common level. Along Piney Mountain the elevation is 2,400 to 2,600 feet; along Wills Mountain, 1,600 to 1,800 feet; along the ridge farther east it is somewhat less, except at the highest peak, which reaches an elevation of 1,940 feet.

The more conspicuous valleys are rudely parallel to the ridges, but the streams cut through the ridges at some points, as northwest of Cumberland. It is to be noted that the valleys are much narrower and their slopes much steeper at such gaps in the ridges than elsewhere.

The only flat surfaces shown on the map are in the valley bottoms. Nearly everywhere else slopes prevail.

The figure at the bottom of the plate represents the profile of the surface along the line $A-B$ of the map above. The vertical scale is the same as the horizontal.

The culture lines, taken by themselves, would appear most anomalous. Their control by the relief is very pronounced. The railways follow the valleys, here and there making a tunnel through a projecting point of rock, as west of Winchester. The wagon roads, less dependent on grade, at some places cross considerable elevations. Most of the settlements are on the valley flats. Numerous little-used roads lead up mountain valleys to lone settlements, without crossing the crests of the ranges. 
As a whole, the region has only a sparse population, but the railways indicate that it lies between more populous regions. The railways have taken advantage of the passes made by the streams through the mountains. The pass at Cumberland was an important thoroughfare during the early settlement of the region west of the Appalachians.

It is instructive to draw a profile along the crest of Wills Mountain, say from the 1,877-foot point on the northeast to the 1,420-foot point on the, southwest, crossing the pass.

PLATKS VI AND VII.

Pls. VI and VII show two distinctly contrasted areas. The area represented in Pl. VI, $A$, has little relief, the altitude ranging only from a little above 860 feet to a little below 780 feet above sea level. 'Though the surface is not flat, its slopes are everywhere gentle, as shown by the wide separation of the contours. The wagon roads and railroads are nearly straight. This map does not show the country houses, but the abundance of roads indicates that the region is well settled. The proximity of two rather large villages likewise indicates a considerable surrounding population. The configuration of the surface and the indications of adequate moisture suggest that the region may be well adapted to agriculture.

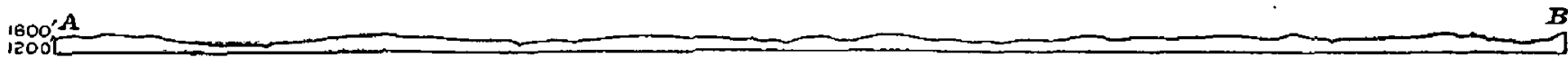

FIG. 6.-Profile along line $A-B$, Pl. VII, $A$. Vertical scale about two and one-half times the horizontal.

The area shown in $\mathrm{Pl}$. VII, $A$, is much rougher, with more valleys and depressions. The fact, however, that the horizontal scale of this map is only one-half that of Pl. VI, $A$, while the contour interval is the same, causes the contours to be more crowded, and so gives an undue impression of the comparative roughness. This impression should be corrected by reference to Pl. VI, $B$, which shows the same area as Pl. VI, $A$, and the same scale and contour interval as Pl. VII, $A$. Pls. VI, $B$, and VII, $A$, are thus fairly comparable. The straight courses of many of the roads shown in Pl. VII, $A$, show that the relief is not excessive. The region clearly belongs to the plain, not to the mountain or plateau type. It is to be noted, however, that there is relief enough to influence the course of the railways and, to some extent, that of the wagon roads. The rectangular system of roads shows that the area is in the region where the section system of land division prevails.

The effect of difference in horizontal scale is shown by a comparison of $A$ and $B$ of PI. VI. The contour interval of both is the same, but the horizontal scale of $B$ is one-half that of $A$. The effect of difference in contour interval is shown by a comparison of $A$ and $B$ of Pl. VII. In $A$ the contour interval is 20 feet; in $B$, representing the same area, the contour interval is 100 feet. The horizontal scale of both is the same.

An east-west profile along the line $A-B$ of Pl. VII, $A$, is shown in fig. 6.

PLATE VIII.

Pl. VIII shows a portion of a plateau, trenched by valleys. The valleys are deep and steep sided-of a type common in high, arid regions, and generally called canyons. The aridity of the region is shown by the intermittency of the streams (see Pl. II) in most of the valleys. The scarcity of culture marks (see Pl. II) indicates the absence of settlement, a condition consistent with aridity. A plateau traversed by valleys, like that shown in the map is said to be dissected (cut up by erosion). A profile along the line $A-B$ of the map is shown in fig. 7. A profile along the bed of a canyon, such as Water Canyon, will be instructive

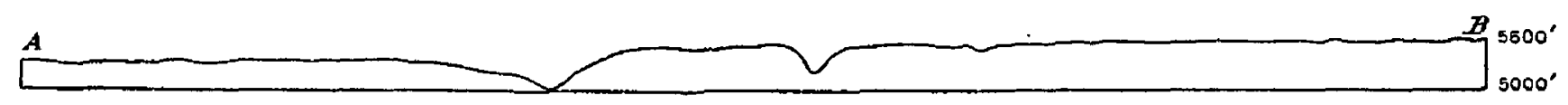

FIG. 7.-Profile along line $A-B$, Pl. VIII, $A$. Vertical scale about six times the horizontal

The contour interval is said to be 25,50 , and 100 feet. For the plane areas the smaller contour interval is used; but for the steep slopes, where, on the map, the lines are much crowded, it would be difficult to insert so many lines; hence some are omitted. Points may 
be found on the slopes of the canyons where a contour line ends abruptly. Beyond the end the contour interval becomes 50 feet if a 25 -foot line drops out, and 100 feet if a 50 -foot contour drops out. Fig. 8 illustrates the method adopted in the dropping of contours.

PI. VIII, $B$, is a sketch of a dissected plateau in a region of the same sort as that represented by the map above, but not in the same locality. At the left are shown some mountain elevations that have no counterpart in the contour map.

\section{PLATE IX.}

Pl. IX, $A$, represents a high mountain with subordinate peaks on its slopes and about its base. Pl. IX, $B$, is reproduced from a photograph of the main mountain. Practice in the interpretation of a topographic map will help the student to visualize some such form as that shown in $B$ from such a map as that shown in $A$.

The name of at least one of the subordinate peaks (Black Crater) suggests that these lower cones are volcanic. This is also the character of the main peak, though it is not shown by the map. The slopes of the main mountain have been to some extent modeled by stream erosion, showing that the cone has been in existence for a considerable time.

The crowded contours indicate that the slopes of the mountain are steep, and as the contour interval is large their crowding

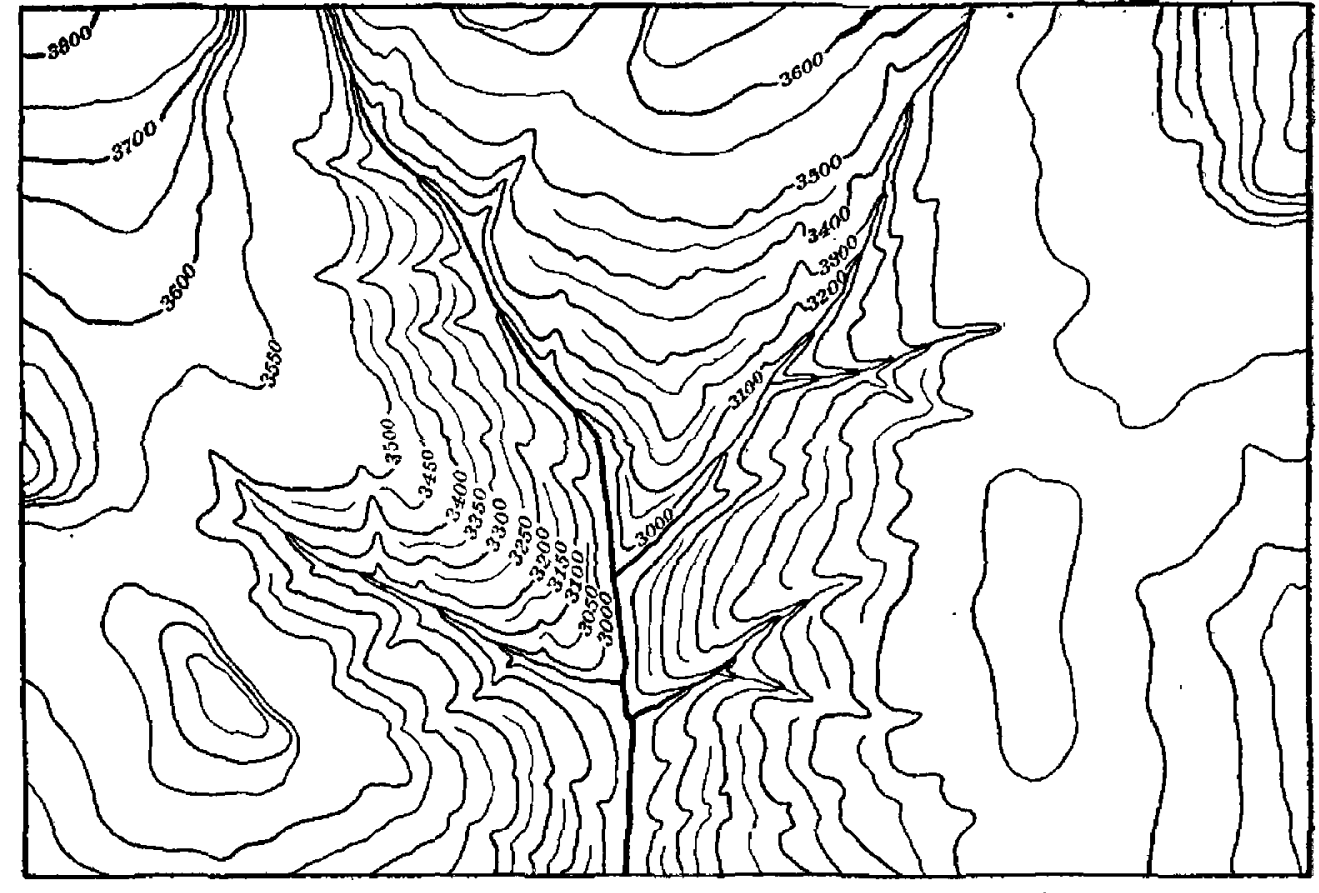

FIG, 8.-Contour map to illustrate the method adopted in the dropping of contours. is more significant of steep slopes than if the interval were smaller. Fig. 9 represents a profile along the line $A-B$ of $\mathrm{Pl}$. IX, $A$. The map shows that the main peak rises more than 11,000 feet above the lowest parts of the surrounding area; and that its top is in the region of perpetual snow is indicated by the fact that several small glaciers (see Pl. II) occupy some of the upper slopes.

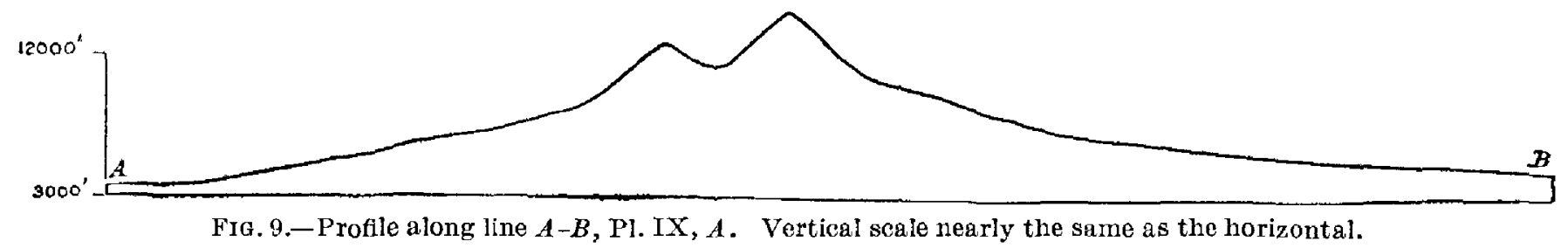

The highest contour of the map is 14,200 feet. This means that the summit lies above this elevation, but that it does not reach 14,400 feet. The highest elevation is indicated (though not by a contour) as 14,380 feet.

The roads on this map are represented by single (not double) lines.

PLATE $\mathrm{X}$.

$\mathrm{Pl}$. X shows two contrasted types of topography, namely, (1) rough, mountainous topography on the left and (2) nearly plane topography on the right. The roughness of the one region is shown by the many contours, and the planeness of the other by the few. The crests of the high peaks approach 9,000 feet; the plain has an elevation of 3,000 to 4,000 feet. All the settlements are on the plain, where roads and houses abound. As in areas of which maps have already been given, the culture is controlled largely by the topography. 
The section at the foot of the plate shows a profile of the surface along the line $A-B$ of the map. The vertical scale is the same as the horizontal.

A special feature of this area is the network of watercourses in the flat valley. Many of these watercourses are irrigation ditches, and the abundance of the ditches indicates the occupation or employment of the people.

PLATE XI.

Pl. XI, like Pl. X, shows a mountain region, but the mountains are of a different type, being well-defined, elongate ridges. This is the Appalachian type of mountain. (Compare Pl. XII.) The slopes of both the mountain ridges shown on this map are steep, but they are not equally steep on both sides of the ridges. The east slope of the west (Dunning) mountain and the west slope of the east (Tussey) mountain are interrupted; that is, they do not descend with even grade. This is illustrated in cross section by fig. 10, which represents a profile along the line $C-D$.

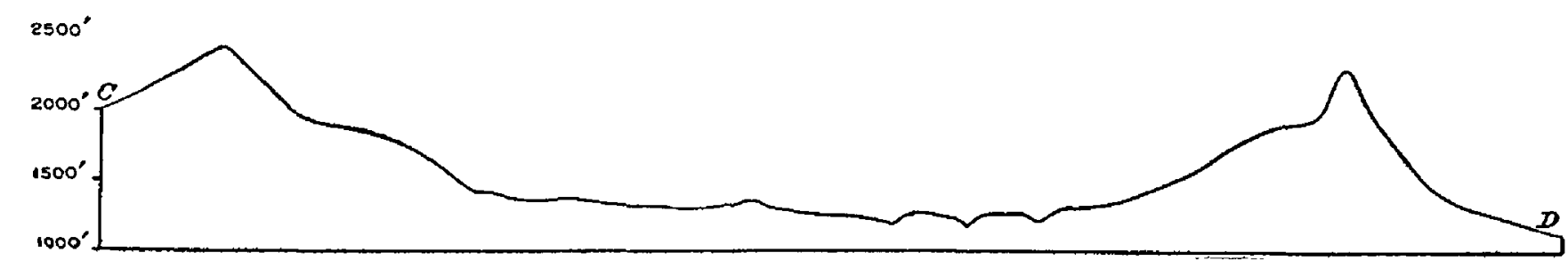

FIG. 10.-Profile along line $C-D$, PI. XI. Vertical scale nearly the same as the horizontal.

The course of one mountain ridge is relatively straight; that of the other is crooked. There is a gap (water gap) in the eastern mountain, through which Yellow Creek flows. The only road connecting the east side of the mountain with the west side also passes through this gap. Two roads cross the western ridge by diagonal courses. The crests of the two mountain ridges approach a common level, though they are not even. The significance of these subeven crests is referred to on page 43 .

Between the mountain ridges there is a tract of lesser elevation and relief, where the slopes are relatively gentle. Determination of the angle of slope by the means already suggested will show that the slopes are not too great to prevent the cultivation of the land, and the distribution of the houses, roads, etc., indicates that agriculture is the industry of the region.

PIATE XII.

Pl. XII represents, in a different way, a large area in which the topography is similar to that shown for a small area on a much larger scale in Pl. XI.

Plate XIII.

Pl. XIII shows two contrasting types of coastal lands. In $A$ the coast represented is low and marshy, the highest point of the land rising less than 30 feet above sea level. $B$, on the other hand, shows a bold coast, with a steep cliff facing the sea and rocky points projecting into it.

It is shown elsewhere (p. 69) that such a coast as that mapped in $A$ suggests that deposits of sand and gravel are being made along the shore, building the land out into the sea; while a coast like that mapped in $B$ suggests wave erosion, or the advance of the sea on the land.

PLATE XIV.

Pl. XIV, $A$, represents, in another way, the type of coast shown in Pl. XIII, $A$. Similarly PI. XIV, $B$, represents the type of coast shown in Pl. XIII, $B$. Pl. XIV therefore helps in the interpretation of Pl. XIII.

PLATE XV.

$\mathrm{Pl}$ XV, $A$, shows an area of rough topography where the relief is not great-that is, a region where elevations and depressions lie close together, though the hills are not very high nor the depressions very deep. Topography of this sort is depicted in $\mathrm{Pl}$. XV, $B$. 
Many of the depressions shown on Pl. XV have no outlets (see Pl. II) and contain lakes and ponds. There are also great areas of marsh. Many of the wagon roads are crooked, but the railways are straight. Although the railways do not traverse the roughest parts of the area, the courses of the roads of these two classes suggest that the hills are composed of material which the railways find it easy to remove, whereas the wagon roads, which are built with less regard to grade, go around or over the hills by the easiest routes.

In contrast with the areas shown on most of the preceding plates, the area represented by this map is ill drained. Though water is abundant, most of the streams have shallow and some of them ill-defined valleys. The principal features of the relief do not stand in very clear and systematic relations to the stream valleys. In this respect also the map is in contrast with most of those preceding.

Topography of the type shown on this map is characteristic of regions that have been recently glaciated.

\section{GROUP 2.-THE WORK OF WIND.}

Pls. XVI-XXII are designed primarily to illustrate the geologic effects of the wind. The maps show other features as well, but these features receive no more than incidental mention in this connection, though some of them are referred to further on, in connection with other topics.

\section{PLATE XVI.}

Pl. XVI shows a series of mounds, hills, and ridges of wind-blown sand along the coast of Chesapeake Bay. Elevations of this sort are called dunes. The surface of the area represented by the map is generally low (note the 5 -foot contour interval), and the highest lands are along the coast. The dunes are indicated by the gray dots; but inasmuch as low coasts are favorite places for dunes, it might be inferred with some confidence that the coast ridges and hills were dunes, even without the legend. At Cape Henry the dunes reach a height of more than 80 (but not 85) feet.

It will be observed that the belt of dunes shuts in water bodies, converting into lakes what would otherwise be bays. Thus Broad Bay, though a bay in name, is really a lake; so is the body of water at Little Creek and other bodies farther east. The openings of these former bays were probably not closed by wind-blown sand, but by bars deposited by waves and currents. After the bars were made the wind piled up the sand, converting the low beach into a belt of relatively high dunes.

The geology and the topography, taken together, indicate that the dune sand was blown up from the shore onto a tract of low land covered by the Columbia formation. The geologic section below the map shows the structure from the surface down to sea level along the line $A-B$.

$$
\text { Plate XViI. }
$$

Pl. XVII, $A$, shows an area at the head of Lake Michigan where dunes abound. They are here represented by contours only, without dots. The dunes are in the form of irregular hillocks and ridges, and the ridges are roughly parallel to the shore. They are conspicuous on both sides of Grand Calumet River, as well as at some points farther from the lake. Some of the dunes near the northeast corner of the area mapped are more than 100 feet high. The dune ridge at this point prevents Grand Calumet River from entering Lake Michigan, and its waters finally reach the lake many miles farther west. It is probable that the river formerly joined Lake Michigan at the point where it now approaches the lake most closely. The strean was probably obstructed in the same way as were the bays shown on the preceding map (Pl. XVI), and its obstruction indicates that its flow was sluggish. Long Lake occupies a depression among the dunes. Except for the dunes the surface of this area is for the most part nearly flat. The principal features of the relief are therefore due to the wind.

Pl. XVII, $B$, shows low moundlike dunes on the coast of Maryland. The dunes here are on a beach or bar that lies at some distance from the mainland, a position in which dunes abound between New York and the Carolinas. This beach is mostly uninhabited except by 
THE INTERPRETATION OF TOPOGRAPHIC MAPS.

Government employees at the life-saving stations along it. Beaches of this sort, especially farther north, are extensively utilized for summer resorts. Between the beach and the low mainland lies a bay, the borders of which are marshy.

PLATE XVIII.

Pl. XVIII represents dunes in two widely separated areas, one on the east shore of Lake Michigan and one on the coast of New Jersey. The topography shown by this plate is not unlike the topography north of Grand Calumet River in Pl. XVII, $A$, and that along the beach in Pl. XVII, $B$.

\section{PLATE XIX.}

The topography on the south side of Arkansas River, in the region shown in Pl. XIX, is in sharp contrast with that on the north. The character of the topography on the north side indicates that it was determined by the erosion of surface waters. On the south there are numerous small hills, most of them defined by a single contour, but some by two, which stand in no systematic relation to drainage lines or to one another. These hillocks are dunes. Among them there are many depressions without outlet. (See Pl. II.) The suggestion of the map is that these depressions were scooped out by the wind or inclosed by the building up of the surrounding dunes. Dune hillocks stand within a few of the depressions. Basins of this sort are common in dune regions, and where the climate is sufficiently moist they may contain ponds or marshes. The absence of ponds and marshes, as well as of tributary streams, from this area points to aridity of climate, which is indicated also by the dunes, for only dry sand is blown about by the wind. The slight settlement and the few roads of the region are consistent with the aridity inferred from the topography. The principal settlements are along irrigation ditches in the valley of the main stream.

Most of the dunes stand 40 feet or more above the river, the flood plain being free from them. The source of the sand in this region is not evident from the map, but the sand of dunes along streams is often blown up from the river banks to the tops of adjacent bluffs, even where the bluffs are much higher than those on the south side of this valley.

Hillocks of the sort shown on this plate, especially along streams or coasts, may as a rule be confidently interpreted as dunes, but it should be noted that the topography of this map has something in common with that shown on Pl. XV, where comparable features are not the work of wind.

A comparison of this map with Pl. XVI and Pl. XVII, $A$, will show that dunes may have the form of either ridges or hills, but the latter form is more common.

The section below the map on this plate gives some idea of the topography as seen in profile; but Pl. XVIII affords, perhaps, a greater aid in the interpretation of the topography shown on Pl. XIX.

PLATE XX.

Pl. XX represents two phases of wind work. $A$ shows an incipient dune gathering about tufts of herbaceous vegetation. $B$ shows a region where the dune sand which once buried a forest has been moved on by the wind, exposing trunks and stumps of trees that had been buried by sand and killed. Timber so exposed has been called a "resurrected forest." This view shows also the first stage of a repetition of the process of destruction, the sand having begun to attack the younger growth on the hill at the right. Both figures are reproduced from photographs of dunes about the head of Lake Michigan.

PIATES XXI AND XXII.

Pl. XXI, $A$, represents an area of dunes not in close proximity to a river or a coast. Among the dunes there are depressions apparently scooped out by the wind. The map shows the topography and geology of the region. Most of the dunes are indicated by only a single contour, but some are represented by two, and a few by three. Some of the associated basins are so deep as to require two depression contours. (See Pl. II.) Two contours show that the depressions are more than 40 feet deep, and less than 60, but they do not give the depth 
more accurately. Thus, the depression east of Hay Valley is surrounded by the 4,220-foot and the 4,200-foot contour lines. The 4,200-foot line, being a depression contour, merely shows that the bottom of the basin is lower than 4,200 feet, but not as low as 4,180 feet. 'So far as the map shows, it may have an elevation of 4,199 feet, or 4,181 feet, or anything between.

The 4,220-foot depression contour shows that the immediate border of the depression has an elevation of 4,220 feet or more, but is not as high as 4,240 feet. It may have any elevation between these limits, so far as the map shows. If the bottom of the depression has an altitude of 4,199 feet and the rim (as at the southeast end) an elevation of 4,221 feet, the depression is only 22 feet deep. If, on the other hand, the bottom of the depression has an elevation of 4,181 feet and its border has an elevation of 4,239 feet, both of which are possible so far as the map shows, the depth of the depression is 58 feet. This indicates that the details of the surface are not always accurately represented by contours. The uncertainty may be relatively greater where but two contours are involved, as in the present case, than where the number is greater, for it applies only to the portions below the lowest and above the highest contours. In the case cited, the maximum possible error is a little less than twice the contour interval. In the determination of the altitude of the bottom of the depression or the altifude of its rim, the maximum possible error is less than one contour interval. In a map comprising many contours the possible error is relatively small.

From the colors in patterns on the map, representing the geology of the region, it is seen that dune sand (bluish dots) lies upon the Arikaree formation (shown in buff) and conceals it in some places. The suggestion of the map is that this formation, which is made up of soft sandstone, furnished the material for the dunes.

The paucity of streams indicates at least a moderate degree of aridity, but the small ponds and intermittent lakes (see Pl. II) indicate that the aridity is not extreme. Streams appear in those parts of the area where dunes are absent, as in the southwest corner, suggesting that in most of this area the texture of the surface is such as to allow the rain water to sink in, rather than to cause it to flow off. Inferences concerning the settlement and development of the region are readily drawn.

$\mathrm{Pl}$. XXI, $B$, shows a few small dunes and wind-formed sinks, but is introduced primarily to illustrate the topographic effects of wind erosion other than by scooping out depressions. The dunes, so far as the map suggests, are the small hillocks especially numerous on the west side of the ridge near the southeast corner of the area mapped. Most of them are represented by but one contour and they are associated with sinks. The high, steep-sided hills are not dunes; they are too high, too steep, and too isolated. Furthermore, their names indicate that they are not composed of loose sand, as dunes are. PI. XXII will help to an understanding of the topography of this area.

The paucity of streams and the presence of irrigation ditches point to aridity. The dunes show that sand is accessible to the wind. Under these conditions the isolated hills, such as Castle Rock, Table Rock, and Chimney Rock, must have been carved more or less by winddriven sand. The fact that many of these isolated hills have individual names is sufficient evidence that they are striking topographic features.

Fig. 11 is a geologic structure section along the line $A-B$ of Pl. XXI, $B$. The letters $\mathrm{Eb}, \mathrm{Ng}$, and $\mathrm{Nar}$ in the section stand for certain sandstones and conglomerate formations capping the hills. These formations are shown in the views on Pl. XXII, which depicts two of the "rocks" of Pl. XXI, $B$. The forms of these hills are due partly to the wind and are characteristic of some parts of the semiarid western interior.

In addition to the foregoing maps, the following topographic sheets of the United States Geological Survey afford good illustrations of dunes: Springfield, Colo.; Dodge, Great Bend, Hutchinson, Kingman, Kinsley, Larned, and Pratt, Kans.; Green Run, Md.-Va.; Browns Creek and St. Paul, Nebr.; Barnegat and Long Beach, N. J.; and Sandy Hook, N. J.-N. Y. (See also Pls. CXXXIV-CXXXVIII.) 


\section{GROUP 3.-STREAM EROSION.}

The primary purpose of Pls. XXIII-XLIV is to illustrate various phases of stream erosion. In the following descriptions other significant features of some of these plates are not noticed, but some of these features are referred to further on in other connections, where the topics under consideration are illustrated by these plates.

Pls. XXIII-XXXVI illustrate, especially, youthful topography and youthful valleys. Some of them show such features in plains; others represent them in plateaus and mountains. Pls. XXXVII-XLIV represent more advanced phases of erosion topography. Pl. XLV is inserted in this group to illustrate, for the sake of contrast, a type of surface not due to stream cutting.

\section{YOUTH (PLATES XXIII-XXXVI).}

PLATE XXIII.

PI. XXIII shows a surface of relatively slight relief, traversed from northwest to southeast by three rather broad depressions nearly parallel to the lake. Their positions are marked by the intermittent streams shown on the map. Between the depressions and east of the easternmost there are broad, low ridges, the one nearest the lake being highest, rising to a maximum height of about 100 feet above the lake. The lake is bordered by an interrupted cliff which suggests that the waves are cutting into the shore and the lake advancing upon the land.

The numerous ravines that lead down to the lake form the special feature which this map is intended to illustrate. These ravines are incipient valleys-gullies grown big. They have steep slopes, as shown by the crowded contours that border them on both sides. Some of them are no more than a quarter of a mile long; others are fully a mile. There are numerous short gullies on the sides of the larger ones. Such a ravine as that north of Ravinia illustrates the general plan of a river-valley system, and many a valley system is but a further development of the sort of ravine shown here. The ravines are lengthened at their heads by successive rains, just as the common gully or "wash" is lengthened by head erosion with every passing shower. The fact that the ravines of the map are short shows that they are young. No one of them. has a permanent stream.

The youth of these valleys along the lake, the absence of similar drainage lines in most other parts of the area represented by the map, and the marshiness of various tracts well above the level of the lake all indicate that the topography of the area as a whole was not shaped primarily by the erosion of running water.

The position of one of the railways was determined in part by the position of the heads of the ravines. It is located just far enough from the lake to avoid the depressions and thereby to obviate the necessity of building bridges.

The profile beneath the map represents the surface along the line $A-B$ on the map. The

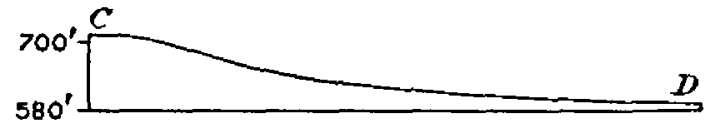

FIG. 12.-Profile of ravine north of Ravinia, $\mathrm{lll}$. $(C D$ on Pl. XXIII). Vertical scale about seven times the horizontal. vertical scale is exaggerated about seven times. Fig. 12 shows the profile of the ravine north of Ravinia, from its lower end at the lake to its head, the vertical scale being about seven times the horizontal. The figure brings out the form of the decrease of gradient from the head of the ravine to its mouth, which the contour lines exhibit equally well to one familiar with their interpretation. The reader will find it instructive to draw to scale a profile of another ravine shown on the map.

Pl. XXVII, $A$, shows a ravine, of the type represented in contours on Pl. XXIII, in an incipient stage of development.

\section{PLATE XXIV.}

Pl. XXIV affords further illustrations of young valleys developed through erosion by running water. A shows a series of young valleys leading to Lake Ontario. With one excep- 
tion, they are short, narrow, and steep sided. The valley of the main stream, though not short, is likewise narrow and steep sided. Vallers having such features are young.

The terms young, mature, old, as applied to rivers and valleys, have reference not so much to the length of their history in years as to the amount of work which the streams have accomplished, in comparison with that which they have before them. In time a valley becomes wide. Wider valleys are shown in $B$ of this plate, and on Pls. XLII, XLIII, and XLIV. The valleys shown on these plates are much older than the valley of the main stream shown in Pl. XXIV, $A$. The exact meaning of the adjectives young, youthful, mature, old, etc., as applied to streams, will become familiar in the reading of the following pages.

Except for the depressions along the drainage lines the surface shown in Pl. XXIV, $A$, is nearly flat. A considerable part of it has little drainage. It is clear that the heads of the present valleys will be extended back into the land, for the surface water running into their heads will wear them back. The lengthening of the valleys at their heads will cause the relatively flat areas in the southern and southwestern parts of the area mapped to become uneven, like the area at the northeast. As the valleys are all young, and as most of the area contains no valleys, though it stands well above the lake, the area is said to be young in its erosion history.

Pl. XXIV, $B$, represents a series of young valleys leading to the large and older valley of the Illinois. The crowded contours about the tributary valleys indicate that their slopes are steep, and the positions of the contours show that the valleys are narrow. Being narrow and steep sided, they are young.

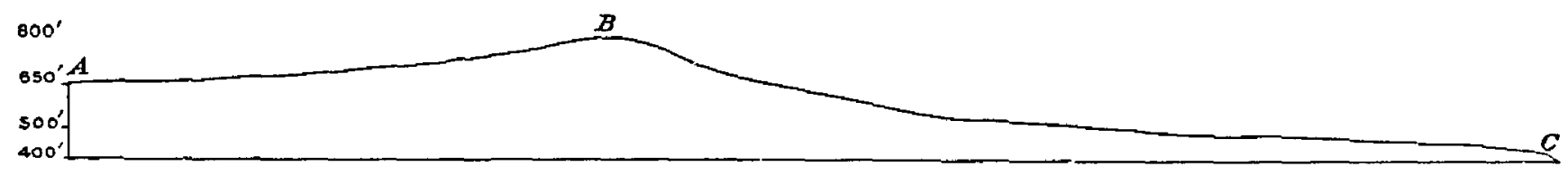

FIG. 13.-Profile along line $A-B-C$, Pl. XXIV, $B$. Vertical seale about five times the horizontal.

It will be readily seen that the gradient of the valleys leading to the east is much greater than that of the valleys leading to the west. This is shown by fig. 13, which represents a profile from a point on the railway about a inile northwest of Alta to the river bank near Mossville, by way of the drainage lines $(A-B-C, \mathrm{Pl}$. XXIV, $B)$. Such a divide as that shown in the figure is evidently unstable, for the water flowing eastward will flow faster and wear faster than that flowing westward. The result will be that the divide between the two valleys will be shifted (or will migrate) toward the west, and the valley leading eastward will presently receive drainage from the area which now sends its waters to the west. Should the divide be shifted westward as far as $A$ (Pl. XXIV, $B$ ), as seems possible, the stream above (south of) $A$ will be diverted to $C$. This sort of change in drainage has often been accomplished. The valley that appropriates the waters of another valley is called the pirate valley or simply the pirate. In the case supposed, the stream below $A$, after it has lost its headwaters, is said to be beheaded, and the stream that is shifted to the new course to be diverted. The whole process is called stream piracy.

There is also a contest among the tributaries to the Illinois. Thus some of the small valleys, like that at $D$, have little chance for much further development, inasmuch as the territory into which they might grow is already preempted by larger valleys.

Pl. XXIV, $B$, represents an area where the erosion history is somewhat more advanced than in Pl. XXIV, $A$. The area as a whole may be said to be in its late youth, or early maturity. Both the maps of this plate, as well as that of Pl. XXIII, represent areas of plains. Pl. XXIV, $B$, may be called a dissected plain.

Inferences concerning the climate and the settlement of both regions represented on Pl. XXIV are readily drawn.

PLATE XXv.

Pl. XXV represents a plateau region. The surface is nowhere flat, though over much of it the slopes are not very steep. One notable elevation, Basalt Butte, rises with steep slopes above the general surface. 
The most conspicuous feature of the map is the deep, narrow, steep-sided valley or canyon of Snake River. This valley is 700 or 800 feet deep in its deeper parts, and less than half a mile wide from rim to rim where narrowest. Deep as the valley is, it is youthful, for it is narrow and steep sided, and such valleys are youthful, whether deep or shallow. The very considerable depth of this valley, as compared with the young valleys shown on preceding maps, is due to the height of the land in which it is cut. Comparison of this map with Pl. XXIV, $A$, shows that the Snake River valley is cut to a depth of 700 or 800 feet in a plateau about 3,000 feet high, and that the valley of the Genesee is cut to a depth of about 140 feet in a plain that stands 400 feet above sea level. It should be borne in mind that distance from the sea, by the course which the drainage follows, is likewise an important factor in determining the depth of a valley. Several other elements besides altitude also affect the depth.

The fact that most of the streams shown in Pl. XXV are intermittent suggests aridity. The scarcity of roads and settlements is in harmony with this suggestion. So also is the narrowness of the main valley. The presence of this large stream, with few tributaries, in the midst of an arid region leads to the inference that the stream must have its source in some less arid tract. As a matter of fact, Snake River heads in mountains where it is continually fed by melting snows, and therefore has a permanent source of supply which enables it to maintain its course through the arid lands.

The meaning of the sort of topography shown on this map will be brought out by a cross section of the canyon, drawn to scale at right angles to the canyon, extending 4 miles on either side. If the vertical scale is exaggerated, the amount of the exaggeration should be noted.

\section{PLATE XXVI.}

PI. XXVI represents a canyon in a plateau notably higher than that illustrated on Pl. XXV, and the canyon is correspondingly deeper. The valley here is about 1,200 feet deep in a plateau that stands about 8,000 feet above the sea, which is much farther from this area, by the course of the drainage, than from that shown in Pl. XXV. A cross section of the canyon along the line $A-B$ of the map is shown on the plate. The vertical scale is not exaggerated. The tributary streams in the northern part of the area shown on the map flow in canyons, but those which join the main stream south of its canyon, above the falls, flow in shallow valleys. Such a relation is well-nigh universal. In other words, where a main stream has a canyon its tributaries also have canyons. This is not accidental. Falls and rapids in streams generally recede upstream, and as they recede they leave canyons or gorges below. $\Lambda$ s the falls or rapids of main streams pass the mouths of tributaries, the tributaries fall or develop rapids, and the recession of the falls and rapids of the tributaries likewise leaves canyons below. Falls breed falls, and canyons breed canyons.

It will be seen that three contours cross the stream at the lower falls and two at the upper. Even if the height of the falls were not given, some inference could be made concerning it from these contours. The two contours at the upper falls $(7,500$ and 7,600$)$ show that the descent of the water is more than 100 feet and less than 300 feet. The first inference needs no explanation. The second is, at first thought, less evident. The map shows (1) that the base of the falls is lower than 7,500 feet, but not so low as 7,400 feet; and (2) that the top is above 7,600 feet, but not so high as 7,700 feet. If the base were down nearly to 7,400 feet and the top up nearly to 7,700 feet, the height of the falls would be nearly 300 feet. The figures given for the fall, viz, 109 feet, show that the base is but little below 7,500 and the top but little above 7,600 feet. It will be seen, therefore, that with a 100 -foot contour interval, the error in the estimate of vertical distances may be considerable. The three contours of the lower falls $(7,400,7,300$, and 7,200$)$ show that the fall exceeds 200 feet in height, but does not reach 400 feet. The maximum uncertainty, as in the other case, is less than 200 feet-that is, less than twice the contour interval. Where there are several contours, the possible error, as already noted, is therefore relatively less than where a few only are involved. 
The student will find it profitable to draw to scale a profile of the stream from some such place as Inspiration Point to a point a mile above the upper falls.

The northwestern part of the area mapped includes mountains.

Like the areas shown in the preceding plates (XXIII, XXIV, and XXV), this is a region of youthful drainage and the topography as a whole is also youthful.

\section{PLATE XXVII.}

Pl. XXVII, $A$, shows the beginning of a valley; Pl. XXVII, $B$, shows the canyon and lower falls of the Yellowstone. Some such view as that shown in Pl. XXVII, $B$, might be inferred from Pl. XXVI, for the latter gives an idea of the height of the falls and shows that the stream is a large one. The map, however, gives no indication of the details of the steep slopes of the canyon.

\section{PLATE XXVIII.}

P1. XXVIII represents the largest canyon in the United States, if not in the world-the Grand Canyon of the Colorado. On the east its width at the top is more than 10 miles. Measured from the plateau on the soutl, the canyon is somewhat less than a mile deep, and from the plateau on the north, somewhat more than a mile. The south wall is the steeper, but even here at the point where the distance is shortest it is 2 miles from the edge of the canyon to the river.

The north slope is characterized by numerous "temples." These are parts of the plateau in which the canyon is cut that have been isolated by erosion. Some of them are of mountainous proportions. There is a deep, narrow gorge at the bottom of the canyon, excavated in crystalline rock. This inner gorge is comparable in size to the canyon of the Yellowstone. The slopes above it are very uneven, being steep in some places and gentle in others. This unevenness gives the sides of the canyon a terraced appearance, the steep slopes, or cliffs, being composed of the more resistant rock outcrops.

The Grand Canyon appears to be due wholly to the erosion of running water.

\section{PLATE XXIX.}

Pl. XXIX shows two views of the Grand Canyon of the Colorado. $A$ shows the canyon as a whole, and $B$ the inner gorge.

\section{PLATE XXX.}

Tuolumne Canyon (Pl. XXX) is very different from the Grand Canyon of the Colorado, and the difference is not simply one of size. So far as the map of the canyon itself is concerned, there is little to indicate that it is not entirely the work of the strean, but the lakes that appear at various points above the canyon and in one or two places on its slopes suggest glaciation, and the photograph that accompanies the map likewise suggests that ice has been a factor in shaping the valley. The glacial influence has, however, been much less pronounced than in the valley represented on $\mathrm{Pl}$. XXXI.

\section{PLATE XXXI.}

Next to the Grand Canyon of the Colorado, Yosemite Canyon (Pl. XXXI) is, perhaps, the most wonderful valley in the United States. It is remarkable for its steep slopes, its wide bottom, and its great depth. The history of this canyon differs from that of the Colorado, for whereas the latter is the work of running water, the Yosemite is partly the work of glacial ice.

During the later glacial epoch the ice of the Sierra moved down the valleys in the form of glaciers. The valley that occupied the site of the Yosemite was probably large, as a result of river erosion before the glaciers developed, and it therefore held a large glacier. The movement of the ice enlarged the valley greatly, deepening it, broadening its bottom, and making 
its slopes, particulariy its lower slopes, steeper. The canyon is therefore not the work of water alone, but of water and ice. Perhaps no other river valley in the country was more profoundly modified by the work of glaciers than this. Both the steep gradient of the valley and the structure of the rock facilitated the erosive work of the ice.

Plate XXXiI.

PIs. XXXII-XXXVI represent areas of youthful topography. These areas include youthful valleys, but attention is directed to the topography of the areas, taken as wholes, rather than to the valleys alone.

PI. XXXII is a good illustration of youthful topography, the area represented being a low plain in which the drainage is very young. The valleys are shallow, narrow, and steep sided in their lower courses, but the youthfulness of this plain is indicated primarily by the fact that large areas are not yet invaded by valleys or ravines. The type of youth shown here is different from that shown on Pl. XXIII. In that area the topography is youthful because the ravines have not yet extended their heads far back into the land. Here streams cross the whole area, but their valleys are very young and considerable parts of the area are wholly destitute of drainage lines.

The configuration of the surface in the area shown on PI. XXXII indicates that streams have been operative on it for only a short period of time; but it also indicates that the valleys are not simply gullies grown big. As a matter of fact it is not long since the waters of Lake Ontario stood over the area. When the lake level was lowered, the streams that joined the lake at the old shore line found their way across the flat, which became land by the withdrawal of the lake waters. These streams have cut their narrow, gorgelike valleys near the lake since the lake receded, and these gorges are being extended landward. This area is therefore young, because the streams flowing across it have not yet had time to make wide valleys or to develop many tributaries. The area shown in Pl. XXIII is young, because valleys developing by erosion at the heads of ravines and gullies have not yet extended themselves far back from the lake. Still other types of youthful drainage will be shown on later plates.

In spite of the extreme shallowness of many of the valleys in the area mapped in PI. XXXII the streams are permanent, indicating abundant rainfall.

The low ridge along the southern part of the area mapped, as at East Gaines, represents an old beach line.

\section{PLATE XXXIII.}

Pl. XXXIII represents another area of youthful drainage and topography. That the region is young in its erosion history is shown by the existence of considerable areas which the valleys have not invaded. The heads of the tributary valleys are working back into the low, interstream areas, but large tracts still remain undissected by them. The area is so low that the development of the drainage will be slower than in areas lying at the same distance from the sea, but at higher altitudes, where the cutting power of the streams is greater. The valleys are not of the ordinary youthful type. On account of the low elevation they are and must always remain shallow, and they have sufficient width to indicate that they are not extremely young. (Compare Pl. XXXII.) However, as explained on page 27, youth is a comparative term when applied to topography, and measured by the amount of work yet before these streams the valleys are still in the earlier stage of their history.

The explanation of this sort of surface is not altogether clear from the topographic map. The marshiness might be due to a slight subsidence subsequent to the development of shallow valleys. It might also be explained by the presence of a relatively impervious bed, as of clay, at the level of the stream flat, or by the lowness of the land. The shortness of the tributary streams is also anomalous, and the map does not make the reason clear. This plate represents poor drainage, as well as youthful topography. 
PLATE XXXIV.

Pl. XXXIV represents the sort of surface shown in some parts of Pl. XXXIII in the conditions which would prevail during a wet season.

PLATE XXXV.

Pl. XXXV, $A$, presents another illustration of youthful topography and imperfectly developed drainage. The heads of the valleys are working back into the area from the north and the northeast, but the larger part of the surface represented is as yet unaffected by them. In most of this area, therefore, the valleys are umborn, and stream-erosion history has not begun. Along the northern edge of the area the topography is youthful. Its type of youth corresponds in soine measure with that of the east border of the land area shown in Pl. XXIII.

$\mathrm{Pl}$. XXXV, $B$, represents another type of youth. Here considerable streams flow through an area which is otherwise largely unaffected by valleys. From neither of the main streams have tributary valleys worked back any considerable distance into the surrounding flats. This type of youthful surface indicates that the valleys did not develop simply by the headward lengthening of gullies and ravines. It looks rather as if streams from some permanent source of water had recently begun to flow across the flat, taking a winding course because the gradient was low and the surface slightly uneven, and had had time to cut only narrow and shallow valleys. Quite independently of this map it is known that this area was at a time geologically recent a lake bottom. It is within the valley of Red River, and the flat was formerly covered by the waters of Lake Agassiz, ${ }^{a}$ which is now extinct. The type of youth shown by PI. XXXV, $B$, corresponds in some measure with that shown on Pl. XXXII.

PLATE XXXVI.

Pl. XXXVI furnishes another illustration of the type of youth shown in Pl. XXXV, $B$. A well-developed young valley, occupied by a considerable stream, crosses the area shown on the map. The tributary valleys have reached a stage of development harmonious with that of the main valley. Valleys of this type are common along the south shores of Lakes Erie and Ontario. The map also shows old shore lines-one at North Ridgeville and one along North Ridge, southwest of Avon. Similar lines appear in the western part of the area. The recent retreat of the lake from this area, exposing a surface which was essentially without valleys, affords the explanation of youthful valleys of this type.

Youthful topography is also well shown on the following topographic sheets of the United States Geological Survey: Calumet, Ill.; Ayden, Kenly, and Newbern, N. C.; Casselton, N. Dak.; Hamlin and Raquette Lake, N. Y.; Maumee Bay and Toledo, Ohio-Mich.; Bowling Green, Elmore, Findlay, Fostoria, and Vermilion, Ohio; Abajo, Utah-Colo.; and in this volume on Pls. VI, VIII, LXXXIII, LXXXIV, XCV, XCVI, $A$, XCVII, XCIX, C, CII, CIV, CXII, CXXVII, CXXX, CXXXIX, CXLVI, and CLXVI.

MATURITY (PLATES XXXVII-XLII).

PLATE XXXVII.

Pl. XXXVII shows a region in advanced youth or early maturity, so far as its erosion history is concerned. The valleys, by head erosion, have pretty thoroughly dissected the plateau, though there still remain somewhat broad divides between them. A large part of the surface is made up of slopes which have been developed by the erosion of running water. Not only is a larger proportion of the surface in slope than in most of the areas shown on the preceding maps, but the valleys are wider, indicating a more advanced stage of development. 
The broad divides at an elevation of 1,600 to 1,700 feet appear to represent a former nearly level surface, which has been made rough by the excavation of the valleys:

The reader will find it instructive to draw a profile to scale across this map in a direction approximately at right angles to the courses of the main valleys.

Early maturity is also shown on Pl. IV of this volume.

PLATE XXXVIII.

Pl. XXXVIII shows an area whose topography is mature-that is, the valleys are developed to such an extent that nearly all the surface has been reduced to slope. Little is to be

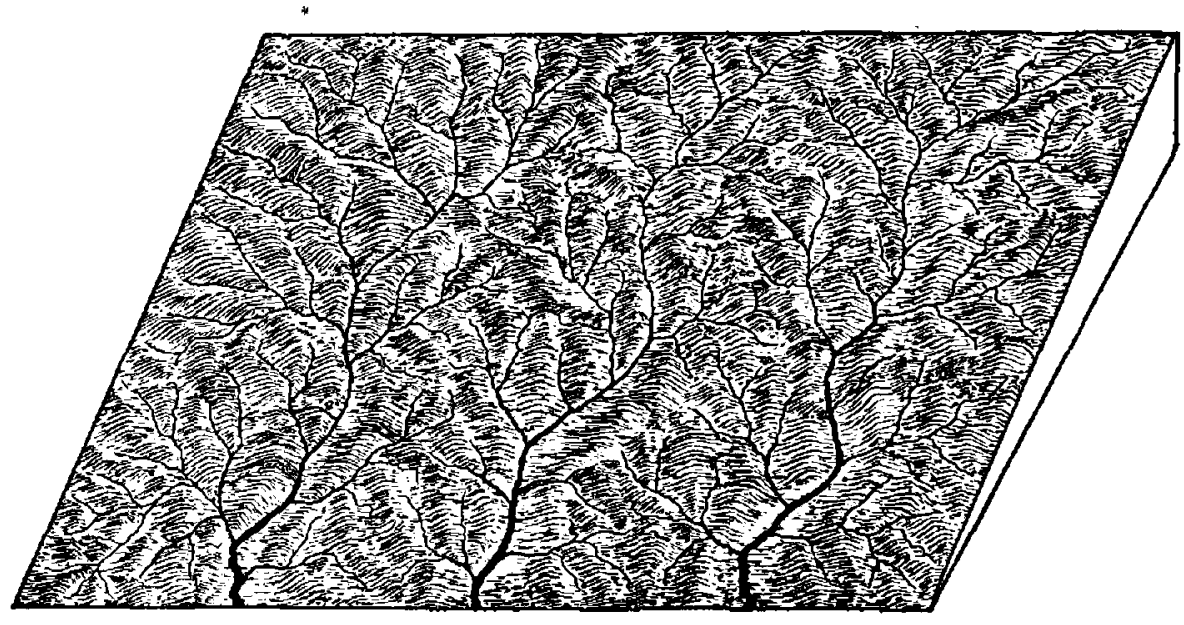

FIG. 14,--Diagram showing the type of surface represented on Pl. XXXVIII-an area of mature topography. seen of the original plateau in which the valleys have been cut, though diminutive remnants of it appear at various points at elevations of 1,100 to 1,200 feet. There is no considerable area where the contour lines are. not moderately crowded. A narrow flat, half a mile to a mile in width, stretches along the valley of the main stream, but everywhere else the surface is sharply undulatory. The type of surface represented by the map is shown in fig. 14 .

The main stream is developing a flat at a very considerable elevation above sea level. The river is, however, many hundred miles from the sea by the route which the drainage follows. The valley, therefore, can not be cut so low as if it were nearer the sea.

Pl. XXXVIII represents a further development of the features shown in Pl. XXXVII. When the valleys of the area shown on Pl. XXXVII have become a little deeper and when the heads of the tributaries have worked back a little farther, destroying the broad divides, the surface will be somewhat similar to that shown on Pl. XXXVIII.

The relief here is sufficient to exert an important influence over the location of roads, settlements, etc. (Compare Pl. XXXVII.) The section at the bottom of the plate shows the profile of the surface along the line $A-B$ of the map, the vertical scale being exaggerated about two and a half times.

\section{PLATE XXXIX.}

Pl. XXXIX presents other types of mature topography developed by drainage. In $A$ the surface is mainly in slope, and the slopes all have definite relations to the drainage lines. There is a small flat developed along the main stream, to which all the tributary valleys lead. The relief of the region is somewhat less than that of the area shown in Pl. XXXVIII, and the topographic control of the culture is less pronounced. The intermittency of many of the tributary streams indicates that the region is not one of great precipitation.

Pl. XXXIX, $B$, shows a mature type of topography in a region of much greater relief. The highest point, Mount Mitchell, is more than 6,700 feet above sea level. The lowest points shown on the map are about 2,200 feet above sea level, so that the area has a relief of about 4,500 feet. Except for some narrow flats along the main streams, the whole area is in slope, and all depressions are occupied by streams. The topography has clearly been shaped by drainage, and the drainage has advanced so far as to cause the development of slopes in every part of this area.

In meither of the maps forming Pl. XXXIX have the ridges any persistent or even prevalent direction. The absence of any well-defined trend to ridges and valleys may mean either that the underlying formations are essentially horizontal or that they are not stratified. 
PLATES XL AND XLI.

Pl. XL represents another area where the drainage and the erosion topography are mature, but the topography is of a type that is radically different from that shown in Pls. XXXVIII and XXXIX. In this area the principal topographic features have a prominent northeastsouthwest trend. Where the main streams cut through the conspicuous ridges their courses are generally at right angles to the rilges.

This peculiar topography is explained by Pl. XLI, which shows the geology of the same region. (See pp. 12-18 for discussion of geologic maps.) From this map it is evident that the courses of the valleys and ridges stand in intimate relation to the geologic structure of the region. The explanation of the topography is found in the fact that the various sorts of rock shown in Pl. XLI are of unequal hardness. The valleys have been developed on the softer and more easily eroded beds, and the harder rocks stand out as ridges, because the less resistant beds adjacent to them have been cut away to lower levels. The ridges have not been "thrown up," but the beds surrounding or bordering the ridges have been cut down. The streams that cross the outcropping belts of the hard rock cross them at right angles, or nearly so, flowing through these belts for as short distances as possible. The most conspicuous topographic features of the region are thus seen to be intimately related to the structure of the rock formations. Such a relation will be more fully illustrated in succeeding maps. Meantime, Pls. XL, and XLI are to be taken as representing a type of mature drainage in which the topography has been determined by the unequal resistance of tilted beds of rock.

PLATE XIII.

Pl. XLII represents another aspect of mature drainage. The area mapped is a tract along a great river. The stream is bordered by a wide flat, and the uplands on each side are thoroughly dissected. The tributary valleys, especially the small ones, are much less advanced in development than the main valley. This is the usual relationship between main streams and their tributaries. The main stream (Kanawha River), to which the minor streams shown in Pl. XXXVIII lead, may in time have a valley comparable to that of the Ohio, shown in Pl. XLII. Indeed, the Kanawha is a tributary of the Ohio, and a comparison of the two valleys shows to some extent the relations that exist between a main stream and one of its large tributaries in respect to age (stage of development).

The section at the left of Pl. XLII shows the profile along the line $A-B$ of the map, the vertical scale being about five times the horizontal.

Mature topography is illustrated in numerous topographic sheets of the Survey. Among them the following are good: Wedowee, Ala.-Ga.; Mount Pinos, Cal.; Huerfano Park, Colo.; Hazard and Salyersvilıe, Ky.; Cranberry and Nantahala, N. C.-Tenn.; Tarboro, N. C.; Ironton, Ohio-Ky.; Siloam Springs, Okla.-Ark.; Waynesburg, Pa.; Abbeville and Pickens (early maturity), S. C.; Grundy, Va.-Ky.; Kanawha Falls and Raleigh, W. Va. Mature topography is also shown on the following plates in other parts of this volume: V, VII, $A$, XIII, $B$, LII, and CXVIII.

OLD AGE (PLATES XLIII AND XLIV).

PLATE XLIII.

Pl. XLIII affords a good illustration of topography in old age. The broad plains of Wabash, White, and Patoka rivers have become one by lateral growth. The flat is characterized by cut-off lakes (ponds) and meandering streams, and ditches have been cut in it to drain the lowlands. One of the railways is shown with a contour line adjoining the track on each side, but it should not therefore be inferred that its embankment stands above the adjacent land at a height equal to the contour interval.

Within the great flat shown on the map there are two conspicuous erosion remnants, the Gordon and the Claypole hills. The height of these hills is nearly that of the uplands shown $1710-08-3$ 
to the east and south, and the inference seems warranted that the valley plain has been degraded from the level represented by the hills and upland borders.

PLATE XLIV.

Pl. XLIV represents two areas which serve to illustrate drainage in old age, and at the same time old topography. In both of these areas the valleys have become very wide and the surrounding lands have been brought to low levels, considering their distance from the sea. The streams have low gradients, and wander about over broad flats which they have developed. In the course of time streams tend to bring the whole basins which they drain to the level of their own flats. When this has been accomplished, the "cycle of erosion" is complete. Both areas of old topography shown in this plate are in the vicinity of considerable streams-a situation where the topography first reaches old age.

Old streams frequently abandon parts of their channels. This is illustrated in the area represented in Pl. XLIV, $A$, where elongate curved lakes, such as Horse Shoe Lake, lie near the streams. Such lakes show former courses of the rivers. Portions of channels which are abandoned by streams in shifting their courses, if not filled with sediment, become lakes. The process of lake development is suggested along Osage River just south of Rockville, mapped on PI. XLIV, $A$. Here the stream is about to abandon its long northward detour. The several stages leading up to the development of the circular water course here shown are illustrated by the curves of the river farther west. South of Papinsville the stream is likely to bring the points of the lesser, horseshoe-shaped northward curve closer and closer together. When they touch the situation shown south of Rockville will have been reached and the current will then take the shorter course. As the former curve is abandoned by the stream, its ends are likely to be silted up and closed, while the main part of the curved depression will remain unfilled by sediment. The result is an oxbow lake of the type so familiar along the flats of most meandering streams.

Pl. XLIV, $B$, illustrates the same general points as Pl. XLIV, $A$.

Topographic old age is also shown in the Little Rock, Ark., and the New Harmony and Patoka, Ind.-Ill., sheets of the Survey.

\section{PLATE XLV.}

PI. XLV does not, strictly, belong in this group, but is introduced here mainly for the sake of bringing into contrast with the preceding maps a type of topography not produced by rivers and surface drainage. The surface is rough, but the hills and depressions stand in no particular relation to drainage lines. The main stream has a relatively young valley, as is shown by its steep slopes and its slight width. The region is clearly in its topographic youth, inasmuch as it is ill drained, undissected, and stands well above the adjacent stream valley.

The principal topographic features of this map are not the result of river work. At first glance many of them seem to resemble the features shown on the dune maps-for example, Pl. XIX. Here, as there, many little elevations and depressions are shown; but the apparent likeness is deceptive, for the topography here is not primarily a dune topography. From this map, however, it could hardly be affirmed that it was not. Similar topography is shown on Pl. CII (see p. 58); in both areas it marks the location of a terminal moraine.

\section{GROUP 4.-A LLUVIATION.}

Pls. XLVI-LXIV are designed especially to illustrate the topographic effects of deposition by running water. Some of the maps represent topographic features of other sorts, which may be mentioned incidentally in the accompanying notes, but emphasis will be placed only on those features that have resulted from alluviation. 
OUTSIDE OF WELL-DEFINED VALLEYS (PLATES XLVI-XLVIII).

PLATE XLVI.

Pl. XLVI represents a mountainous region on the north and a bordering plain on the south. The topography of the highland is in its early maturity and has been developed by stream erosion, whereas the plain has a slope due primarily to alluviation. The crenulate courses of the contours on the plain and the relation of the curves to the valleys leading out from the mountains tell the history of the topography of the plain. Each stream descending from the highland builds an alluvial fan (or cone) (see Pl. XLVII) where it issues from its mountain valley, for at that point its diminished gradient does not allow the current to carry all of its mountain load. Over any such fan the contours should curve outward from the mountain. By growth, these alluvial fans have merged into one another laterally, and the result is a compound alluvial fan, or piedmont alluvial plain. Piedmont alluvial plains of the type shown on this map are found in similar situations in all parts of the world.

The section at the right of the plate shows the profile of the surface along the line $A-B$, the vertical scale being the same as the horizontal.

This map shows that all the streams descending from the mountain disappear on the piedmont plain, primarily because (1) the material of the plain is loose and porous, allowing the water to sink into it, and (2) the region is relatively arid. The belts shaded with brown dots show the courses of the waters when the streams are flooded and do not at once disappear from the surface on reaching the plain.

Though the plain region is relatively arid, as is shown by the absence of permanent streams, the numerous roads and houses clearly indicate abundant settlement, and the arrangement and location of the cultural features show that the inhabitants follow some occupation that distributes the population outside the villages subequally over the country. These various data seem to warrant the inference that the land is tilled and that the water supply is derived from wells sunk into the alluvial deposits down to the water that sank below the surface just outside the mountains. It is to be expressly noted that these points are not represented on the map, but they are rational inferences from it. It should be understood, also, that inferences may sometimes be rational without being, of necessity, true, so that in most cases of this kind nothing short of investigation on the ground can be considered an adequate basis for final conclusions.

PLATE XLVII.

Pl. XLVII represents an alluvial cone or fan of simple type. The front of the main fan has been cut off, and a secondary fan has been built out in front of the original one. The merging of many such deposits would give rise to the sort of plain shown on PI. XLVI.

Alluvial fans and slopes are also well shown on the following topographic sheets of the Survey: Elcajon, Pasadena, Pomona, San Antonio, San Bernardino, and San Jose, Cal.; Silver Peak, Nev.-Cal.

\section{PLATE XLVIII.}

Pl. XLVIII shows a great depression nearly surrounded by highlands, from which débris is being brought down. The basin is partly waste filled, and represents a type characteristic of the arid plateau region of the West. The numerous streams near the mountain edge disappear in the alluvial plain, and the rivers and creeks at the northwest show a distinctive feature of actively depositing streams, namely, a complex network of channels.

IN WELL-DEFINED VALLEYS (PLATES XLIX-LV).

PLATE XLIX.

PI. XLIX, $A$, shows a river valley which, throughout the larger part of its course, is being built up (aggraded) by deposits washed down from the uplands on either side and by the deposits 
of the main stream itself. The anastomosing watercourses just below (north of) Ennis, especially, indicate active deposition. The map suggests that an alluvial piedmont plain is well developed on the east side of the river. The wide, open valley above Meadow Creek is in striking contrast with the canyon near the northern border of the area.

Pl. XLIX, $B$, shows the geology of the region represented in $A$. The special feature to be noted here is the wide belt of alluvium along the stream. Alluvial material is not represented on the slopes above the valley flat. This may indicate its absence, or it may mean that the cover of alluvium is so thin that the underlying rock is known. Thin bodies of alluvial material are omitted from some geologic maps.

\section{PLATE L.}

The maps of Pl. L are designed to show both the widening of valley flats and the deposition of alluvium. A shows the winding Meramec swinging here against the bluff on one side of its valley, and there against that on the other. The bluffs are thus driven back by undercutting, and the valley is being widened by planation. In the process alluvium is being deposited on the flat. Nothing in this map shows explicitly which way the stream flows, but this can be inferred from its course relative to the bluffs, and particularly from the courses of the tributaries.

Pl. L, $B$, shows two nearly parallel valleys, the streams in both of which show evidences of deposition. This is indicated in the larger stream by the islands, and in the smaller by its anastomosing or "braided" channel. The several subordinate channels of the South Platte are continually being choked by sediment which the currents can not carry, and the water then breaks out into new courses. The numerous channels are thus constantly shifting. It is evident from this map that with continued widening the two valleys will become one by the elimination of the narrow ridge between.

It may be conjectured that some of the small elevations of the uplands shown in $B$ are dunes, and that the depressions without outlets have been scooped out by the wind. The bed of the South Platte suggests a sandy alluvium, and so a source of dune sand. The map, however, does not make this inference necessary, for depressions of this general type are found in regions where the topographic effects of wind work are slight or are absent. (Compare Pls. XXI, B, and XLV.)

\section{PLATE LI.}

Pl. LI represents later stages of some of the changes suggested by the preceding plate. In $A$ a curve of the stream has become so pronounced that a cut-off is imminent. The current cuts in on both sides of the narrow neck of land, and when the neck is cut through the river will abandon the loop for the more direct course.

$B$ shows a cut-off recently completed. Other lakes indicate earlier cut-offs, as does also the lake in $A$.

In both maps it is evident that the streams have meandered more or less widely over their flats. The bars in the channel of the stream in $A$ and the islands in the channels of the streams in both maps indicate that deposition is now in progress.

\section{PLATE LII.}

Pl. LII shows a characteristic flood plain of a large stream, at a point where its valley is not very wide. The topography of the adjacent uplands is still in early maturity. The anastomosing channels and the ponds are characteristic of the flood plains of streams, though these features are unusually striking in the area shown on this map.

It may be noted also that valley widening is in progress, or would be but for the protection afforded by the structures of man. At the north end of the area mapped the river is working against its left bluff. It would doubtless be undercutting if the base of the bluff were not 
protected by a securely built railway embankment. At the south end of the area the river is flowing against its right bluff, and is probably prevented from undercutting in the same way.

This map illustrates well the effect of topography on cultural features, shown by the courses of the roads and railways and by the location of the villages and cities. Thus McGregor, Waukon Junction, and Lynxville are situated in the lower ends of tributary valleys, perhaps to escape floods. Harpers Ferry and Prairie du Chien are built on terraces in the main valley, and so are above the reach of disastrous floods.

PLATE I.III.

Pl. LIII represents a portion of the valley of the Mississippi near St. Louis. The valley flat is here several miles wide, and much wider at the north than at the south side of the area. The flat stands but a few feet above the river, and the numerous elongate and curved lakes, characteristic of the plains of meandering streams, indicate some of the changes which the channel has undergone. The river now flows at the western edge of its valley, but the steep bluff bordering the plain on the opposite side, as well as the flood-plain lakes, indicates that the river not long ago flowed against its eastern bluff: The migration of a stream from bluff to bluff is one of the means of widening a valley. In the process the valley flat is always covered with more or less alluvium.

In spite of the evidence of considerable age which the main valley affords, the upland southeast of the valley has reached only the stage of advanced youth or early maturity. This shows that the terms youth, maturity, old age, etc., have a somewhat different significance when applied (1) to valleys and (2) to areas which include more than a single valley.

The diagram below the map represents a profile along the line $A-B$. The vertical scale is about four times the horizontal.

PLATE LIV.

PI. LIV represents a river plain of a sort somewhat different from those shown in preceding plates. Here the whole flat is marshy. The exact cause of this marshiness can not be determined from the map. If the region has been recently depressed, so as to make drainage more sluggish, the marshiness may have been the result of the depression. The same result may have been brought about, so far as the map shows, by a dam or other obstruction across the stream at some point below the area shown on this map. Or, again, the explanation of the marshiness may be that the valley flat has been cut down to an impervious bed of rock, the strata above which are charged with water; or it may be due to the lowness of the valleys and the slightness of their slopes.

The upland at the north is in its youth; that at the south has reached a slightly more advanced stage of its history.

PLATE LV.

Pl. LV illustrates another phase of river work. In this part of its course the Mississippi is doing little in the way of erosion and much in the way of deposition. As it overflows its banks it spreads sediment over the flooded area. The velocity of the overflowing water is checked most abruptly at the point where it first escapes its channel, and therefore the immediate banks of the channel are the site of the principal deposition. It follows that a stream with a flood plain tends to build up the flood plain along its banks more than elsewhere. This map shows that the immediate banks of the river are distinctly higher than the country back from the channel. These low ridges along the banks, built up by the aggradation of the flooded stream, are natural levees. In many places the height of these natural levees has been increased and their gaps have been filled by human agency, to protect the surrounding country against flooding. (For the convention which represents the artificial levee, see Pl. II.) 
The section (fig. 15) gives some idea of the relation of the levees as seen in profile. The vertical scale is exaggerated about twenty-five times, and the levees are much less conspicuous than the diagram indicates.

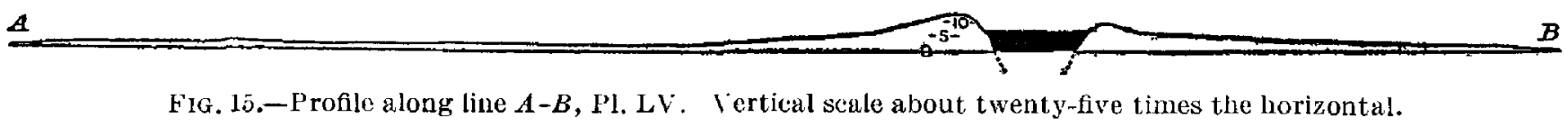

The following Survey topographic sheets afford good illustrations of flood plains: Little Rock, Ark.; Patoka, Ind.-Ill.; Owensboro, Ind.-Ky.; Clinton and Savanna, Iowa-Ill.; Atchison, Kans.-Mo.; Donaldsonville, New Orleans, and Quarantine, La.; Independence, Lexington, Marshall, Glasgow, Boonville, Jefferson City, Fulton, Hermann, O'Fallon, and Joplin, Mo.; ${ }^{a}$ and Gainesville, Tex.-Okla. Flood plains are also shown on several maps of this volume; for instance, Pls. XXI, CXVII, and CXVIII.

DELTAS (PLATES LVI-.LXI):

PLATES LVI AND LVII.

Pl. LVI shows a number of striking features. At the head of Seneca Lake there is a flat corresponding in width to the lake. This flat is really a delta, being an area which was formerly a part of the lake, but which has been converted into land by the deposition of sediment brought down by the streams. In many parts of the world deltas are thus encroaching upon lakes.

The map represents an area of considerable relief, as is shown by the numerous contours. The slopes on both sides of the lake are steep. Another interesting feature shown by the map consists of the narrow gorges Excelsior Glen, IIavana Glen, and Watkins Glen. These glens are types of extremely youthful valleys. It is evident at a glance that they are out of harmony with the main valley to which they lead, for they are in a different stage of erosion. The glens have been developed since the last glacial epoch, but the main valley is preglacial.

Pl. LVII presents views in Watkins Glen.

PLATE LVIII.

Pl. LVIII represents a delta being built into the head of a bay. The peculiar behavior of the streams as they flow across the delta is characteristic. Above the delta proper wide alluvial plains appear along the streams. It might safely be inferred from the topography that these plains were somewhat deeply covered with alluvium, and this conclusion is borne out by the geologic map, on which the distribution of alluvial deposits is shown. This map, however, gives no indication of the depth of the alluvial material. The letter symbols within the driftcovered area refer to subdivisions of that deposit as follows: Qsd, Stratified drift; Qvm, Vashon drift modified; Qv, Vashon drift; Qs, Steilacoom gravels; Qm, Midland sands; Pa, Admiralty till. A description of these formations may be found in the Tacoma folio (Geologic Atlas U. S., folio 54, U. S. Geol. Survey).

PLATE LIX. :

Pl. LIX presents another illustration of a depositing stream. The numerous lakes, channels, and sloughs in the flood plain and the bars and islands in the channels are readily understood in the light of preceding maps. This flood plain may be considered estuarine, as its surface lies but little above sea level.

No contour lines on this map cross the stream, and the direction of its flow must therefore be inferred. The shapes of the bars in the stream afford a firm basis for inference, but the courses and relations of the sloughs and lakes and the relative positions of low and high lands along the north side of the river also give some suggestion as to the direction of its current.

a The Missouri maps (except Joplin), arranged in the order in which they are here named, show a considerable length of Missouri River without interruption. 
PLATES LX AND LXI.

Pl. LX represents the delta of the Mississippi as far up as Lake Pontchartrain. The figures in the water area represent the depth of the water in fathoms. Pl. LXI represents, on a much larger scale, a portion of the terminus of the delta. The main streams shown on this map give off branches, or distributaries, repeatedly. The anastomosing tendency is evident, and the development of the land (marsh) surfaces along the immediate channels of the streams is like that of natural levees.

The following topographic sheets of the Survey afford other illustrations of deltas: San Luis, Cal.; Pointe a la Hache, Dime, La Fortuna, Fort Livingston, Quarantine, Forts, West Delta, and East Delta, La.; and Naples, N. Y. The Louisiana sheets, grouped in the order named, show the Mississippi delta in detail.

\section{RIVER TERRACES (PLATES LXII-LXIV).}

PLATE LXII.

Pl. LXII, $A$, is introduced especially to illustrate stream terraces, which appear on both sides of the main stream. Fig. 16 represents a profile across the valley of the Illinois along the line $A-B$. Thesurfaces of the terracesare notaltogether flat, and the terraces on the opposite sides of the stream are not of exactly the same elevation. The mapand profile show a narrow, steep-sided, and not very deep valley below the terraces.

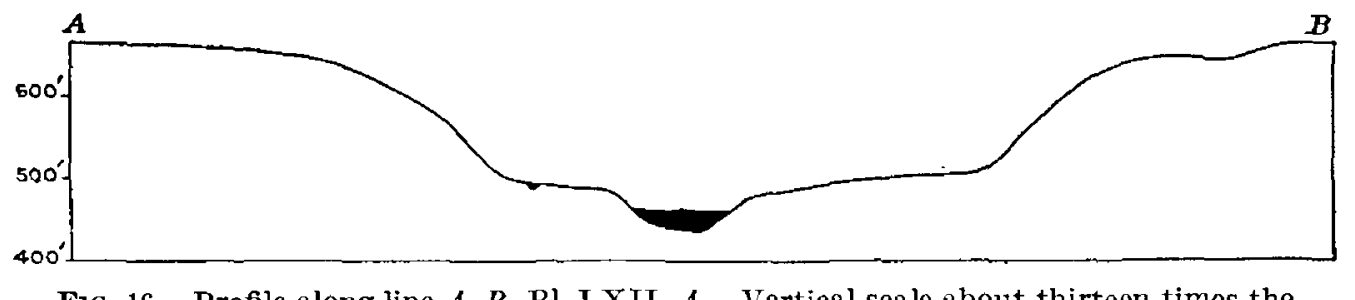

F1g. 16.-Profile along line $A-B$, Pl. LXII, $A$. Vertical scale about thirteen times the horizontal.

Pl. LXII, $B$, likewise shows terraces, but in this area there are at some points two terraces, instead of one, on each side of the river. These terraces are brought out by fig. 17 , which repre-

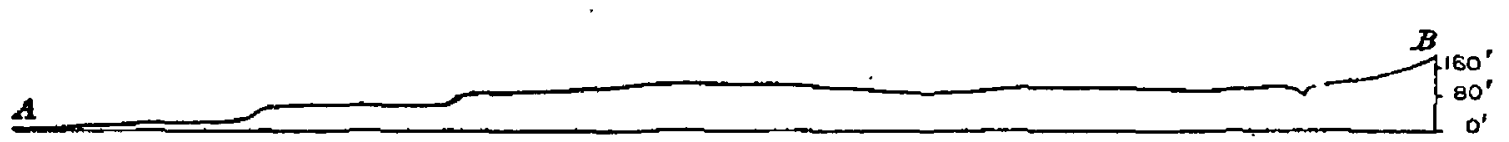

FIG. 17.-Profile along line $A-B$, Pl. LXII, $B$. Vertical scale about eight times the horizontal. sents a profile along the line $A-B$. Both these terraces are remnants of former flood plains, the higher terrace representing the older plain. A topographic map showing terraces does not always make it clear whether they were developed from flood plains or in other ways.

The higher parts of the area shown in $A$ are cut by young valleys. Young valleys have also developed in the terraces of the area represented in $B$.

\section{PLATE LXIII.}

PI. LXIII represents an area in which terraces have pronounced development. They are readily located from the contour map, and are brought out in profile by the section at the bottom of the plate, which represents the topography along the line $A-B$, the vertical scale being exaggerated about two and a half times. The map shows that there are two terraces at some points, and but one at others.

Various causes may develop terraces from flood plains. Uplift of the region, quickening of the stream, increase of volume of water, decrease of load (if the stream is a depositing stream), removal of obstructions below-any or all of these may be effective in producing terraces. Without discussing these possible causes, it may be said that terraces can be formed by anything that makes a stream with a flat deepen its channel notably.

PLATE LXIV.

Pl. LXIV affords an illustration of terraces in a region of a very different sort from that shown in Pl. LXIII. The terraces appear at various points and are best brought out by sections across the valley of the principal stream. A north-south section through Little Camas 
Prairie, from the uplands on the north to the higher points on the south, will show clearly the terraces in this longitude. A section at right angles to Boise River anywhere in the lower 2 miles of the part of its course represented on this map will disclose the existence of two terraces. The lower of these terraces disappears when traced upstream, and the map indicates that it disappears because its surface rises until it joins the higher terrace. The upper terrace is probably not alluvial.

River terraces are well shown on the following additional topographic sheets: Fonda and many of the maps along Hudson River, N. Y.; Tarboro, N. C.; Cleveland, Ohio; Beaver and Latrobe, Pa.; Elk Point, S. Dak.-Nebr.-Iowa; and Guyandot, W. Va.-Ohio; also on Pl. LXXVIII of this volume.

\section{GROUP 5.-TOPOGRAPHIC EFFECTS RESULTING FROM UNEQUAL HARDNESS OF ROCKS.}

The set of maps included in Pls. LXV-LXXI is designed especially to illustrate the modifications in the effects of erosion induced by inequalities of hardness of the rocks.

PLATE LXV.

Pl. LXV, $A$, represents a low plain above which conspicuous ridges and hills with steep slopes rise several hundred feet. These ridges and hills are due to the hardness of the rock of which they are composed. The less resistant rock which once surrounded the elevations has been removed by erosion, while the harder parts remain unreduced. More than this the map does not clearly show. Such isolated elevations are termed monadnocks. The structure of the rocks along the line $A-B$ is shown in fig. 18.

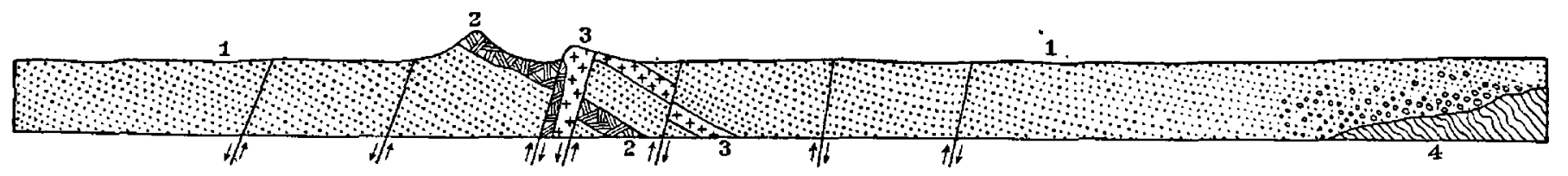

Fig. 18.-Structure section along line $A-B$, PI. LXV, A. 1, Sandstone; 2, Holyoke diabase; 3, Hampden diabase; 4, gneiss.

The valley of Connecticut River is wide both above and below the Holyoke Range, but is greatly constricted where the river passes through the range. Furthermore, there is a fine example of an oxbow lake (a sign of age) above the range, whereas a cross scetion of the valley between Mounts Holyoke and Nonotuck would indicate early maturity only. These phenomena illustrate the fact that a valley may be "old" in those parts of its course where the formations are relatively soft and "young" in those parts where the rock is relatively hard and therefore less easily eroded.

Characteristics similar to those of the Connecticut are exhibited by valleys generally where they cut through ridges of hard rock. They are especially conspicuous if the cycle of erosion is well advanced, though not to old age. Such constrictions in valleys occupied by streams are often called narrows or water gaps.

Pl. LXV, $B$, shows a curved monadnock ridge. The hard rock of which it is formed is of igneous origin, although this could not be knovn from the map.

\section{PLATE LXVI.}

Pl. LXVI affords three distinet illustrations of the effects of unequal hardness. The most conspicuous is, perhaps, the line of narrow ridges extending from north-northwest to southsoutheast; the second is the mountain region along the western edge of the area mapped, and the third the table mountains near Golden.

The structure that causes the long, narrow ridges or "hogbacks" and the mountains at the west is shown in fig. 19, which represents a section along the line $A-B$; but even without 
knowledge of the structure or of the geology as shown on this map, an inference as to the structure could be made with much confidence from the topography. The long, narrow ridges can hardly mean anything other than the outcrop of a hard layer of rock which has been partly isolated by the degradation of its surroundings. Valleys at right angles to the strike have cut the outcropping bed into several short ridges. The trend of the ridges indicates the strike of the hard formation. The lack of a very definite trend in the highlands at the west indicates that these mountains are not composed of tilted beds of stratified rock-at least not of tilted

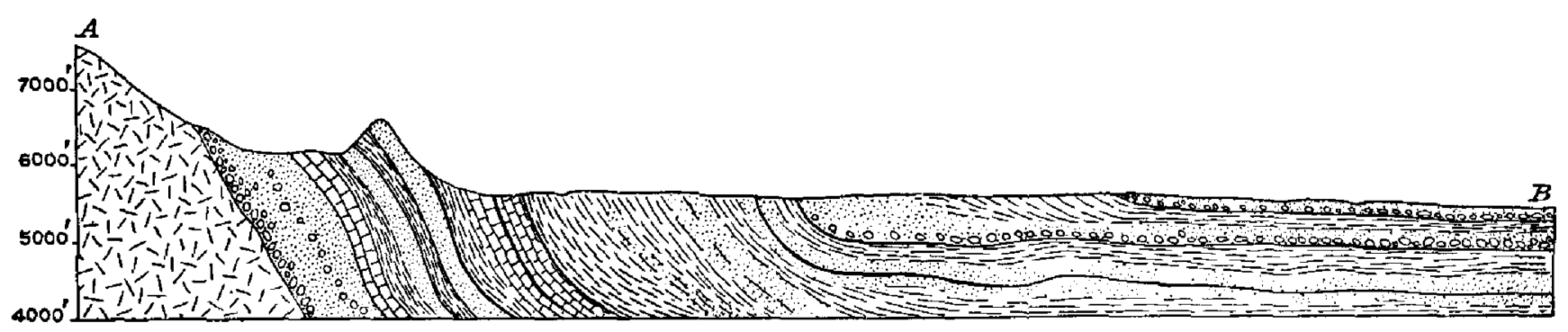

FIG. 19.- Structure section along line $A-B$, Pl. LXV1. Vertical scale about two and a half times the horizontal.

beds of unequal hardness. So far as the topography shows, they may be either of massive rock or of rock that is horizontally stratified. As the beds to the east are tilted at a high angle, the inference that the mountains to the west are of massive rock is the more reasonable.

The table mountains east of Golden owe their flat tops and their cliff slopes to the presence of a sheet of lava, which has helped to preserve the rock beneath. The hard capping of the mountain causes the cliffs for the same reason that hard rock along the sides of a valley causes steep slopes.

The map is an extract from the geologic map in "Geology of the Denver Basin,inColorado," " and the letter symbols used on the map are explained in the following table:

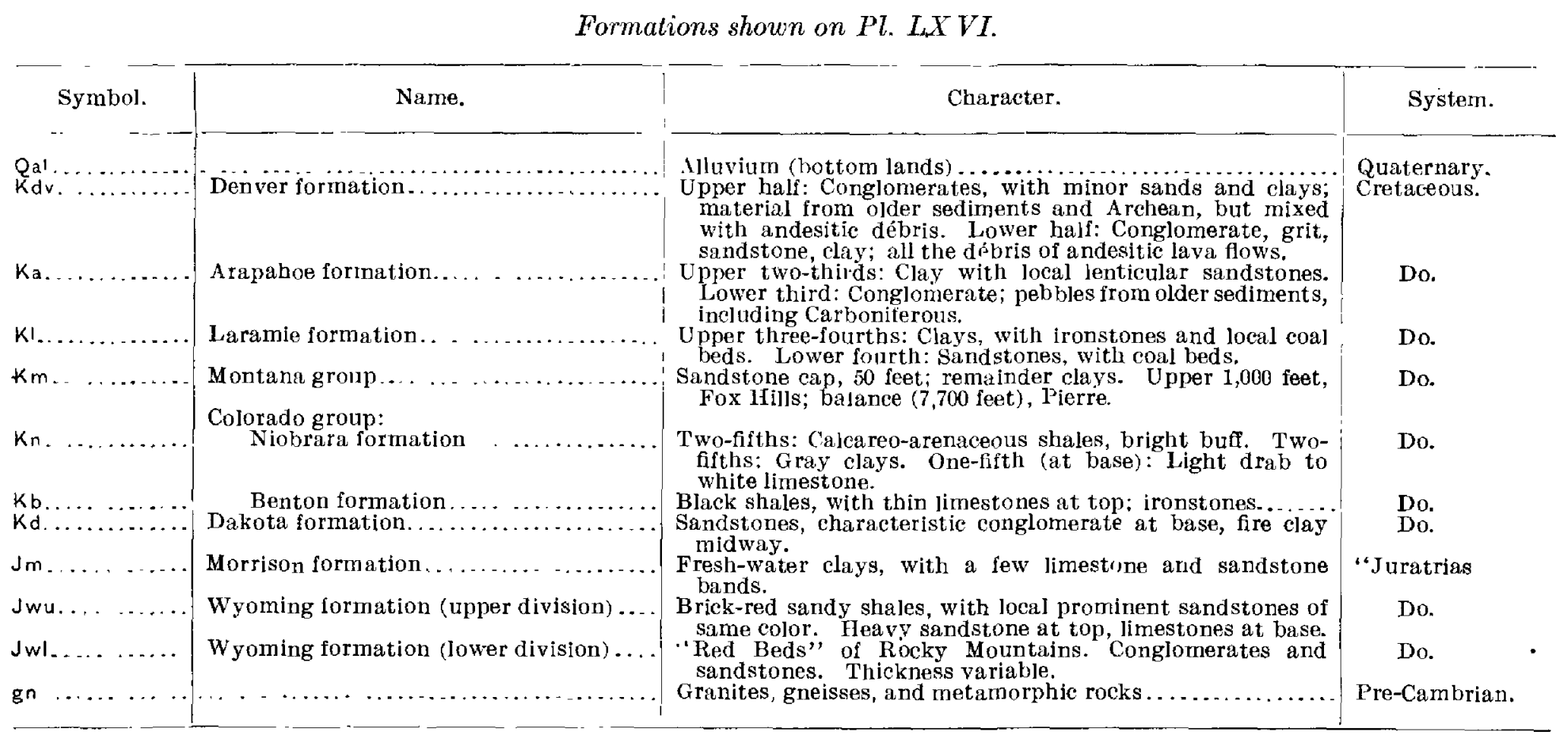

PLATE LXVII.

Pl. LXVII affords a good illustration of one of the features shown on PI. LXVI, namely, the conspicuous north-south ridges, which appear to be formed by the outcropping edges of tilted layers of hard rock.

PLATE LXVIII.

The explanation of the topography of the area shown on Pl. LXVIII is found, in large part, in the distribution of the rock formations. Blue Mountain, Black Mountain, Sulphur Mountain, Inge Mountain, Chatfield Hill, Obi Hill, Lewis Hill, and Nueces Hill, as well as numerous 
others that are not named on the map, are composed of igneous rock. The topographic forms of these igneous masses indicate clearly that they are harder than the surrounding rocks. So far as the topography shows, these hills might be volcanic cones; but their forms and relations suggest rather that they are monadnocks. At least it is evident from the geologic map that the surface of the stratified rocks of the region once stood at a much higher level than now. This is indicated, for instance, by Big Mountain, in the central portion of the area. This mountain, which is composed of horizontal beds, shows that the surface has been reduced from a higher level. It is quite possible that during this reduction the hard igneous rock has been exposed here and there and left as monadnocks.

At the bottom of the plate is a cross section along the line $A-B$.

In general, the eastern part of the area shown on the map seems to have been cut down to an elevation of 900 or 1,000 feet from some such level as that now prevailing in much of the northwestern part of the area, namely, 1,600 to 1,700 feet.

Inferences as to the climate, settlement, and some other features of the region may be readily drawn from the map. The geology shows numerous other points of interest, which will be referred to in the discussion of other plates.

\section{PLATE LXIX.}

The conspicuous feature of PI. LXIX is the curved mountain ridge that rises about a thousand feet above the surrounding land. The form of this ridge is hardly that which would have been developed by erosion had there not been a hard layer or body of rock whose outcrop determined the location of the ridge. This conclusion is strengthened by the presence of subordinate ridges parallel to the main ridge. The water gap (McKee Gap) and the wind gap (Dry Gap) are consistent with this interpretation.

\section{PLATES LXX AND LXXI.}

It may be inferred that the mountains of PI. LXX owe their origin to the hardness of their rocks, the surrounding less resistant rocks having been removed by erosion. It is also a fair inference from the map that this is a region of folded or at least tilted formations, and that the ridges represent the outerops of the hard layers. Certain other inferences may be readily drawn af ter the structural features are considered.

PI. LXXI shows the structure of the region represented by PI. LXX along certain lines. The vertical scale of the sections is not exaggerated. They show that the ridges are composed of hard rock (sandstones, indicated by dotted pattern). The following table explains the significance of . the latter symbols used on this plate:

Formations shown on Pl. LXXT.

\begin{tabular}{|c|c|c|c|}
\hline Symbol. & Name. & Character. & System. \\
\hline $\mathrm{Cl}$ & Lookout sandstone. & Conglomerate, sandstone, and sandy shale, with thin coal & Carboniferous. \\
\hline $\mathrm{cb}$ & Bangor limestone. & Blue limestone with chert nodules.... & Do. \\
\hline & Oxmoor sandstone & White and brown sandstone and conglomerate & Do. \\
\hline & Floyd shale. & Carbonaceous shale and thin beds of limestone. & \\
\hline & Fort Payne cher1.. & Cherty limestone and bedded chert....... & Do. \\
\hline & Chattanooga shale. & Black carbonaceous shale... & Devonian. \\
\hline & $\begin{array}{l}\text { Armuchee chert } \\
\text { Rockwood formation }\end{array}$ & White, brown, and purple sandstone and shale, with beds of & $\begin{array}{l}\text { Do. } \\
\text { Silurian. }\end{array}$ \\
\hline $\begin{array}{l}\text { Sc.. } \\
\text { ESk. }\end{array}$ & $\begin{array}{l}\text { Chickamauga limestone. } \\
\text { knox dolomite......... }\end{array}$ & $\begin{array}{l}\text { Blue flaggy limestone, with somechert conglomerate... } \\
\text { Massive gray limestone containing chert nodules..... }\end{array}$ & $\begin{array}{l}\text { Do. } \\
\text { Silurian and Cam. }\end{array}$ \\
\hline$\epsilon_{c s}$ & $\begin{array}{l}\text { Siliceous layers in Conasauga formation } \\
\text { Cona sauga forma tion......................... }\end{array}$ & 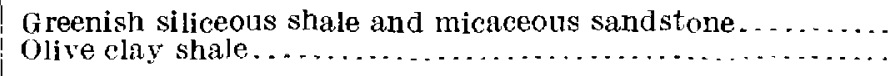 & $\begin{array}{l}\text { Cambrian. } \\
\text { Do. }\end{array}$ \\
\hline
\end{tabular}

The following topographic sheets may be profitably studied in connection with the subject of unequal hardness of rocks: Plainfield, N. J.; Delaware Water Gap, Pa.-N. J. (Pl. LXXX); Everett (PI. XI), Harrisburg (Pl. LXXVI), Hummelstown, and Lykens, Pa.; and the following plates in other parts of this volume: X, XL, LXXII, LXXVII, LXXXVI, LXXXVIII, and XCIII. To these maps may be added most of those covering areas in the Appalachian Mountain region and many of those representing the western mountains. 


\section{GROUP 6.-EROSION CYCLES.}

The set of maps included in Pls. LXXII-LXXXII is designed primarily to illustrate cycles of erosion. An understanding of the meaning of this term is presumed, inasmuch as it is explained in most of the recent text-books on geology and physical geography and is also discussed in the publications of the Survey.

PLATE LXXII.

PI. LXXII represents a great plain, bordered on the northwest and on the east by low mountain ridges. The plain between the mountains resembles somewhat a great valley, yet is without the features of a river flat. (Compare Pls. LI and LIII.) It appears to have been developed by several streams rather than by one.

The mountain ridges are nearly straight and nearly parallel. The crests of all of them are interrupted, the eastern ranges by the notable water gap of the Potomac, and the western by shallower passes. The crests of the easternmost ridge have elevations ranging from 1,100 to 1,300 feet. The crests of Elk Ridge and its southerly continuation have elevations of 1,300 to 1,600 feet, and the crest of Little North Mountain, in the northwest corner of the area, ranges from 1,500 to 1,700 feet in height. The crests therefore increase in altitude toward the west, or that part of the area which is most remote from the sea. The crests of the eastern ridges are higher at a distance from the main river than near it. The conditions thus described are illustrations of general principles.

The greatest interruptions of the mountain ridges are those east of Harpers Ferry, where the gaps are clearly the work of the river. The origin of the lesser gaps is suggested at various points, as at the south end of Little North Mountain, where valleys from opposite sides head near the crest of the ridge. These gaps point to erosion by streams as the cause of the uneven crests of the mountains. Furthermore, the valley of the Potomac, where it crosses the mountain ridges, has the appearance of youth. At this point the valley is narrow and steep sided, and apparently out of harmony with the broad flats farther upstream. (Compare Pl. LXV, A.)

If the gaps and passes in the mountain crests excavated by erosion were filled, the crests would be nearly even, as they probably once were.

By comparison of Pl. LXXII with PI. LXXI it will be readily inferred that the mountain ridges represent the outcrops of layers of hard rock. Even crests in such layers are developed only at low levels, for where erosion is active it tends to make the outcrop of hard strata uneven. These old mountain crests therefore represent an old base-level plain. When they were developed they were a part of a general plain that stood at their level. This plain was probably slightly higher to the west, away from the sea, and lower to the east, nearer the sea, for the same reason that a valley flat is higher at a distance from the sea than near it. The crests of the ridges are therefore remnants of a surface that existed at the close of one cycle of erosion--the oldest cycle which the map records.

Later the region was uplifted, relatively to sea level, and the streams were thus rejuvenated. They cut most effectively in the weaker formations which lay between the present mountain ridges and reduced this broal area to a peneplain (that is, nearly to base-level), which is now represented by the surface that stands'at an elevation of 500 to 600 feet. The degradation of the softer rocks left the edges of the hard layers standing out as ridges. The general surface at 500 to 600 feet therefore seems to record a second incomplete cycle of erosion. In this flat the streams have excavated shallow valleys, which are still rather young. The youth of these valleys, shown by their steep slopes (note the large contour interval) at various points, as along the Potomac just above Harpers Ferry, indicates a renewal of activity of the streams, causing them to cut new valleys in the plain that marks the peneplain of the second cycle. These young valleys point to a third cycle of erosion, which has only well begun.

A profile across the area along the line $A-B$ is shown in the section below the map. The vertical scale of the section is exaggerated about twice. This profile shows the three cyclesthe first represented by the mountain erests, the second by the great plain between, and the third by the new valleys in the plain. 
Some of the features shown on this map might be accounted for in ways other than those - here recited, but the attempt is not made in these notes to take account of all the possibilities.

A profile along the crest of Elk Ridge and its continuation to the southwest, drawn to scale, will be instructive.

\section{PLATE LXXIII.}

The maps forming Pl. LXXIII present further illustrations of topography suggesting successive cycles of erosion. The essential features of $A$ are readily seen. The summit elevations at the southwest are about 1,050 feet above sea level, though the areas at this altitude are small. Below these summits there is an extensive plain (peneplain) at an elevation of about 400 feet, and still lower is the flood plain of the river valley, a little below 250 feet. The flats of the tributary streams are not so well developed and their channels are slightly higher. Above the 400-foot plain there are numerous elevations which are probably unreduced remnants of the old 1,050-foot plain. Deane Mountain is the most conspicuous example. The essential features of the topography of the region are brought out by fig. 20, a profile drawn along the line $A-B$ on Pl. LXXIII, $A$.

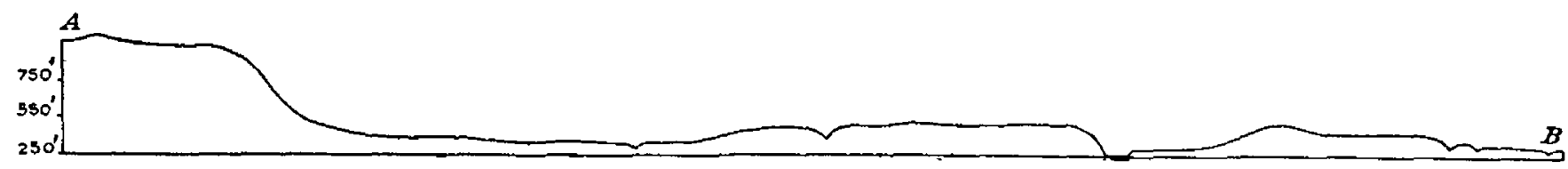

FIG. 20.-Profile along line $A-B, \mathrm{Pl}$. LXXIII, $A$. Vertical scale exaggerated about five times.

Pl. LXXIII, $B$, represents the same phenomena and the same sequence of events, but the intermediate plain is a little higher and not so well developed. Fig. 21 brings out the general features as seen in profile.

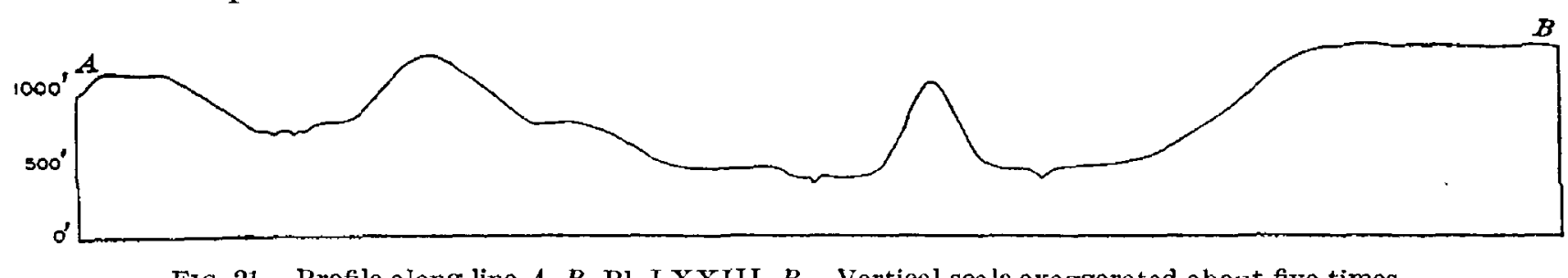

The absence of definite trends in the prominent topographic features of the regions shown on this plate points to the absence of rock formations of unequal hardness at the surface. There is nothing in the maps to suggest that the beds of rock which underlie the region are not horizontal. The steep slopes between the hilltops and the intermediate levels indicate that the upper plain is capped with moderately resistant rock.

\section{PLATE LXXIV.}

Pl. LXXTV, like the preceding plate, suggests several cycles of erosion, which are brought out by the profile at the left. The suggestion of the map is that the highest part of the surface, shown at $A$ on the map, represents the level $(1,500$ feet) from which the remainder has been degraded; that the level of $1,250 \pm$ feet, which is of great extent, represents a plain developed by the degradation of the higher plain; and that a still later cycle is represented by the valleys at lower levels.

The excavation of the valleys in the 1,250-foot level might have resulted from the uplift of the land. On this interpretation at least two cycles are represented-one, which was nearly completed, so far as this region was concerned, by the 1,250-foot plain, and the second, which is only well begun, by the valleys below it. There is some indication that the second cycle was interrupted by an uplift, for there are wide terraces at an elevation of about 1,000 feet, as if flats were developed along the streams at what is now the 1,000-foot level, before a relative uplift of the region caused the streams to cut narrow and deep valleys below. So far as the map shows, these 1,000-foot terraces may, however, be occasioned by a horizontal layer of hard rock at about this level. 
There is nothing on the map to show whether the 1,500-foot level represents the original surface from which the rest has been reduced or whether it is itself a remnant of an earlier base-level plain.

The flat top and the steep slopes of Wolf Mountain suggest that the rocks lie in horizontal beds and that the uppermost layer of the rock is hard rather than soft, for beds of hard rock in such a position are more likely to develop cliffs.

The diagram at the left of the map represents the profile along the line $A-B$. The vertical scale is exaggerated about twice.

PLATE LXXV.

Pl. LXXV furnishes a possible illustration, differing from those already given, of a second cycle of erosion, though the topography here shown is open to a second interpretation. If all parts of a drainage basin were elevated equally, the debouchure of the stream being unchanged in position, there would be a fall at the lower end of the

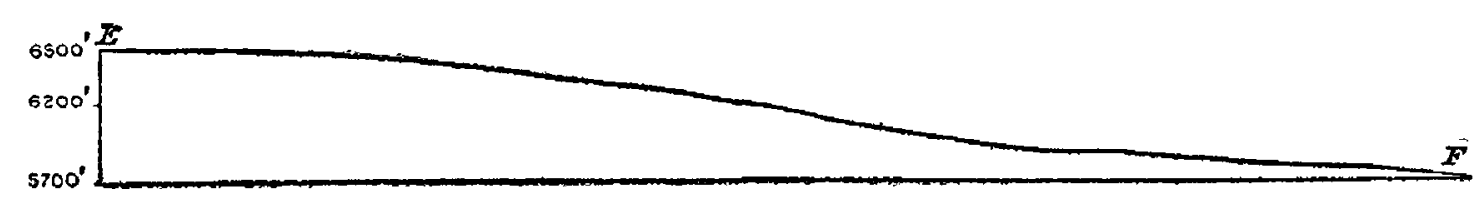

FIG. 22.-Profile of a valley shown in PI. LXXV along line $E-F$. Vertical scale about five times the horizontal.

stream. The fall would advance upstream, and below the fall at each stage there would be a gorge or canyon-a new valley-in the bottom of the old one. If the elevation were such as to quicken the stream at its lower end, but not at its upper, the result would be much the same, even if no falls were developer. The rejuvenated lower portion would develop a new gorge in the bottom of its former valley. The gorge would advance upstream, on the general principle of head erosion.

This plate shows a deep canyon along the lower course of the stream $E-F$ and a wide, open valley above. This might mean that the lower course of the stream has been quickened and that the new canyon is advancing upstream, but that it has not yet reached the upper part of the valley. Fig. 22 is a profile of this valley along the line $E-F$. It shows the low

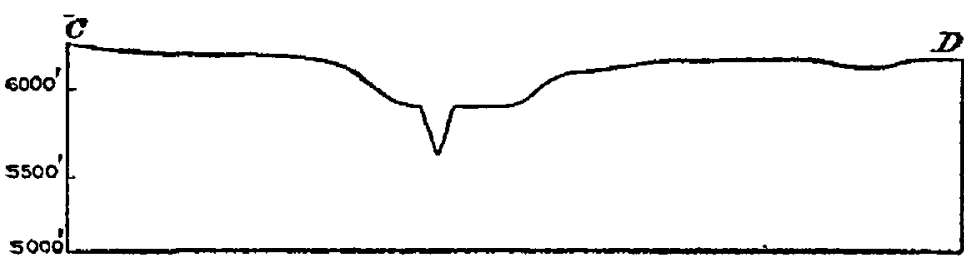

FIG. 23.-Profile along line $C-D, \mathrm{Pl}$. LXXV. Vertical scale ahout five times the horizontal. gradient near the mouth and at the head of the stream, and the steep gradient between, corresponding to the upper end of the canyon.

Valleys of this sort may be developed in other ways, as by the recession of falls not due to a change of level; but such a valley always suggests rejuvenation. To verify the suggestion in any particular case the valleys of the surrounding region should be studied. If they show the same phenomena, in harmonious relations, the inference of rejuvenation is supported.

The map also shows pronounced terraces along some of the valleys, further illustrated by fig. 23, which is a profile along the line $C-D$, and fig. 24, which is a profile along the line $A-B$. In fig. 24 one set of terraces is high and the other low. Such terraces might

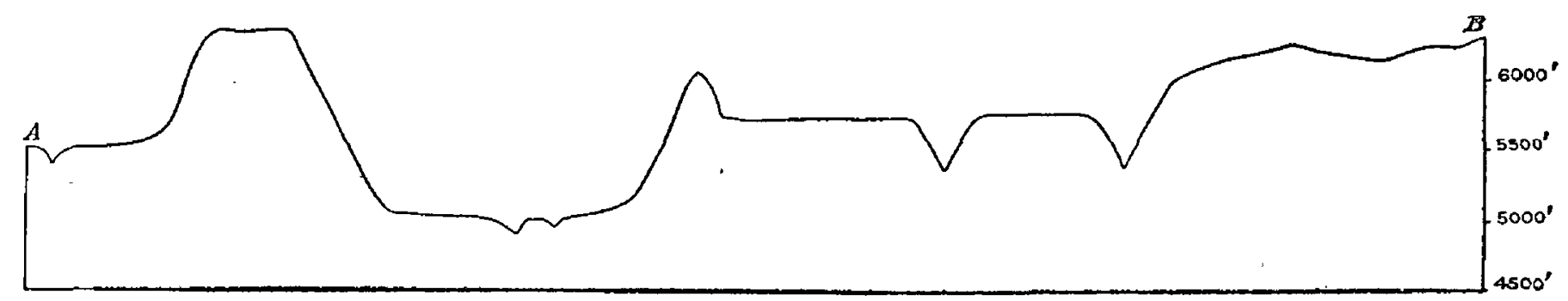

FIG. 24.-Profile along line $A-B$, PI. LXXV. Vertical seale about five times the horizontal

result either from rejuvenation or from notable inequalities of hardness in horizontal strata. It will be noted that the deepest valley (toward the left) seems to have acquired a broad flat, while the lesser valleys (toward the right) were still being deepened and bad not reached the stage of development in which flats were formed. If at this time uplift, or something which had a similar effect on erosion, had permitted the excavation of narrow gorges in the bottom 
of the broad valley, converting the remnants of the old flat into terraces, while erosion in the lesser valleys continued much as before, some features of the relief here represented would have been produced. On this interpretation the largest valley would give a suggestion of two cycles, whereas the lesser valleys would show no evidence of the second cycle, because in them the first was so slightly advanced when the second began.

It should be noted, on the other hand, that the "rincones" in the southeastern part of the area point rather strongly to the control of the topography by strong horizontal or nearly horizontal beds. All the features of the relief shown on the map might be due to the influence of such beds, lying at the tops of the cliffs and forming the floors of the wide flats, so that rejuvenation is not a necessary inference.

The map is somewhat anomalous in that the stream shown in the deepest valley is represented as intermittent, though one of the shallower valleys has a permanent stream.

This map gives many indications of aridity. There are numerous intermittent ponds, the origin of which is not evident from the map. They may occupy basins scooped out by the wind. Lakes of this class are not rare on arid and semiarid plains.

\section{PLATE LXXVI.}

Pl. LXXVI furnishes another illustration of cycles of erosion. Three sets of levels are clearly seen-(1) the mountain crests about 1,300 feet high in the northern range and 1,100 to 1,200 feet high in the southern; (2) the plain about the mountains at an elevation of 500 to 600 feet, and (3) the valley flat at an elevation of a little more than 300 feet along the main stream and the valleys without flats at harmonious levels. As in the area covered by $\mathrm{Pl}$. LXXII, the ridges here shown rise to greater heights as they recede from the stream, and the northern ridge - that is, the ridge farther from the sea by the course of the stream-is higher than the other.

The crests of the mountain ridges represent an old base-level. The evenness of the crests has been somewhat marred during subsequent cycles of erosion. The position of the mountains and their straight courses indicate that they are formed by the outcropping edges of hard layers of rock tilted at high angles.

The dissected plain at 500 to 600 feet represents the plain of a second cycle of erosion. It was developed after the earlier plain, represented by the mountain crests, was uplifted relatively to sea level. The softer rocks of the plain were degraded, while the harder rocks of the ridges suffered relatively little erosion, though the crests of the ridges were made somewhat uneven. Further uplift (also relative) has allowed the streams to cut new valleys about 200 feet deep in the plain that stands at 500 to 600 feet.

In addition to the other evidences of erosion cycles, the course of Conodoguinet Creek nay be mentioned. Its valley is narrow and gorgelike, yet its irregular, singularly winding channel resembles the courses of streams that meander on flood plains. The phenomenon may be interpreted thus: The stream was meandering much as now, in a flood plain corresponding approximately in level with the 500- to 600 -foot plain. It was then rejuvenated, by regional uplift or otherwise, deepening its channel along its meandering course. The meanders were thus intrenched, and intrenched meanders are an evidence of uplift-that is, of the inauguration of a new cycle. The third cycle of erosion shown on the map is still young and has inherited these meanders from the preceding cycle.

It should also be noted that the map illustrates the fact that when a main valley is deepened, as here, all tributaries are affected, and affected first at their lower ends. As the main stream develops a gorge, all the tributaries develop gorges, which at the outset are more conspicuous near the main stream than farther up.

Though the valleys of the last cycle are young, the surface that represents the plain of the second cycle shows a relatively mature topography. This is, in itself, evidence of a new cycle. Were the 500-foot plain the surface in which these new valleys first developed, and were the valleys no older than those shown on this map, the surface of the plain as a whole would have 
been young, not mature. The explanation of the apparent anomaly is to be found in the fact that the 500-foot plain is not an original surface, but a plain of erosion. When it was uplifted and its streams rejuvenated, enabling them to start their new valleys (those of the third eycle), streams and valleys were already abundant over the plain, though the valleys were all shallow. Drainage lines were thus already established when the last cycle began. The development of the new valleys has therefore proceeded much more rapidly than in the first eycle, though they have not yet reached maturity.

The section at the left of the plate shows a profile of the surface along the line $A-B$ of the map, the vertical scale being two and one-half times the horizontal.

\section{PLATE LXXVII.}

Pl. LXXVII furnishes a good example of intrenched meanders, which appear to have been inherited from a previous cycle of erosion. The surface on which the meanders appear to have developed seems to have been well below the level of Terrace Mountain, and the crest of this mountain suggests an old plain of erosion - a peneplain or base-level. The map therefore indicates at least three cycles of erosion-the oldest, which appears to have been nearly complete, represented by the crest of Terrace Mountain and the somewhat higher erest at the northwest; the second, less nearly complete, though well advanced, represented by various areas a little above and below 1,200 feet; and the third, which has not yet advanced far enough in its history to develop pronounced flats.

The courses of the minor streams are not meandering. This may be because they were less advanced than the main stream when the meanders of the latter were developed.

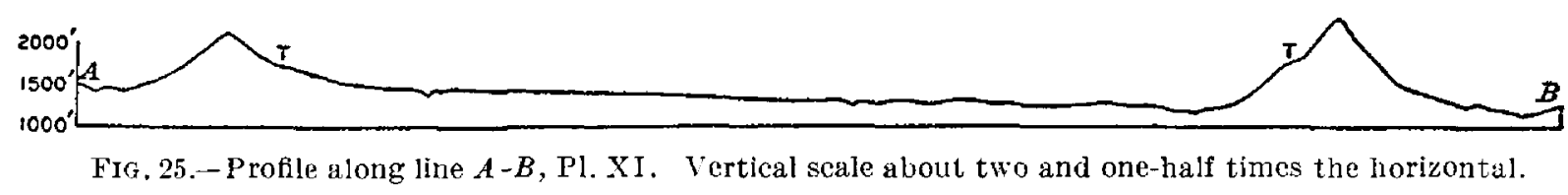

Fig. 25 is a profile along the line $A-B$ on $\mathrm{Pl}$. XI and presents a further illustration of the topic under discussion. Three eycles are evident (the last only begun), and a fourth is suggested by the terraces on the slopes of the mountains ( $T, T$ on the profile). These terraces may, on the other hand, be simply the result of the superior hardness of the rock at this level, as compared with that above and below.

\section{PLATE LXXVIII.}

Pl. LXXVIII shows three sets of levels, one represented by Rib Hill, 1,940 feet; a second, at 1,400 to 1,500 feet, including much of the area shown on the map; and a third, represented by the valley flats, somewhat below 1,200 feet. The Mosinee Hills lie between the first and second of these levels, but the surroundings of these hills have been largely degraded to the third level, so that they are conspicuous.

The map suggests that the hills consist of very resistant rock. The inference may be drawn that when the general surface was reduced to, say, 1,400 or 1,500 feet, Rib Hill and the Mosinee Hills stood up as unreduced remnants - that is, as monadnocks. The Mosinee Hills have since been reduced somewhat more than the larger hill to the northwest.

Later rejuvenation of the streams has allowed them to develop new valleys in the $1,400-$ to 1,500-foot plain. These valleys still have the appearance of youth, but the general surface above has the appearance of maturity. The explanation of this apparent anomaly is probably the same as that given in connection with Pl. LXXVI.

Certain alternative explanations of such features as Rib and Mosinee hills may appropriately be suggested. So far as this map shows, these hills might be volcanic cones; or, again, they might represent hills or mountains about which the surface was leveled up by deposition, but not so much as to bury them. Both these interpretations are consistent with the map, though the shape of Rib Hill would be rather against the suggestion of a voleanic cone. 
A topographic map, therefore, does not always give a sure indication of the history of the surface which it represents.

Some pronounced terraces appear at various points along Wisconsin River.

The section at the left of the map gives the profile along the line $A-B$, the vertical scale being about twice the horizontal.

PLATE I.XXIX.

PI. LXXXIX, $A$, furnishes another illustration of cycle development. The 600-foot elevations appear to represent an old surface below which, at 400 to 500 feet, a plain was developed, and later the streams formed still lower flats. The interruption between the development of the plain at 400 to 500 feet and that of the valley flats does not appear to have been very pronounced.

So far as the map shows, the Ditney Hills might be either eroded volcanic cones or monadnocks of hard rock. As a matter of fact, they are neither, but merely unreduced hills of horizontal beds of rock. They are composed of material similar to that which was removed in the development of the plain represented by the 400- to 500-foot levels. This map is to be contrasted with the preceding (Pl. LXXVIII), which shows monadnocks due to the hardness of the rock.

Pl. LXXIX, $B$, shows the geology of the same region. 'The letter symbols are explained in the following table:

Formations shown on Pl. $L X X I X, B$.

\begin{tabular}{|c|c|c|c|}
\hline Symbol. & Name. & Character. & Systern. \\
\hline $\begin{array}{l}\text { Qal ... } \\
\text { Cd... } \\
\text { Cs... } \\
\text { Cm... } \\
\text { Cp... }\end{array}$ & 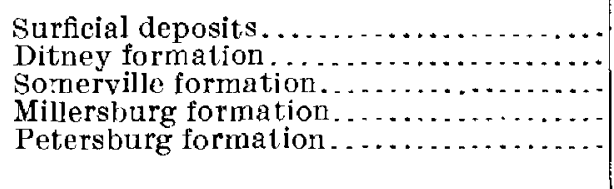 & 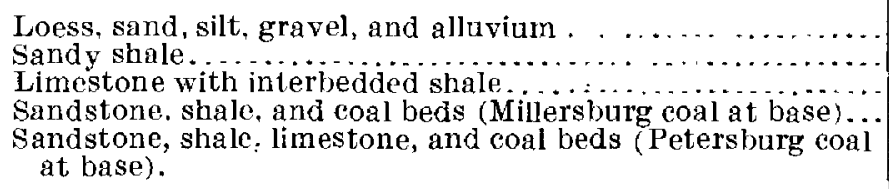 & $\begin{array}{l}\text { Quatemary. } \\
\text { Carboniferous. } \\
\text { Do. } \\
\text { Do. } \\
\text { Do. }\end{array}$ \\
\hline
\end{tabular}

PLATES LXXX AND. LXXXI.

Pl. LXXX gives an illustration of cycles in a well-known and picturesque region-the Delaware Water Gap. After the preceding explanations, this map requires little additional comment. The first cycle is represented by the mountain crests $(1,600$ feet in elevation in the main range), now somewhat interrupted; a second (incomplete) cycle is represented by the 800 -foot summits on the plains to the south, and by the 900 - to 1,000-foot crests north of the main range on both sides of the Delaware. Below this level one and perhaps two cycles are shown, though they are not very clearly separated. At various points there are considerable flats at an elevation of about 500 feet, and some of the streams, including the Delaware itself, have narrow valleys, the bottoms of which have an elevation of about 300 feet. The general topography as seen from the south is depicted in Pl. LXXXI, where three levels are distinctly shown.

In PI. LXXX, and in most other maps showing even-crested mountain ridges, the highest elevation represents an old base-level, not the original surface, for the outcrop of such rocks as appear in these ridges probably becomes level only at or near the base-level stage.

The map also presents an evidence of rejuvenation similar to those already cited, in that some of the tributary valleys show sharp gorges below and open valleys above.

\section{PLATE LXXXII.}

Pl. LXXXII shows a simple and somewhat unusual type of topography resulting from erosion. The larger part of the surface has an elevation of about 6,000 feet. Above the general level large and small areas (mesas and buttes) rise 200 to 600 feet or more. The suggestion of the map is that the lower portion of the area, standing at 6,000 feet, was developed by the reduction of a plateau whose surface corresponded with the elevations represented by the tops of the buttes and mesas, or by the reduction of a surface still higher. No streams are shown on the 
map, and if the 6,000-foot plateau is the work of streams, the map would suggest that the surface which now stands at this altitude is much higher than when it was developed. The absence of streams, on the other hand, raises the question whether wind may not have been an important factor in the degradation of the surface from the higher to the lower level.

The cliffs of the elevations, the absence of streams, and the disappearance of the water of the springs somewhat promptly after issuing all point to aridity. The springs are mostly near the bases of the elevations and show that the region is not without some rainfall.

Some elevations, such as volcanic peaks, may be built up above their surroundings, but the elevations of this map bear none of the marks of volcanic peaks. They are too flat-topped and their slopes are too steep. They are plainly remnants of an earlier surface.

The following Survey topographic sheets afford further illustrations of erosion cycles: Yelllville, Ark.-Mo.; Mesa de Maya and Walsenburg, Colo.; Pawpaw, Md.-W. Va.-Pa.; Tuscumbia and Versailles, Mo.; Bernal, Corazon, and Lamy, N. Mex.; Hummelstown, Latrobe, and Lykens, Pa.; Nashville, Tenn.; and Austin, Tex.; also Pl. LXIX and some others of this volume.

\section{GROUP 7.-STREAM PIRACY AND ADJUSTMENT.}

Pls. LXXXIII-LXXXIX are designed especially to illustrate the effects of structure and inequalities of hardness on the relations of streams to one another.

\section{PLATE LXXXIII.}

Pl. LXXXIII affords two illustrations of stream piracy. One is seen in Kaaterskill Creek, the other in Plattekill Creek. As to the first the following points may be noted: (1) The steep gradient of Kaaterskill Creek and the youthful character of its valley; (2) the slight gradient of the headwaters of the north branch of Schoharie Creek $(B-A)$; (3) the low divide (shown at $B$ ) between the Kaaterskill and the north branch of the Schoharie; (4) the course of the drainage from North and South lakes and the character of the valley through which it flows, this drainage starting westward in an open valley and then turning southward to the Kaaterskill and descending by falls into a deep, narrow, steep-sided gorge; (5) the fact that, if the narrow valley of the upper Kaaterskill and its tributaries were filled up, there would be a declining surface of gentle gradient westward from North and South lakes to the valley of the north branch of Schoharie Creek, and the gradient between the lakes and the head of that stream $(B)$ would be altogether harmonious with the grade of the Schoharie Valley below $(B-A)$.

A profile of the valley which drains the lakes, down to its junction with the Kaaterskill $(E-D)$, is shown in fig. 26. Taken by itself, this profile suggests rejuvenation. (Compare fig. 22.) A profile of Kaaterskill Creek, of the divide between it and the north branch of Schoharie Creek, and of the upper part of the latter stream $(A-B-C$ of the map), is presented in the section at the bottom of the plate, which shows that the divide between the two streams is in an unstable position and must be in process of shift-

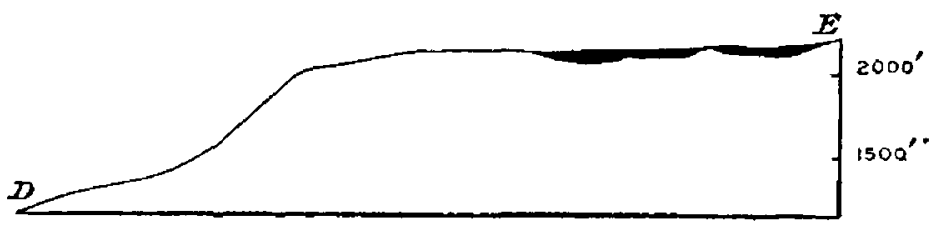

Fig. 26.--Profile from the east end of North Lake to Kaaterskill Creek, by way of the present drainage ( $E-D$, Pl. LXXXIII). Vertical scale about two and one-half times the horizontal.

ing to the west, unless notable irregularities in the hardness of the rock prevent. The Kaaterskill Valley is clearly a young valley, but that of the north branch of Schoharie Creek has the appearance of much greater age. The vertical scale of the profile is not exaggerated.

The above-noted features suggest the following sequence of events: ${ }^{a}$ (1) The drainage from the lakes once went westward to the north branch of Schoharie Creek in a valley of gentle grade. At that time the drainage from High Peak and Roundtop Mountain was probably also tributary to the same stream. (2) A valley was then developed in the face of the steep slope of the Catskills, and by head erosion worked its way back into the high land, shifting westward the 
divide between its head and the head of the north branch of Schoharie Creek. (3) Presently one of the tributaries of this new stream, working its head northward, tapped the stream that carried off the lake waters. This tributary thus became a pirate, diverting the discharge creek of the lakes to the Kaaterskill. As the pirate stream had a deep valley, the water from the lakes descended to it at a high gradient, forming rapids or falls and cutting a deep gorge. The falls are still in existence and the gorge is still being lengthened headward. It is clear that when the head of the gorge reaches the lakes, they are likely to be drained, unless their basins are very deep. Other westward-flowing tributaries of the Kaaterskill have developed in a similar manner.

Plattekill Creek, farther south, shows somewhat the same history. The low divide (shown at $G$ ) between this creek and Schoharie Creek is unstable, as indicated by fig. 27, which rep-

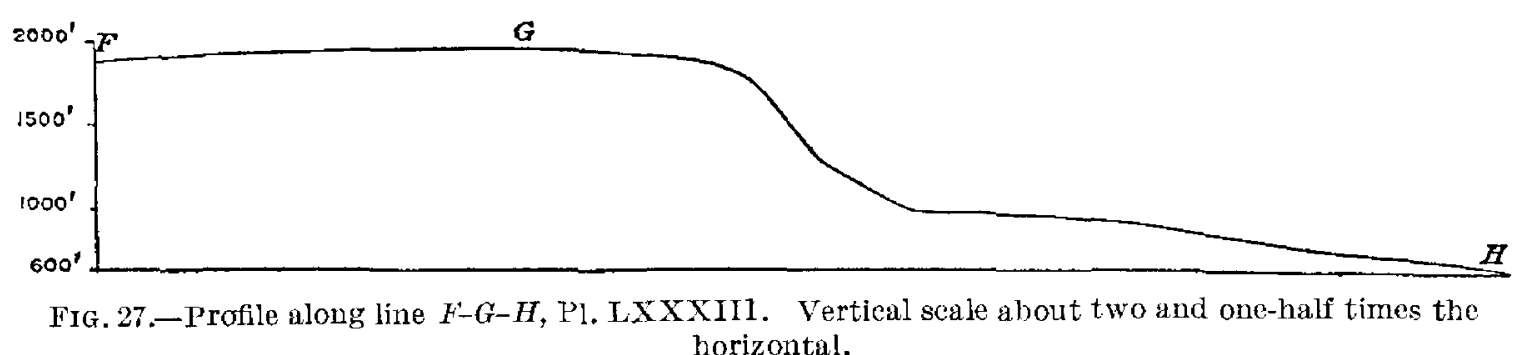
resents a profile along Plattekill Creek and the headwaters of Schoharie $\operatorname{Creek}(F-G-$ $I I$ of the plate). The headwaters of one of the tributaries of the Plattekill on its north side have a course which suggests that this stream once joined the Schoharie. The map indicates that Plattekill Creek has already encroached upon the former drainage basin of Schoharie Creek, and that the campaign of conquest is still in progress.

PLATE LXXXIV.

PI. LXXXIV presents further illustrations of changes in drainage. In $A$ it is to be noted that Outlet Creek has a deep and narrow valley near its head, and that this valley, not far from its head, is notably lower than Yellowstone Lake, an arm of which is shown on the map. The profile along Outlet Creek and over the divide to Yellowstone Lake by way of Grouse Creek is shown in fig. 28.

This profile shows that the divide is unstable and must shift toward the lake. It would be quite possible for the valley of Outlet Creek to work its head back to the lake, if no conditions other than those shown on this map affected the problem. The map suggests, indeed, that the lake may once have discharged by way of Outlet Creek, and that the lowering of the

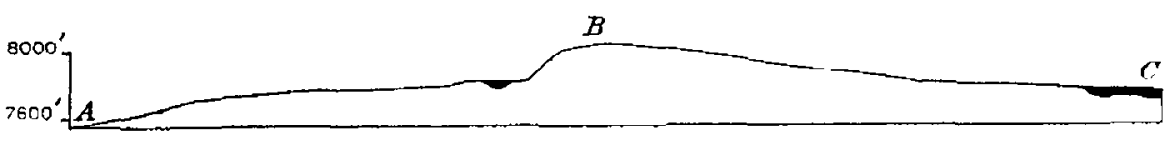

FIg. 28.- Profile along line $A-B-C$, Pl. LXXXIV. Vertical scale exaggerated about five times. lake level, perhaps by the deepening of some other outlet, stopped the outflow in this direction. The name Outlet Creek is probably due to this supposition.

Pl. LXXXIV, $B$, shows two other remarkable divides-(1) that between the heads of Mink and Falcon creeks and (2) that between Atlantic and Pacific creeks. Both the divides are low. The steeper slope of the first is to the northeast; of the second, to the southwest. The map suggests that Falcon Creek is driving the divide between it and Mink Creek to the west, and that Pacific Creek is lengthening at the expense of Atlantic Creek. The headwaters of Mink Creek appear to be in danger of capture by Falcon Creek. The low gradient at the head of Pacific Creek is consistent with the low gradient of Atlantic Creek, and it is possible that the uppermost tributaries of Pacific Creek on the south have been stolen from Atlantic Creek. The headwaters of Atlantic Creek, on the northwest, seem liable to fall a prey to Pacific Creek, through the lowering of the divide at Two Ocean Pass.

In many mountainous regions and in the northern part of the United States east of the Cordilleran Mountains drainage changes have been much complicated by glaciation. 
PLATE LXXXV.

The preceding illustrations of drainage changes have had to do with waters of different systems. Pl. LXXXV shows drainage changes within a single system. Little Maquoketa River probably once flowed southward through the narrow valley between Sageville and Dubuque. The outline of the Mississippi flood plain shows that the main stream probably once swung westward against the bluffs west of Peru Bottoms. When it was in this position, a tributary probably worked back and tapped the Little Maquoketa, carrying it directly to the Mississippi. When the Mississippi swung back to the east side of its flat, the Little Maquoketa held its course across the flood plain of the main stream. ${ }^{a}$

\section{PLATE LXXXVI.}

Pl. LXXXVI illustrates a change in drainage whose history has been worked out ${ }^{b}$ and is indicated by figs. 29 and 30 . The plate shows the present topography of the area.
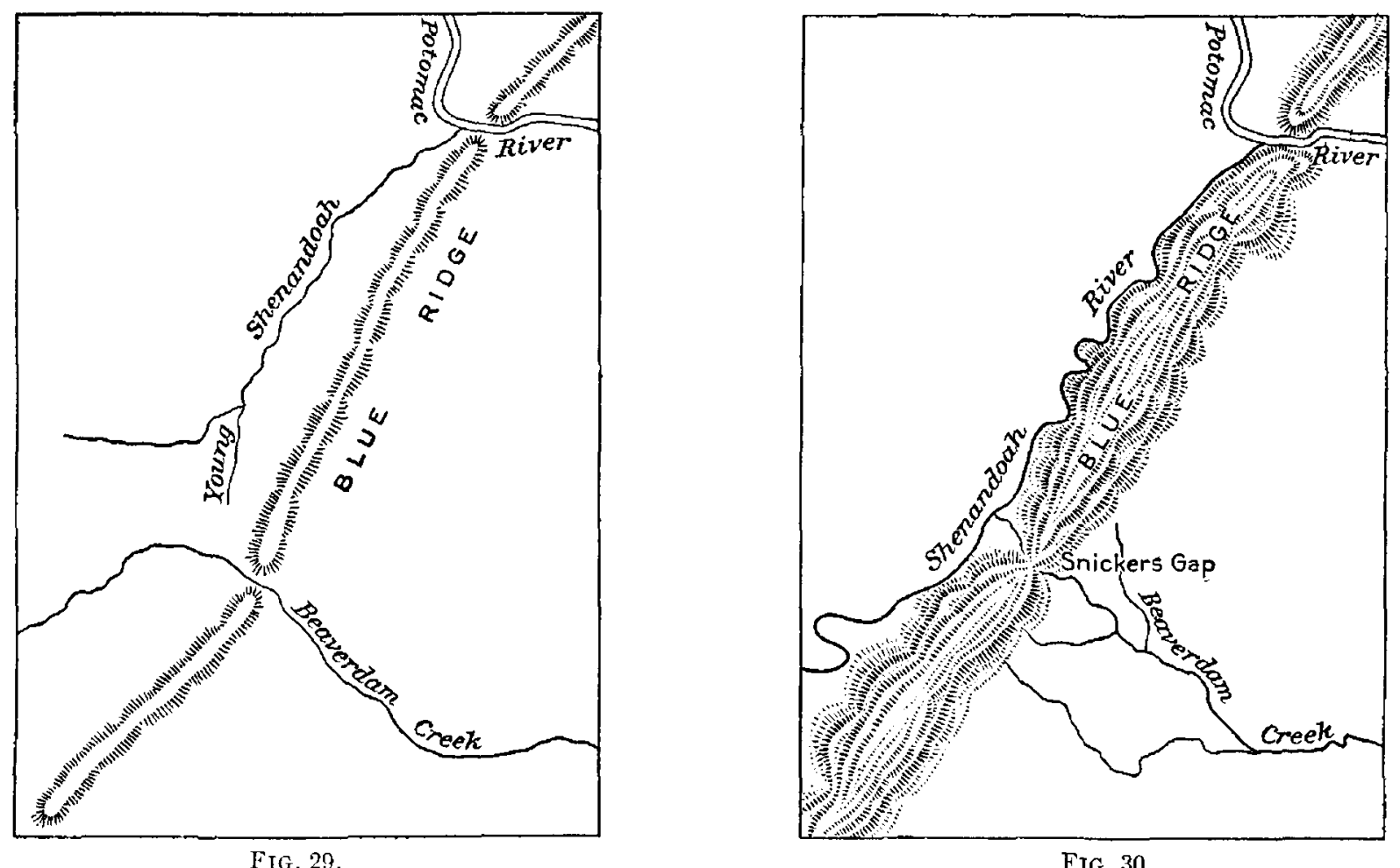

Sketch maps to illustrate the captture of the head of Beaverdam Creek by the Shenandoalh, Virginia-West Virginia. (After Willis.)

As shown in fig. 29, Beaverdam Creek once flowed across the Blue Ridge, which, at Snickers Gap, is composed of hard rock. The stream was unable to deepen its bed across the hard rock of this ridge as rapidly as the larger Potomac lowered its channel across similar rock. The result was that the head of a tributary of the Potomac worked back and tapped Beaverdam Creek, establishing the relations shown in fig. 30 and on Pl. LXXXVI. By this process the water gap (at Snickers Gap) became a wind gap. ${ }^{c}$

The manner in which the present divide was established may be worked out by the application of familiar principles. Any divide between headwaters shifts as long as there is unequal erosion on opposite sides.

Plate LXXXVI shows three cycles of erosion. (Compare Pls. LXX and LXXVI.)

\section{PLATE LXXXVII.}

Pl. LXXXVII shows an interesting relation of drainage to structure. A main stream, the Sequatchie, flows through a deep and wide valley. The valley bluffs are high and steep, 
and the tops of the bluffs are distinctly higher than the surface back of them. The general relations are shown by the section across the valley.

A subordinate line of elevations is seen in the valley itself near the stream, especially in the northeastern part of the area mapped. These subordinate elevations are here on one side of the stream and there on the other, but their crests lie in a nearly straight line, and this line is essentially parallel with the line of bluffs on either side of the valley. Though the stream's course is in a large way parallel to the bluffs, it makes a series of sharp turns which are not at all like the curves of a meandering stream. (Compare Pl. LI.) Where the stream departs from its general northeast-southwest course it does so for a short distance only, and its turns are generally right-angled.

All these features are consistent with the structure of the rocks of the region, and the structure may be inferred with a good deal of confidence from the topography. The main valley is located on the axis of an anticline, the stream flows nearly along the strike of the beds, and in the short stretches where it departs from this direction its course is along the dip of the beds. The position of the valley on the anticline shows that the Cambrian, Ordovician, and Silurian rocks of the area are, on the whole, more easily eroded than the Carboniferous. The subordinate ridge of the valley is formed of the upper beds of the Knox dolomite, which appear to be harder than the lower beds of the same formation, or than the lower beds of the Chickamauga limestone.

The main stream is in a general way adjusted to the structure, but not wholly so. Perfect adjustment would require it to cross the subordinate valley ridge fewer times, or not at all.

As the main stream flows parallel to the strike, the tributaries must of necessity have a tendency to flow athwart the strike, and many of them enter the main stream at right angles. But the tributaries are affected by the structure in the same way as the main stream, and depart more or less from a direct course, especially in their upper portions. The control, however, is less complete. The main stream is affected primarily by the structure; the tributaries are affected both by the structure and by the main stream.

The effect of structure on the courses of tributaries is shown, for example, by Hixon Creek. The lower course of this stream is at right angles to that of the Sequatchie, but its middle portion runs parallel to the river. The position of this portion doubtless represents the outcrop of a layer of rock less resistant than the surrounding beds. Near its upper end Hixon Creek again flows at right angles to the Sequatchie and to the strike of the rock, but two of its tributaries show a tendency to assume courses parallel to the strike. The same tendency is shown by other tributaries of the minor streams in similar positions.

These phenomena illustrate the facts (1) that streams have a pronounced tendency to follow the strike when they flow through a region of tilted strata of unequal hardness and (2) that when streams can not follow the strike they are likely to flow at right angles to it. Wh $\mathbf{n}$ in such regions streams flow as much as possible parallel to the strike, and as little as they must in other courses, the drainage is said to be adjusted. Northeast of that part of Hixon Creek which is parallel to the Sequatchie there is a stream that flows northeastward and joins the Sequatchie. It is separated from a tributary of Hixon Creek by a low divide only. If the head of this last-named tributary were to work back far enough, it might capture this little creek, foot by foot, pushing the divide to the northeast. If this divide were driven to the Sequatchie, the main stream would be diverted to the present course of Hixon Creek and would thus avoid one crossing of the hard rock represented by the ridge east of Mount Airy. A little shifting of the lower end of Hixon Creek would eliminate another crossing of the hard layer. It is by such changes in streams-that is, by piracy-that stream adjustment is effected.

The map also shows instability of drainage in other places. The grade of the stream which heads above Henson Gap is steep, while Gray Creek, the stream just to the northeast, flowing southeastward from the divide, has a lower gradient. The former creek descends about 3 miles before it reaches an altitude of 700 feet; the latter flows fully 15 miles to reach the same level. This is a condition of instability, and the creek flowing westward from Henson 
Gap is likely to work its head back so as to capture and decapitate Gray Creek. Conditions of the same sort may be found in other parts of the area.

In the shifting of divides inequality of hardness often modifies the results which inequalities of slope would produce. A divide shifts as long as erosion is greater on one side than on the other, and it is not necessary that the slopes of the two sides should be unequal. On the other hand, a divide may remain constant in position even when these slopes are very unequal, if there is notable inequality of resistance between the two sides.

\section{PLATE LXXXVIII.}

Pl. LXXXVIII illustrates the same general principles as Pl. LXXXVII in somewhat different relations. The main drainage lines stand in somewhat definite relations to an anticline; 'but, instead of being located near the axis of the fold, as in the area represented by Pl. LXXXVII, the streams are well over on its flanks.

The significant streams of the map, in connection with piracy and adjustment, are North and South forks of Lunice Creek, flowing out through Cosner and Kline gaps, respectively, and New Creek, which joins North Fork of the Potomac near Hopeville. Both forks of Lunice Creek have narrow valleys where they cross the hard layers of rock, but farther up both valleys are broader where they are parallel to the strike of the less resistant Devonian beds. The valley of New Creek is parallel to those of the headwaters of the creeks just named. It is to be noted that the divide between the headwaters of New Creek and South Fork of Lunice Creek, that between the latter and North Fork, and that between North Fork and the stream flowing to the northeast and passing through Greenland Gap are all low.

The map shows that all these creeks are located on the basal beds of the Devonian, which are therefore inferred to be less resistant than the beds above and below. The several valleys really constitute one, though occupied by the waters of streams which finally flow eastward across the hard beds of Walker Ridge, New Creek Mountain, and Little Mountain in four separate places.

Kline and Cosner gaps are about equally deep. The headwaters of the streams which flow through them therefore have a measurably balanced contest both west of Little Mountain and west of Walker Ridge. If either gap were deeper than the other, the stream flowing out by the deeper gap would drive its divide back at the expense of the tributaries of the stream discharging by the other.

New Creek, it will be noticed, joins a larger stream, which crosses the range at a much lower level than that of North and South forks of Lunice Creek. It follows that New Creek has a great advantage over the others. Its head is now pressing hard against the headwaters of a tributary to South Fork. Should the divide be driven back another quarter of a mile, one tributary of South Fork would be diverted. New Creek, reinforced by the waters thus captured, would deepen its valley faster than now, while the impoverished South Fork would deepen its valley more slowly. New Creek might then shift its headwaters still farther northeastward, along the valley west of Walker Ridge, until it had captured all the headwaters of South Fork, and it might go even farther until it had captured the headwaters of North Fork. Were this accomplished, the waters of the valley west of Walker Ridge would cross the outcrop of the hard ridge-forming rocks along one line, instead of along several, as now. It seems quite possible, from the map, that the head of New Creek has already begun its piratical work and that its uppermost tributaries have already been taken from South Fork, though the inference can not be established from the map. A study of the area north of that here mapped will show - that piracy by the stream flowing north-northeastward beyond the head of North Fork and crossing the range through Greenland Gap might bring about a different result.

It is clear that other contests also are in progress at the heads of valleys, as (1) between the two streams west of Little Mountain, one tributary to North Fork and the other tributary to South Fork; (2) between the headwaters of the streams just southwest of Robinson Gap; and (3) between the streams north of Cosner Gap.

The tributaries flowing eastward from the Allegheny Front have high gradients, and their heads are working back. The tributaries northwest of Cosner Gap, for example, stand a good 
chance of working back so as to capture the headwaters of Stony River on the plateau above. The profile from this stream through Cosner Gap by way of the tributaries is shown in fig. 31 . The topography suggests, however, that the formation marked $\mathrm{Cbw}$ is a resistant one, and the great advantage of the southeastward-flowing stream, as indicated by the profile, is therefore partly or perhaps wholly offset by inequality in the resistance of the rocks traversed.

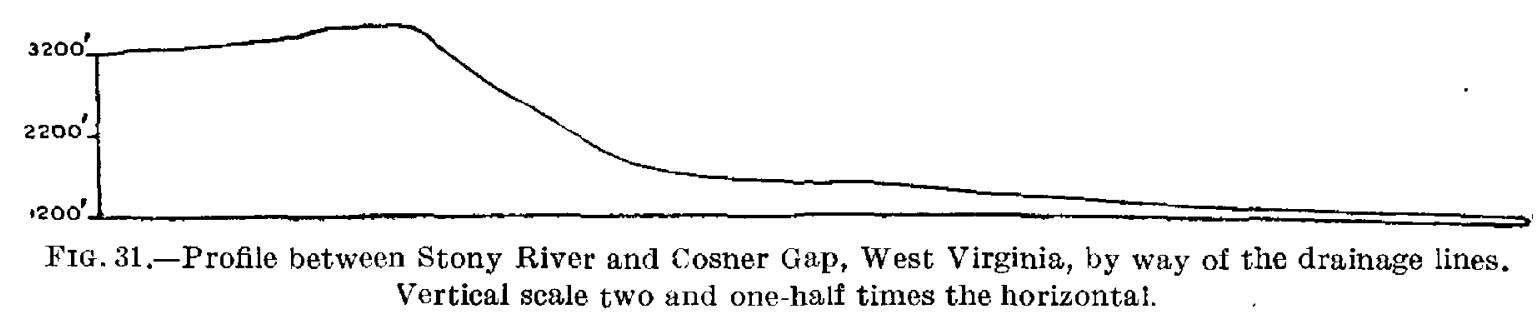

PLATE LXXXIX.

The conspicuous features of Pl. LXXXIX are (1) the pronounced cliffs with a general northeast-southwest course, but with striking irregularities; (2) the valleys parallel with the cliffs; and (3) uplands of plateau type between the ridges. The map indicates that the region is one where the rocks are folded, and that the folds run from northeast to southwest. The broad plateaus are located where the folding is not close. It will be seen that this map shows the disappearing ends of three folds. The anticline shown at the left of the upper section does not appear in the section farther south; the anticline at the left of the lower section has greatly diminished in sharpness (is plunging) where the northern section crosses it, and disappears altogether a little farther north; and the end of the anticline at the right of the lower section is plunging southward.

The main streams are moderately well adjusted to the structure of the beds where the dip is considerable. The streams that appear not to be in adjustment to a folded structure flow in regions where the strata are not folded. Nearly every topographic feature shown finds its explanation in the geologic structure of the region.

Pls. LXVII and LXIX of this volume also illustrate the effects of structure and inequality of hardness on streams.

\section{GROUP 8.-TOPOGRAPHIC EFFECTS OF GROUND WATER.}

The set of maps comprising Pls. XC-XCIV is designed to illustrate the topographic influence of the solution effected by ground water.

\section{PLATES Xo-XCII.}

Pl. XC shows mature drainage in a plateau where the climate is moist and the strata are apparently nearly horizontal. The depressions (sinks without surface outlets) form the special feature of the map. Round Cove, Icy Cove, Big Sink, and Morrison Cove are examples. Some of the coves have three depression contours and are therefore more than 200 feet deep, but not so much as 400 feet. The map shows that short creeks flow into many of these coves and disappear, indicating that their waters find an outlet downward, through underground courses, perhaps to issue at the surface elsewhere in the form of springs. Such features are most common in regions where the underlying rock is limestone, a relatively soluble rock. Many sinks are produced by the collapse of underground caves. PI. XCII shows a small sink of this sort.

The map also shows many coves with outlets - such as Dyer and Whitaker coves and Cowan and Madewell hollows. Some of these may have been developed from depressions without surface outlets. If, for example, the head of the valley just south of Beaver Hill (near the northeast corner of the area mapped) worked back to the basin of Sinking Cove, the depression might acquire a surface outlet; or if for any reason the downward outlet in the cove became clogged, as it might be by caving, water might collect in the basin and finally overflow. Under such conditions Sinking Cove might be drained to the north and would become somewhat like 
the coves with surface outlets. The subterranean watercourses in this region were probably developed in large part before the topography had reached its present maturity, at a time when the rainfall was less perfectly carried away from the surface.

The geologic map of the region (Pl. XCI) shows the distribution of the rock formations, and the section at the bottom of the plates shows the structure.

\section{PLATE XCIII.}

Pl. XCIII, $A$, shows a series of sinks arranged in two parallel belts running northeast and southwest, one on either side of the main stream. The position or arrangement of these sinks suggests that limestone formations outcrop in these two parallel belts, a fact that is shown in Pl. XCIII, $B$. $€ O \mathrm{k}, \mathrm{Oc}_{\mathrm{c}}$ and $\mathrm{C}$, the formations in which the sinks occur, are limestone. It should be noted, however, that some limestone belts are without sinks. Limestones are not all equally soluble nor equally well situated for the development of sinks.

Clinch River shows entrenched meanders. The outcropping hard layers, as $\epsilon_{\mathrm{rl}}$, etc., form belts of hills, and the general linear arrangement of the elevations is determined by outcrops of rock of different degrees of resistance, their strikes being northeast and southwest. This arrangement is well marked throughout the central part of the area mapped but not in the northwest or southeast portions.

Pl. XCIII, $A$, also shows three cycles of erosion, the successive levels being $2,500 \pm, 2,000$ to 2,200 , and $1,500 \pm$ feet. The last of these cycles is but well begun and the second was very incomplete when the third was initiated.

The profile and structure of the region alorg the line $A-B$ of Pl. XCIII, $B$, are shown in the section at the bottom of the plate.

\section{PLATE XCIV,}

Pl. XCIV shows the geology of an area in Tennessee that includes Grassy Cove, a remarkable sink with underground drainage. The cove is at the northern end of a plunging anticline and its history appears to be somewhat as follows: At the outset the drainage must have flowed to the northwest and southeast from the axis of this anticline. Favored by slope, the streams presently cut through the hard sandstone capping the anticline, a result not yet accomplished to the east and west, on the synclines. When the sandstones, $\mathrm{Cw}$ and $\mathrm{Cl}$, had been cut through, the limestone, $\mathrm{Cb}$, was exposed, and solution began to play an important part. A subterranean drainage system was developed. Sinks were then formed, and the surface drainage was diverted downward. The inward-flowing streams had the advantage over those that flowed down the sides of the anticline, both in slope and in erodibility or solubility of rock bed. Piracy followed, the outgoing streams being everywhere the losers, their former channels being now represented by wind gaps on the outcropping edges of the hard sandstone which forms the divide between the interior and exterior systems of drainage. Further encroachment by the inflowing streams is likely to occur, inasmuch as their gradient is higher than that of the outflowing streams.

Good illustrations of the topographic effects of ground water are also furnished by the following topographic sheets: London, Ky.; Jonesville, Ky.-Va.-Tenn.; Greeneville and Knoxville, Tenn.-N. C.; and Maynardville, Morristown, and Pikeville, Tenn.

\section{GROUP 9.-GLACIATION.}

The group of maps forming Pls. XCV-CXXIX is designed especially to illustrate the various phases of topography developed by glaciation. They have been selected both from areas affected by ice sheets and from areas affected by local glaciers. Phases of topography originating through the deposition of drift by water that arises from the melting of the ice are also included. The group comprises (1) maps showing primarily the topography resulting from glacial and fluvioglacial deposition by the North American ice sheets (Pls. XCV-CVII); 
(2) maps showing changes of drainage brought about by glaciation (Pls. CVIII-CXX); (3) maps showing mountain glaciers and the effects of mountain glaciation (Pls. CXXI-CXXVII); and (4) maps showing glaciated coasts (Pls. CXXVIII-CXXIX).

\section{GLACIAL AND FLUVIOGLACIAL DEPOSITS (PLATES XCV-CVII).}

GROUND MORAINES (PLATES XCV-XCIX).

PLATE XCV.

Pl. XCV illustrates the topography developed by glaciation in a region of rather slight relief. The characteristic features are the numerous undrained areas represented by marshes and lakes; the river valleys, which have not the normal characteristics of valleys shapod by surface drainage; and the lack of systematic relations between the higher lands and the courses of the streams. In some parts of the area the elevations show a distinct northeast-southwest trend, which suggests the direction of ice movement. A few of the hills, such as that about a mile south of New Berlin, have the form of drumlins.

The map does not show whether the hills are made up of rock or of drift, but it suggests that they consist of drift, for there is no systematic relation between ridges and hills on the one hand and stream valleys on the other. It is not improbable that the underlying rock affects the configuration of the surface to the extent of determining the position of the higher and the lower lands, though this can not be affirmed from the map. The topography is that of ground moraine rather than of any other phase of glacial drift.

The topographic effects of glaciation may be sharply brought out by comparing this map with Pl. LXXXV.

This map, as well as most of the other maps in group 9, shows both youthful drainage and youthful topography. The type of youth illustrated, however, is different from that presented in Pls. XXIII-XXXVI. Those maps show normal youth; these show a youth which was superimposed upon surfaces that were in various stages of their erosion history before the ice affected them.

PLATE XOVI.

The maps forming Pl. XCVI show other phases of ground-moraine topography. $A$ illustrates a surface more nearly plane than is common to ground moraine. Ponds and lakes are lacking, and the low mounds stand in no definite relation to drainage lines. Stream erosion since the deposition of the drift has developed some shallow valleys, but, as measured by such erosion, the topography is distinctly young.

Pl. XCVI, $B$, shows a glaciated surface where the topographic features due to glaciation have been so obscured by subsequent stream erosion as to be indistinct. Glaciation of the region could not be affirmed from this map. (Compare Pl. XCV.) As a matter of fact, the area shown in Pl. XCVI, $B$, was glaciated much earlier than those shown in Pl. XCVI, $A$, and Pl. XCV. The drift of the area shown in PI. XCVI, $B$, has therefore been subject to subaerial erosion much longer than that of the areas shown in PI. XCVI, $A$, and PI. XCV.

Both these maps illustrate the general fact that a glaciated surface does not necessarily contain ponds and lakes, though ponds and lakes are characteristic of regions recently glaciated. In the area represented by Pl. XCVI, $A$, lakes appear never to have been present; if the area represented by Pl. XCVI, $B$, ever contained any lakes, they have been destroyed by erosion.

\section{PLATE XOVII.}

Pl. XCVII represents an area of drift, presumably ground moraine, where the surface has little relief except for one deep gorge, and where marshes and ponds are absent. A few low hills stand in no definite relations to the stream valleys. The extreme youth of the region, in terms of erosion, is shown by the narrowness of the gorge of the main stream, the absence of considerable tributary valleys, and the shortness of the gorges of the tributaries that join the main valley below the falls. The quickening of the tributaries due to the recession of the falls past their 
debouchures was brought about so recently that the gorges developed since have worked back but a little way from the main gorge. (Compare PI. XXVI.)

Topography due partly or wholly to ground moraines is shown on many topographic sheets covering areas within the glaciated region of the continent. The Morris and Wilmincton, Ill.; Marion and Tipton, Iowa; Canton, Findlay, Fostoria, and Wooster, Chio; and Milwaukee, Shopiere, and West Bend, Wis., maps, also Pl. XV of this volume, represent various phases of such topography.

PLATE XCVIII.

PI. XCVIII represents a special phase of ground-moraine topography. The important features shown are two-(1) the poor drainage, indicated by the marshes, the lakes, and the streams practically without valleys, and (2) the elliptical hills of drift known as drumlins. The drumlins are elongated in the direction of ice movement and occur either singly, in pairs, or in groups. The steep ends of most of them are to the northeast, the direction whence the ice came. This map affords a good illustration of the Wisconsin type of drumlins.

\section{PLATE XC1X.}

Pl. XCIX illustrates drumlins of another type, a type common in western New York. They are much more crowded, have steeper slopes, and are higher and narrower than most of those in Wisconsin. The youthful drainage will also be noted.

Drumlins are also well shown on the following topographic sheets: Brockport, Clyde, Fulton, Oswego special, Palmyra, and Sodus Bay, N. Y., and Madison, Sun Prairie, and Watertown, Wis.

$$
\text { TERMINAL MORAINES AND OUTWASH PLAINS (PLATES C-CV). }
$$

The maps showing terminal moraines have been selected with reference to the illustration of (1) their different types of topography and (2) their different topographic relations. Many of the same maps show stratified drift in valleys (valley trains) or on plains (outwash plains) outside the terminal moraines, but closely associated with them. Most of them show youthful drainage.

\section{PLATE C.}

Pl. C shows several phases of drift in characteristic relations. These are (1) the groundmoraine topography at the east, occupying about half the area shown on the map; (2) the terminal-moraine topography, represented by the rough belt running from north to east of south, and marked by numerous ponds (indicated by horizontal ruling), marshes, and hillocks; and (3) the outwash plain topography, represented by the sloping plain at the western border of the terminal moraine.

The notable feature here is the terminal-moraine topography, which is much more uneven (hummocky) than that of the ground moraine on the one hand or that of the outwash plain on the other.

PLATE CI.

PI. CI shows a .strongly developed terminal moraine on Long Island, extending from Greenwood Cemetery in Brooklyn to the eastern border of the area mapped. North of it lies the less rough ground moraine, and south of it the outwash plain, somewhat modified by postglacial erosion.

The relation of the culture to the topography, which is here due almost wholly to the disposition of the drift, is well shown. One belt of principal settlement east of Brooklyn lies along the base of the steep terminal front and was clearly determined by it.

The section at the left of the plate shows the profile along the line $A-B$, the vertical scale being exaggerated about twelve and a half times. 
Plate CII.

Pl. CII represents terminal moraines in two different regions in Wisconsin. In $A$ the terminal moraine is represented by the north-south belt of rough topography shown near the center of the map. Unlike the terminal moraines of preceding maps, this belt is without many depressions and marshes, though hillocks are numerous. As a whole it is higher than the less rough ground moraine to the east. At its western base is the outwash plain. The relations shown in Pl. CII, $A$, and in PI. CI are much the same, though the topography of the terminal moraine is somewhat different.

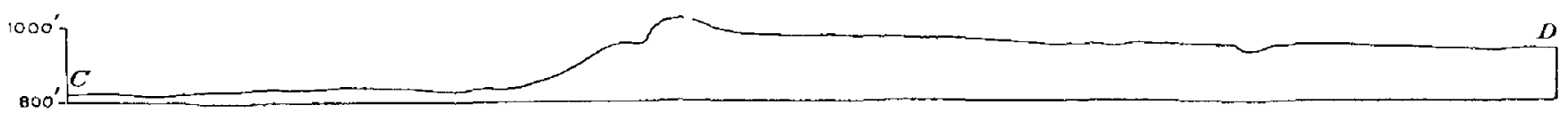

FIG. 32.-P rofile along line $C-D$, Pl, (II, $B$. Vertical scale about six and one-half times the horizontal,

PI. CII, $B$, shows another terminal moraine, the position of which is marked by the belt of rough topography extending from northeast to southwest across the area mapped. To the northwest is the ground moraine, with its poor drainage, and to the south and southeast is a plain of stratified drift deposited by the water which flowed out from the moraine. Its surface is marked by many depressions, making it a pitted plain. (See fig. 32.) The fact that this plain is composed of stratified drift is of course not shown on the topographic map, though the inference, that such is its composition is suggested both by its position with reference to the terminal moraine and by its topography.

Plate CIII.

Pl. CIII ${ }^{a}$ furnishes an illustration of a terminal moraine in a region where the relief of the surface is much greater than in the areas mapped on Pls. CI and CII. The course of the terminal moraine is shown on the map by the belt of irregular topography marked Qtm. It is not bordered by an outwash plain. The contrast of the topography of the terminal moraine with that to the north and south is pronounced. The topography to the south is determined primarily by the underlying rock; that to the north is due largely to the rock, but is somewhat modified by the ground moraine.

The irregular faint black lines on this map and on PI. CVII indicate forest boundaries.

PLATE CIV.

PI. CIV shows a wide terminal-moraine belt running from northeast to southwest across the area mapped. The more pronounced moraine features lie southeast of White River, in the eastern part of the area. This belt is locally known as "the knobs." Many lakes and ponds are associated with this terminal moraine. Lake Geneva, one of the most beautiful glacial lakes in this part of the world, occupies a portion of a preglacial valley, parts of which were filled by the drift deposited by the ice. The maximum depth of the lake is 142 feet. $^{b}$ The northwestern part of the area shows ground-moraine topography.

Plate OV.

Pl. CV shows a terminal moraine of not very pronounced topography. The moraine has a north-south course and is best shown east of the flat about Pains Corners, in the northern part of the area. The flat about Pains Corners and Kings Corner's stretches off down the Wisconsin Valley and becomes a broad, flat valley train. To the north, however, before it enters the valley proper, it may be looked upon rather as an outwash plain.

a Geol. Survey New Jersey, vol, 5, 1902, PI, X LV

b Fenneman, N.M., Bull Wisconsin Ceol. Survey No.8, 1902. This bulletin gives an interesting and readable account of many of the glacial Iakes of southeastern Wisconsin. 
The principal hills in the eastern and western parts of the area shown on the map are due to the underlying rock.

The narrow and shallow gorge of the Wisconsin above Prairie du Sac is of postglacial origin.

Terminal-moraine topography is also well shown on the following topographic sheets: Plainfield, N. J.; Staten Island, N. Y.; and Eagle, Hartford, Silver Lake, and Wausau, Wis.

KAMES (PLATES CVI AND CVII).

PLATE CVI.

The principal hills just south of Rochester, N. Y. (Pl. CVI, A), are kames. The topography of the rest of the area shown on this map appears to be that of a ground moraine with little relief.

Pl. CVI, $B$, furnishes another illustration of kames, the most notable of which are the hills near the southeast corner of the area. The height of the highest of these kames is nearly 50 feet, but several of them are sufficiently high to stand conspicuously above the surrounding plain. There are numerous smaller kames just north of Springfield, each represented on the map by a single contour.

The steep slopes shown on the map are clifis of rock. The rough, hummocky area between Milburn and Summit is a portion of a terminal moraine.

\section{PIAATE CVII}

Pl. CVII ${ }^{a}$ shows a number of prominent kames in a region of strong relief. The greater elevations are due to the underlying rock, but the kames among these rock hills are large enough to form pronounced features. The position of the kames is indicated on the plate by the device marked $Q k$ in the legend.

This plate also shows other interesting features, especially the delta plain of stratified drift (Qdg). The delta features brought out by the map are (1) the gently sloping plane surface above and (2) the steep, lobate slope at the southern edge of the delta. The delta is made up of stratified drift, deposited in a temporary lake which existed when the edge of the ice sheet lay a short distance north of this locality.

DERANGEMEN'T OF DRAINAGE EFFECTED BY GLACIATION (PLATES CVIII-CXX).

Pls. CVIII-CXX are introduced principally to illustrate changes of drainage occasioned by glacial ice and by the drift which it left. Most of the maps of this subgroup show superimposed youthful drainage. (See p. 56, Pl. XCV.)

PLATE CVIII.

Pl. CVIII illustrates drainage changes effected by glaciation in a region of notable relief. Greenwood Lake occupies part of a deep preglacial mountain valley. 'The direction in which the drainage flowed through this valley in preglacial time is not evident from the map. Important drainage lines appear to have extended both southwestward and northeastward from the ends of the lake. The map does not indicate how much the valley was deepened by ice erosion. It seems clear, however, that the valley was partly filled with drift at the ends of the lake, and that this filling converted a part of the river valley into a basin. The origin of Sterling Lake was probably similar to that of Greenwood Lake. So far as the map suggests, such ponds as Iittle Cedar Pond may occupy depressions in the surface of the drift.

The more pronounced topographic features shown on the map are due to the underlying rock, not to the drift; but the poor drainage, of which there are several indications, is the result of glaciation. 


\section{PLATE CIX.}

Pl. CIX illustrates changes in drainage effected by mountain glaciers. Well-defined preglacial valleys, cut out by river erosion, appear to have been dammed by deposits of drift, or gouged out locally by the ice erosion, so as to give rise to basins. Three valleys have been thus affected. The flats below the lakes suggest that plains of stratified drift occupy the valleys below the basins. If so, these plains must have been aggraded to their present level while the ice still occupied the sites of the lakes. The amount of postglacial erosion seems to be slight, so far as can be judged from the map.

It is probable that the minor lakes above the main valleys either are held back by morainal dams or occupy basins hollowed out of the rock by glacial erosion. Some of those lying in the heads of cirques are very likely of the latter class.

The ice not only developed basins, and so interfered with drainage, but perhaps changed the courses of streams. At some time a stream probably flowed through Snoqualmie Pass, north-northwest of Keechelus Lake, but it can not be determined from the map whether this stream was diverted from its course by the ice.

It is possible to tell, approximately, from the map, the altitude (about 7,000 feet) which is now necessary for perennial snow and glaciers in this region, and also the altitude which was necessary at the time of the glacial epoch (5,000 feet or a little less).

\section{PLATES CX AND CXI.}

Lake Chelan, a part of which is shown on $\mathrm{Pl}$. CX, occupies a portion of a preglacial valley. The lake is surrounded by a mountainous area and is remarkably deep, its bottom being well below the level of the sea, a fact not shown on the map. It is not in the region affected by the continental ice sheet, but its valley contained a huge mountain-valley glacier. So far as the map shows, the basin might be due to the filling of the valley below the lake by drift; but as a matter of fact this is not the case to any notable extent, and there appears to be no alternative but to believe that the lake basin was gouged out by glacial erosion, or that it was deepened through the depression (by faulting or warping) of its bottom.

The general topography of the region is that of early maturity. The small lakes suggest glaciation, which may have been either local or general, though the fewness of these lakes shows that glaciation was not both general and recent. If it was general, it took place so long ago that erosion has destroyed the more distinctive glacial features. The absence of a pronounced trend to the leading topographic features indicates that the mountains are not composed of folded stratified rocks.

PI. CXI, which represents a slope north of the south end of Lake Chelan, is here introduced to show a topographic unconformity such as is likely to be developed in a region situated as this is. As this illustration shows, the upper slopes of the bluffs bordering the lake have wide, open drainage depressions, such as are common in mountain regions; but, instead of continuing down to the lake with increasing width, these erosion depressions seem to end far above the lake, and narrow gorges lead down to the water. In other terms, an older topography, at higher elevations, is succeeded by a younger topography at lower elevations. The line of junction of these two types of topography represents approximately the upper limit of the glacier that occupied the valley. The effect of the ice was to obliterate or to obscure the preglacial erosion features of the surface on which it worked. The lake level was formerly much higher than now, and its waters helped to efface the preglacial topography of the lower slope shown in PI. CXI. Since the ice melted the lake level has been lowered and postglacial erosion has developed the narrow gorges that lead down from the older valleys above to the lake.

\section{PLATE CXII.}

Pl. CXII illustrates primarily one way in which glaciation interferes with drainage. It shows one lake occupying parts of two valleys, and two other lakes occupying different parts of one valley. These lake basins were formed chiefly through the obstruction of the valleys by drift, and perhaps partly through the local deepening of the valleys by glacial erosion. 
The map also shows other significant points. The principal features of the relief are due to the underlying rock and are of preglacial origin. So far as can be judged from the map the drainage may have been mature in preglacial time. It is probable that glaciation effaced many of the minor topographic features, perhaps filling and obliterating many small valleys and smoothing down many hills. In these ways, and by blocking the valleys so as to make lake basins, topographic forms typical of youth were superimposed upon the region.

After the ice departed subaerial erosion began anew. In many places it. followed lines already marked out, for the greater preglacial valleys were not obliterated. New gullies were formed in abundance on the slopes leading down to the greater valleys, and some of them have developed into "glens," of .which Wagener Glen is an example. These glens are good illustrations of one type of postglacial valleys.

Glaciation interrupted the cycle of erosion that was in progress before the ice epoch, and since the glaciers withdrew erosion has been renewed. It can hardly be said that the resumption marks a new cycle of erosion, for the previous cycle was interrupted, rather than ended.

\section{PLATE CXIII:}

The area represented on' PI. CXIII has little relief, but comprises the irregularly distributed hills, the narrow valleys, and the generally youthful aspect of regions that have been recently glaciated.

The points to be noted are-(1) the extreme youth of the larger part of James River Valley and its tributaries; (2) the interruptions in the eastern bluff of the valley, as between Jim Lake and Arrowwood Lake; (3) the notable lakes in the valley of James River; (4) wellmarked valley depressions which are streamless; and (5) the notable chain of lakes extending from Spiritwood Lake on the southeast to Medicine Lake on the northwest, all lying in local depressions in a common valley.

The narrowness of the valley of James River points to its youth. It is doubtless largely of postglacial origin. The comparative lowness and the more interrupted continuity of the bluffs on the east in the vicinity of Jim Lake are probably due to the fact that the drift deposits did not build up the surface here to the same level as farther south. The streamless valleys might represent (1) preglacial valleys that were not filled by the drift, (2) valleys that were cut in the surface of the drift by waters which arose from the melting of the ice, (3) valleys of subglacial streams, or (4) valleys of streams marginal to the ice. The elongate marshy depression near the center of the mapped area might represent a line of temporary drainage when the ice was melting, the water discharging southeastward to Spiritwood Lake, and thence southward or eastward. The decline in elevation of the depression in this direction is consistent with this interpretation, but does not establish it.

The depression containing Medicine, Alkali, Spiritwood, and other lakes may be due partly to one of the causes mentioned above and partly to another. That it is not primarily a postglacial stream channel from which the drainage has been diverted is indicated by the lakes themselves, for the normal valley of a small river would hardly contain such basins. The probability is that this belt of lakes represents the course of a preglacial valley, partly filled at intervals by drift. The sections of the valley between the localities of greater filling constitute basins. If the drainage went southeastward through this valley for a time, as seems probable from the gorgelike depression south of Spiritwood Lake, the channel was not lowered sufficiently to remove the drift divides between the basins of the lakes.

If James River were diverted from its present valley, Jim Lake, Mud Lake, and Arrowwood Lake would remain. This valley therefore seems to be very much like the one in which the string of lakes lies, except that it contains a river. Its history is probably much the same as that outlined above.

On the whole, the drainage problems of this area are complicated, and data other than those furnished by the contour map would be needed as a basis for confident conclusions.

By means of strings of lakes and streamless valleys, the courses of some preglacial valleys may be conjectured or even determined. The courses of such valleys are also determinable by borings or excavations. 
Inferences as to the culture, climate, and other features of the region can be readily drawn. If the region were very humid, the lakes would have outlets, and the chain in the southeastern part of the area would be connected, as the lakes in James River valley are.

This map affords an illustration of a surface controlled primarily by the topography of the drift. None of the topographic features, except possibly the valleys referred to, can be recognized as having been determined by the character of the underlying rock. The glacial topography has been modified to some extent by postglacial erosion. This map is in contrast with Pls. CVIII-CXII, which show topography controlled primarily by the underlying rock and only modified by drift.

\section{PLATE CXIV.}

Pl. CXIV shows certain features that exhibit anomalous relations between topography and drainage. These are (1) the wide valley south of Syracuse, with steep bluffs on either side, occupied by an inharmoniously small creek; (2) the pronounced channel which looks as if freshly eroded, connecting the valley of Onondaga Creek with that of Butternut Creek to the east, but not occupied by a continuous stream; (3) the channel that connects the valley of Butternut Creek with that of Limestone Creek at High Bridge, and the low divide-so low as to be marshy nearly to its crest - that turns the waters in one part of this valley eastward and those in the other part westward; (4) the pronounced valley followed by the Erie Canal, running eastward from Syracuse, with no stream, and (5) another anomalous valley followed by the creek west of De Witt. The valleys south and east of Syracuse have about the same elevation, but those east of Onondaga Creek are more than 100 feet higher.

Most of these channels were outlets of glacial lakes. The history of the channels can not be read with certainty from the map, but the history of the region makes the channels intelligible. $^{a}$ This history can not be appropriately presented in detail in connection with this map. Suffice it to say that during the retreat of the continental ice from this region lakes of various sizes, and at various levels, came into existence. The waters of these lakes escaped by the lowest outlets open to them at the various stages of ice retreat. Thus the present valley of Onondaga Creek was the outlet of a lake which occupied the valley to the north-the valley iil which Onondaga Lake (not shown on this map) now lies. Later the waters from Lake Warren (the most expanded stage of Lake Ontario) entered this valley, and its waters found egress to the east by several outlets. One of these outlets was the channel connecting Onondaga Creek with Butternut Creek, and the outflowing water formed a cataract where it entered the valley of Butternut Creek. The channel between Butternut Creek and Limestone Creek, by way of White Lake, was likewise utilized by the outflow of glacial lake waters.

The region south and east of that represented on this map furnishes many illustrations of the same sort, and their history is outlined in the paper cited.

\section{PLATE CXV.}

Pl. CXV affords another illustration of drainage modification caused by the drift. The significant points ${ }^{b}$ are (1) the wide valley between Big Flats and Horseheads, not occupied continuously by a stream; (2) the large valley between Horseheads and Elmira, occupied by a relatively small stream, and (3) the much narrower valley of Chemung River, occupied by a large stream. These features indicate that the drainage of the region has been deranged. The history of this region has been interpreted as follows: ${ }^{c}$ The area about Horseheads was notably aggraded by the deposition of drift, a valley train from the north, the surface being built up so that the drainage from the west found an outlet along the course of a tributary valley between Big Flats and Elmira, lower than by the former route through the main valley by way of Horseheads and Elmira IIeights. The filling by drift near IIorseheads therefore diverted the main stream from its large valley, but Singsing Creek coming out from the mountains, found its way across the old valley flat to the Chemung below.

$a$ Fairchild, H. L., Glacial waters in the Finger Lakes region of New York: Bull. Geol. Soc. America, vol. 10, 1899, pp. 27-68.

$b$ Tarr, R. S., Physical geography of New York, p. 168.

$c$ Idem. 
The more important topographic features of the area are due to the underlying rock. This is indicated both by the great relief and by the paucity of distinctive glacial features. The elevations throughout the higher portions of the area stand in somewhat definite relations to drainage lines.

\section{PLATE CXVI.}

PI. CXVI is introduced to illustrate a peculiarity of drainage not rare in glaciated regions, and not unknown elsewhere. Mohawk River has a relatively wide valley at the east and west in this area, while at a point between, about Little Falls, it is much narrower.

Narrow portions of river valleys may originate in various ways, and the map does not show the history of this particular narrow stretch. The abrupt widening of the valley below Little Falls suggests that the rock is harder where the valley is narrow than at other points. Another inference that might be drawn is that two valleys, formerly separate, one leading eastward from the vicinity of Little Falls and the other westward, have been connected at their heads. In this case the narrow part of the valley would represent the position of the former divide.

The history, as worked out in the field, has been interpreted as follows: The rock where the valley is narrow is harder than that above or below. In preglacial time this hard belt of rock had become a divide, and from it valleys descended in opposite directions. After the ice melted from the region the valley of the Mohawk was for a time the outlet for the waters of the Great Lakes, and the former divide, which was probably low, was cut down by the river. Both inequality of hardness and drainage changes brought about by glaciation were therefore concerned in shaping this valley.

\section{PLATE CXVII.}

Pl. CXVII is introduced especially to exhibit the valley of Esopus Creek. Throughout half its course as here shown the creek flows in a narrow valley, much of which might be postglacial, so far as may be judged from the map. About midway in its course it enters a wide valley, which appears to be much older, and which it follows to the edge of the area. The meanders and cut-offs of the lower part of the valley are altogether out of keeping with the narrow gorge in the vicinity of Stone Church.

Southwest of Marbletown a broad valley leads southwestward, in the line of the wide part of the valley followed by Esopus Creek. This valley, a small part of which is shown on this map, was probably the site of the main stream of the region in preglacial time. Just south of the border of this area (see the map of the entire quadrangle-the Rosendale sheet) this valley seems to have been filled with drift to such an extent as to cause postglacial drainage to follow other lines.

\section{PLATE CXVIII.}

The striking features of the map forming Pl. CXVIII are (1) the relatively old valleys of the Little Miami and the Licking and (2) the relatively young valley of the Ohio, especially at the west. These peculiarities clearly signify drainage changes, inasmuch as the rock of the several valleys is of about the same degree of hardness throughout.

The history of the drainage of the region has been worked out, at least in part, though it could not be read from this map. It is believed that the master stream of the region once flowed along the line indicated on the map as the "old Ohio channel," making a northward detour of about 20 miles from the present course of the Ohio, to which it returned near the mouth of the Great Miami. The changes from this course may have been brought about in either of two ways: (1) Glacial filling may have obstructed the valley at the north, or (2) a tributary from a lower portion of the valley may have become a pirate, working back and tapping, first, Mill Creek, then the Licking, and finally the main stream itself, near the mouth of the Little Miami, carrying its waters off westward. This may have happened in preglacial time, or glacial filling at the north may have made the piracy possible ${ }^{a}$ 
PLATE CXIX.

PI. CXIX shows several remnants of an old river course, now occupied by minor streams flowing in various directions, while the valley of the main stream is narrow in some places and wide in others - that is, the main stream appears to flow here in a preglacial valley and there in a postglacial valley. The course of the former stream is shown on the map by the deposits of Carmichael clay. More than this the map does not indicate. The history of the changes has been studied, however, and suggestions as to the method in which they were accomplished have been made. ${ }^{a}$

It is thought that in preglacial time the water followed the valley whose course is represented by the clay deposits. Tributary streams are supposed to have occupied the present position of the river where it departs from its former course. It has been suggested that in glacial time ice jams, which became ice dams, were formed at certain points in the old valley, and that the dams ponded the water above them so that it rose high enough to find a new outlet along the line now followed by the river. As the old channel, now ponded, was being silted up, the new one was being cut down; and when the conditions which gave rise to the ponded waters passed away the new channel was deeper than the old one and continued to claim the river. It should be added that other explanations of the abandoned channels are possible.

\section{PLATE CXX.}

Pl. CXX shows various phases of drift and complex relations of drift and rock topography in a region of notable relief (about 800 feet). The region lies at the border of the drift sheet in south-central Wisconsin. The position of the terminal moraine is indicated on the map by the crooked shaded belt.

In the eastern part of the area glacial features are evident; in the western part they are lacking; yet even in the eastern part there are pronounced features due to the underlying rock, and the western part contains features that are not the result of river erosion alone.

The higher elevations are due to hard rock. The gap at Baraboo Narrows is cut in a ridge of quartzite running east and west, and there is a similar but wider gap in another ridge of hard rock at Devils Lake. Pronounced drift topography is present in a belt running from the north edge of the area, near its center, to Devils Lake. Notable flats appear to the northwest.

The map indicates that various changes in drainage have occurred. The narrows at the lake are very similar to the narrows of the river, both gaps being so like the gorges cut by streams where they cross ridges of hard rock as to leave no doubt that such was their origin. Though the lake gap is wider than that of the river, the lake stands nearly 200 feet higher than the river at Baraboo Narrows.

Southeast of the lake there is a deep valley, which is really a continuation of the lake basin. The bottom of this valley is nearly as low as the river at its narrows, and a little south of the area mapped the valley deepens notably. It extends to Wisconsin River, which it joins about 4 miles south of the border of the area here shown. Baraboo River also flows into the Wisconsin, but by a route so long that its waters flow in that stream for more than 30 miles before they are joined by the waters of the creek that occupies the valley southeast of Devils Lake. The course of the Baraboo is therefore extraordinary. The drift north of Devils Lake and also east of its south end is of great depth, its base being far below the level of the lake and even well below its bottom. Were this drift filling removed, Baraboo River would probably flow southward from some point west of Baraboo, via Devils Lake, to the valley on the east. This is believed to have been the former course of some large river.

The diversion of the drainage is readily understood. The terminal moraine blocked up the old river valley at the north end of the old narrows (that is, at the north end of the lake) and also at the south end. The ice failed to reach and fill that part of the valley which is now

a Campbell, M. R., Description of the Masontown and Uniontown quadrangles: Geologic Atlas U. S., folio 82, U. S. Geol. Survey, 1902, p.4. 
occupied by the lake. The lake is therefore held in by two great morainal dams, and these dams have become drainage divides.

The exact course of the preglacial Baraboo between the mouth of Skillet Creek and Devils Lake is unknown. The river now has a wide valley except at the narrows, and in the bottom of this wide valley, near the center of the area mapped, there is a shallow, steep-sided gorge where the river crosses the moraine. This gorge, which is about 40 feet deep, is clearly postglacial. There is another rather deep gorge just above the narrows of the Baraboo. Were the upper of these gorges filled, so that the surface would be restored to its condition as the ice left it, there would be a lake over the river flat west of Baraboo. Were the lower gorge filled there would be a lake over the flat between it and Baraboo. So much may be readily inferred, tentatively, from the map; but the conclusion could hardly be accepted as final unless confirmed by more positive evidence. If, for example, lakes once existed on these flats, the character of the material now covering them should give indications of the fact. On the ground, too, one might judge much more safely than from the map whether the gorges are certainly postglacial. As a matter of fact, both flats are underlain by lacustrine clays, and the inference which the map suggests relative to the postglacial origin of the shallow gorges is confirmed on the ground. ${ }^{a}$

Various other drainage features of interest are shown on this map. Erosion at the head of the valley east of the south end of Devils Lake might cut back the head of the valley to the lake, when it would be drained (the lake is not very deep). The same process might lead the little creek near the north end of the lake to tap it there, causing it to discharge to the Baraboo. Piracy is, therefore, a future possibility.

The upper part of the valley of Skillet Creek is preglacial, but the lower part is postglacial. The lower portion of its preglacial valley was filled by the moraine or by outwash from it.

The relations of outwash and moraine are well shown north of Baraboo, where the flat is outwash and the ridge to the east of the flat is the terminal moraine. The position of the moraine over the high rock ridges at the south is significant of the influence of topography on the course of ice movement.

Drainage changes occasioned by glaciation are well shown on numerous topographic sheets, among them Clinton and Le Claire, Iowa-Ill.; Baldwinsville, Binghamton, Canandaigua, Morrisville, Naples, Oriskany, Skaneateles, Tully, and Wayland, N. Y.; and Brandon, Vt.

MOUNTAIN GLACIATION (PLATES CXXI-CXXVII).

Some of the maps presented in Pls. CXXI-CXXVII show existing mountain glaciers in the United States, and others the topographic effects of mountain glaciation in recent time.

PLATE CXX1.

Pl. CXXI represents certain existing mountain glaciers in Washington. In the area shown in $B$ they radiate from a mountain, occupying the valleys; in that shown in $A$ some of them have a similar position, but many of them lie at the bases of steep slopes just below elongate mountain crests. Glaciers of the type shown in $B$ are generally much longer than wide, whereas many of those shown in $A$ are wider than long. The convention which represents the ice suggests also the direction of the ice movement. Several of the glaciers shown in $A$ head in pronounced cirques. (Compare Pls. CXXIV-CXXVI.)

Bench Lake suggests that glaciation was at one time more extensive than now. In a region of so great relief and of so high altitude small lakes due to glaciation would not be likely to endure long, and only one or two others are shown on this map. One other evidence of the more extensive glaciation in former times is seen in the cirques at the heads of some of the valleys that do not now contain glaciers, but as this point is more clearly illustrated by several other maps it will be brought out more fully in connection with them. 
PLATE CXXII.

PI. CXXII, $A$, is a view of Avalanche Basin, Montana, a notable cirque near the southwest corner of the area mapped in Pl. CXXIV. Pls. CXXIV-CXXVI show other notable cirques in contour. Pl. CXXII, $B$, represents glaciers of the general type shown in PI. CXXI, $B$, and Pl. CXXIV.

PLATE CXXIII.

Pl. CXXIII, $A$, shows a series of glaciers radiating from a lofty mountain. The general relations are similar to those about Glacier Peak (Pl. CXXI, ${ }^{*} B$ ). The fact that the development of glaciers is greater on the north side of the mountain than on the south side is to be noted. The lakes on Shastina suggest more extensive glaciation at some earlier time.

Pl. CXXIII, $B$, illustrates the effect of glaciation in a mountain region, the special mark of glaciation shown being the lakes. The glaciation here was local, not continental.

PLATE CXXIV.

The mountains of western Montana contain several glaciers of the type represented in Pl. CXXIV (compare Pl. CXXII, $B$ ), which is introduced primarily to show the effects of mountain glaciation on topography.

The glaciers are all small and as a rule their width exceeds their length. The conspicuous effects of the former glaciation of the region, so far as shown on the map, are two, namely, (1) the series of lakes along the courses of the valleys and (2) the peculiar upper ends (cirques) of several of the valleys that contain lakes.

The map does not show the extent to which the lake basins were gouged out of the solid rock by the ice, or the extent to which they were formed by the obstruction of the valleys by drift dams. The peculiar heads of the glaciated valleys should be especially noted, such as the valley that heads between Mount Brown and Edwards Mountain, near the southwest corner of the area mapped. The upper mile or more of this valley is deep and steep sided, and its bottom is not narrow. The steep slopes on the sides are continued around the head, so that the wide, open upper end of the valley has a depth of many hundred feet. The peculiar head of this valley is a cirque, and cirques are a characteristic mark of mountain glaciation. They were formed by the action of glacier ice in preglacial valleys developed by drainage.

It should be noted that there is an abrupt descent of about 500 feet between the two principal lakes in the cirque just referred to. Below this cliff lies another cirque, succeeded by a stretch of open valley which is not cirquelike. The features noted are characteristic of glaciated mountain valleys.

Avalanche Basin, northwest of Mount Brown, is another pronounced glacial cirque of slightly different type, and Iceberg Lake, near the northern border of the area, lies in a third. Many of the lakes in cirques occupy rock basins. Some of the cirques are now occupied by glaciers, of which Grinnell and Sperry glaciers are examples. The cirques and lakes of this map clearly indicate former severe glaciation of the region.

The drainage of this area has pronounced features of youth, but the youth was superimposed by glaciation upon topography of somewhat greater age.

PLATE CXXV.

Pl. CXXV, like the preceding map, shows several small glaciers near the crest of the mountains and also the effects of glaciation developed when the ice was much more extensive than

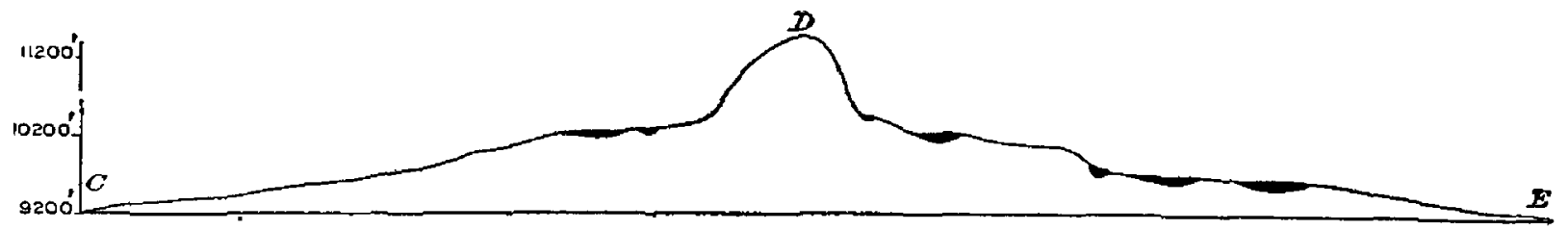

FIg. 33.- I'rofile a long line $C-D-E$, Pl. CXXV. Vertical scale about two and one-half times the horizontal. Black shading represents lakes.

now. Conspicuous cirques abound. The head of the valley of South Fork of Clear Creek is a good example. The valley just across the divide to the west has the same sort of head. Fig. 33 
represents a profile from $C$, northwest of West Tensleep Lake, to $E$, in the valley of South Fork of Clear Creek. The profile follows the two valleys just mentioned. The features characteristic of these valleys are repeated at many places within the area of the map.

This map, like the last, furnishes an illustration of glacially superimposed youth.

PLATE CXXVi.

Pl. CXXVI is introduced primarily to show the large cirques, many of them separated by very narrow divides, which occur in some parts of the Uinta Mountains. The glaciers of this region must have been large and the glaciation severe. It is probable that the extreme narrowness of many of the divides between the cirques is due largely to erosion at their sides by the glaciers. It is easy to see from this map that the destruction of a narrow divide between cirques would cause them to unite. It is possible that wide cirques have sometimes been developed in this way.

The numerous lakes furnish another evidence of former glaciation. As the lakes have not been destroyed by subsequent drainage, the glaciation must have been relatively recent. Here again the youthful drainage is superimposed upon an older surface. (See p. 56.)

\section{PLATE CXXVII.}

Pl. CXXVII shows the effects of glaciation by the continental ice sheet in a mountain region. The principal features of the relief are clearly due to the underlying rock. Glaciation interfered with the drainage and developed numerous lakes. The map does not indicate how far the lake basins are due to the blocking by drift of preglacial valleys and how far they have been gouged out in the rock itself. Presumably the former is the more important factor. This map should be compared and contrasted with Pls. CXXI-CXXVI, which represent mountain areas in which glaciers started and in which the glaciers were confined to valleys. One of the especial points of difference is the absence of cirques in the area shown on this plate.

This map affords a good illustration of youthful drainage superimposed upon a mature topography by glaciation.

The following topographic sheets of the Geological Survey aflord further illustrations of the effects of mountain glaciation: Dardanelles and Mount Lyell, Cal.; Needle Mountains, Silverton, and Teliuride, Colo.; Browning, Mont.; Salt Lake, Utah; Mount Stuart, Wash.; and Crandall, Dayton, and Grand Teton, Wyo. See also PI. CLX of this volume.

The following maps, among others, show the effects of glaciation in mountainous regions, or in regions of strong relief, affected by the ice sheet: Orland, Me.; Monadnock, N. H.; Canada Lake, Indian Iake, Lake Placid, Raquette Iake, and Santanoni, N. Y.; and Pawlet, Vt.-N. Y.; also Pl. CVIII of this volume.

EFFECTS OF GLACIATION ON COASTS (PLATES CXXVIII AND.CXXIX).

PLATE CXXVIII.

The topography of the area represented by PI. CXXVIII is due partly to variations in the character of the rocks and to inequalities of erosion before the glacial epoch, but its details were shaped by the ice of the continental glaciers. It is probable that glaciation was one of the factors in isolating many of the islands from the mainland, but changes of level were involved also. It will be readily seen that if the present surface were depressed 60 to 80 feet, numerous islands would be formed out of what are now the higher parts of the mainland. So far as the map shows, some of the existing islands may have been separated by just such a process.

I'LATE ('XXIX.

Pl. CXXIX shows another glaciated coastal region. The land shown is not the mainland, but consists of numerous small islands and portions of two large ones. The nature of the islands is shown by the fact that there are quarries on many of them, as, for example, on Russ, Green, Crotch, and Moose islands. The islands were doubtless formerly a part of the mainland, 
having been cut off by the erosion of glacier ice, or probably to a greater extent by the sinking of the region. The small islands appear to represent the tops of hills which were not reduced to sea level by glacial planation and which have not been submerged by subsidence. The type of surface here shown is not uncommon in coastal regions composed of hard rock, where glaciation was pronounced.

Other good illustrations of coasts notably affected by glaciation are afforded by the following topographic sheets: Freeport and Petit Manan, Me.; Barnstable, Gloucester, Salem, and Yarmouth, Mass.

GROUP 1O. COAST LINES.

The set of maps comprising Pls. CXXX-CLIV is designed to illustrate various types of coast lines.

PLATE CXXX.

Pl. CXXX, $A$, represents a simple coast line developed primarily by wave erosion, as is indicated by the steep though low cliffs along the shore. The straightness of the coast indicates that the material of the coastal land is of nearly uniform resistance. Were some parts more resistant than others, wave erosion would have developed irregularities of horizontal configuration.

The topography of the region is young in terms of erosion. The tendency of the topographic features to trend parallel to the shore is connected with the history of the lake, which once submerged the lower lands adjacent to it. The steep slope just south of the railroad between Wallace Junction and Avonia has the appearance of an old shore cliff. The low ridge farther north, extending eastward from Fairplain, suggests an old beach ridge.

Pl. CXXX, $B$, represents the sort of shore shown in $A$.

PLATES CXXXI AND CXXXII.

Pl. CXXXI represents a somewhat less simple coast line than that shown in Pl. CXXX. Near the southern border of the area there is a steep though low cliff, denoting wave erosion. Along the greater part of the coast, however, there has been recent deposition by waves and shore currents, and the wind has piled up the beach sand into dunes. The great bar which shuts in Morro Bay appears to have been deposited by currents drifting northward. The bar has been built in a line which is a more or less direct continuation of the shore line to the south. North of Morro Bay also deposition is going on, and the land is apparently advancing on the sea. At the head of Morro Bay a delta is in process of building.

Morro Rock is an island presumably isolated from the mainland by subsidence, by wave erosion, or by both subsidence and wave erosion. Black Hill is a similar elevation not isolated. So far as this map shows, both these hills might be volcanic cones. If the region were submerged a little more than 100 feet, Black Hill would become an island comparable to Morro Rock.

This map illustrates a feature that is common along coasts, viz, a tendency to simplification. Ocean deposition is straightening the coast line, and deposits made by streams entering the bay are filling this partly isolated water body. In the process of simplification of a coast line by deposition notable irregularities are developed. If the coast line shown on this map is followed through all of its devious course, it will be seen that the incomplete bar, which nearly shuts in Morro Bay, greatly increases the irregularity and the length of the line of contact between land and sea. The drainage entering the bay tends to prevent the completion of the bar; but if it were completed the irregularity of the coast line would be greatly reduced and Morro Bay would become a lake. The lake a mile northeast of Morro Rock is a water body that was probably once a bay, but has now been completely shut off from the sea. How long it will be before Morro Bay is completely filled and so converted into land depends on the depth of the water and the amount of sediment which the inflowing streams bring. 
PI. CXXXII, $A$, shows the bar west of Morro Bay. Morro Rock appears beyond the north end of the barrier. Pl. CXXXII, $B$, shows Morro Rock as seen from the east. The steep slopes are due to the resistant nature of the rock of which the butte is composed. ${ }^{a}$

\section{PLATE CXXXIII.}

PI. CXXXIII, like Pl. CXXXI, illustrates the simplification of a coast line by deposition (and subordinately by erosion), but here the process has gone much further. The most striking example of simplification appears along the southern shore of Marthas Vineyard west of Katama Bay. Here the coastal bars deposited by waves and shore currents have closed in a series of bays, converting them into ponds. Little drainage enters these ponds, though the basin of each one extends northward in a valley developed by surface erosion. It is probable that in general the water coming into the ponds finds its way to the sea by seeping through the sand and gravel of which the beach is doubtless composed. The only permanent stream is that entering Tisbury Great Pond, and the inflowing water seems to be sufficient here to keep an outlet open across the beach. Other large ponds, such as Sengekontacket and Poucha ponds and Cape Poge Bay, have been nearly shut off from the ocean. Bars or beaches appear to be in process of development south of Katama Bay, and may in time connect with each other unless the tidal flow between Edgartown Harbor and Katama Bay is sufficiently strong to keep the passage open.

All in all, this map illustrates clearly the effect of coastal deposition in simplifying a shore line. In the eastern part of the area there are also examples of the marked irregularities of the coast line before the simplification is complete. The material for the building of the bars was probably cut from the points of land which formerly projected into the water. The map, therefore, illustrates coastal cut and fill. The narrowness of the bars suggests sea encroachment, by wave cutting, and the absence of deltas at the heads of the drowned valleys suggests that subsidence may be now in progress.

\section{PLATES CXXXIV AND CXXXV.}

Pls. CXXXIV and CXXXV illustrate land extension rather than coast-line simplification. In each of the areas mapped a beach has been developed some miles out from the mainland. The sand of these beaches has been piled up into dunes by the wind, and a tract of shallow water has been shut off from the ocean by each beach. The areas between the mainland and the beaches are being filled up by the growth of vegetation, the sand blown in from the beach, and the material washed and blown out from the mainland. The two plates represent stages of advancement after the building of the beach. In the area shown on Pl. CXXXIV, filling behind the beach has only begun; in the area shown on Pl. CXXXV the larger part of the former lagoon has become marsh land.

The inlets through the beaches shown on PI. CXXXV are kept open by the flow and ebb of the tides and by the water descending from the land. The tides "scour" out the inlets, channels, and "thorofares," which are, in some places, deep.

When the area between the beach and the mainland has become land, the coast line will be relatively simple. At the present stage of development it is somewhat difficult to say just where the coast line is.

\section{PLATE CXXXVi.}

Pl. CXXXVI illustrates the development of pronounced coastal irregularities through processes which will ultimately result in coastal simplification. At the extreme south the sea cliff indicates wave erosion. From this point débris has been shifted northward, building the beach which terminates at the north in Sandy Hook. The tendency of the Hook to turn westward is the result of its position. The waters from the open ocean to the east have a strong westward sweep when winds and tides favor. 
The surface of the deposits made by the waves and shore currents has been notably modified by the wind, which has developed long ridgelike or mound-shaped dunes.

At the northwest, beach deposition is also in progress, straightening the coast line northwest of Port Monmouth. Just east of that place filling by sedimentation and by the growth of vegetation is building out the coast line. This region is now protected from strong waves by Sandy Hook. The north border of the Highlands of Navesink is marked by cliffs, but to the east lowlands have been developed by deposition at the base of the cliffs. These cliffs were doubtless cut by wave erosion before Sandy Hook had its present position. The Hook now protects the Highlands against the waves.

The bays marked as Navesink River and Slrewsbury River form one of the most conspicuous features of the map. These bays or estuaries are probably the result of recent subsidence of the area. (Compare Pl. CLIII.) The subsidence has drowned the lower ends of the rivers, converting them into bays. The building of the bar across their mouths is therefore another illustration of the process of coastal simplification shown on preceding plates.

The topography of the mainland indicates at least three cycles of erosion.

\section{PLATE CXXXVII.}

The coast line of Pl. CXXXVII shows two distinct features-(1) a cliff produced by wave erosion and (2) a great hook developed by wave and current deposition. The cliff is shown not only along the lake, but also fronting Presque Isle Bay. The cliff facing the bay was probably cut by wave erosion before the outlying hook was made. The development of the hook was probably the result of the configuration of the bottom of the lake in the vicinity, a configuration which influenced the course and velocity of waves and shore currents.

The topography of the hook is diversified. The suggestion of the map is that the low ridges on its surface, shown by contours, are dunes. The ponds have been developed somewhat as those shown on Pl. CXXXIII and those at the northwest end of the area mapped on Pl. CXXXVIII.

The topography of the mainland is in its youth, so far as its erosion history is concerned. Beautiful examples of very young valleys leading down to the shore are seen at several points.

PLATE CXXXVIII.

Pl. CXXXVIII affords an excellent illustration of the simplification of coast lines both by erosion and by deposition, and at the same time shows some of the irregularities developed in the process of simplification.

Wave erosion is indicated by the cliffs along the east side of the cape as far north as the Highland life-saving station and at some points on the west side. On both sides the coast line is regular where the cliffs occur. Between the Highland station and Race Point also the coast is regular, but here the map suggests that the regularity has resulted from deposition, the material derived by erosion from the southeastern part of the coast having been deposited farther northwest. Erosion and deposition have therefore conspired to develop regularity.

At the point of the peninsula water bodies have been or are being shut in between new deposits and older land. In the process notable irregularities of the coast line are being developed.

A marked instance of the simplification of outline which has resulted from deposition is afforded by the area about Moon Pond Meadow. ITere a considerable lake has been shut in by the building of a beach. From the map it may be conjectured that the Provincetown region was once an island and that it has been joined to the Truro area by the development of the two beaches, one on each side of the peninsula. This conjecture finds some support in the fact that above Moon Pond and Salt meadows there are cliffs which have the appearance of sea cliffs. If the island-tying theory is correct, these cliffs were cut by waves before the development of the beaches which join Provincetown to Truro. Similarly, that part of Truro which lies north of Pamet River has probably been joined to the part farther south by shore deposits. (Compare Pl. CXXXIX.) 
The topography of most of the peninsula appears to be due largely to glaciation, the surface having somewhat the appearance of a terminal moraine. (Compare Pls. C-CIV.) It is not possible to say from the map how far the topography at the end of the peninsula is the result of glaciation and how far it is the work of wind. The long ridges at the north, however, appear to be dunes, and the more irregular surface in the vicinity of the ponds among the hills appears to be the result of glaciation.

The northeast coast is mature in its outlines, and southeast of Provincetown Harbor the west coast is also mature, but Long Point is a feature of immaturity. The time necessary to bring a coast to maturity is dependent chiefly on two factors, namely, the strength of the waves and the character of the rock formations. The contrast between the east coast shown on Pl. CXXXVIII and the coasts shown on Pls. CXXVIII and CXXIX is in part the result of difference in resistance of the rock. The rock along the Maine coast is resistant, whereas that along the coast of Cape Cod is weak. (Compare also Pl. CXLV.)

PLATE CXXXIX.

Pl. CXXXIX affords further illustrations of features already mentioned. The series of ponds along the south shore indicate the building of a beach by wave deposition. (Compare Pl. CXXXIII.) A larger pond has been shut in on the east, and the process of shutting in water bodies and preparing for a future regular coast is shown in the northern part of the island. Meantime the preparation for regularity has resulted in great irregularity. The notable cusps on the southeast side of Coatue Beach have been ascribed to the action of the tidal currents. "The tidal waters are thrown into a series of whirlpools, which excavate the shore between these salients and accumulate the sand on the spits" (points). ${ }^{a}$

The topography of the belt running through the Shawkemo, Altar Rock, and Folger hills suggests a terminal moraine, and the area south of this belt resembles an outwash plain. Dunes are not readily identified on this map.

In terms of erosion the topography of the region is extremely young.

\section{PLATE CXL.}

Pl. CXL illustrates the tying of islands to the mainland by wave deposition. The two higher areas of the main part of Nahant have probably been joined by beaches and tied to Little Nahant, and Little Nahant has been tied to the mainland. 'The topography of the higher lands at the north appears to be the result of glaciation.

Pl. CXL, $B$, represents island tying as shown by a photograph. The Biddeford (Me.) map also shows a good example of island tying.

\section{PLATE CXL1.}

Pl. CXLI shows a rather simple shore line and low coastal lands. This lowland is the result of one or both of two processes-(1) alluviation, that is, the building of alluvial fans out into the water, causing the land to encroach on the sea; or (2) uplift of the land (or sinking of the sea level), causing the former sea bottom lying beneath shallow water to emerge. If the lowland is primarily the result of alluviation which has built up the bottom where shallow water stood, the process would have been favored by the position of the area, which fronts a bay, not the open ocean. The line separating the plain at the west from the highlands to the east has the appearance of a line of old sea cliffs. If this is the case, the sinking of the sea level, or the rise of the land, seems to be indicated. Whatever the origin of the plains, the map affords good illustrations of alluvial fans and of numerous drainage features peculiar to lowlands.

The Coyote ITills at the south appear to represent isolated remnants of a highland. They may once have been connected with the highlands in the northeastern part of the area. Their isolation appears to have antedated the development of the flat lands. 
PLATE CXIII.

PI. CXLII shows both coasta erosion and coastal deposition. By far the larger part of the coast is suffering erosion, but deposition is going on in front of Bolinas Lagoon. The effects of wave erosion are indicated by the steep cliffs along a part of the coast, and from the jagged outline of this part inequality of resistance of the rocks may be inferred. Deposition, as always, is tending to develop regularity of coast line. Bolinas Lagoon lacks but little of being shut off and is in process of being filled by sediment brought down from the land. When the lagoon is filled the coast line will have been somewhat simplified.

The map shows well-defined coastal terraces west of Bolinas Bay. There seems to be a broad terrace at an elevation of slightly less than 200 feet, and a sloping terrace running up to 300 feet, where a higher cliff appears. Suggestions of a terrace at similar levels are found elsewhere, though in no other place are they so pronounced.

\section{PLATE CXLIII.}

Pl. CXLIII, $A$, shows overhanging cliffs on the coast of California. The locality is considerably south of the area covered by PI. CXLII, but the general type of coast shown in the view is similar to that along much of the coast of that area. The overhanging of the cliffs is due to the attitude of the beds. ${ }^{a}$

Pl. CXLIII, $B$, represents wave-cut terraces at Mallagh Landing, a few miles northwest of the cliffs shown in $A$. This view represents in principle, if not on the same scale, such terraces as might be seen northwest of Bolinas Bay (Pl. CXLII).

\section{PLATE CXLIV.}

Pl. CXLIV presents illustrations both of wave erosion and wave deposition. Erosion has cut off the ends of numerous drumlins (compare PI. XCVIII); deposition has built bars across the bays. The two processes are therefore conspiring in this region to produce regularity of coast line.

\section{PLATE CXLV.}

The area shown on Pl. CXLV presents striking contrasts. The coast facing the ocean is mature. It is relatively straight, and the straightness is clearly the result partly of erosion and partly of deposition. Erosion has cut back the projections, and deposition has filled out or shut off reentrants. Resistant portions of rock, as at San Pedro Point (in the extreme southwest cormer of the area), Mussel Rock, and Point Lobos, have formed projecting points and isolated islands. Bodies of water, such as Lake Mathilde, Laguna Salada, and Merced Lake, have been shut off from the ocean, and now discharge their waters by seepage through the beach and dune deposits.

On the east side of the area, facing San Francisco Bay, where wave action is slight, the coast is more irregular and furnishes a good illustration of immaturity. Beach deposits have not filled up the reentrants between the projecting points of rock, but land is being made in these reentrants by material washed down from the higher land and vegetation growing in shallow water. This process is deposition out from shore, in contrast with the deposition along shore which is taking place on the west coast. The difference between the two coasts seems to be the result chiefly of difference of exposure. The points of ligh land projecting into the bay may be accounted for either by vigorous wave action at some former time or by relatively recent subsidence.

The topography of the land suggests notable irregularities of resistance in the rocks which compose it. 
PLATE CXLVI.

PI. CXLVI is introduced especially to show the elevated shore cliff that stands about 2 miles back from the present border of the lake. The map gives a good illustration of a simple coast line, the form of which was determined primarily by erosion.

The valley of Euclid Creek is worthy of study and interpretation.

PLATE CXIVII.

Pl. CXLVII represents a coast which is being straightened by deposition. The northern part of the coast line is very straight. The irregularities of the middle part are apparently connected with small rock islands which have affected the course of the shore currents and determined the site of shore deposition. South of Cape Blanco the coast is again relatively smooth.

Another feature of the map is the low land bordering high land. As shown by the contours, the surface, except so far as modified by erosion, has a gentle slope from the coast up to an elevation of about 200 feet, above which it rises somewhat abruptly to considerable heights. The junction of plain and upland may represent an old sea cliff. The topography of the low land is young, and that of the high land mature. These contrasted types of surface appear to be the result of recent change of relative levels of land and sea. This is shown by the distribution of the formations, for young marine sands overspread the surface of the low land. The map also shows that there are some higher, though young, marine sands well above the 200-foot level. They appear, however, in isolated remnants only, at an elevation of 500 or 600 feet. These remnants point to a relative rise of the coastal lands earlier than that which brought the low coastal plain out of the water.

Lagoons and lakes are associated with the coast, indicating recent shore deposition.

The letter symbols on the map, which correspond to the formations as indicated in the legend, are a guide to the distribution of the different rock formations in the region.

\section{PLATES CXINIII-CL.}

Pls. CXLVIII-CL represent in contour, and two of them in perspective also, shore terraces. All the areas represented are on the shores of the ancient Lake Bonneville.

$\mathrm{Pl}$. CL shows a shore terrace of a phase somewhat different from that represented on Pls. CXLVIII and CXLIX. The special feature of Pl. CL is a great delta which has been bisected, since its development, by Logan River. $\Lambda$ profile along the line indicated is shown at the foot of the plate.

These maps do not show how far the terraces are wave cut and how far they are wave built.

PLATE CLI.

Pl. CLI shows a simple coast line, developed chiefly by deposition. In its development marshes and lagoons have been shut in and one considerable river seems to lave been completely stopped. The water from this river must find its way to the ocean through the sand.

The coastal terraces constitute the special feature for which the map is introduced. There is a pronounced terrace at an elevation of 80 to 100 feet, and others are present at higher levels. Through these terraces the older streams have cut narrow valleys. This is especially well illustrated along the San Juis Rey Valley, shown at the top of the map, where the wide, marshy, baylike old valley above is continued by a narrow, steep-sided valley of youthful aspect below. The old valley above was probably cut at a time when the land stood higher than now, relative to sea level. Later the land sank, and the lower ends of the valleys were drowned and converted into bays. While they were in this condition, the mouths of the bays were obstructed by bars deposited by shore currents. The lagoons behind the bars were then partly silted up. 
When the land was again uplifted, the drainage discharged across the bars and the deposits behind them, cutting the narrow valleys across the lowland. Subsequently the land may have sunk a little, drowning the valleys, which are now nearly silted up.

This map furnishes a good illustration of topographic unconformity. ${ }^{a}$ The unconformity here is between the youthful topography of the recently emerged coastal land and the mature topography of the higher land farther from the shore. The diagram at the bottom of the plate gives a profile along the line $A-B$.

PLATE CLII.

Pl. CLII, $A$, shows an elevated wave-cut terrace north of Port Harford, on the southern California coast. $B$ represents a tidal lagoon comparable to those shown on Pl. CLI. This view, however, represents an area at the mouth of San Luis Obispo Creek, farther south on the California coast.

PLATE CLIII.

Pl. CLIII is introduced primarily to illustrate the effect of subsidence on the coast line. Chesapeake Bay itself is a river valley that has been drowned, and in this process the lower end of every tributary was drowned also. This is the fundamental element in the explanation of the coast line shown on this map. Similar phenomena are present along much of the coast between New York and Florida.

This map represents an immature coast. As it is poorly exposed to wave action its immaturity will be of long duration, so far as the development of maturity depends on waves. The numerous minor bays may be silted up by the growth of deltas starting at their heads, thus reducing the irregularities of outline.

\section{PLATE CLIV.}

Pl. CLIVं represents a coast of a complex type, the special features of which are due to several processes. The topographic features of the land are primarily of glacial origin. Subsidence has apparently helped to develop irregularities by submerging the former lowlands. Minor irregularities have been produced by the deposition of bars and beaches at various points. The coast line is immature and, like many such coasts, faces a bay instead of the open ocean.

Further studies of coast lines may be carried on with the help of the following topographic sheets: Low, regular coasts: Calumet, Ill--Ind.; Hamlin, Niagara, Ridgeway, and Wilson, N. Y.; Maumee Bay and Toledo, Ohio-Mich. Coasts made regular by erosion: Evanston and Highwood (PI. XXIII), Ill.; Bayview, Milwaukee, and Port Washington, Wis. Deposition along shore: Green Run, Md.-Va.; Muskeget and Plymouth, Mass.; Newburyport, Mass.-N. H.; Asbury Park, Barnegat, Cape May, and Long Beach, N. J.; Hempstead, Ontario Beach, and Rochester, N. Y.; Oyster Bay, N. Y.-Conn.; Block Island, R. I.; also Pl. XVII, B, of this volume. Former shore lines (their present position being due to elevation of the land or the withdrawal of sea or lake waters): Goleta, Hueneme, La Jolla, Santa Ana, and Santa Barbara, Cal.; Calumet, Ill.; Niagara, Oak Orchard, and Ridgeway, N. Y.; Euclid (Pl. CXLVI) and Oberlin (PI. XXXVI), Ohio. Recently sunk coasts: Boothbay, Bucksport, and Castine, Me.; Betterton, Choptank, and Gunpowder, Md.; Piney Point, St. Mary, and Wicomico, Mrl.-Va.; also Pls. XVI and CXXVIII of this volume. 


\section{GROUP 11...VOI.CANISM.}

The set of maps forming Pls. CLV-CLXIV is designed primarily to illustrate the effect of volcanism on the topography, other effects of volcanism not being considered at this point.

PLATE CLV.

Pl. CLV represents a mountain or a group of mountains built up by volcanic extrusions in a low country. The surrounding plain has, however, been aggraded to some extent since the mountains ("buttes") were built up.

From the evidence of the topographic map alone it would not be possible to affirm that the mountains were due to volcanism, though such an inference might be drawn. It is known that the rocks are voleanic, but the map does not show whether the several peaks are separate volcanic cones or whether they are remnants isolated by erosion. The topography, however, suggests that erosion has had much to do with the present form of the buttes.

From the geology of the region it appears that the present topography is the result of the partial degradation of the former volcanic cone.

\section{PLATES CLYI ANI CLVII.}

Pl. CLVI represents a remarkable lake occupying a deep depression. The height of the rim of the lake is shown by the contours, and the depth of the water in the lake, in feet, is shown by the numbers at various points within its area. The high island in the lake is also a significant feature.

This lake occupies what is popularly known as the crater of an old volcano. The island within the lake is a volcanic cone subordinate to the great cone represented by the mountain, in the heart of which the lake lies. These inferences, which might be made tentatively from the topography, find some corroboration in the geology. The map shows that all the solid rock of the region is igneous and that there are other volcanic peaks besides Mount Mazama in the vicinity.

Pl. CLVII represents a view along the western border of the lake, from Victor Rock to Llao Rock.

The structure and topography of the region are thought to indicate that the present Mount Mazama is but the stub of a volcanic cone which was once much higher. It has even been conjectured that the height of the cone may have been comparable to that of Mount Shasta14,380 feet. It has been concluded that the original Mount Mazama collapsed and that its summit portion has sunk out of sight, leaving the basin in which the lake lies. The way in which some of the valleys, notably that of Sand Creek, terminate at the rim of the crater is evidence that the mountain has lost its top, but this line of evidence would not show whether the cone collapsed or whether its top was blown off by a volcanic explosion. The present depression is what is technically known as a caldera. ${ }^{a}$

\section{PLATES ClVIII AND CLIX.}

PI. CLVIII shows a region of strong relief. The origin of the topography in most parts of the area could not be readily determined from this map, but the names Crater Peak and Cinder Cone suggest volcanic cones, and the form of the elevation at the eastern border of the area, with its summit lake; is so characteristic of a volcanic cone that there is little doubt of its voleanic origin. The topography of this elevation is such as to indicate that erosion has modified its slopes notably since it was formed.

PI. CLIX, $B$, shows Cinder Cone, and Pl. CLIX, $A$, is a sketch of its crater. The form of the cone and the crater indicate extreme youth, for there is no evidence of more than trivial modification of form by drainage erosion. The last eruption at Cinder Cone is said to have 
occurred about two hundred years ago, and is believed to be one of the latest if not the latest eruption south of Alaska within the limits of the United States. Field study of the region has led to the conclusion that the lava issuing from Cinder Cone obstructed drainage and caused the development of Snag Lake, which lies at its border. ${ }^{a}$ Some of the other lake basins had a similar origin.

$$
\text { PLATE CLX. }
$$

Pl. CLX is introduced primarily to show the craters along the eastern borders of the area. These craters, indicated by minute hachures, were formed by recent volcanic action, the recency being indicated by the fact that erosion has produced little modification of their outlines. Some of the craters have two depression contours, and are therefore more than 100 feet but not 300 feet deep.

The topography of the western part of the area shows that this is a region of recent glaciation. This is indicated both by the numerous lakes and by the pronounced cirques. (Compare Pls. CXXIV and CXXV.) The map also represents three small existing glaciers.

It has been thought that the site of June Lake was occupied by a detached mass of ice after the glacier of Rush Creek valley ceased moving, and that owing to the dam formed by this ice mass the drainage was reversed, flowing around to the west of Reversed Peak instead of to the east, as it may have done in former times. ${ }^{b}$ By the time the ice dam melted, the new course of the drainage was so well established that it has continued to the present time. These conclusions relative to the origin of June Lake and the change in drainage are based on field work. They could not be reached from a study of the topographic map.

\section{PLATE CLXI.}

Pl. CLXI shows a pronounced peak, Mount Taylor, and a great mesa, Sierra Chivato. There is also a smaller mesa, Prieta, farther east. The history of this topography could not be certainly inferred from the map, beyond the fact that the chiffs about the mesas indicate clearly that the mesas are capped with somewhat resistant rock.

The lava capping the larger mesa was probably once continuous with that of the smaller. Subsequent erosion has cut through the resistant igneous rock between the mesas and a considerable thickness of the softer Cretaceous beds beneath has been removed. Mount Taylor has been much affected by erosion, but the topography of the mesa is young. The lake basins on the mesa are probably due to irregularities in the surface of the lava flows.

So far as this map shows, the several isolated areas of igneous rock might represent volcanic plugs, such cones as existed above them having been worn away by erosion; or they might represent isolated remnants of the lava sheet.

\section{PLATE ClXiI.}

Pl. CLXII represents a notable mountain group, surrounded by many minor elevations which are much more considerable than would be inferred from the map unless the large contour interval (250 feet) were kept in mind. The origin of the topography is not certainly shown by the map. As a matter of fact, the main mountains consist of voleanic rock.

The San Francisco Peak group has suffered notable erosion, indicating that it has been long in existence. The curved crest line of the main mountain suggests a part of a crater rim, the east wall of which has been breached.

Many of the minor elevations about the major group of mountains are of relatively recent origin. The group of peaks in the eastern part of the area, especially Sunset Peak and the minor elevations around it, are mostly young volcanic cinder cones. In some of them the craters are still pronounced, though these are not shown on the map. West of San Francisco Peak also there are many recent volcanic cones.

$a$ Diller, J. S., Lassen Peak folio, No. 15, Geologic Atlas U.S.

b Russell, I. C., Quaternary history of Mono Valley, California: Eighth Ann. Rept. U. S. Geol. Surrey, p)t. 1. $18 \times 0$, p. 368. 
Pl. CLXXIII shows the topography of the Henry Mountains region and includes four somewhat conspicuous peaks partly separated from one another. A view of a relief model covering a part of this area is shown on Pl. CLXIV.

The origin of these mountains would not be known from the topographic map or from the relief model. As a matter of fact, they are laccolithic-that is, great bodies of igneous rock were intruded from the magma below into the surface formations, which were thus raised in the form

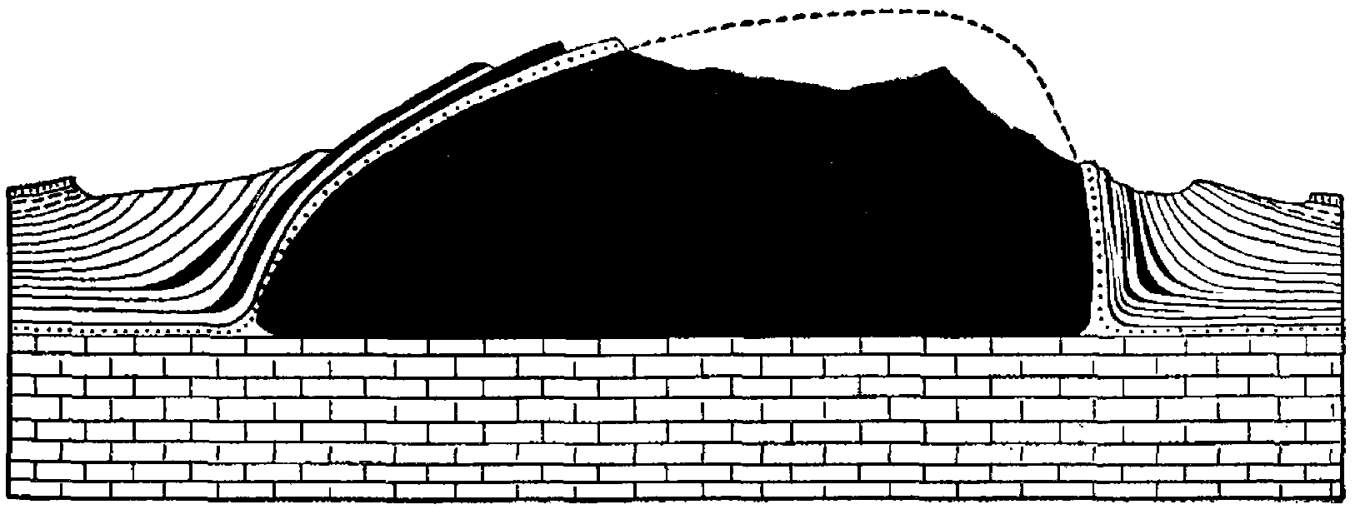

FIG. 34.-Cross section of Mount Hillers, Utah, with ideal representation of the underground structure. (After G. K. Gilbert.) Scale, 1 inch $=4,000$ feet. The full black lines represent trachyte sheets and the broad black area the Hillers laceolith. of arches (fig. 34). Erosion has since affected the surface with the result indicated on Pls. CLXIII and CLXIV and fig. 34.

One phase or another of volcanism or of the effect of volcanic rocks on topography is also illustrated on Pls. IX, LXV, and CLXVII.

\section{GROUP 12.-FAULTS.}

Pls. CLXV_CLXVII are designed primarily to illustrate the effects of faults on topography.

PLATE CLXY.

The cliff extending from north to south through the central part of the area shown on PI. CLXV is a fault scarp, somewhat softened by erosion. As the map shows, it is for the most part more than 750 feet high and in some places more than 1,250 feet.

The fact that this is a fault scarp could not be determined from the map, as similar cliffs might arise in other ways. ${ }^{a}$

\section{PLATE CLXVI.}

PI. CLXVI shows another great fault scarp, which lies just east of the Grand Wash. The fault crosses Colorado River and is followed for some distance by the valley which joins the river at Pierce Ferry. ${ }^{b}$

Cliffs similar to the Grand Wash Cliffs, but not the result of faulting, are seen in other parts of the area. The cliffs east of the Grand Wash Cliffs are examples. These and some of the other cliffs shown on the map are due to the erosion of nearly horizontal formations of unequal hardness.

\section{PLATE CLXVII.}

The cliff running in a northwest-southeast direction southwest of Honey Lake and constituting the east face of the Sierra Nevada in this region is a fault scarp, though, as in the preceding examples, its origin could not be inferred from the map. ${ }^{c}$ This map also presents a good illustration of a volcanic cone-Shaffer Peak, north of Honey Lake-as well as other interesting features, among them the peculiar ending of Susan River.

\footnotetext{
a For an account of this region, see Dutton, C. E., Tertiary history of the Grand Canyon district: Mon. U. S. Geol. Survey, vol.2, 1882, with accompanying atlas.

$b$ A general account of this region is given by C. E. Dutton in Mon. U. S. Geol. Survey, vol. 2, 1882.

c See Russell, I. C., Mon. U. S. Geol. Survey, vol. 11, 1885, especially Pl. III.
} 


\section{GROUP 13.-LAKES OF SPECIAL TYPES.}

Three maps illustrating special phases of lakes not already included are introduced at this point.

\section{PLATES CLXVIII AND CLXIX.}

Pl. CLXVIII represents an area of curiously undulatory topography, hills and depressions being about equally conspicuous. Many of the depressions contain lakes, some of which are intermittent and some permanent. Except for the excess of depressions at the west, the topography of this map has some resemblance to glacial topography. (Compare Pls. XV, C, and CII, B.) In its depressions, to which streams run and in which they disappear, it bears some resemblance to regions of limestone sinks.

Pl. CLXIX represents an area of similar but larger lakes in Florida. No other portion of the eastern Coastal Plain has lakes of this type.

\section{PLATE CLXX.}

The maps constituting PI. CLXX show types of lakes, intermittent and permanent, which occur at many points on the Great Plains. Marks of aridity are distinct in $A$, and the course of Little Laramie River in $B$ indicates that the stream is sluggish and its waters overloaded.

The origin of lakes in such situations is not invariably the same, and the topographic map does not usually give any distinct clew to their history. Some of them occupy basins eroded by the wind.

Lakes of the type illustrated in Pl. CLXX are also shown on the Arroyo, Big Springs. Catlin, Greeley, Kit Carson, Lamar, Las Animas, and Springfield, Colo., topographic sheets, Other exceptional types of lakes are shown on various maps in this volume-for example Pl. CLVI, etc. 


\section{N D E X.}

$A$

Adjustment. See Stream adjustment.

Age, geologic divisions of.

Aggradation, processes of.

Alluvial fans. See Fans, alluvial.

Alluviation, description of maps illustrating. See also Rivers, sedimentation by

Alluvium, description of representation of

Anastomosing channel, explanation of ..................... 35-36 maps illustrating................................... xlix, I, lii

Anson (Tex.) quadrangle, part of, description of ........... 31 part of, map of.

Anticlines, nature of

Appalachian Mountain type, maps showing ................. Pls. $v, x$

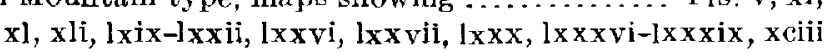

Appalachians, northern, relief map of ................. Pl. xii

Aqueduct, representation of

Pl. ii

Aqueduct tunnel, representation of . .......................
$\Lambda$ rredondo (Fla.) quadrangle, part of, description of $\ldots \ldots \ldots \ldots$
78 art of map of ca.

retic coast, view of

A real geology map, description of ...................... 16

Atlantic City (N. J.) quadrangle, part of, deseription of......... 69 part of, map of. .

$\Lambda$ tlas sbeets, designation of $\ldots$ See also Maps, topographic.

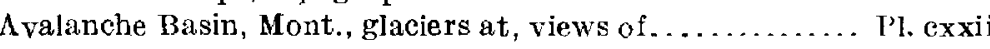
B.

Bahylon (N. Y.) quadrangle, part of, deseription of.. part of, map of.

Paboo (Wis.) quadrangle........................ Pl. exxxiv of ..... is-59,64-65 parts of, maps of . . . . .......................... I'l. cv, cxx

Base level, nature of

Batesville (Ark.) quadrangle, part of, description of part of, map of profile in, figure showing .

Bays, cutting off of. cutting off of maps illustrating

exxxi-cxxxvii, exxxix, cxlii, cxliy, exlvii, cli

Beach building, description of ................. $69-71$ maps illustrating.................... Pls, cxxxiv-cxxxix, cx]i Bench marks, representation of . ....................... Pl. ii

Bisuka (Idaho) quadrangle, part of, description of......... 27-28

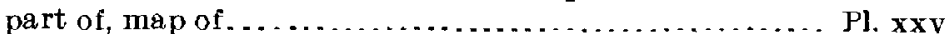

Bonneville, Lake, ancient delta in, map of ................. J'l.

Boothbay (Me.) quadrangle, part of, description of. part of, map of....

Boston Bay (Mass.) quadrangle, part of deseription .... I'l. exxviii part of, map of ................................ pl Boundaries, representation of $\ldots \ldots \ldots \ldots \ldots \ldots \ldots \ldots \ldots \ldots \ldots$ 12, Pl. ii Breakwaters, representation of $\ldots \ldots \ldots \ldots \ldots \ldots \ldots \ldots \ldots \ldots$ Pl. i

Bridges, representation of ............................ Pl. i1

Briggsville (Wis.) quadrangle, parts of, descriptions of ..... 58,64-65 parts of, maps of ............................. Pl. cii, exx Bright Angel (Ariz.) quadrangle, part of, description of... part of map of..

Bristol (Va.) quadrangle part of, deseription of
Bro Brooklyn (N. Y.) quadrangle, part of, description of......... 57 part of, geologic map and sections of ................. Pl. ci

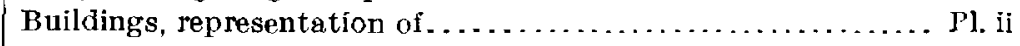
Butler (MO.) quadrangle, part of, description of ............ 34 part of, map of ................................ xliv

\section{(.}

Calca reous sandstones, representation of ................. 17 California coast, terraces and cliffs on, views of ............ Pl. cxliii Camas Prairie (Idaho) quadrangle, part of, description of..... 39-40 part of, map of ............................... Pl. lxiv Camp Clarke (Nebr.) quadrangle, part of, description of . . . . . 24-25 part of, map of .............................. Pxi section in, figure showing .......................... 25 Canals, representation of . . . . . . . . . . . ii Canyon (Wyo.) quadrangle, part of, deseription of . . . .......... 28-29 part of, map and section of ...................... Pl. xxvi

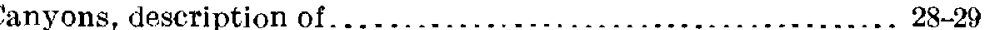
maps illustrating.............. Jls. $x \times v, x \times v i, x \times v i i i, x \times x, x \times x i$

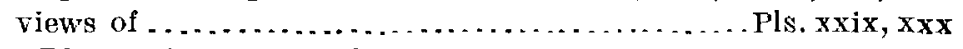
Cape Blanco, Oreg., view of . ......................... Pl. xiv Cayucos (Cal.) quadrangle, part of, description of............ 68 part of, map of ......................... Pls. $x \times x$, exxxi Cha rleston (W. Va.) quadrangle, part of, description of...... 32 part of map and section of................... Pl. xxxviii Chattanooga (Tenn.) quadrangle, part of, description of ..... 51-53 part of, geologic map and sections of............ Pl. lxxxvii Cholan, Lake, Wask., view of......................... Pl. exi Chelan (Wash.) quadrangle, part of, description of ............ 60

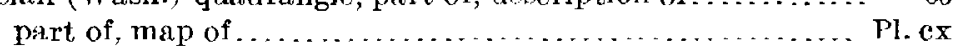
Chemical rocks, nature of ............................. 13

Chicago, South, sand dune at......................... 24 sand dune at, view of . . . . . . . Chief Mountain (Mont.) quadrangle, part of, deseription of... 66 part of, map of ................................ Pluiv Churches, representation of . ............................ li Cincinnati, Ohio, drainage changes near, description of....... 63 drainage changes near, map showing............... Pl. cxviii Cinder Cone, Cal., views of ........................ Pl. elix

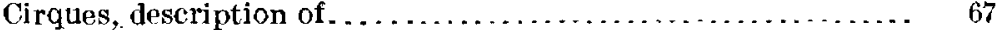
mapsillustrating.............................. exxvi

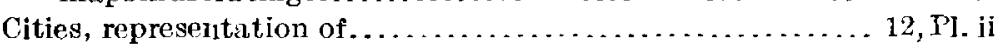
Cleavage, description of . . . . . . . . . . . . . . . . . . . . . Cliffs, representation of ......................... 11

Cloud Peak (Wyo.) quadrangle, part of, description of . . . . . . 66-67 part of, map of ................................... profile in, figure showing..

Clyde (N. Y.) quadrangle, part of, description of............ 72

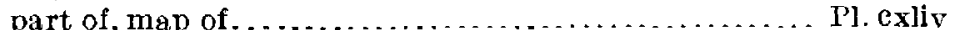

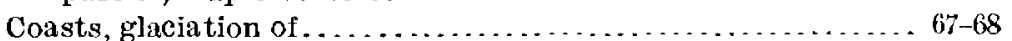
glaciation of, maps illustrating ........... PIs. exxviii, exxix phases of ................................. 22,68-74 maps illustrating.... Pls. xili, xvi, exxviii-cxxxi, exxxiii-cliv views of $\ldots \ldots \ldots \ldots \ldots \ldots \ldots \ldots \ldots$ Pls. $x i v, \operatorname{exxx}, \operatorname{exx} x i$ Cohoes (N. Y.) quadrangle, part of..................... $\quad 39$ part of, map and section of .......................... Ixiii Coke ovens, representation of . ....................... Pl. ii Colfax (Cal.) quadrangle, part of, deseription of............ 66 
Colorado River, Grand Canyon of, description of ............ Page.

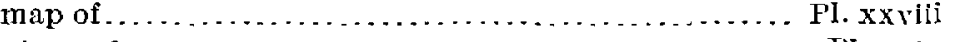

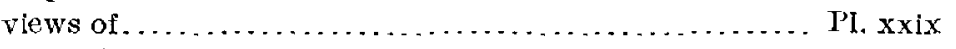

Colors, assignment of...

Columnar section, nature of

Conformity, definition of...

Contour intervals, difference in, effect of, maps illustrating.... PI. vii explanation of. .

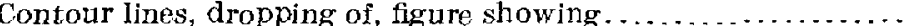
dropping of method of explanation of . . . . . . . . . . . . . . . . . . . . . . .

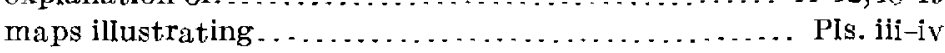
representation of $\ldots \ldots \ldots \ldots \ldots \ldots \ldots \ldots \ldots \ldots \ldots \ldots \ldots \ldots, 12, \mathrm{Pl}$ i

Contours. See Contour lines.

Conventional signs, sheet showing . . . . . . . . . . . . . . . . I'I. il

Cottonwood Falls (Kans.) quadrangle, part of, deseription of.. 20-21 part of, map showing... profile in, figure showing

Crater Lake, Ores viow of.

Crater Lake (Oreg.) quadrangle, part of, description of ........ part of, geologic map of...................... PI. clv

Cucamonga (Cal.) quadrangle, part of. part of map and section

Culture, map illustrating. relief and, relations of representation of.

\section{$1 \%$.}

Dams, representation of

Deer Islc (Me.) quadrangle, part of, description of . . . . . . . . 67-68 part of, map of .............................. Pl. cxxix

Degradation, processes of..

Delaware Water Gap, vicw of.

PI. 16

Delaware Water Gap (Pa.-N. J.) quadrangle, part of, description of.

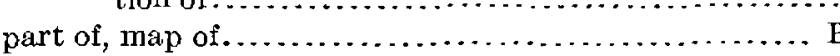

Dells (Wis.) quadrangle, part of, description of part of, map of.

PI. Ixxx part of, map of

Deltas, formation of $\ldots+38-39$ maps illustrating........................... PIs. Ivi-Ixi

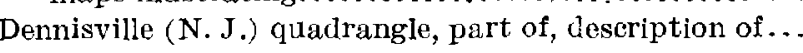
part of, map of ................................... PIij

Denver (Colo.) quadrangle, part of . . . . . . . . . . . . . . . . 40-41 part of, geologic map of ...................... PI. Ixvi section in, figure showing.

Denzer (Wis.) quadrangle, parts of, descriptions of....... 58-59,64-65 parts of, maps of............................ PI. cv, exy

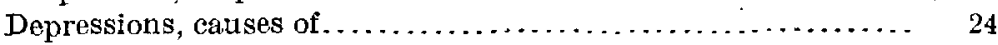

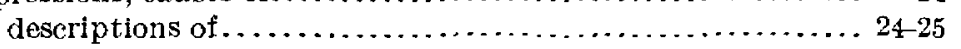
maps illustrating................... Pls. $x v, x i x, x x i, x c-x c i v$ representation of.

Diamond (reek (Ariz.) quadrangle, part of, description of part of, map of.

11, Pl. ii

Dikes, description of

Dip, definition of .................................... 17

Dissected plateaus, maps illustrating.................. Pls. viii, xxvi, xxvili, $\mathrm{xxx} v \mathrm{iii}, \mathrm{Ixx}$

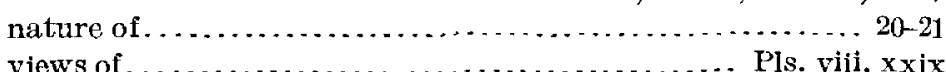
tches, representation of ........................ Pls. wh, xxix

Ditney (Ind.) quadrangie, part of description of .................. part of, geologic map of ....................... PI. $1 x x i$ map of..

Dove Creek, Utah, ancient lake shore at . . . . . . . . . . . . . ancient lake shore at, map of .................... Pl. cxlix

Drainage, adjustment of derangement of, by glaciation........................ $59-65$ maps illustrating ....................... PIs. cviii-exx maps illustrating........................... Pls, iil, iv, $x v$ topography and, relation of.................... 18-19,23 See also Streams.

Drawbridges, representation of ........................ PI

Drift, nature of...

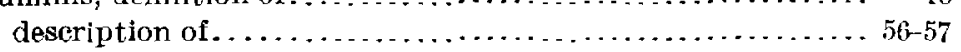

Drumlins, maps illustrating .................. Pls. sevii-xcix Dune Park, Ind., sand dunes in ....................... 24 sand dunes in, view of ............................... PI Dunes. See Sand dunes.

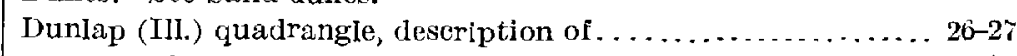

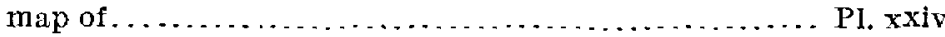

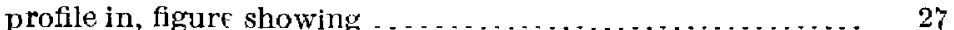

Durant (Iowa) quadrangle, part of, description of.......... 56 part of, map of ................................. xevi E.

Economie geology map, description of $\ldots \ldots \ldots \ldots \ldots \ldots \ldots \ldots$

Elevations, representation of ....................... 11-12; Pl.

limira (N. Y.-Pa.) quadrangle, part of, descriptlon of ...... 62-63 part of, map of .................................. exv Eolian deposits. See Wind.

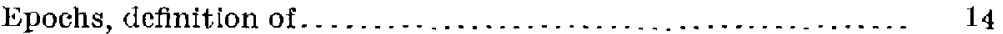

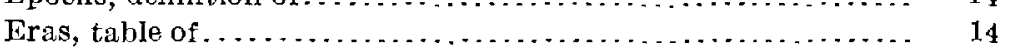

Frie (Pa.) quadrangle, part of, description of . . . . . . . . $\quad 70$

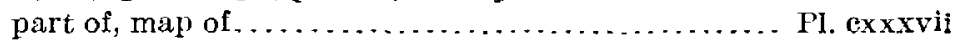

Erosion maps illustrating............ Pls. $\mathrm{xix}, \mathrm{xxii} i-\mathrm{xliv}, \mathrm{Ixv}-\mathrm{Ixxxii}$

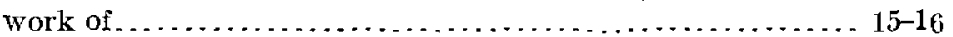
See also Sea; Streams; Wind.

Lrosion cycles, description of . . . . . . . . . . . . . . maps illustrating....................... Pls. Ixxii-Ixxxii, lxix

Fuclid (Ohio) quadrangle, part of, description of............ 73

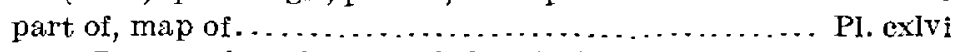
Everett (Pa.) quadrangle, part of, description of ........... 22

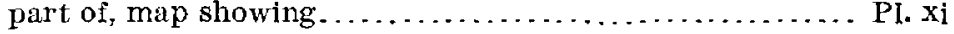
profiles in, figures showing . . . . . . . . . . . . . . . . . . 22,47 Extrusive rocks, description of . . . . . . . . . . . . . . . . . . . . .

Fairview (Pa.) quadrangle, part of, description of .......... 68

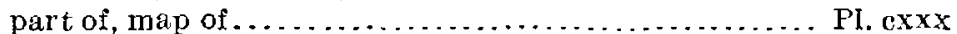

Falls, representation of ............................ PI Falmouth (Mass.) quadrangle, part of, description of........ 74 part of, map of ................................ Pliv

Fan, alluvial, description of $\ldots \ldots \ldots \ldots \ldots \ldots \ldots \ldots \ldots \ldots, 35$ maps illustrating. . . . . . . . . . . . . . . . . . .

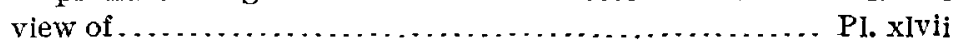
Fargo (N. Dak.-Minn.) quadrangle, part of, description of.... 31 part of, map of . . . . . . . . . . . . . . $x \times x v$

Faulting, effects of . . . . . . . . . . . . . . . effects of, maps illustrating ................. Pls. clxv-clxvii

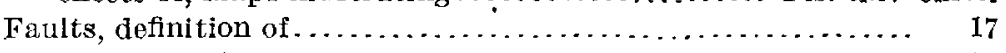
figure showing $\ldots \ldots \ldots \ldots \ldots \ldots \ldots \ldots \ldots \ldots \ldots \ldots, 17$

Fault scarps, maps showing ................... Pls. clxv-clxvii

Ferries, representation of $\ldots \ldots \ldots \ldots \ldots \ldots \ldots \ldots \ldots \ldots \ldots \ldots$, PI. ii

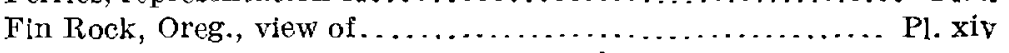

Fire Isiand (N. Y.) quadrangle, part of, description of........ 69

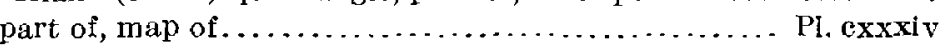

Flood plains, description of . . . . . . . . . . . . . . . . . . . 35-38 maps illustrating.................. Pls. xxi, lv, cxvii, cxvii Fluvioglacial deposits, description of................. $56-57$ maps illustrating............................. Pls. xev-xcix

Folios, description of .............................. 9

Fords, representation of $\ldots \ldots \ldots \ldots \ldots \ldots \ldots \ldots \ldots \ldots \ldots \ldots \ldots \ldots$ PI. ii

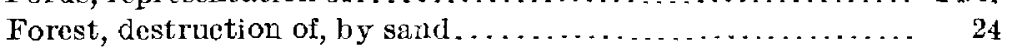
destruction of, by sand, view of .................... PI. $x x$

Formations, explanation of ........................... 14

Fossils, evidence from ................................. 14-15

Franklin (W. Va.-Va.) quadrangle, part of, description of ..... 53-54 part of, geologic map and sections of.............. Pl. lxxxviii sectionl in, figure showing .......................... 54

Fresh marshes, maps illustrating.............. Pls. xxxiii, liv, lv

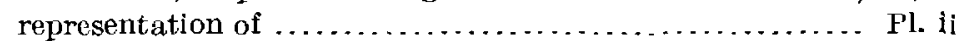

F rostburg (Md.-W. Va.-Pa.) quadrangle, part of, description of. 19-20 part of, map and section of . . . . . . . . . . .

G.

Gallatin (Wyo.) quadrangle, part of, description of . . . . . . 28-20 part of, map of . .............................. Pl. xxvi Geological Survey, maps by. See Maps.

Geologic time, divisions of .

Geologic maps. See Maps, geologic. 
Glacial deposits, description of.

Page. | maps illustrating.

. $x$ ev-evii

aciation, effect of, on drainage ....................... 59-65 effect of, on drainage, maps illustrating.......... Pls. cviii-exx on topography ................................ $55-68$ maps illustrating............. PIs. $x v, x \times x i, x e v-e x x i x$ representation of See also Mountain glaciers; Coasts, glaciation of.

Glacier Peak (Wash.) quadrangle, part of, deseription of part of. map of

......................... 1l. exxi representation of $. \ldots \ldots \ldots \ldots \ldots \ldots \ldots \ldots \ldots \ldots, \mathrm{Pl}, \mathrm{i}$ views of. .

Granada (Colo-Kans.) quadrangle, part of, description of part of map of

Greenwood Lake (N. Y.-N. J.) quadrangle, part of, deseription

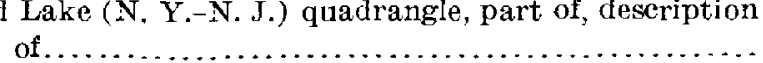

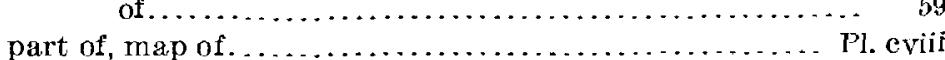

Ground moraines, deseription of ................... $56-57$ maps illustrating............................ PIs. xev-cy See also Moraines.

Ground water, topographic effects of . . . . . . . . . . . . $54-55$ topographic effeets of, maps illustrating......... Pls, xe-xeiv

Group, definition of

\section{H.}

IIackettstown, N. J., moraine near, description of . moraine near, geologic map of

Hahnville (La.) quadrangle, part of, deseription of part of, map of profile in figure showing ............

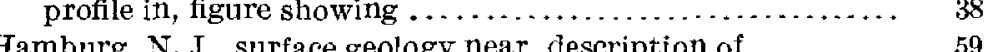
surface geology near, map showing................. Pl. cvii IIamilton (Mont.-Idaho) quadrangle, part of, description of .. 21-22 part of, map and section of ........................ Pl. $x$

Hammondsport (N. Y.) quadrangle, part of, deseription of ... 60-61 part of, map of .............................. Pl. exii

Eardness, differential, effect of, on drainage................ $49-54$ effect of, on drainage, maps illustrating ...... Pls. Ixxxiii-lxxxix on topography........................... 33, 40-42 maps illustrating........................... Pls. $x$, xl, xli, lxv-lxxii, lxxvii, lxxxvi, lxxxviii, xeii

Harlem (N. Y.-N. J.) quadrangle, part of, description of. part of, geologic map and section of.

Harpers Ferry (Va.-W. Va.-Md.) quadrangle, parts of, descriptions of...... parts of, figures showing. map and section of. .

Tarrisburg ( $\mathrm{Pa}$ ) quadrangle, part part of, map and scetion of ..................... Pl. Ixxvi

Hartford (Conn.) quadrangle, part of, deseription of. part of, map of .

profile in figure showing.

Haycen Peak (Utah-Wyo.) quadrangle, part of, deseription of. $\quad 67$ part of, map of .............................. exxvi

Ifaywards (Cal.) quadrangle, part of, description of . part of map of . strueture of, description of.. section of, figure showing.

Ilenry Mountains (Utah) quadrangle, part of, description of part of, map of

High Bridge (N. J.) quadrangle, part of, description of........ 40 part of, map of.

Highwood (Ill.), quadrangle, part of, description of part of map and section of Pl. xxiii profile in, figure showing $\ldots \ldots \ldots \ldots \ldots \ldots \ldots \ldots \ldots \ldots \ldots .26$

IIogbacks, cause of... maps illustrating............... I I section illustrating ................................. 41

Hollidaysburg ( $\mathrm{Pa}$.) quadrangle, part of, deseription of ....... part of, map of. part of, map of.
Honey Lake (Cal.) quadrangle, part of, description of ........ 77 part of, map of . . . . . . . . clxvii Huntingdon (Pa.) quadrangle, part of, deseription of ......... 47 part of, map of .............................. Pl. lxxvii

Ice, work of. See Glaciation.

Igneous rocks, age of .

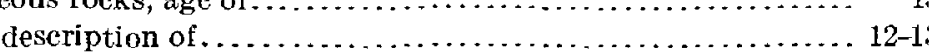

representation of $\ldots \ldots \ldots \ldots \ldots \ldots \ldots, 15$

Intrusive rocks, deseription of........................ 13

Islands, tying of . . . . . . tying of, maps illustrating ........................ l'l. $\mathrm{cxl}$ :

$$
\text { . . }
$$

K.

Kaaterskill (N. Y.) quadrangle, part of, deseription of ........49-50 part of, map and section of ..................... Pl. lxxxiii profiles in figures showing...................... 49,50

Kames, description of . . . . . . . . . . . . . . . . . . . . . . 59 maps illustrating................................... Pls evi Kingston (Tenn.) quadrangle, part of, description of .......... 55 part of, geologic map of ........................ 1'l. xei

L.

Laccolith, nature of . . $\ldots \ldots \ldots \ldots \ldots 13,77$ section of, figure showing ............................ section of, figure showing................
Lake Bonneville. See Bonneville, Lake.

Lake Geneva (Wis.) quadrangle, part of, deseription oi....... 58 part of, map of .................................... Piv Lake Grinnell, N. J., view at end of ...................... I'l, xy

Lake (Wyo.) quadrangle, parts of, description of............... parts of, maps of............................... Pl .xxiv profile in, figure showing $\ldots \ldots \ldots \ldots \ldots \ldots \ldots \ldots \ldots \ldots ., 50$

Lakes, beaches of, maps illustrating ................. Pls. $x$ viii xxiii, xxiv, xxxii, xxxrii, exl $\nu^{-1}$ ereation of.............................. 23,33-34,36 maps illustrating.................. Pls. $x v i, x$ liii $x$ li $v, l i$

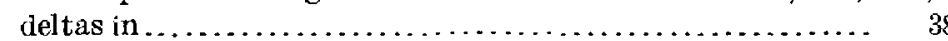

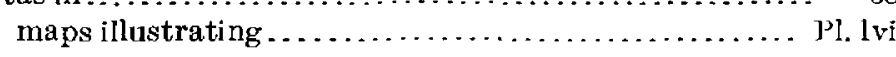

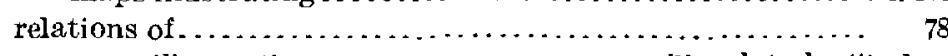
maps illustrating.................. Pls. clvi, clxviii-clxx representation of $\ldots \ldots \ldots \ldots \ldots \ldots \ldots \ldots \ldots \ldots \ldots \ldots \ldots \ldots \ldots$, Pl. ii

Lakes, ancient, shore terraces of ..................... 73 shore terraces of, views of ................................... cxi, cxlvii-cl Lakin (Kans.) quadrangle, part of, description of........... 24 part of, map and section of....................... Il xix Lancaster (Wis.-Iowa-Ill.) quadrangle, part of, description of. . 51 part of, map of ............................ Pl. $1 \times x \times v$ Laramie (Wyo.) quadrangle, part of, deseription of........... 78 part of, map of ................................ I'l clxx Lassen Peak (Cal.) quadrangle, part of, description of . . . . . . 75 part of, map of ............................... Pl vii

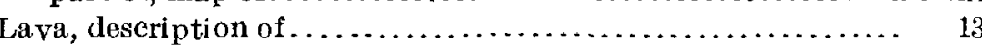
Legend, explanation of .............................. 16

Levees, representation of. . . . . . . . .

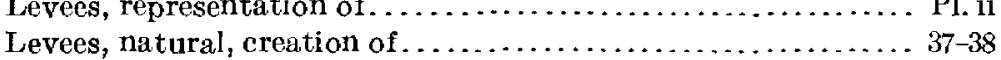

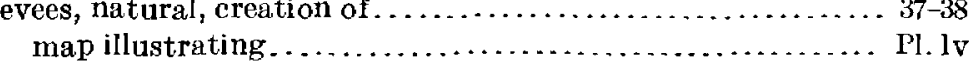
section of, figure showing........................... 38 Life-saving station, representation of $\ldots \ldots \ldots \ldots \ldots \ldots \ldots$ I'l. ii

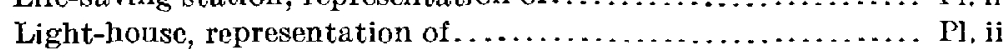

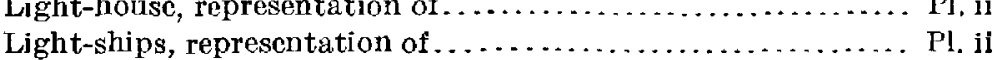
Limestone, representation of . ...................... 17 Little Falls (N. Y.) quadrangle, part of, description of ........ 63 part of, map of ............................... Pl. exvi Locks, representation of .......................... Pl. ii Loess, nature of ................................ 13 $\mathbf{M}$

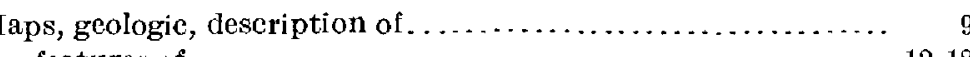

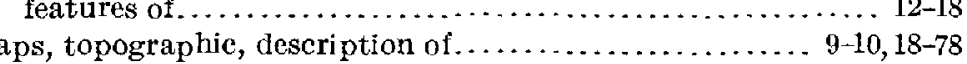

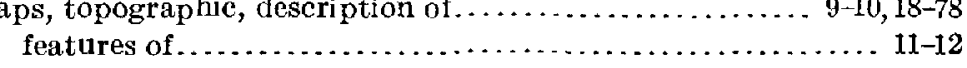

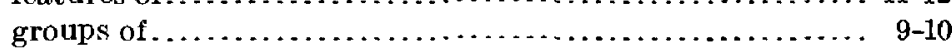
preparation of, progress in, map showing.............. Pl.i

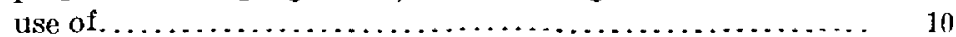

$1710-08-6$ 
Marseilles (Ill.) quadrangle, part of, description of . . Page. part of, map of. profile in, figure showing

39

Marshall (Mo.) quadrangle, part of, description of ............ 30 part of, map of ................................... . Pl

Marshes, maps illustrating ............ PIs. xiii, xvii, xxxiii, liv, $l_{v}$ representation of ............................... 11, Pl. il

Marthas Vineyard (Mass.) quadrangle, part of, description of .... 69

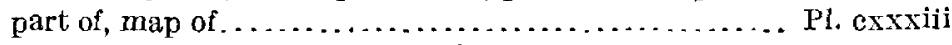

Marysville (Cal.) quadrangle, part of, description of ......... 75 part of, geologic map and section of ................... Pl. clv

Masontown (Pa.) quadrangle, part of, description of .......... 63 part of, geologic map of . ........................ Pl. exix

Maturity, region in, description of . . . . . . . . . . . . . . . . . .

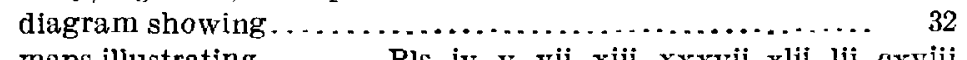
maps illustrating ......... Pls. iv, $\mathrm{v}$, vil, $\mathrm{x}$.

Medicine Lodge (Kans.) quadrangle, part of, description of ..... 32 part of, map of................................. Pl. $\mathrm{xxxix}$

Mesa de Maya (Colo.) quadrangle, part of, description of....... 19-20 part of, map of................................. Pl. viii profile in, figure showing .......................... 20

Mesa Verde, Colo., view of........................... Pl. viii

Metamorphic rocks, age of ............................. 15 nature of $\ldots \ldots \ldots \ldots \ldots \ldots \ldots \ldots \ldots \ldots \ldots \ldots \ldots \ldots \ldots \ldots \ldots \ldots \ldots, 13-14$ representation of ................................... 15

Methow (Wash.) quadrangle, part of, description of........... 60

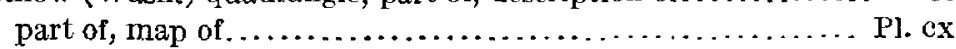

Mine dumps, representation of ......................... Pl. ii

Mines, representation of $\ldots \ldots \ldots \ldots \ldots \ldots \ldots \ldots \ldots \ldots \ldots \ldots \ldots \ldots$ Pl. if

Mine tunnels, representation of....................... Pll. it

Minneapolis (Minn.) quadrangle, part of, deseription of . . . . . 22-23

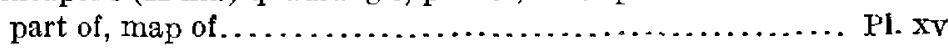

Mississippi River, delta of, description of ................. 39 delta of maps of .............................. Pl. lx, lxi

Monadnocks, explanation of........................... 40 maps illustrating........................... Pls. Ixv, lxviii

Monterey (Va.-W. Va.) quadrangle, part of, description of ...... 33 part of, geologic map and sections of ................... Pl. $x]$

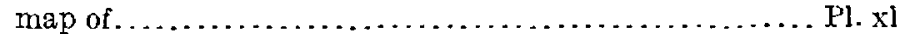

Montross (Va.-Md.) quadrangle, part of, description of ........ 18-19 part of, maps of .............................. Pls. iii-iv profile in, figure showing ........................... 19

Monuments, representation of........................... Pl. ii

Moraines, definition of................................. 16 deseription of . . . . . . . . . . . copography due to, maps, illustrating.......... Pls. xlv, xcv-cv view of. See also Terminal moraines

Morrillton (Ark.) quadrangle, parts of, descriptions of . . . . . . 34,36 parts of, map of.

Morro Bay, Cal., view of ............................. Pl. exxxii

Morro Rock, Cal., view of......... Pl. exxxii

Mountain glaciers, effects of ............................ $65-67$ effects of, maps illustrating.................... Pls. exxi, exxvii

Mountain Home (Idaho) quadrangle, part of, description of ..... 39-40 part of, map of ................................. Pl. Ixiv

Mountains, types of, maps showing................ Pls. ix, $x$, xi wash from. See Fans, alluvial.

Mountain View (Ark.) quadrangle, part of, description of. part of, map of. (n) 44

Mount Hillers laccolith, description of.................... 77 section of, figure showing. ........................... 77

Mount Lyell (Cal.) quadrangle, part of, description of.......... 76 part of map of ................................ Pl. clx

Mount Mazama (Oreg.) quadrangle, part of, description of .... part of, goologic map of ........................... Pl. clvi

Mount Mitchell (N. C.) quadrangle, part of, description of

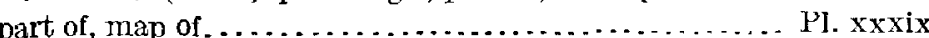

Mount Shasta, Cal., map of.......................... Pl. ix section of, figure showing. . . . . . . . . . . . . . . . . . .

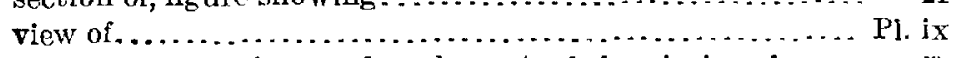

Mount Trumbull (Ariz.) quadrangle, parts of, description of ..... 77 parts of, maps of .......................... Pl. clxv, clvi

Muskego (Wis.) quadrangle, part of, description of ........... 56 part of map of ................................ Pev
N.

Page.

Nantucket (Mass.) quadrangle, part of, description of........... 7 part of, map of .

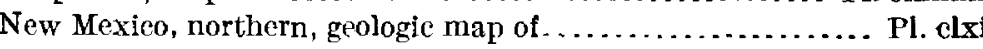
geology of, description of . ............................ 76

Niagara Falls (N. Y.) quadrangle, part of, deseription of . . . . . $56-57$ part of, map of . . . ........................... Pl. xcvi

Norfolk (Va.-N. C.) quadrangle, part of, description of ...........

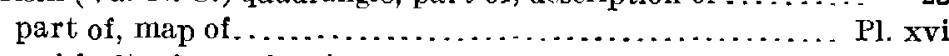

Normal faults, figure showing.........................

o.

Oak Orchard (N. Y.) quadrangle, part of, description of........ 30 part of, map of .................................... Oberlin (Ohio) quadrangle, part of, description of............. 31 part of, map of ............................... xl. xxxvi

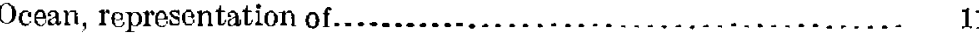

Ocean City (Md.-Del.) quadrangle, part of, description of . ....... 23-24 part of, map of . .............................. Ji. xvii Oceanside (Cal.) quadrangle, part of, deseription of............. $73-74$ part of, map and section of .......................... Pl. eli

Oil wells, representation of .

Old age, regions in, description of ........................ $33-34$ maps illustrating ............................. Pls. xliii-xliv

Organic rocks, nature of............................. 13

Outwash plains, description of........................ $57-59$ maps illustrating. ................................. Pls. c-cy See atso Moraines.

Oxbow lakes, formation of ........................... $33-34,36$ maps illustrating ..................... 1'ls. xliii, xliv, li, Ixv P.

Palo Pinto (Tex.) quadrangle, part of, description of ..........44-45 part of, map and section of ........................ Pl. Ixxiv Paradox Lake (N. Y.) quadrangle, part of, description or........ 67 part of, map of ............................. PI. cxxvii Parmelee (N. C.) quadrangle, part of, description of............. part of, map of.............................. Pl. xxxiii

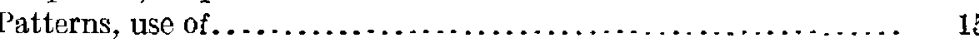

Paxton (Nebr.) quadrangle, part of, description of.............. 36

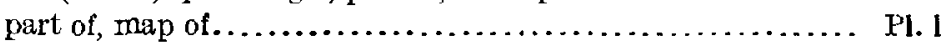
Peneplain, description of............................... 16 maps illustrating.......................... Pls. Ixxii-lxxxii Penn Yan (N. Y.) quadrangle, part of, description of........... $60-61$ part of map of .................................. Pl. cxi

Periods, definition of

Piedmont alluvial plan.. See Fan, alluvial.

Piedmont (Md.-W. Va.) quadrangfe, part of, description of...... 53-54 part of, geologic map and sections of .............. l'l. lxxxviii profile in, figure showing .....................

Pingree (N. Dak.) quadrangle, part of, description of......... 61-62 part of, map of ................................... cxiii Piracy. See Stream piracy.

Pitted plain, description of .............................. 58

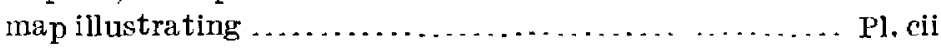

Plainficld, N. J., moraine near, map of .................. Pl. $\mathrm{c}$

Plainfield (N. J.) quadrangle, part of, description of ........... 59 part of, map of .................................... Pl

Plateau region, canyons in ...... maps illustrating....................... Pl. $\mathrm{xxv}$, $\mathrm{xxvi}$ See also Dissected platean.

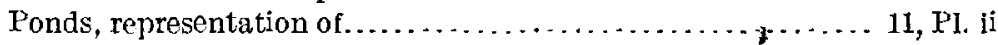

Port Marford, Cal., wave-cut terrace at.................... 74 wave-cut terrace at, vicw of . ........................ PI. clii

Port Orford (Oreg.) quadrangle, part of, description of .......... 73 part of, geologic map of .......................... Pl. cxlvii Portland (Oreg.-Wash.) quadrangle, part of, description of...... 38

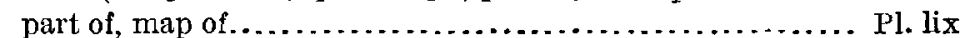

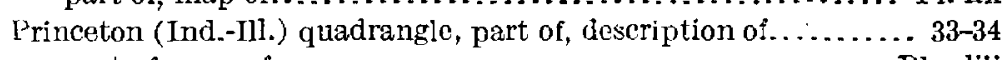
part of, map of . . ................................ Pliti ['rofiles, delineation of $\ldots \ldots \ldots \ldots \ldots \ldots \ldots \ldots \ldots \ldots \ldots \ldots \ldots \ldots, \quad 19$ figures showing................................... 19 $20,21,22,26,27,38,39,44,45,47,49,50,54,58,66$

Progress, map showing................................. Pl. i Prospects, representation of ............................. Pli Provincetown (Mass.) quadrangle, part of, description of........
part of, map of............................... Pl. exxxviii 
Q.

Quadrangle, definition of.

Quarries, representation of...

$\mathrm{R}$.

Racine, Wis., lake cliff at, view of.

Railroads, representation of

Rapids, representation of.

Rejuvenation, effects of .....

Relief, maps illustrating..................... Ils. iii-xiii, passim. representation of. See Contour lines.

Relief, contrasting, map showing................ Pls. viii, $x$, xi

Relief, gentle, maps shor

Relief, marked, maps showing.

Relief map, plate showing.

Residua deposits, description of .....

13

part of, geologic map and sections of ................. Pl. lxxyix
See Streams.

Roads, inferenecs fron representation of

Rochester (N. Y.) quadrangle, parts of, descriptions of........ 26-27 parts of, maps of ............................ xls. xiv, cvi

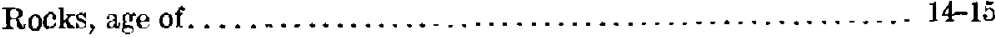

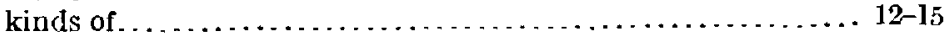

representation of .............................. 15, 17

unequal hardness of. See Harduess

wind erosion of, views of $\ldots \ldots \ldots \ldots \ldots \ldots \ldots$ Pl. xxii

Rome (Ga.) quadrangle, part of, description of. part of, geologic map and sections of

42 map of .

Rosendale (N. Y.) quadrangle, part of, description of . ........ 63 part of, map of.

Pl. cxvii

S.

St. Croix Dalles (Wis.-Minn.) quadrangle, part of, description of. part of, map of.

St. Louis (Mo.) quadrangle, parts of, descriptions of . parts of, maps of. . section in. representation of

Sand, movement of. movement of effect of, view of . . . . . . . . . . . . . . . . Pl. $x x$ representation of.

Sand dunes, ereation of descriptions of....... maps illustrating. ..... 23-25 representation of views of.....

Sandstones, representation of xvi, xvii, xix, $x$ xi, oxxxiv-exxx, viii .

( part of, map of . ........................... exxxvi

San Franeisco (Cal.) quadrangle, part of, description of. . part of map of ............................... 72

San Franeisco Mountains (Ariz.) quadrangle, part of, description of... part of, map of

San Luis Obispo Creek, Cal., tidal lagoon at tidal lagoon at view of

San Mateo (Cal.) quadrangle, part of, description of part of, map of.

Saypo (Mont.) quadrangle, part of, deseription of part of map of...

Scales, different, effect of... use of.....

Schistosity, deseription of

Schists, representation of

Schools, representation of.

Sea, erosion and sedimentation by maps illustrating. representation of

Seetion. See Structure seetions; Calumnar sections.

Sedimentary rocks, representation of. .
9 Sedimentation, work of...

Page. See also Streams; Sea.

Series, definition of................. table of .................... Is

Shafts, representation of ..........................

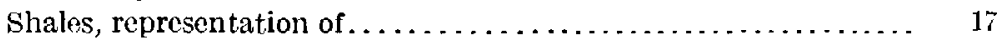

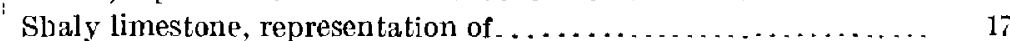

Shaly sandstones, representation of . . . . . . . . . . . . . . . . . .

Shasta (Cal.) quadrangle, part of, description of . ............. 66 part of map of ................................. Pl. exxiii profile in, figure showing . . . . . . . . . . . . . . . . . . . . . .

Sheets, description of ................................

Shenandoah River, piracy by................................. piracy by, figures showing . . . . . . . . . . . . . . . . . . .

Sierraville (Cal.) quadrangle, part of, deseription of........... 35

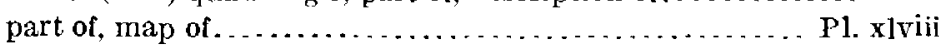

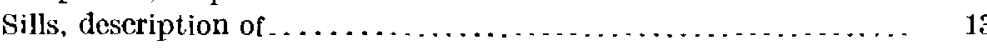

Sinks, maps illust rating . . . . . . . . . . . . . . . . . representation of .................................. 11

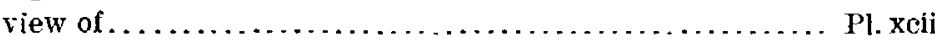

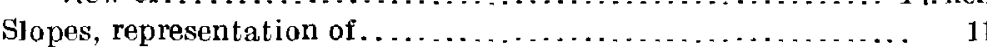

Smokestack Rock, Nebr., view of.................... Pl. xxii

Snoqualmie (Wash.) quadrangle, part of, description of....... 60

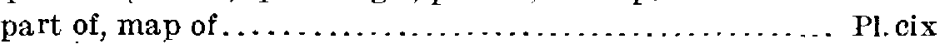
Sodus Bay (N. Y.) quadrangle, part of, description of.......... 72 part of, map of.................................... Pliv

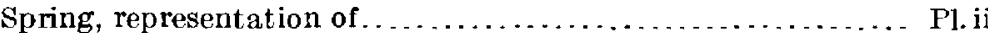

Spruce Head Island, Me., view of .................... Pl. exl

Stages, definition of . . . . . . . . . .

Standingstone (Tenn.) quadrangle, part of, deseription of..... 54-55 part of, geologic map and section of................ Pl. xci

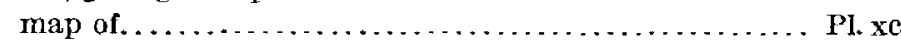
Steepness, estimation of....................................... 19 Stevenson (Ala.-Ga.-Tenn.) quadrangle, part of, description of. 54 part of, geologic map and sections of .............. Pl. Ixxxix Stocks, description of $\ldots \ldots \ldots \ldots \ldots \ldots \ldots \ldots \ldots \ldots \ldots \ldots \ldots \ldots \ldots \ldots \ldots \ldots \ldots \ldots \ldots \ldots$
Strata, description of $\ldots \ldots \ldots \ldots \ldots \ldots \ldots \ldots$ St ream piracy and adjustment, description of........... 27,49-54 maps illustrating....................... Pls. lxxxiii-lxxxix

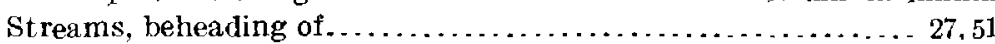
beheading of, maps illust rating..................... 51 channel ehanges in ................................. maps illustrating........................ Pl. xliii xliv

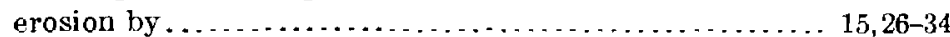
maps illustrating.............. Pls. xix, xxiii-xliv, 1xv-1xxi See also Youth; Maturity; Old age.

obstruction of .................................... 23 maps illust rating. ............................ Pl. representation of..................... sedimentation by ................................ $13,15,35-40$ maps illust rating........................ Pls. xlvi-lxiv representation of See also Alluviation.

terraces built by. See Terraces.

Strike, definition of................................ 17

Structure, explanation of ............................. 16-17

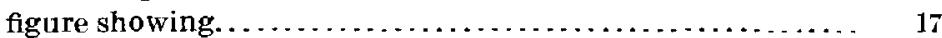

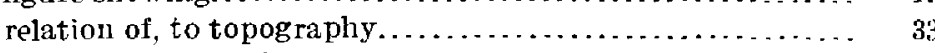
maps illust rating.......................... Pls. $x l, x$

Structure sections, explanation of.................... 16-17

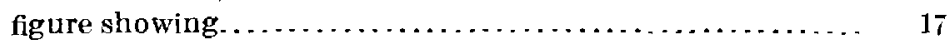

Structure section sheet, deseription of.................. 16

Subsidence, occurrence of................................ 13 maps illustrating ........................ Pls. exxviii, clii

Surface forms, description of . . . . . . . .

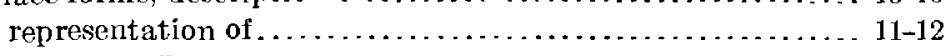

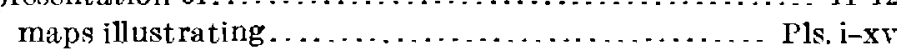

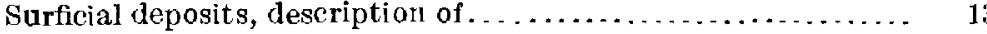

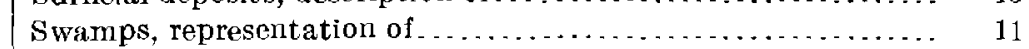

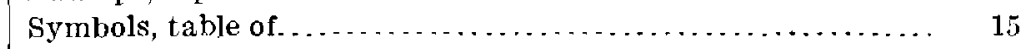

11 Syracuse (N. Y.) quadrangle, part of, description of .........

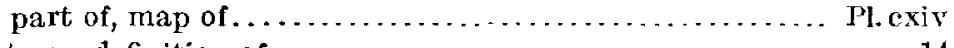
Systems, definition of $\ldots \ldots \ldots \ldots \ldots \ldots \ldots \ldots \ldots \ldots \ldots \ldots \ldots \ldots \ldots \ldots \ldots \ldots \ldots \ldots \ldots \ldots \ldots \ldots \ldots \ldots \ldots$
table of $\ldots \ldots \ldots \ldots \ldots \ldots \ldots \ldots$ 
T.

Tacoma (Wash.) quadrangle, part of, description of. . part of, map of................................... parts of, maps of ............................ Pls. xiii, cxlii

Tell City (Ky.-Ind.) quadrangle, part of, deseription of part of, map and section of . maps illust rating. ............................. Pls. c-cr See also Moraines.

Terraces, river, descriptions of . . . . . . . . . . . . . . . . . . . . . 39-40 maps illustrating.............. Pls. lxii-lxiv, lxxv, lxxvi, lxxviii sections of figures showing ..

Threeforks (Mont.) quadrangle, part of, description of . ...... $35-36$ part of, geologic map of .......................... Pl. xlix map of ....

Thrust faults, figure showing ............................ 17

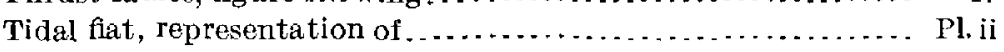

Till, nature of . . . . . . . . . . . . .

Tipton (Iowa) quadrangle, part of, description of .......... 20 part of, map showing . . . . . . . . . . . . . . . . . .

Tolchester (Md.) quadrangle, part of, description of part of, map of.

pert of map of cud rangle, part of descript part of, map of . .................................. Plij

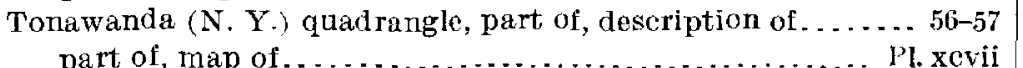
Topographic contrasts, maps illustrating............. Pls. viii, $x, x i$

Topographic maps. See Maps, topographic.

Tower (N. Dak.) quadrangle, part of, description of.......... part of, map of ............................... I'l. xevi

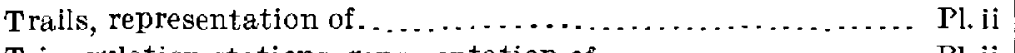

Triangulation stations, representation of ................. Pl. ii

Timnels, representation of ............................. Pli

tTuolumne Canyon, deseription of $\ldots \ldots \ldots \ldots \ldots \ldots \ldots \ldots \ldots, 29$ map of. view of part of, map of ............................... Pl. lxxxii Twin Sisters, Nebr., view of....................... Pl. xxii

U.

Unconformity, definition of.......................... 18 Uplift, occurrence of . ................................. 13 maps illustrating................... exliii, exlvii, cli, clii

Uvalde (Tex.) quadrangle, part of, description of .......... $41-42$ part of, geologic map and sections of .............. Pl. lxviii

V.

Valleys, alluviation in. ............................... $35-38$ alluviation in, maps illustrating................ Pls. xlix-ly growth of ...................................... $\quad 27$

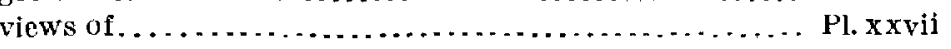
See also Youth; Maturity; Old age.

Volcanism, effects of .............................. $75-77$ effects of, maps illustrating..................... Pls. clv-clxiv
W.

Page.

Wartburg (Tenn.) quadrangle, part of, description of......... 31-32 part of, map of ............................... Pl. xxxvi Water, representation of ........................... 11, Pl. ii work of. See Streams; Coasts; Erosion.

Water, underground. See Ground water

Water gaps, explanation of........................... 40 maps illust rating................. Pls. $1 \times \uparrow,[x i x, 1 \times x i \mathrm{i}, 1 \times x v i, 1 \times x x$

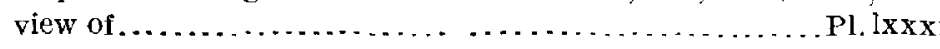
Waterloo (Wis.) quadrangle, part of, description of .......... 57

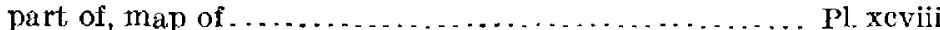
Watkins Glen, N. Y., views in...................... Pl.lvii Watkins (N. Y.) quad rangle, part of, description of .. ........ 38

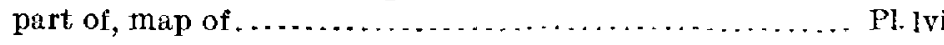

Watrous (N. Mex.) quadrangle, part of . . . . . . . . . . . . . . 45-46 part of, map of . . . . . . profiles in, figures showing ....................... 45 Waukon (Iowa-Wis.) quad rangle, part of, description of. . . . 36-37 part of, map of................................ Pli

Wausau (Wis.) quadrangle, part of, description of . . . . . . . . 47-48 part of, map and section of .................... Pl. lxxviii Weedsport (N. Y.) quadrangle, part of, description of . . . . . 57 part of, map of . . . . . . . . . . . . . . . . . . . . . . . . . . . . . . .

Tellfleet (Mass.) quadrangle, part of, description of . . . . . . . 70-71 part of map of ........ Wellsville, Utah, ancient lake shores at . . . . . . . . . . . . . . 73 ancient lake shores at view of ................... Pl. exlviii

Wharves, representation of .......................... Pl. ii

Whitewater (Wis.) quadrangle, part of, description of ........ 58 part of, map and section of ...................... Pli

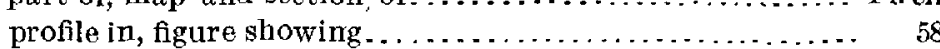
Williamston (N. C.) quadrangle, part of, description of........ 37 part of map of ................................ Pliv illiston (Fla.) quadrangle, parts of, description of .......... 78 parts of, maps of ........................ Pls, clxviii, clxix Winchester ( $W$. Va.-Va.) quadrangle, part of, description of... 43-44 part of, map and section of ....................... Pl. lxxii

Wind, work of .......... work of, maps illustrating. . . . . . . . . . . . . . . . . Pls. xvi-xxii represcntation of...

Wind gaps, creation of $\ldots \ldots \ldots \ldots \ldots \ldots \ldots$ maps illustrating ....................... Pls. v, lxix, lxxxvi

$\mathrm{Y}$.

Yellowstone National Park. See Lake quadrangle.

Yosemite (Cal.) quadrangle, parts of, description of .......... 29-30 parts of, maps of .......................... Fls. $x x x, x \times x i$

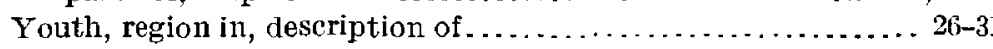
region in, maps illustrating. ........................ Pls. vi, viii, xxiii-xxxvi, lxxxiii, lxxxiv, xev-xcvi, xcix, c, cii, civ, cxii, cxxvii, exxx, cxxxix. cxlvi, clxvi. 


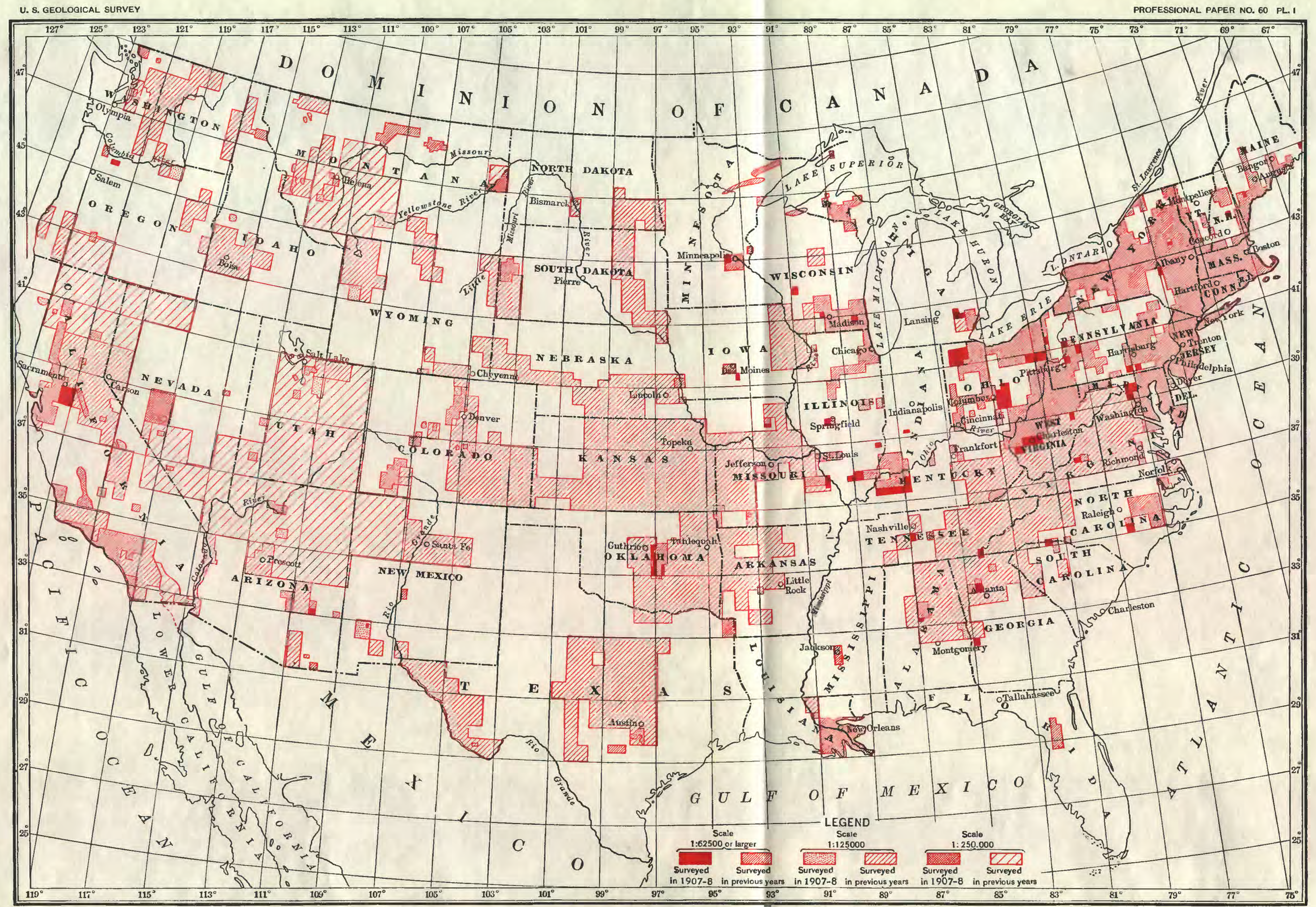

MAP OF UNITED STATES, SHOWING AREAS COVERED BY TOPOGRAPHIC SURVEYS

$$
\begin{aligned}
& \text { AND THE SCALE EMPLOYED FOR EACH AREA. } \\
& \begin{array}{ccc}
100 \quad 0 \quad 100 \quad 200 \quad 300 \text { miles } \\
1808 & 000
\end{array}
\end{aligned}
$$




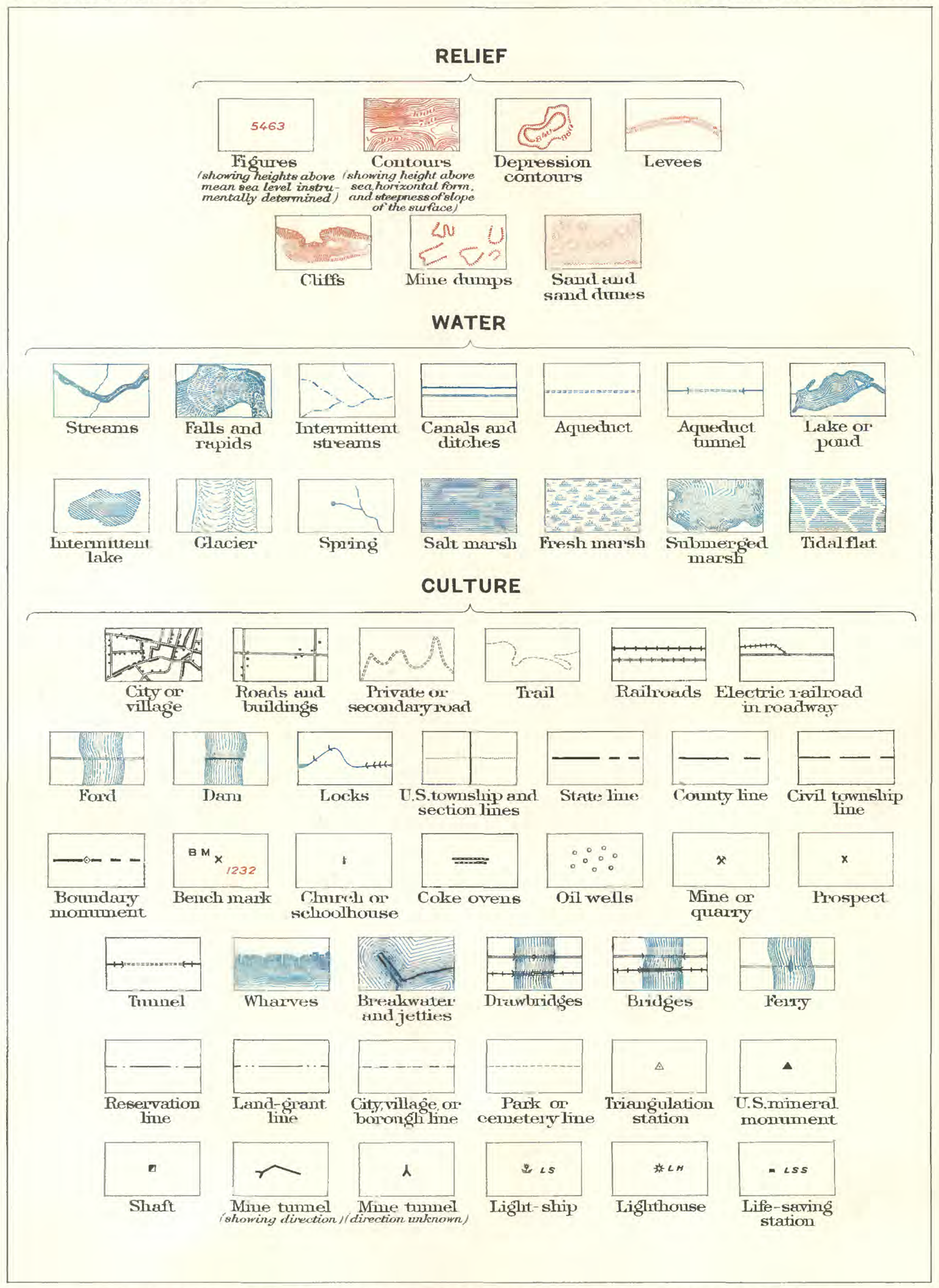




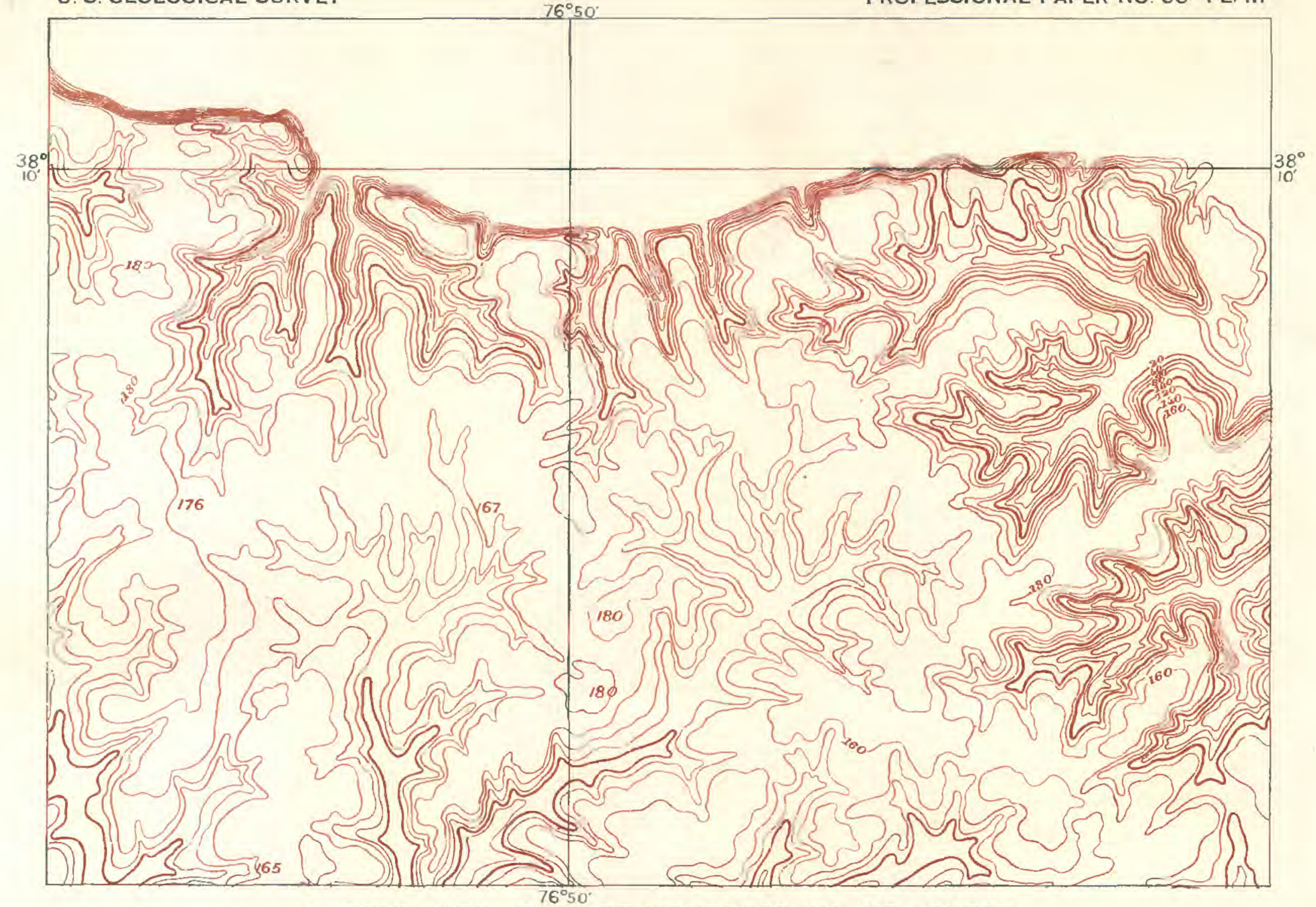

A. CONTOURS: PART OF MONTROSS (VA.-MD.) SHEET

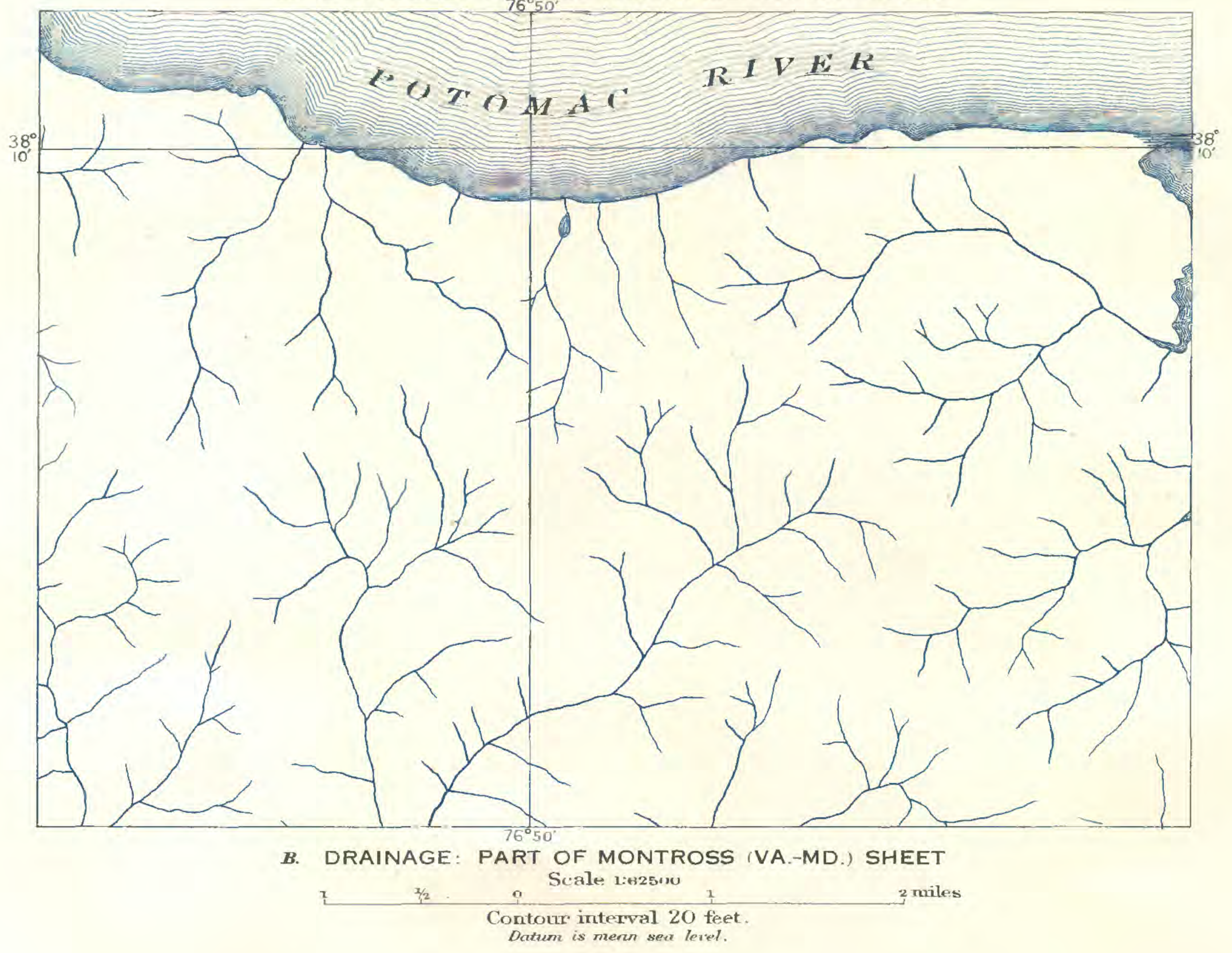




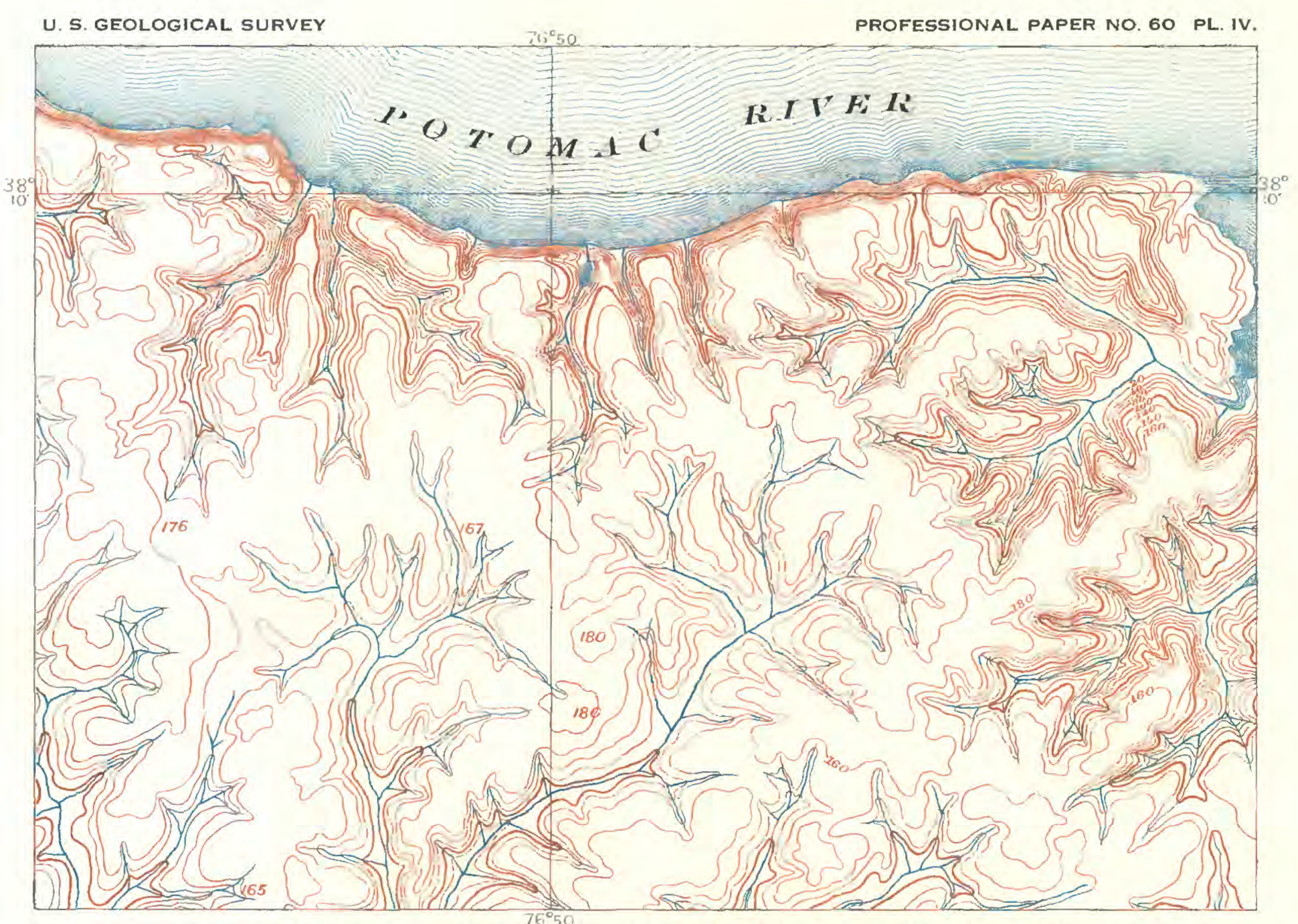

A. CONTOURS AND DRAINAGE: PART OF MONTROSS (VA.-MD.) SHEET

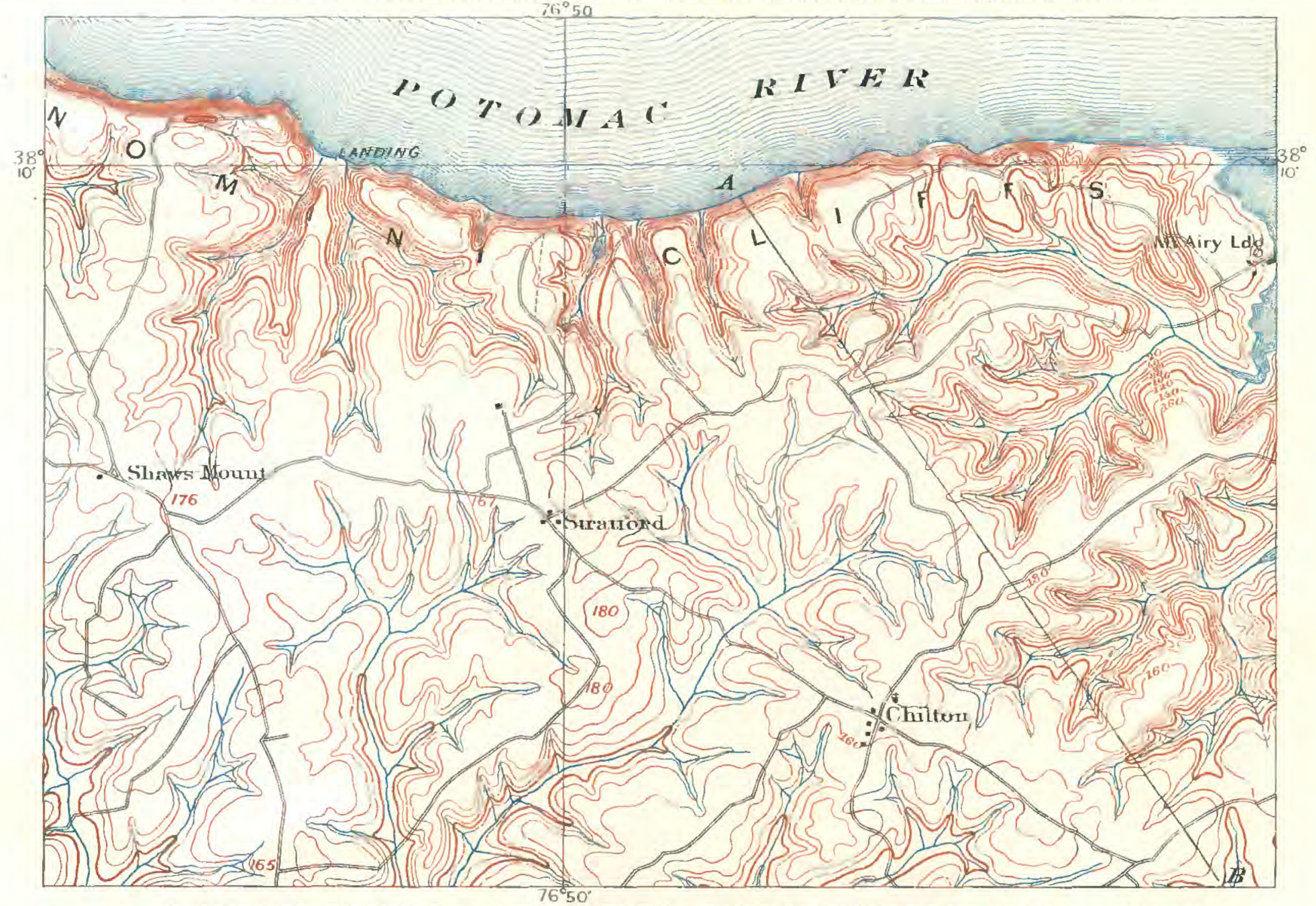

B. CONTOURS, DRAINAGE, AND CULTURE: PART OF MONTROSS (VA.-MD.) SHEET

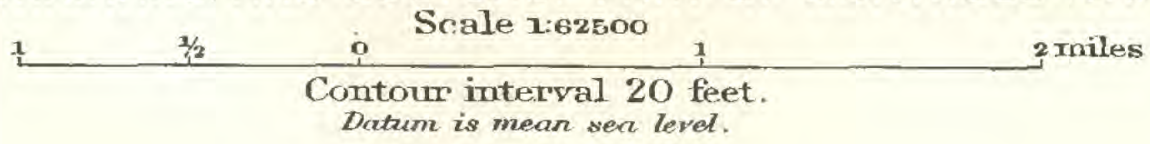



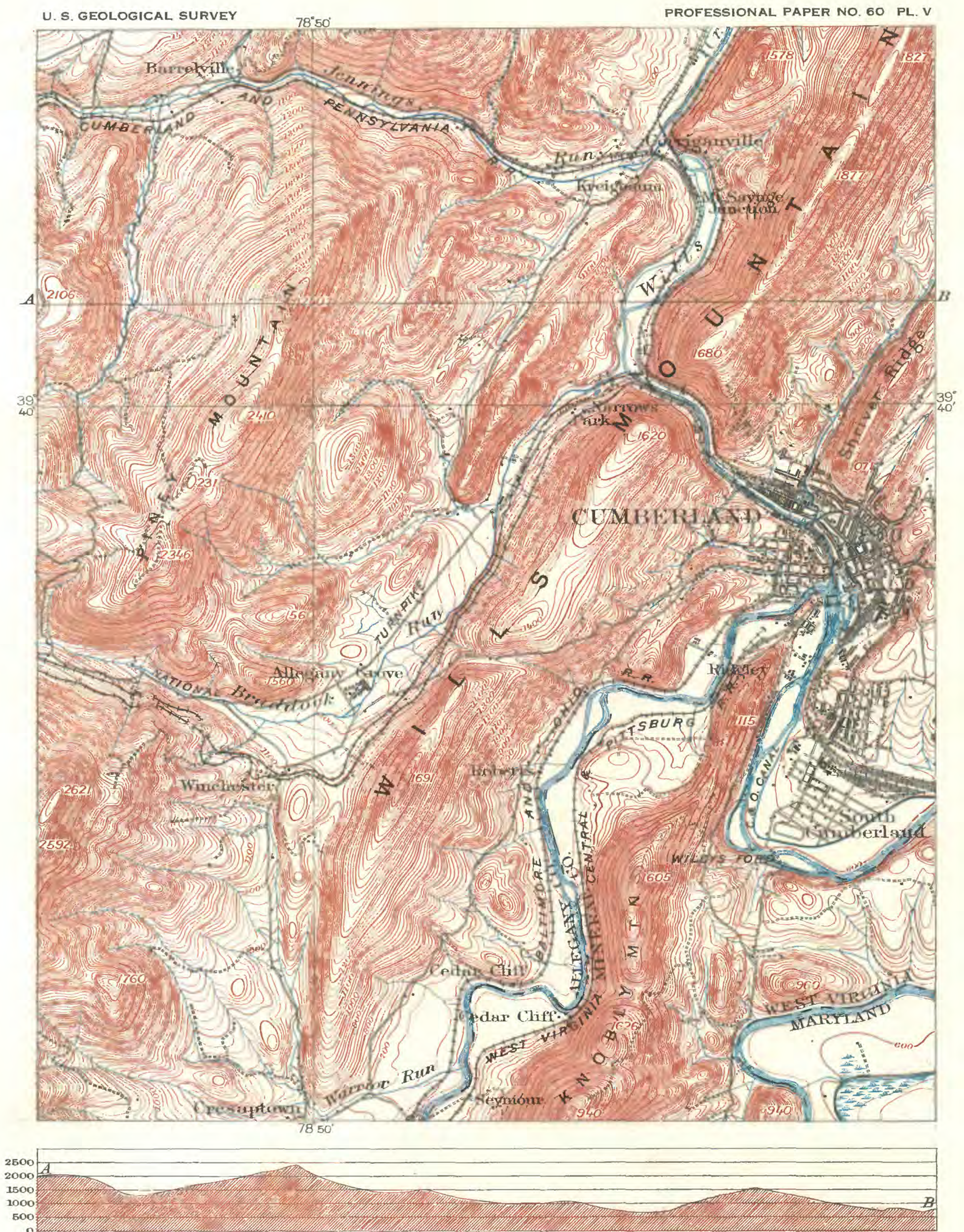

AREA OF MARKED RELIEF: PART OF FROSTBURG (MD.-W. VA.-PA., SHEET, WITH SECTION ON LINE A-B $\underbrace{1 / 2 \quad \text { Scale 1:62500 }}_{\text {Contour interval } 20 \text { feet. }}$ 2 miles 


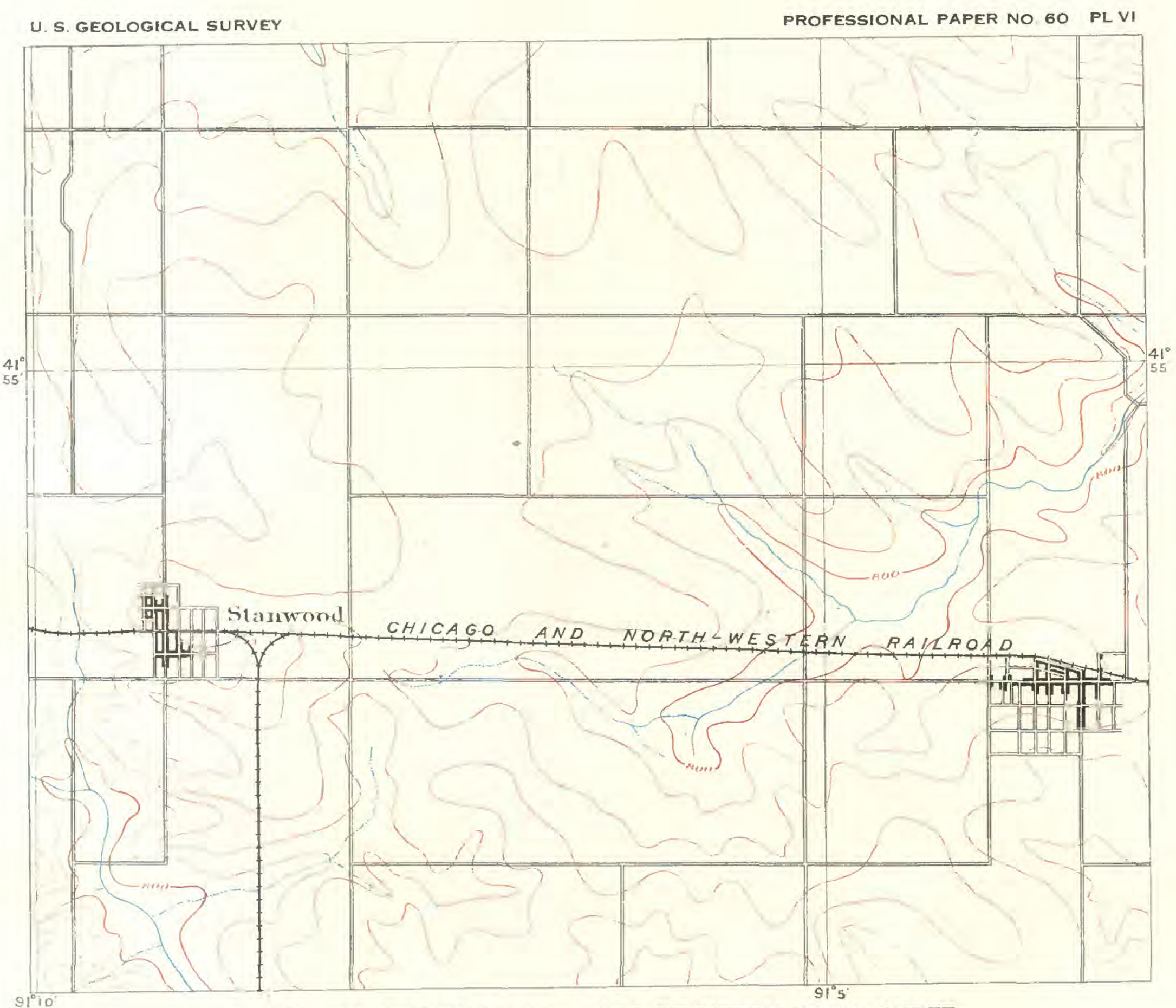

A. AREA OF SLIGHT RELIEF: PART OF TIPTON (IOWA) SHEET

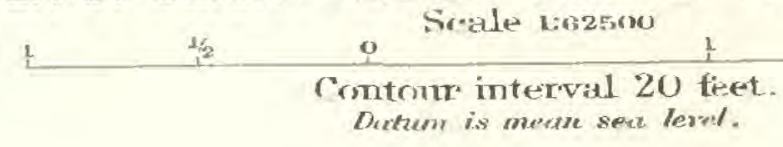
y nuites

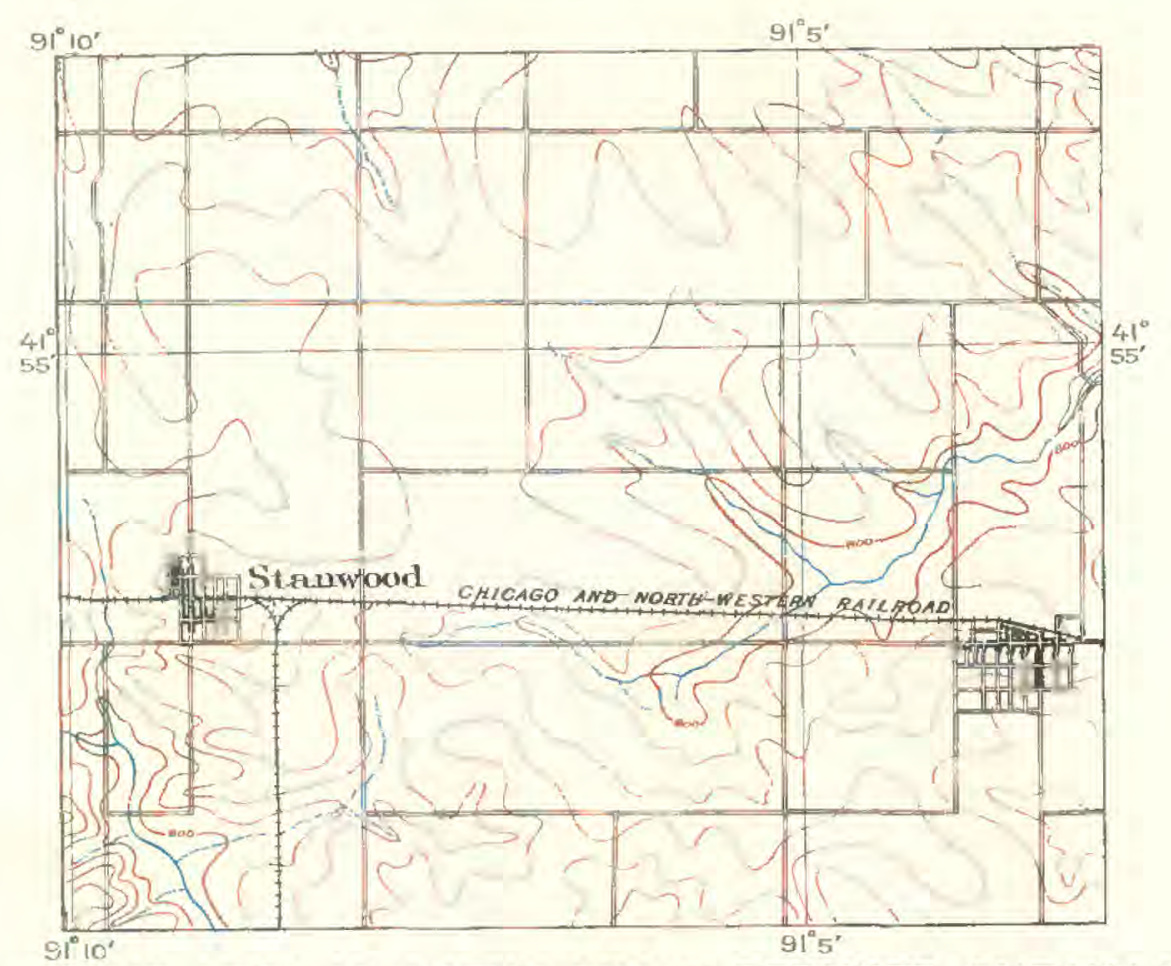

B. SAME AREA AS ABOVE. SCALE REDUCED ONE-HALF

$$
\begin{aligned}
& \underbrace{1 / 2} \text { o Scale } \begin{array}{l}
1 \\
\text { Contour interval } 20
\end{array} \\
& \text { Dafum is mean sou lewet. }
\end{aligned}
$$




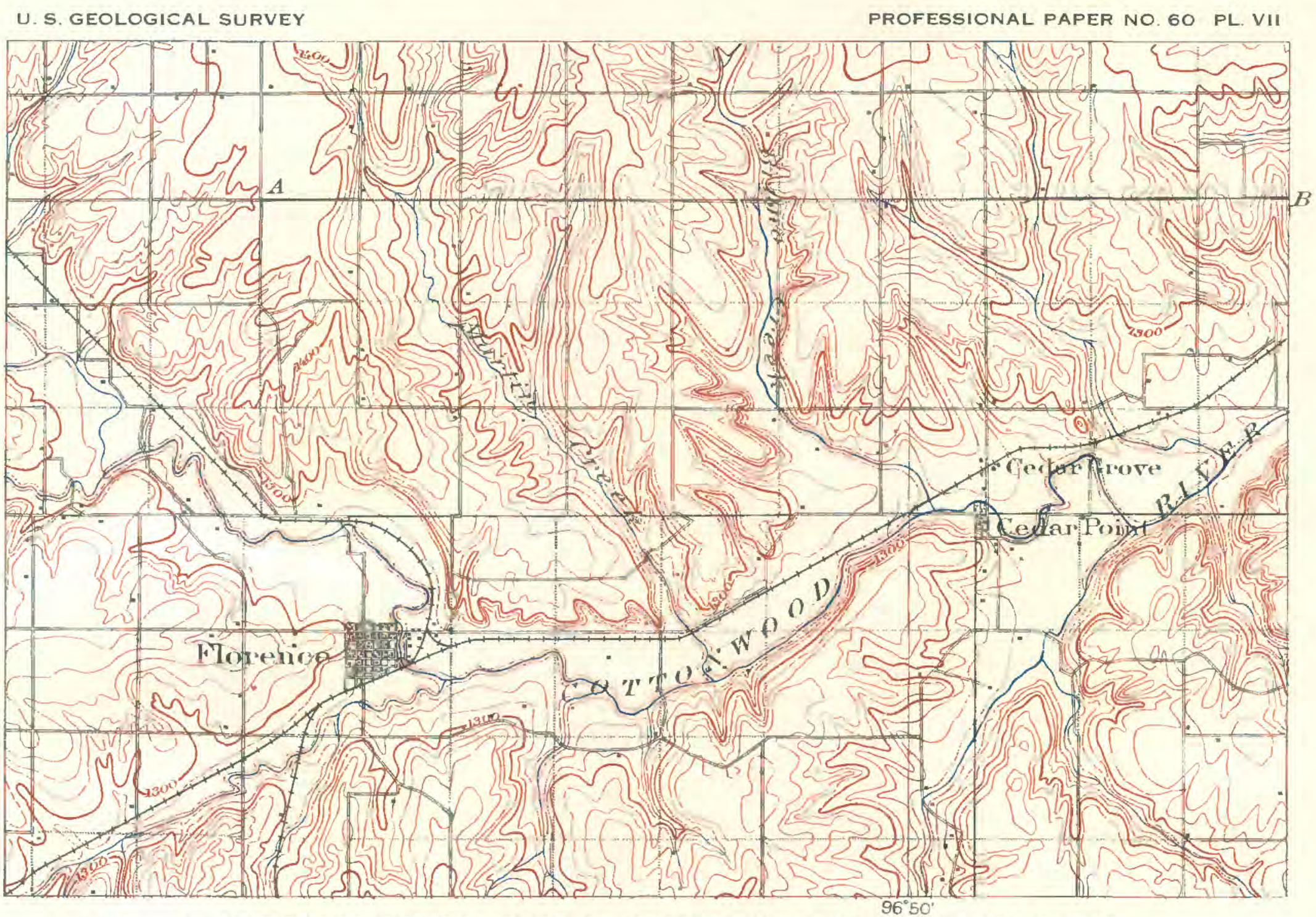

A. MODERATE RELIEF: PART OF COTTONWOOD FALLS (KANS.) SHEET.

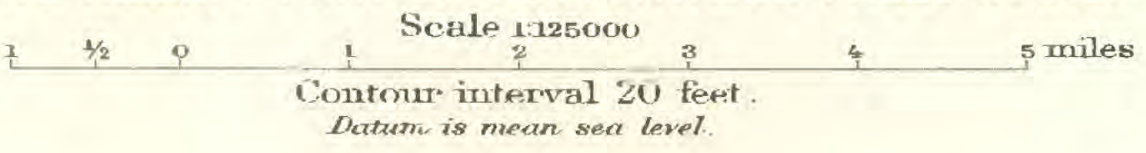

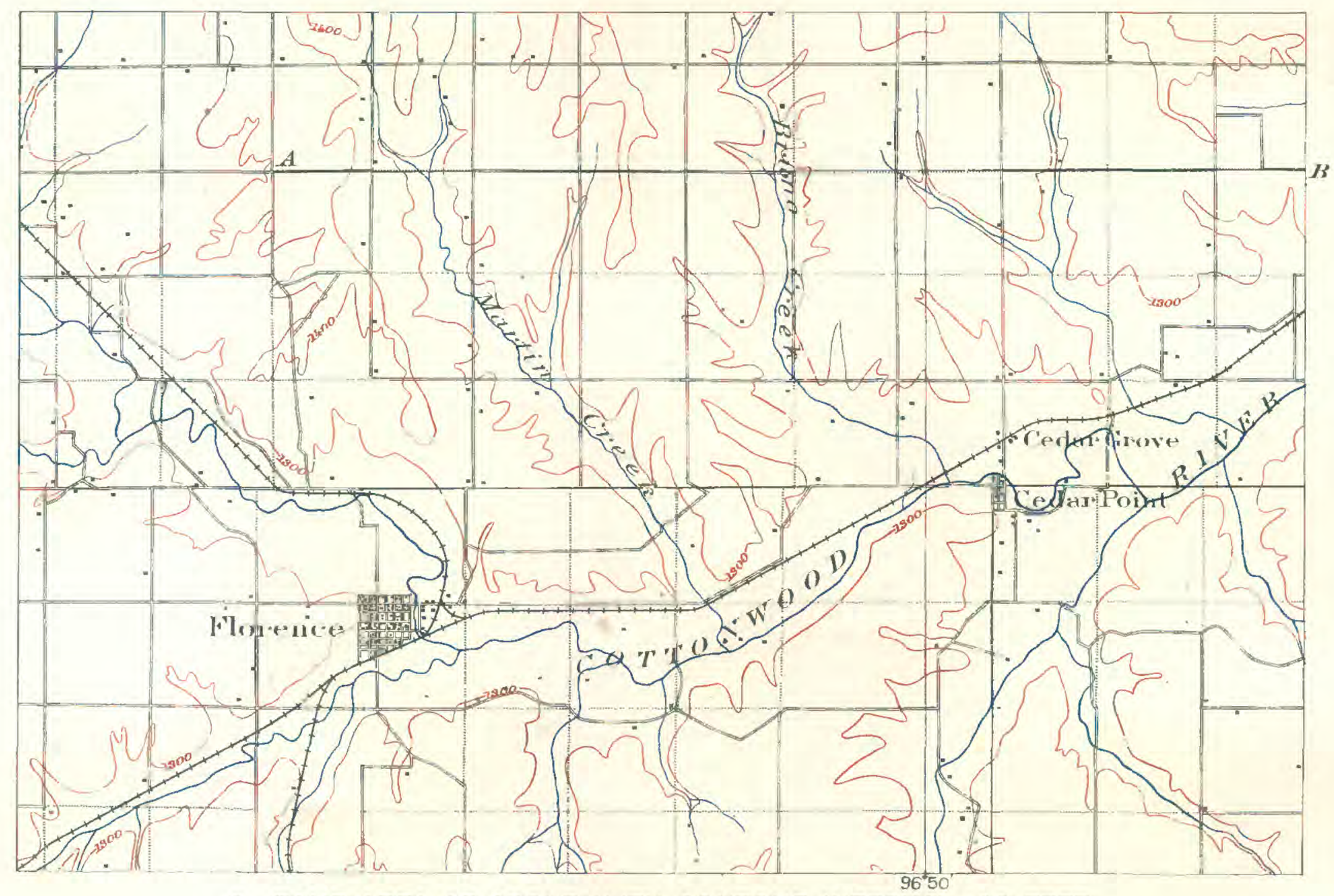

B. SAME AREA AS ABOVE. WITH CONTOUR INTERVAL 100 FEET 


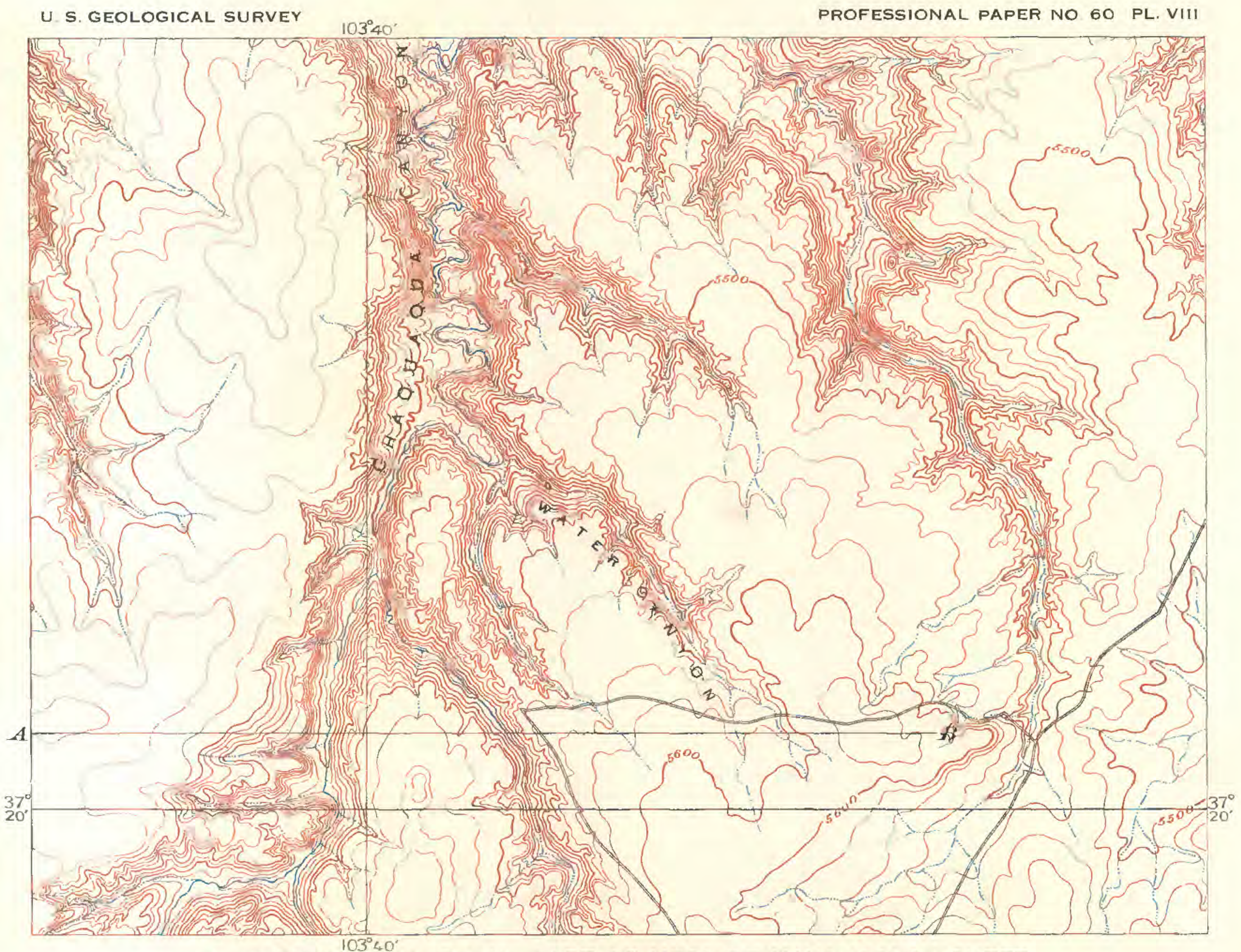

A. DISSECTED PLATEAU: PART OF MESA DE MAYA (COLO.) SHEET

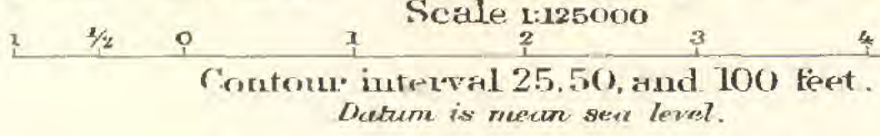

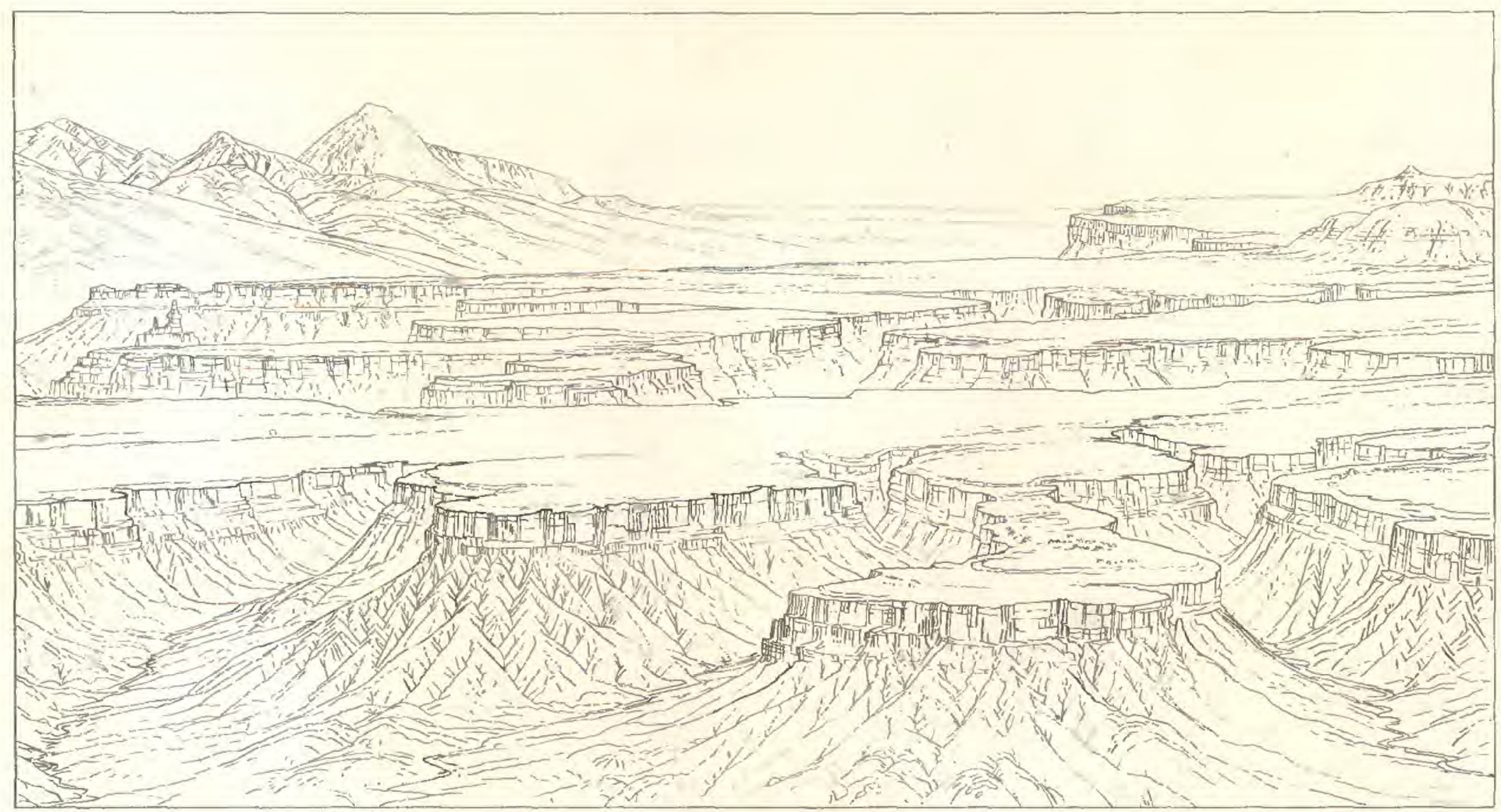

B. Dissected PLATEAu. MESA VERDE, COLORADO 
U. S. GEOLOGICAL SURVEY

$122^{\circ} 15^{\prime 2}$

PROFESSIONAL PAPER NO. 60 PL. IX

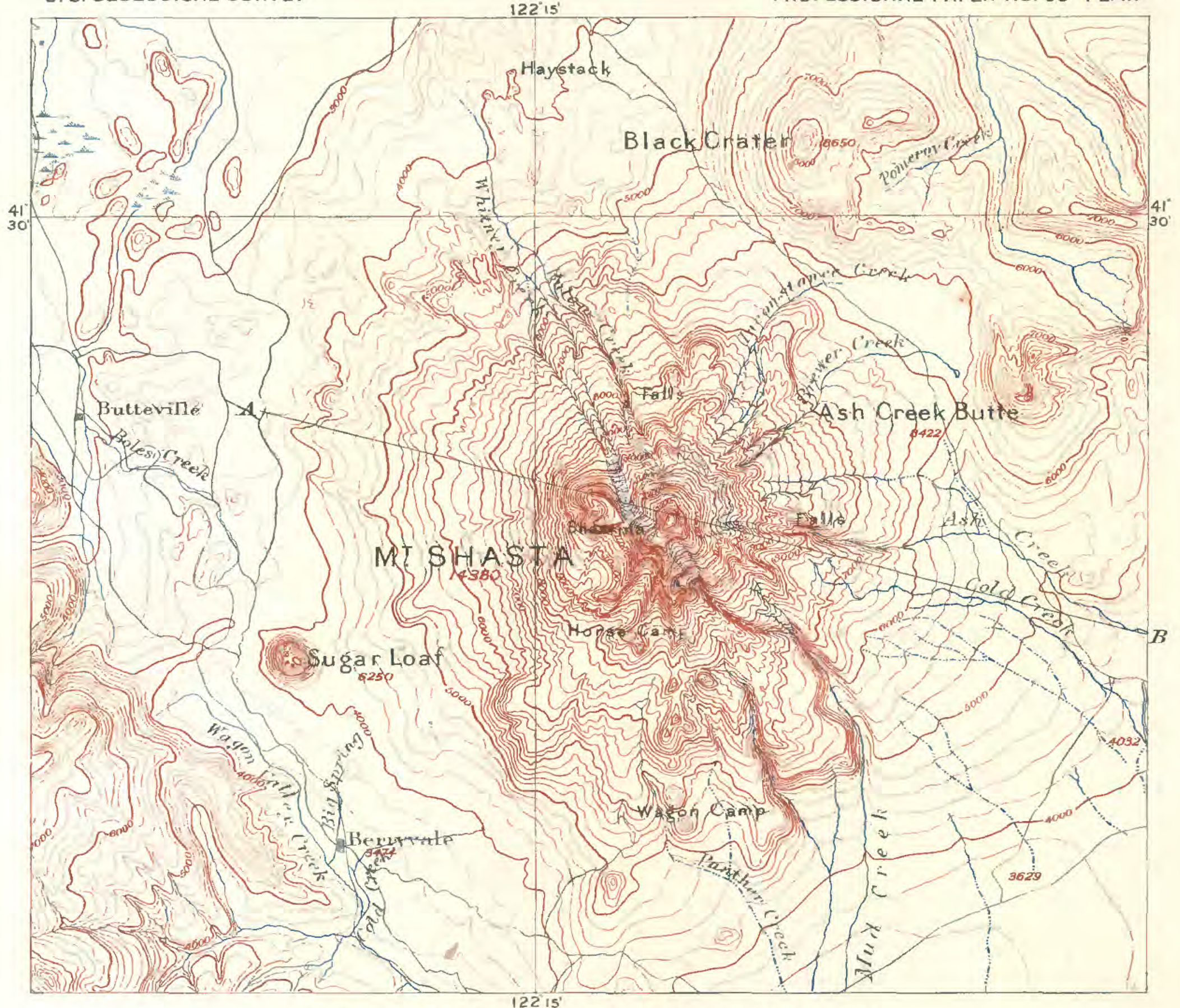

A. TOPOGRAPHIC MAP OF MOUNT SHASTA, CAL.

Part of Shasta

Cal., sheet.

i

Scale z:250000

${ }_{1}^{8}$

10

12 miles

Daturn is moun sea level.

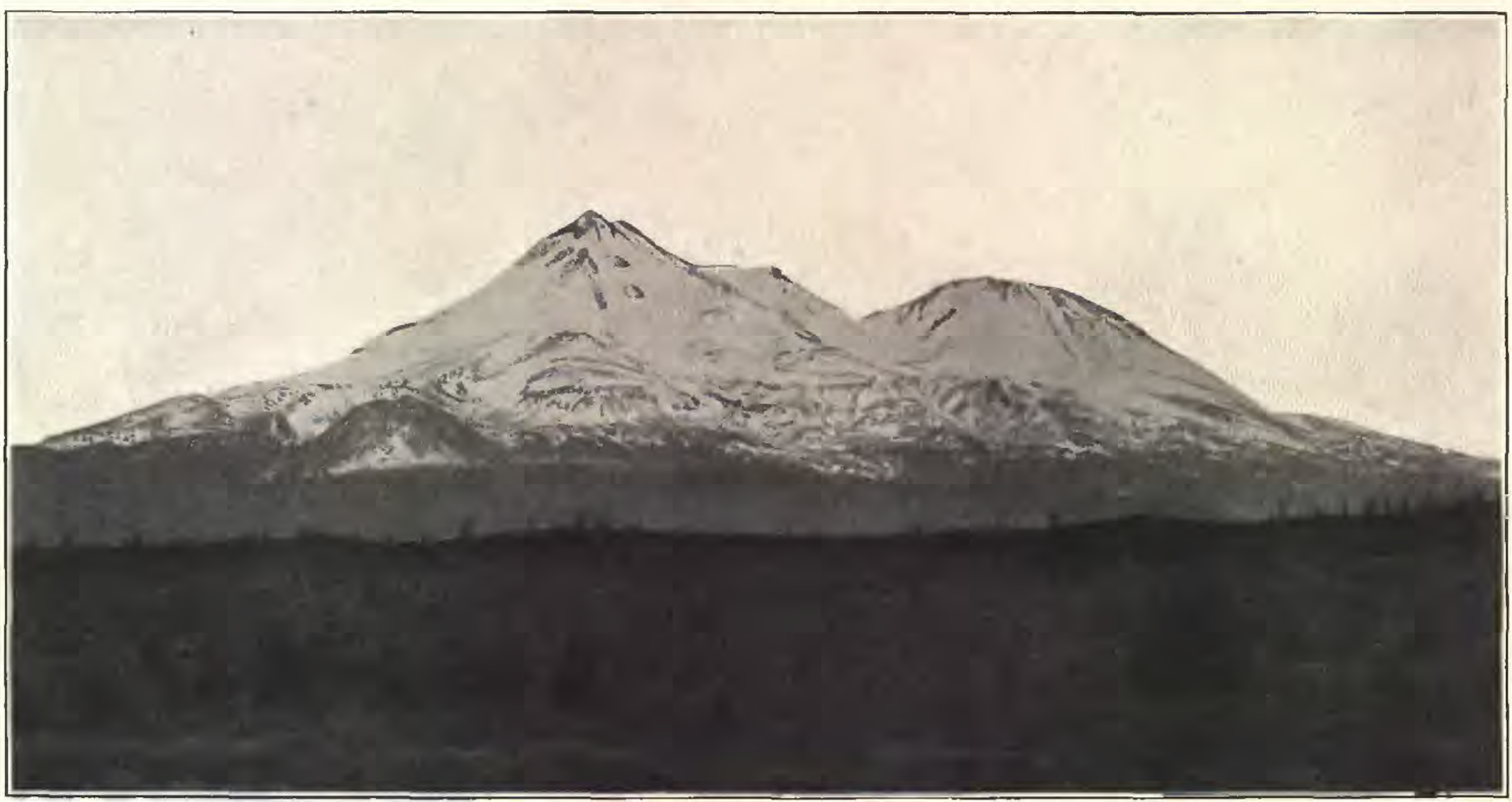

B. VIEW OF MOUNT SHASTA. CAL 

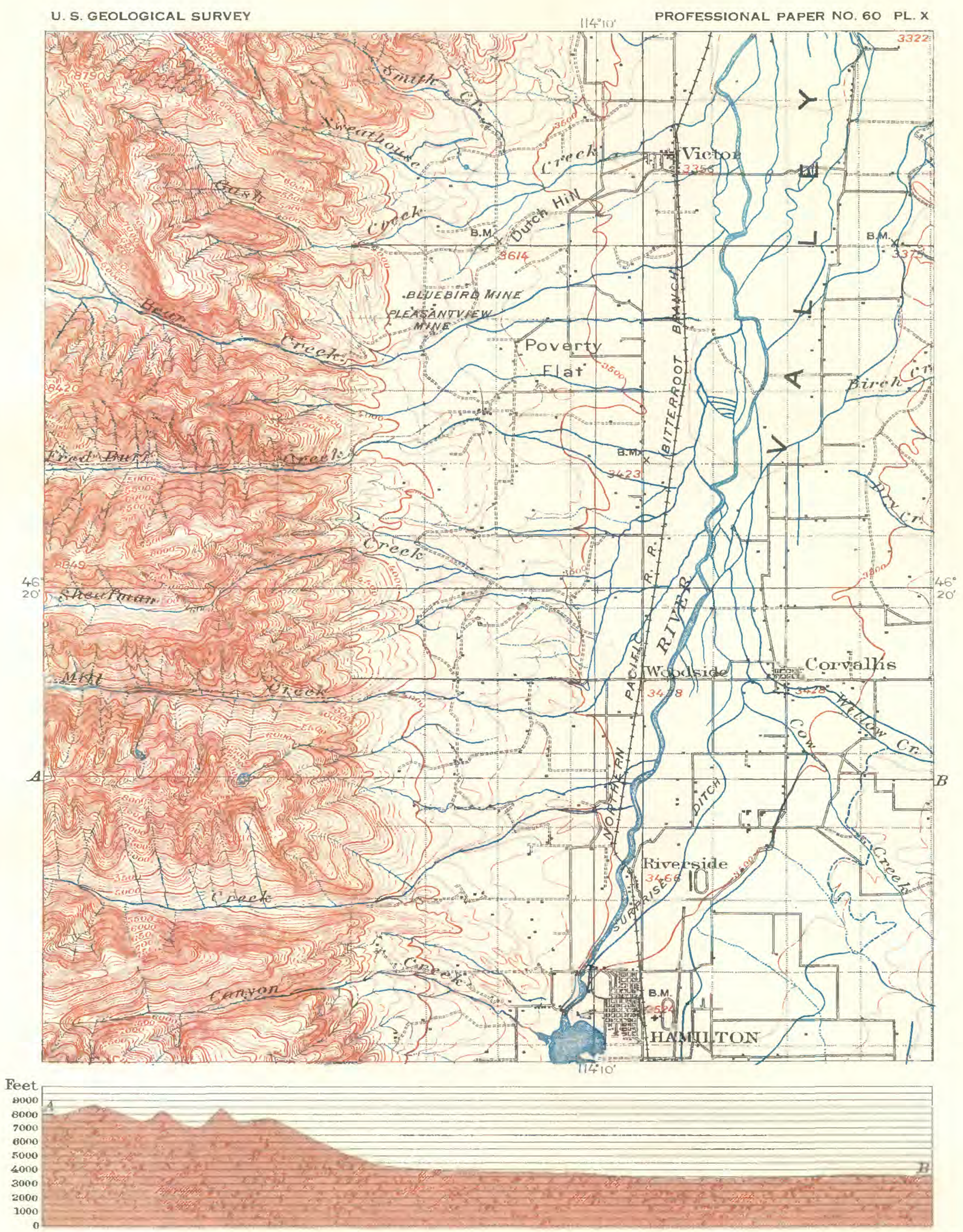

TOPOGRAPHIC CONTRASTS: PART OF HAMILTON (MONT.-IDAHO) SHEET, WITH SECTION ON LINE A-B

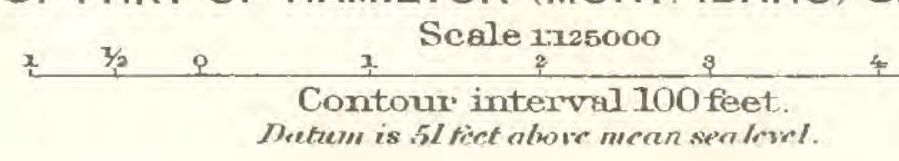




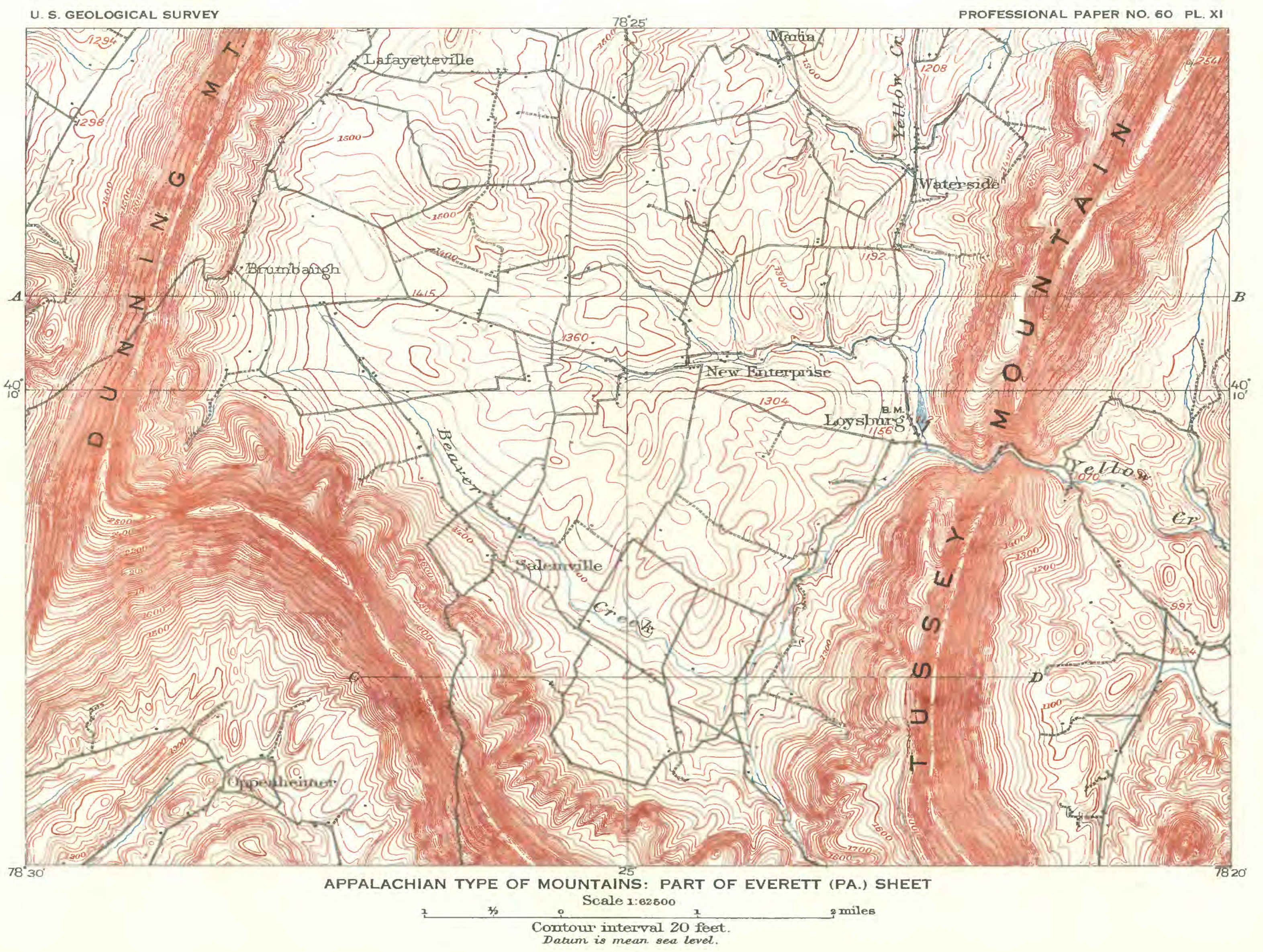




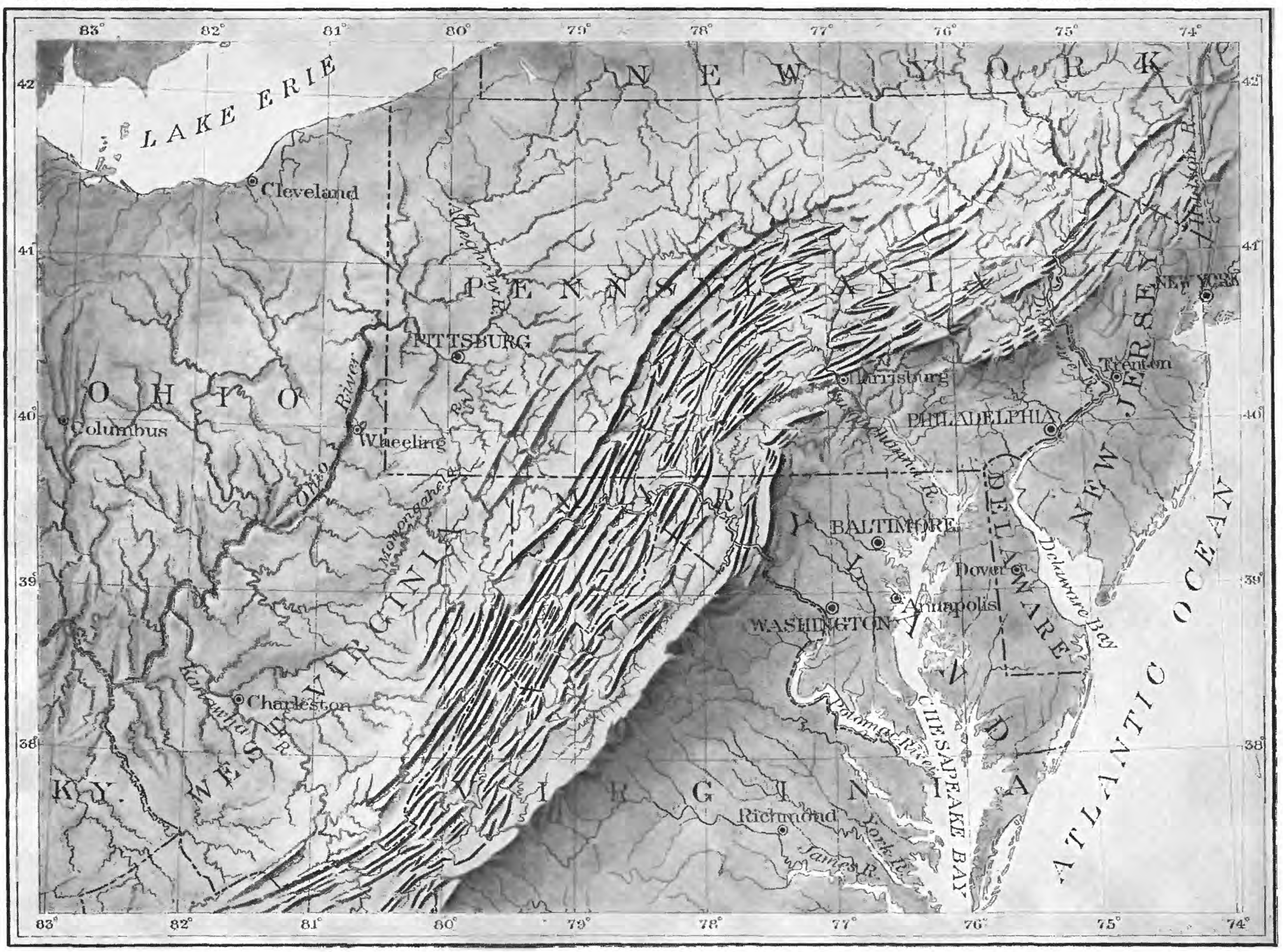

RELIEF MAP OF NORTHERN APPALACHIANS. 


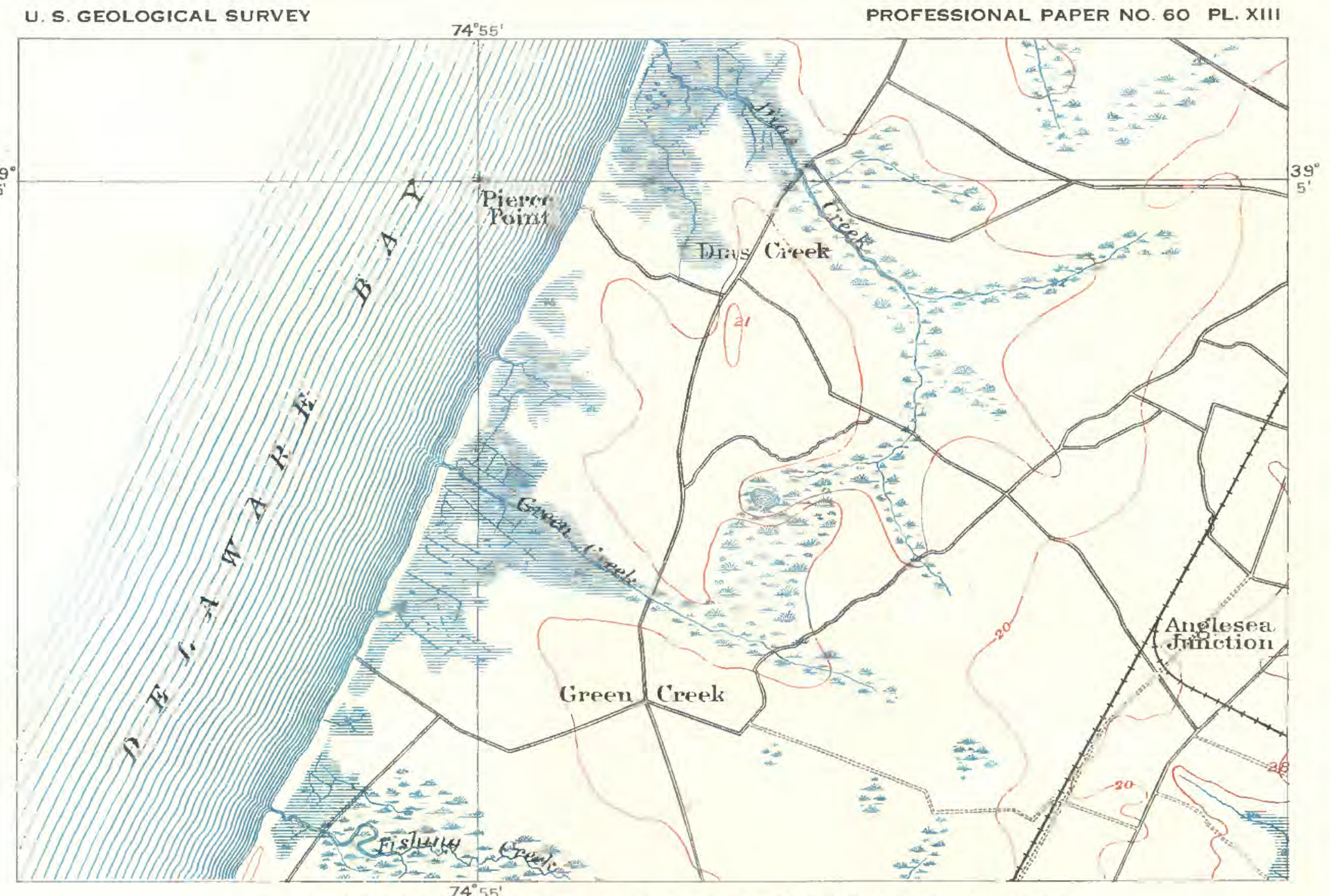

A. A LOW, MARSHY COAST: PART OF DENNISVILLE (N. J.) SHEET

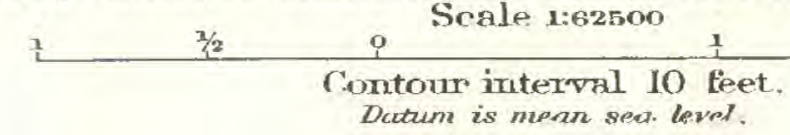
2 miles

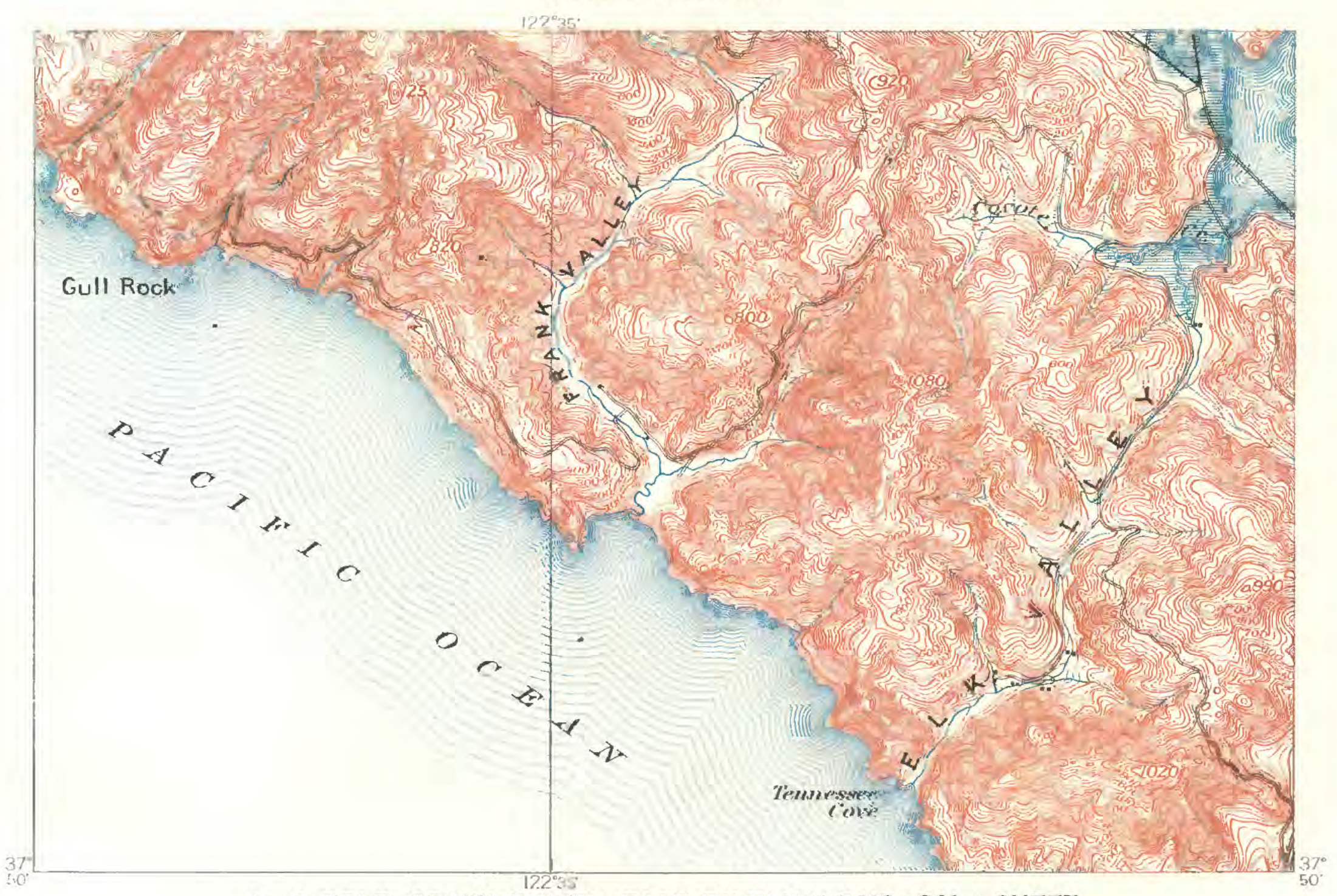

B. A BOLD, ROCKY COAST: PART OF TAMALPAIS (CAL.) SHEET

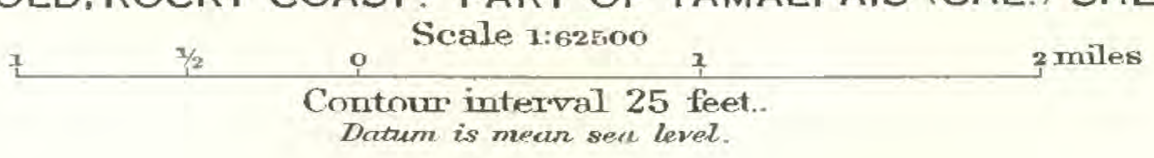




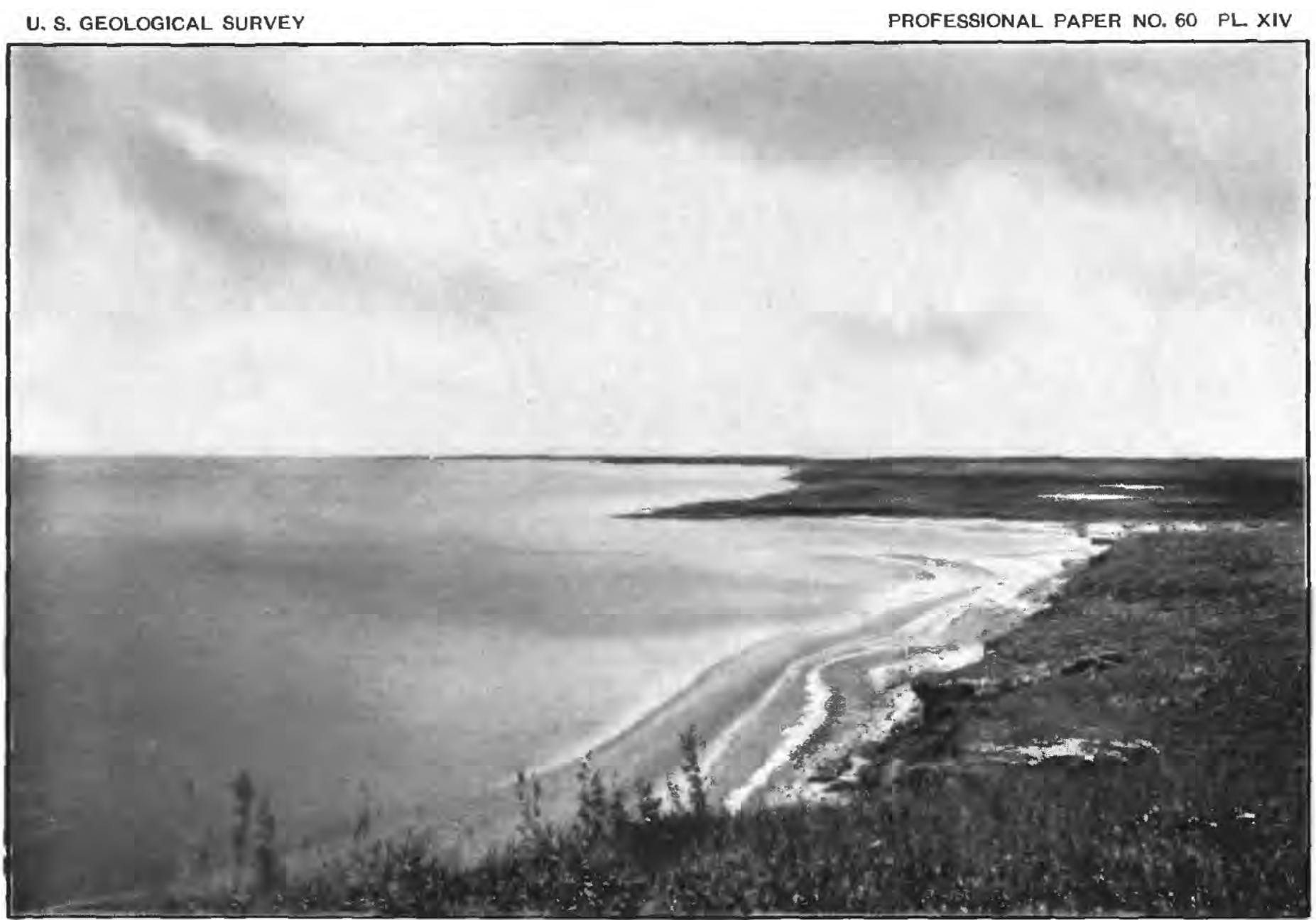

A. ARCTIC COAST AND EDGE OF MOSS-COVERED ARCTIC COASTAL PLAIN.

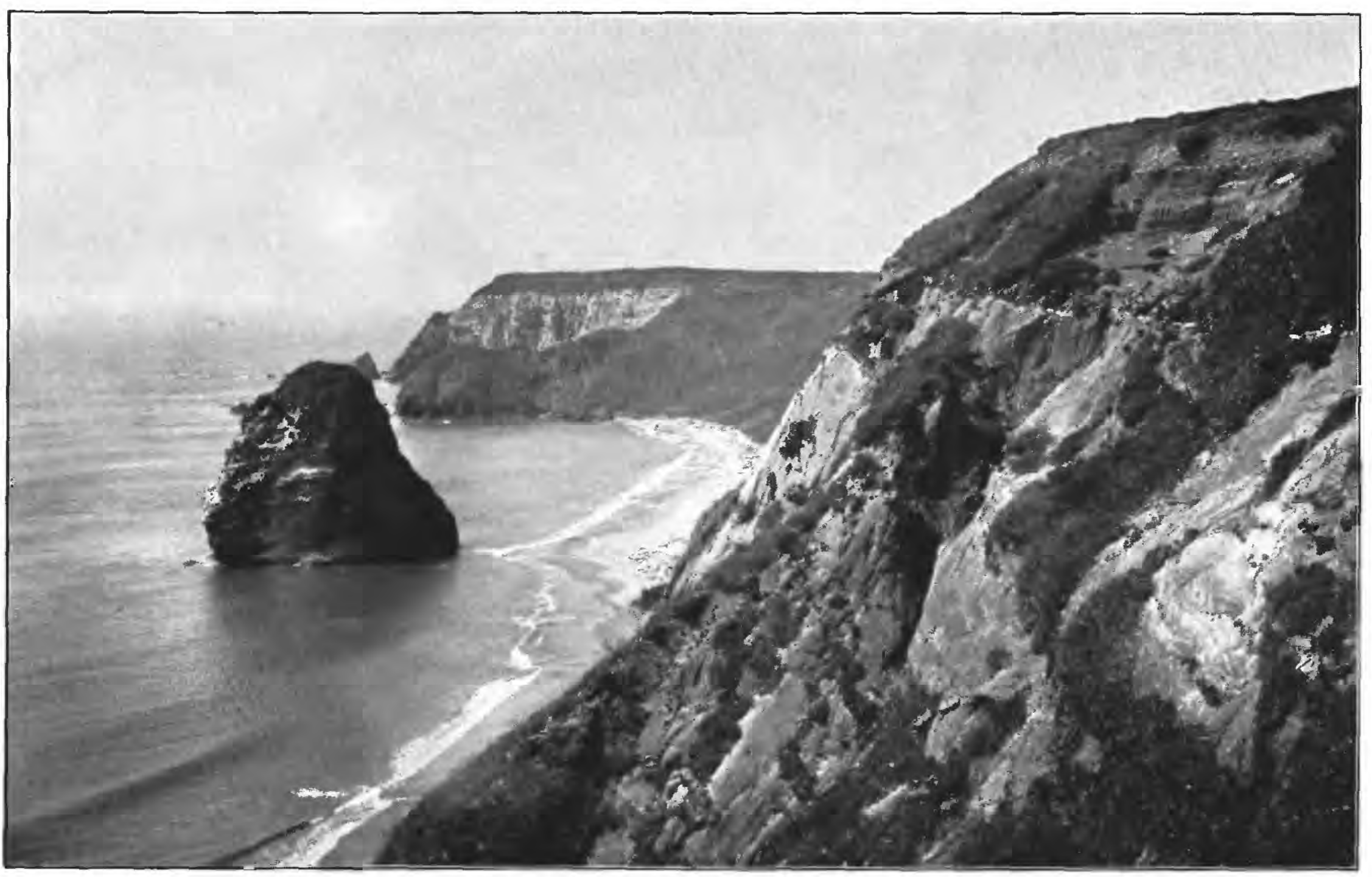

B. FIN ROCK AND CAPE BLANCO, OREGON. 


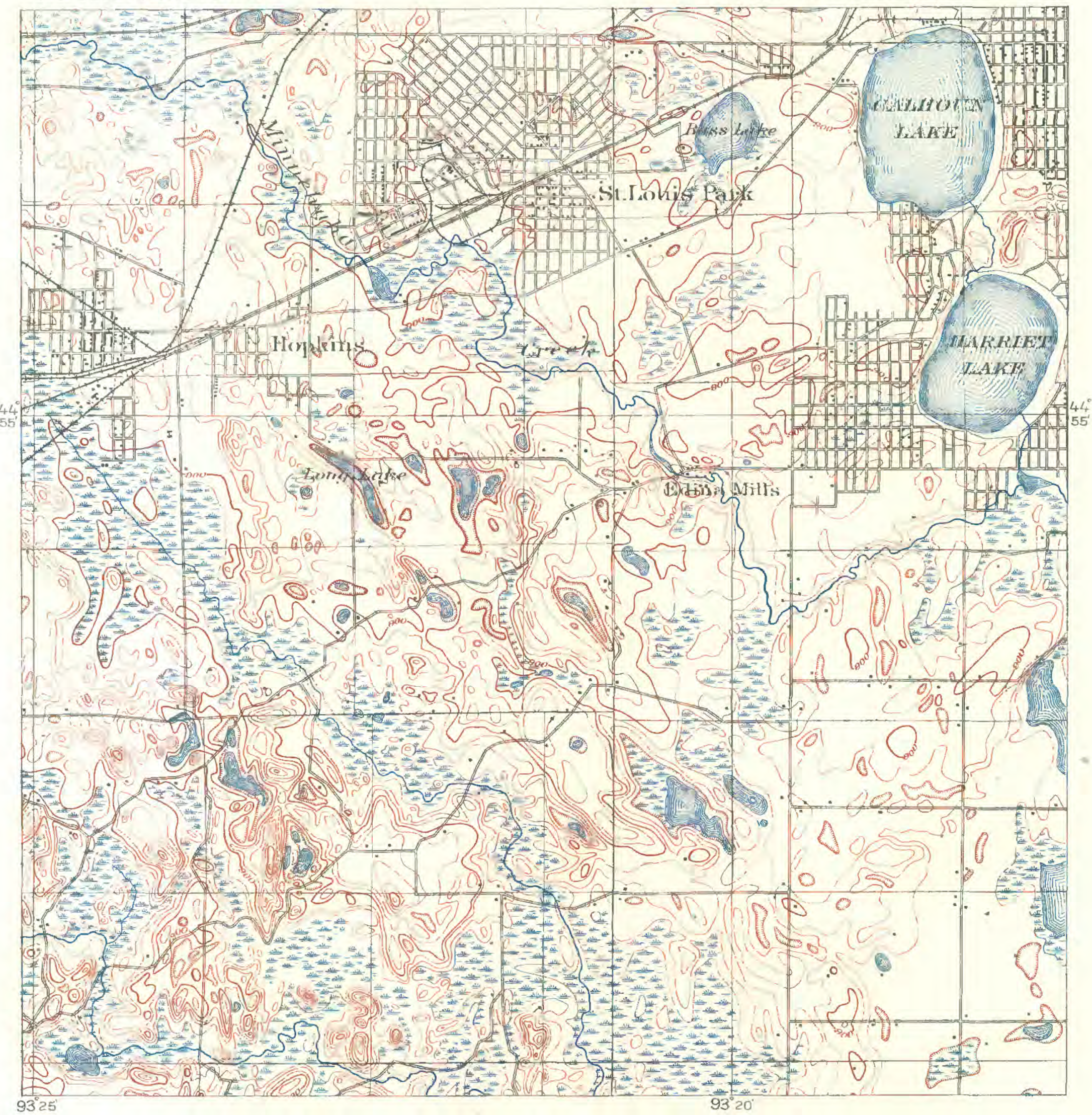

A. AN ILL-DRAINED, GLACIATED AREA: PART OF MINNEAPOLIS (MINN.) SHEET

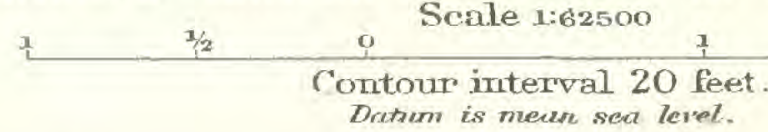
2 miles

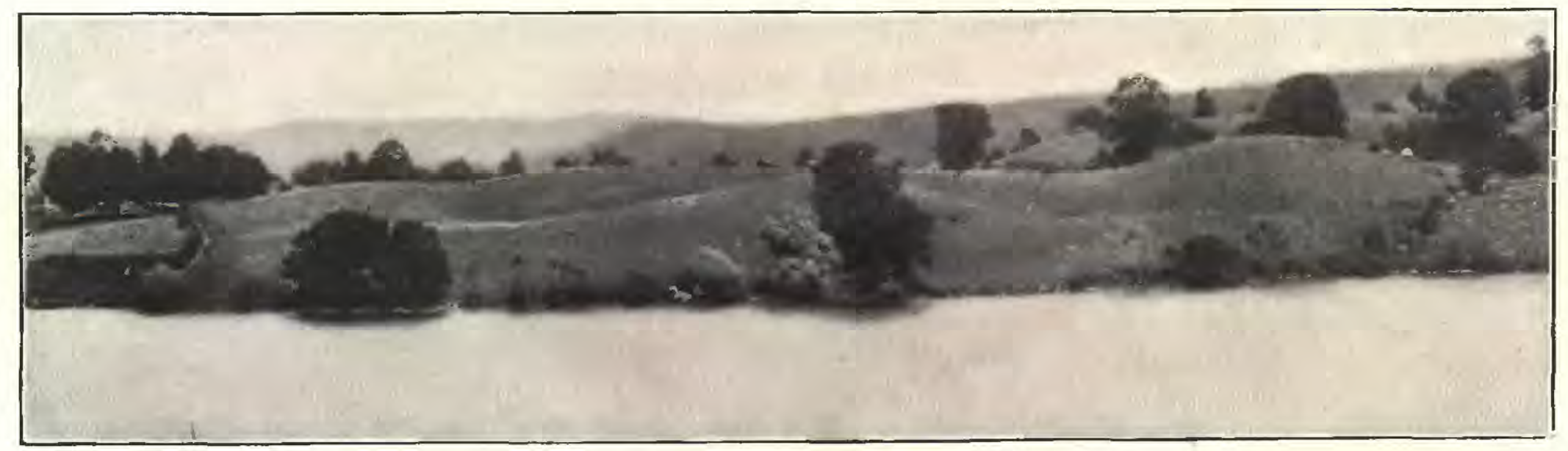

B. MORAINE TOPOGRAPHY AT NORTH END OF LAKE GRINNELL. N. J. 


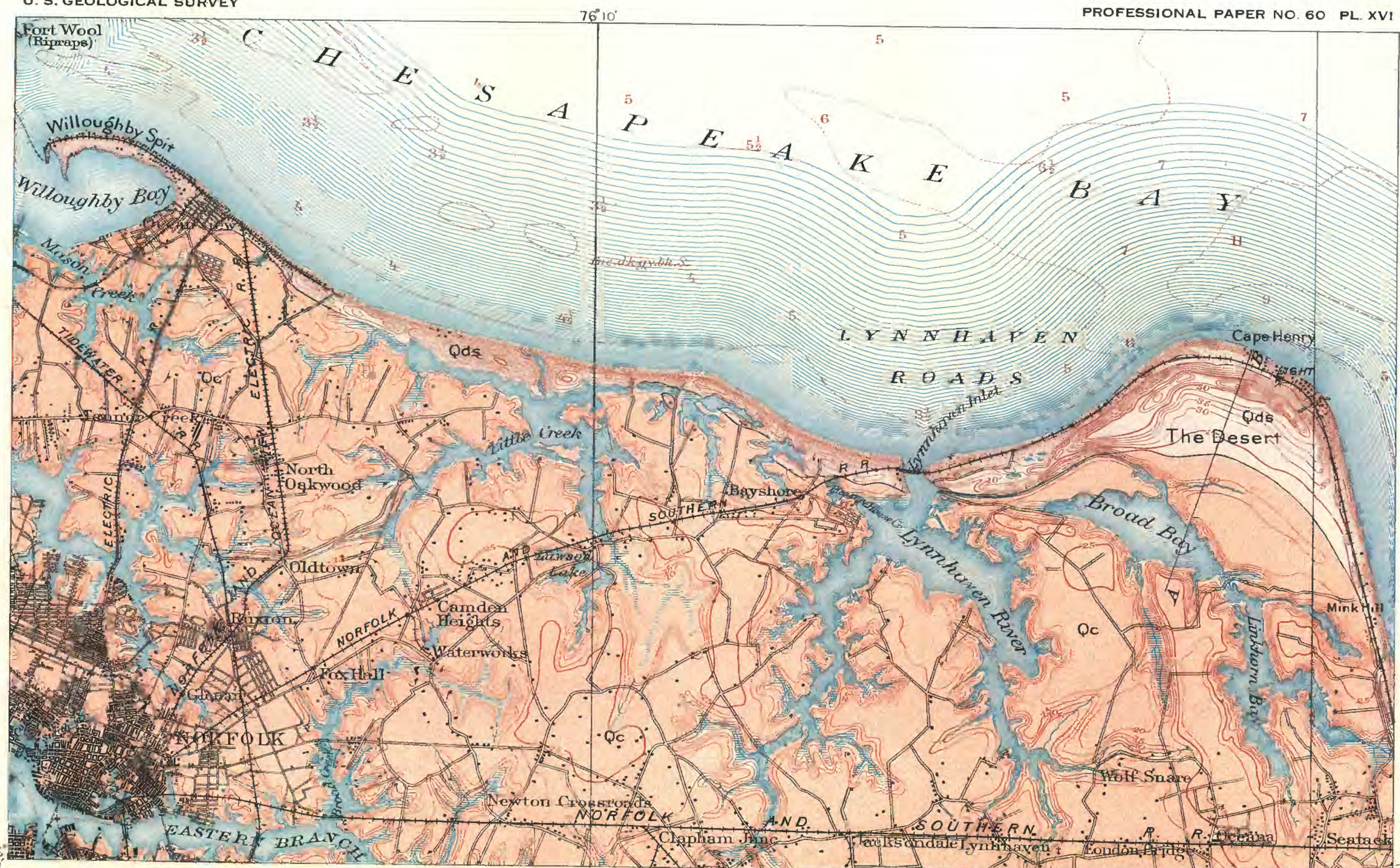

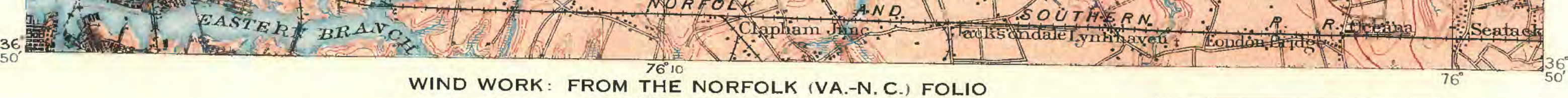

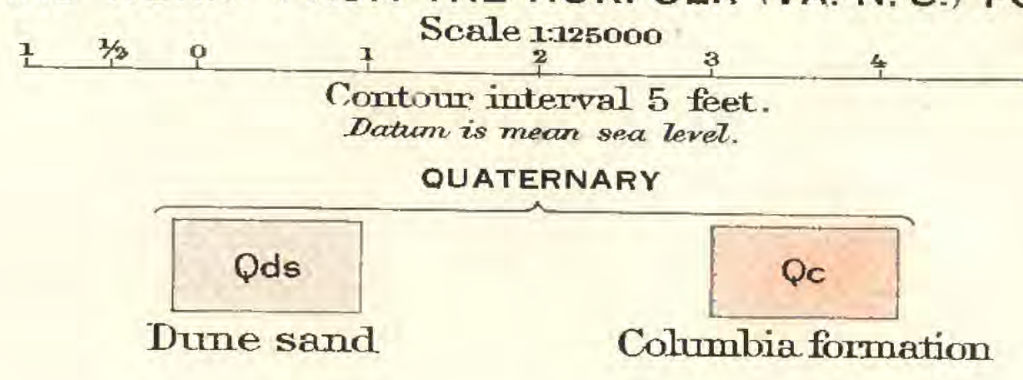




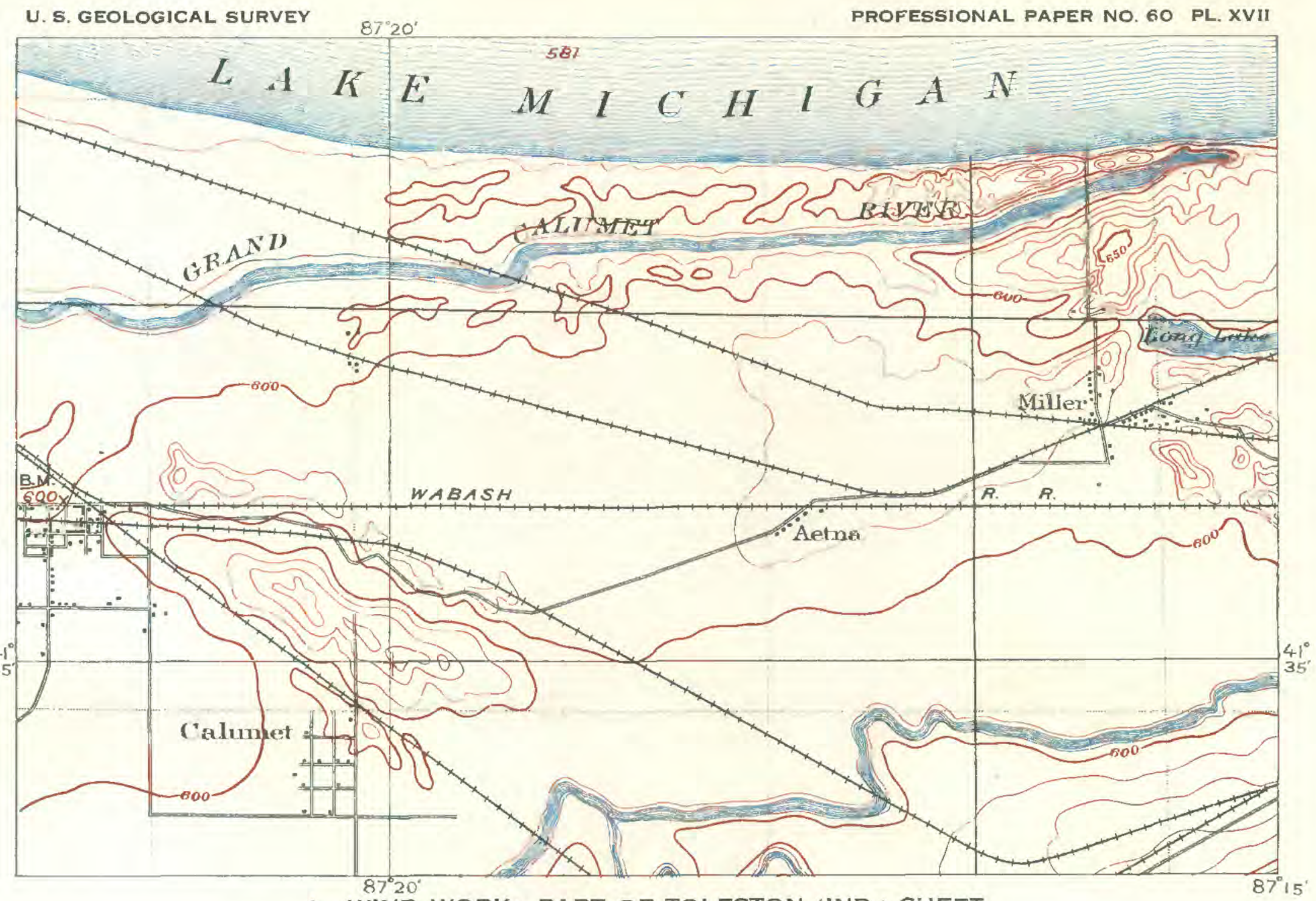

A. WIND WORK: PART OF TOLESTON (IND.) SHEET
$1 \underbrace{1 / 2}_{\text {Contour interval } 1 / 2}$ feet
2 miles

$75^{\circ} \mathrm{r}$

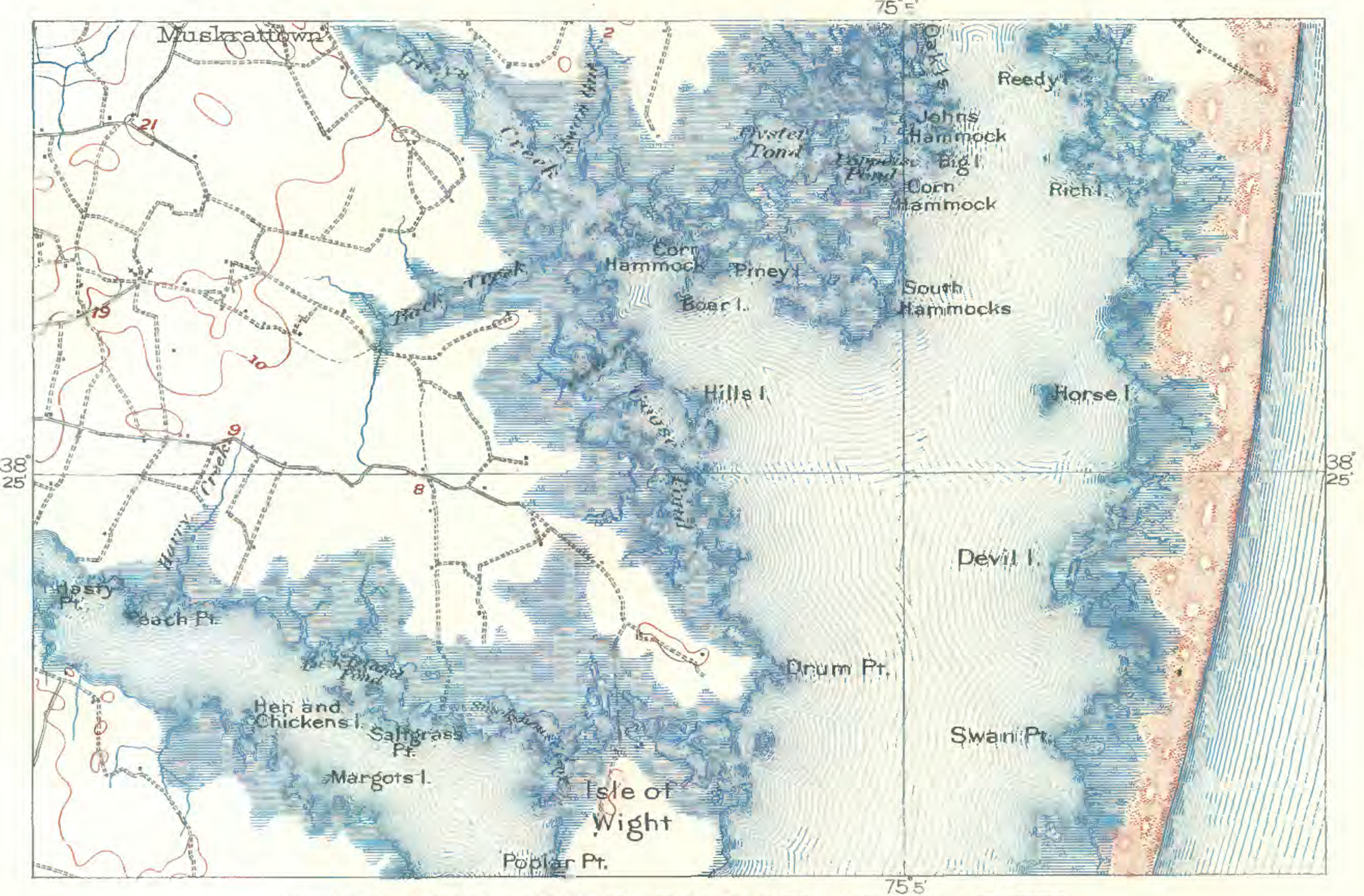

B. WIND WORK: PART OF OCEAN CITY (MD.-DEL.) SHEET

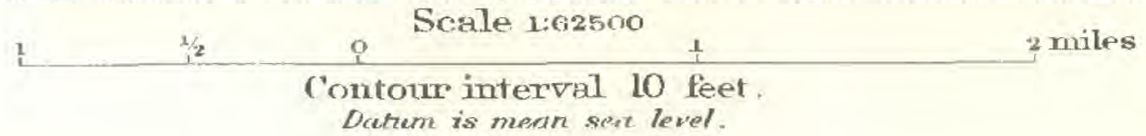




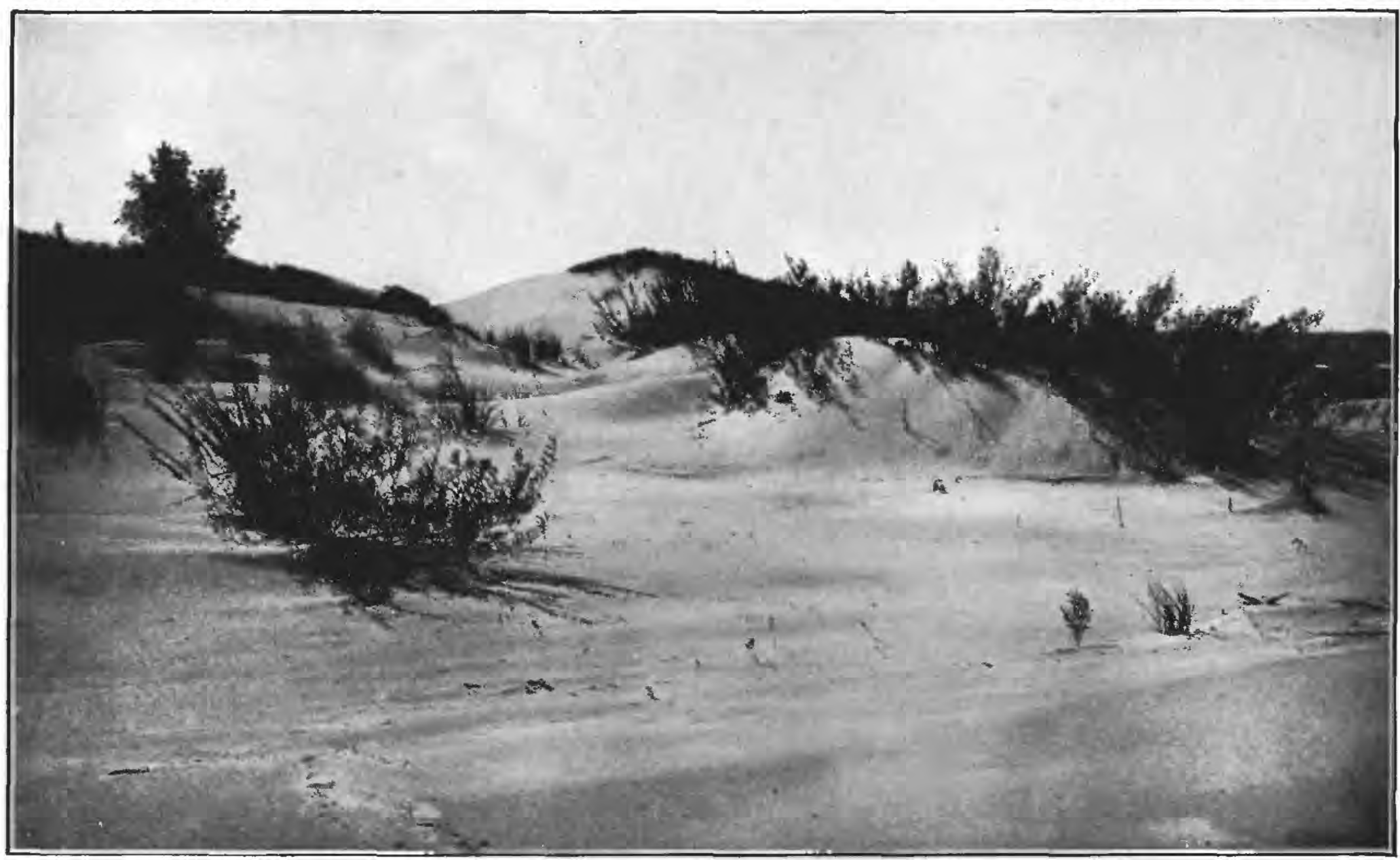

A.

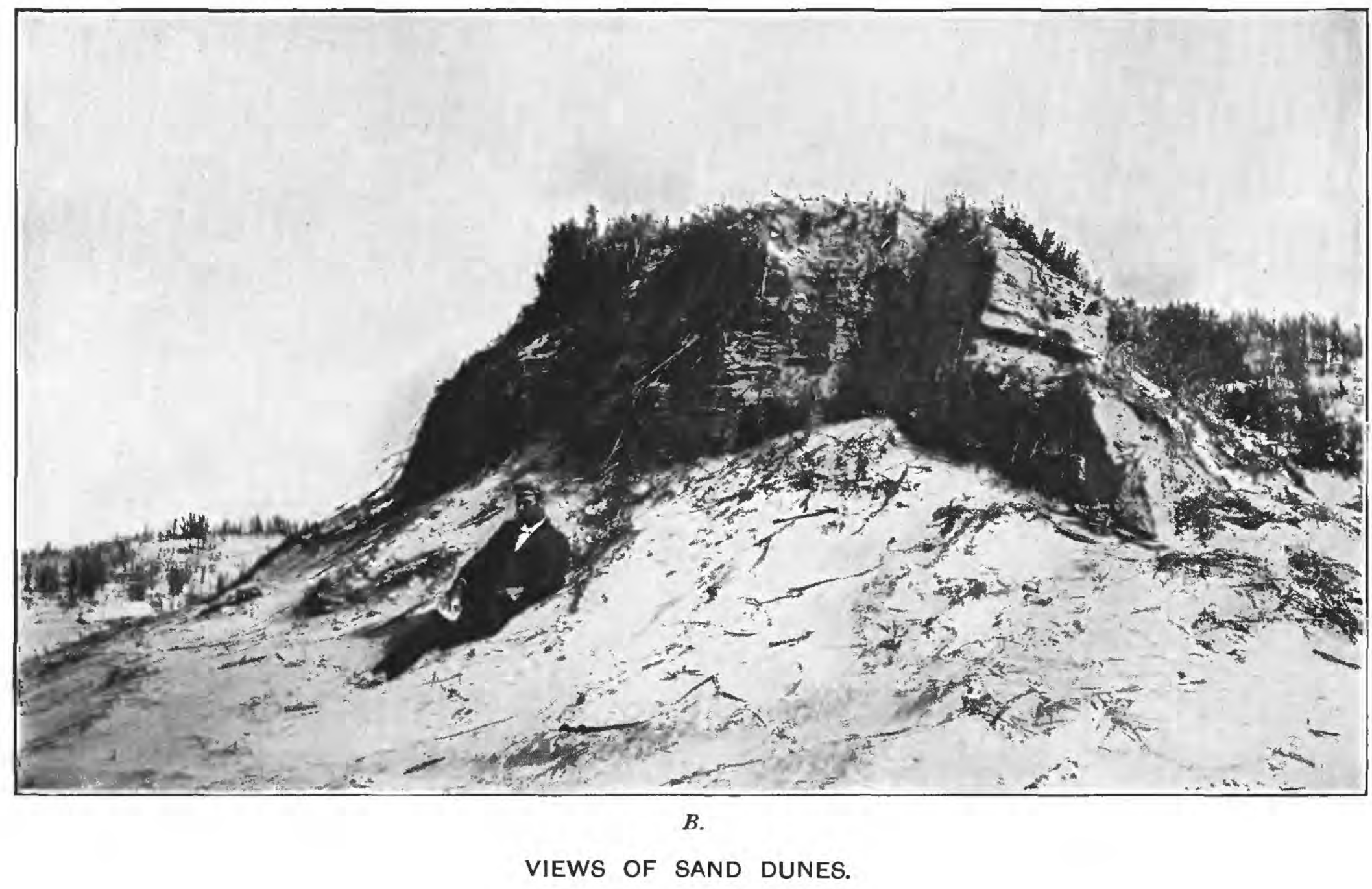


U. S. GEOLOGICAL SURVEY

PROFESSIONAL PAPER NO. 60 PL. XIX
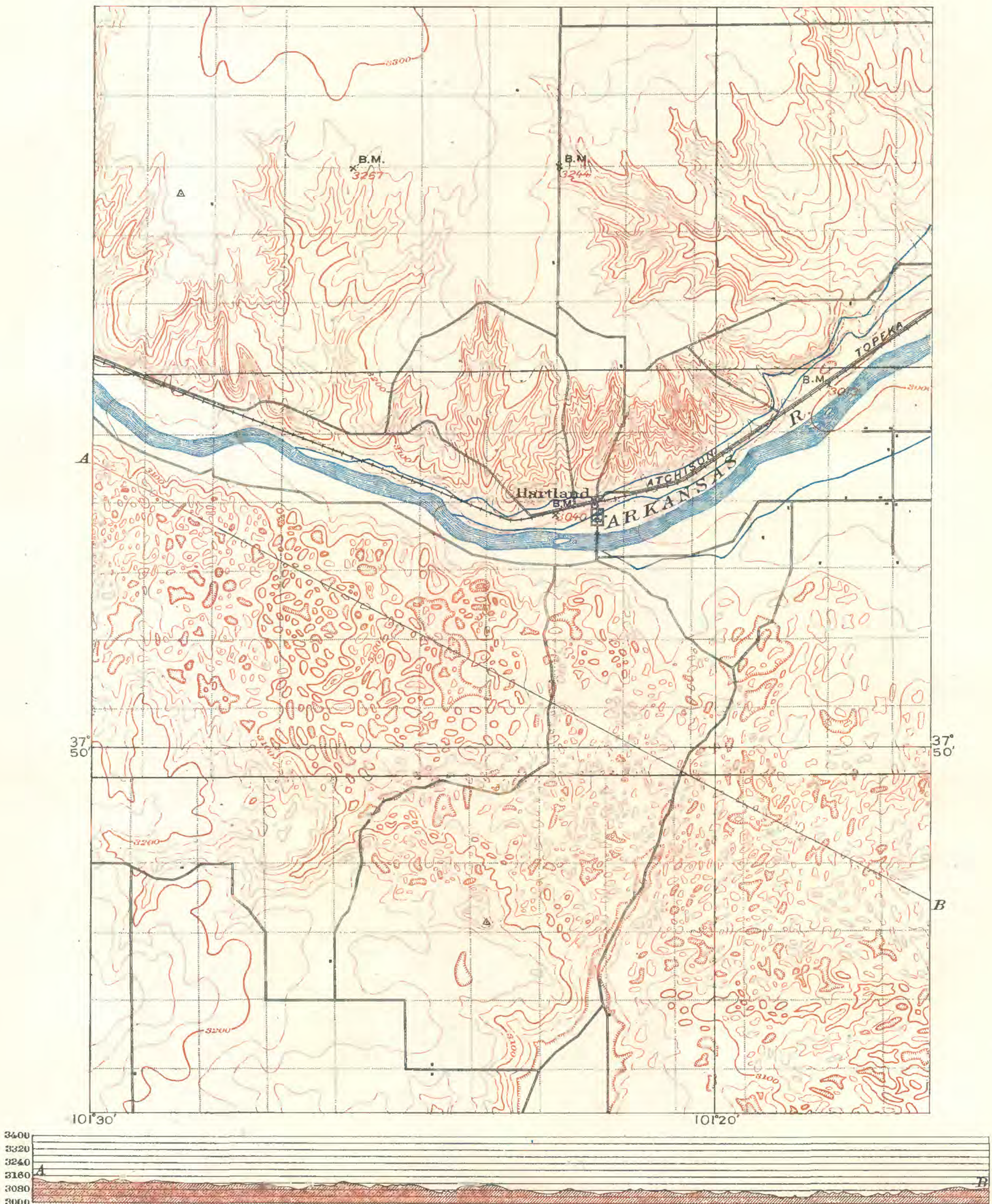

WORK OF THE WIND: PART OF LAKIN (KANS.) SHEET, WITH SECTION ON LINE A-E

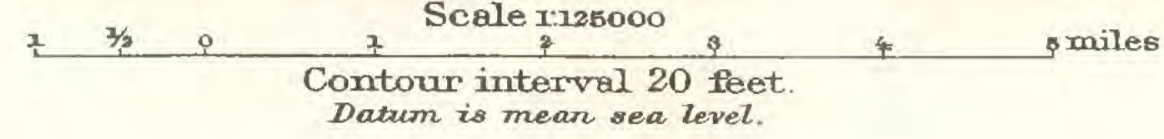




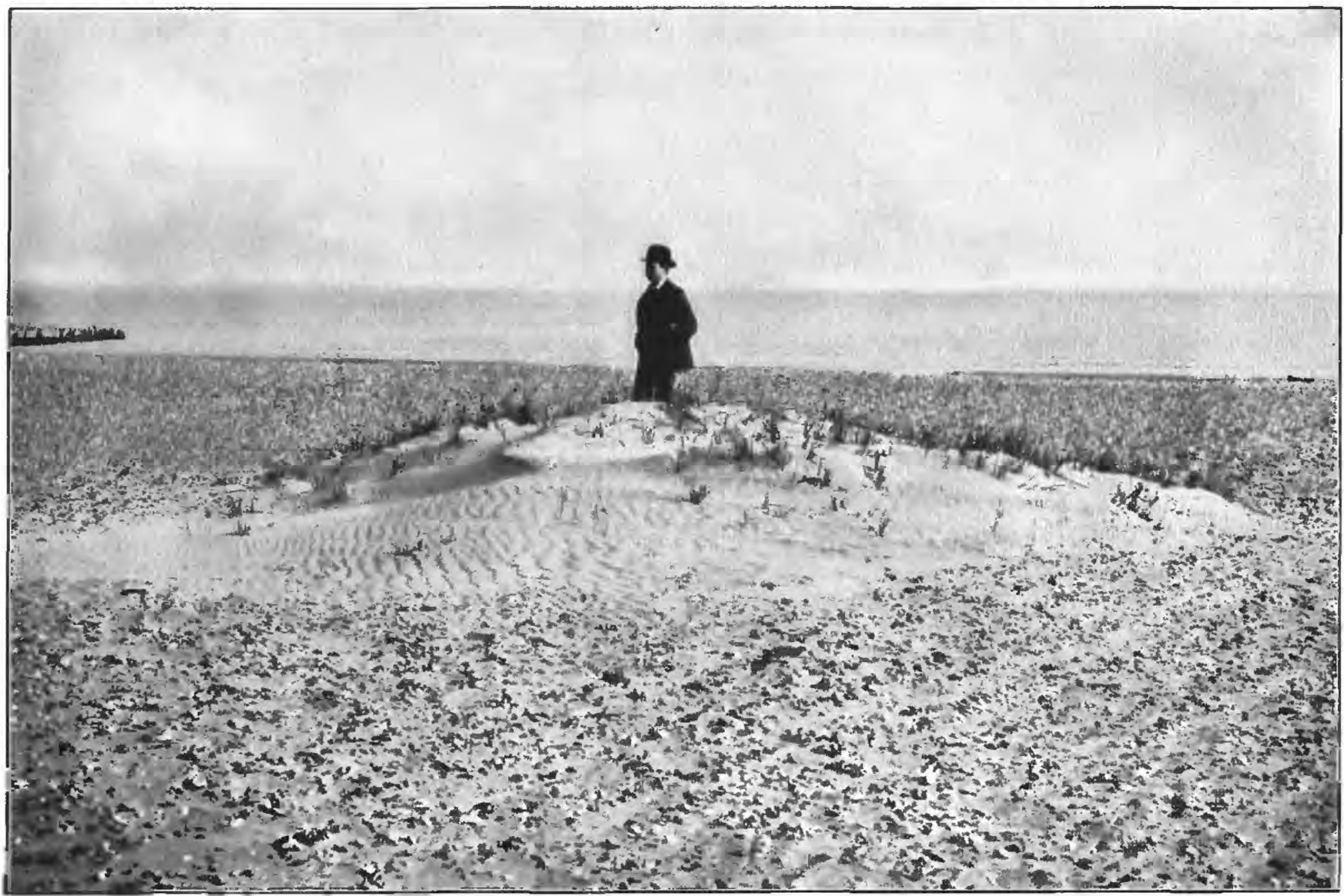

A. INCIPIENT DUNE AT SOUTH CHICAGO.

The leeward trail of sand is seen at the left and wind ripples occur in the foreground.

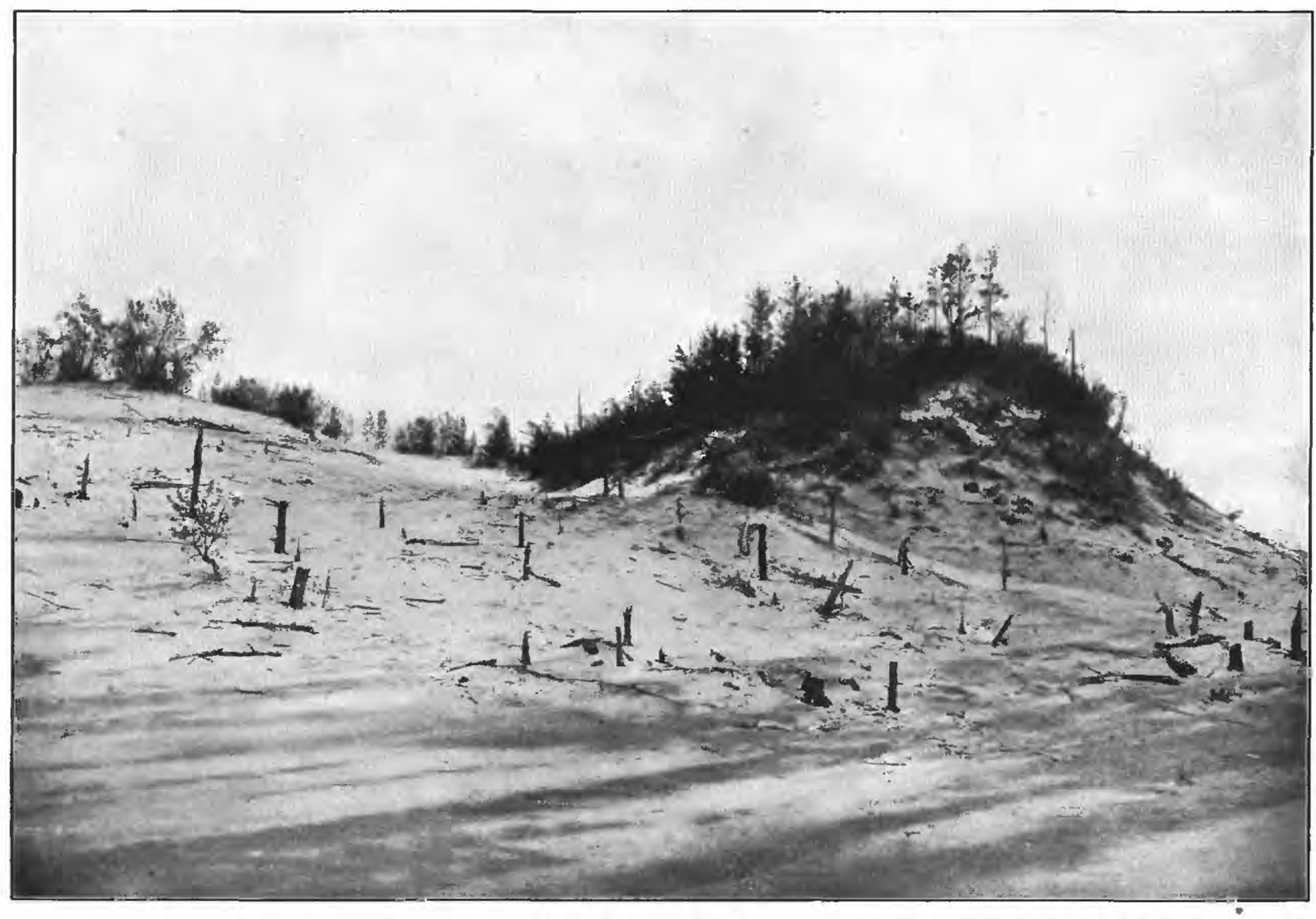

B. SURFACE OF DUNE, DUNE PARK, INDIANA, SHOWING "RESURRECTED FOREST" AND DESTRUCTION OF THE REFORESTED GROWTH BY THE MOVING SAND. 


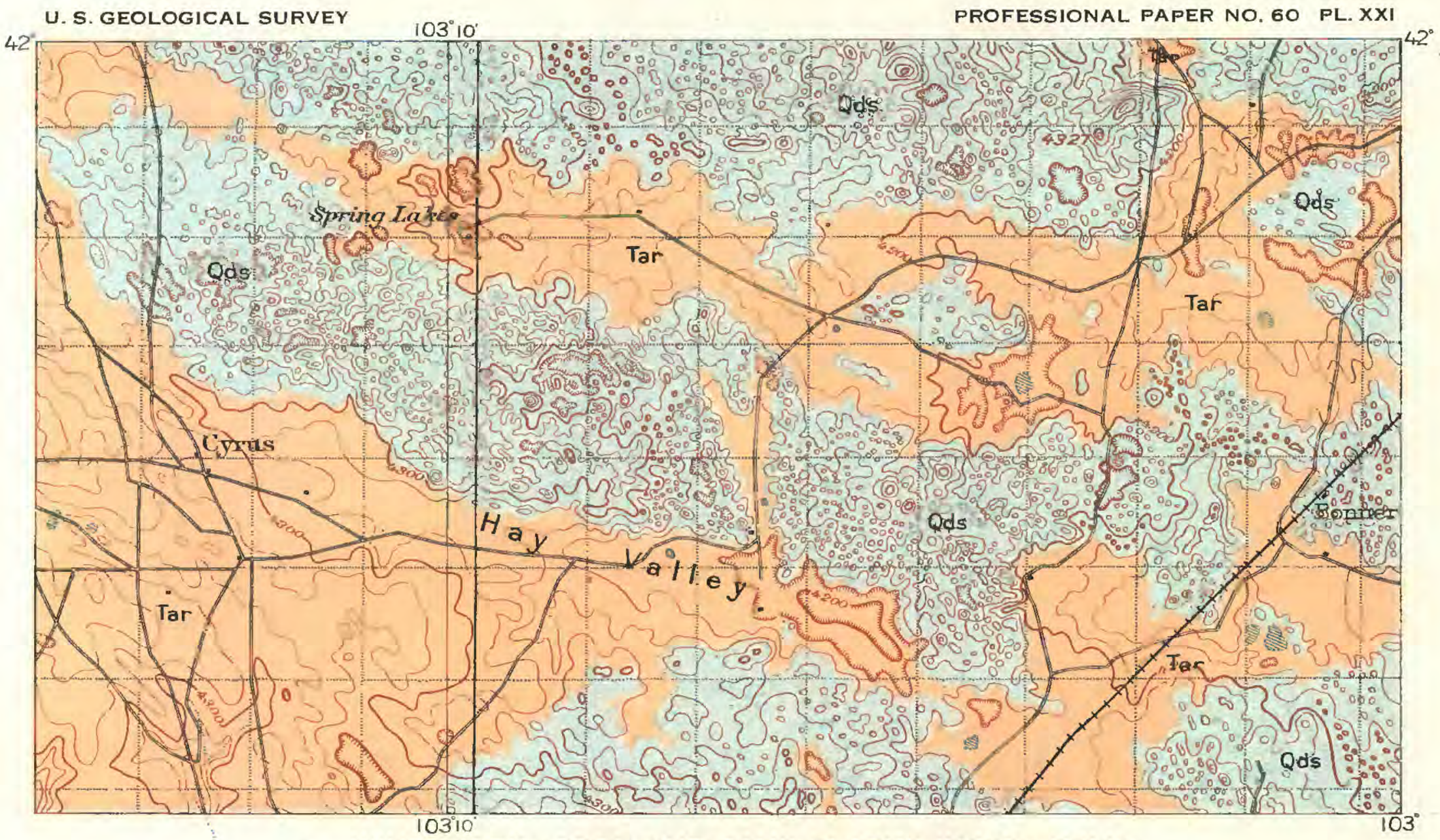

A WIND WORK: FROM THE CAMP CLARKE (NEBR.) FOLIO
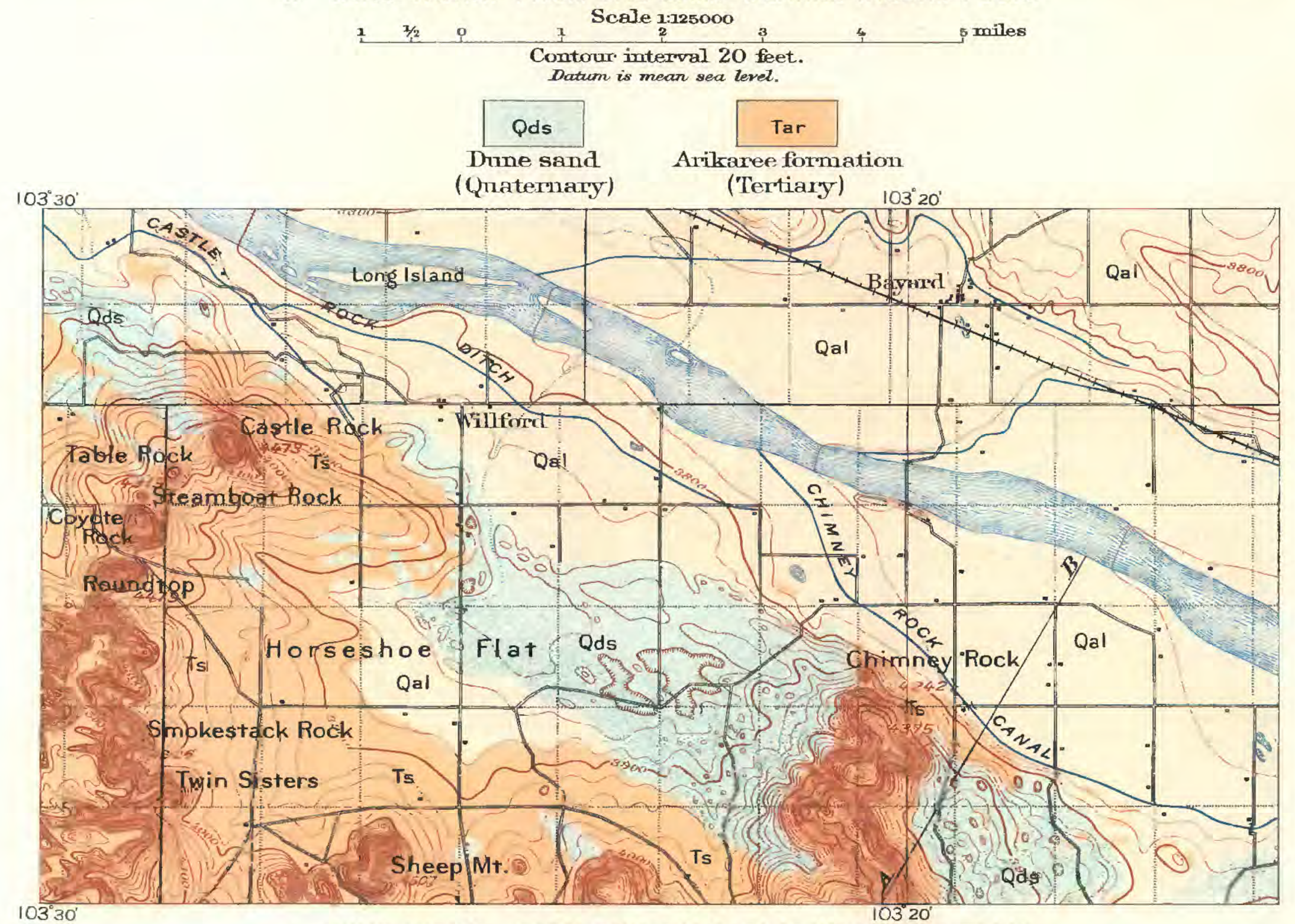

B. WIND WORK: FROM THE CAMP CLARKE (NEBR.) FOLIO

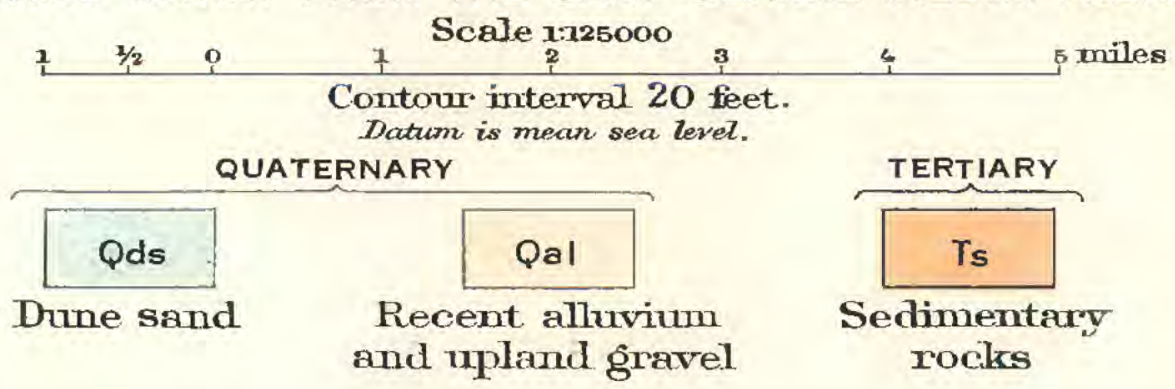




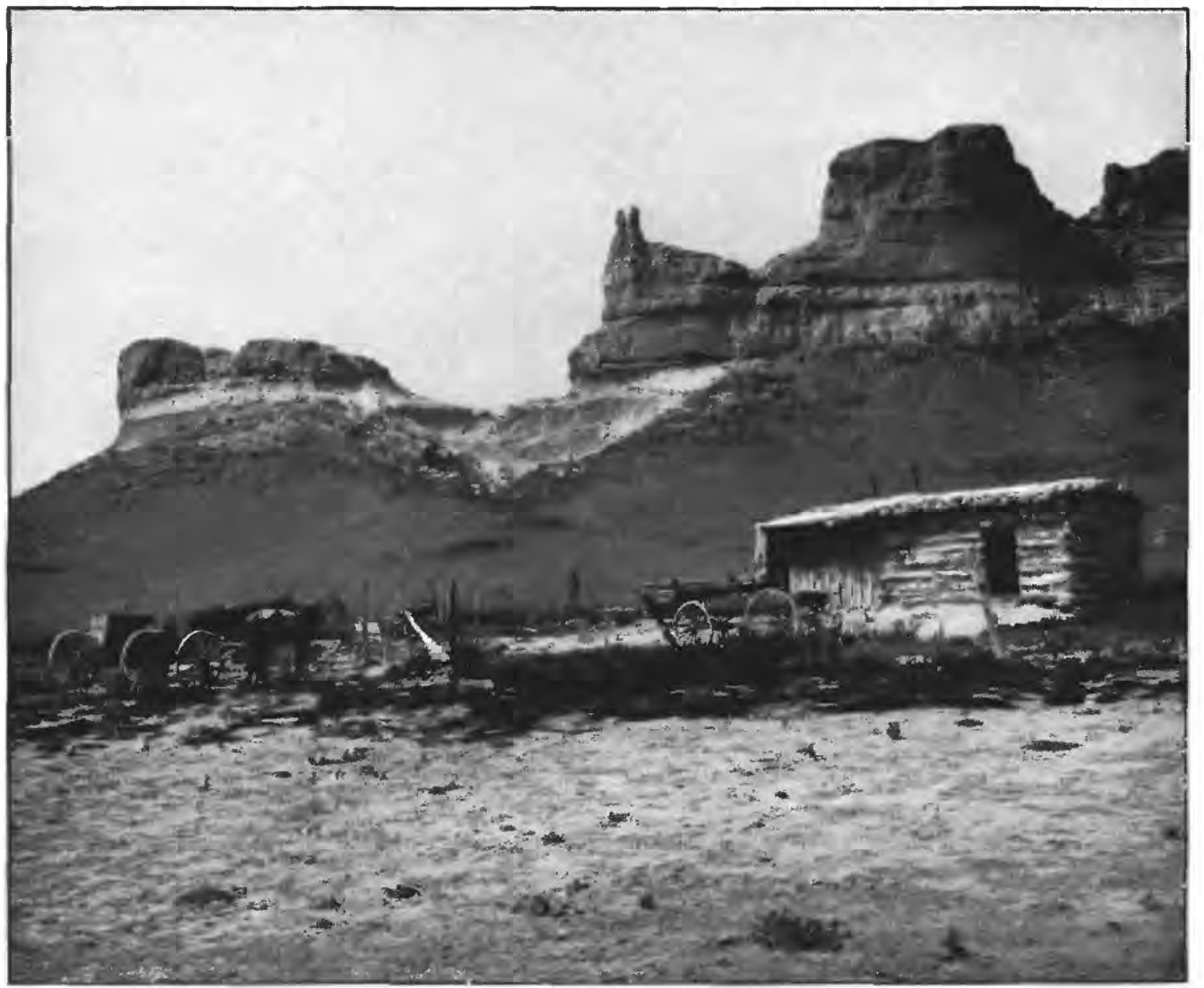

A. TWIN SISTERS, NEBRASKA.

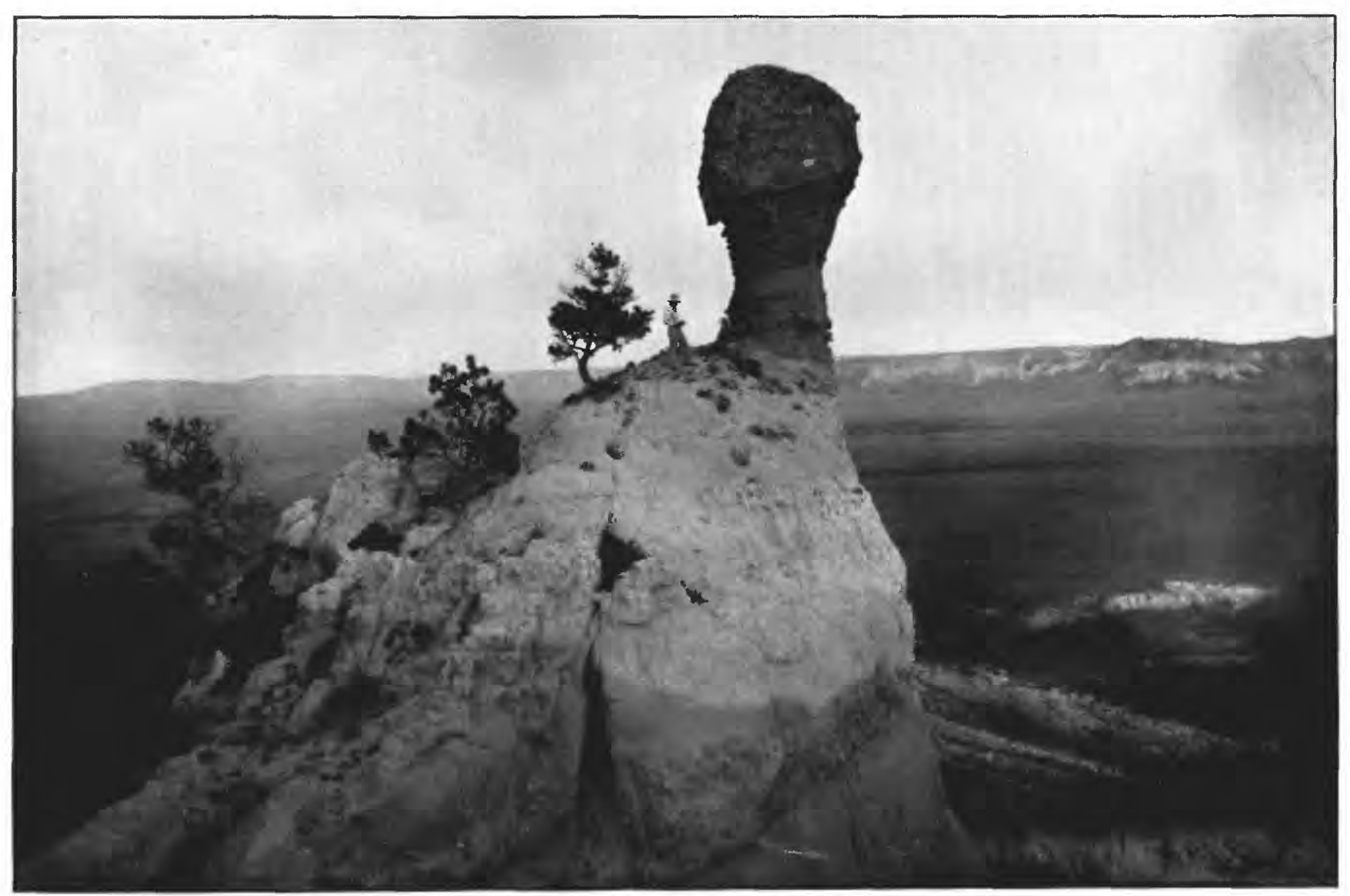

B. SMOKESTACK ROCK, NEBRASKA. 


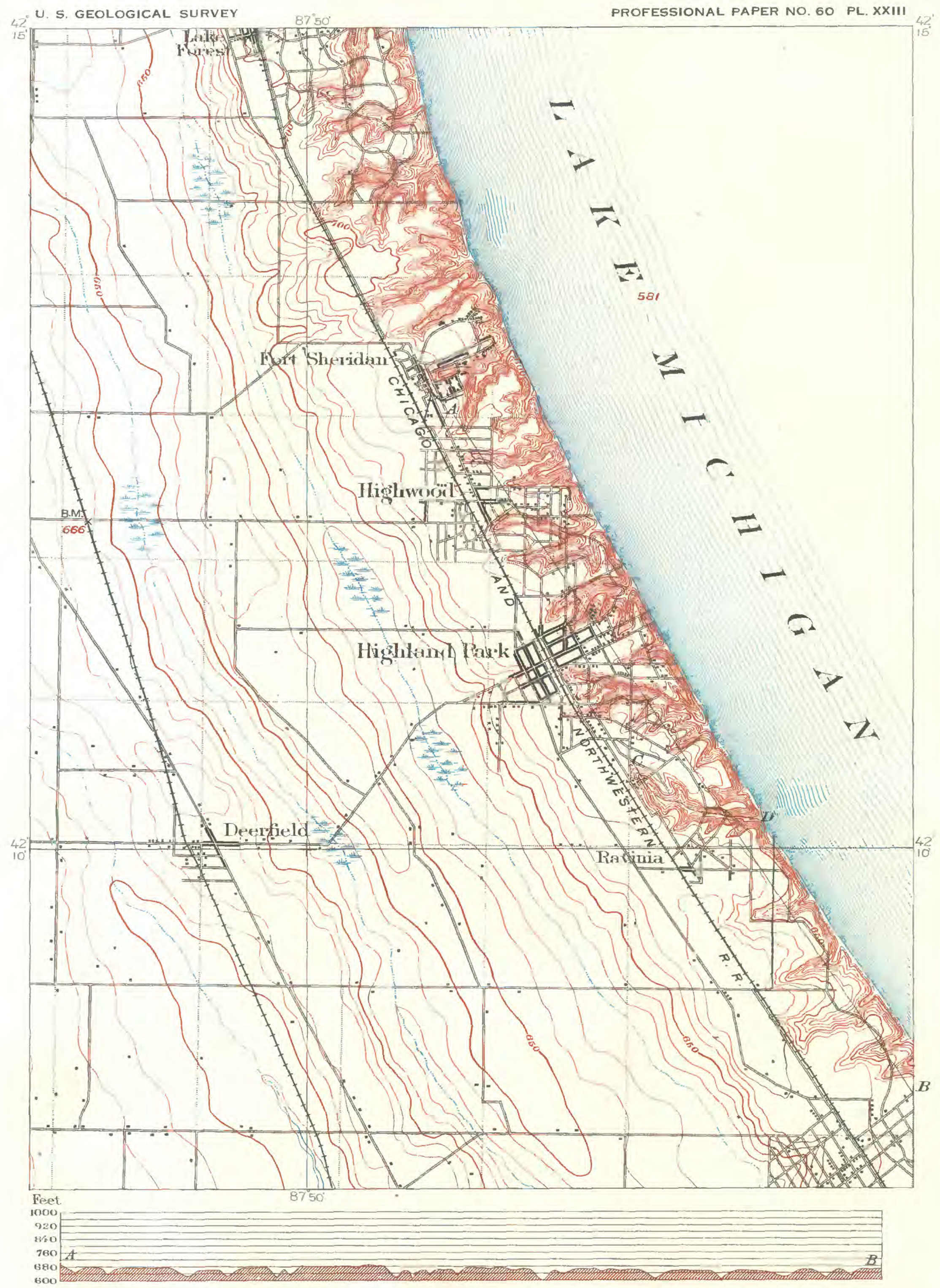

STREAM EROSION-YOUTH: PART OF HIGHWOOD IILL.) SHEET, WITH SECTION ON LINE A-B

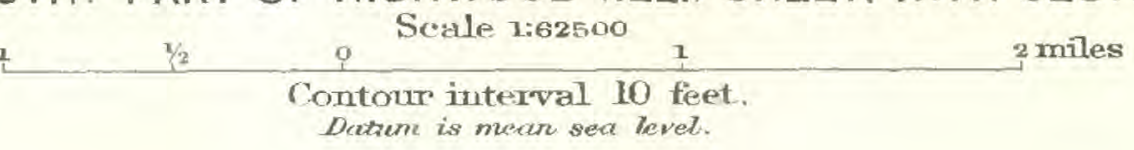




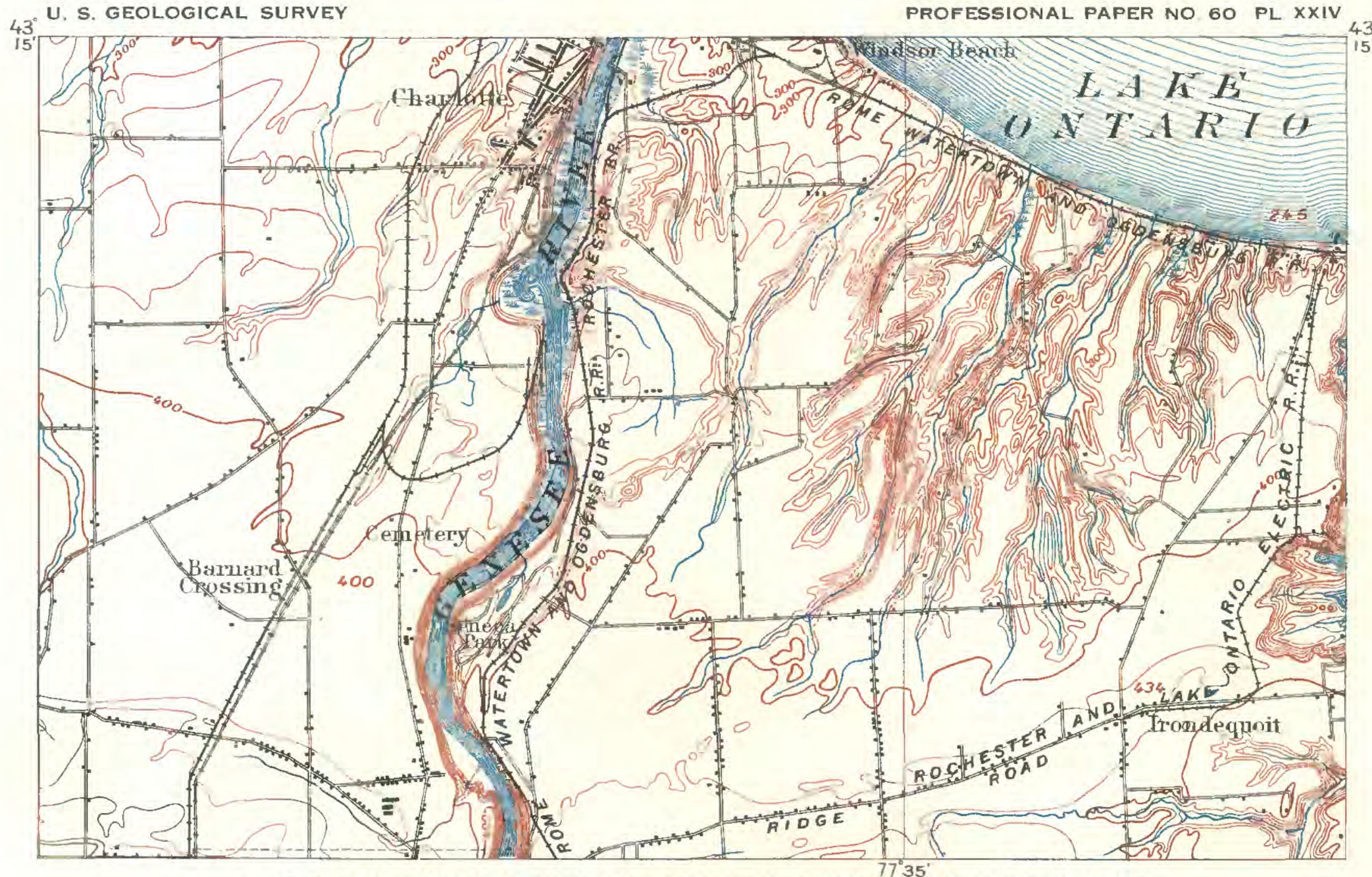

A. STREAM EROSION-YOUTH: PART OF ROCHESTER (N. Y.) SHEET
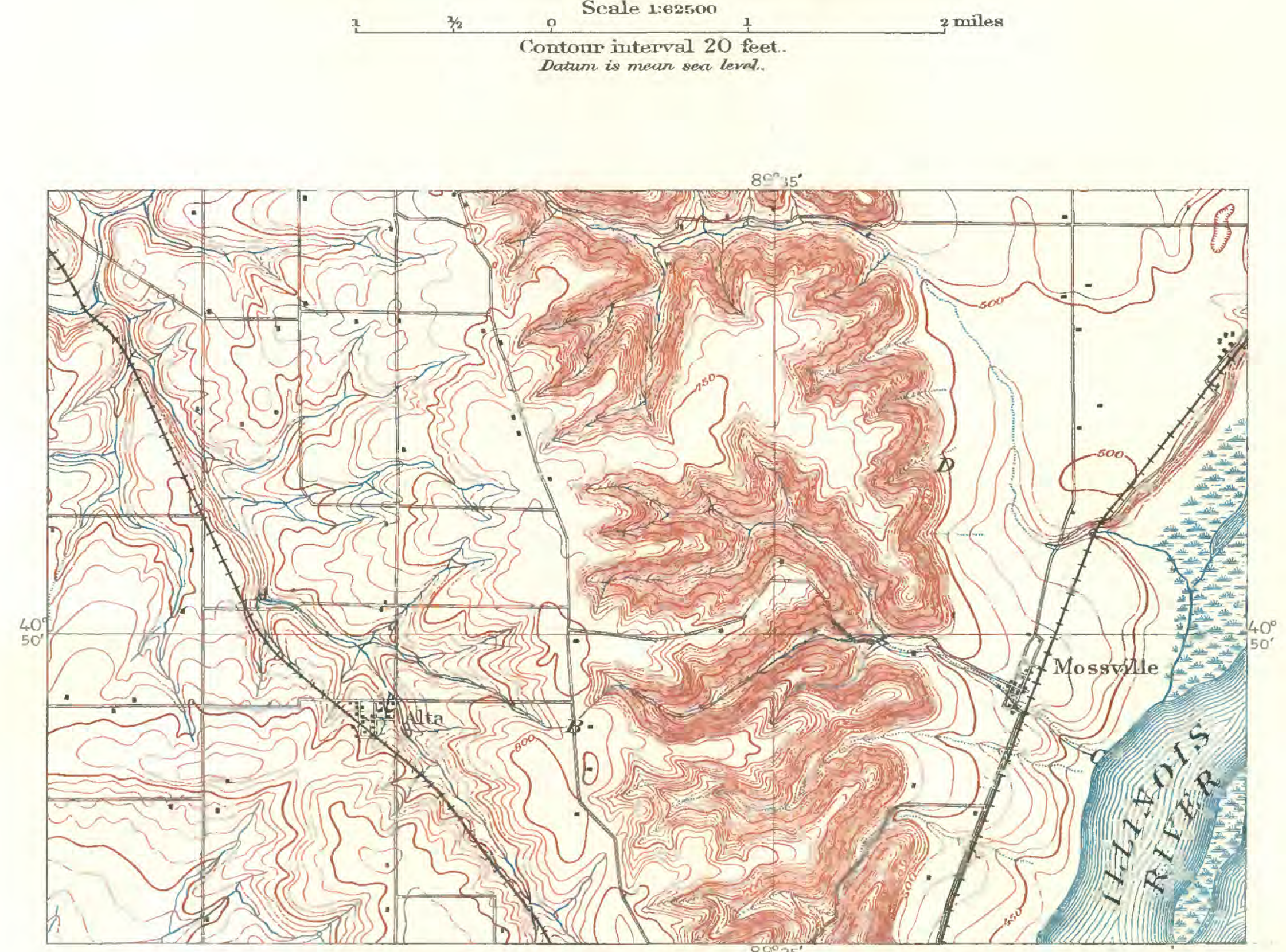

B. STREAM EROSION-YOUTH: PART OF DUNLAP (ILL.) SHEET

$$
\text { Contour interval. } 10 \text { feet }
$$
2 miles 


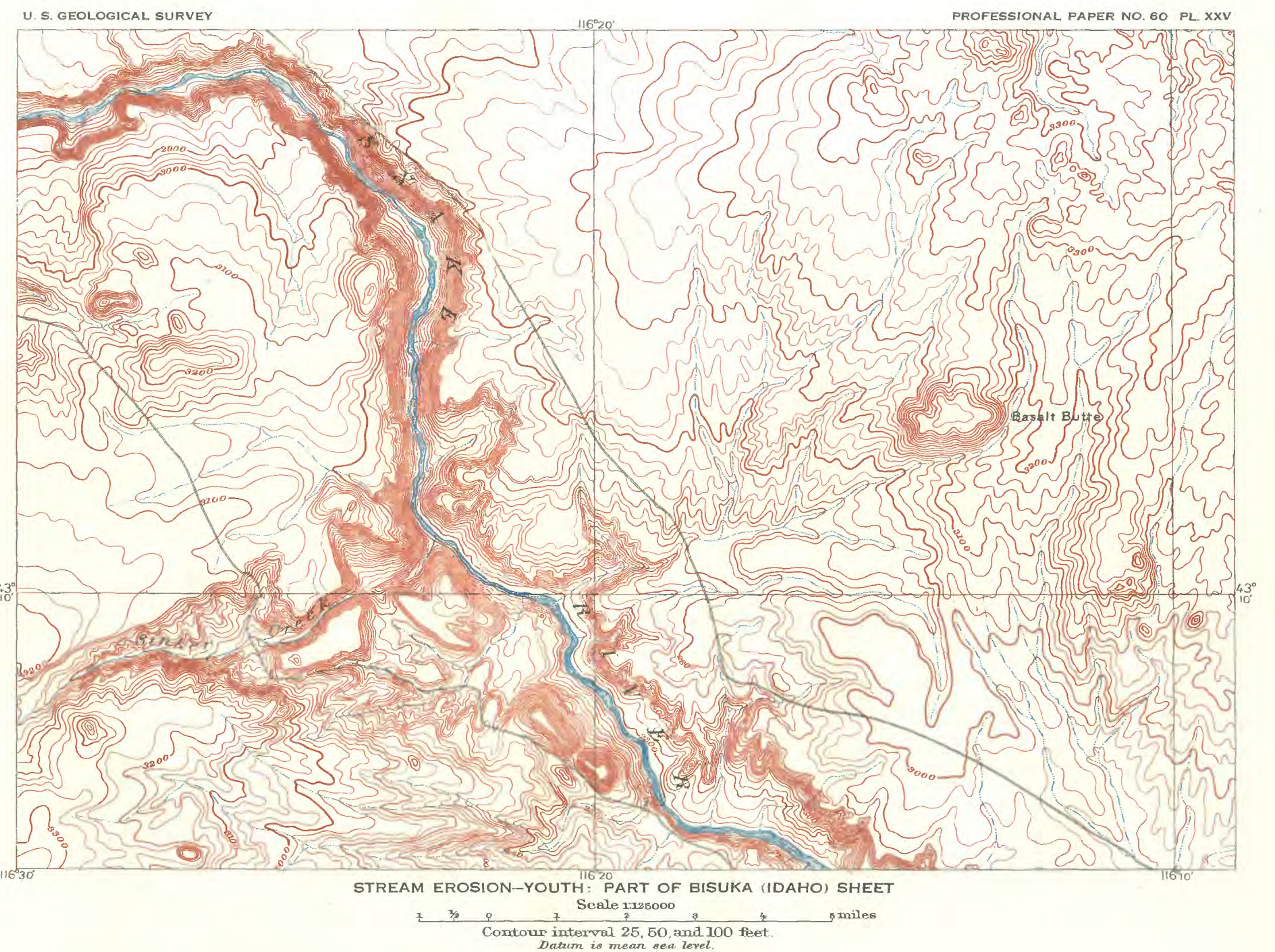


U. S. GEOLOGICAL SURVEY

PROFESSIONAL PAPER NO. 60 PL. XXVI

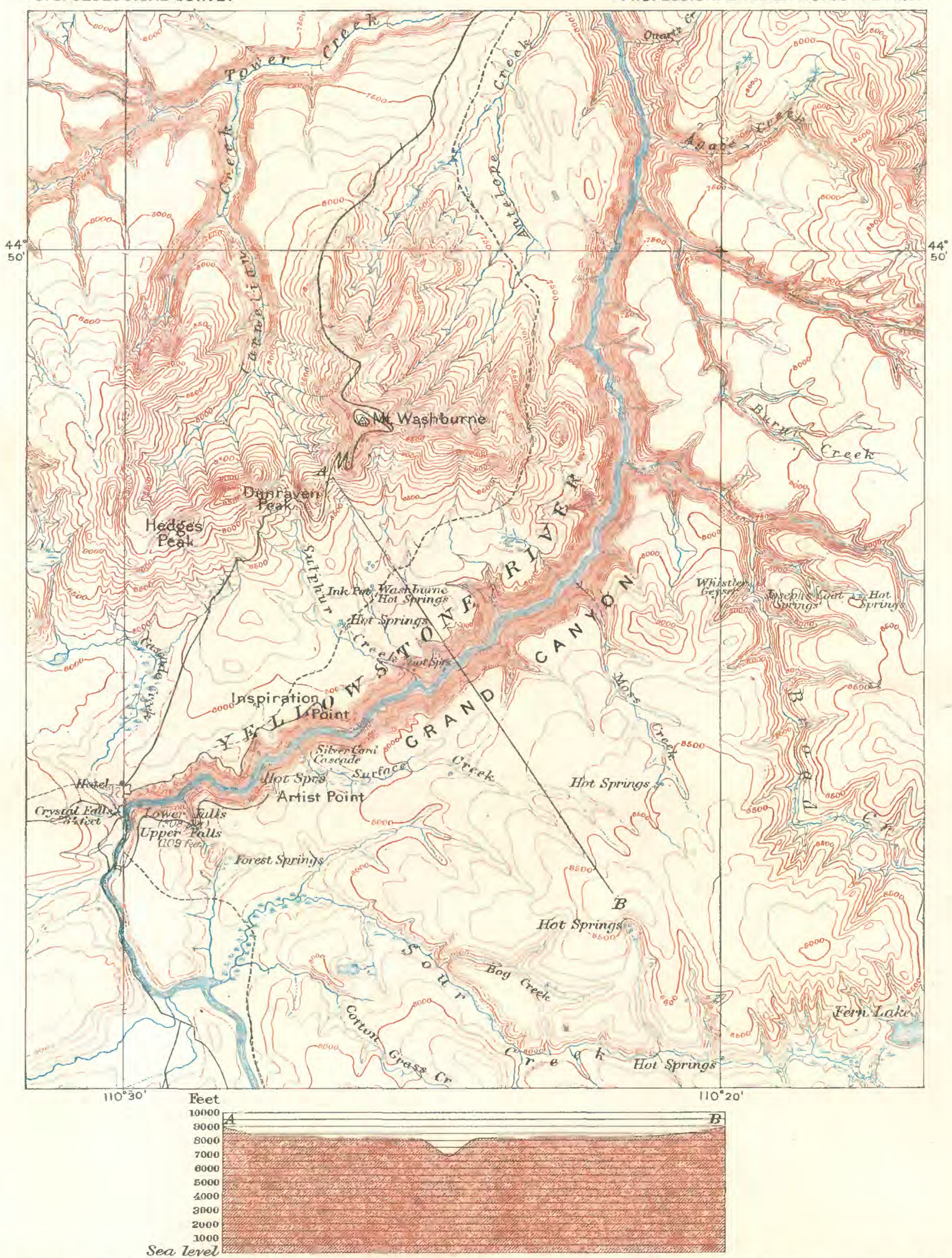

STREAM EROSION-YOUTH: PARTS OF GALLATIN AND CANYON SHEETS, YELLOWSTONE NATIONAL PARK, WITH SECTION ON LINE A-B

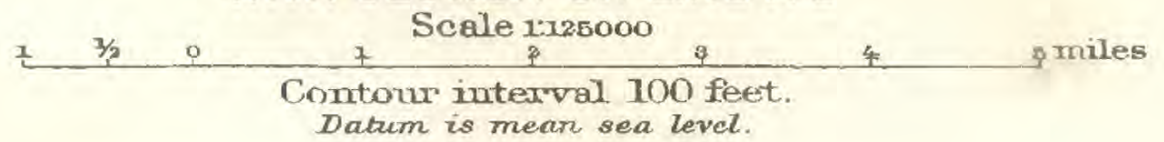




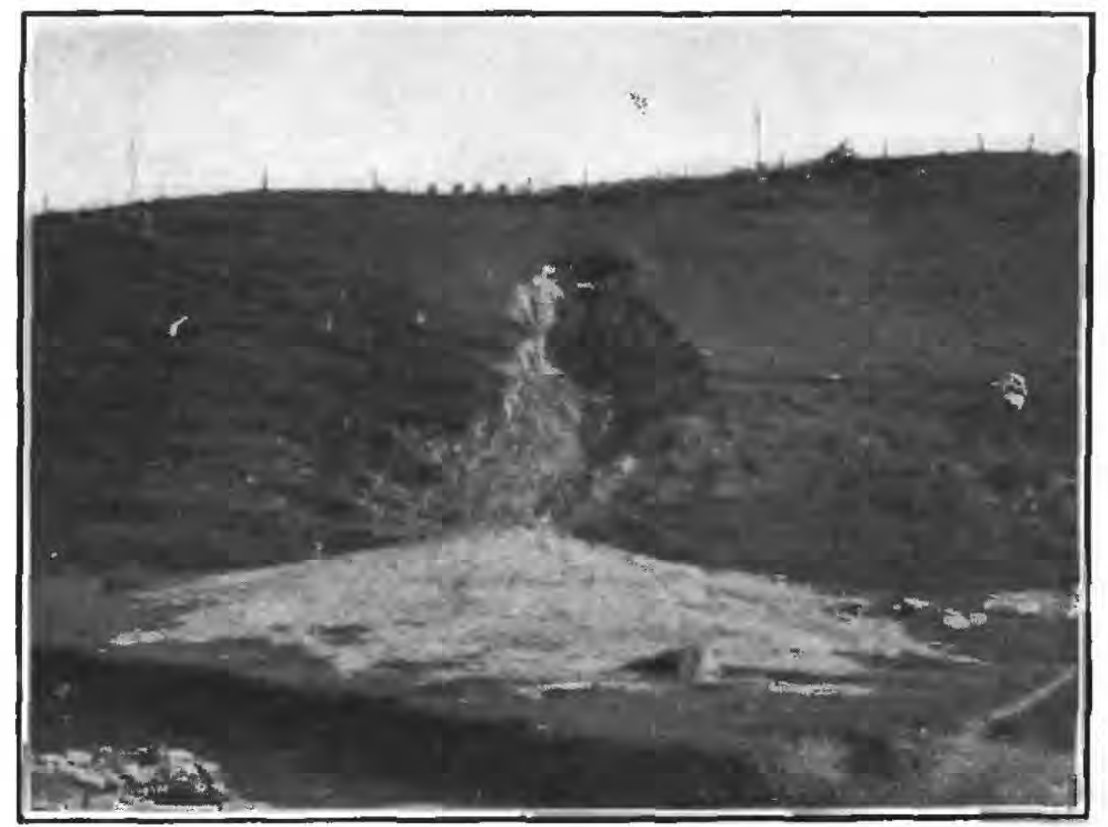

A. VIEW OF YOUNG VALLEY.

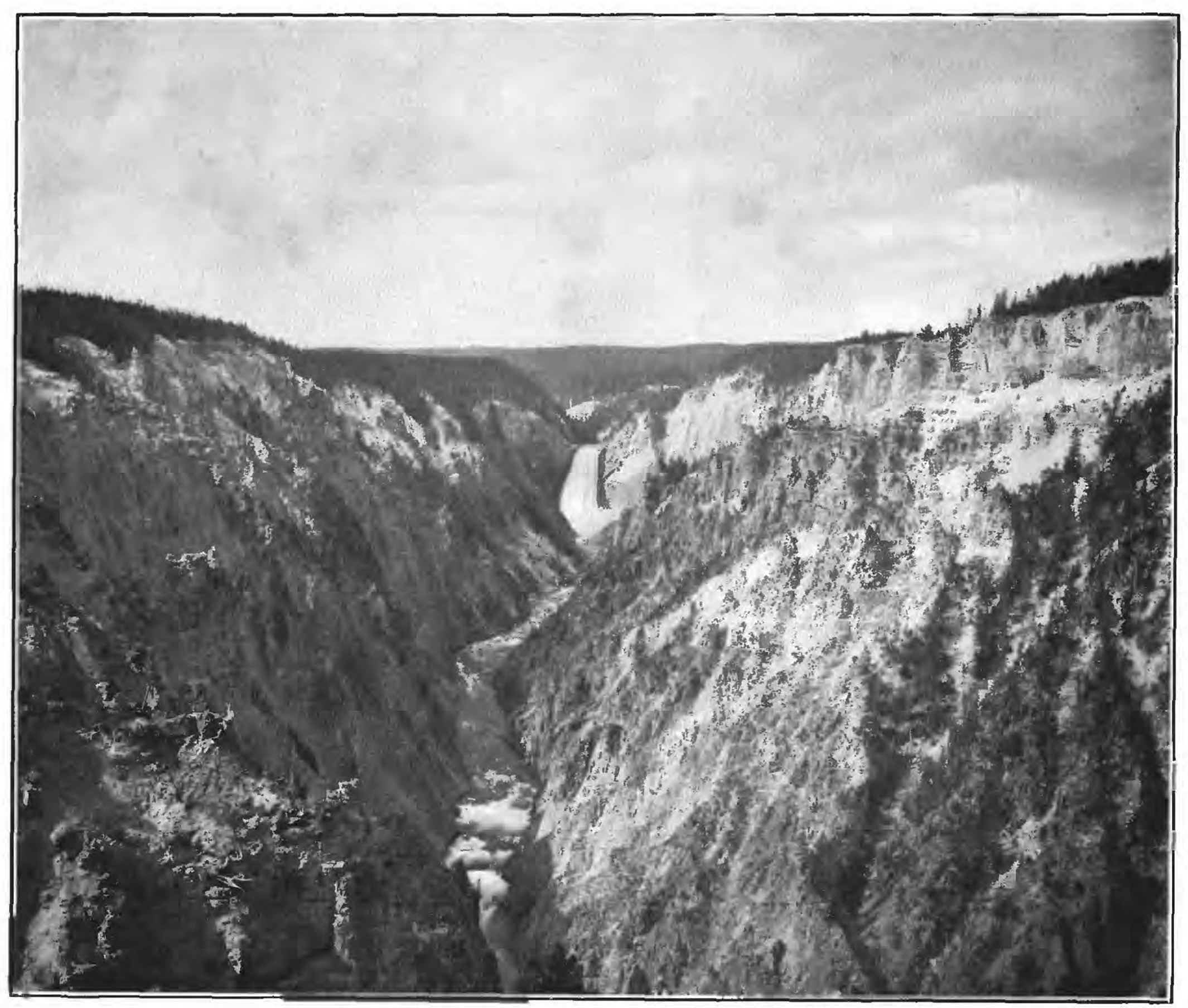

B. LOWER FALLS OF THE YELLOWSTONE. 

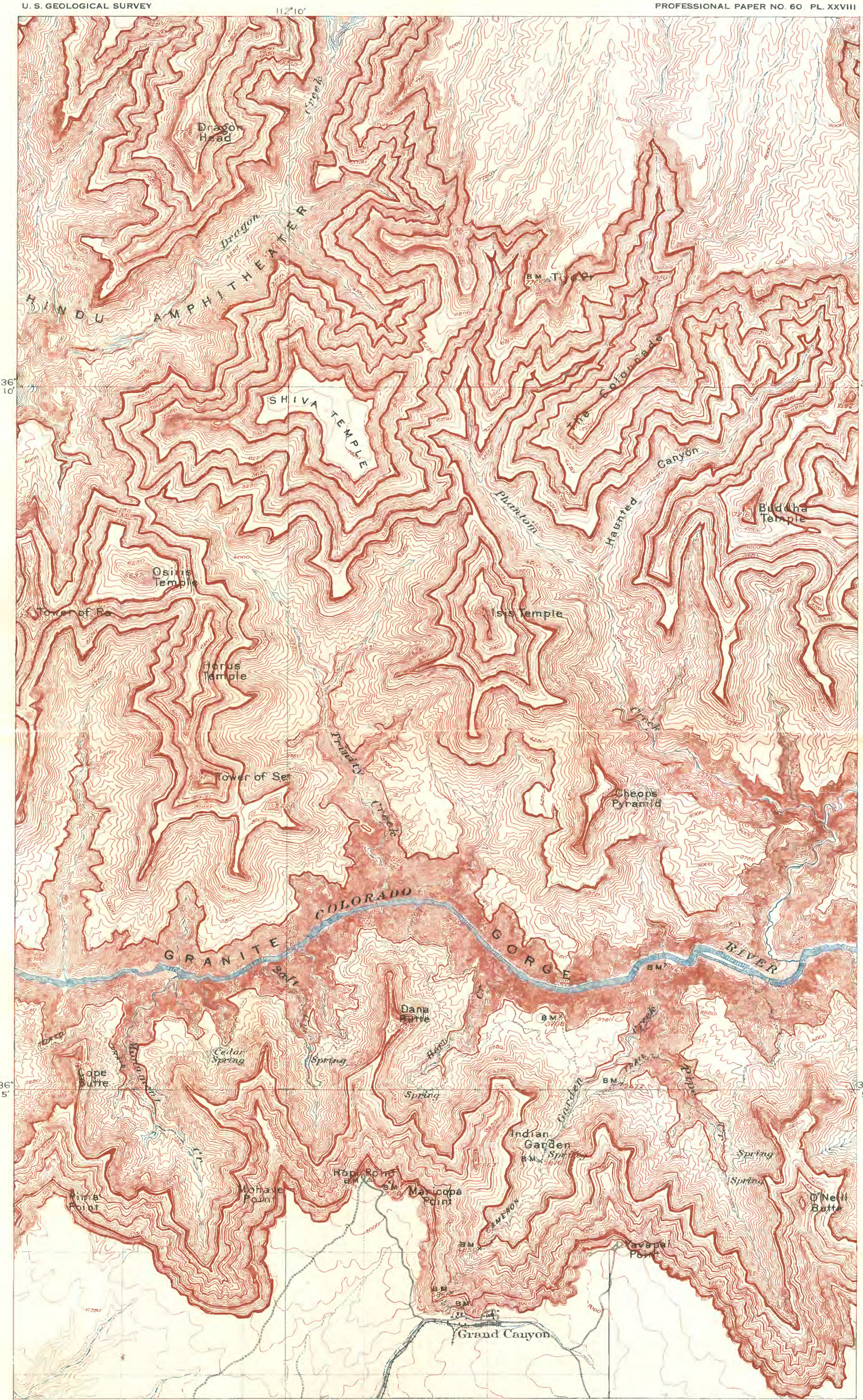


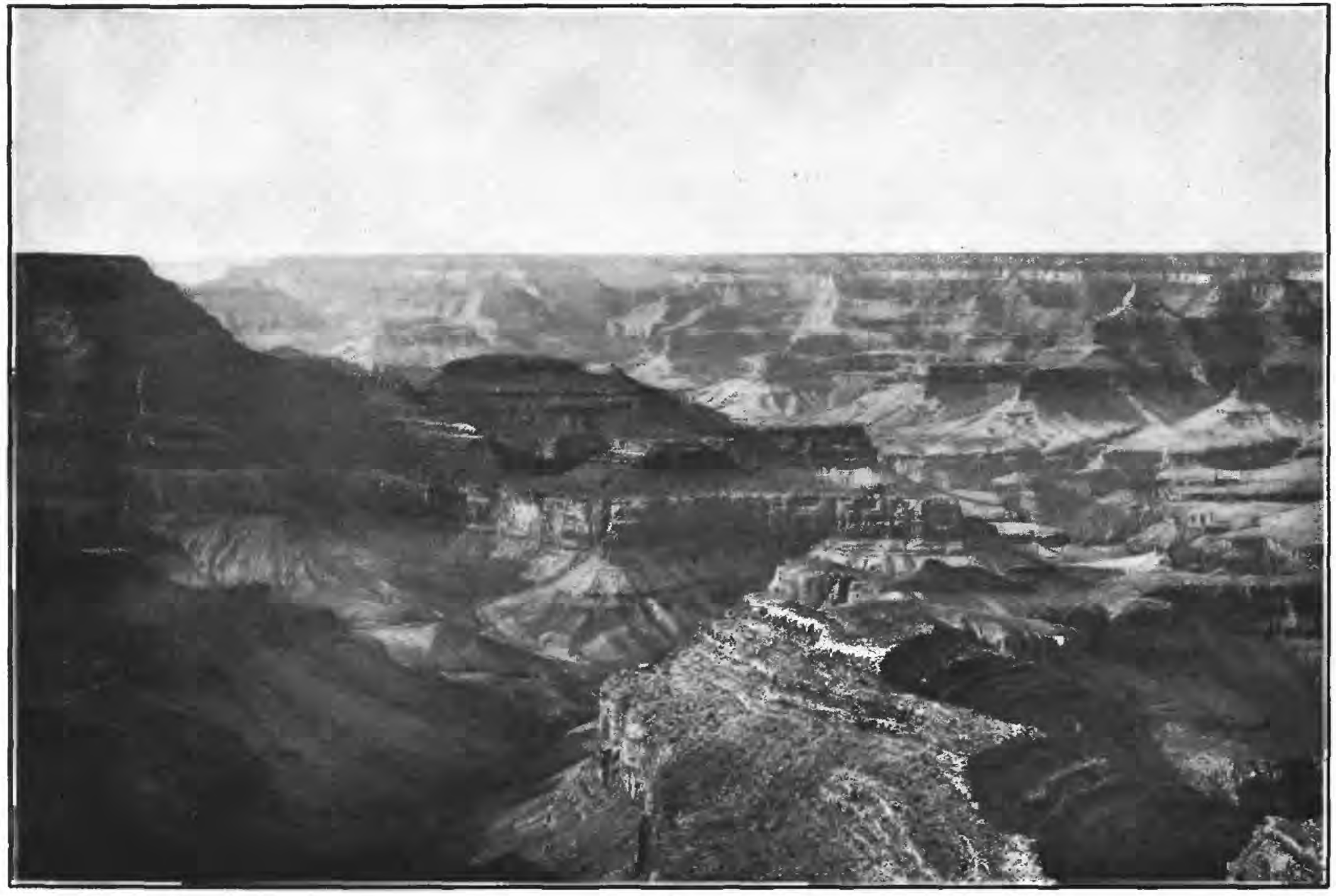

A.

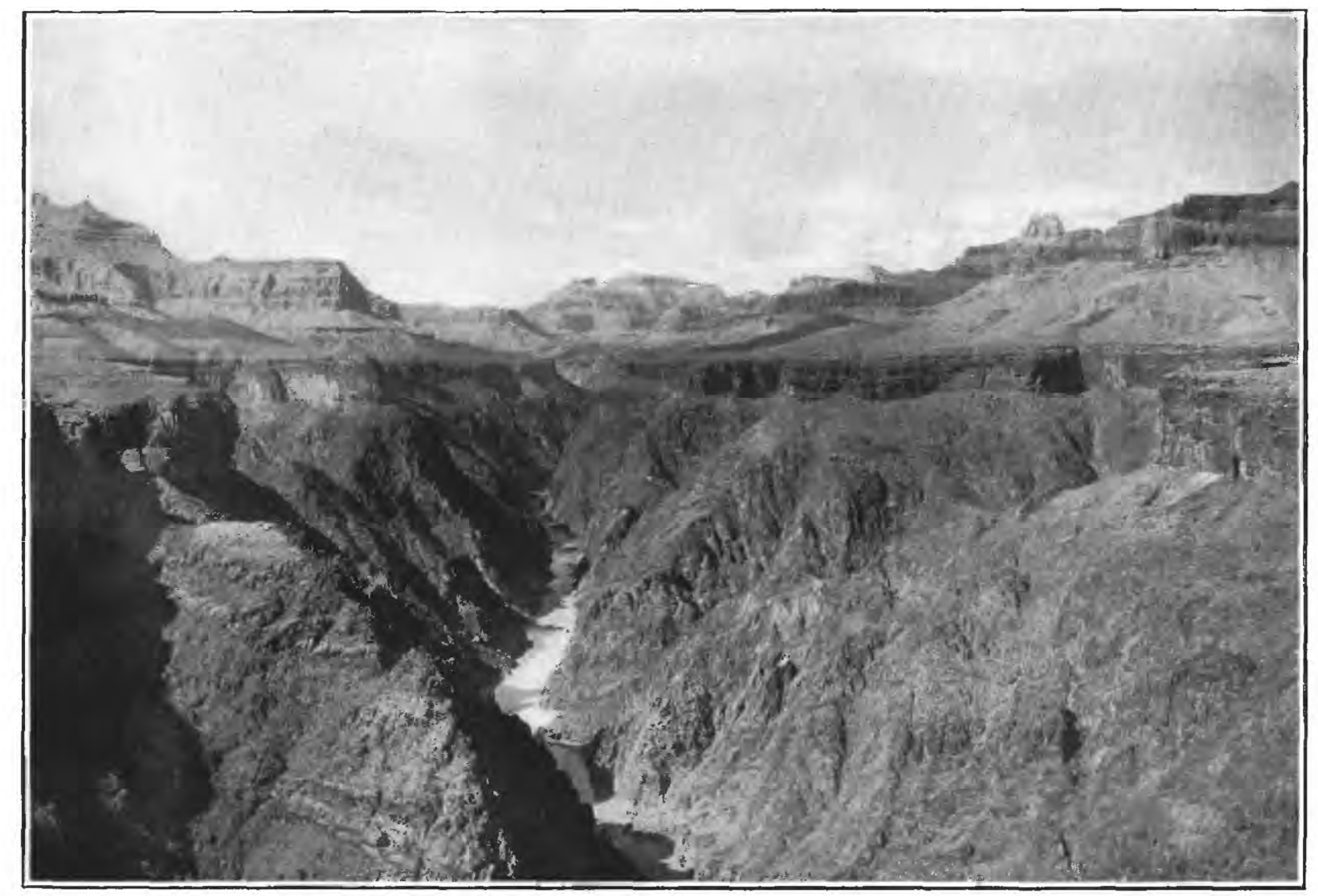

$B$.

VIEWS OF GRAND CANYON OF THE COLORADO. 


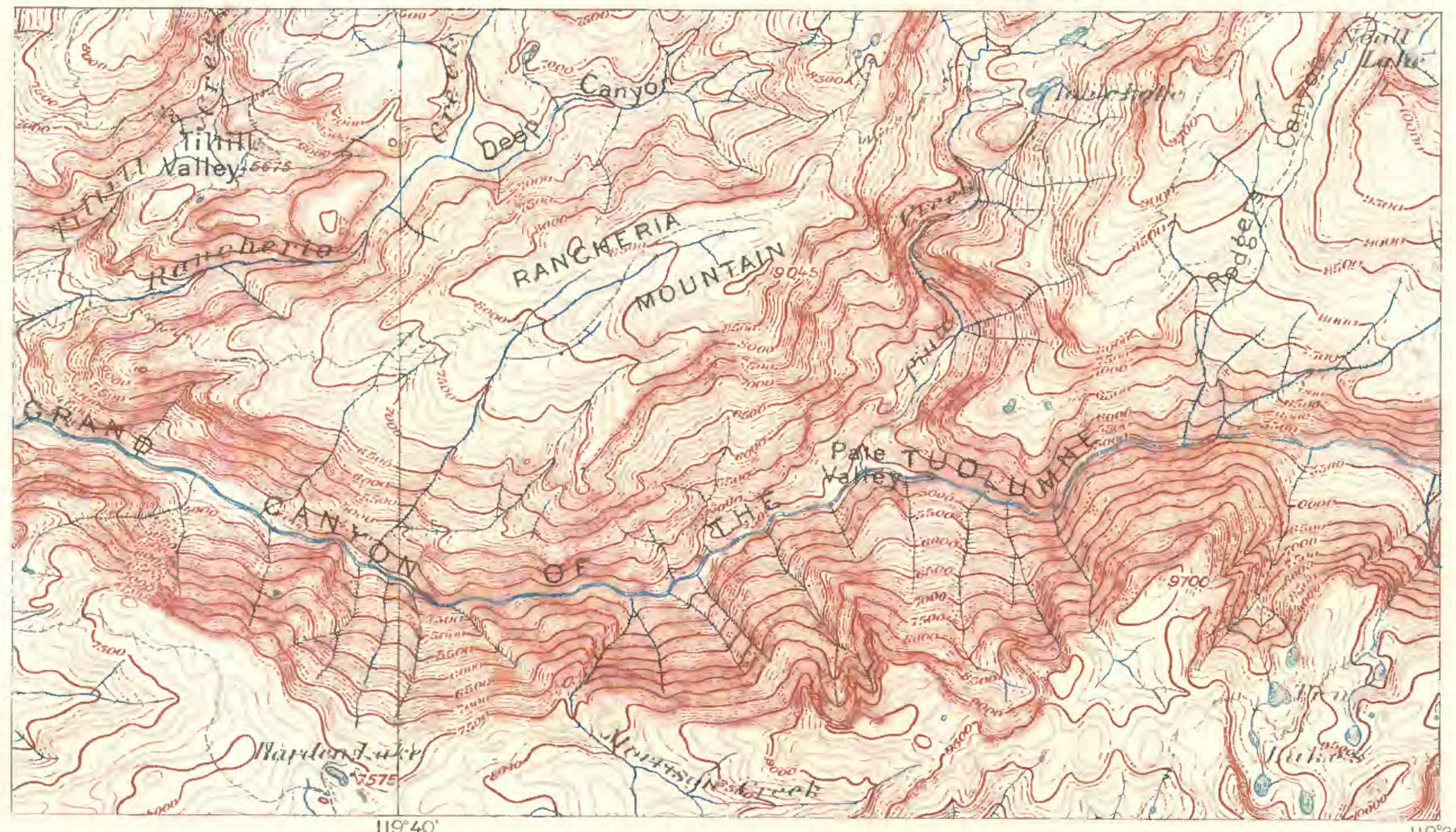

A. STREAM EROSION: PART OF YOSEMITE (CAL.) SHEET

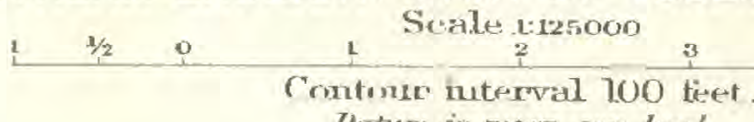

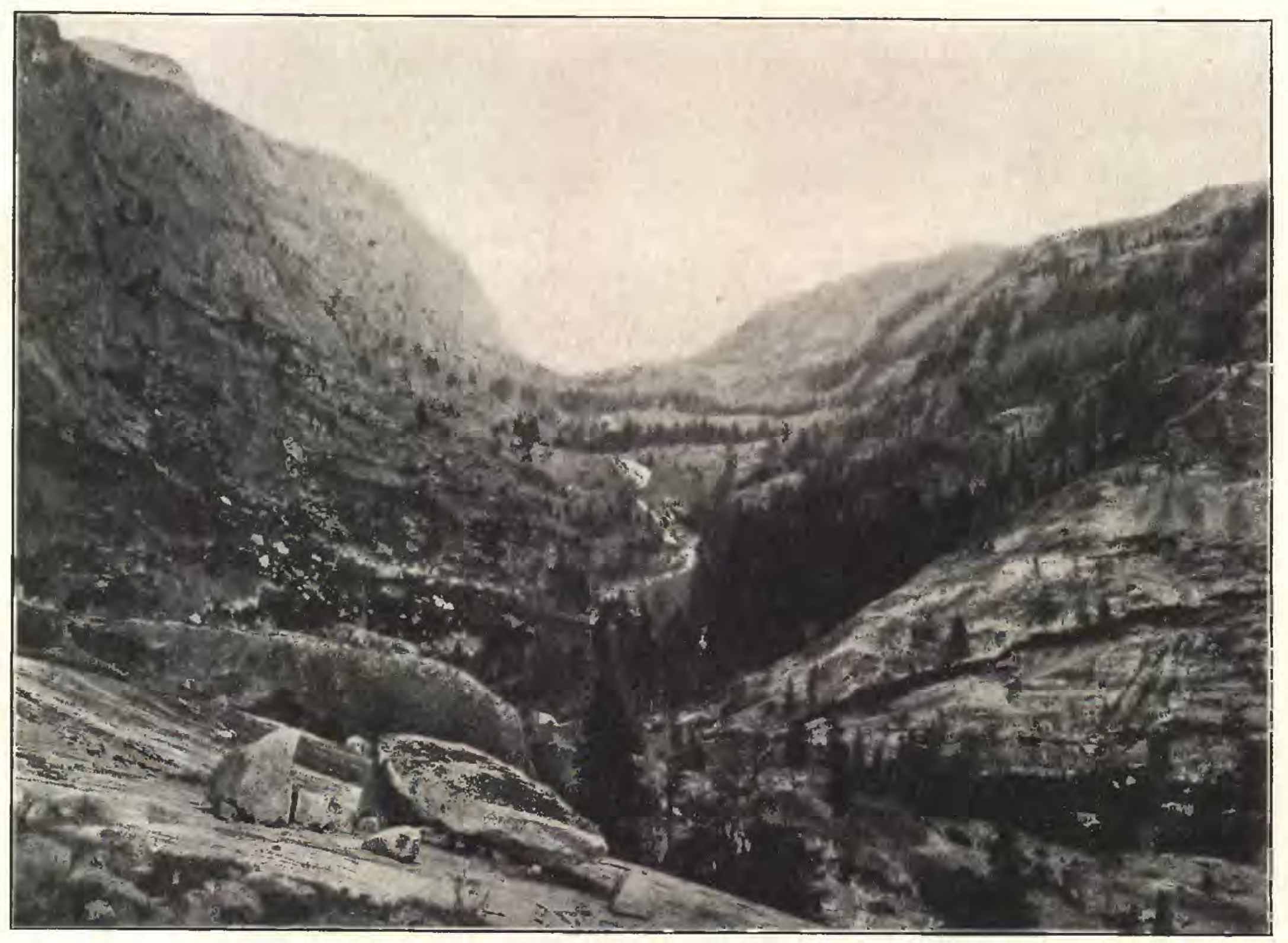

B. STREAM EROSION: UPPER TUOLUMNE CANYÓN, CAL. 


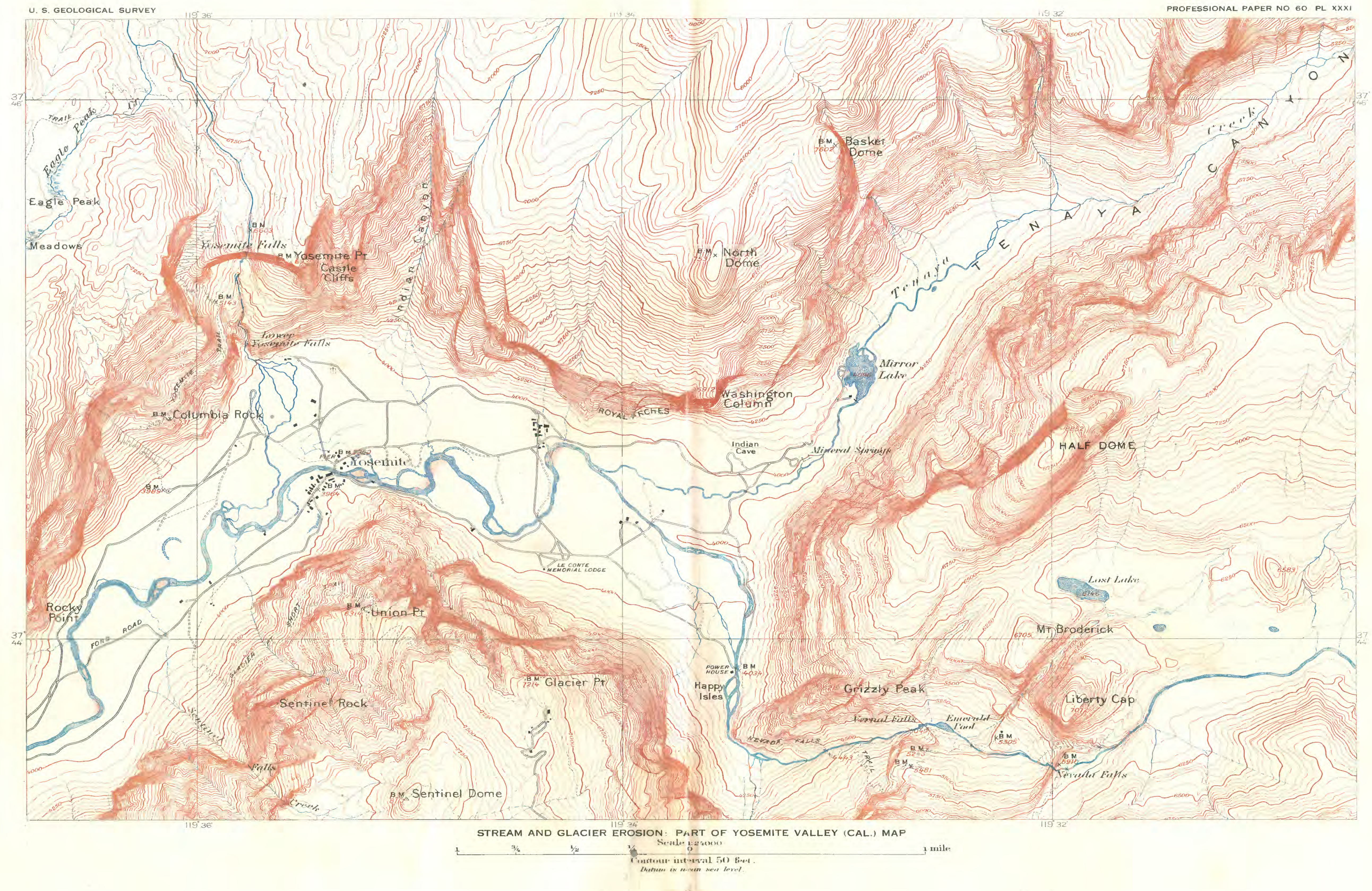




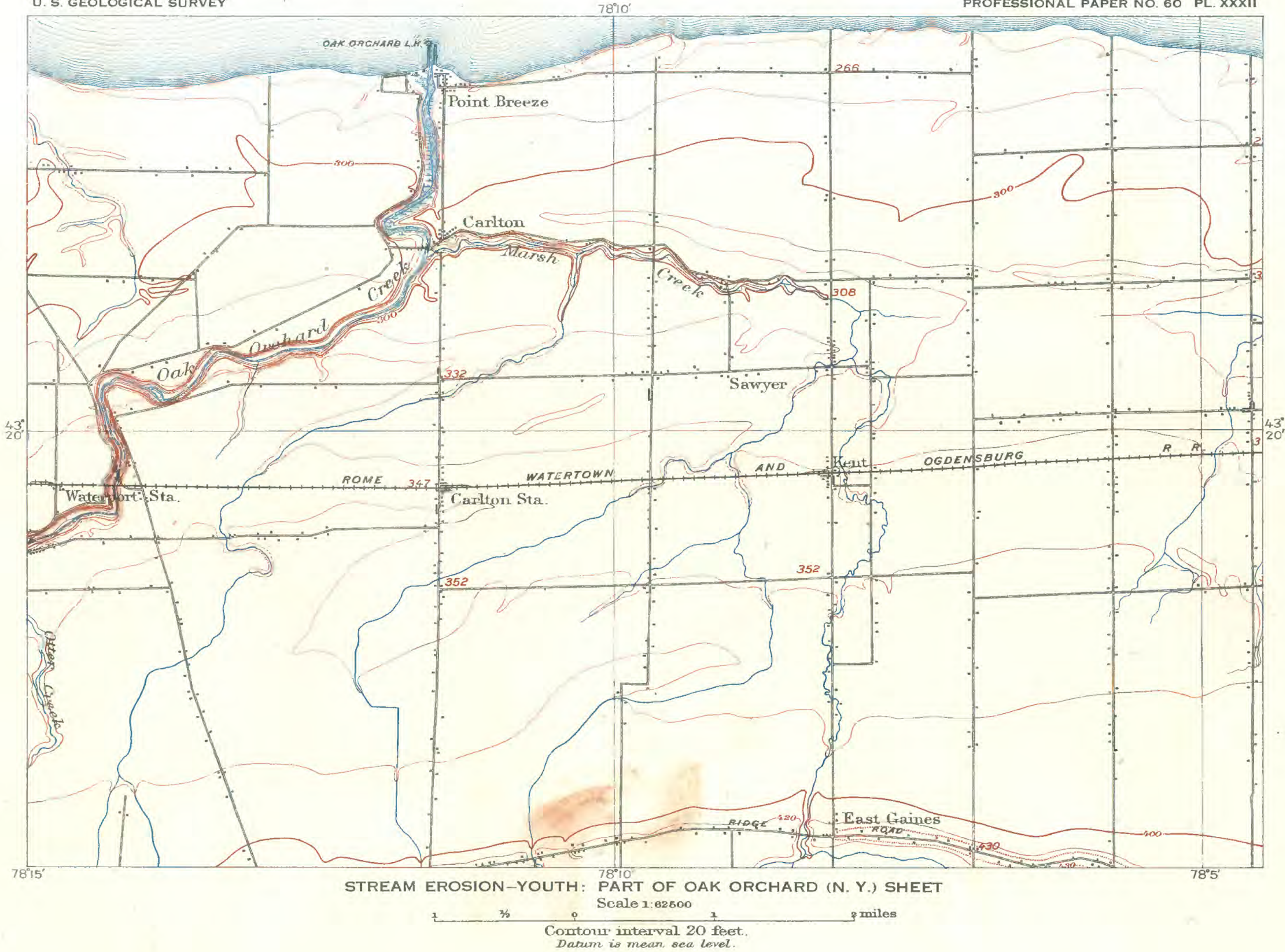




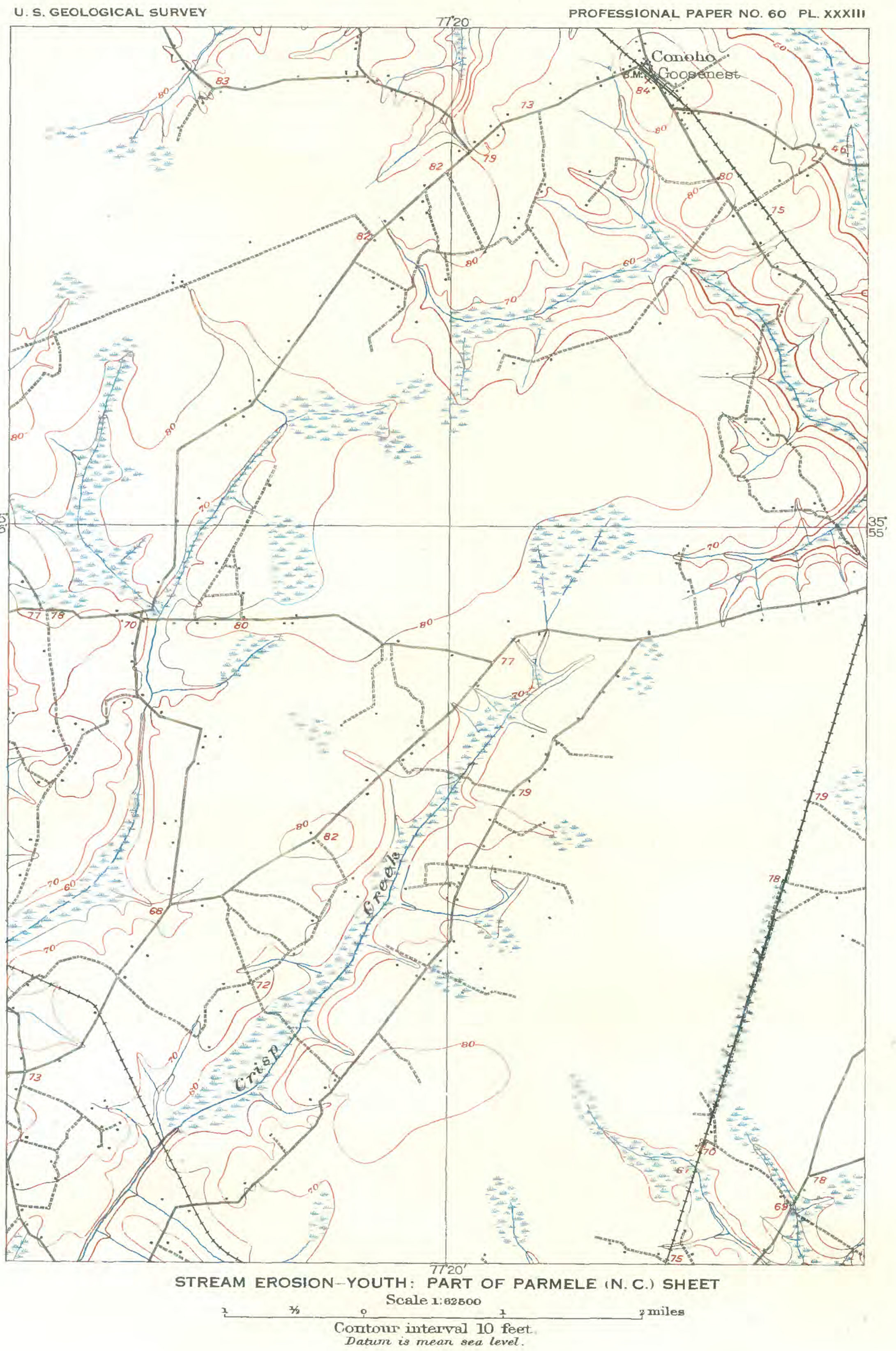




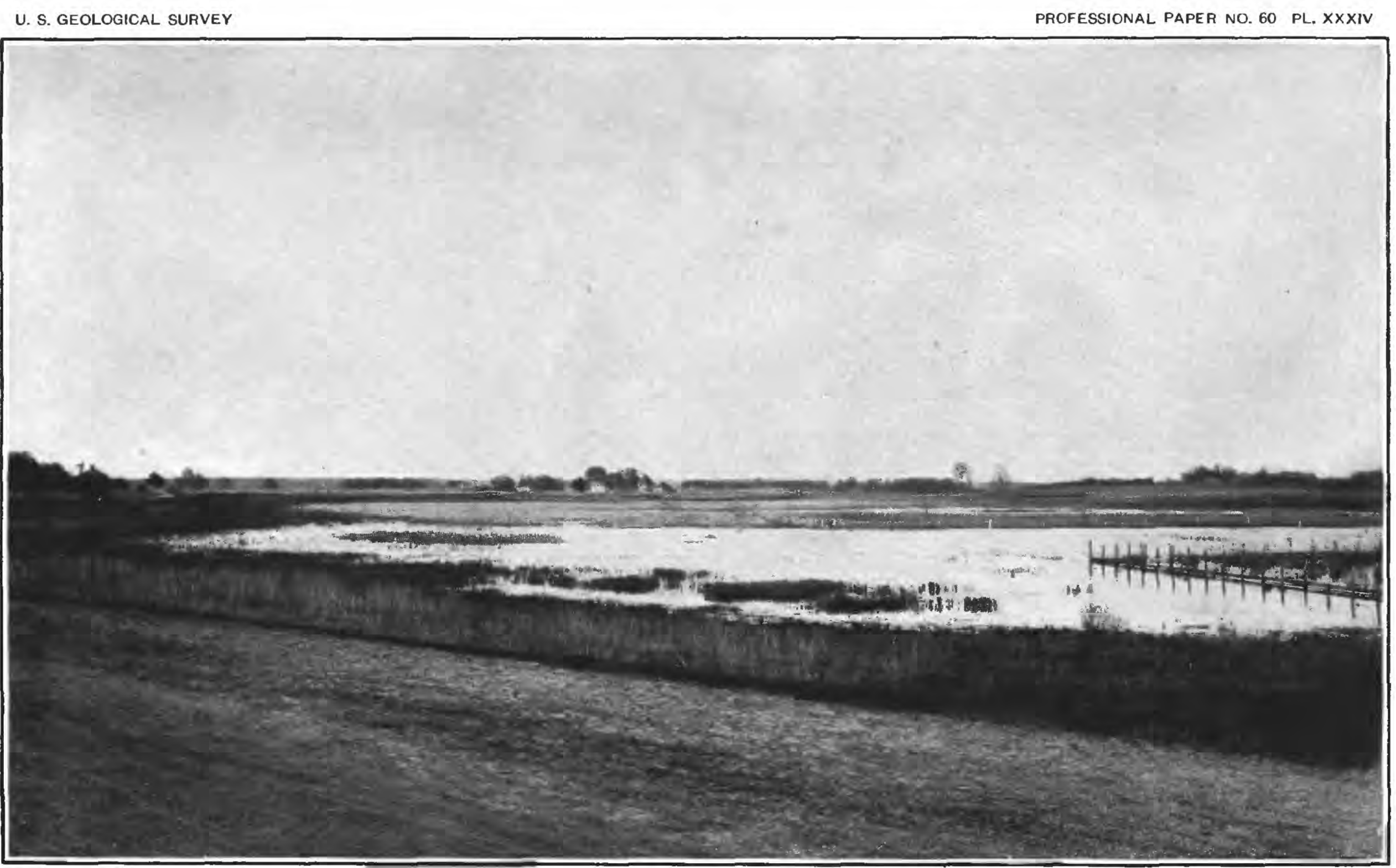

VIEW ILLUSTRATING YOUTHFUL TOPOGRAPHY AND DRAINAGE. 


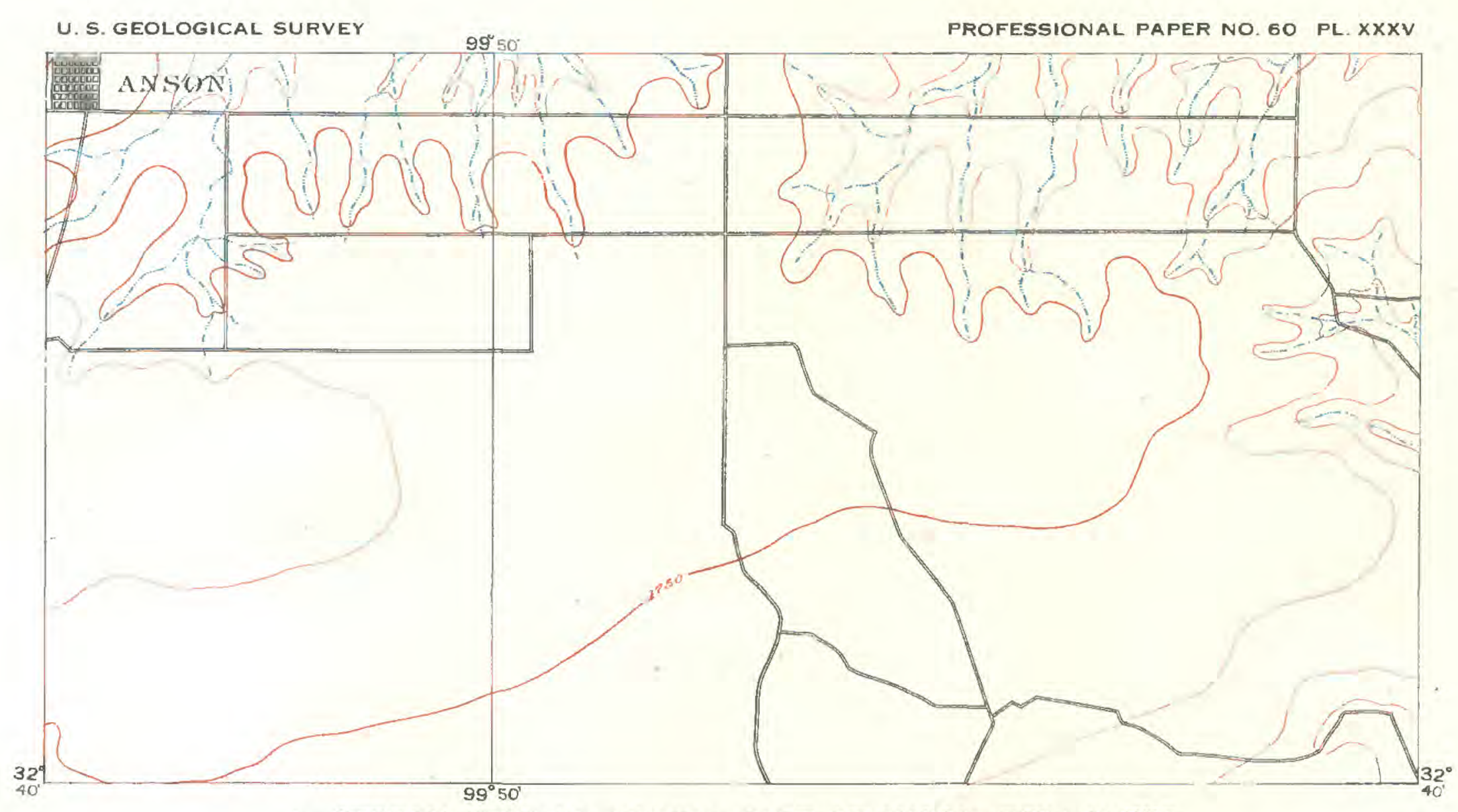

A. STREAM EROSION-YOUTH: PART OF ANSON (TEX.) SHEET

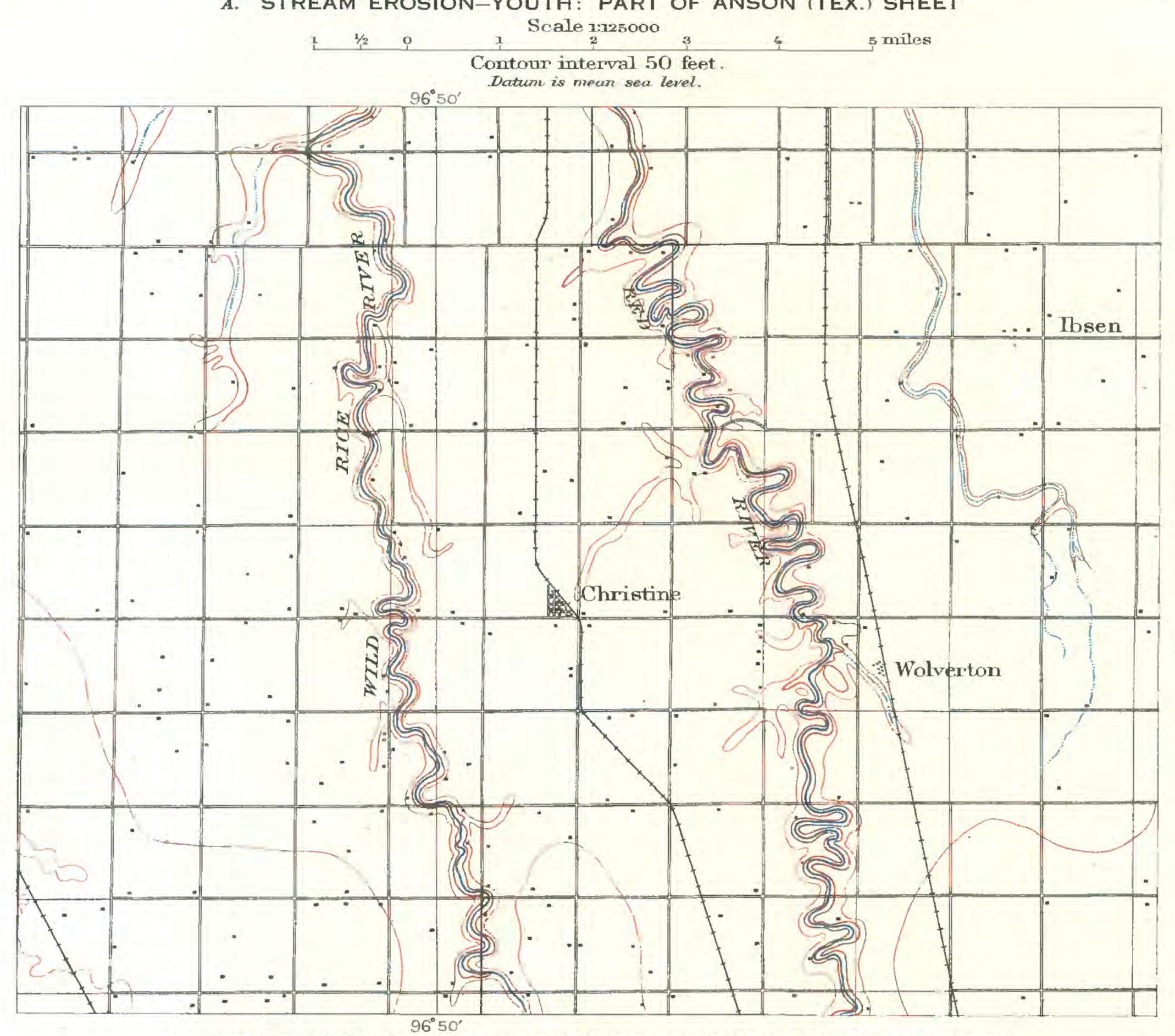

B. STREAM EROSION-YOUTH: PART OF FARGO (N. DAK-MINN.) SHEET

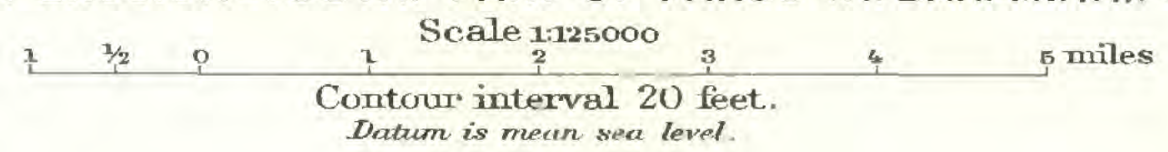




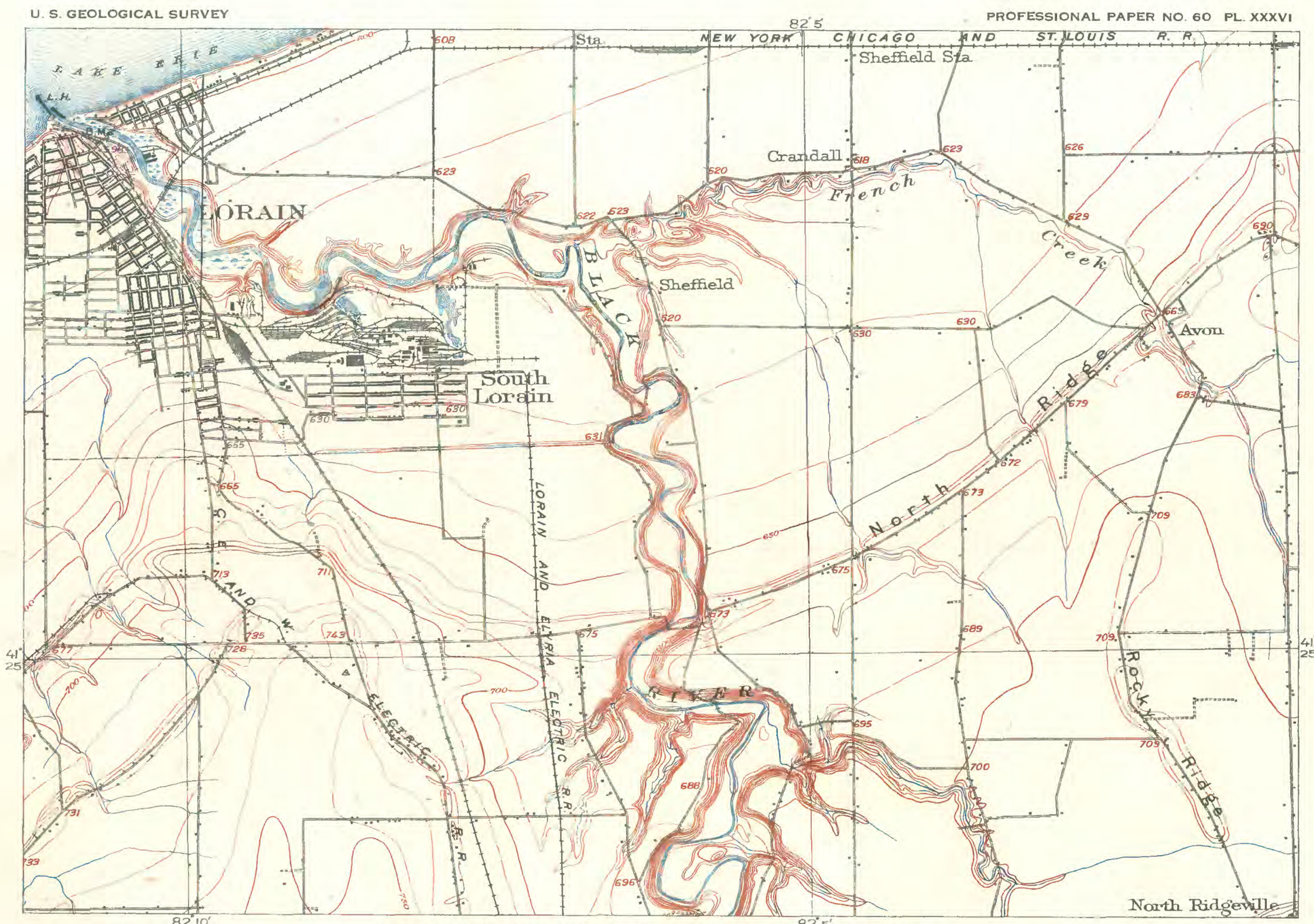

STREAM EROSION-YOUTH : PART OF OBERLIN (OHIO) SHEET

Scale $x: 62500$

3 miles 
U. S. GEOLOGICAL SURVEY

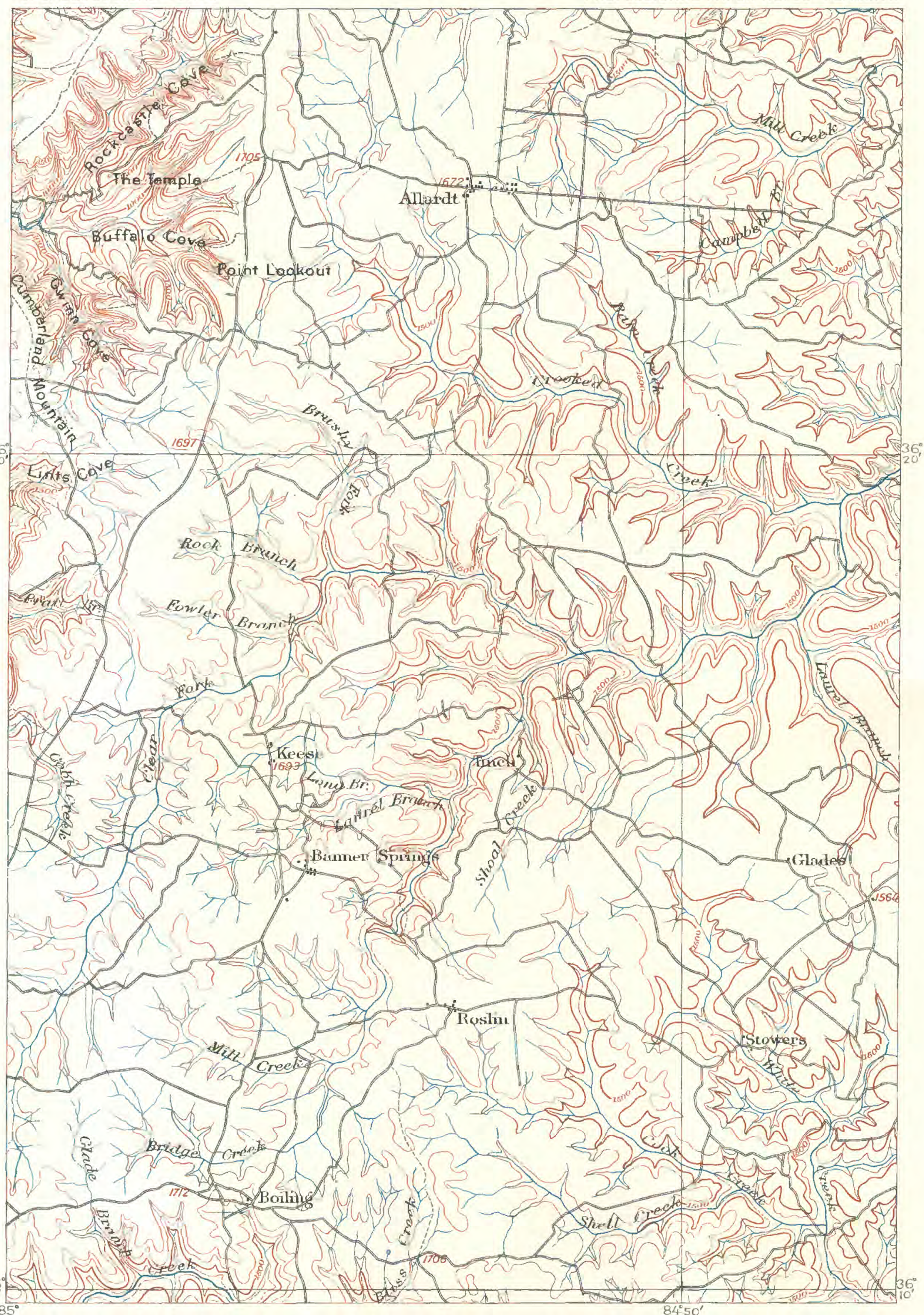

STREAM EROSION-MATURITY: PART OF WARTBURG (TENN.) SHEET

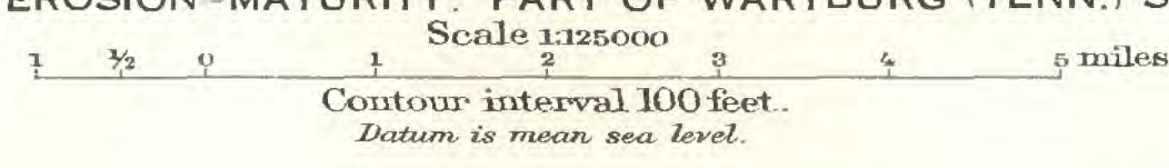



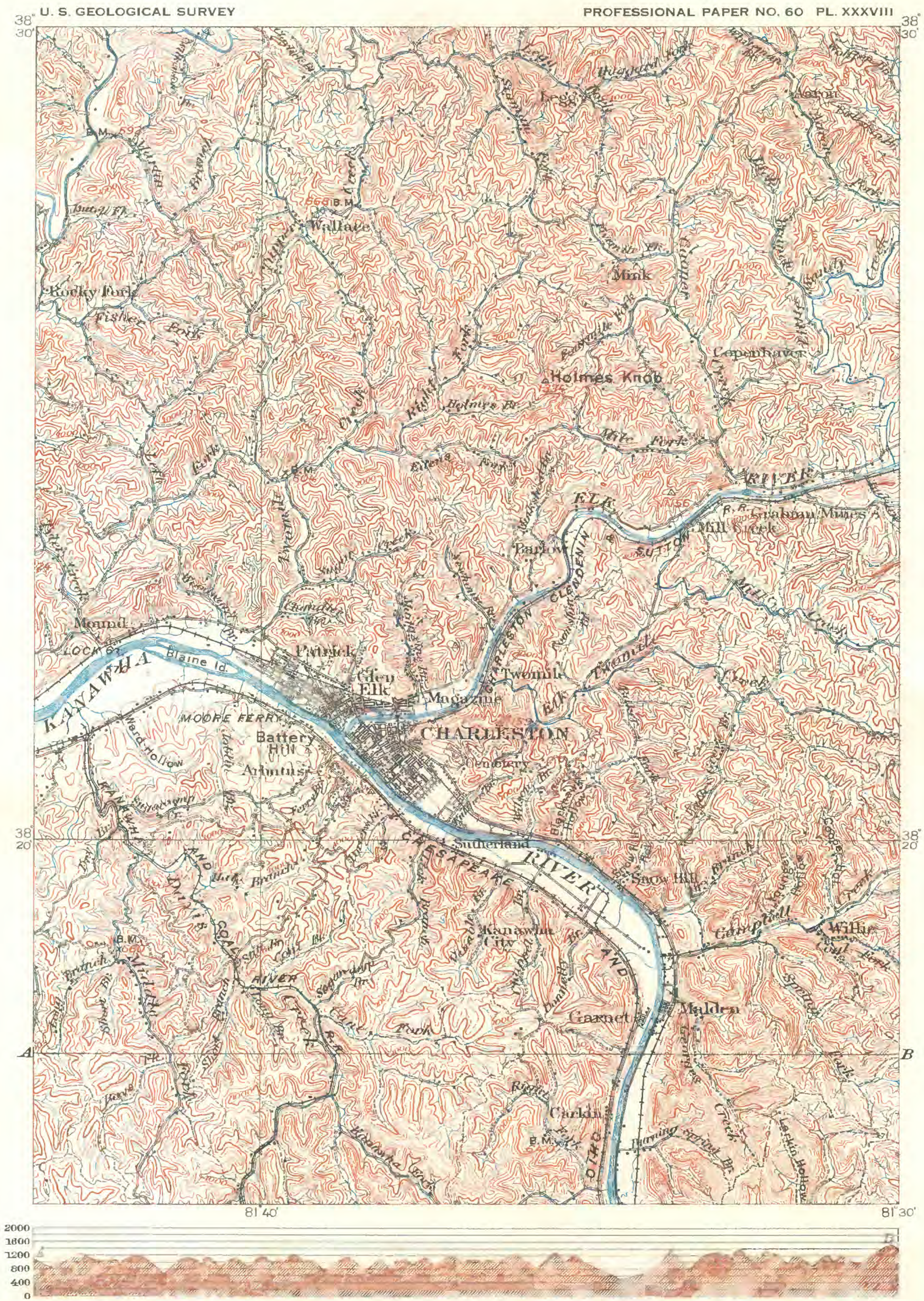

STREAM EROSION-MATURITY: PART OF CHARLESTON (W. VA.) SHEET, WITH SECTION ON LINE A-B 


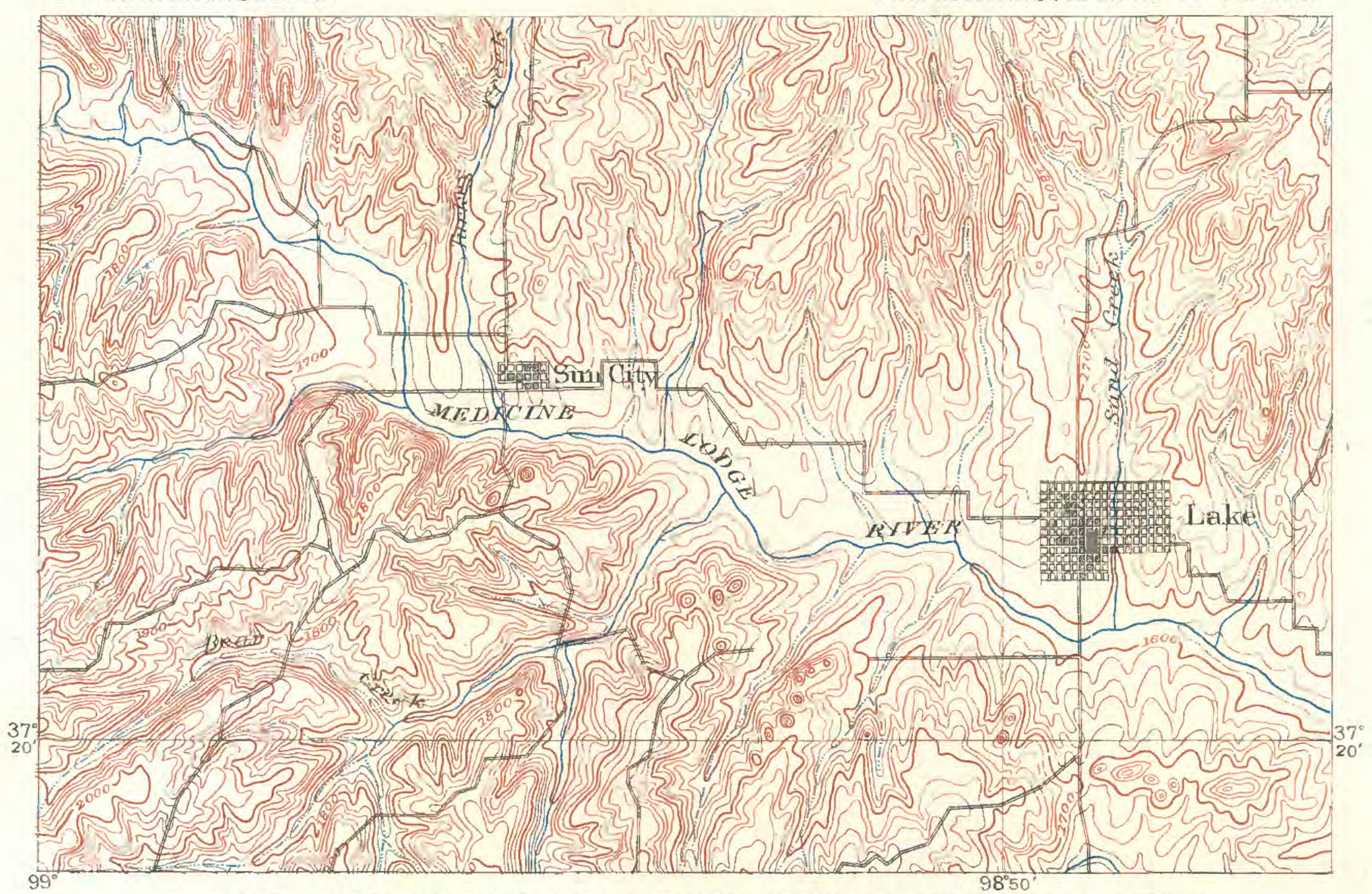

A. STREAM EROSION-MATURITY: PART OF MEDICINE LODGE (KANS.) SHEET

\begin{tabular}{|c|c|c|c|c|c|}
\hline $1 / 2$ & o & & Dodue $\frac{1}{2} 25000$ & 3 & 5 miles \\
\hline
\end{tabular}

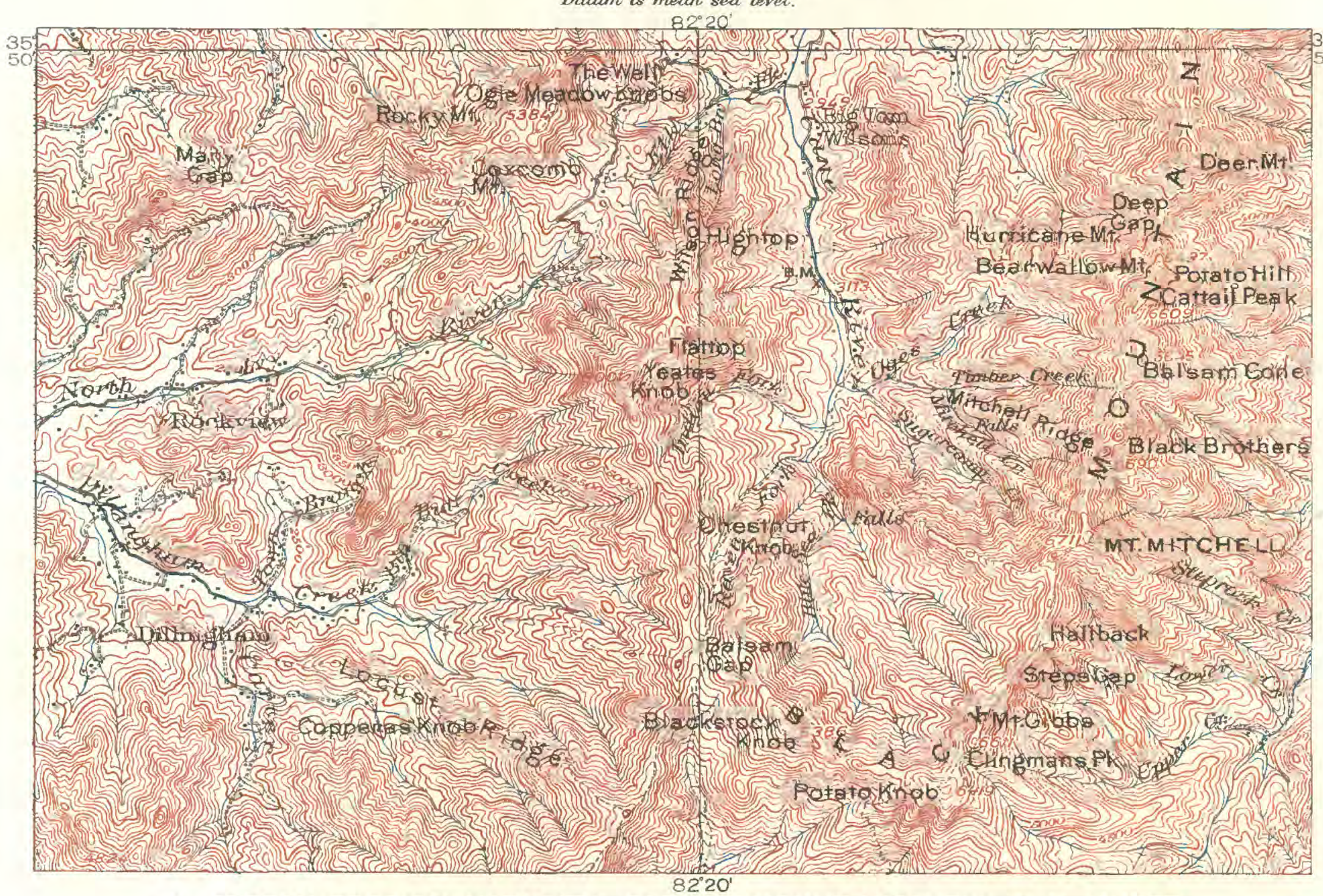

B. STREAM EROSION-MATURITY: PART OF MOUNT MITCHELL (N. C.) SHEET

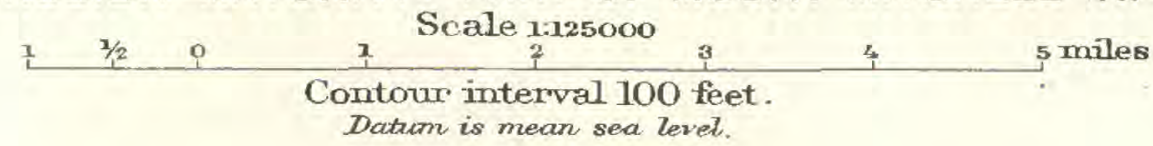




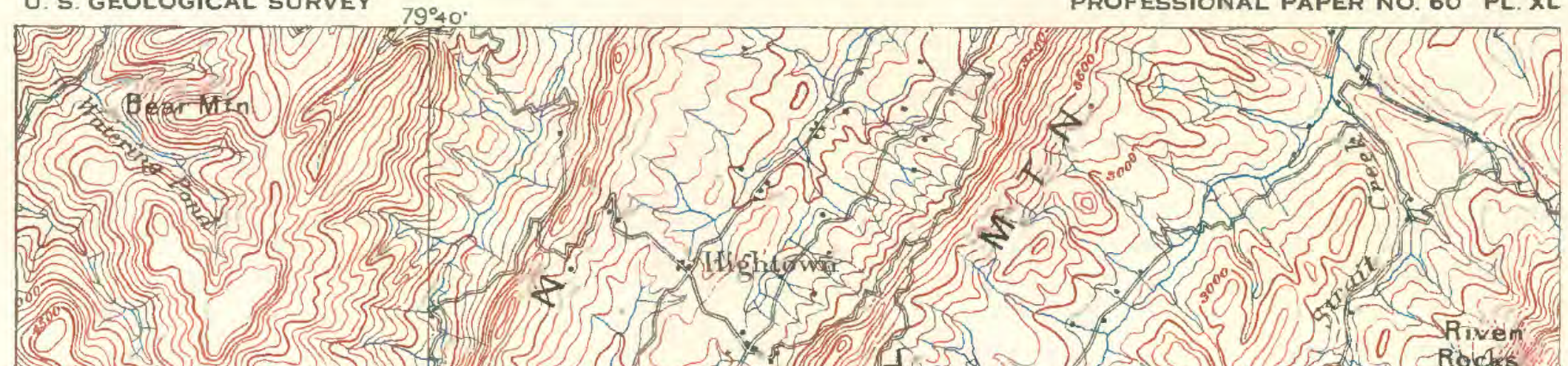

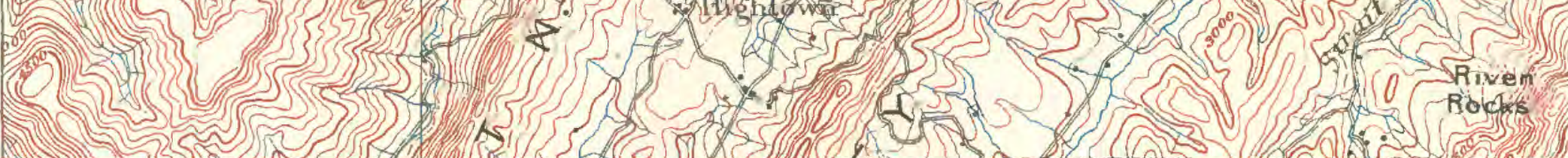

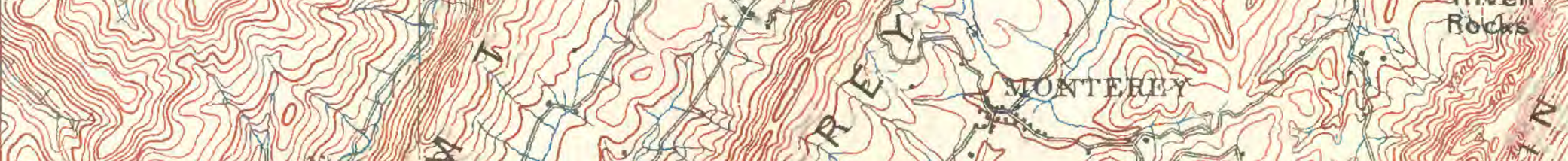
a.t? 3.13) (5) (3)

STREAM EROSION-MATURITY: PART OF MONTEREY (VA.-W. VA.) SHEET

Scale 1:25000 
LEGEND

SEDIMENTARY RDCKS

\begin{tabular}{|c|}
\hline$D$ \\
\hline Devonian \\
\hline$S$ \\
\hline Silturian \\
\hline 0 \\
\hline Ordovician \\
\hline Co \\
\hline
\end{tabular}

Cambro-

Ordovirian

IGNEOUS ROCKS

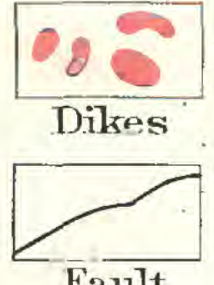

FORMATION NAMES

AND SYMBOLS

Dh

Hampshire

$\mathrm{Dj}$

Jemmings

Dr

Romney shale

SDm

Nonterey

sandstone

SI

Lewistomn

limestone

$\mathrm{Sr}$

Rockwood

formation

Scn

Cacapon

sandstone

Stc

Tuscasora

quartzite

Sj

Jumiata

formation

$\mathrm{Omb}$

Martinsburg

shase

Shenandoal

limestone

Basal

gf

Felsophre 


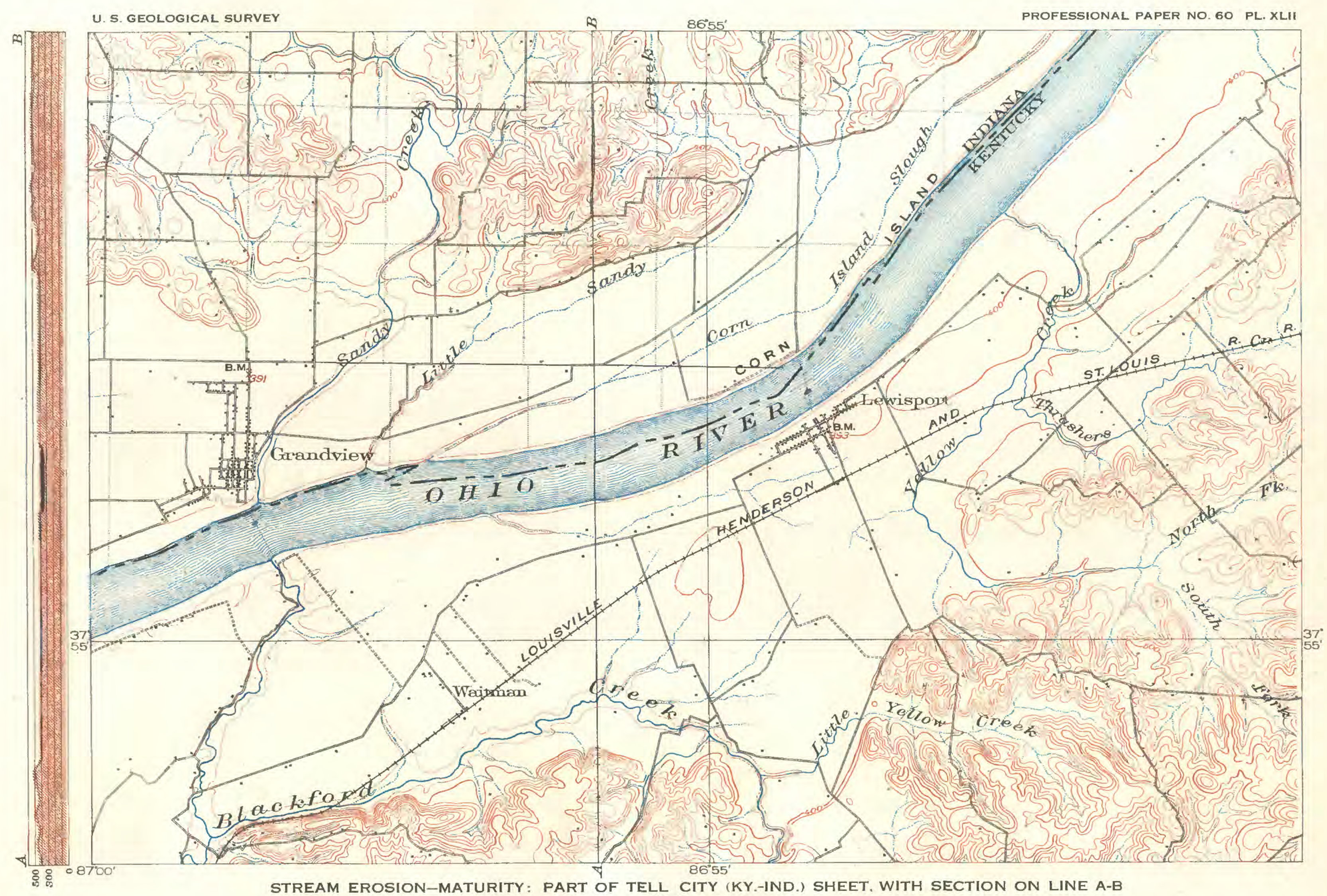

STREAM EROSION-MATURITY: PART OF TELL CITY (KY.-IND.) SHEET, WITH SECTION ON LINE A-B

$$
\begin{gathered}
\text { Contour interval } 20 \text { feet. } \\
\text { Datum is mean, sea level. }
\end{gathered}
$$




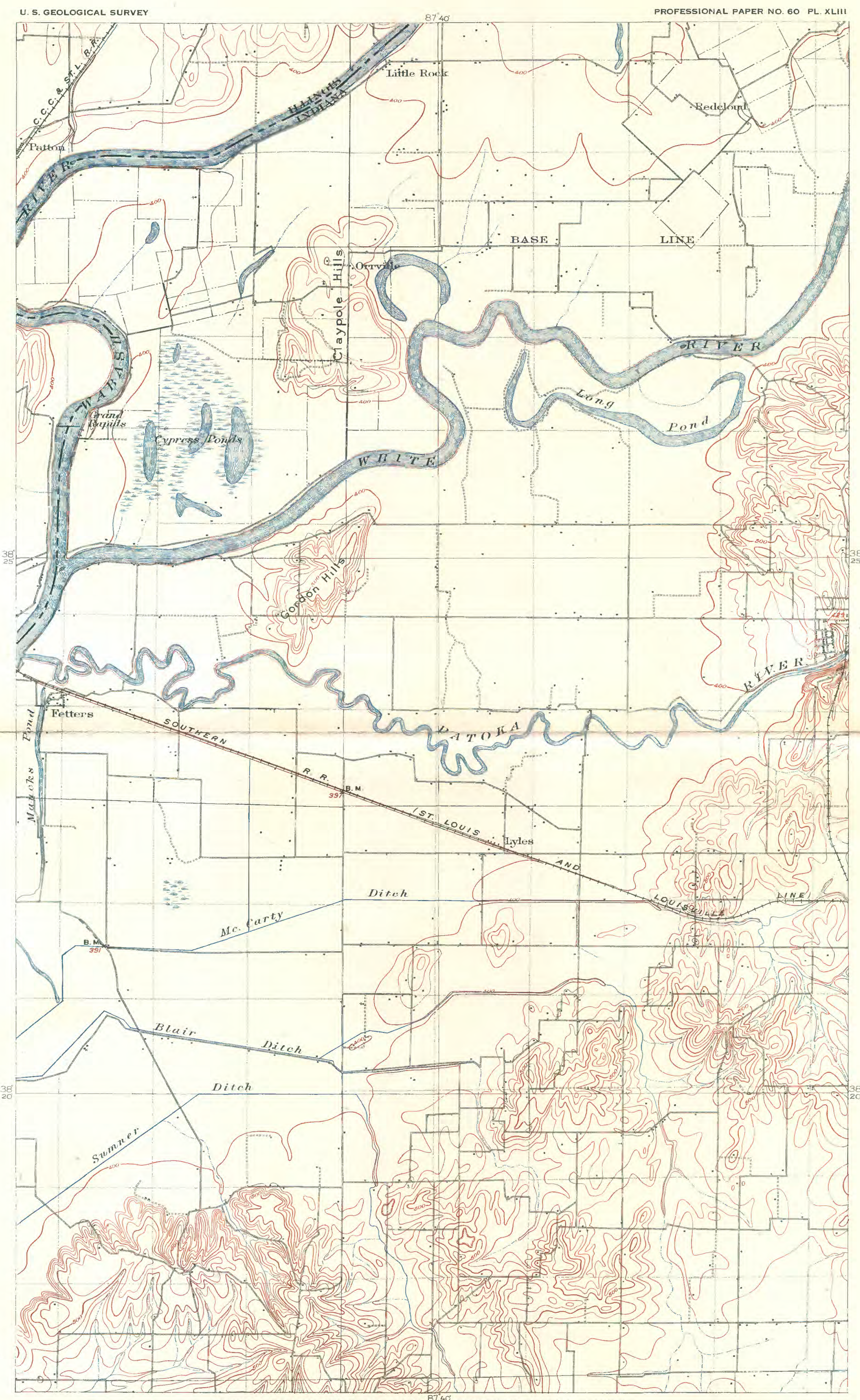


U. S. GEOLOGICAL SURVEY

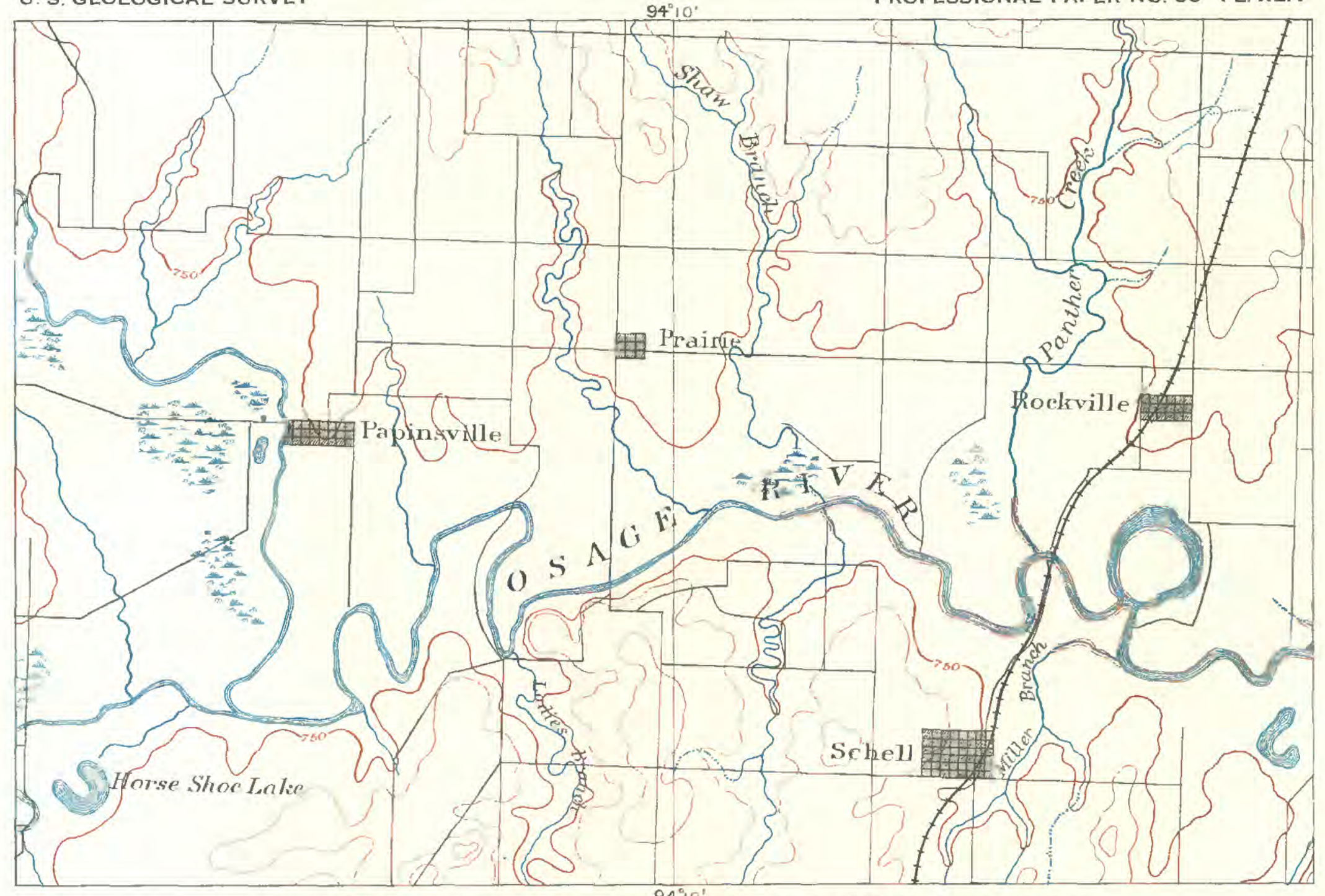

A. STREAM EROSION OLD AGE: PART OF BUTLER (MO.) SHEET

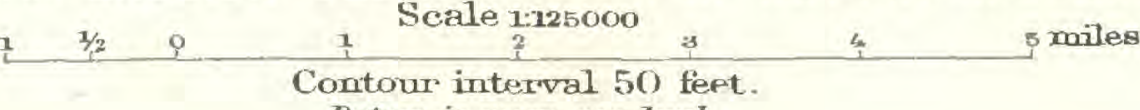

Datum is mean sers level.

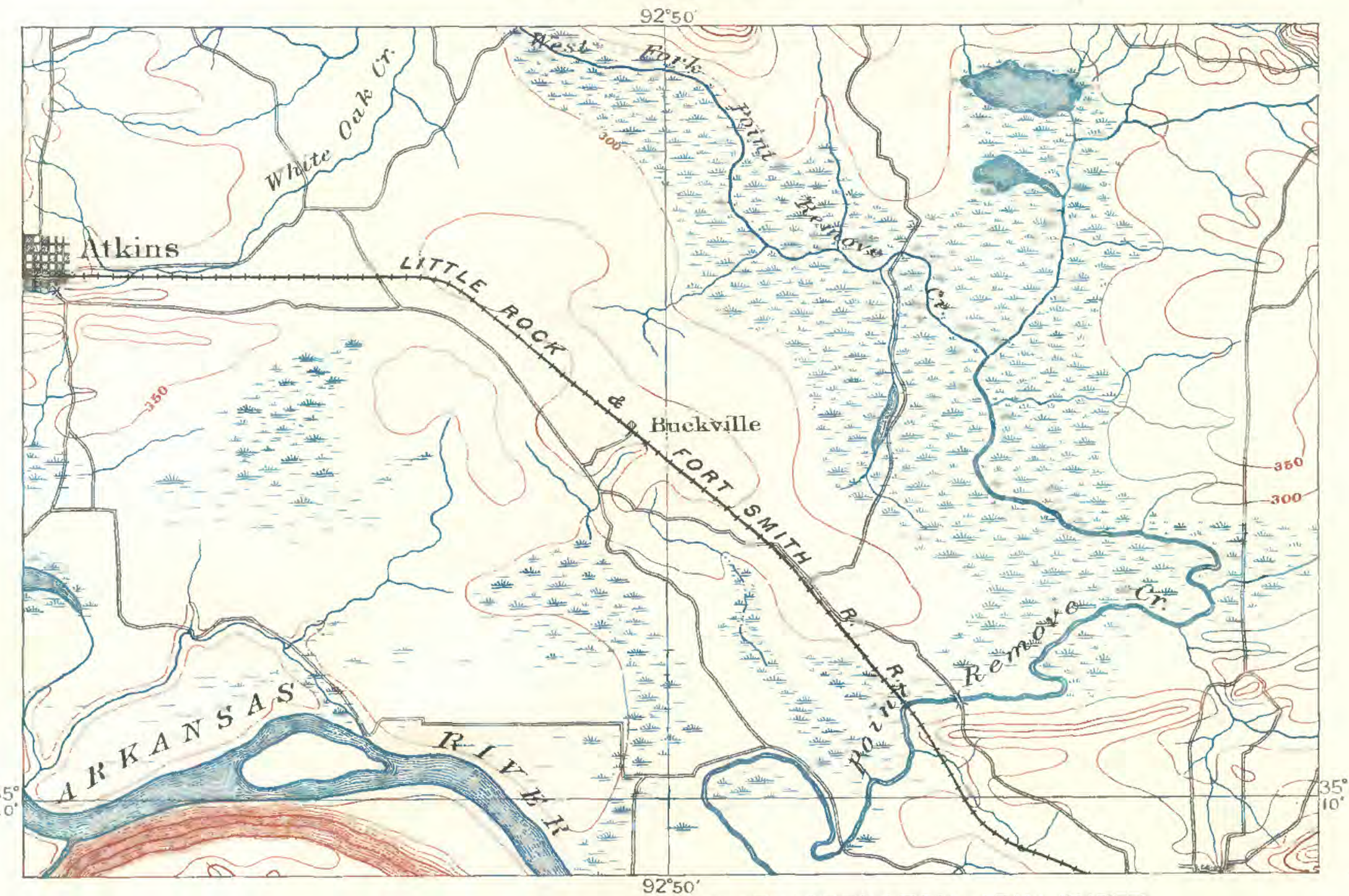

B. STREAM EROSION-OLD AGE: PART OF MORRILLTON (ARK.) SHEET

Scale $1: 125000$

$1 \quad \frac{1 / 2}{1 / 2} \quad \frac{1}{\text { Contour interval } 50 \text { feet }}$

Datum is mean sea level. 


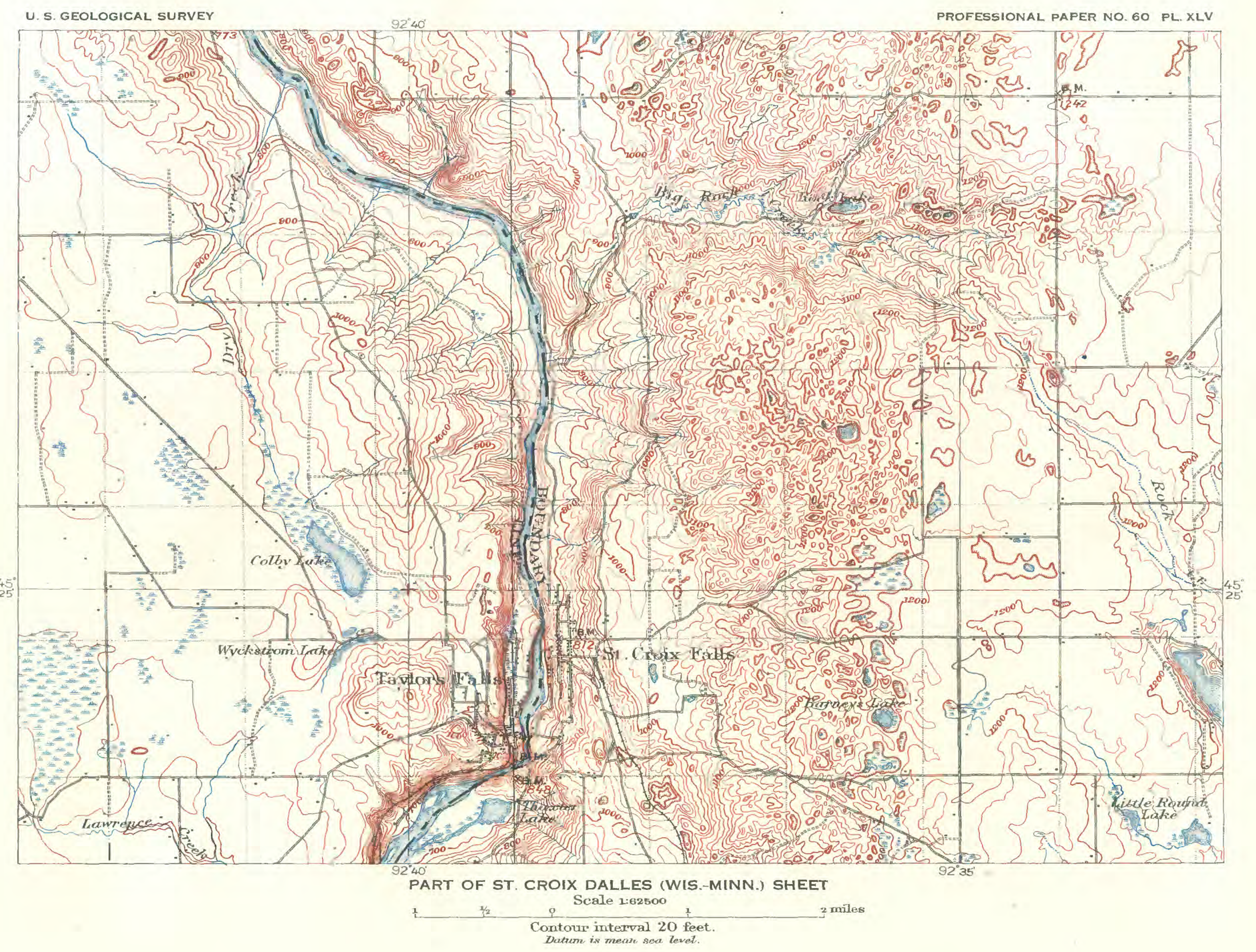




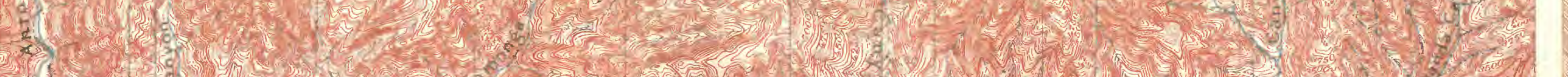

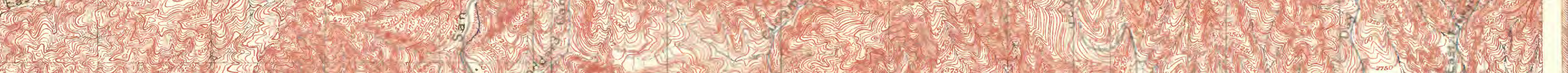
The.

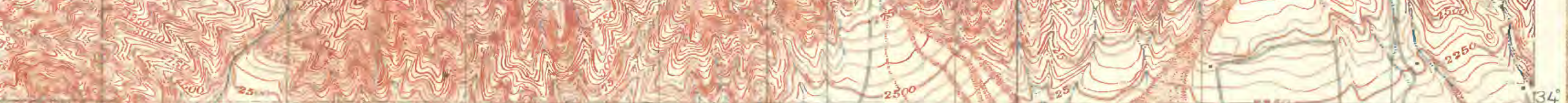

ALLUVITATION: PART OF CUCAMONGA (CAL.) SHEET. WITH SECTION ON LINE A-B 


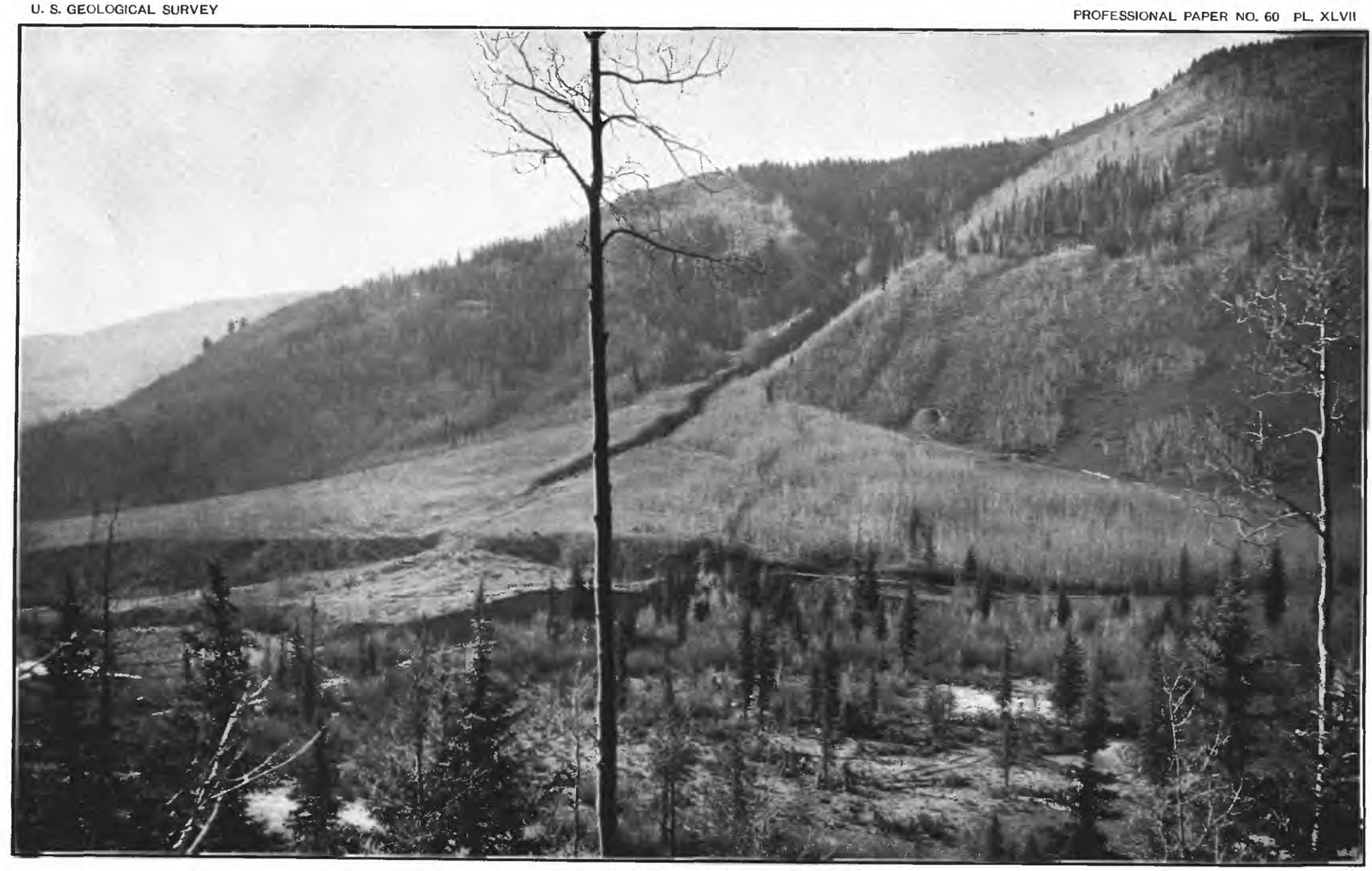

VIEW OF ALLUVIAL FAN. 


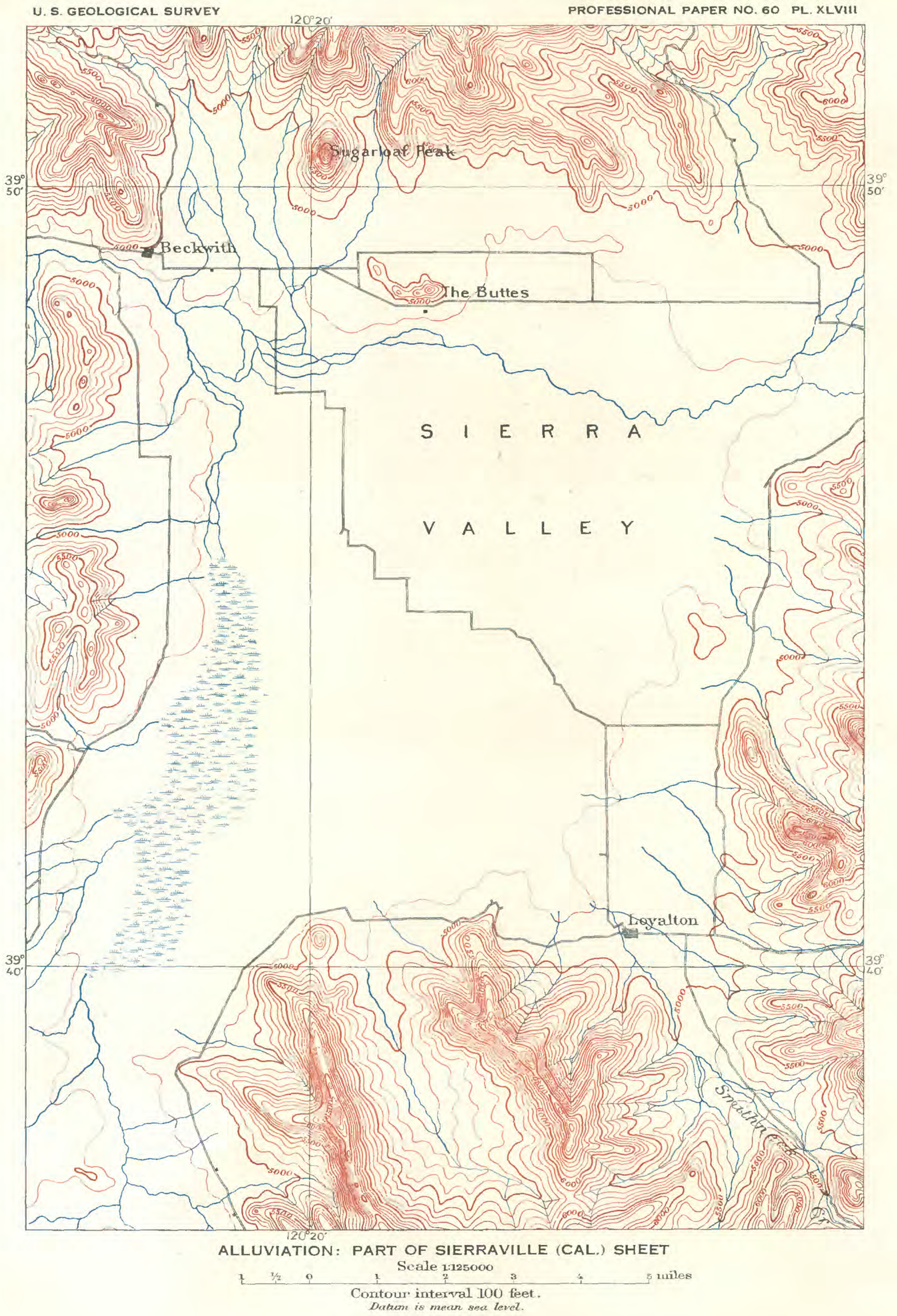


U.S. GEOLOGICAL SURVEY

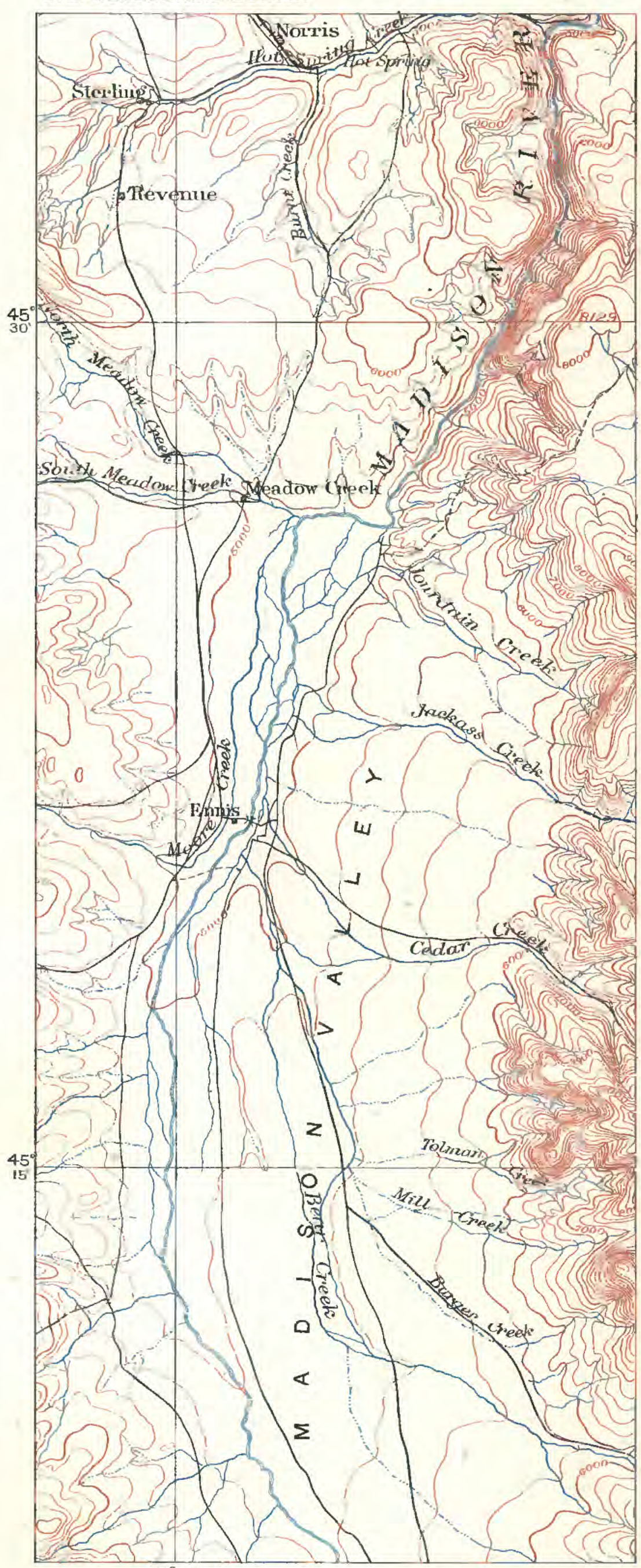

$111^{\circ} 45^{\prime}$

A. TOPOGRAPHY
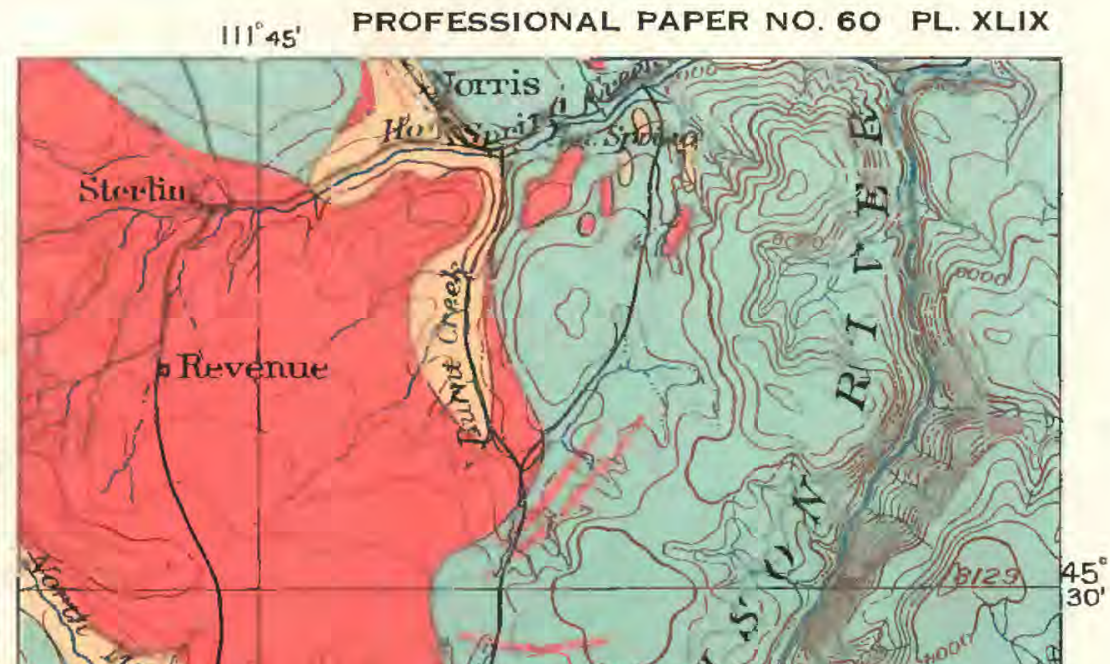

ALLUVIATION : FROM THE THREEFORKS (MONT, FOLIO
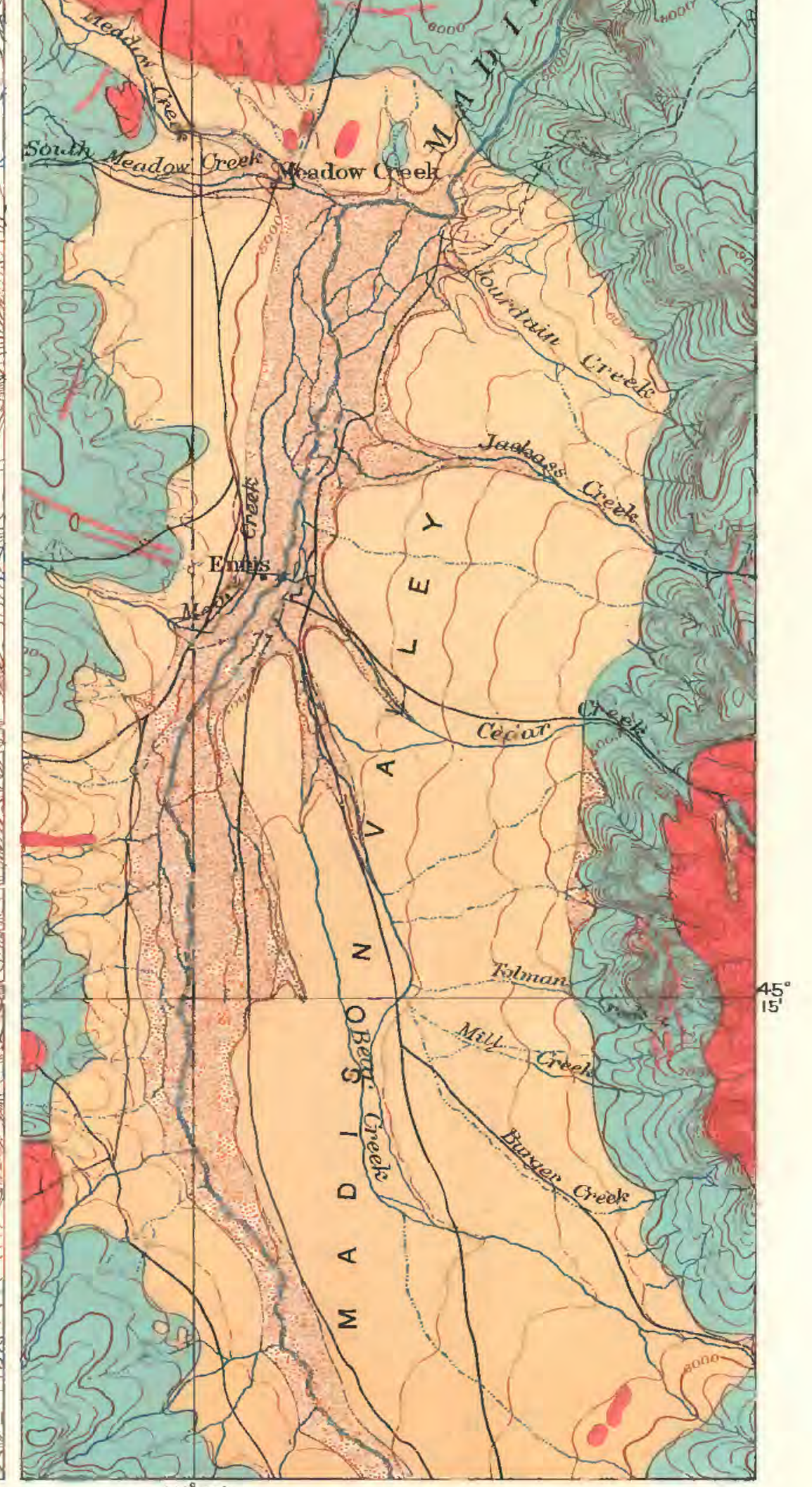

B. GEOLOGY

12 miles

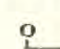

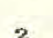
4 Scale 1:250000 Contour interval 200 feet.
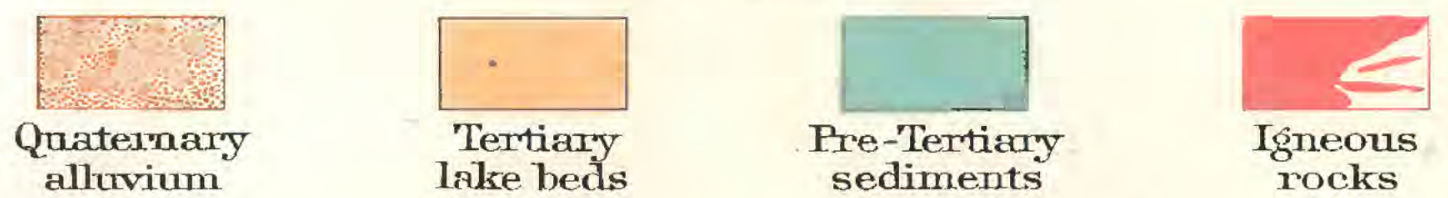


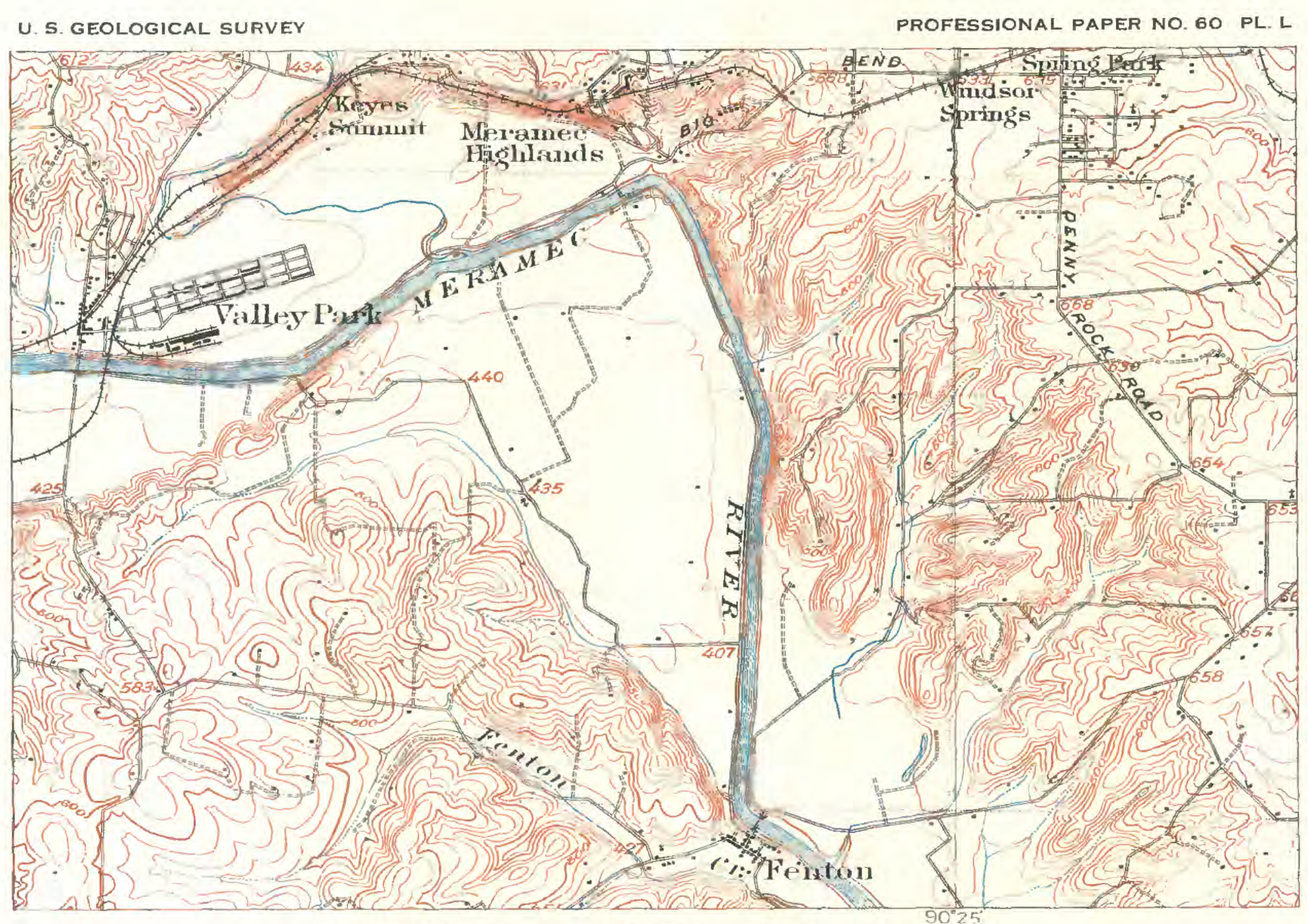

A. ALLUVIATION: PART OF ST, LOUIS (MO, SHEET
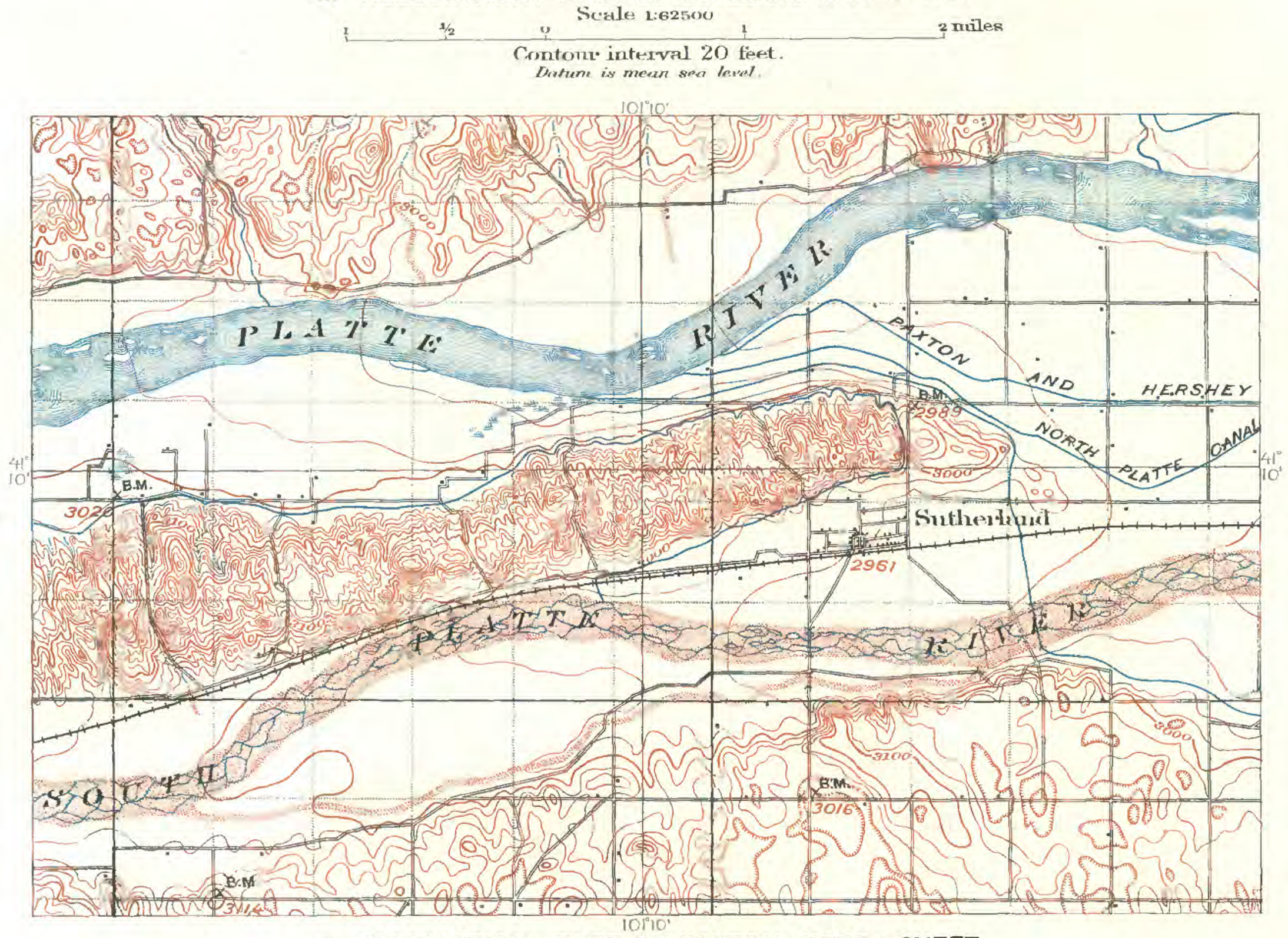

B. ALLUVIATION: PART OF PAXTON (NEBR.) SHEET

$x \quad 1 / 2 \quad$ S I Scale $1: 25000$
Contour interval 20 feet.
Datum is mean sea level. 


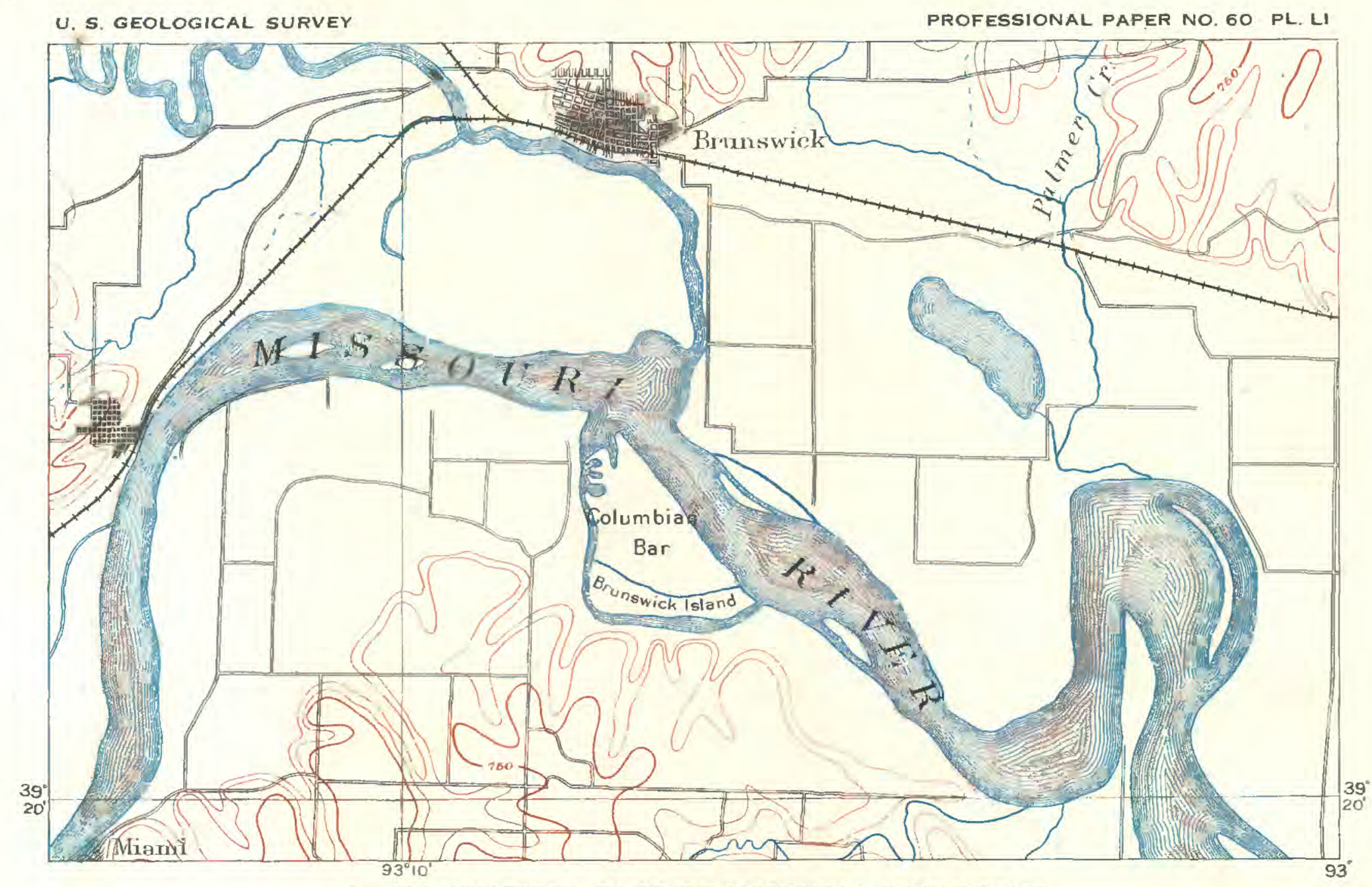

A. ALLUVIATION: PART OF MARSHALL (MO.) SHEET
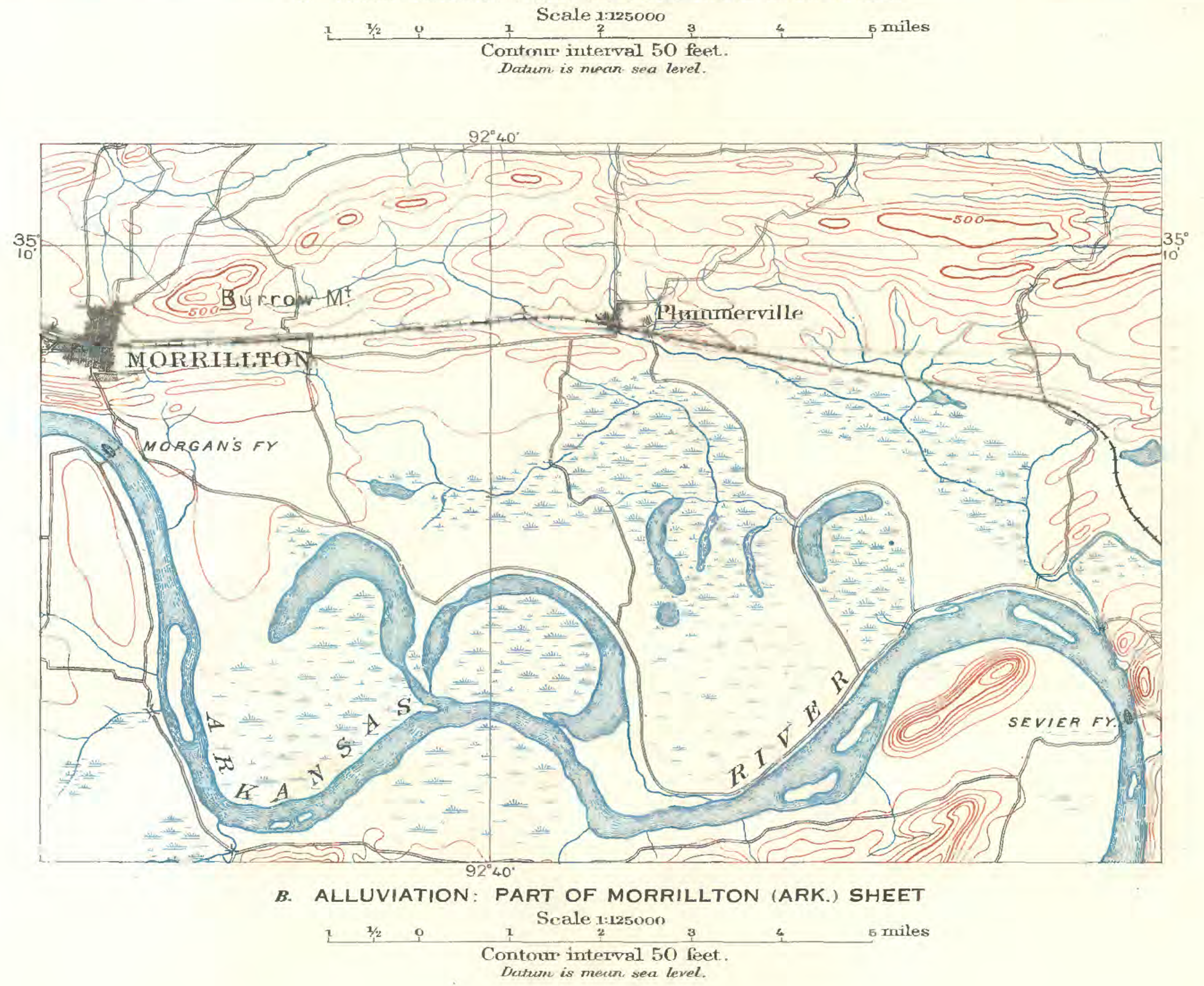


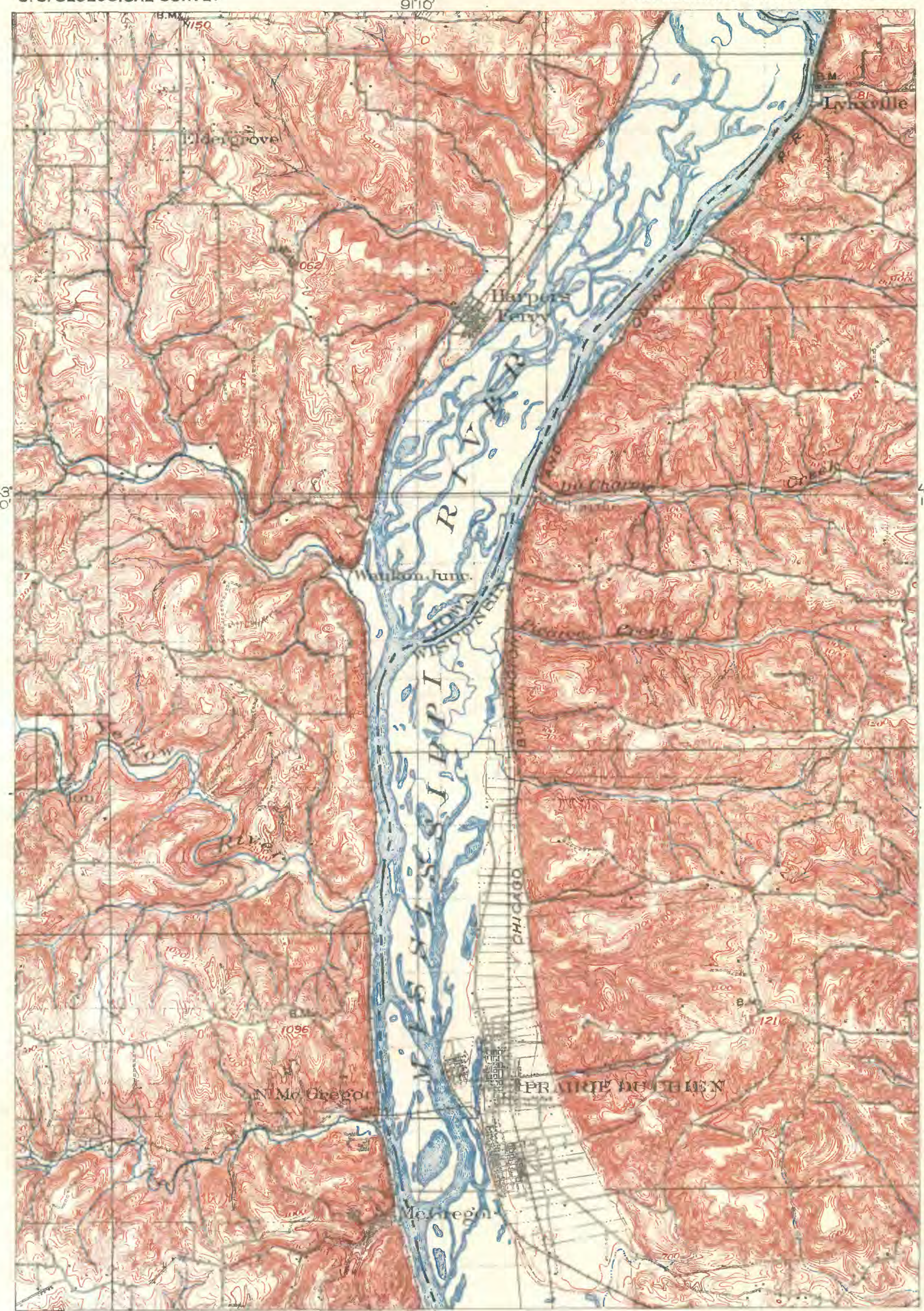

ALLUVIATION: PART OF WAUKON (IOWA-WIS.) SHEET 


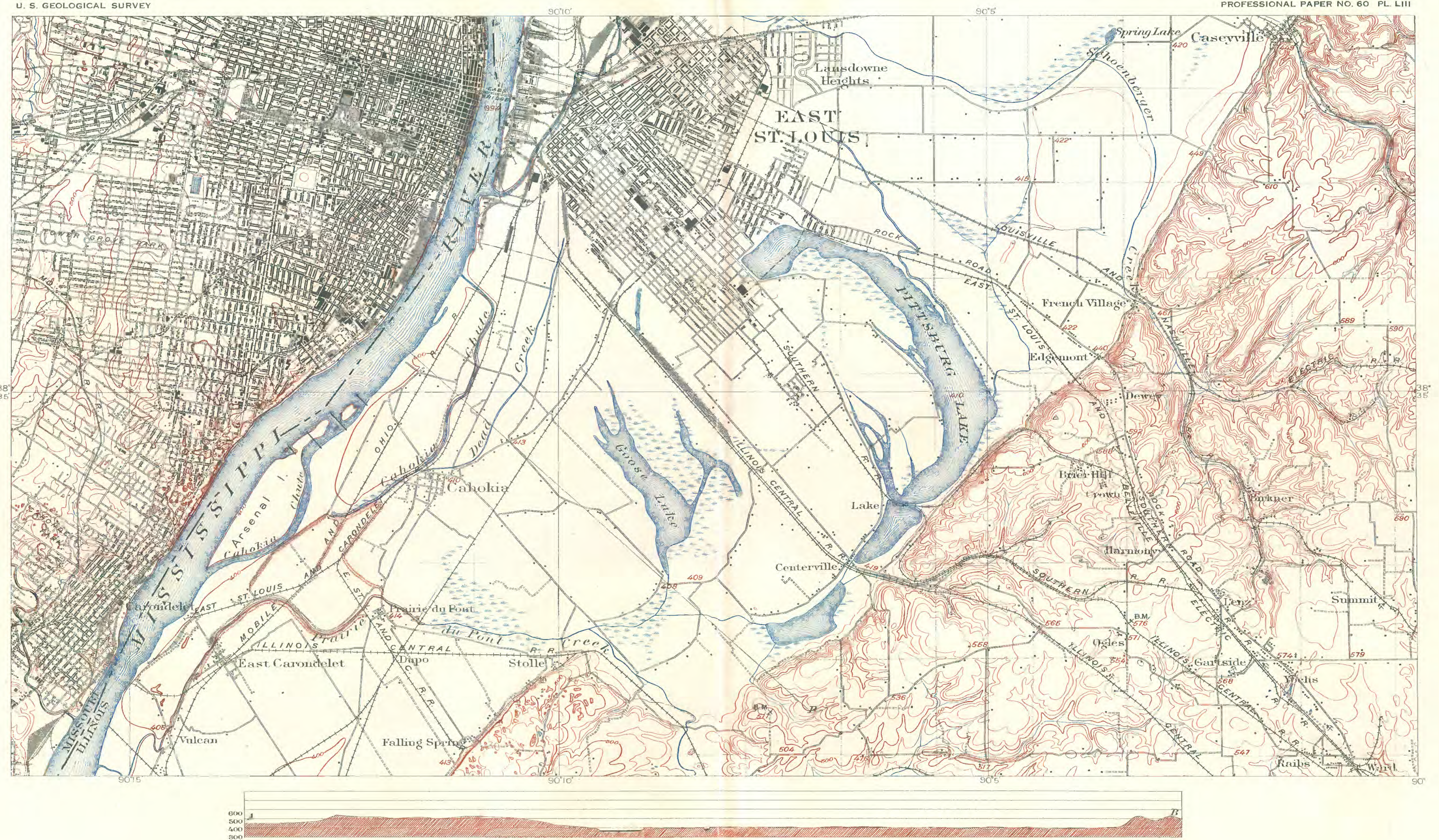

ALLUVIATION: PART OF ST. LOUIS IILL.-MO., SHEET. WITH SECTION ON LINE A-B

P
Contour interval 20 feet.
Datum is meens sen level. 


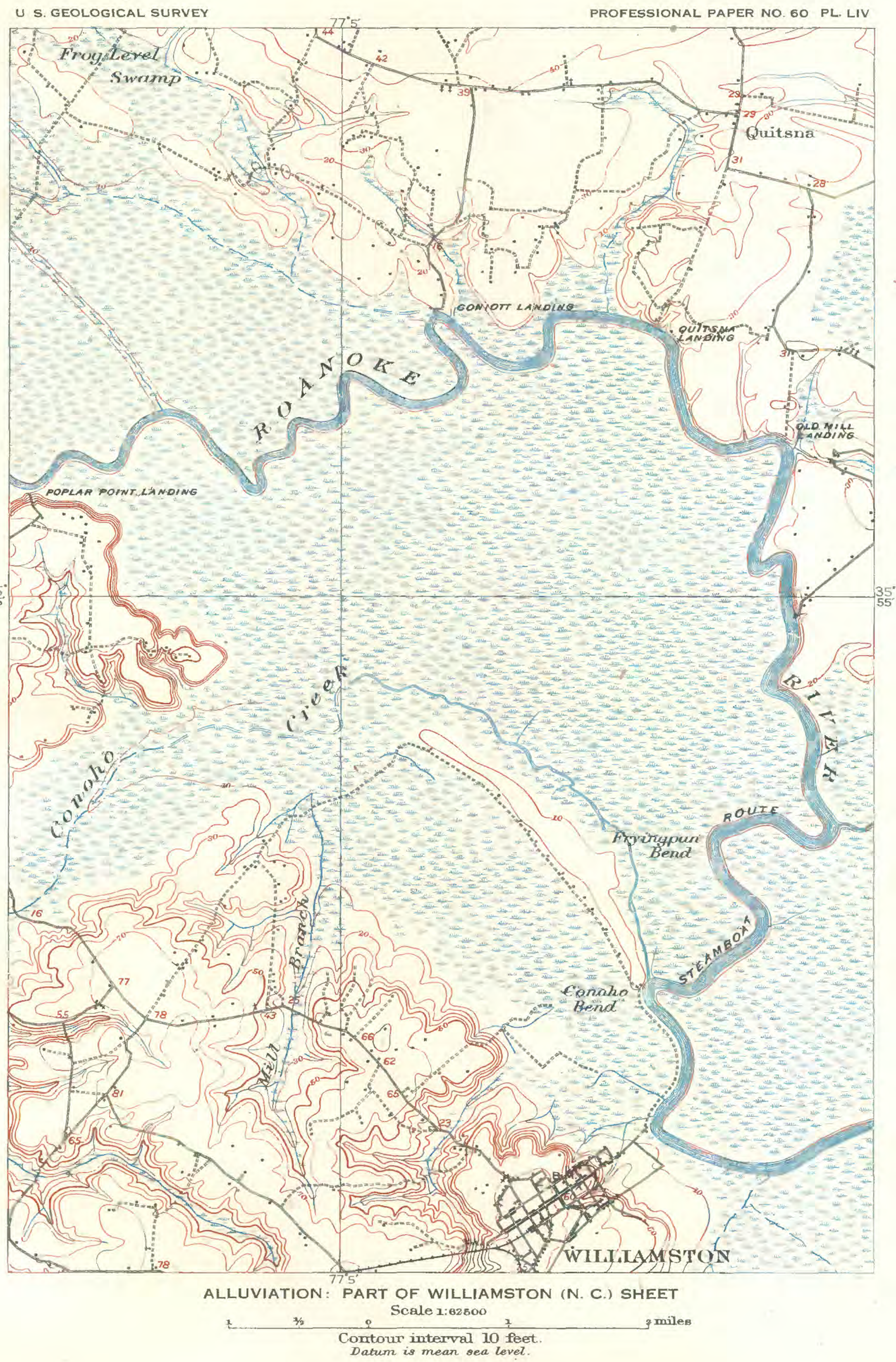




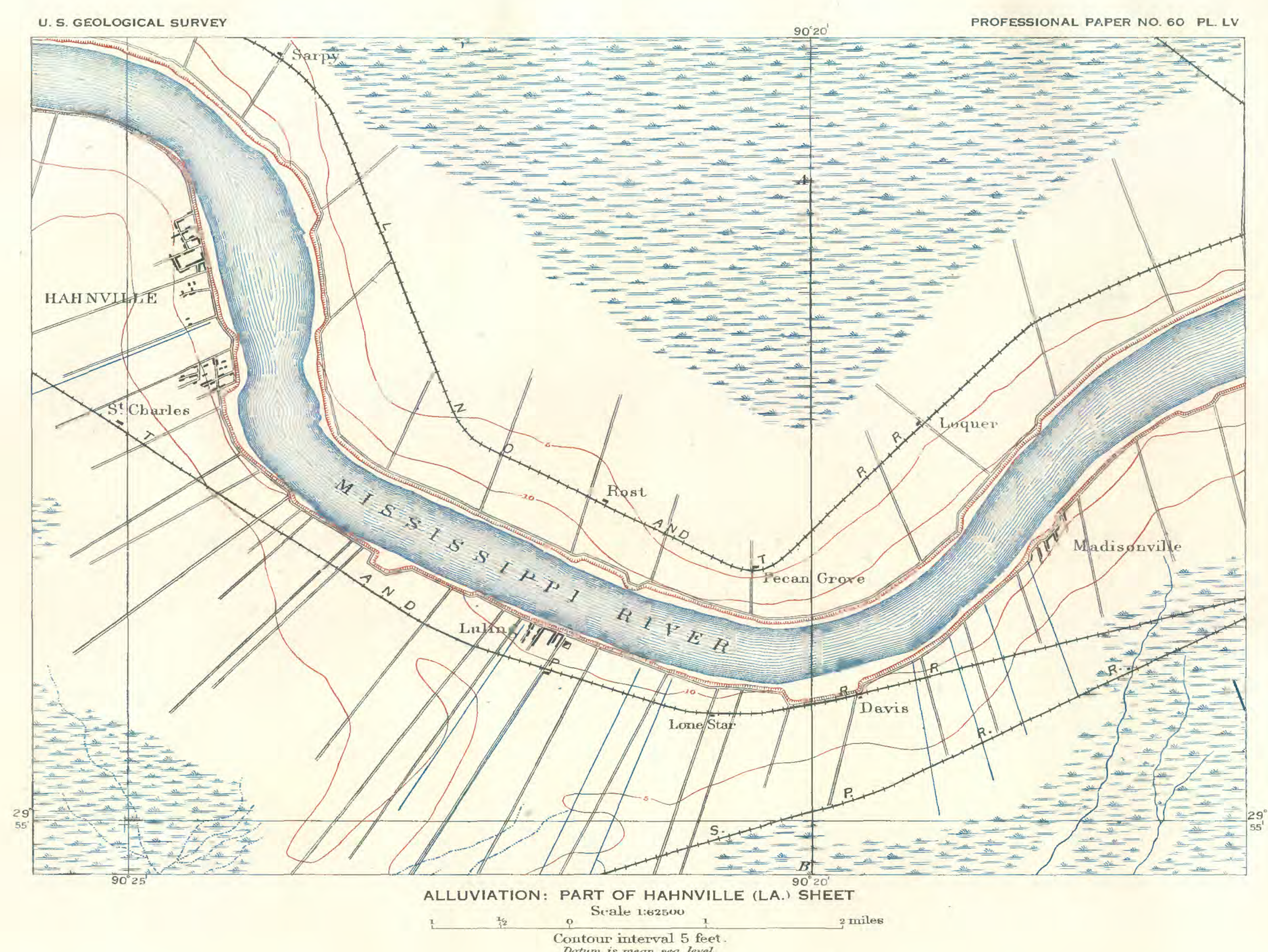


U. S. GEOLOGICAL SURVEY

PROFESSIONAL PAPER NO. 60 PL. LVI

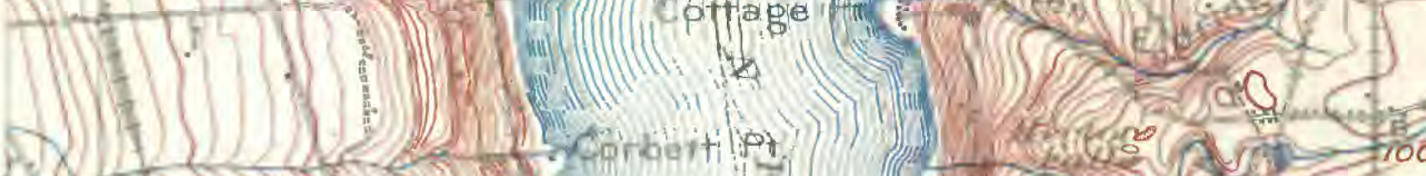
25:

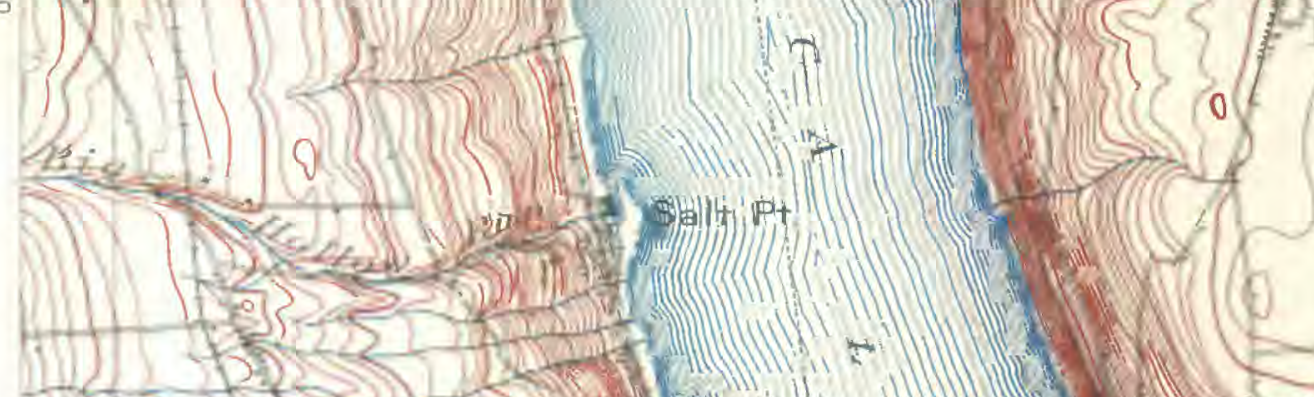
23is (1)
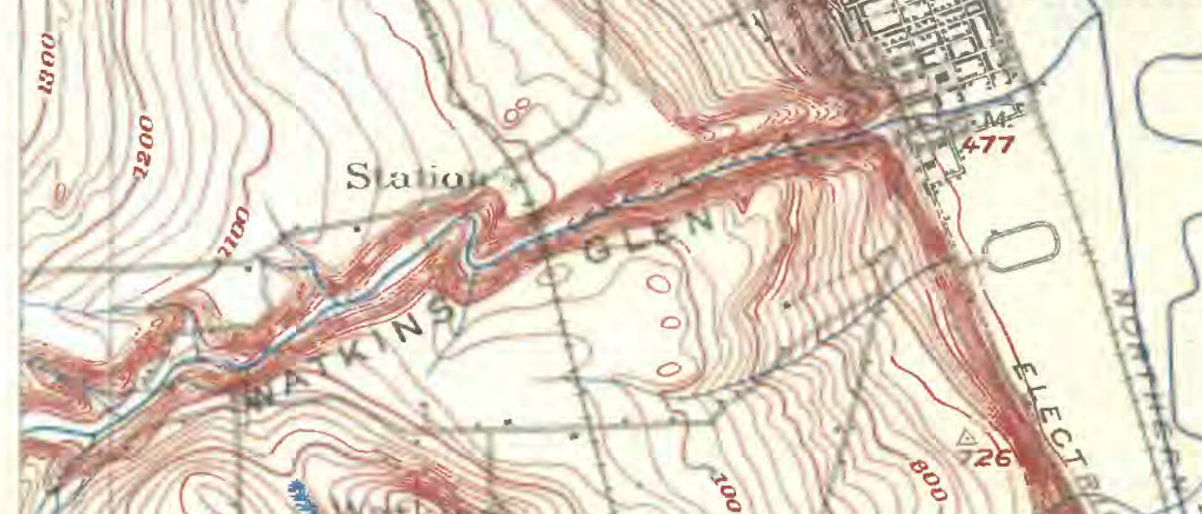
I.

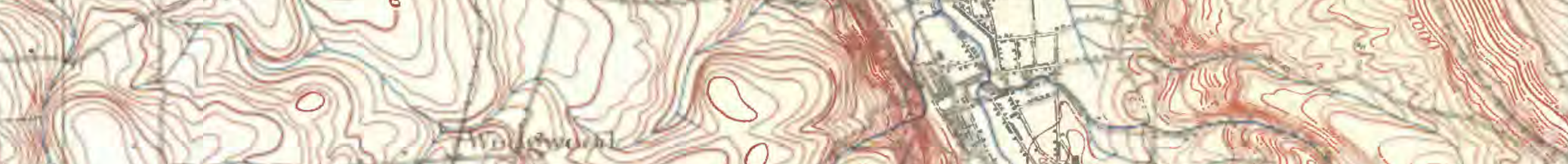

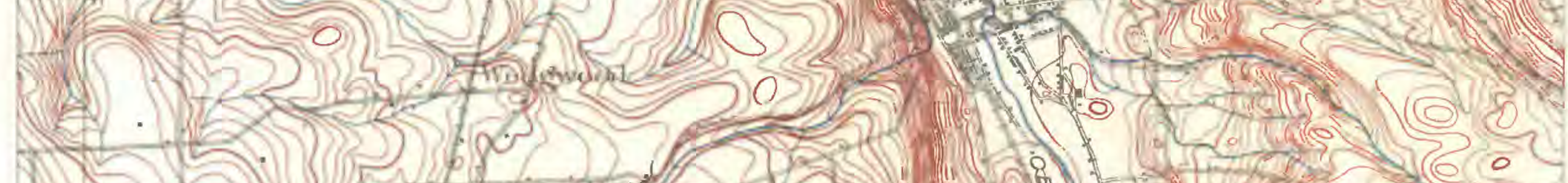

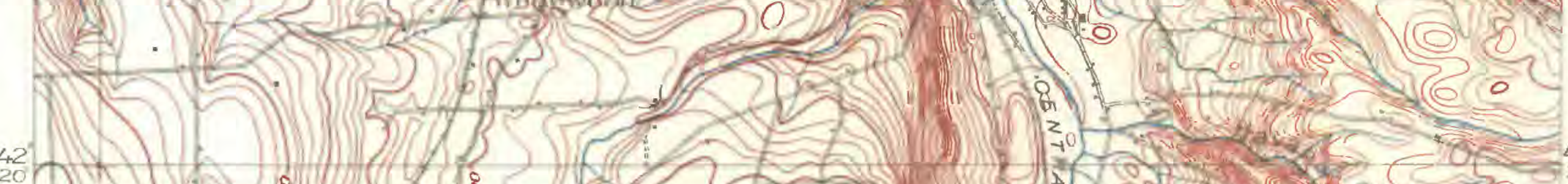
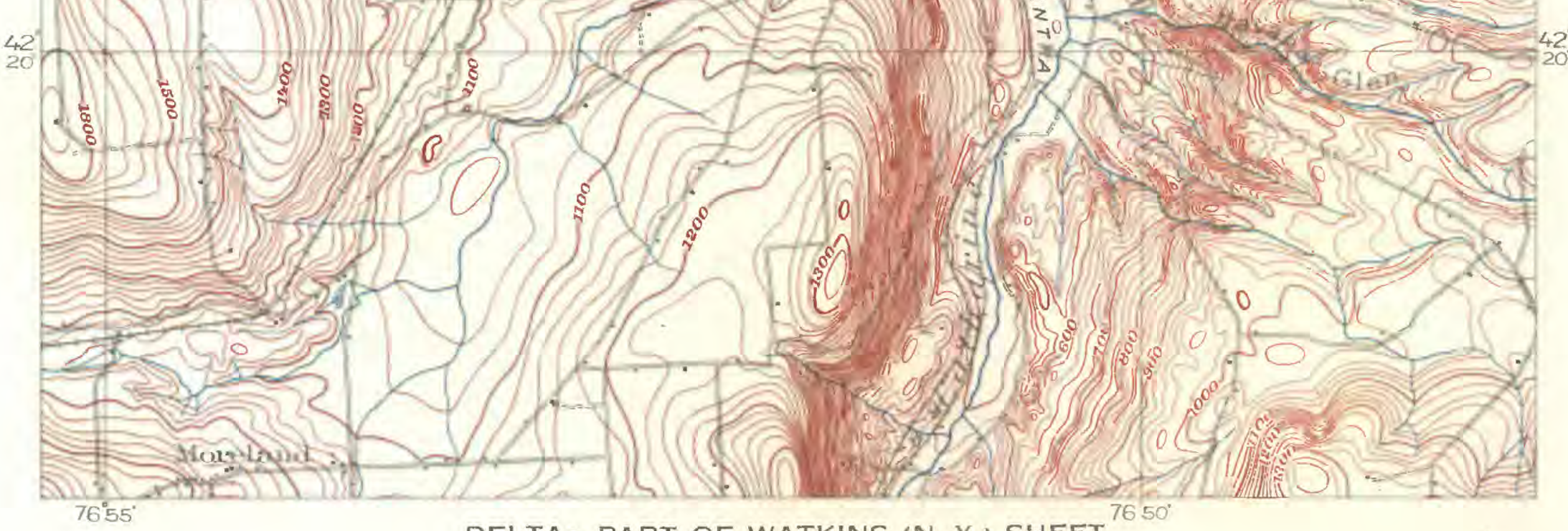

$76^{\circ} 55^{\circ}$

DELTA: PART OF WATKINS (N. Y, SHEET

$\mathbb{1}$

Contom interval 20 feet 
U. S. GEOLOGICAL SURVEY

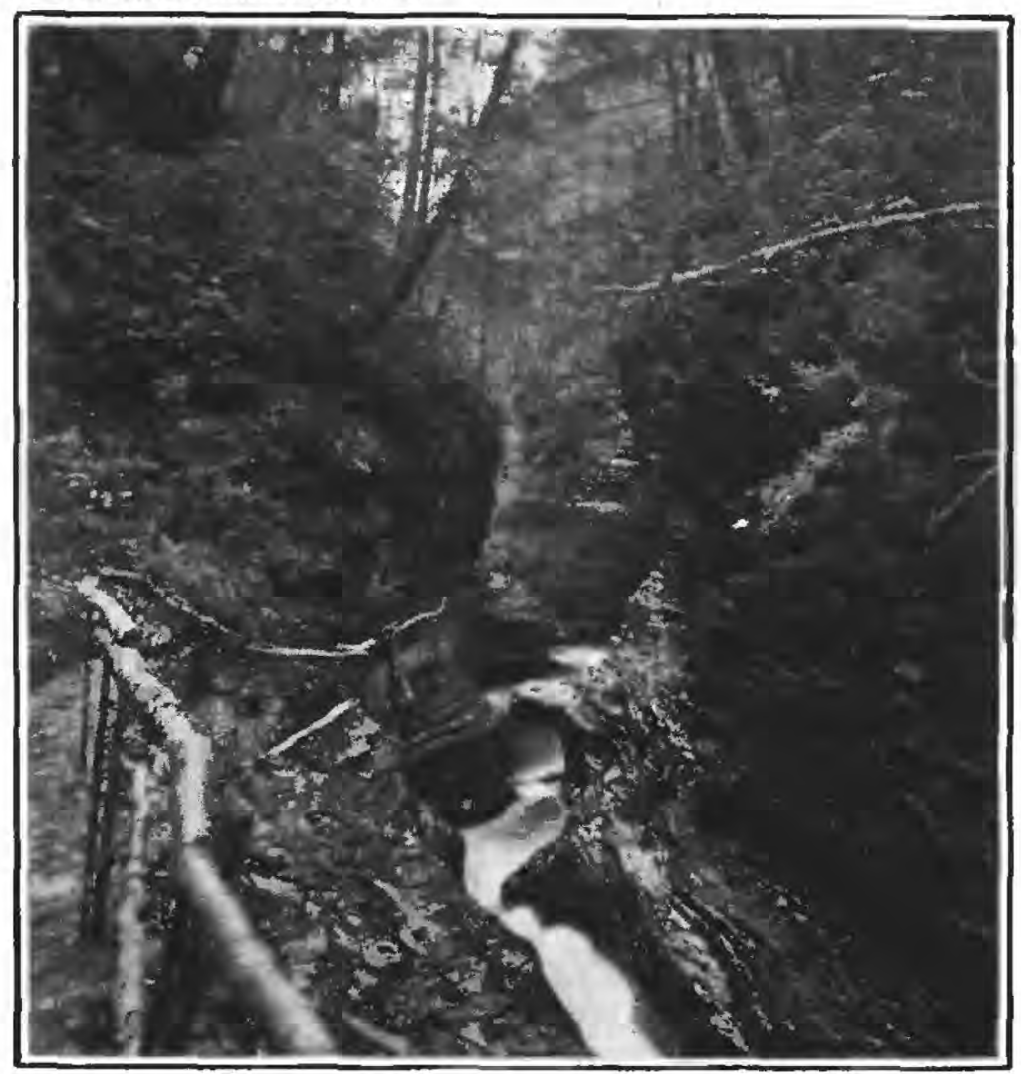

A.
PROFESSIONAL PAPER NO. 60 PL. LVII

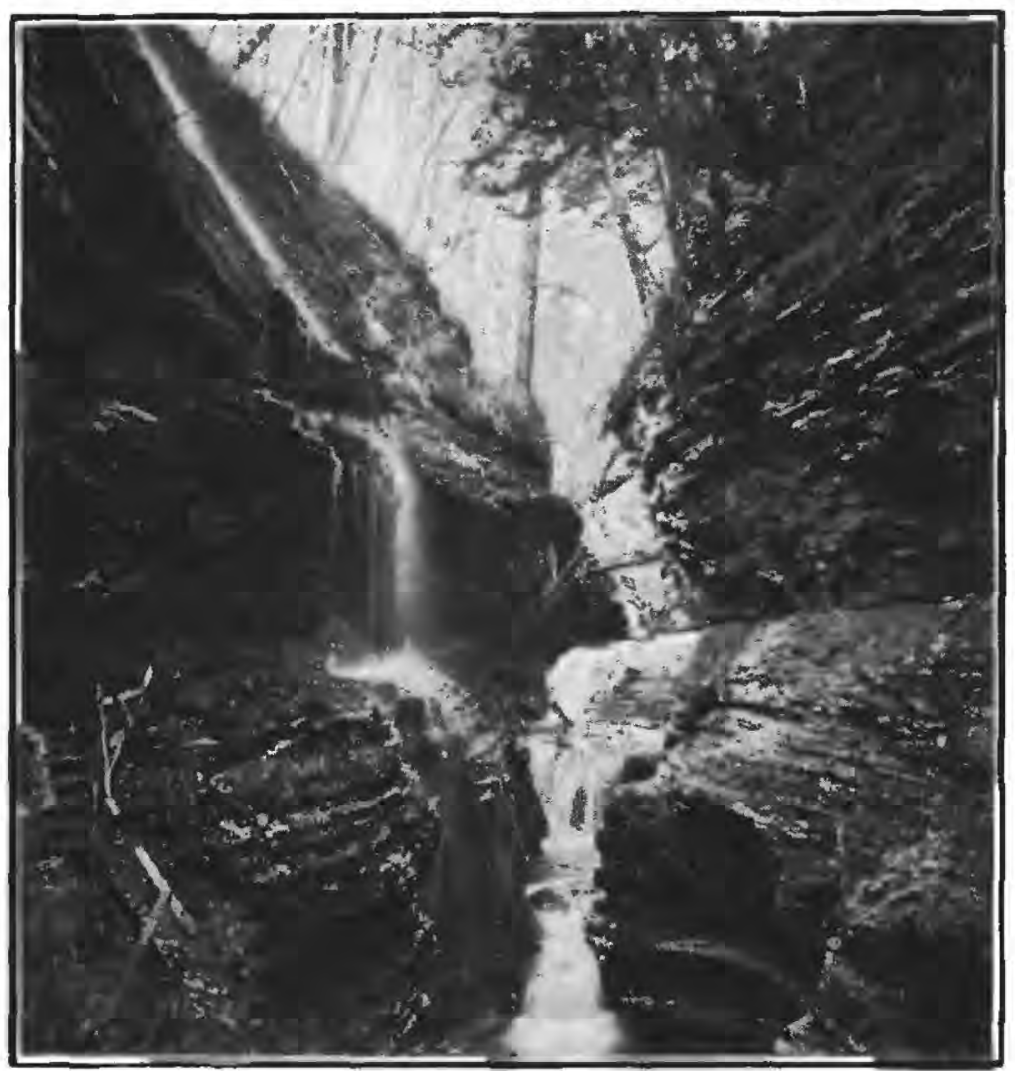

B.

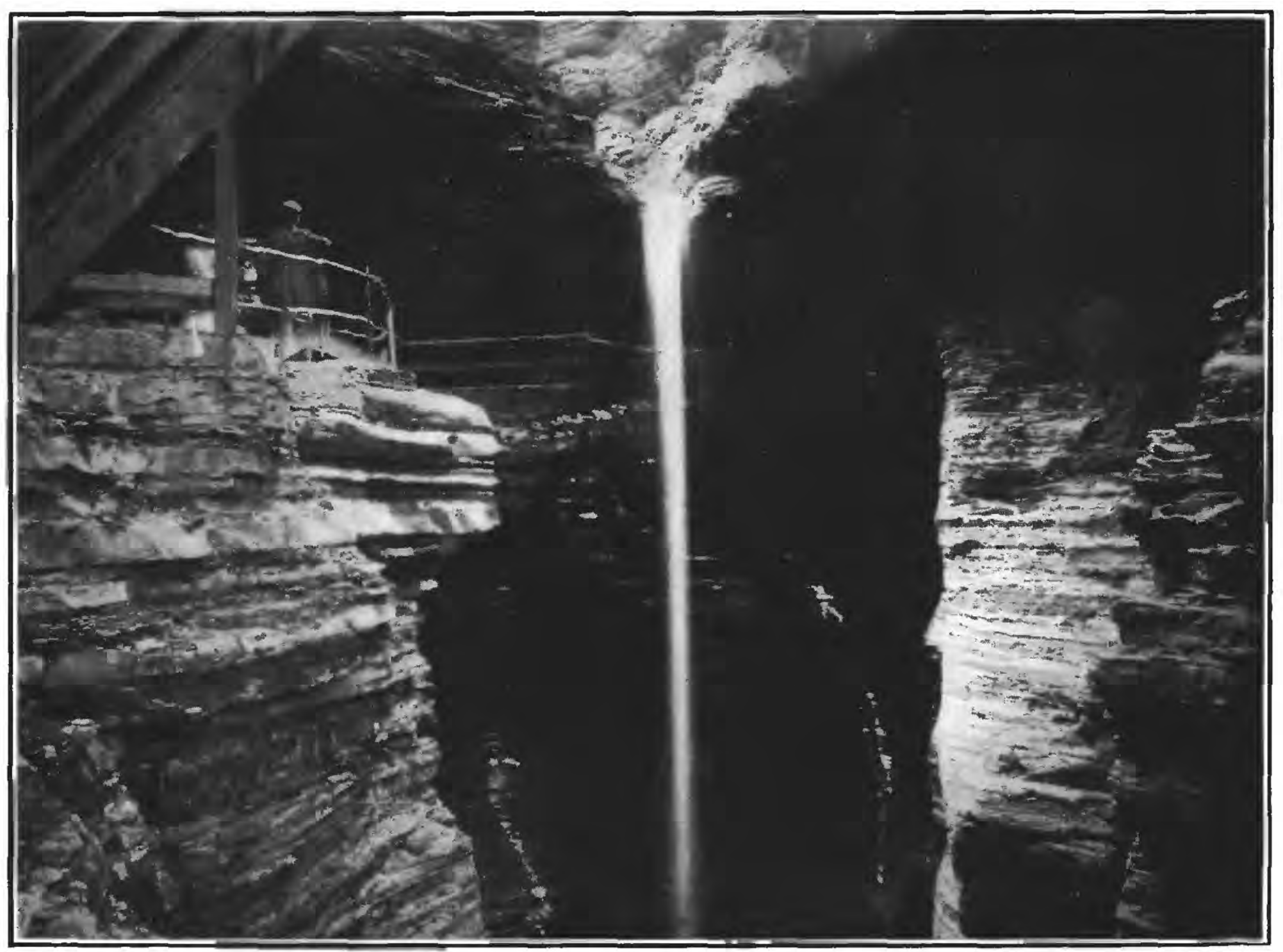

C.

VIEWS OF WATKINS GLEN. 


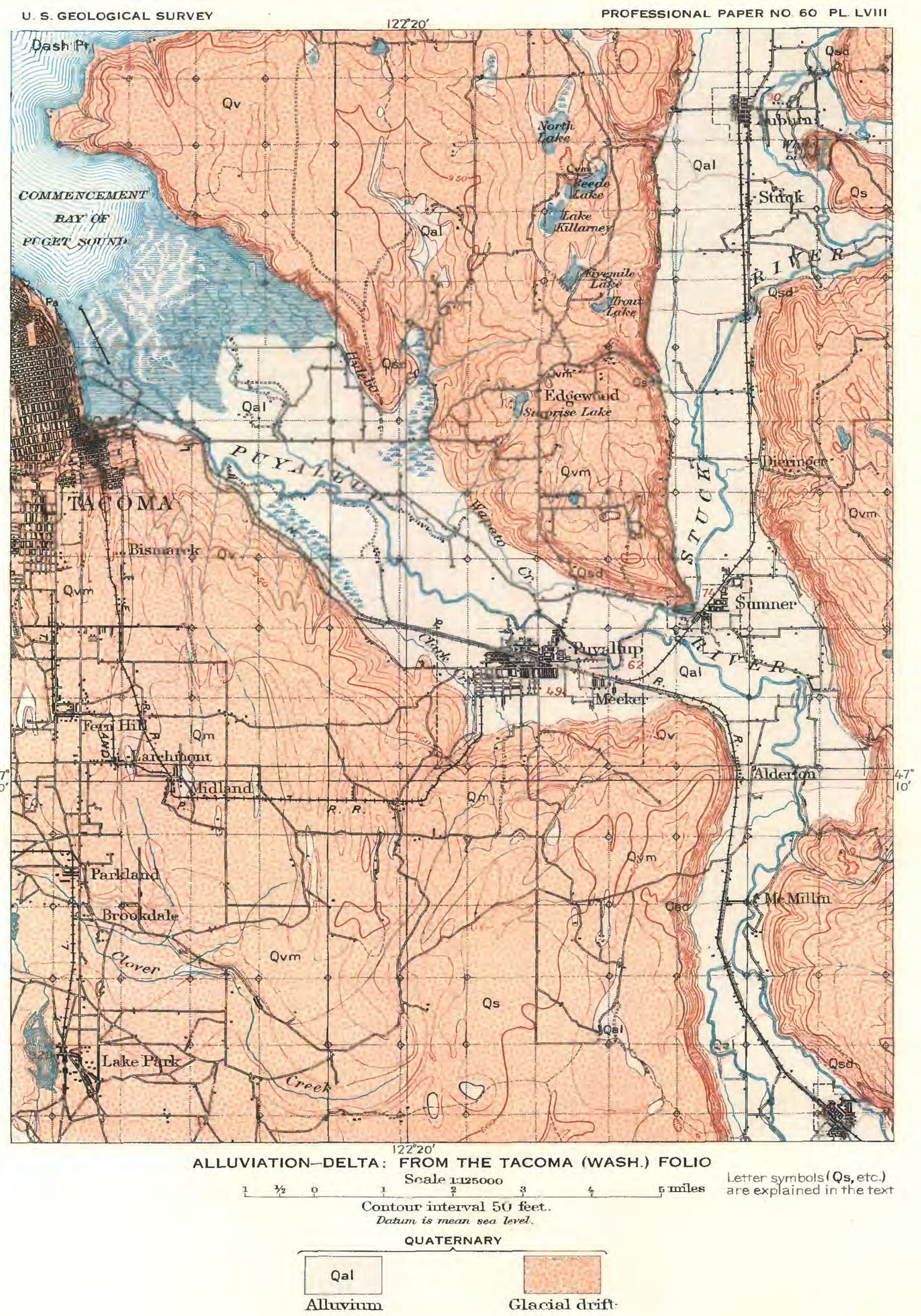




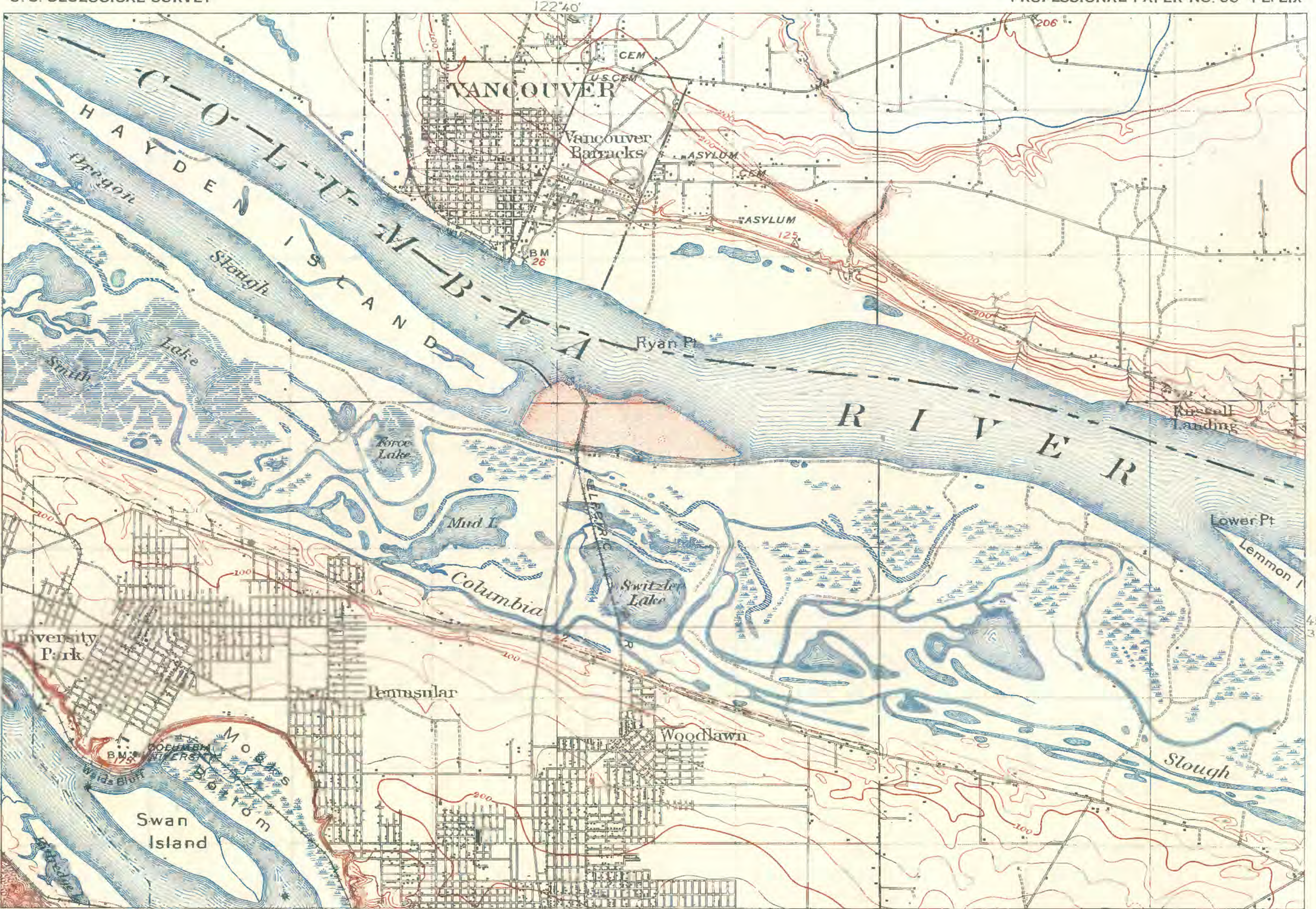

ALLUVIATION: PART OF PORTLAND (OREG.-WASH.) SHEET

$$
+\frac{9}{\text { Contour interral } 25} \text { f feet. }
$$




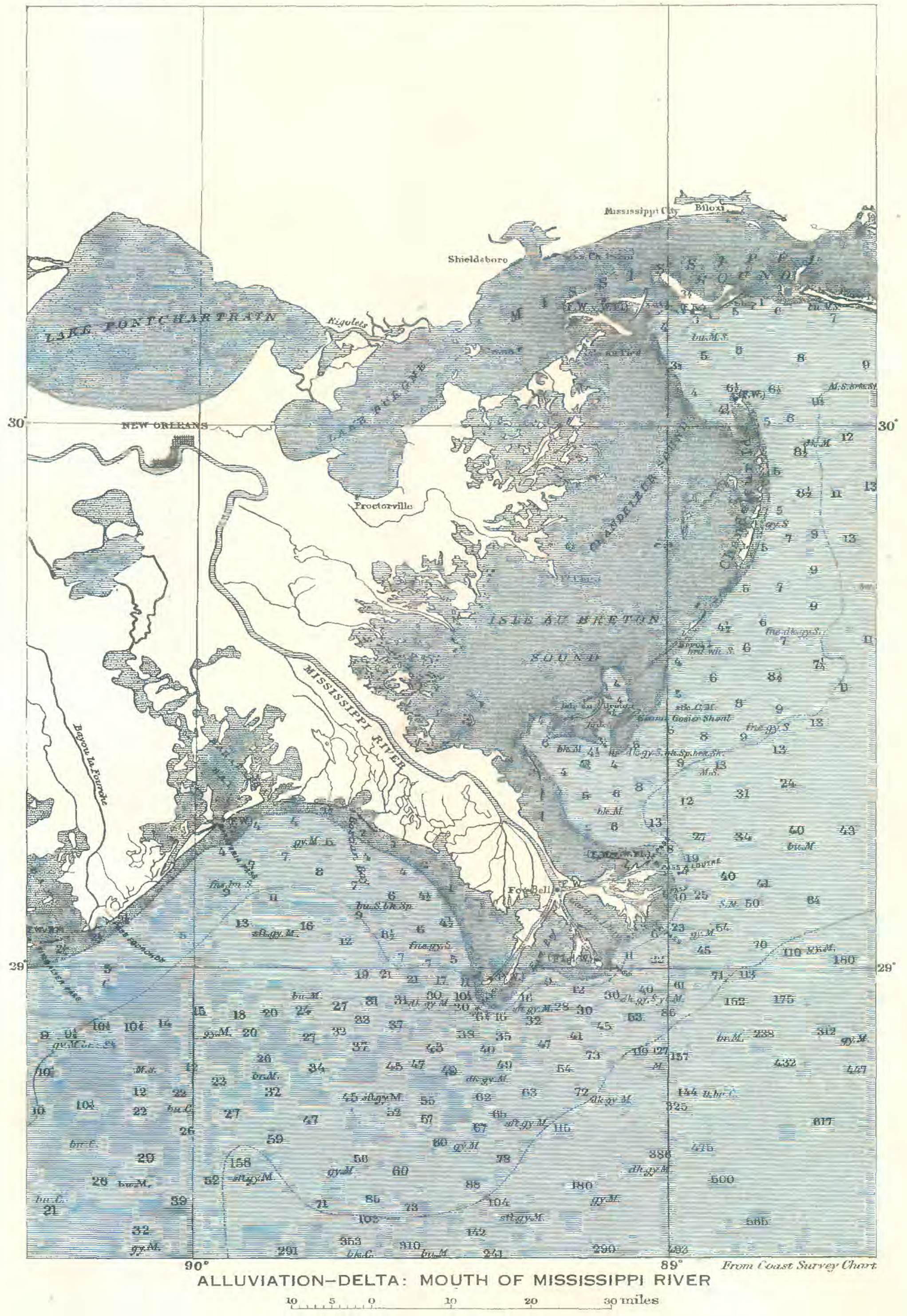




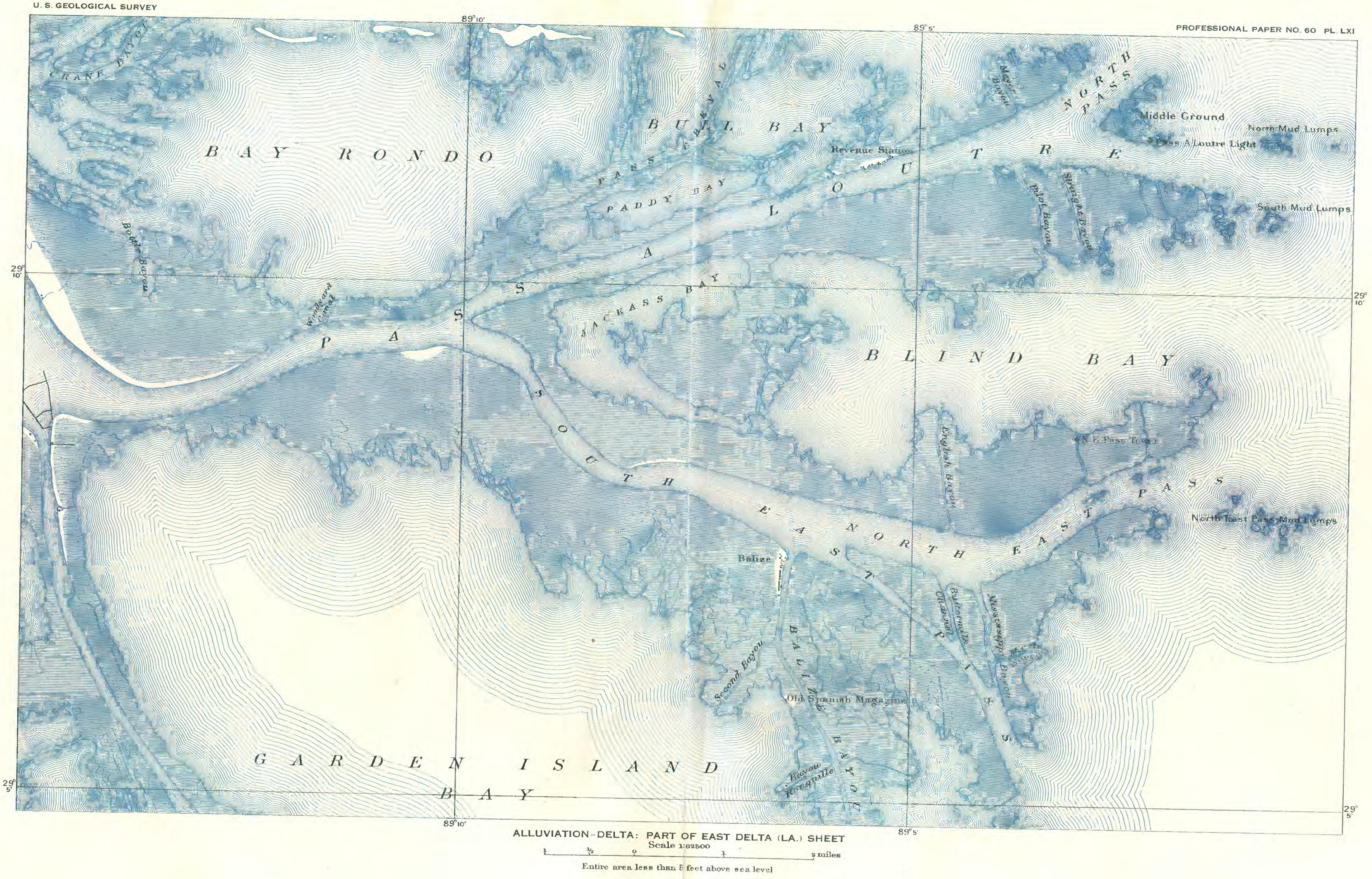




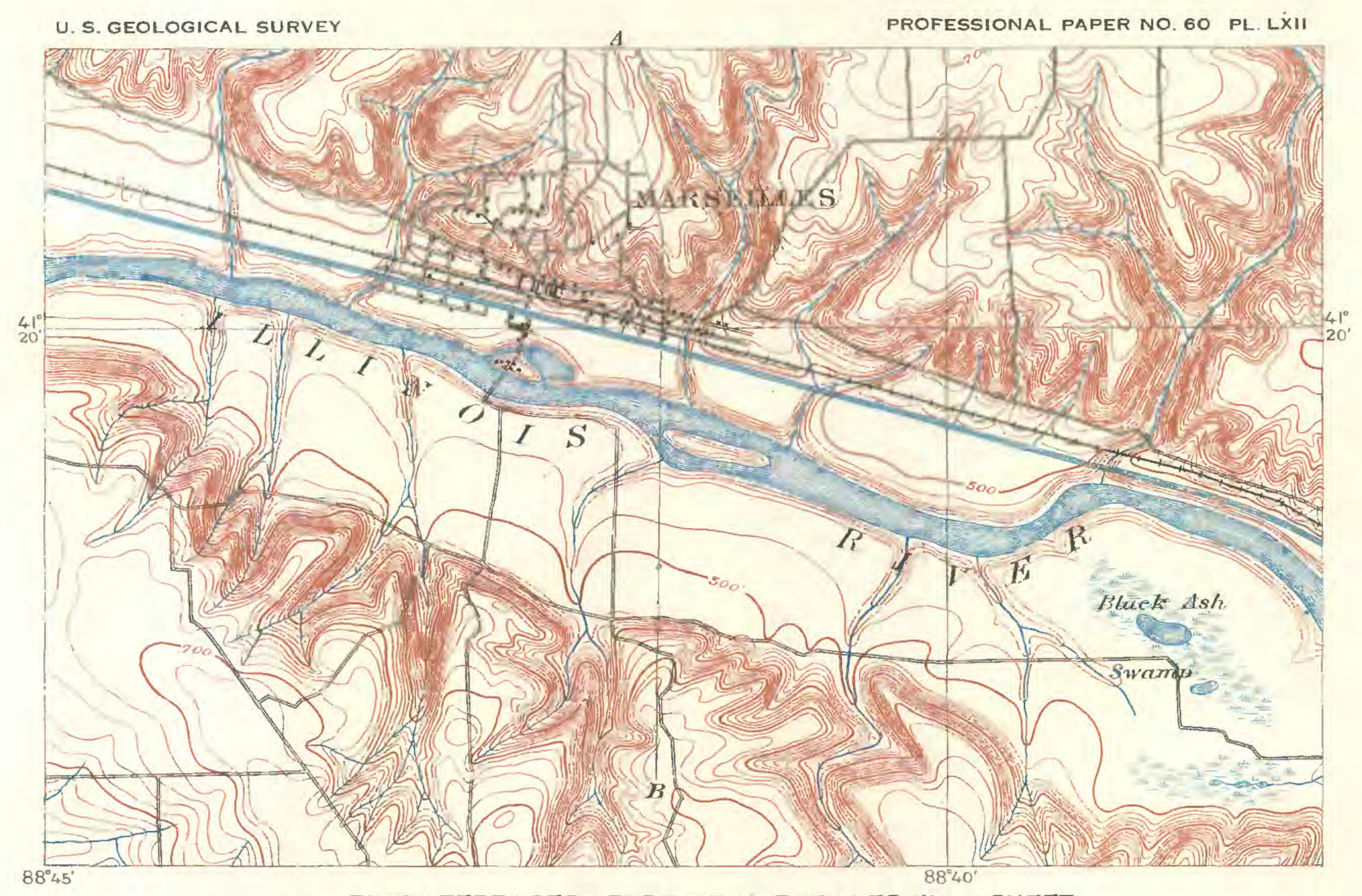

A. RIVER TERRACES: PART OF MARSEILLES (ILL.) SHEET

$1 / 2 \quad$ Scale 1:62500
$\begin{gathered}\text { Contour interval } 10 \text { feet. } \\ \text { Datum is meun sea levet. }\end{gathered}$

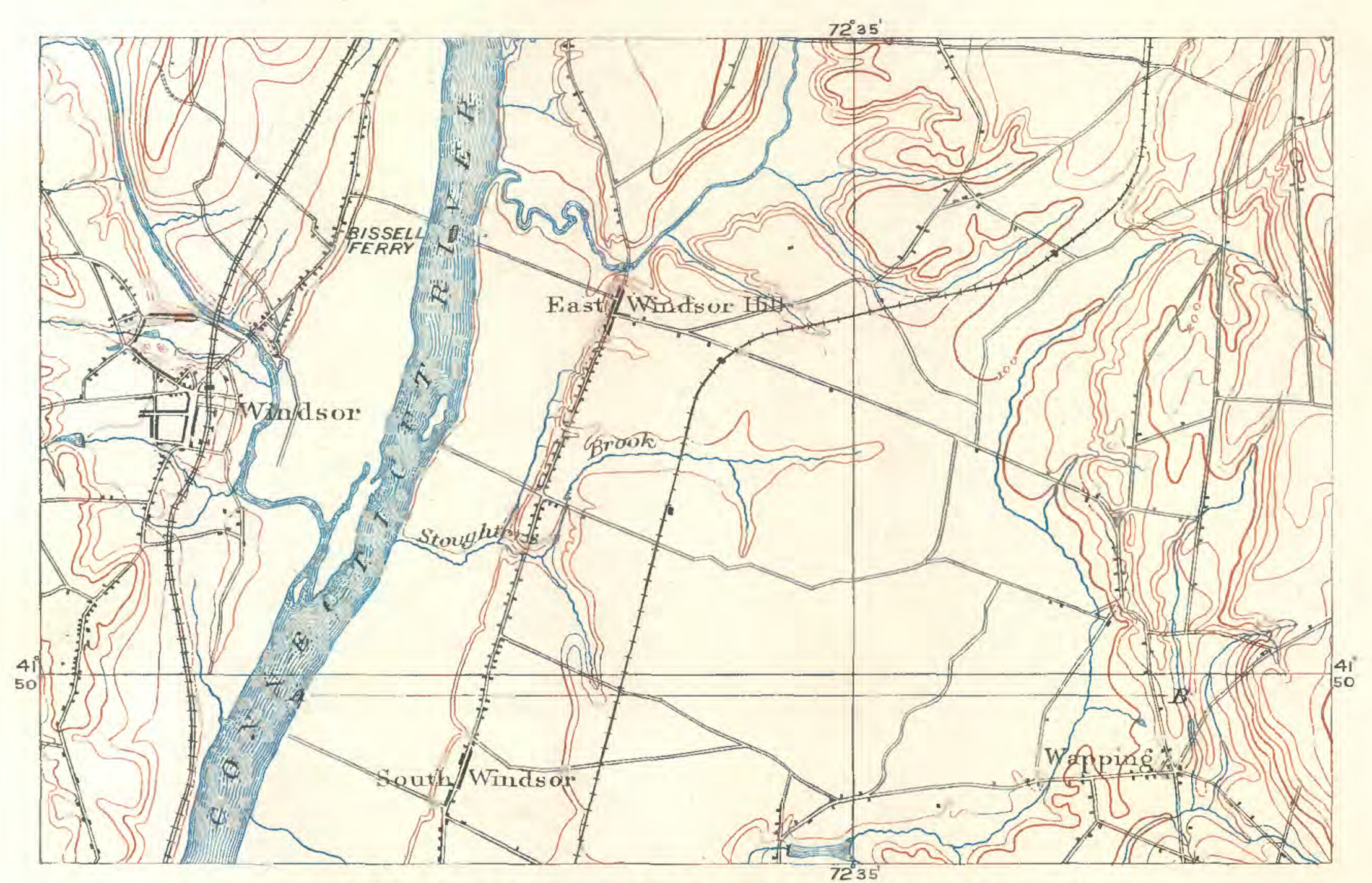

B. RIVER TERRACES: PART OF HARTFORD (CONN) SHEET

Scale 1:62500 


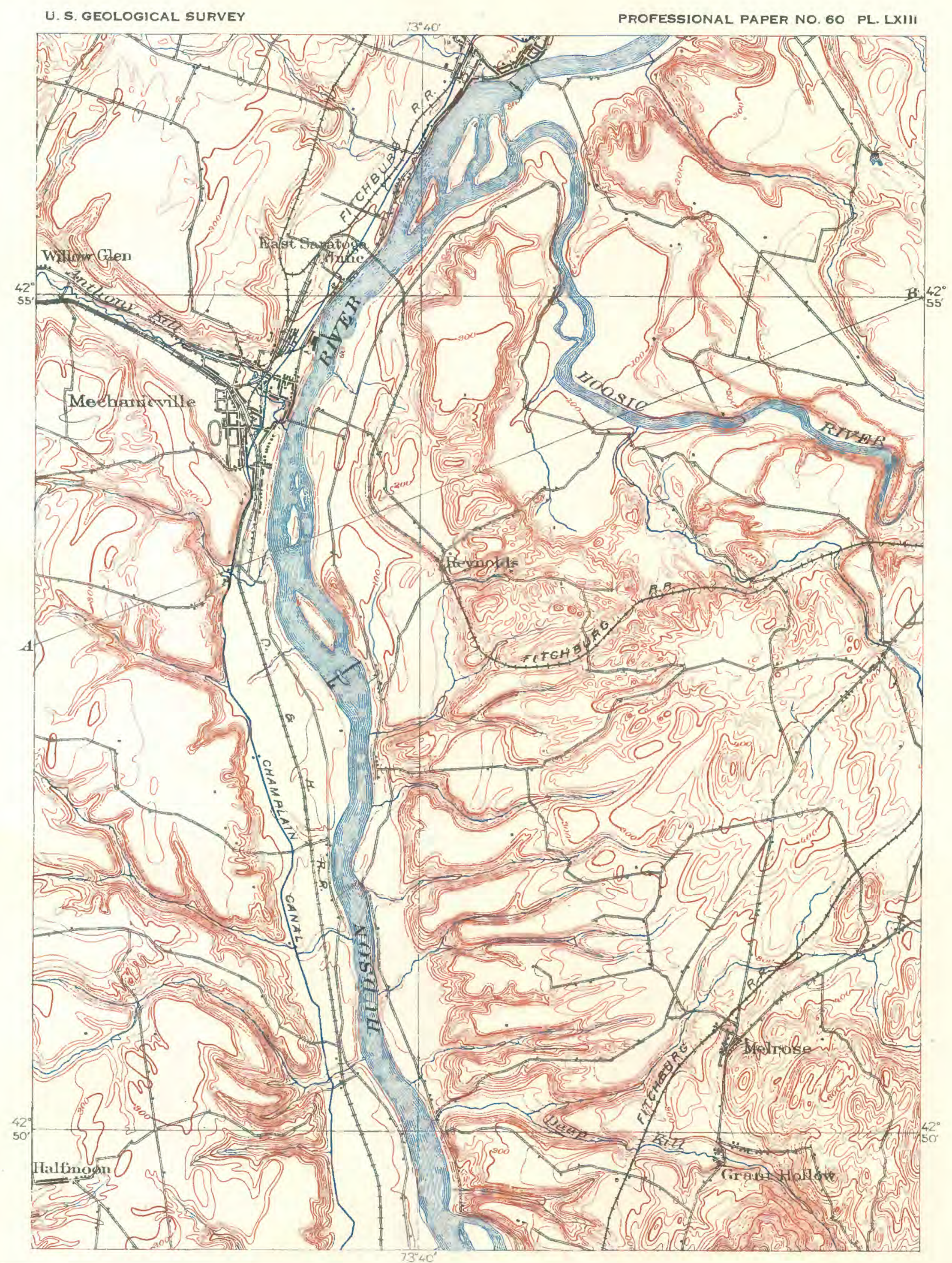

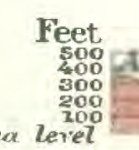

ALLUVIATION-RIVER TERRACES: PART OF COHOES (N. Y.) SHEET, WITH SECTION ON LINE A-B $x_{12} \quad$ Seale t:62500
Conthur interval 20 teet.
Dutam is nean sen level. 
U. S. GEOLOGICAL SURVEY

PROFESSIONAL PAPER NO. 60 PL. LXIV

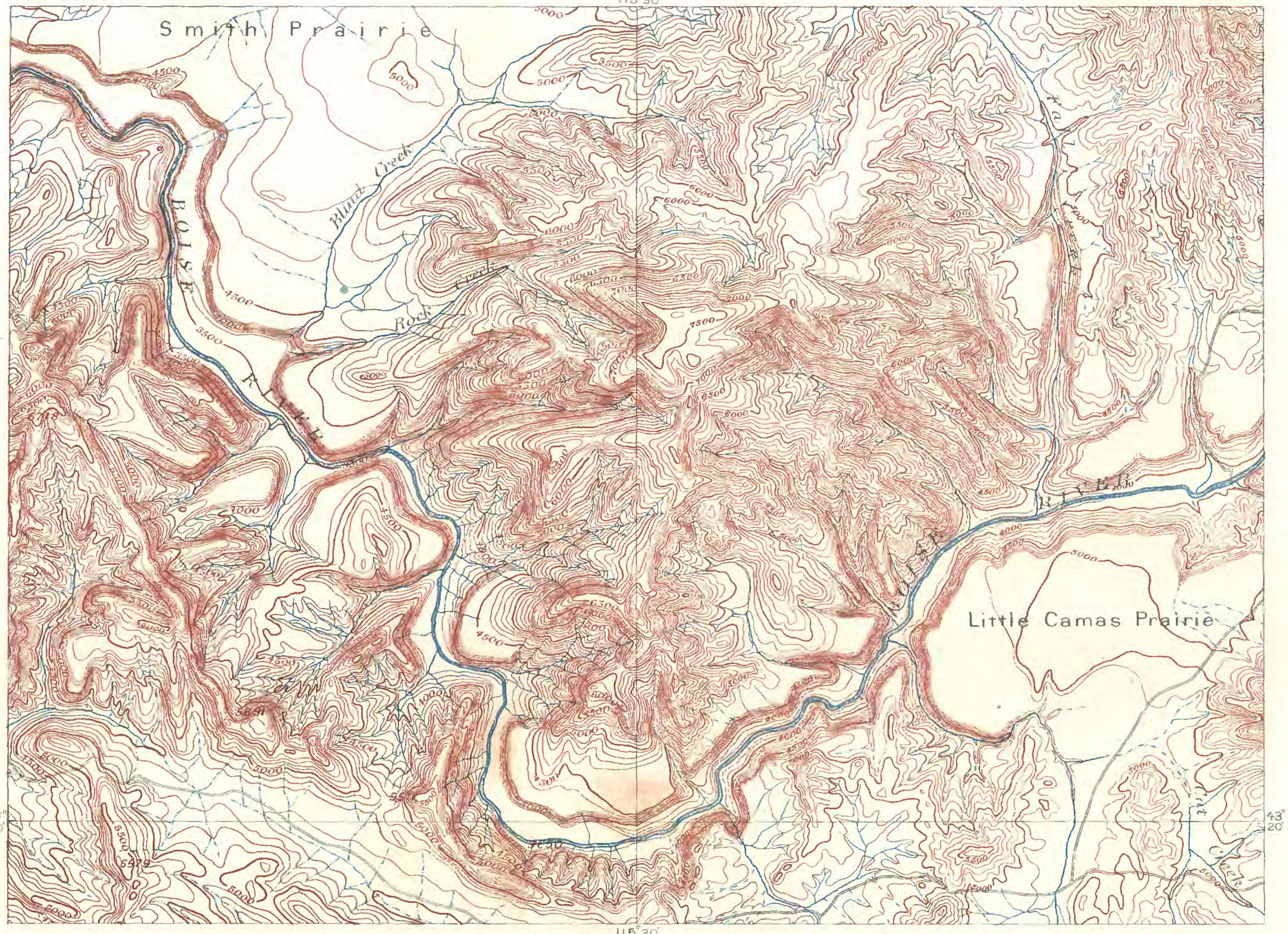

ALLUVIATION-RIVER TERRACES: PARTS OF MOUNTAIN HOME AND CAMAS PRAIRIE (IDAHO) SHEETS 


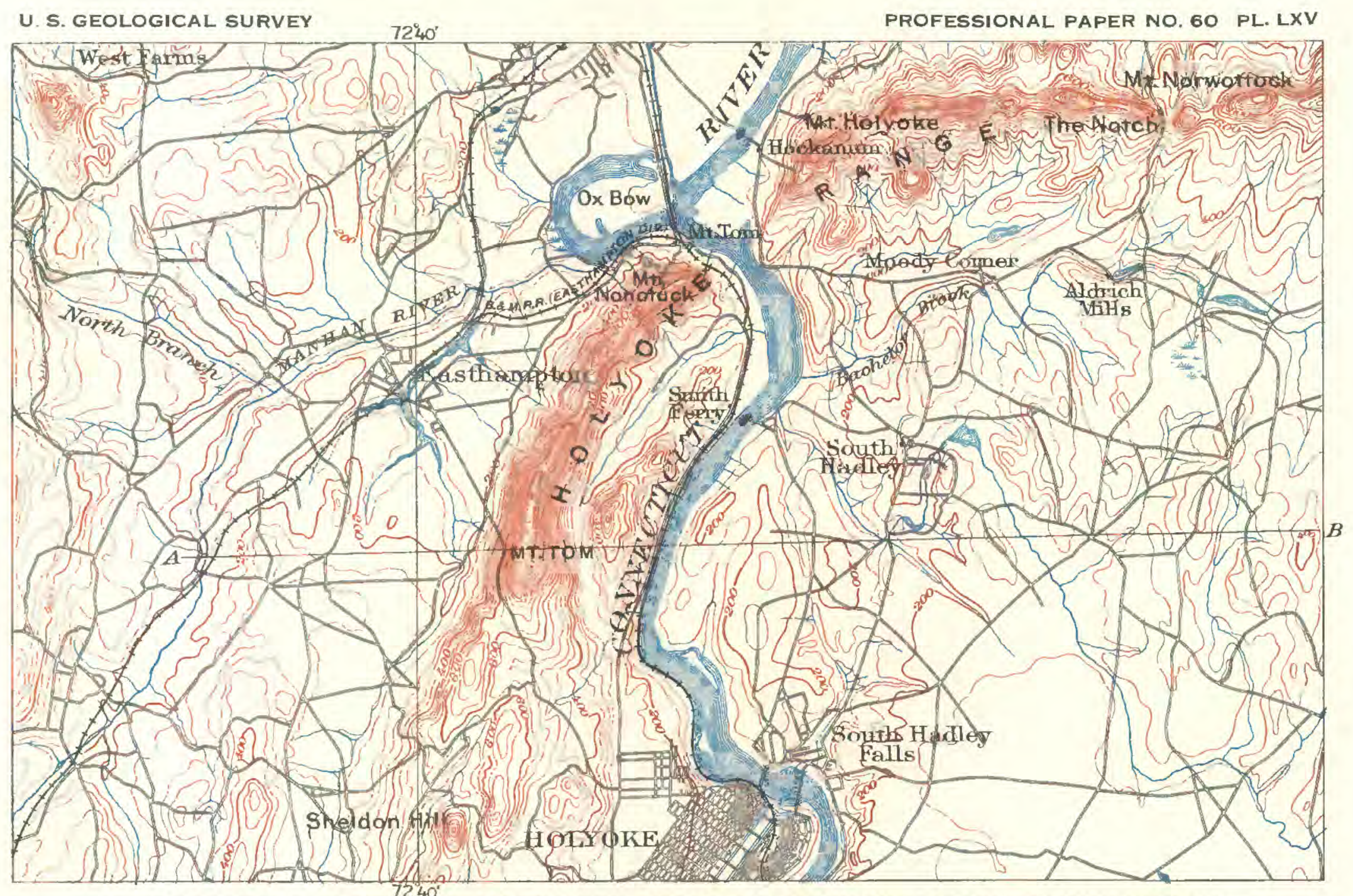

A. EFFECTS OF UNEQUAL HARDNESS: PART OF HOLYOKE (MASS.-CONN.) SHEET

Contour interval 40 feet.
Datum is mean sea level

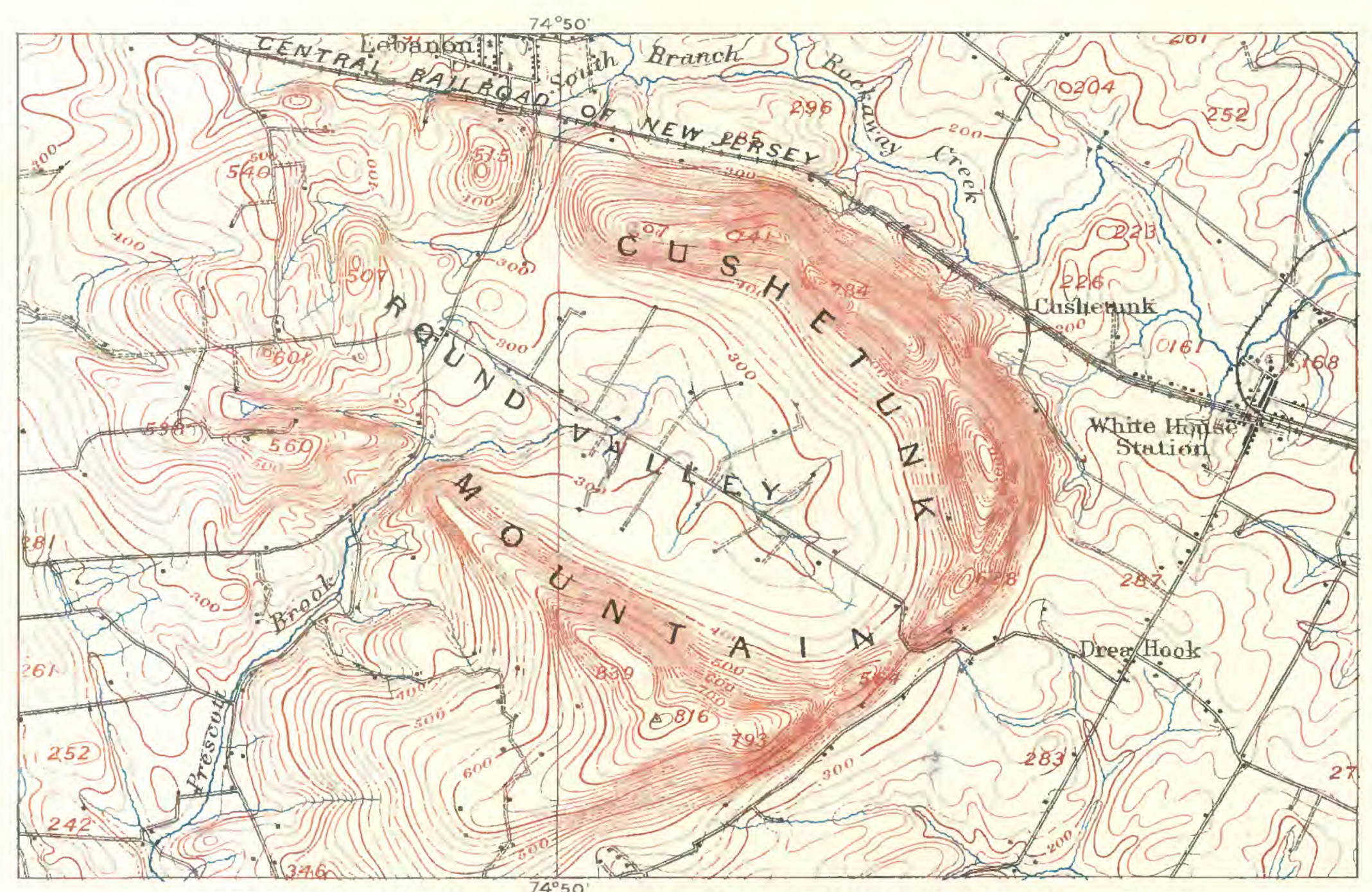

B. EFFECTS OF UNEQUAL HARDNESS: PART OF HIGH BRIDGE (N. J.) SHEET

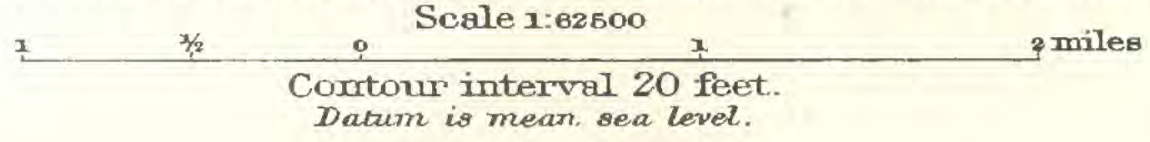




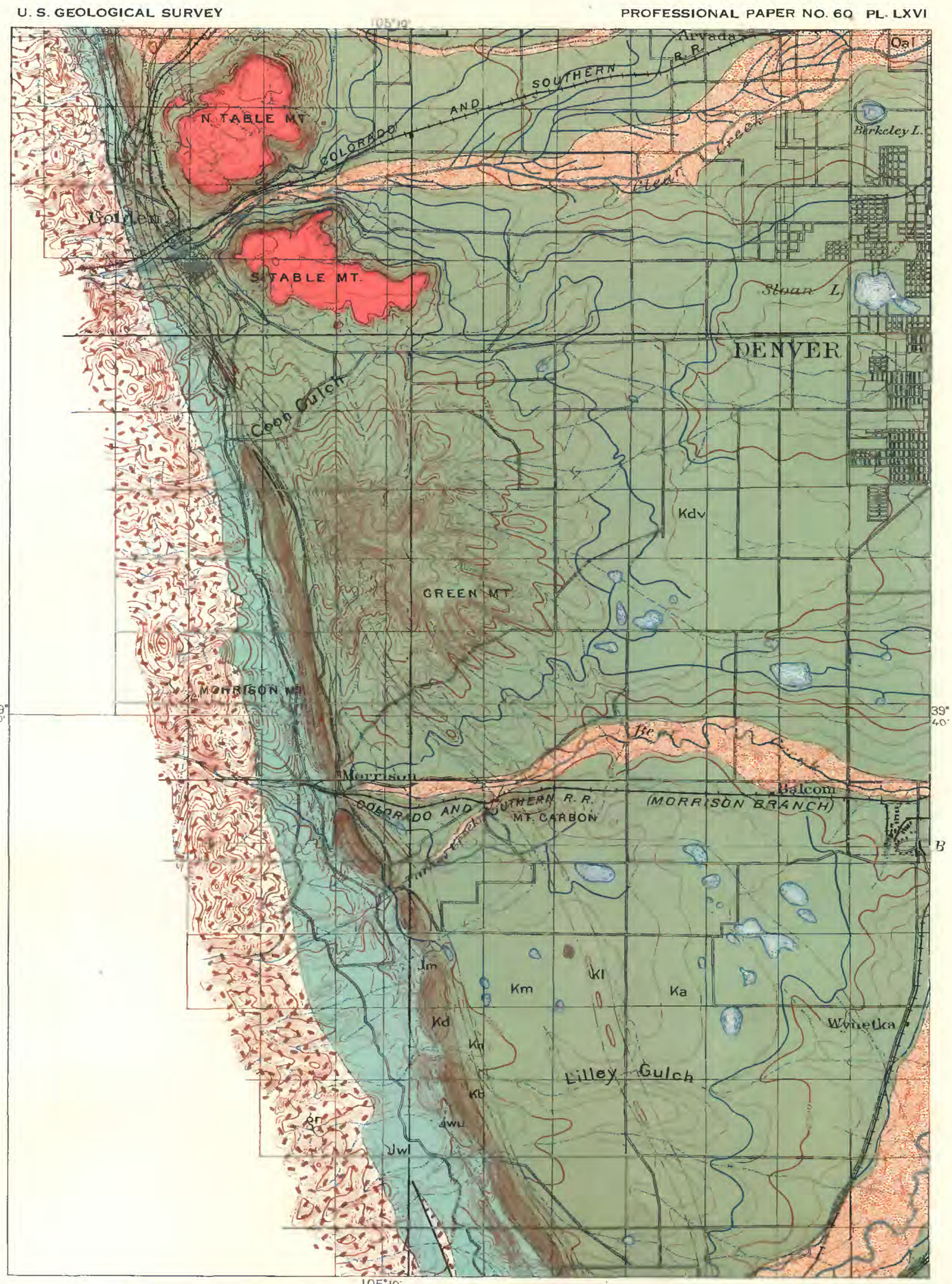

EFFECTS OF UNEQUAL HARDNESS: PART OF DENVER (COLO.) QUADRANGLE

$3 \quad 3 / 2 \quad 0 \quad 3 \quad$ Scale $1: 125000,5$ miles Letter symbols ( $\mathrm{Km}$, etc.) Contour interval 50 and 100 feet.

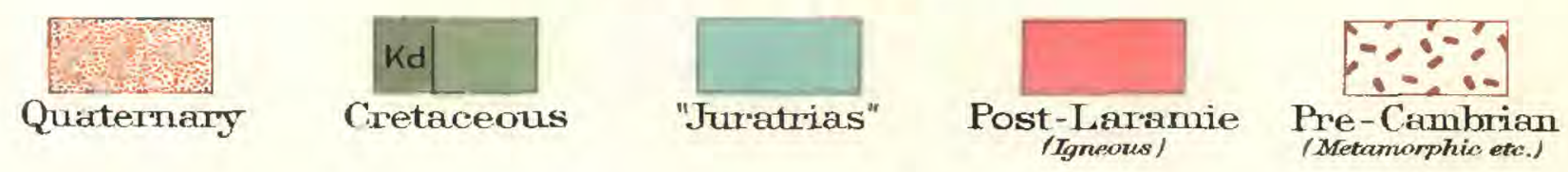




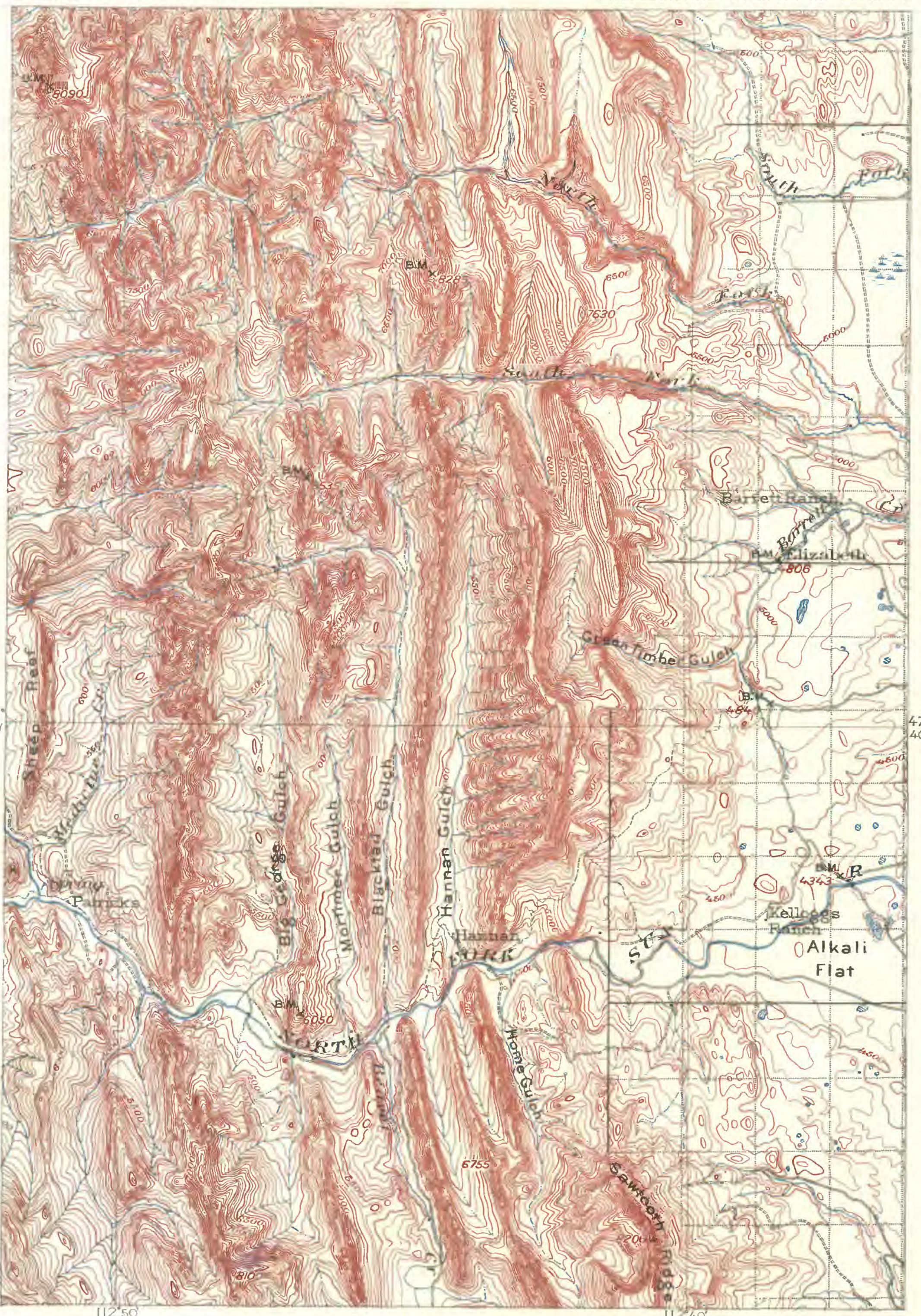

EFFECTS OF UNEQUAL HARDNESS: PART OF SAYPO (MONT.) SHEET 


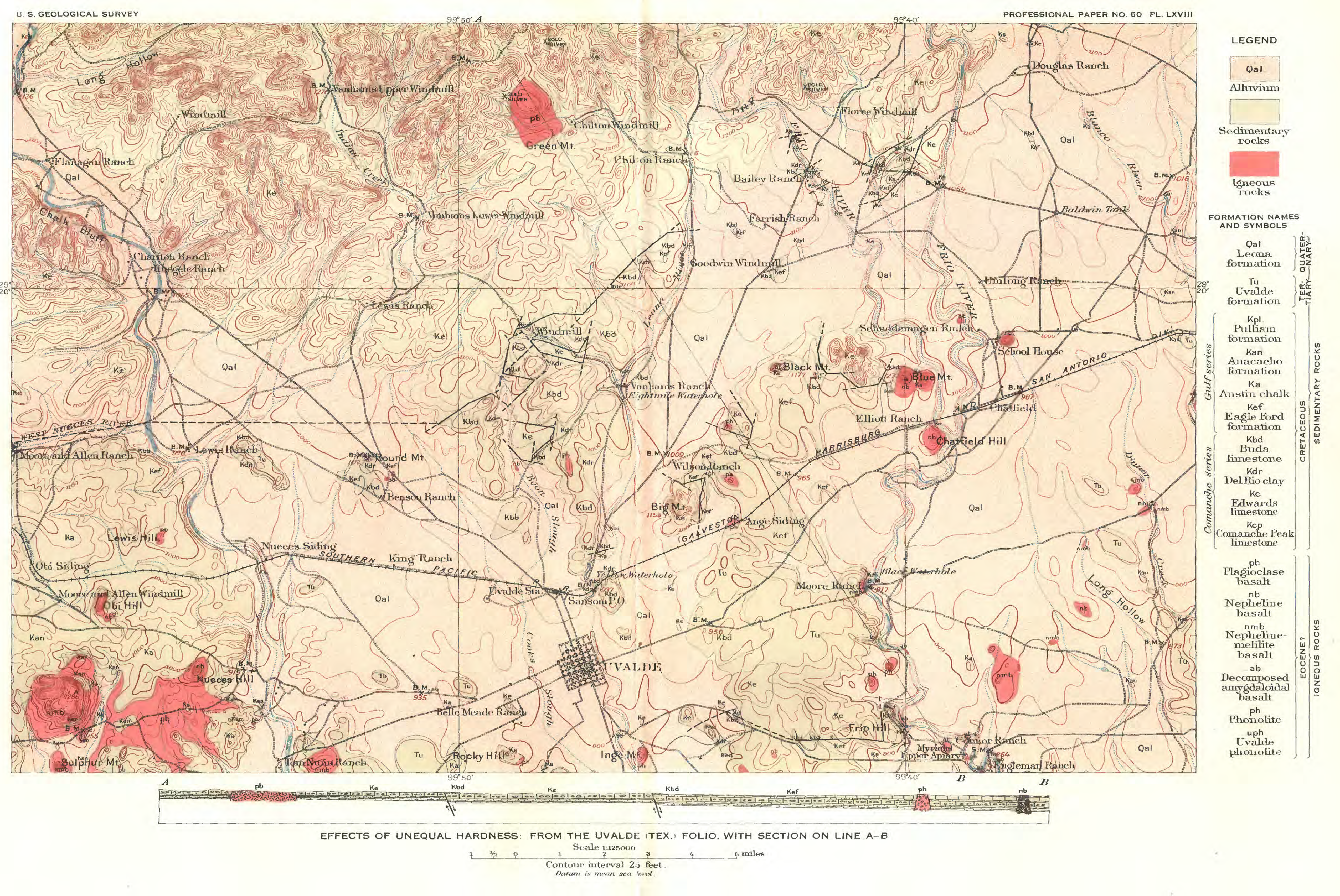




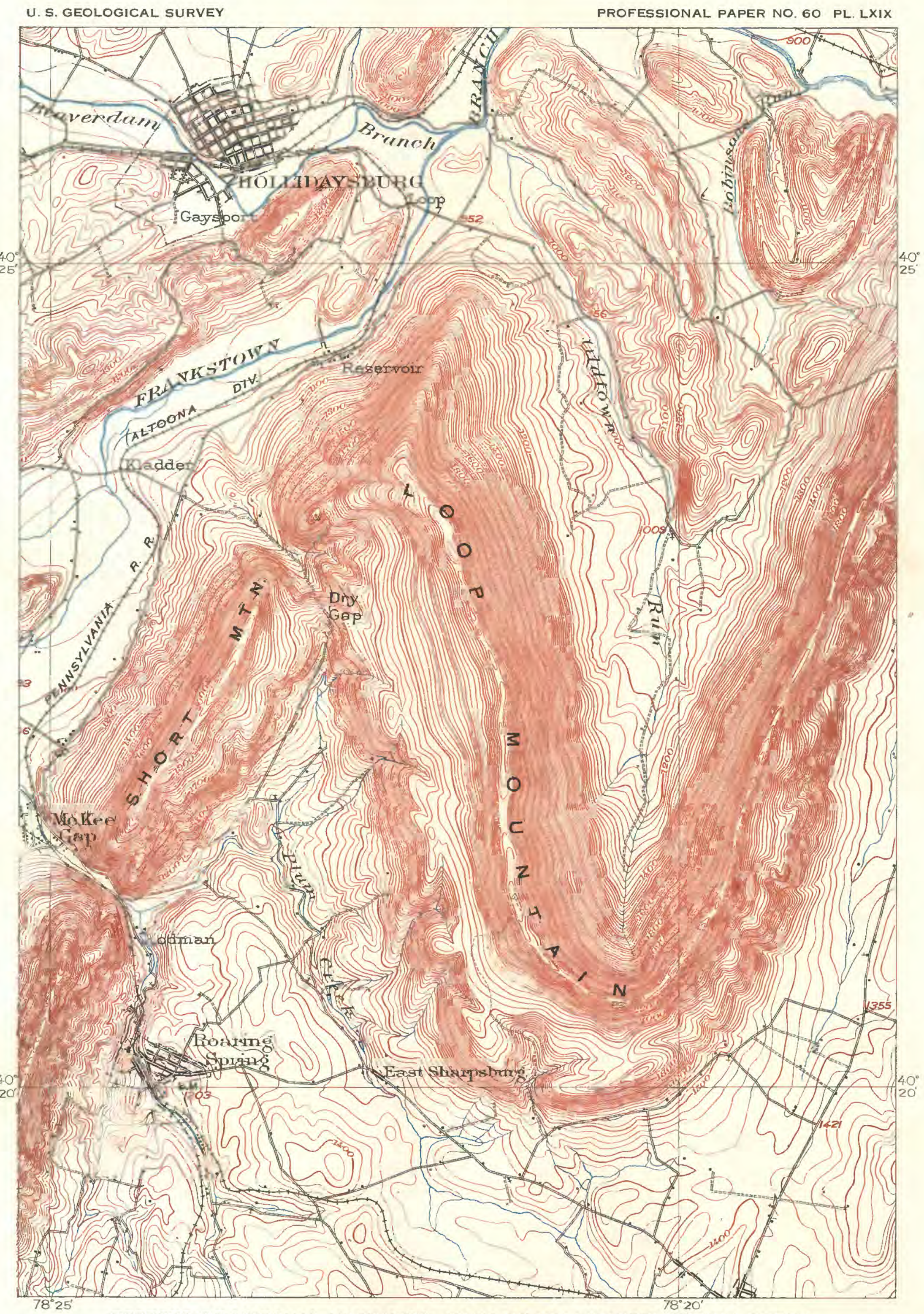

EFFECTS OF UNEQUAL HARDNESS: PART OF HOLLIDAYSBURG (PA.) SHEET

$1 / 2$ Scale 1:62500 miles 


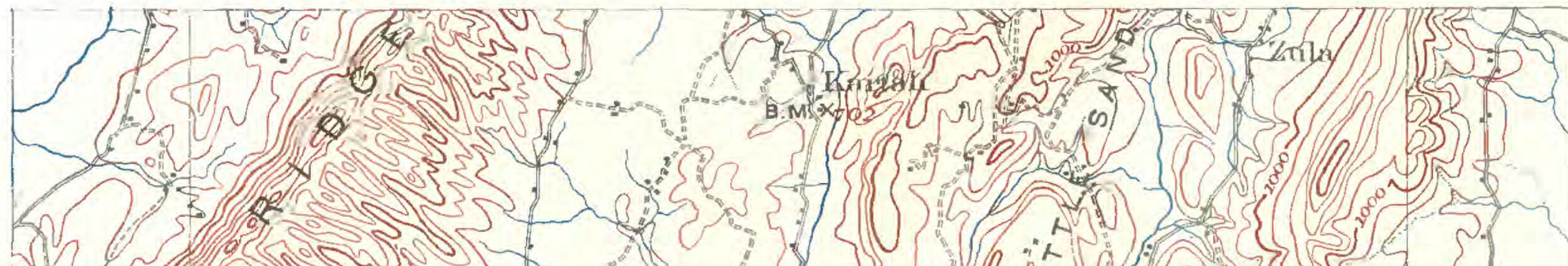

by

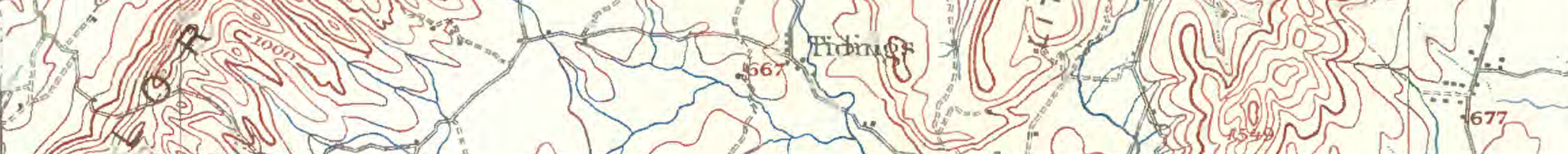
3)

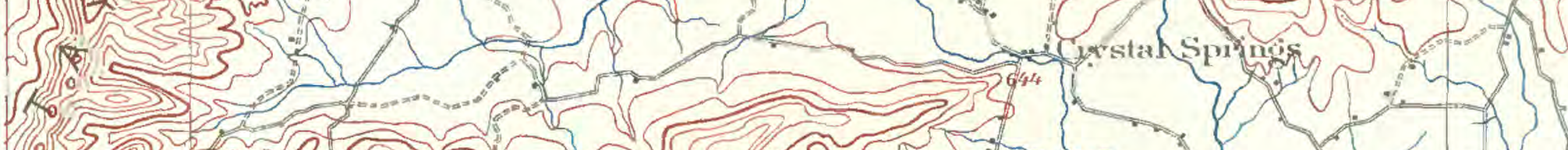

(3)

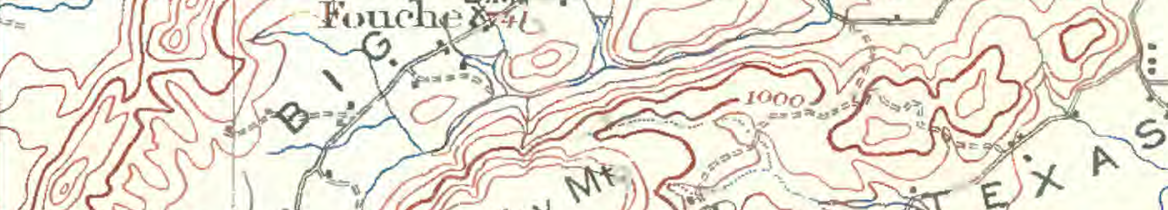

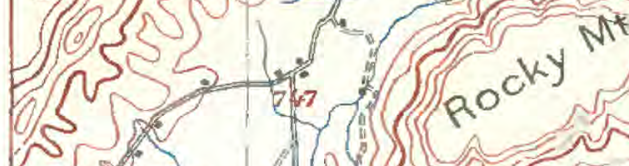

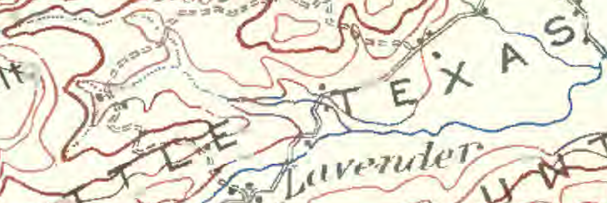

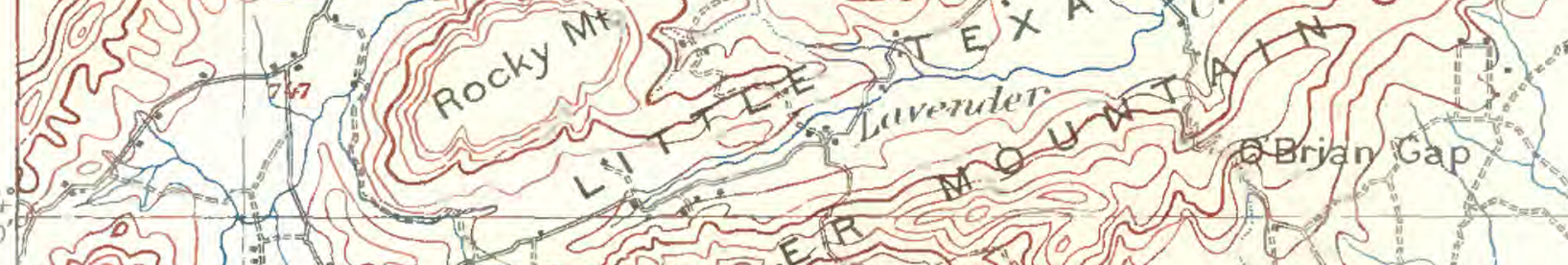

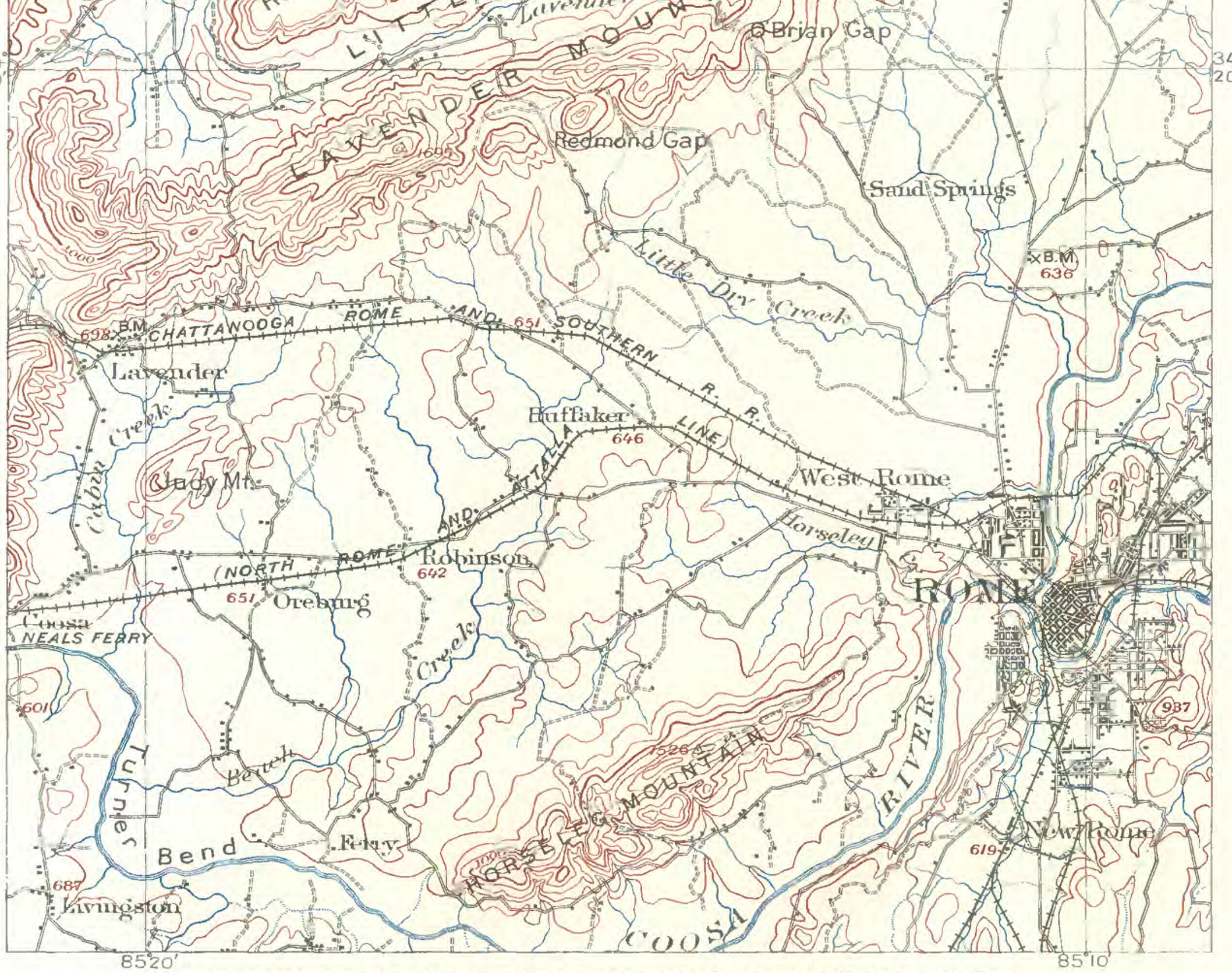

EFFECTS OF UNEQUAL HARDNESS: PART OF ROME (GA.) SHEET 


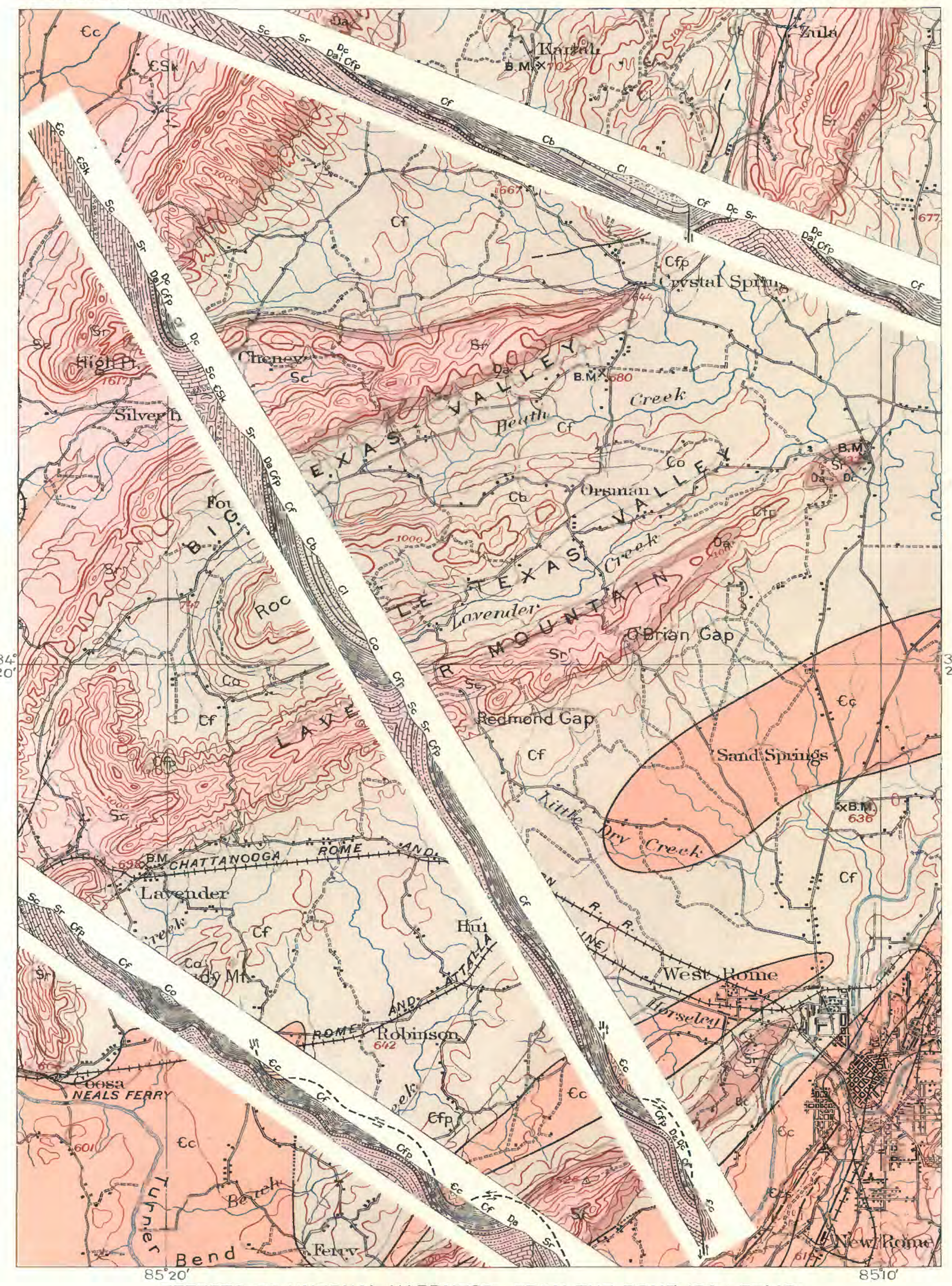

EFFECTS OF UNEQUAL HARDNESS: FROM THE ROME (GA.) FOLIO

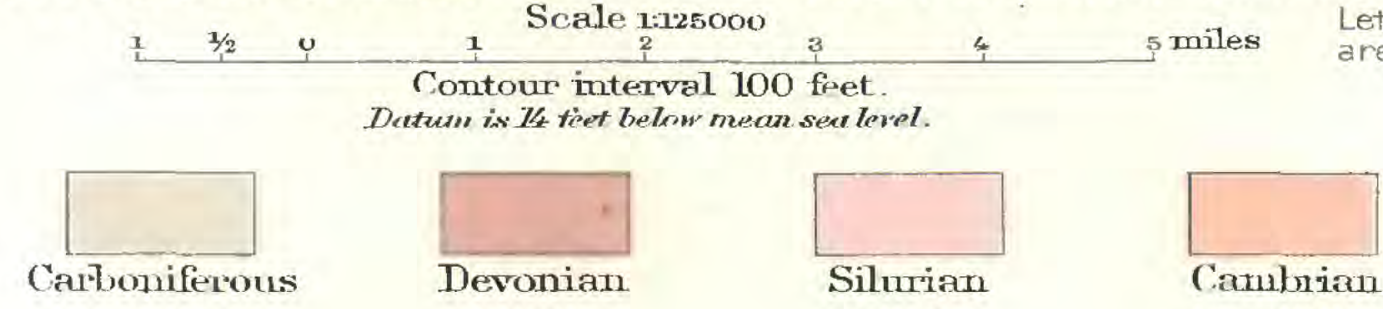




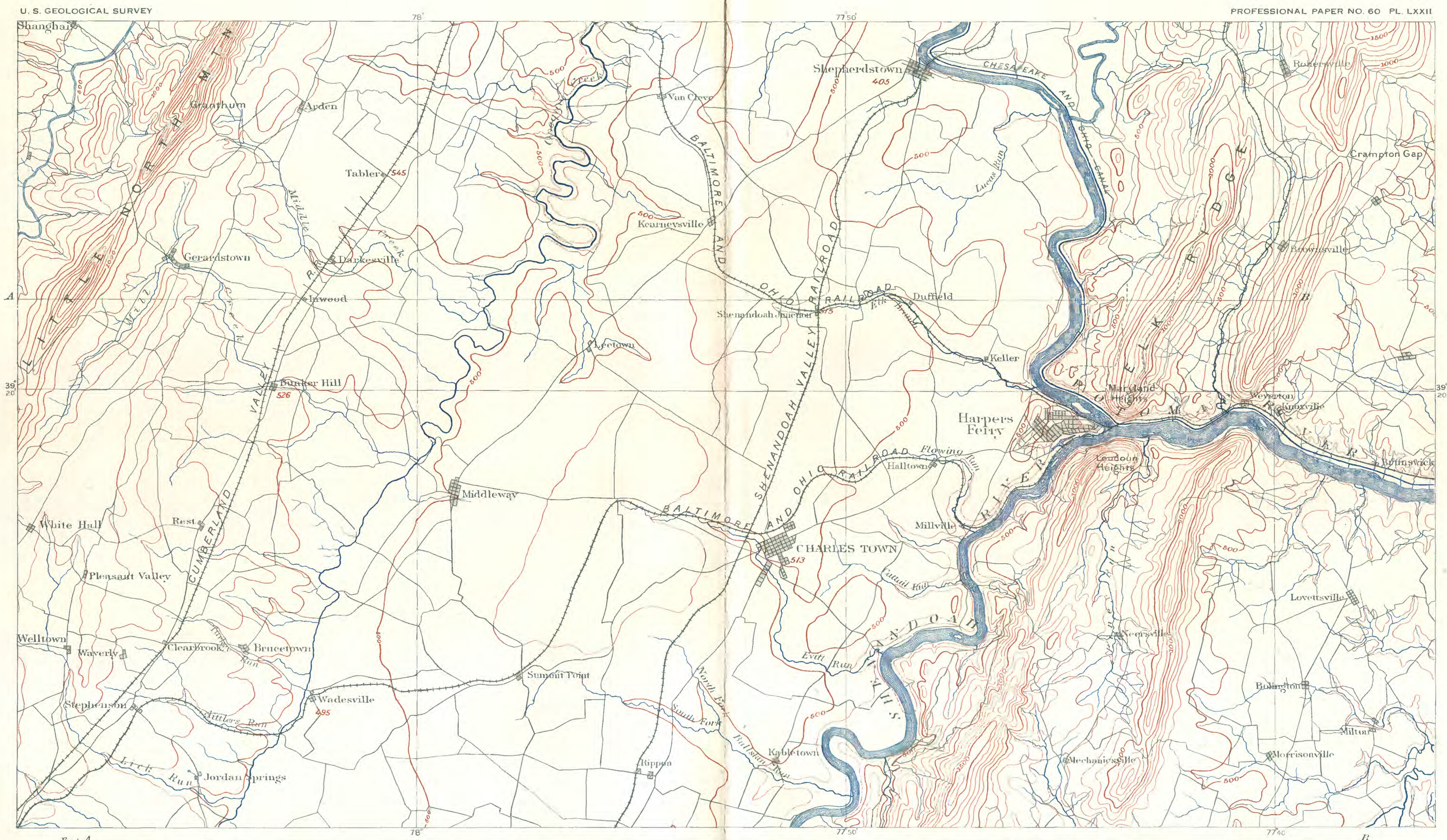




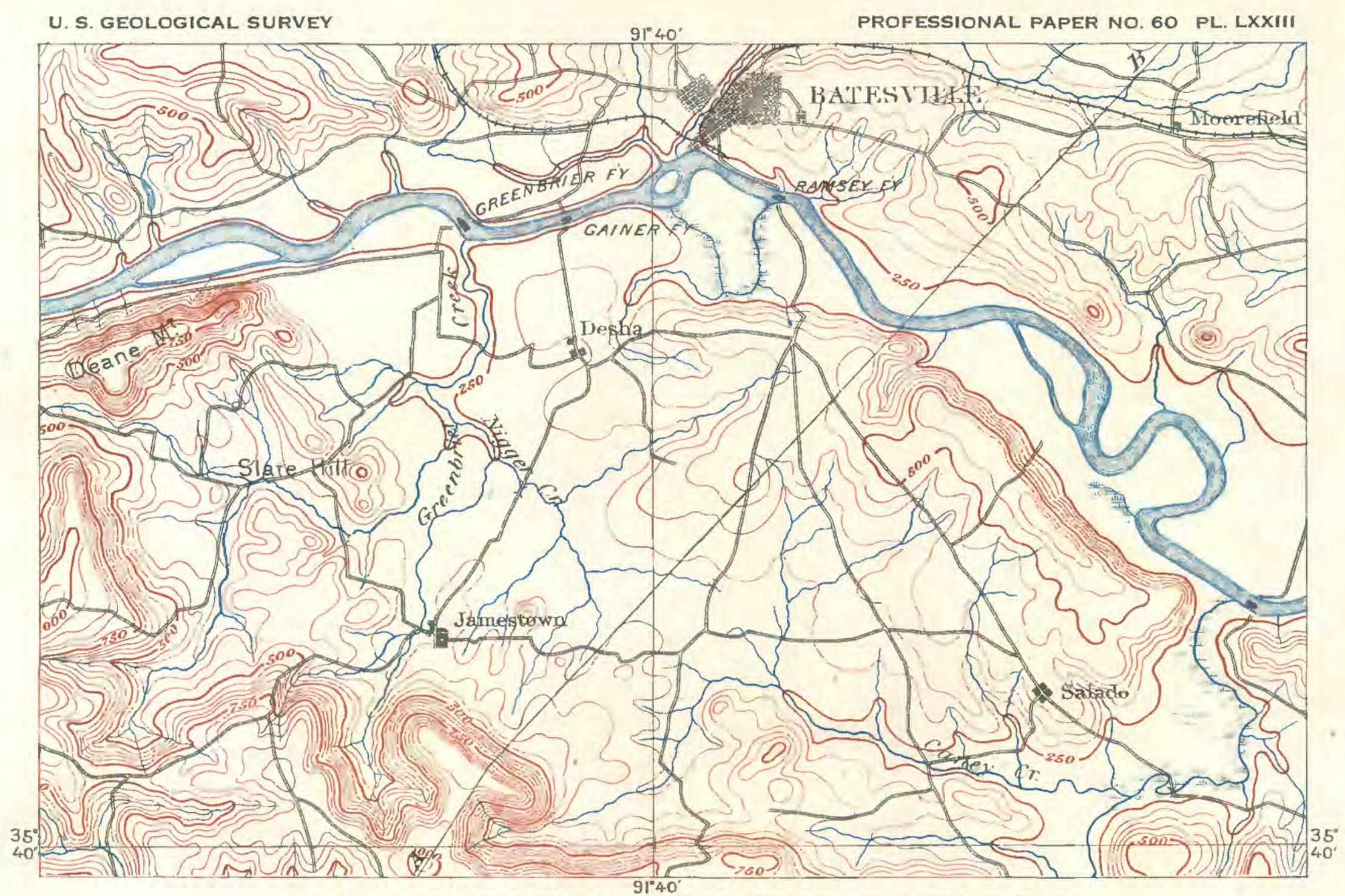

A. EROSION CYCLES: PART OF BATESVILLE (ARK.) SHEET

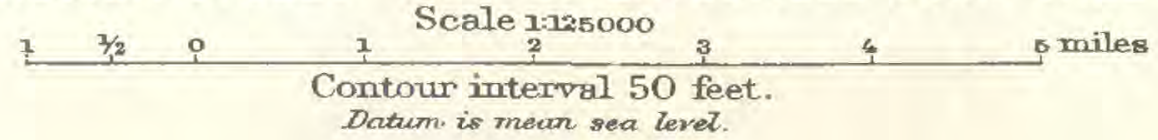

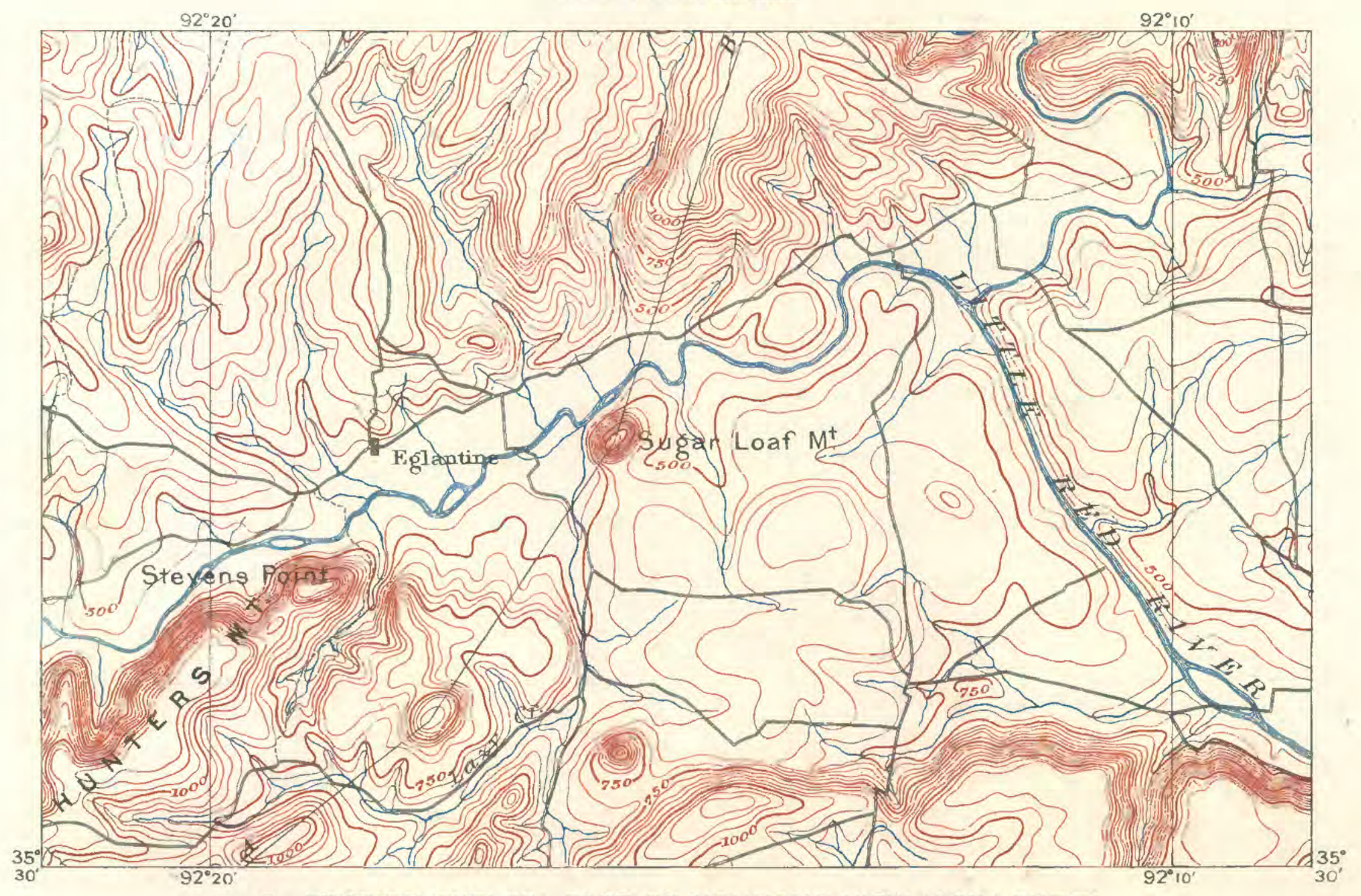

B. EROSION CYCLES: PART OF MOUNTAIN VIEW (ARK.) SHEET

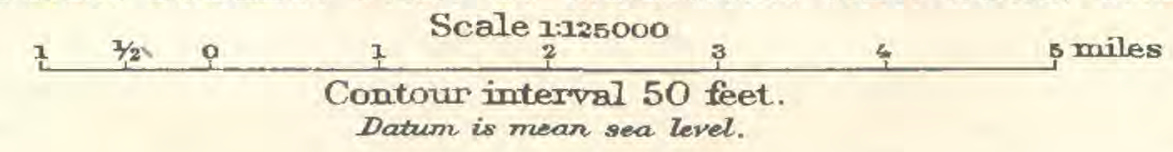




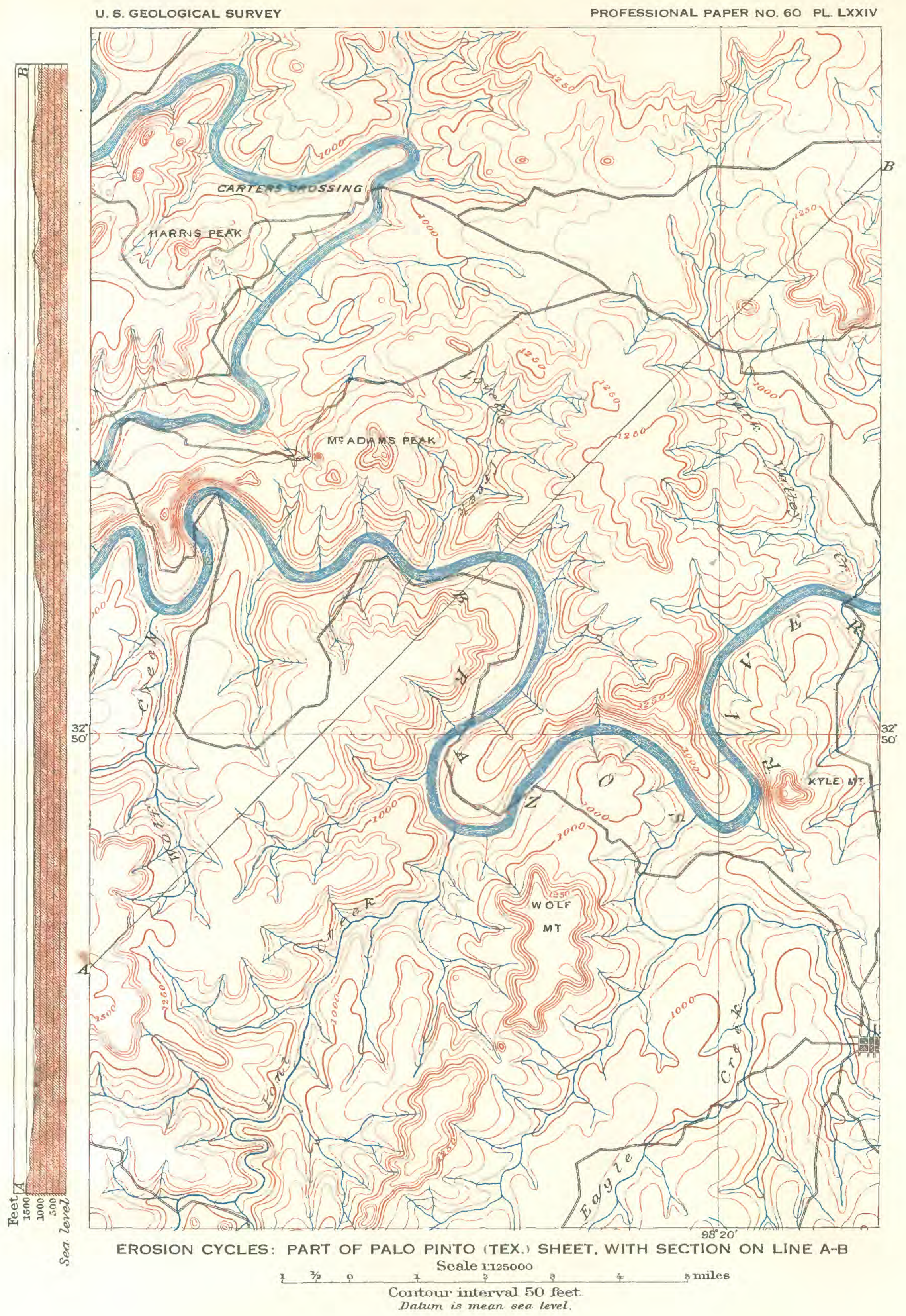




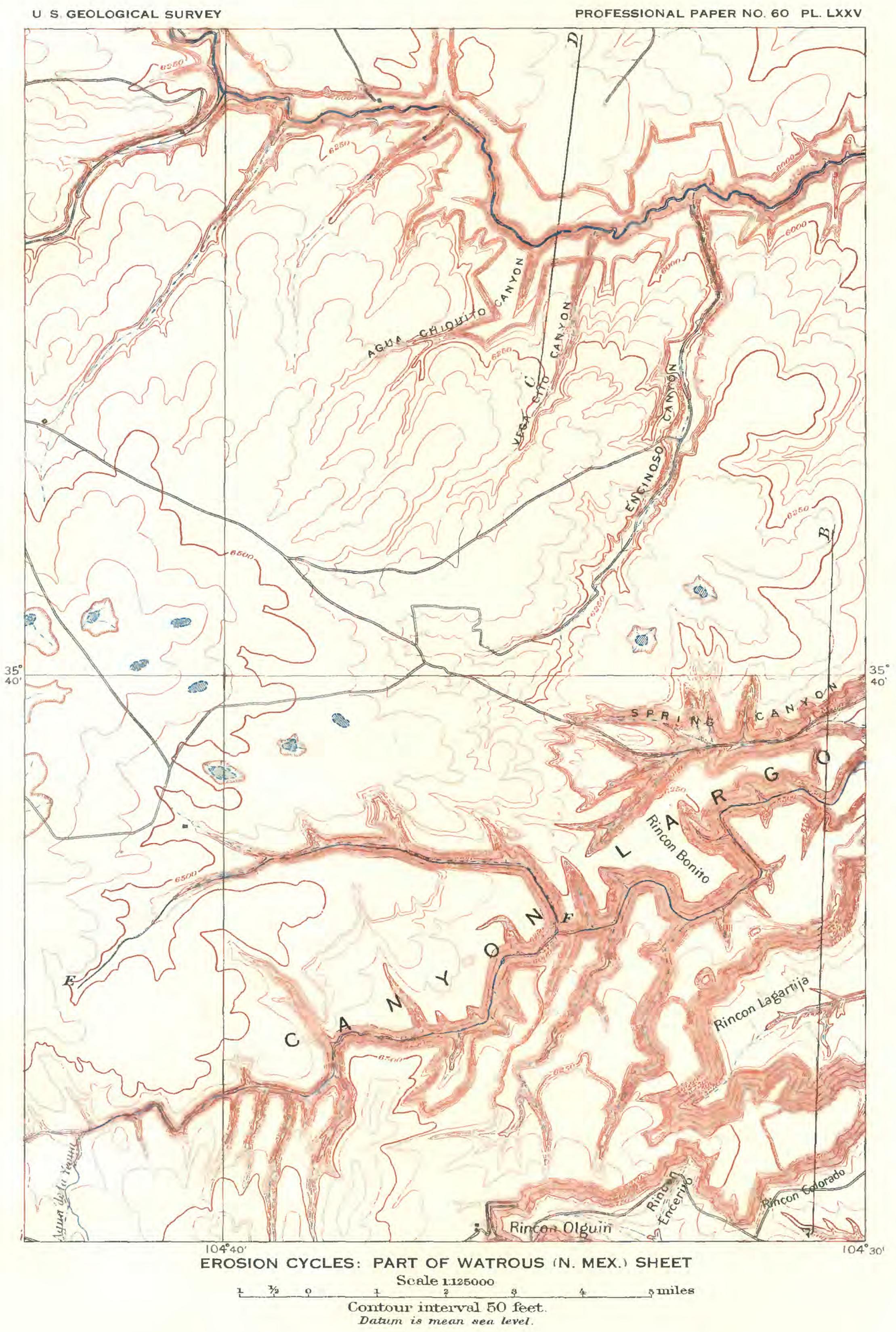


U. S. GEOLOGICAL SURVEY

PROFESSIONAL PAPER NO, 60 PL. LXXVI
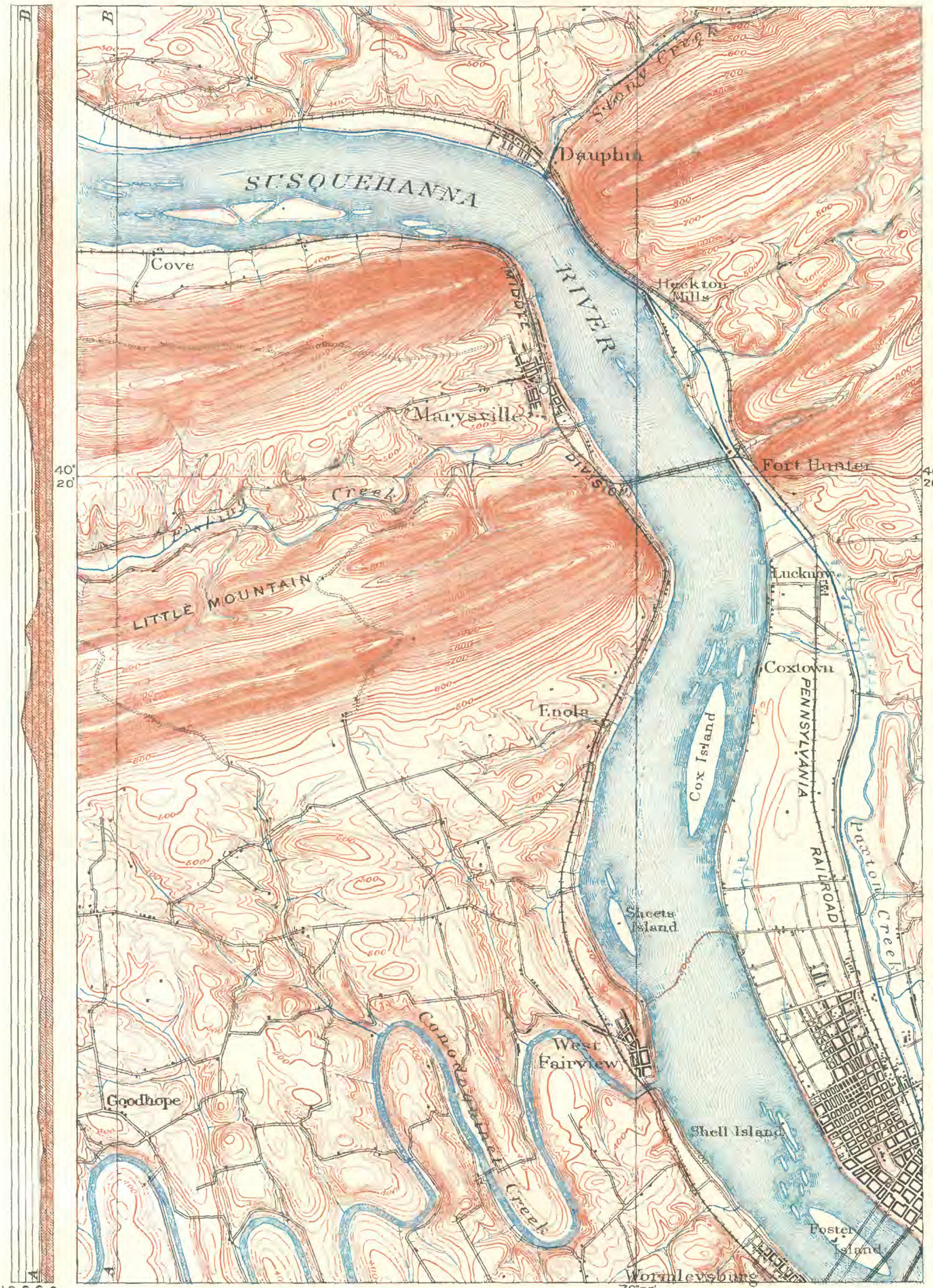

EROSION CYCLES: PART OF HARRISBURG (PA.) SHEET. WITH SECTION ON LINE A-B

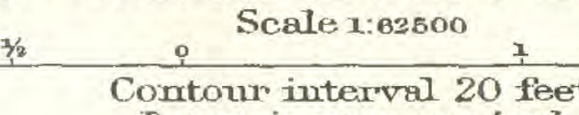
amiles 


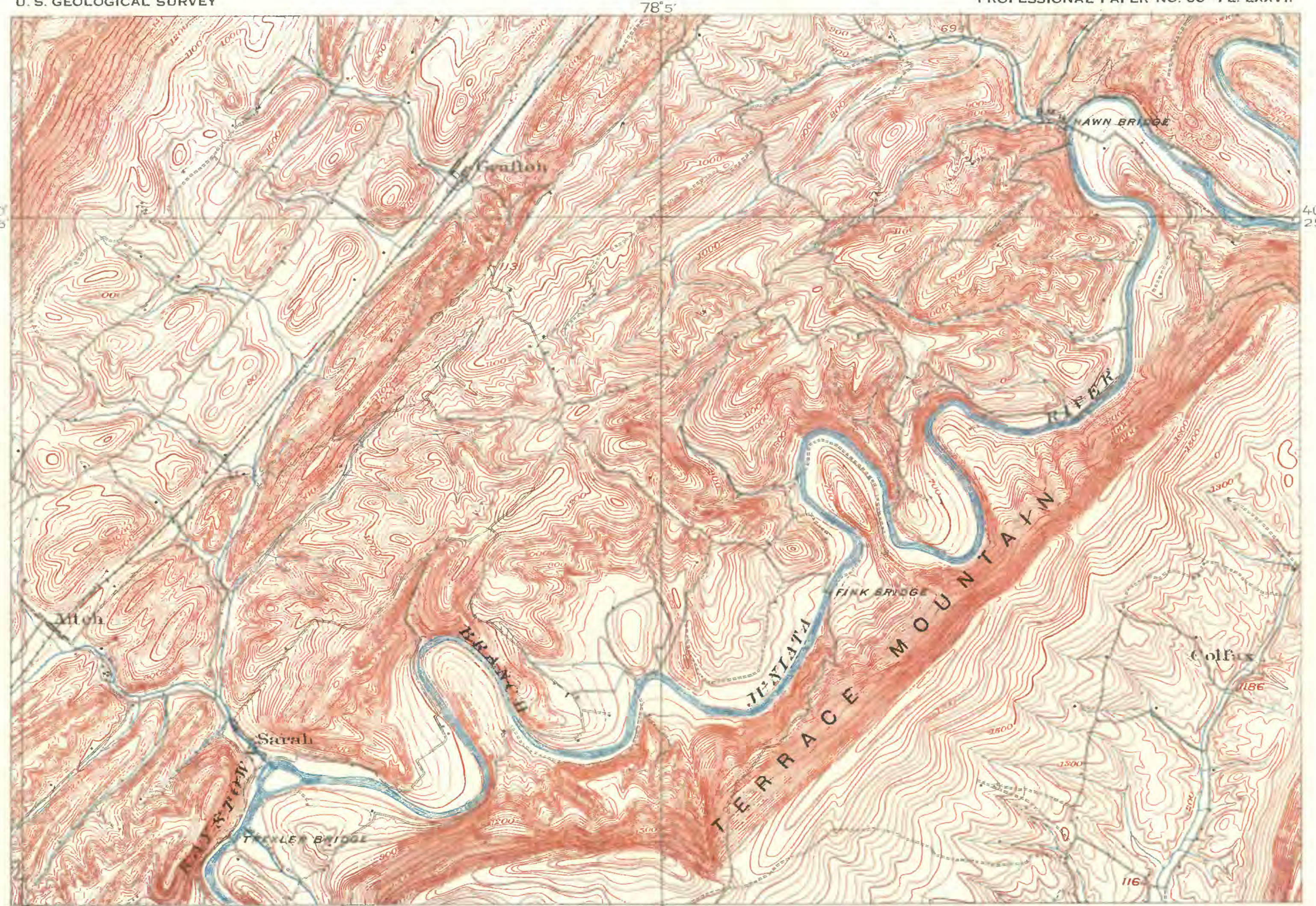

EROSION CYCLES: PART OF HUNTINGDON (PA.) SHEET

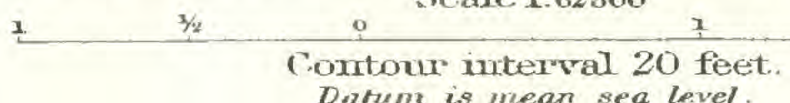


U. S. GEOLOGICAL SURVEY

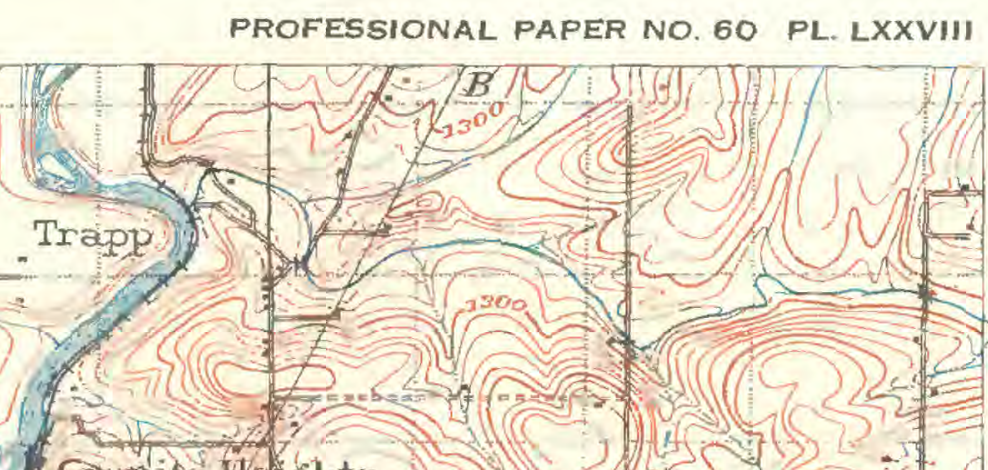

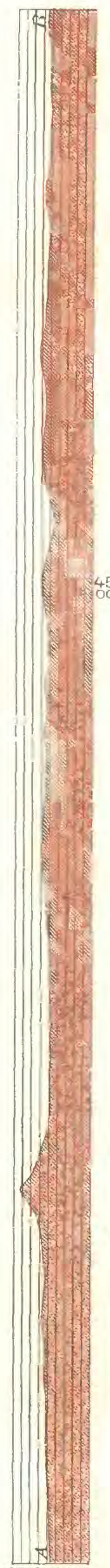

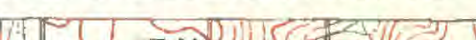
A.

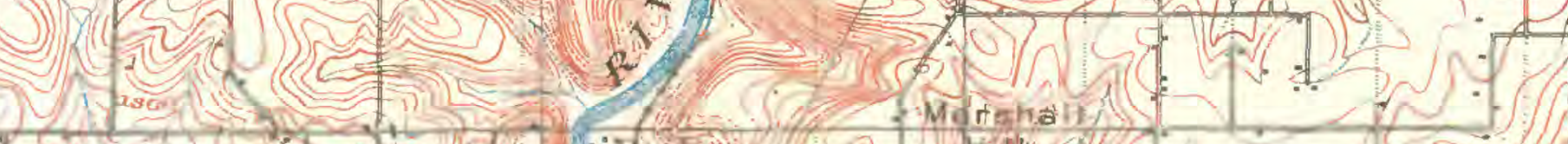
(4) (m)

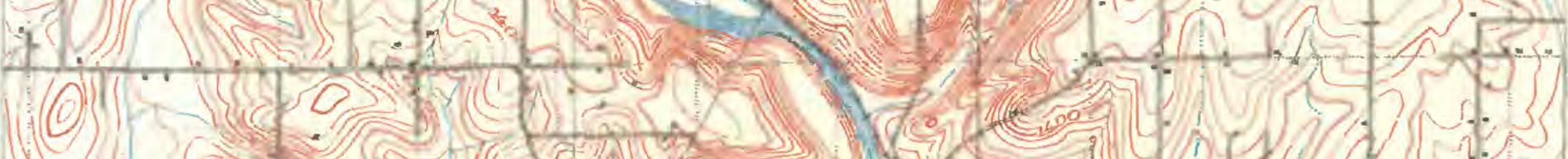
${ }^{4} 5^{\circ}$

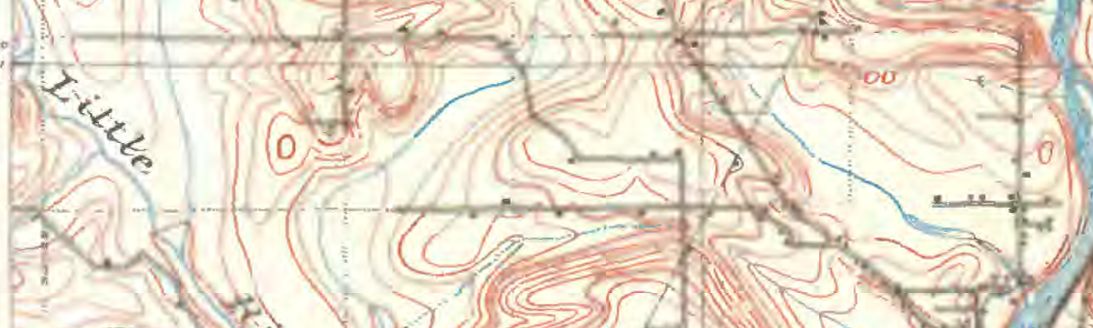

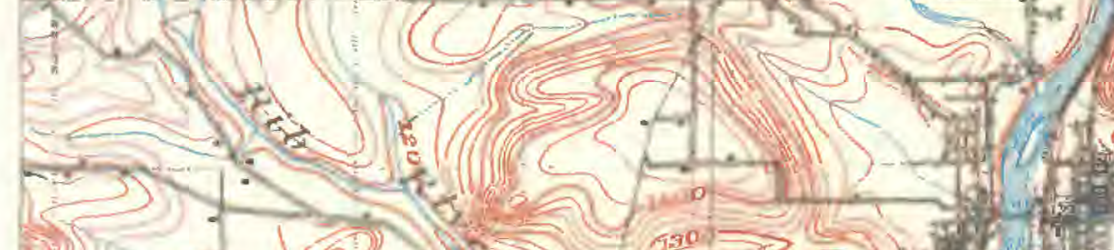

1.2)

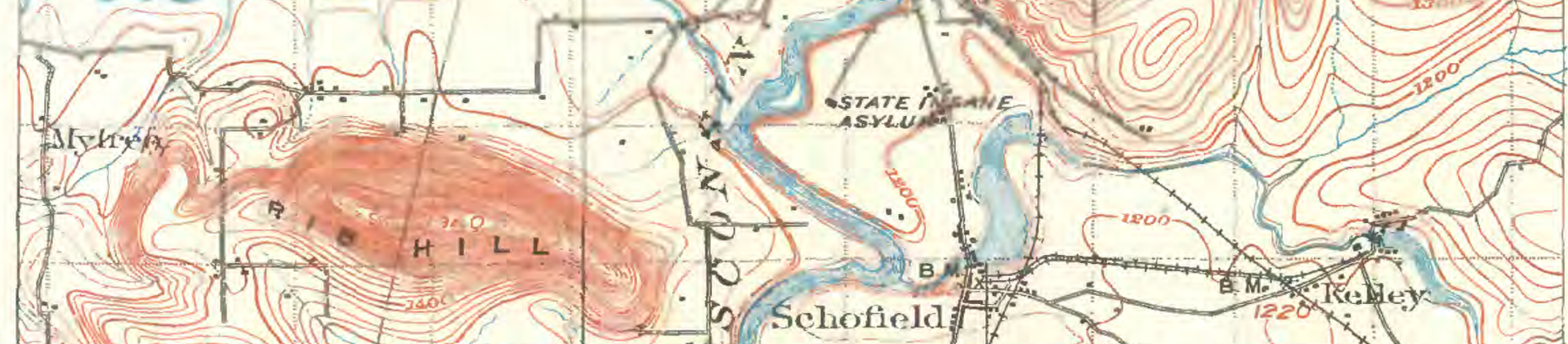

屯i:

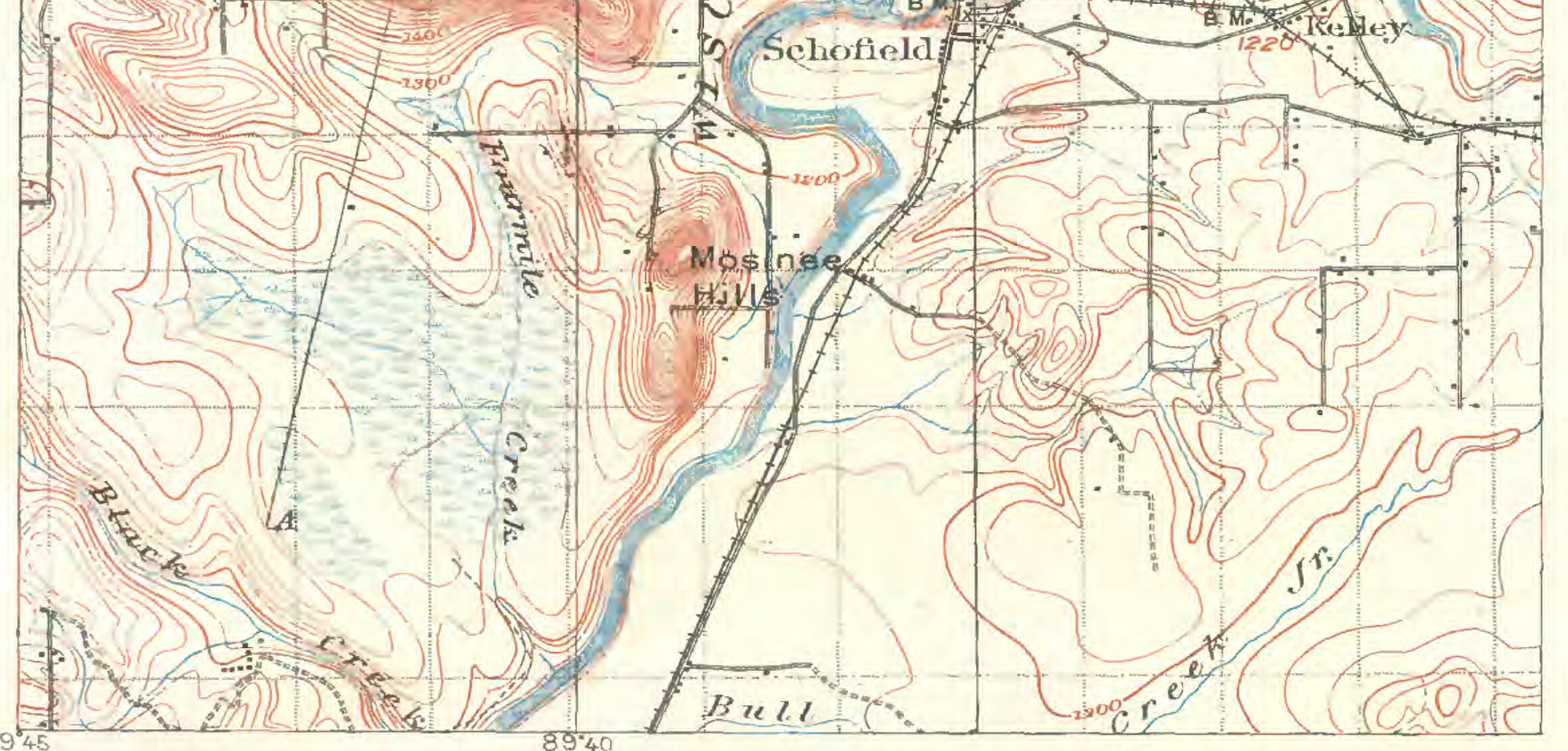

EROSION CYCLES: PART OF WAUSAU (WIS.) SHEET, WITH SECTION A-B

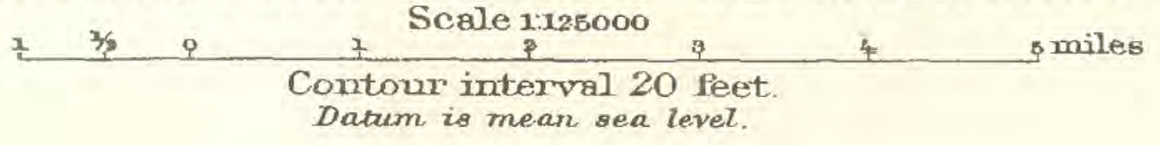




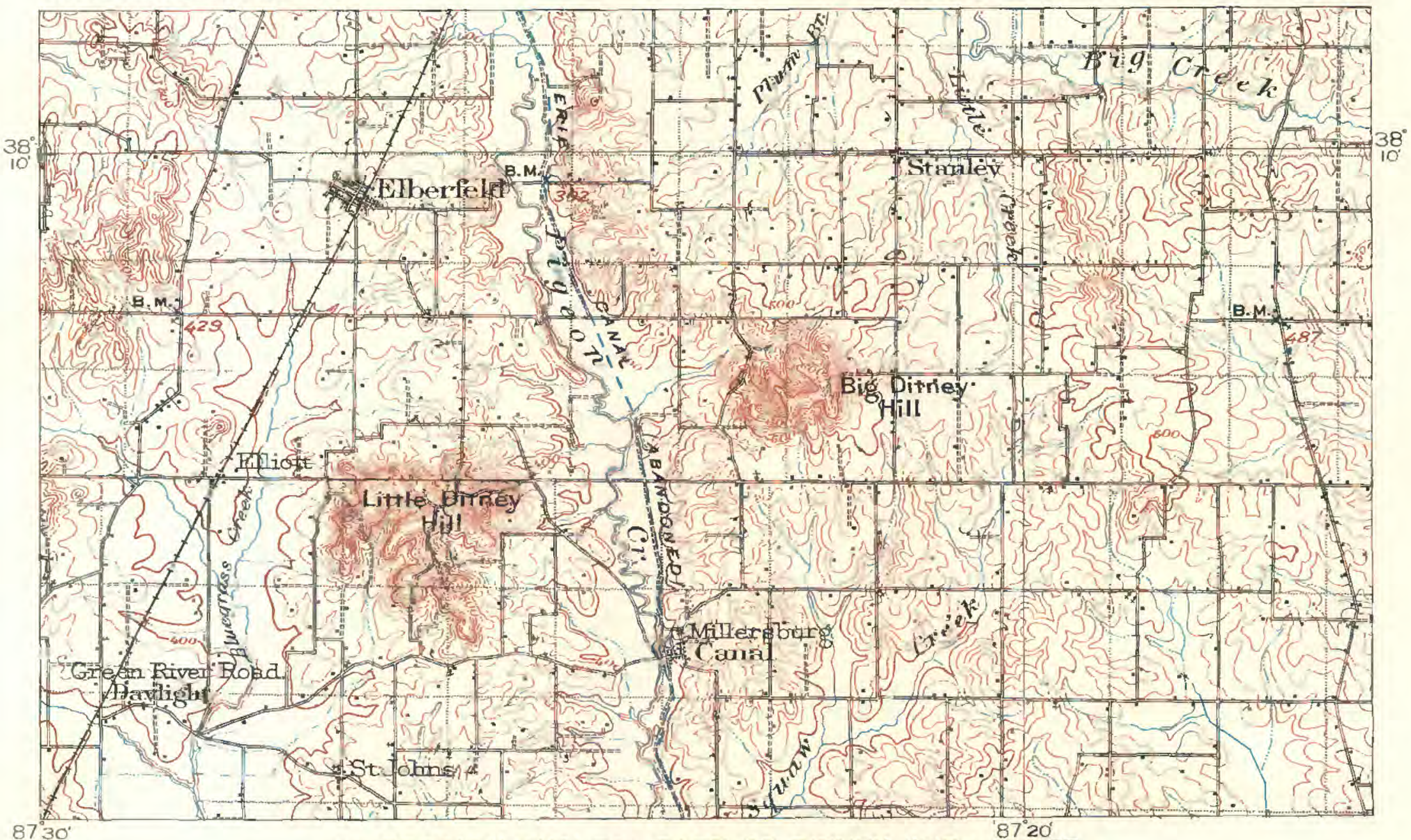

A. EROSION CYCLES: PART OF DITNEY (IND.) SHEET

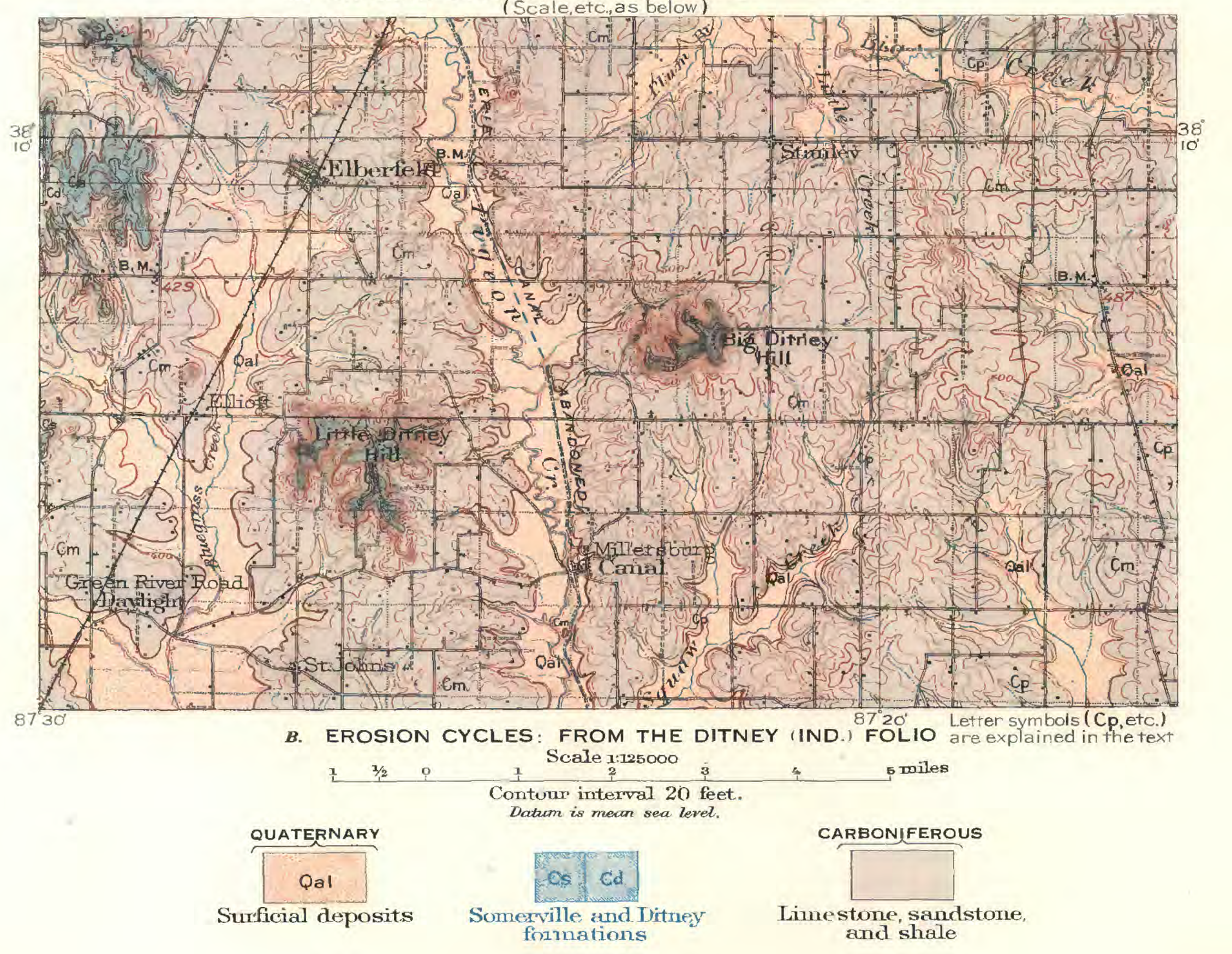




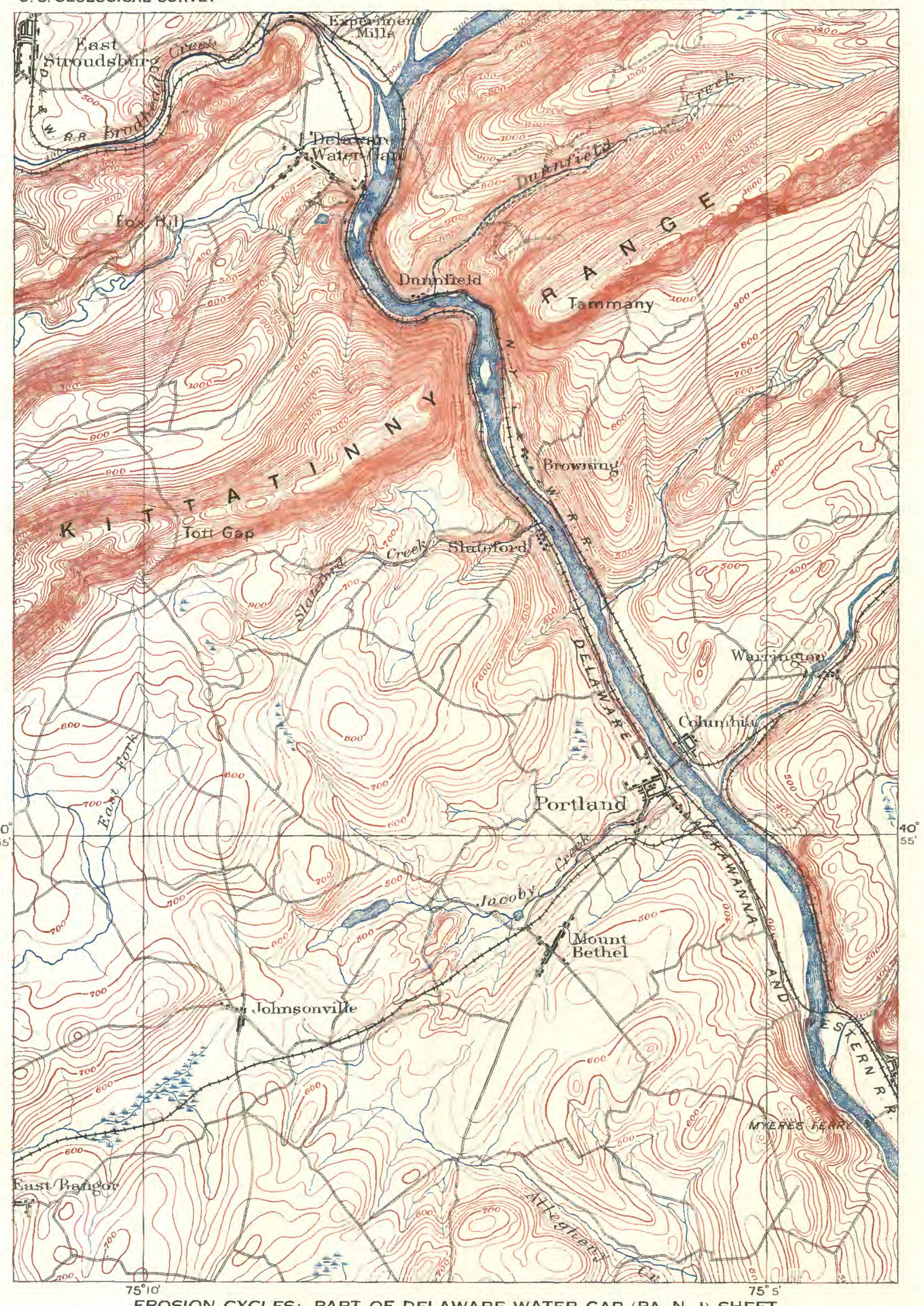

EROSION CYCLES: PART OF DELAWARE WATER GAP (PA.-N. J) SHEET 


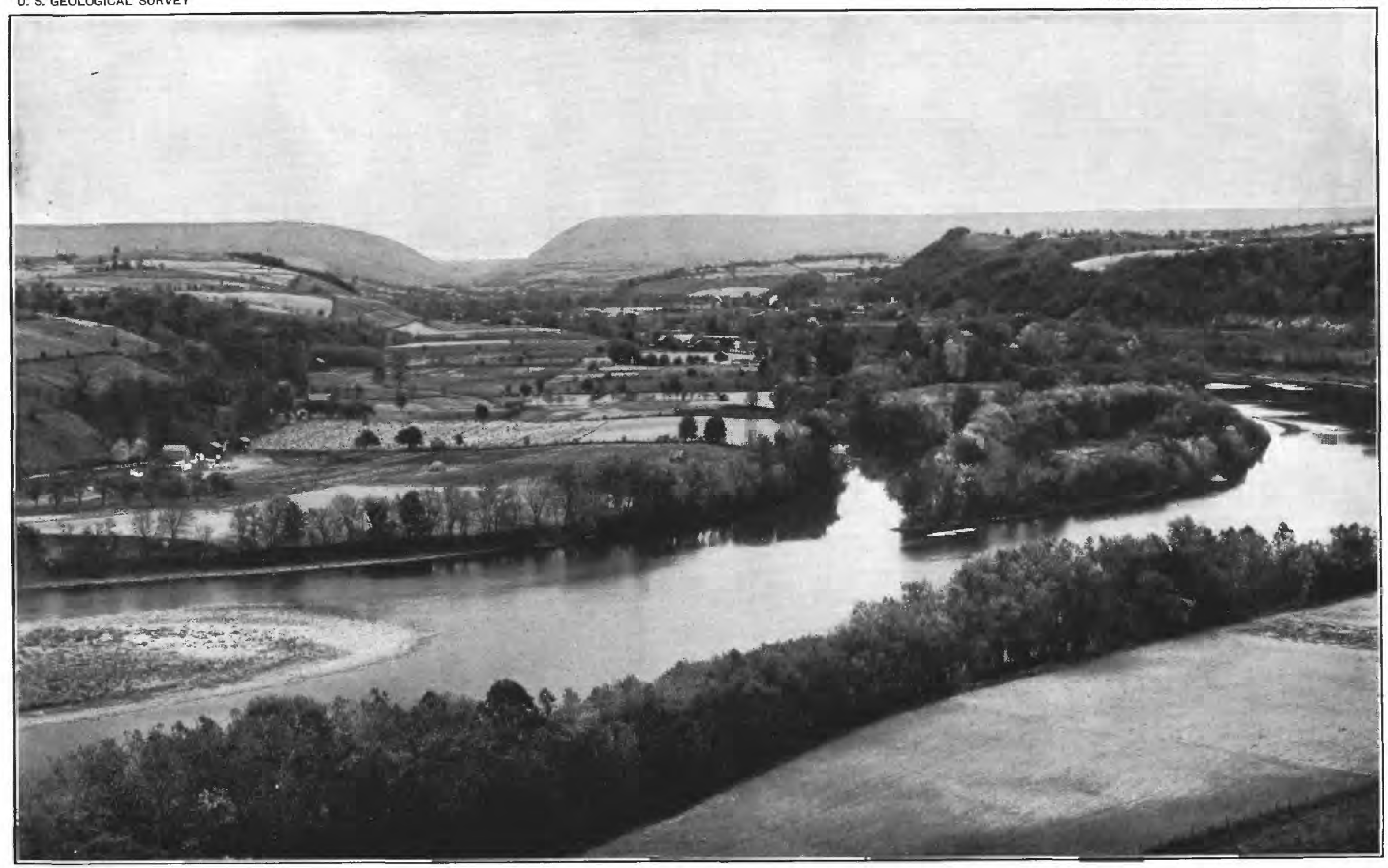




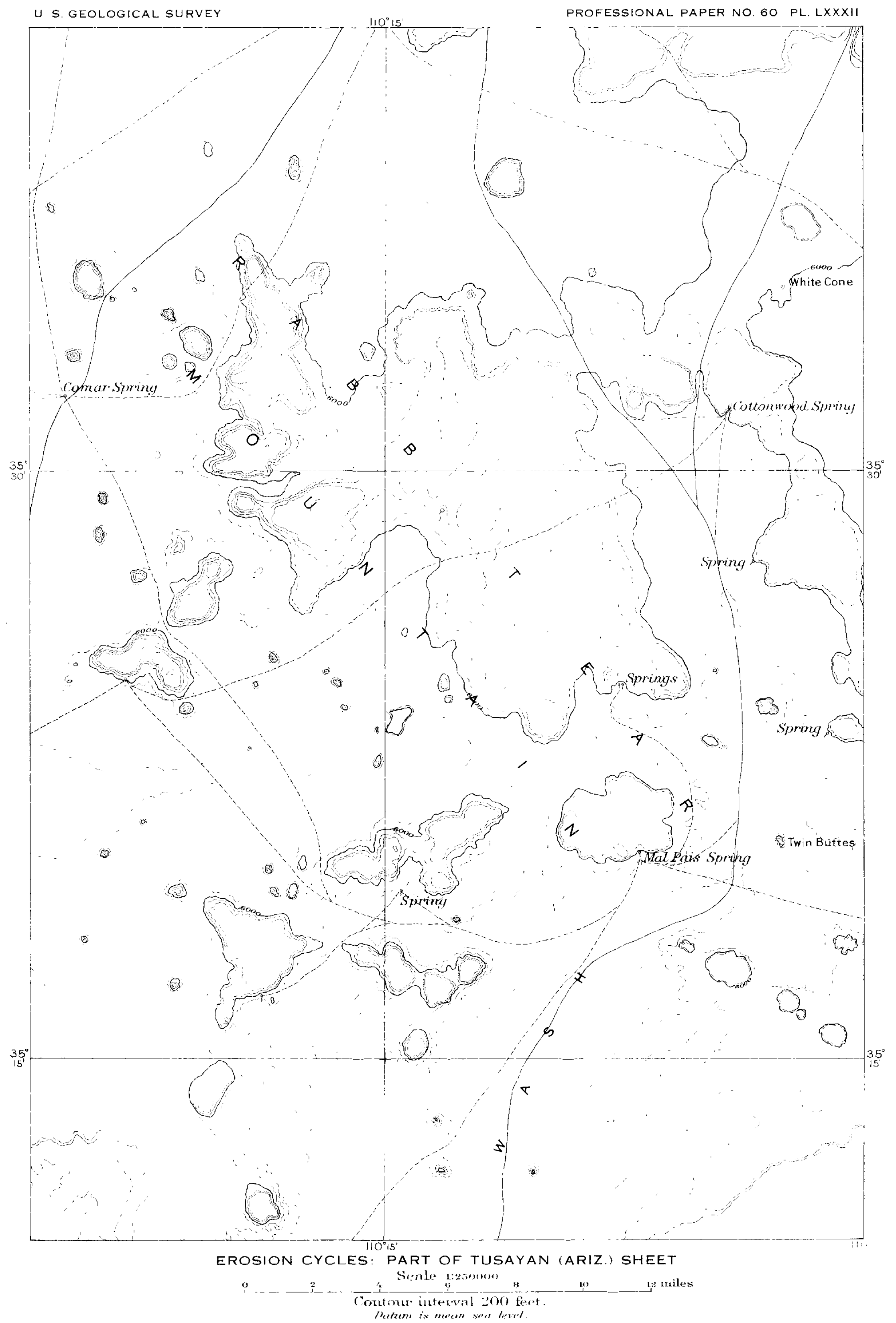




\section{U S GEOLOGICAL SURVEY}

PROFESSIONAL PAPER NO, 60 PL. LXXXIII
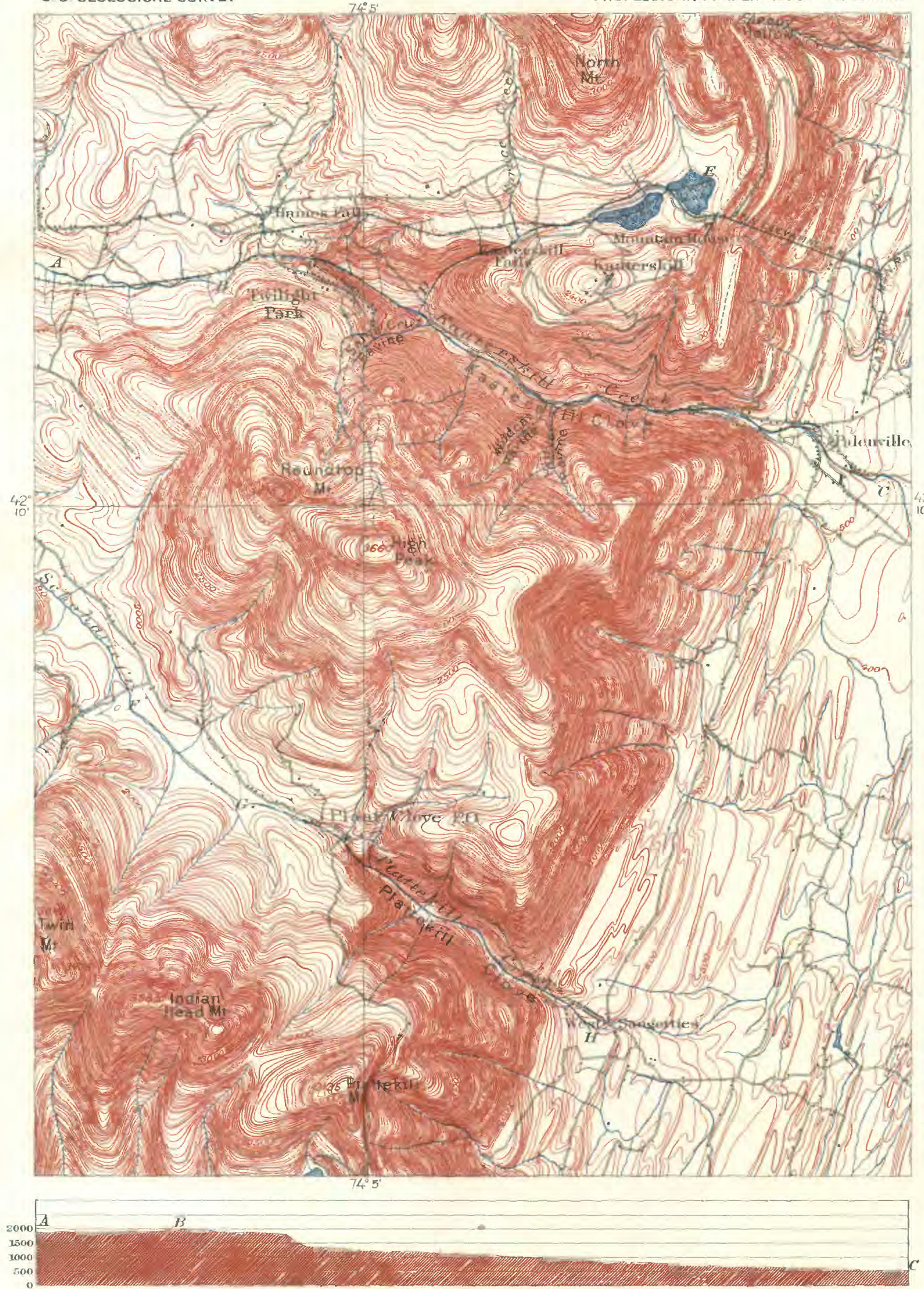

STREAM PIRACY: PART OF KAATERSKILL (N. Y.) SHEET, WITH SECTION ON LINE A-B-C 


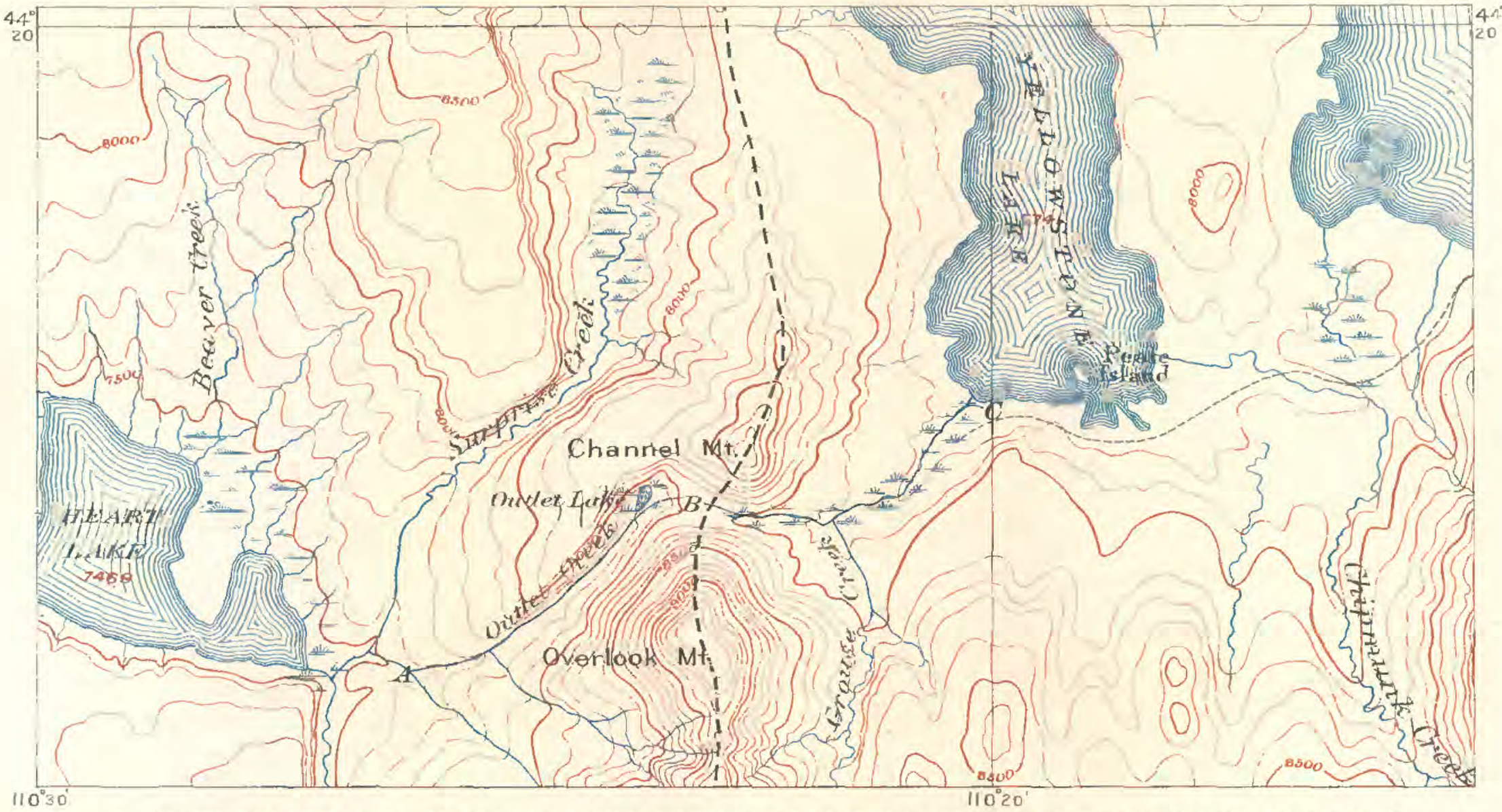

A. STREAM PIRACY: PART OF LAKE SHEET, YELLOWSTONE NATIONAL PARK, WYOMING (Scale etc. as below)

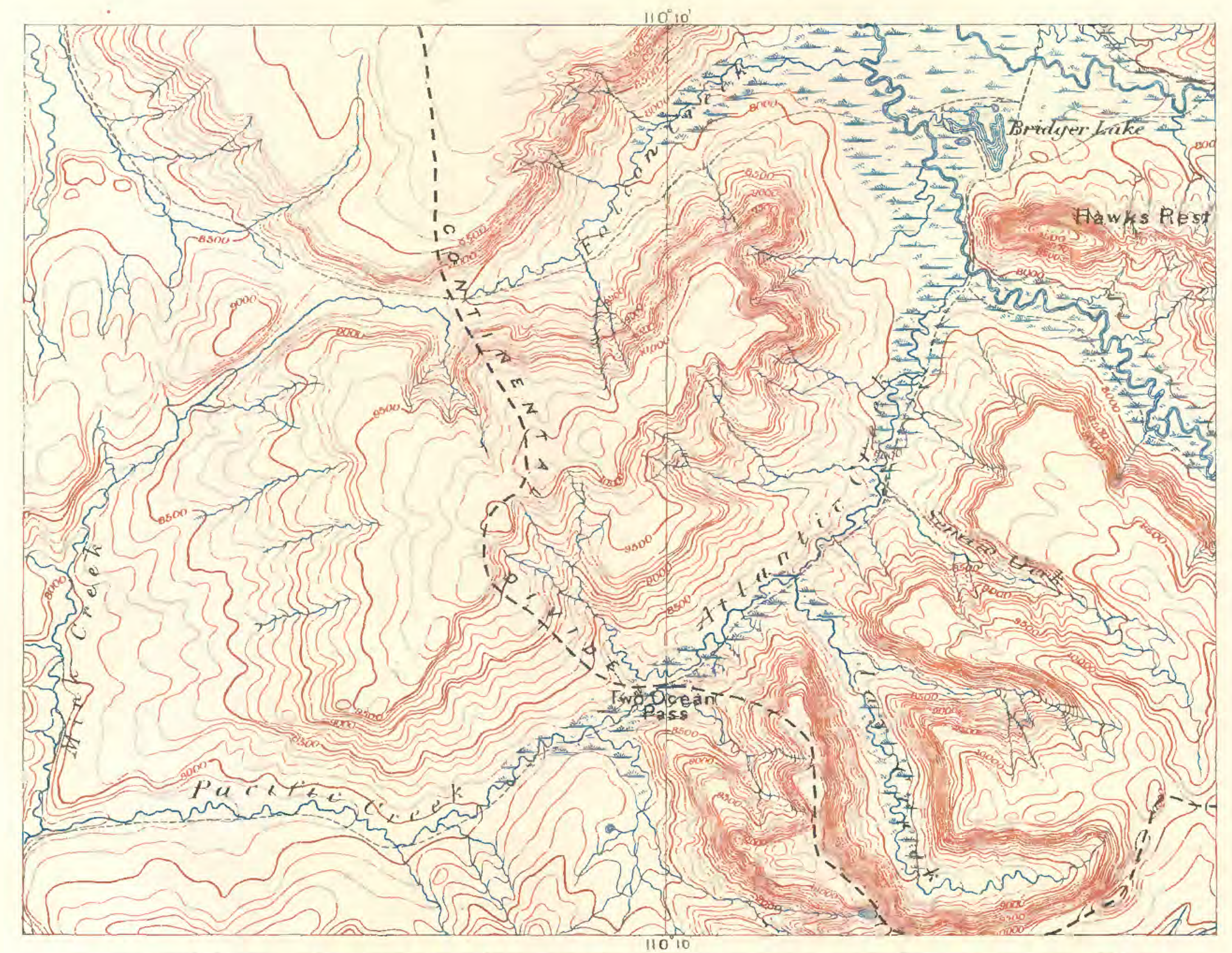

B. STREAM PIRACY: PART OF LAKE SHEET, YELLOWSTONE NATIONAL PARK, WYOMING $11 / 2$ i Scale $1: 125000$
Contour interval 100 feet.
Daturn is meun sea level. 


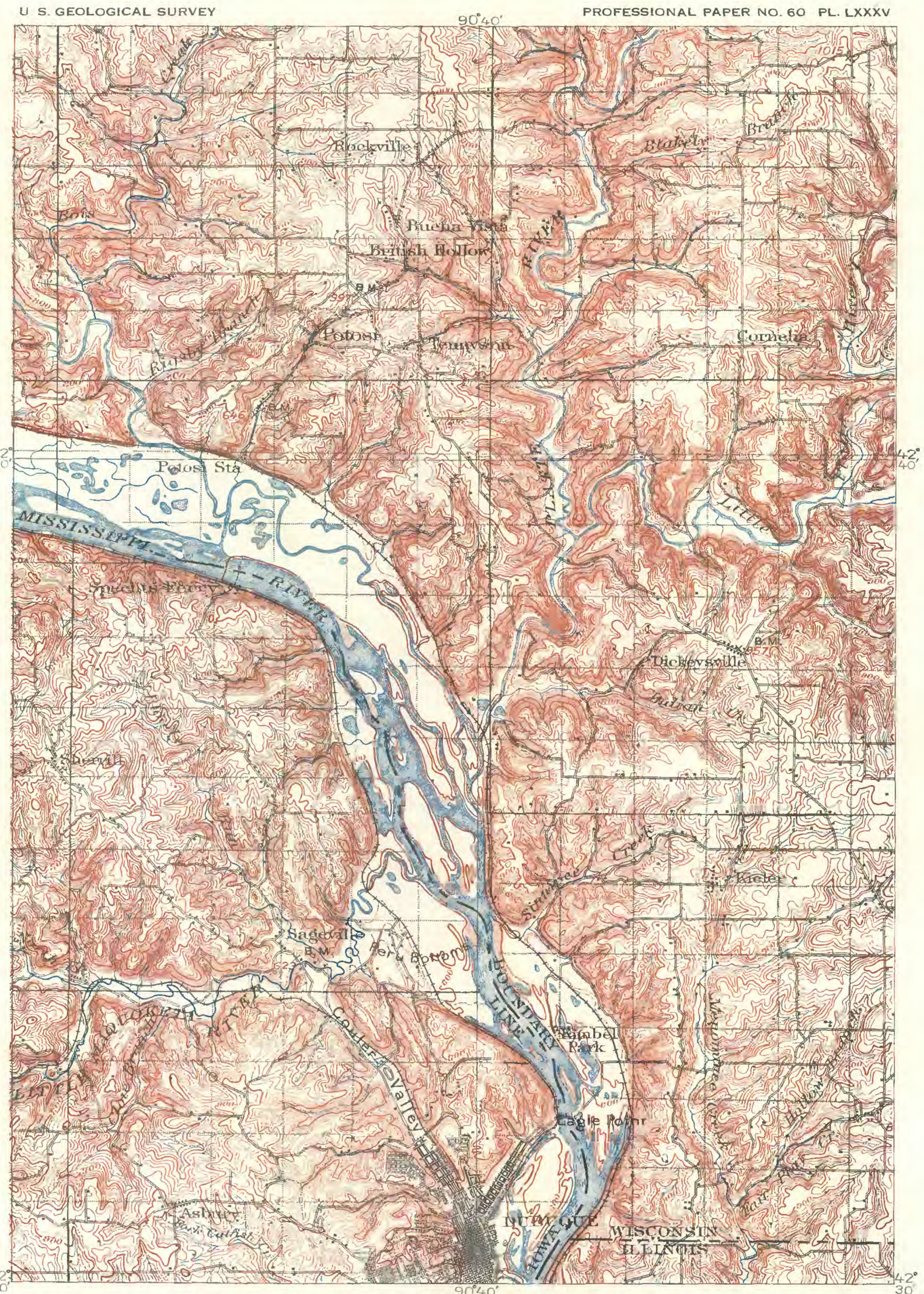

STREAM PIRACY: PART OF LANCASTER (WIS.-IOWA-ILL.) SHEET

Scale 1:12500

Contour interval 20 feet.

smiles 


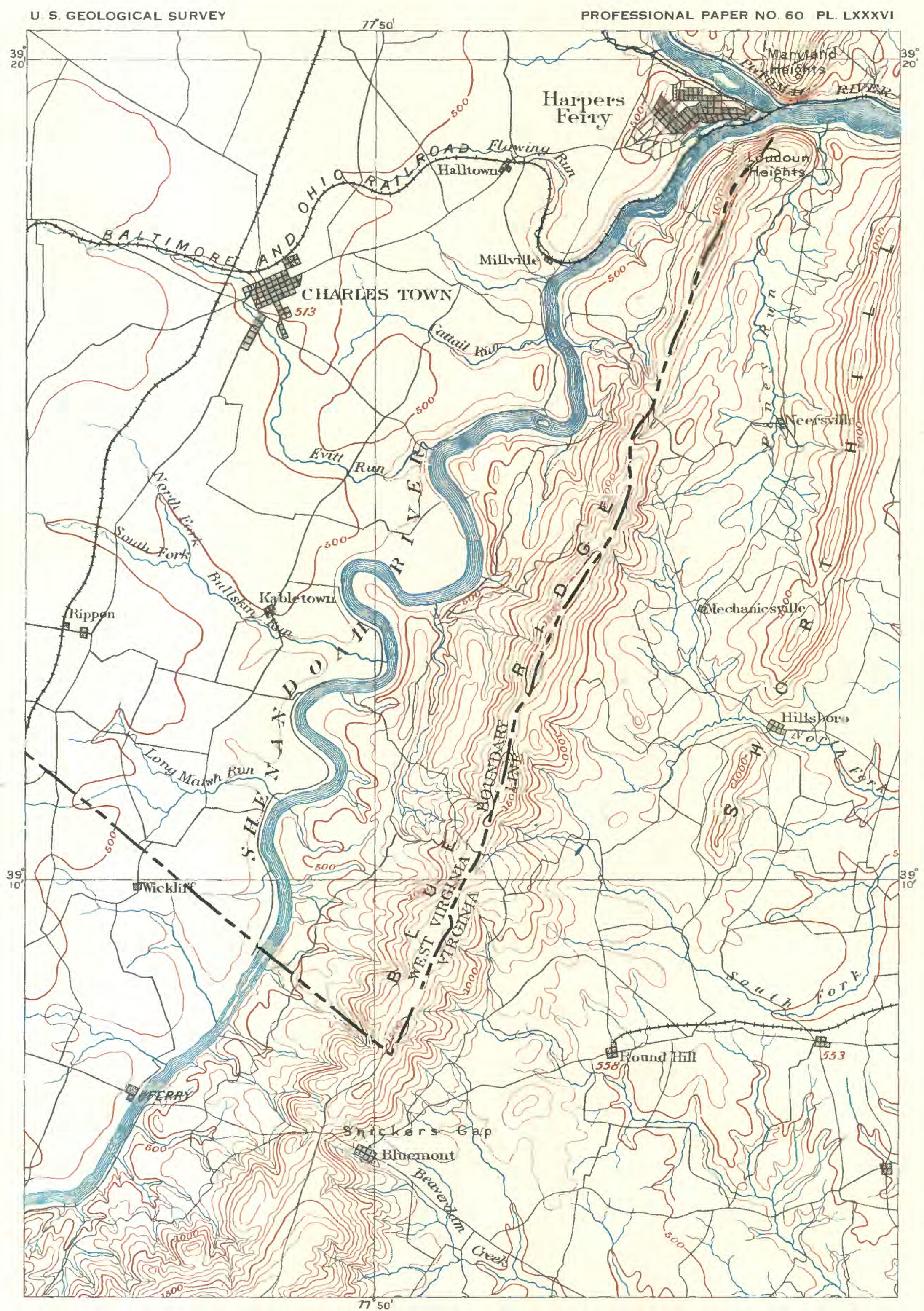

STREAM PIRACY: PART OF HARPERS FERRY (VA.-W. VA.-MD.) SHEET

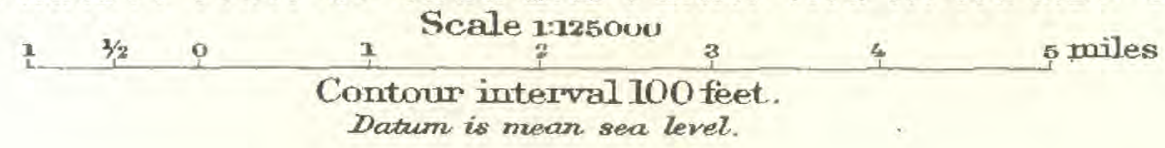




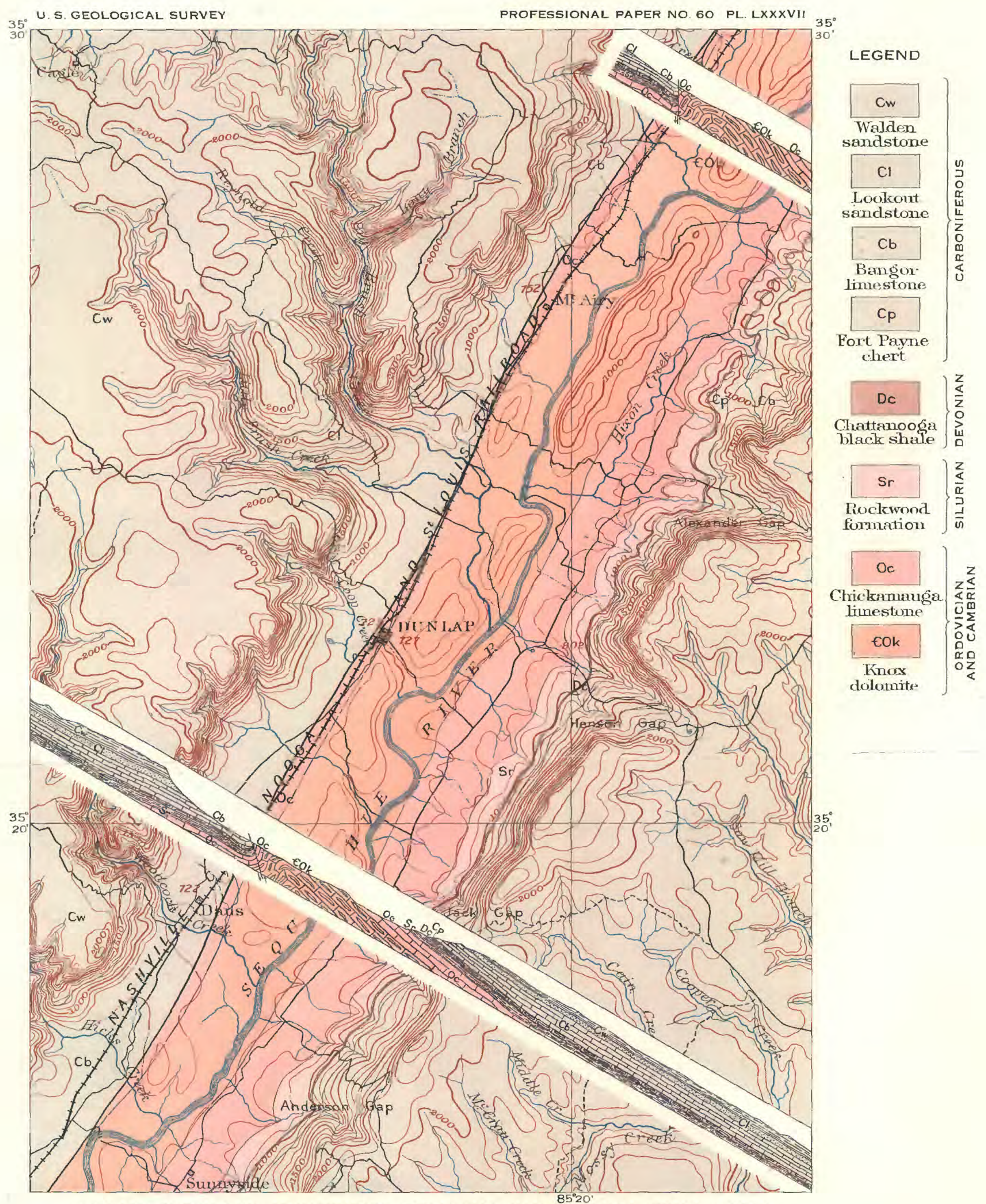

STREAM PIRACY AND ADJUSTMENT: FROM THE CHATTANOOGA (TENN.) FOLIO

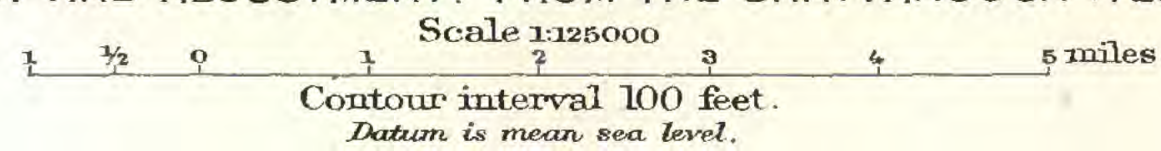




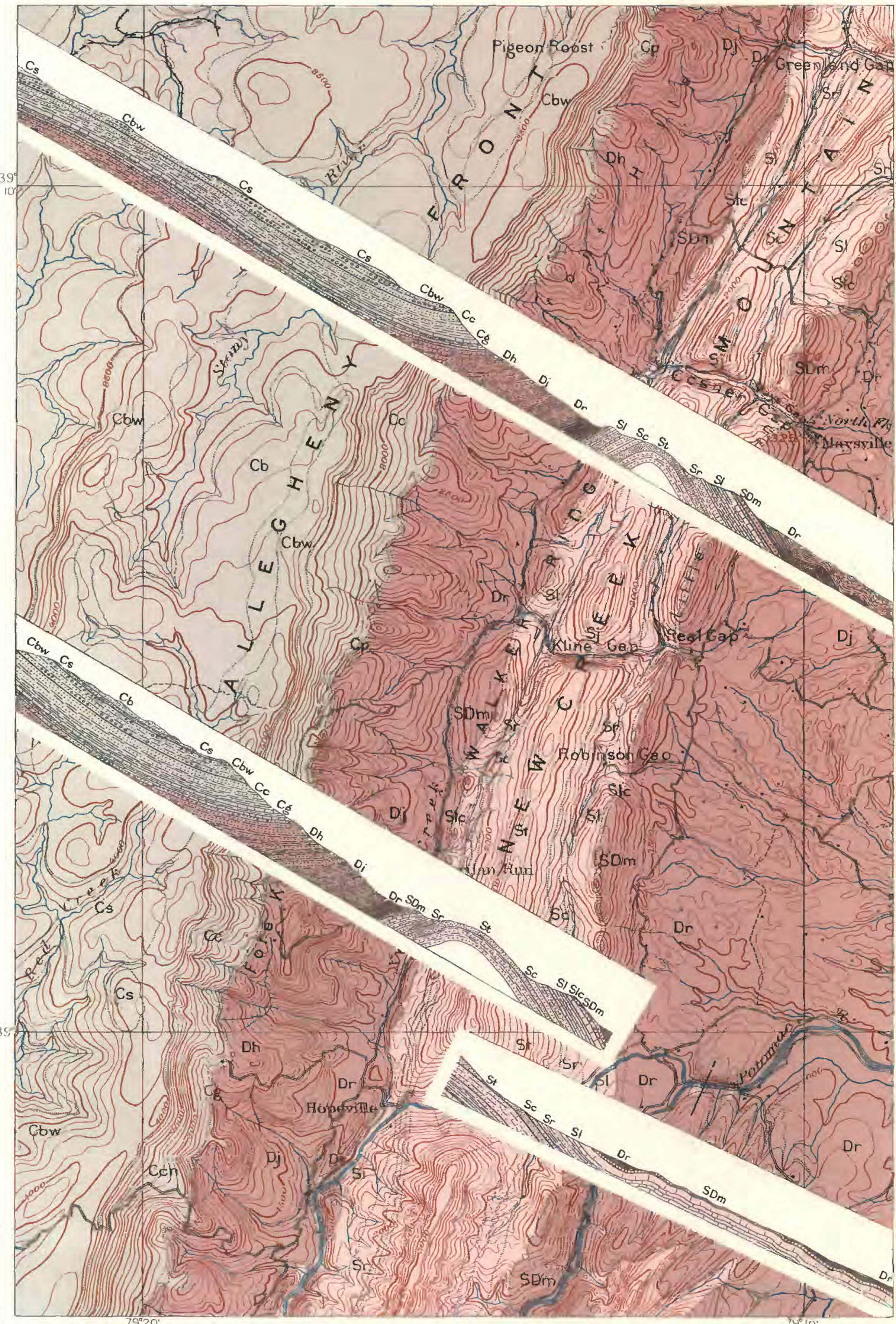

LEGEND

\begin{tabular}{|c|}
\hline $\mathrm{Cb}$ \\
\hline $\begin{array}{l}\text { Bayard } \\
\text { formation }\end{array}$ \\
\hline Cs \\
\hline $\begin{array}{l}\text { Savage } \\
\text { formation }\end{array}$ \\
\hline Cbw \\
\hline $\begin{array}{l}\text { Blackwaten } \\
\text { formation }\end{array}$ \\
\hline $\mathrm{Cc}$ \\
\hline $\begin{array}{l}\text { Caunan } \\
\text { formation }\end{array}$ \\
\hline $\mathrm{Cg}$ \\
\hline $\begin{array}{l}\text { Greenbrier } \\
\text { limestone }\end{array}$ \\
\hline$C_{p}$ \\
\hline $\begin{array}{l}\text { Pocono } \\
\text { sandstone }\end{array}$ \\
\hline
\end{tabular}

\section{Dh}

Hampshire formation

\begin{tabular}{c}
\hline Dj \\
$\begin{array}{c}\text { Jenningis } \\
\text { formation }\end{array}$ \\
\hline Dr \\
$\begin{array}{c}\text { Rommey } \\
\text { shale }\end{array}$ \\
SDm \\
\hline
\end{tabular}

\section{$\frac{z}{z}$ 岕}

Monterey sandstone Sic

Lewistown chert lentil Si

Lewistown limestone $\mathrm{Sr}$

hockwood formation $\mathrm{Sc}$

Cacapon saudstone St

Tiscaxore (j)artzile sj

Truiata. formation 


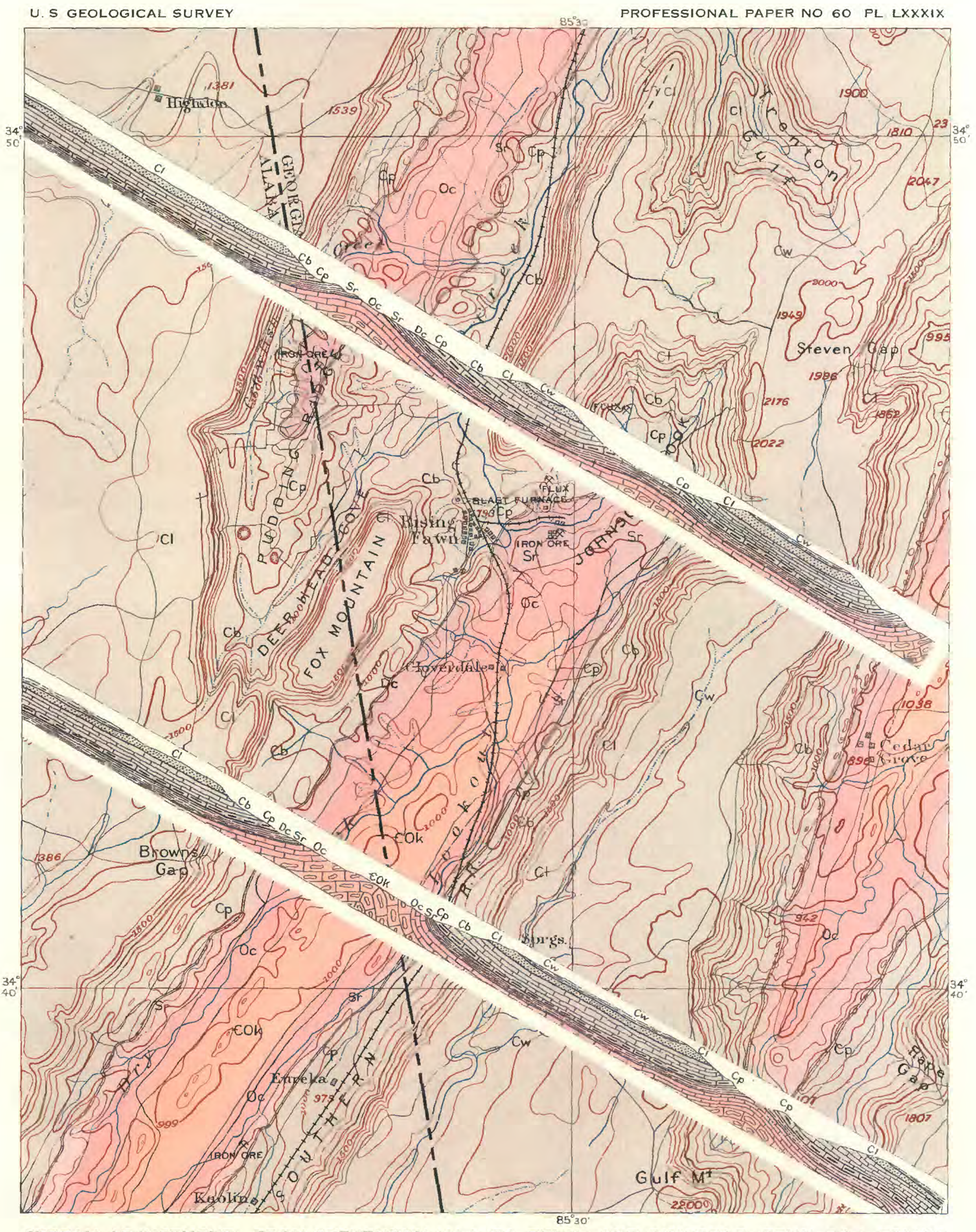

STREAM ADJUSTMENT: FROM STEVENSON (ALA.-GA.-TENN.) AND RINGGOLD (TENN-GA.) FOLIOS

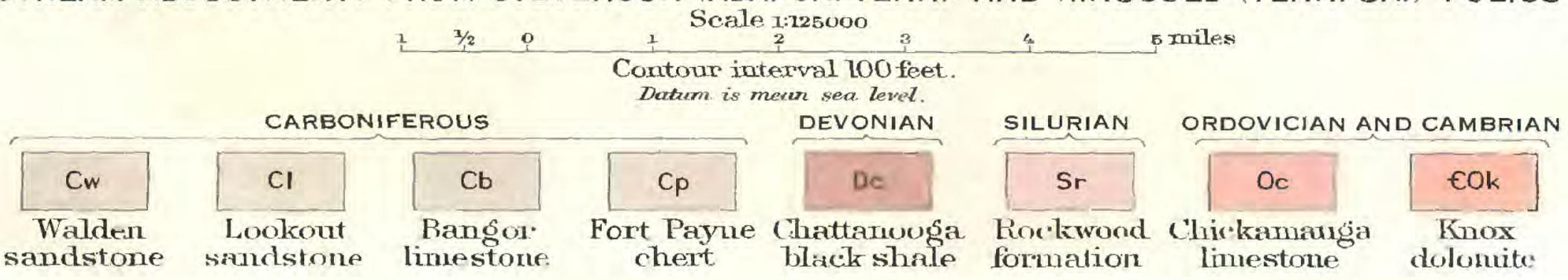




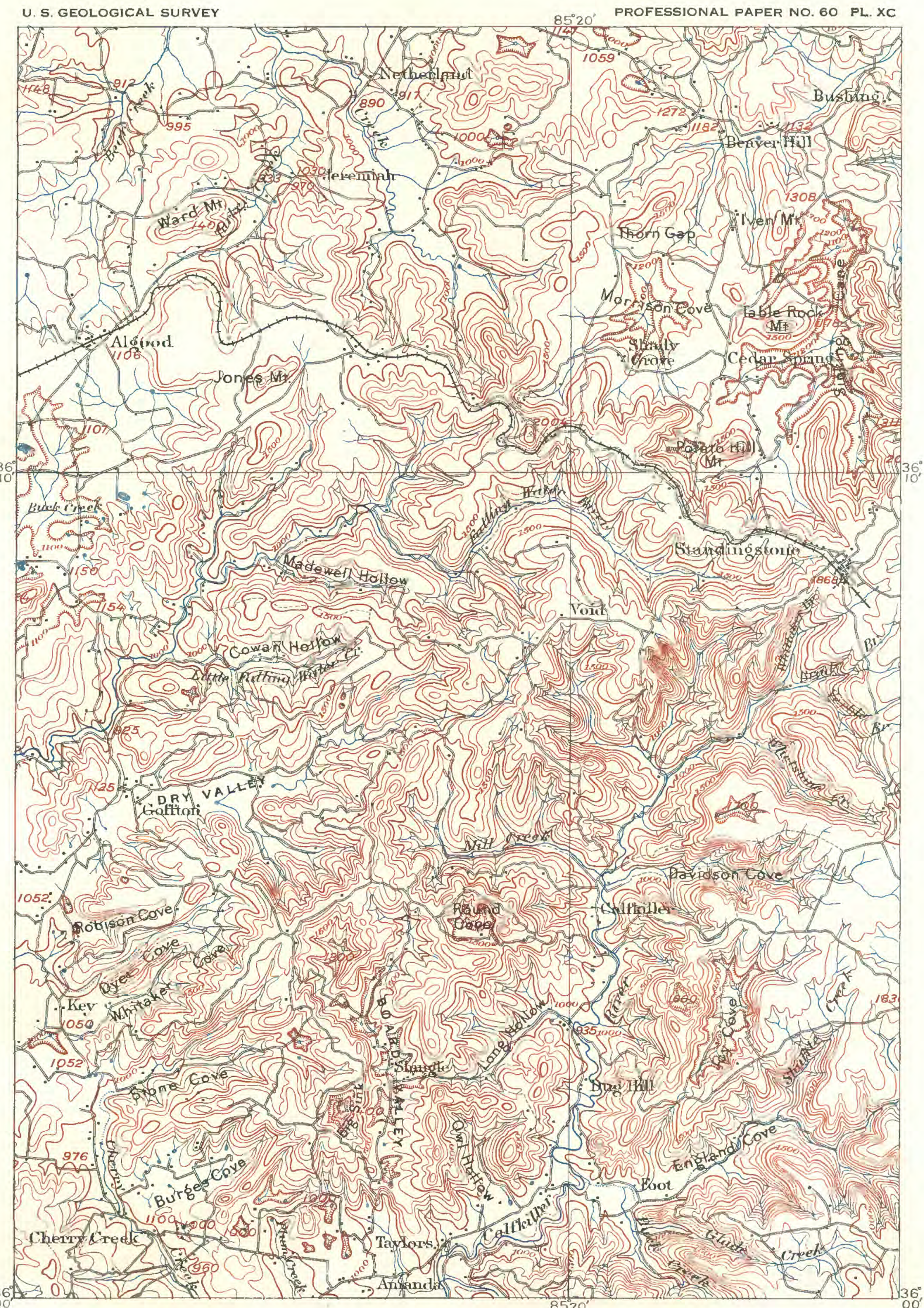

EFFECTS OF GROUND WATER: PART OF STANDINGSTONE (TENN.) SHEET

Contour interval 100 feet.
Datum is mean sea level




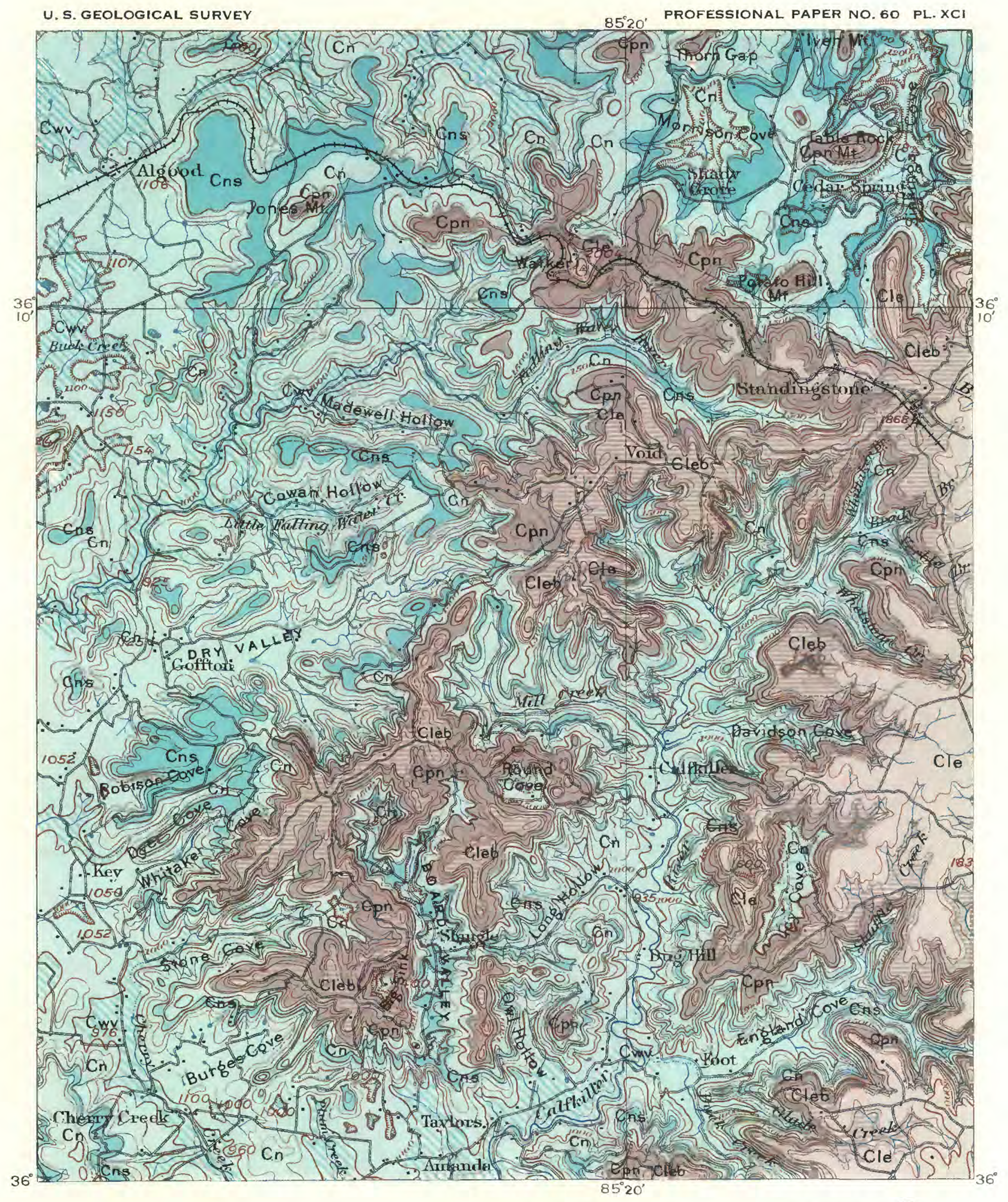
$85^{\circ} 20^{\prime}$

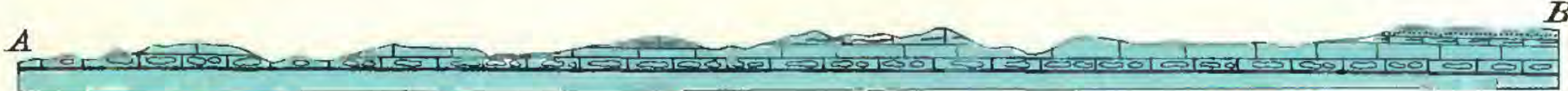

EFFECTS OF GROUNDWATER: FROM STANDINGSTONE (TENN.) FOLIO, WITH SECTION ON LINE A-B

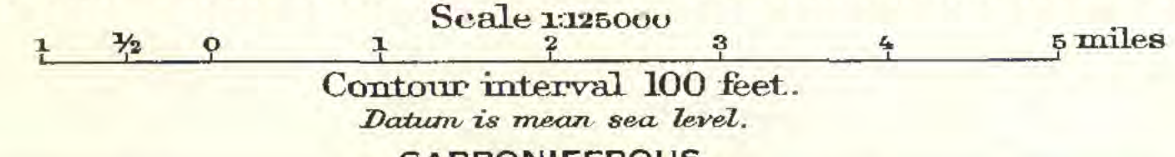

CARBONIFEROUS

\begin{tabular}{|c|c|c|c|c|c|}
\hline Cle & Cleb & $C_{p n}$ & $\mathrm{C}_{\mathrm{n}}$ & Cns & $C_{w V}$ \\
\hline $\begin{array}{l}\text { Lee } \\
\text { formation }\end{array}$ & $\begin{array}{c}\text { Bomair } \\
\text { cunglomerate lentil }\end{array}$ & $\begin{array}{l}\text { Pennington } \\
\text { shale }\end{array}$ & $\begin{array}{l}\text { Newman } \\
\text { limestome }\end{array}$ & $\begin{array}{c}\text { Newmau } \\
\text { sandstome lentil }\end{array}$ & $\begin{array}{l}\text { Waverty } \\
\text { formation }\end{array}$ \\
\hline
\end{tabular}




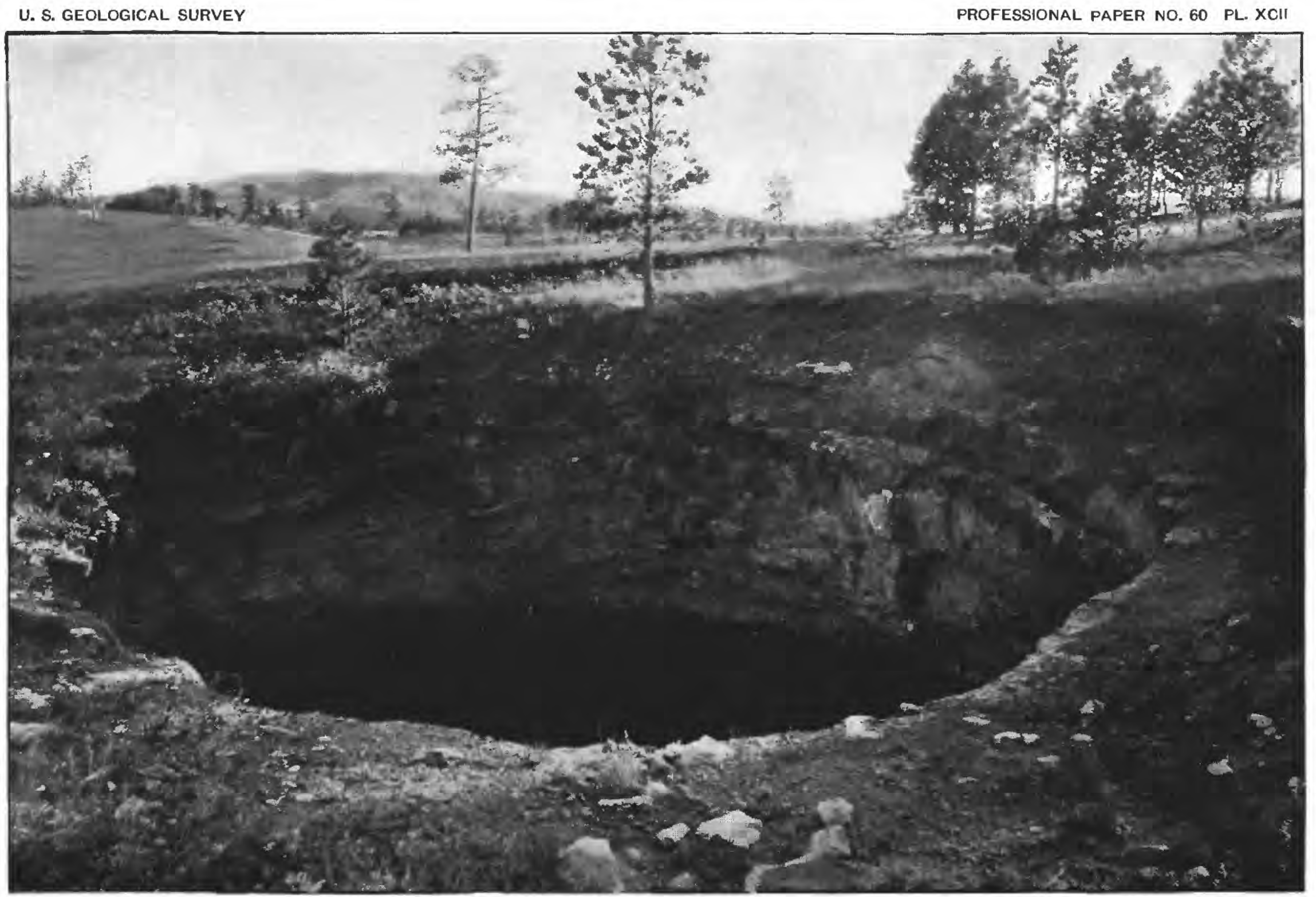

SINK HOLE IN MINNEKAHTA LIMESTONE, EAST-NORTHEAST OF CAMBRIA, WYO 


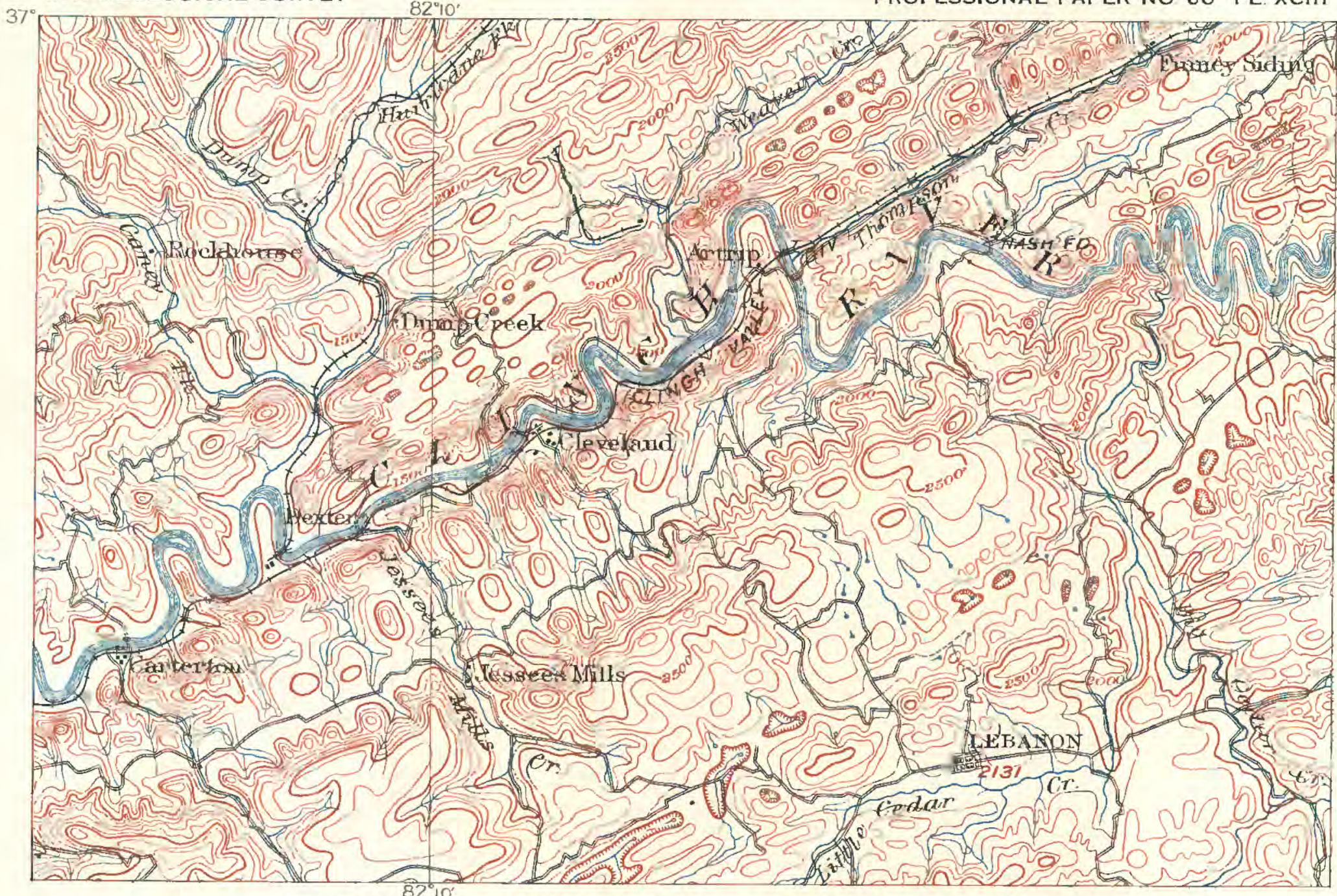

A. DRAINAGE CHANGES: PART OF BRISTOL (VA.) SHEET,

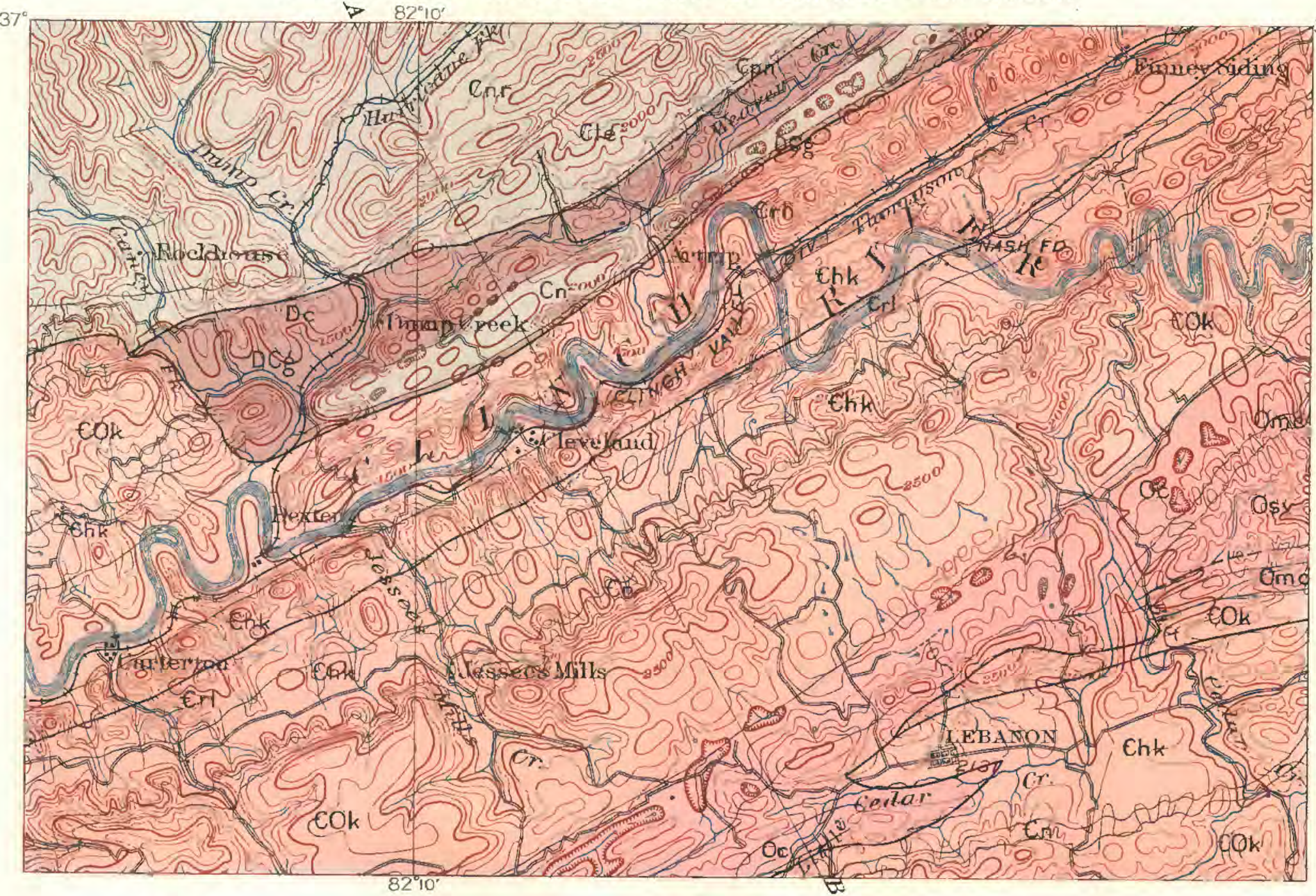

LEGEND

SEDIMENTARY ROCKS
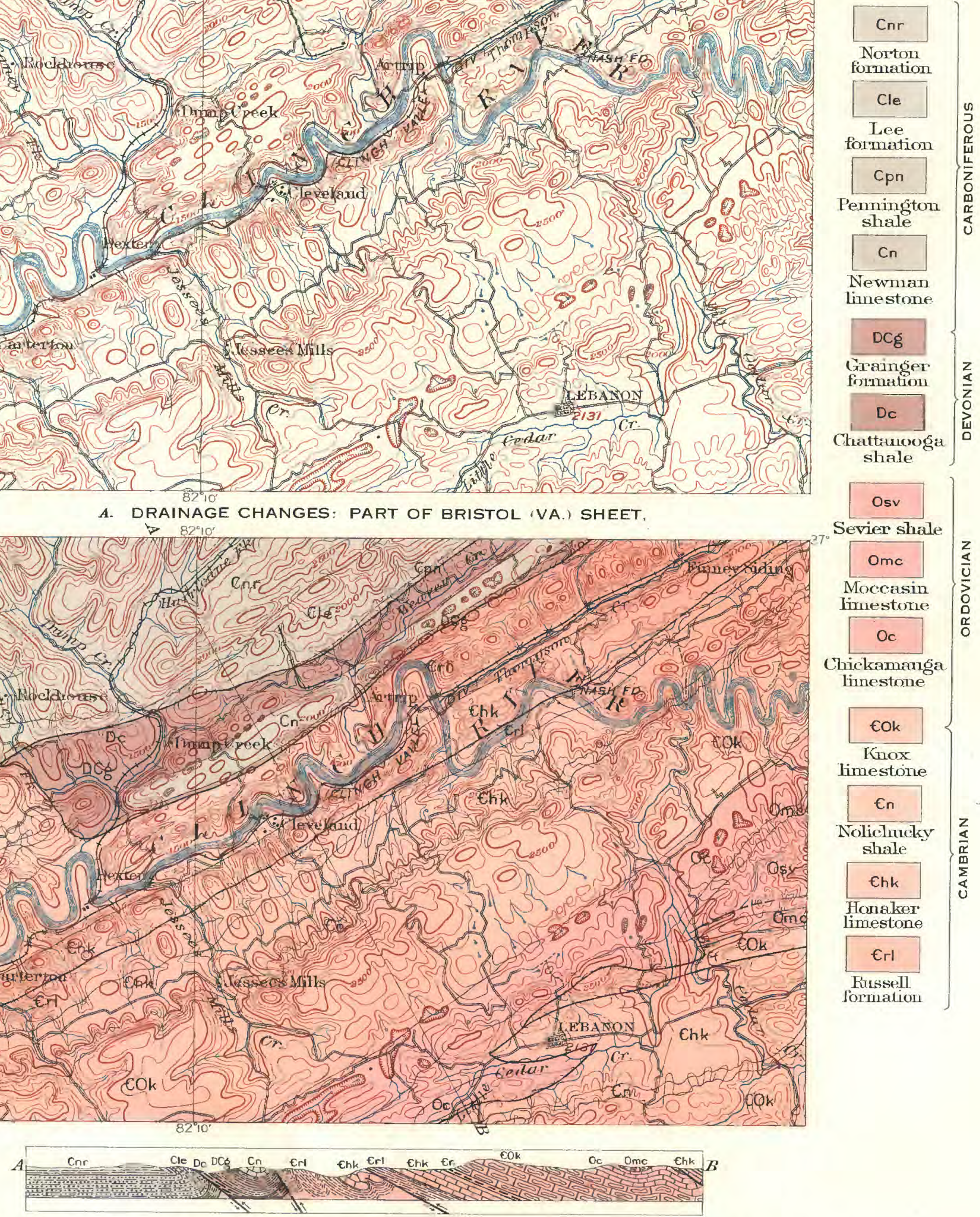

B. EFFECTS OF GROUND WATER: FROM THE BRISTOL (VA.) FOLIO. WITH SECTION ON LINE A-B $1 / 2$ O Scale i:m25000 a
Contour interval 100 feet.
Datum is mean sea level. 


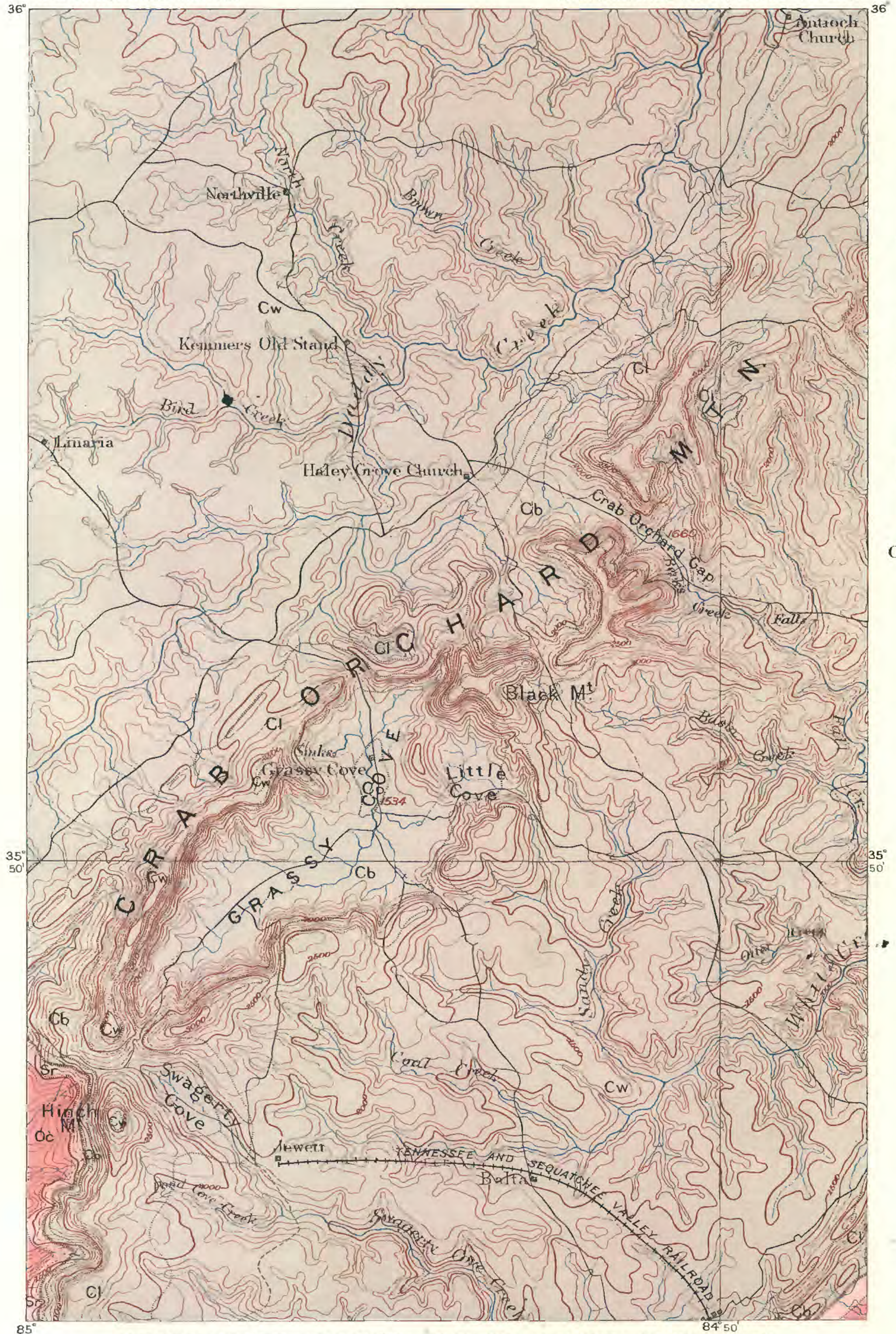

LEGEND

\begin{tabular}{|c|}
\hline $\mathrm{Cw}$ \\
\hline $\begin{array}{l}\text { Walden } \\
\text { saudstone }\end{array}$ \\
\hline $\mathrm{Cl}$ \\
\hline $\begin{array}{l}\text { Lookout } \\
\text { samdstone }\end{array}$ \\
\hline $\mathrm{Cb}$ \\
\hline $\begin{array}{c}\text { Bangox } \\
\text { limestone }\end{array}$ \\
\hline $\mathrm{Cp}_{\mathrm{p}}$ \\
\hline $\begin{array}{c}\text { Fort Payne } \\
\text { chert }\end{array}$ \\
\hline $\mathrm{Sr}$ \\
\hline $\begin{array}{l}\text { Rockwood } \\
\text { formation }\end{array}$ \\
\hline $\mathrm{Oc}_{\mathrm{c}}$ \\
\hline $\begin{array}{l}\text { hickamaugi } \\
\text { limestone }\end{array}$ \\
\hline
\end{tabular}




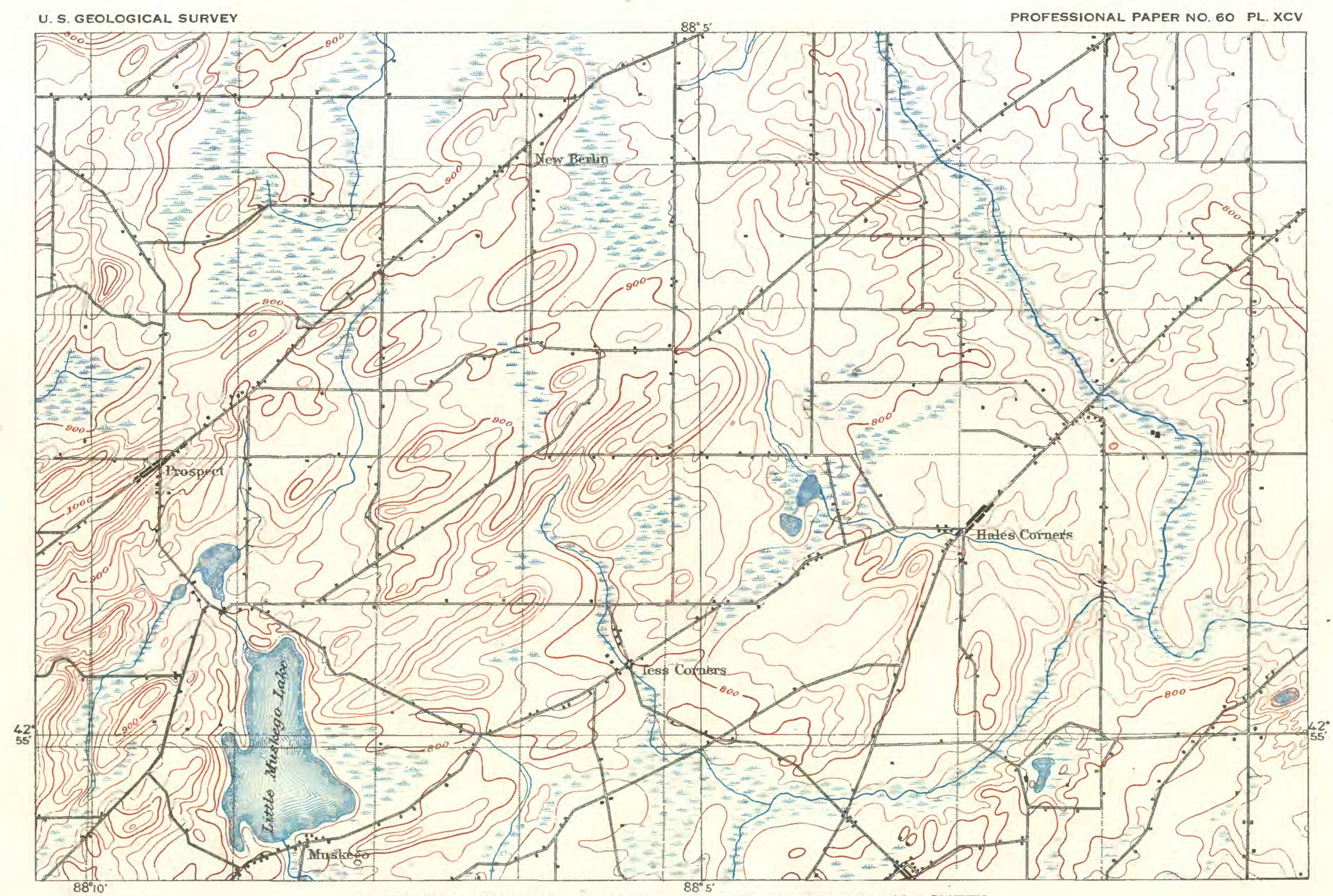

GLACIATION-GROUND MORAINES: PART OF MUSKEGO (WIS.) SHEET

$$
\begin{gathered}
\text { Contour interval } 20 \\
\text { Drotum is mean sea level. } \\
\text { D. }
\end{gathered}
$$




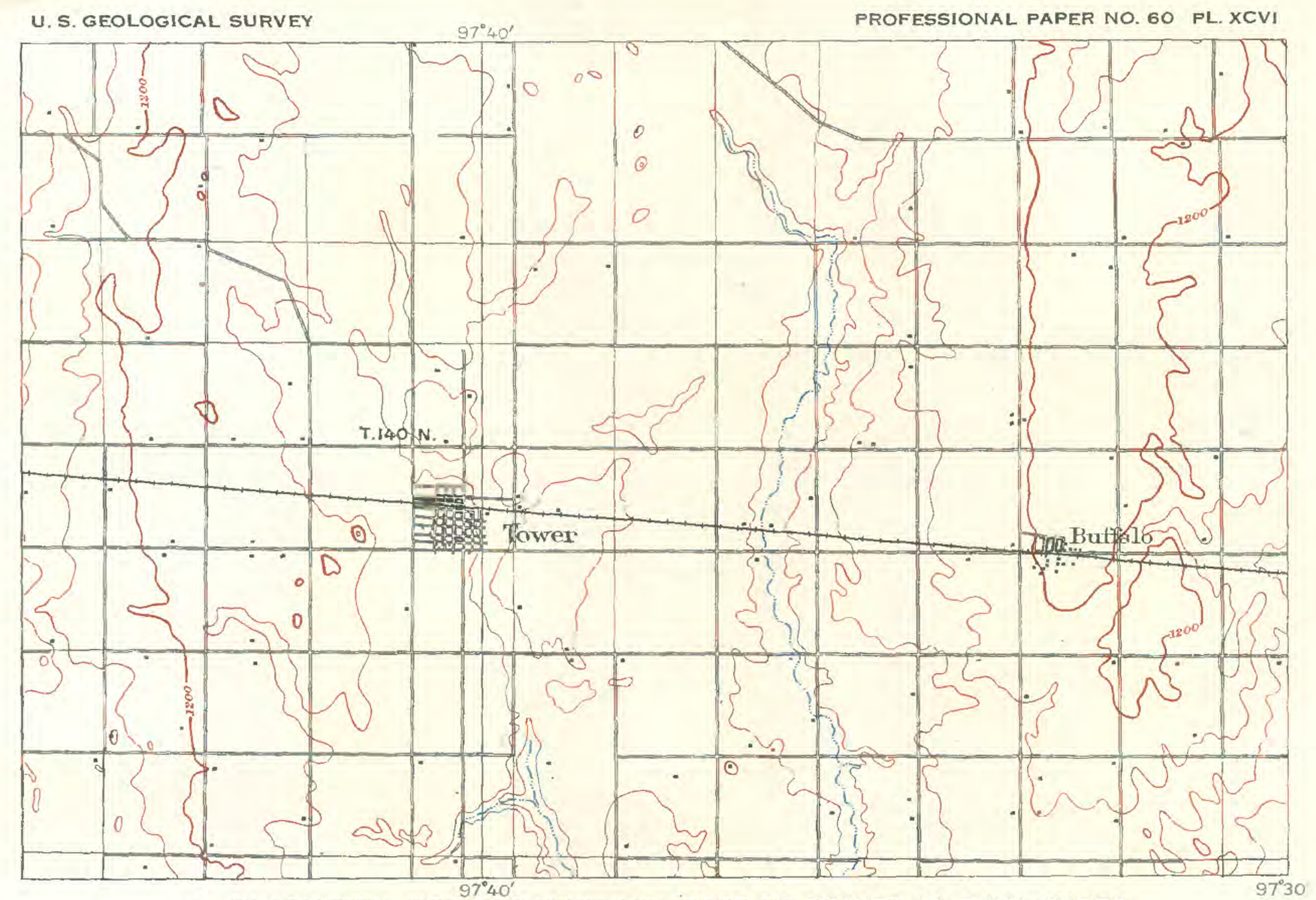

A. GLACIATION-GROUND MORAINE: PART OF TOWER (N. DAK.) SHEET

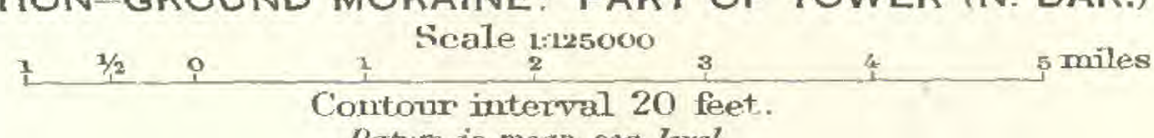

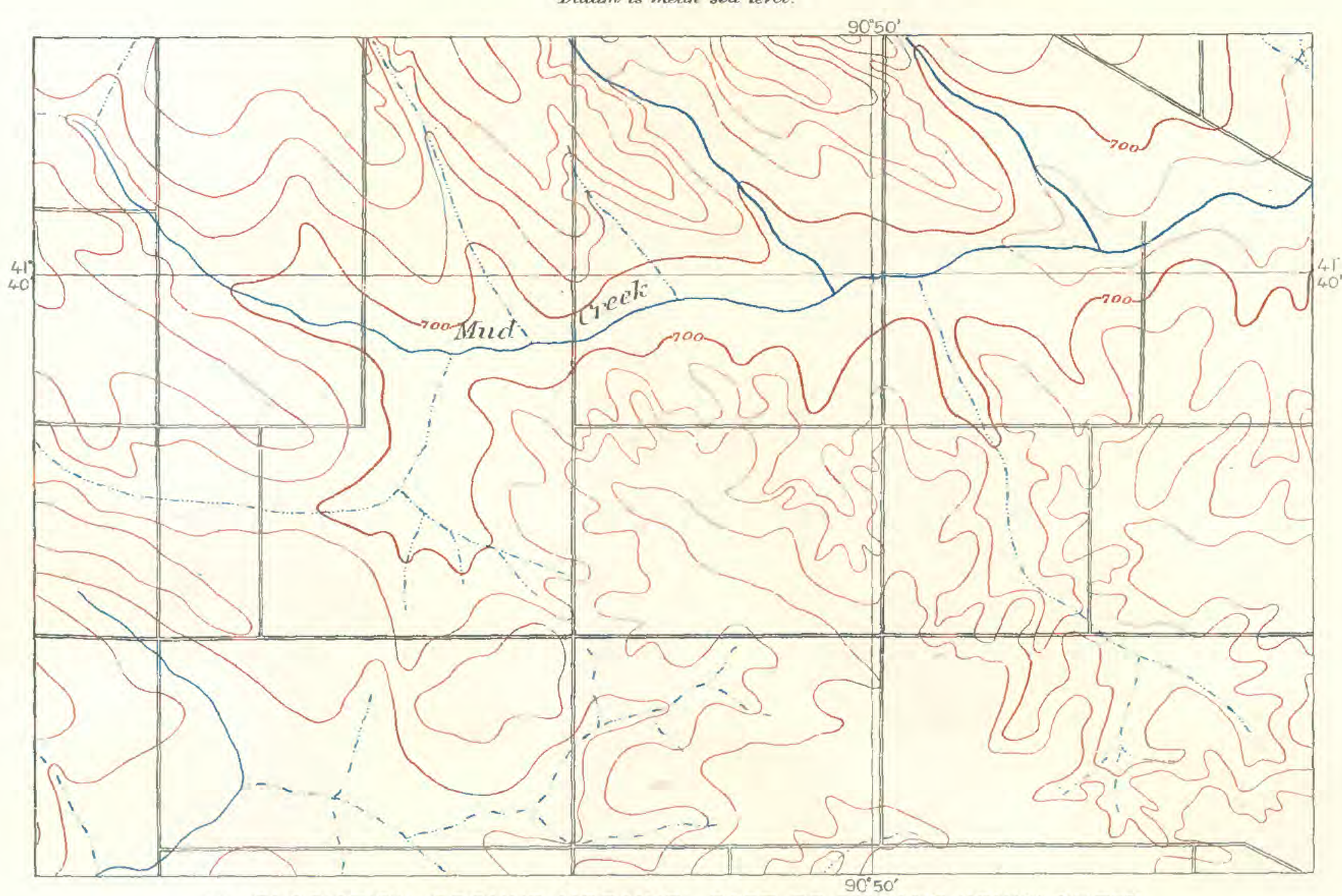

B. GLACIATION-GROUND MORAINE: PART OF DURANT (IOWA) SHEET

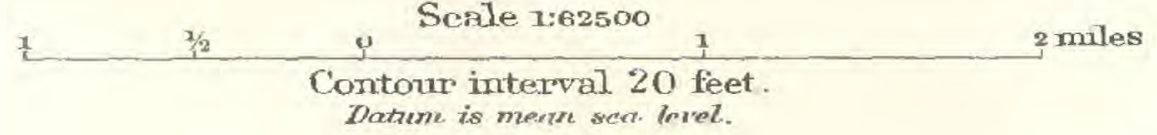




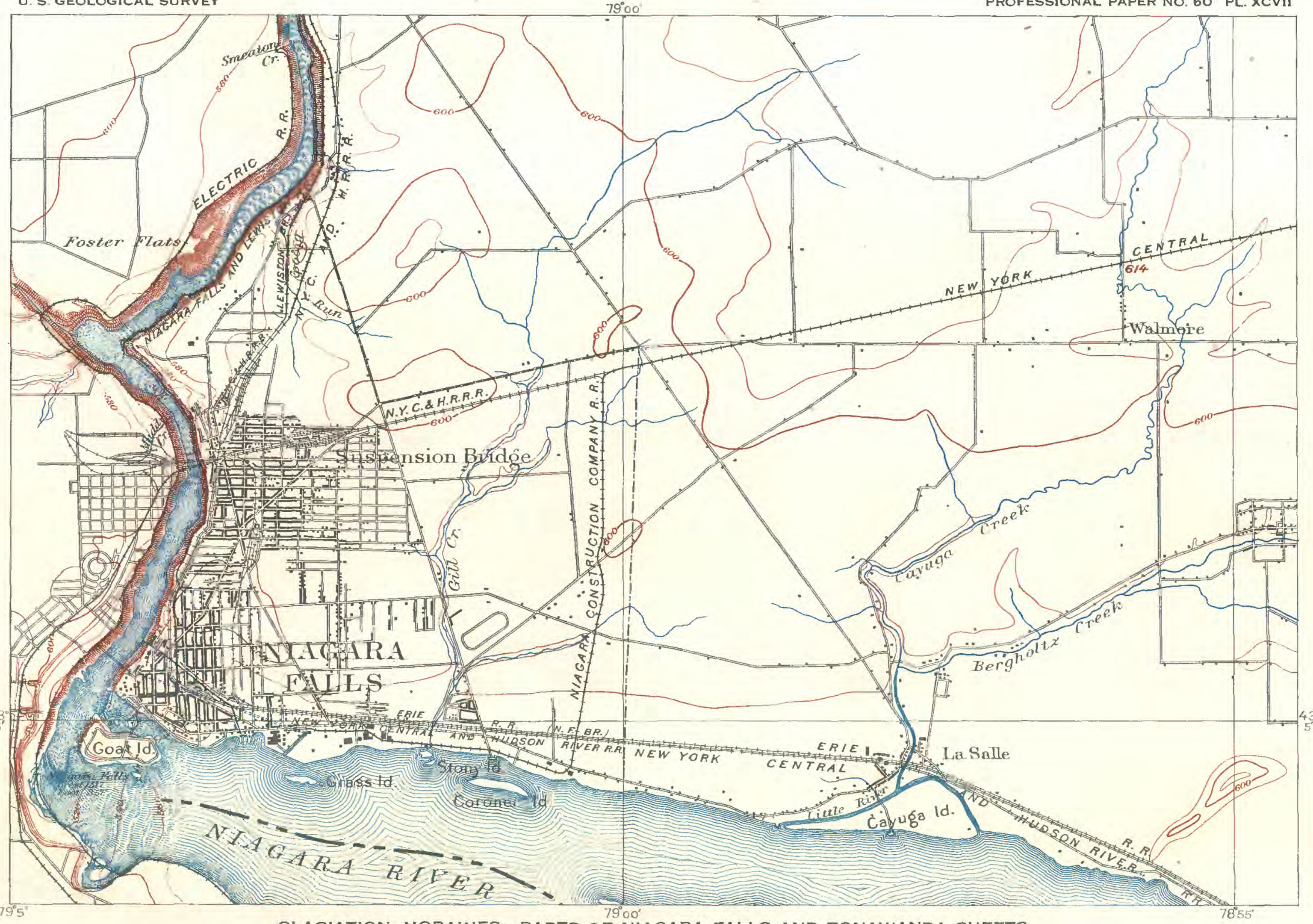

GLACIATION-MORAINES: PARTS OF NIAGARA FALLS AND TONAWANDA SHEETS

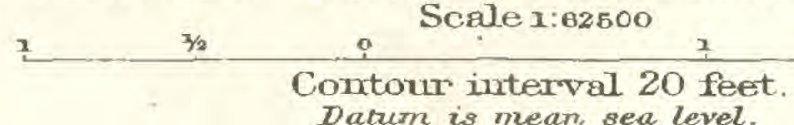




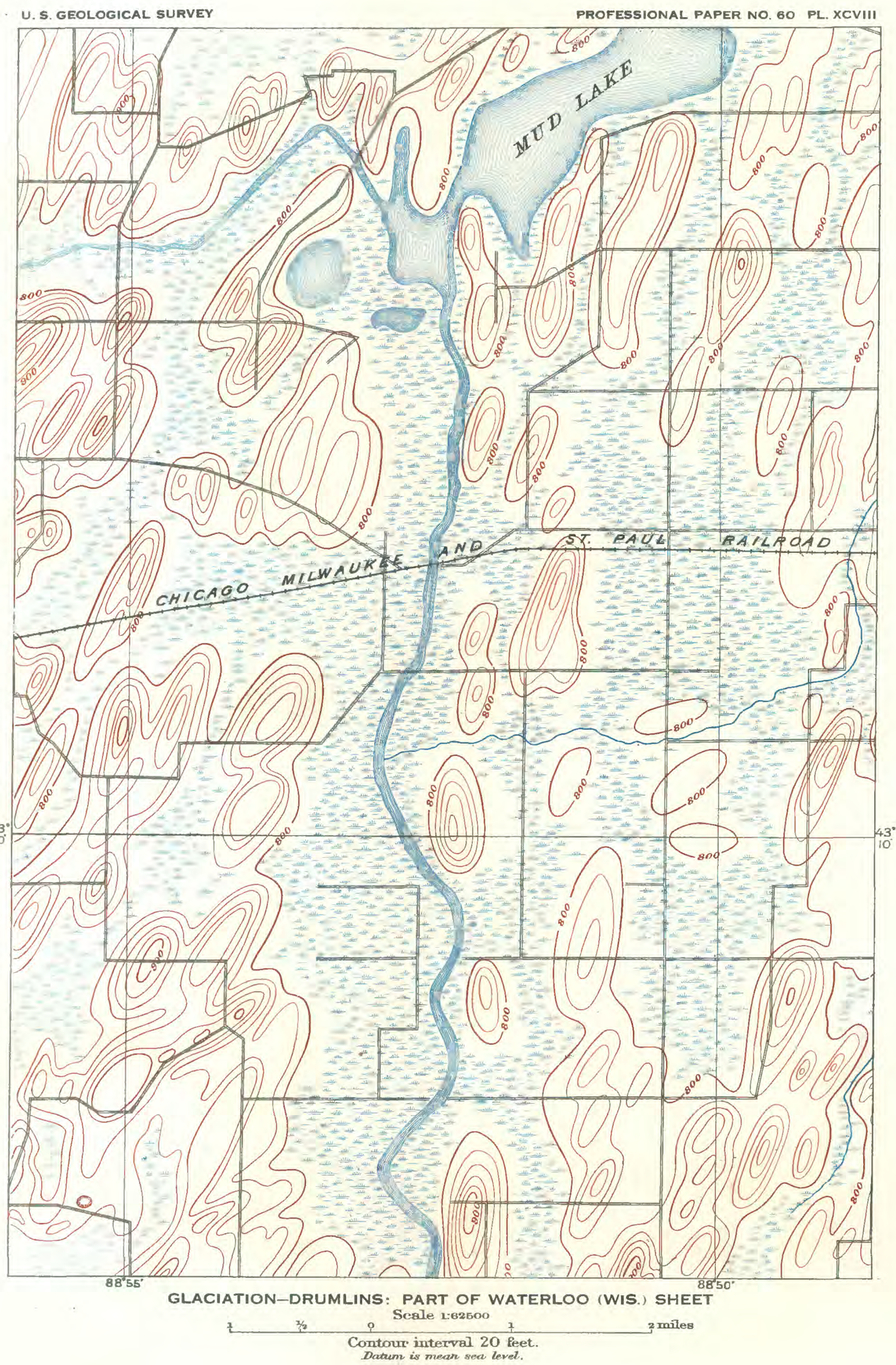




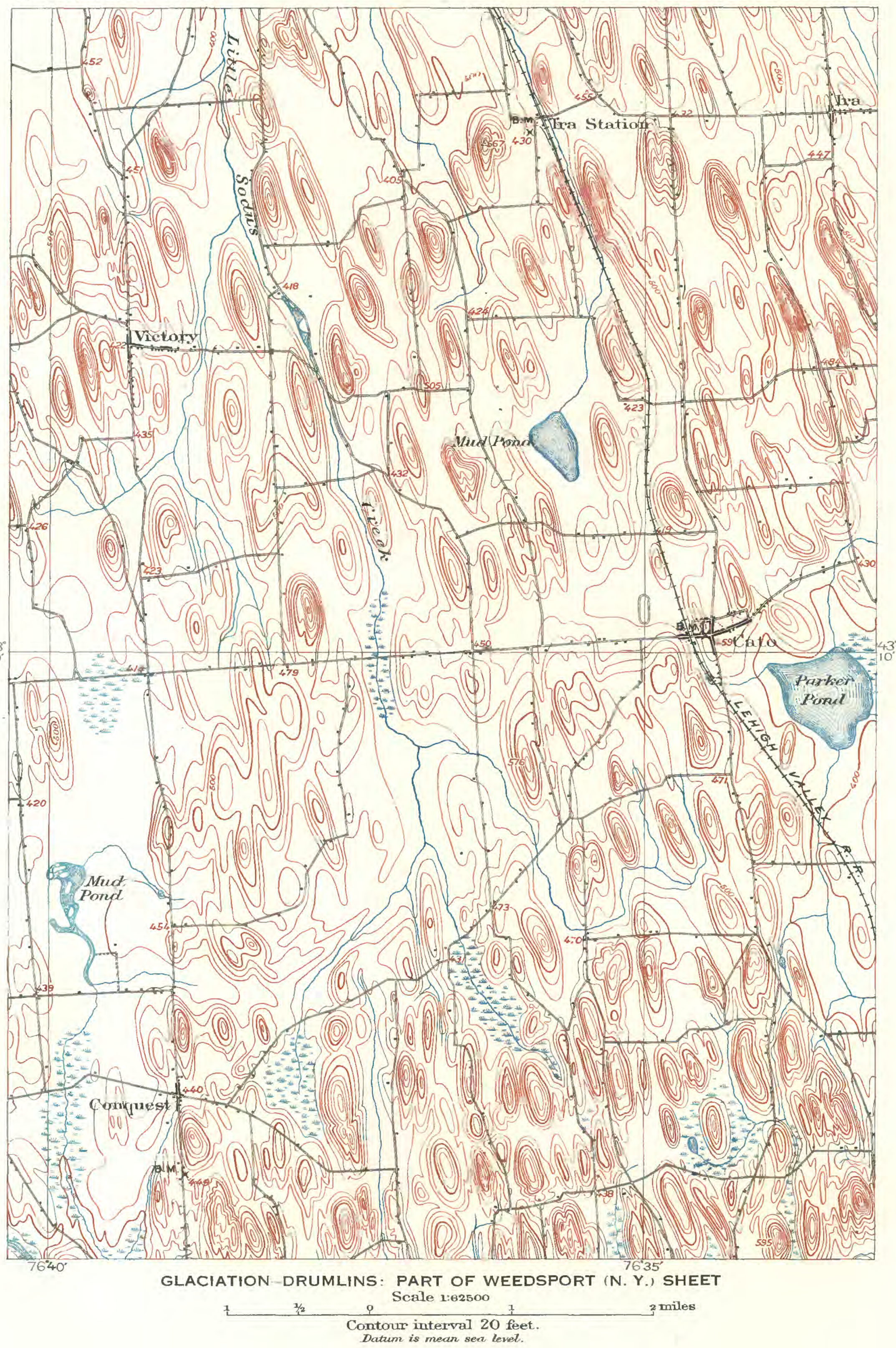




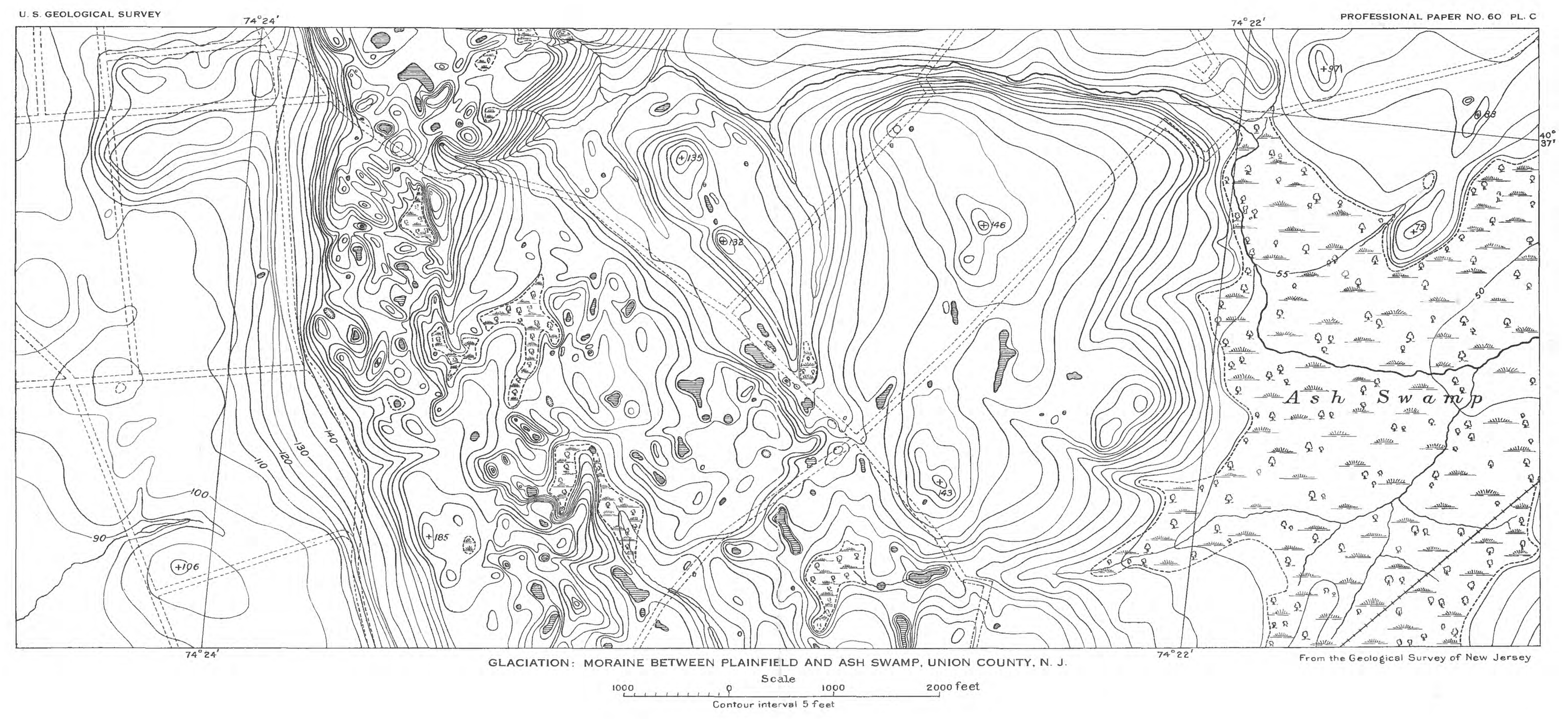




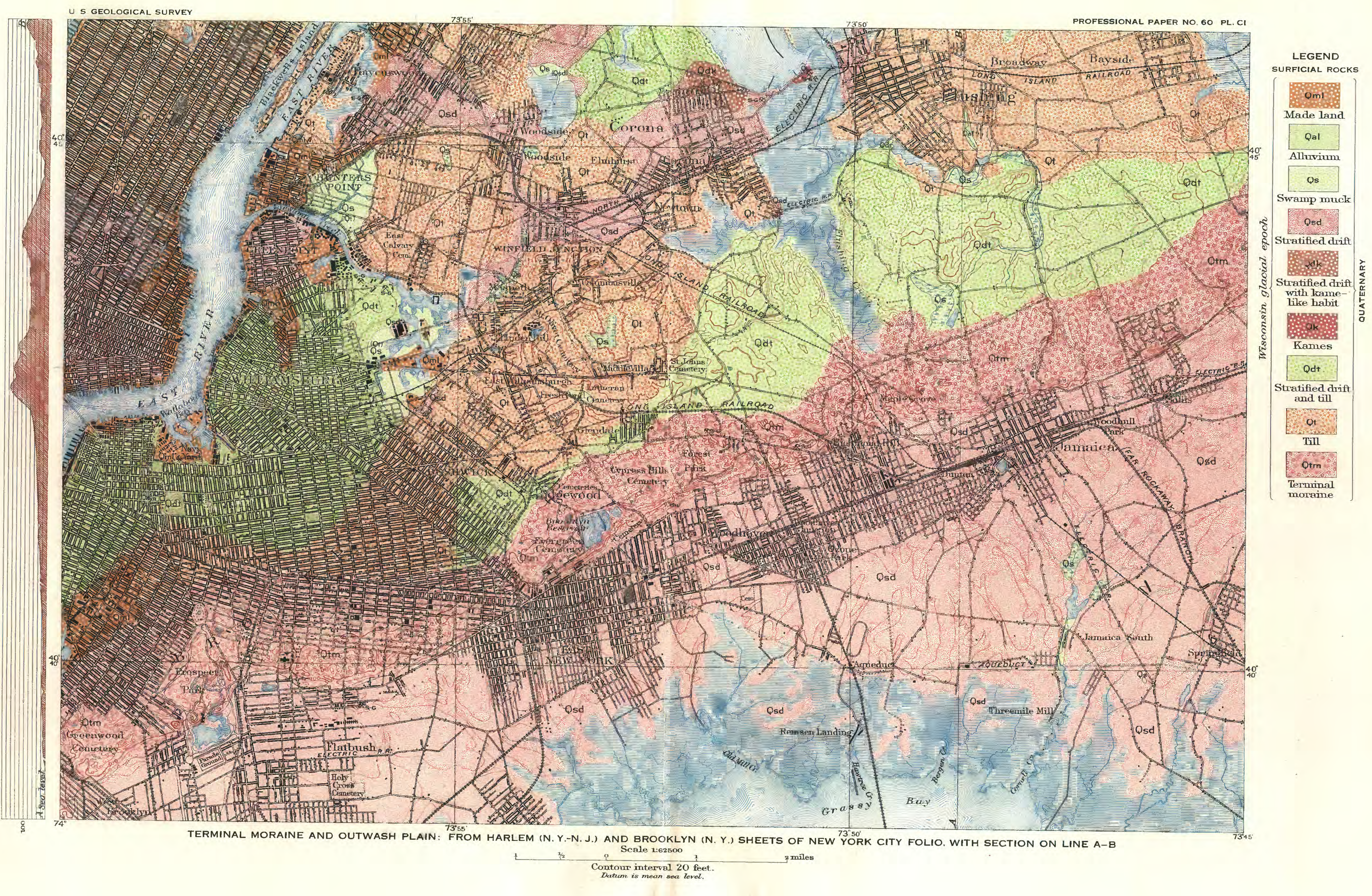




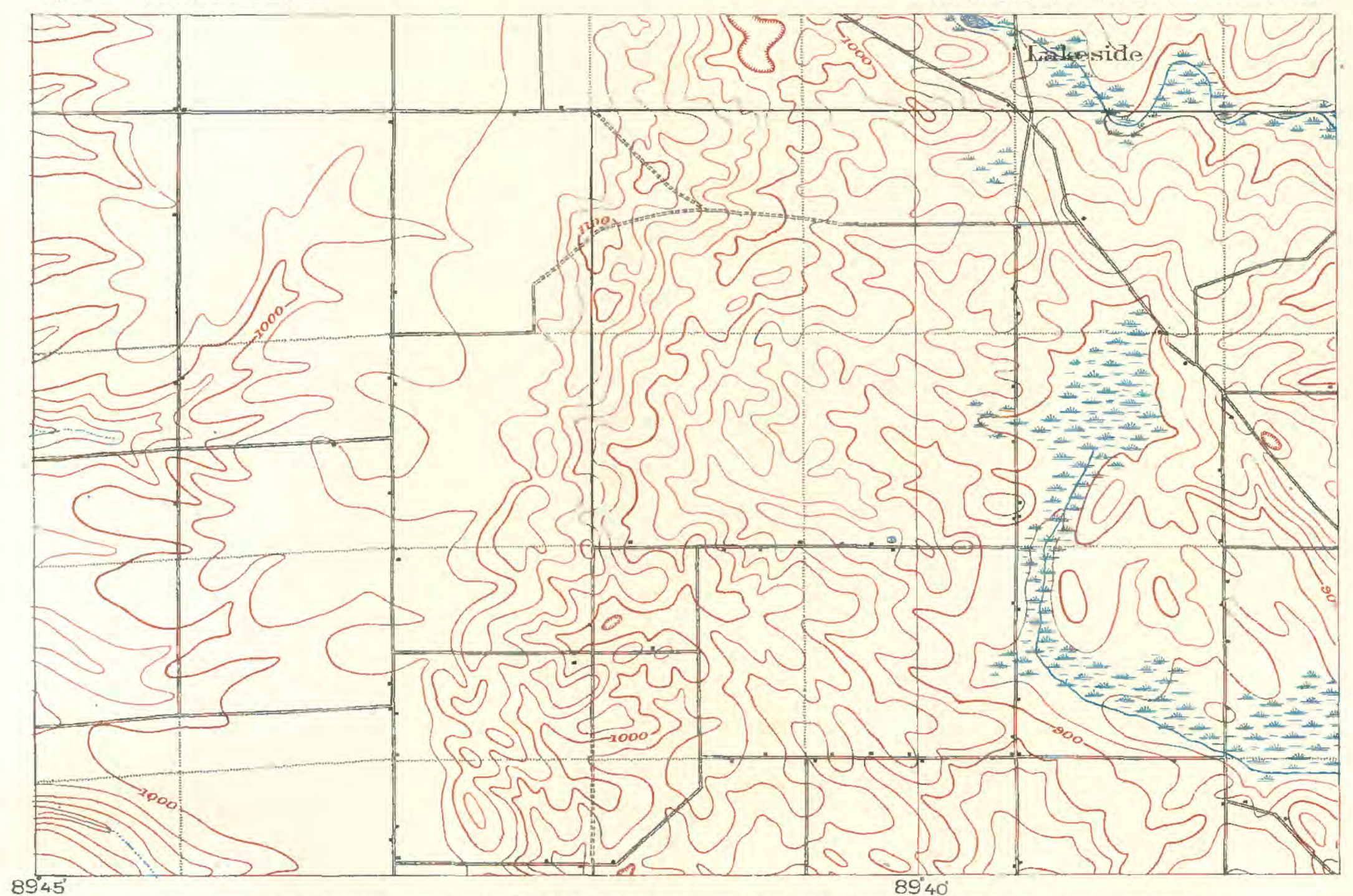

A. GLACIATION-TERMINAL MORAINES: PART OF BRIGGSVILLE (WIS.) SHEET Contour interval 20 feet 2 miles

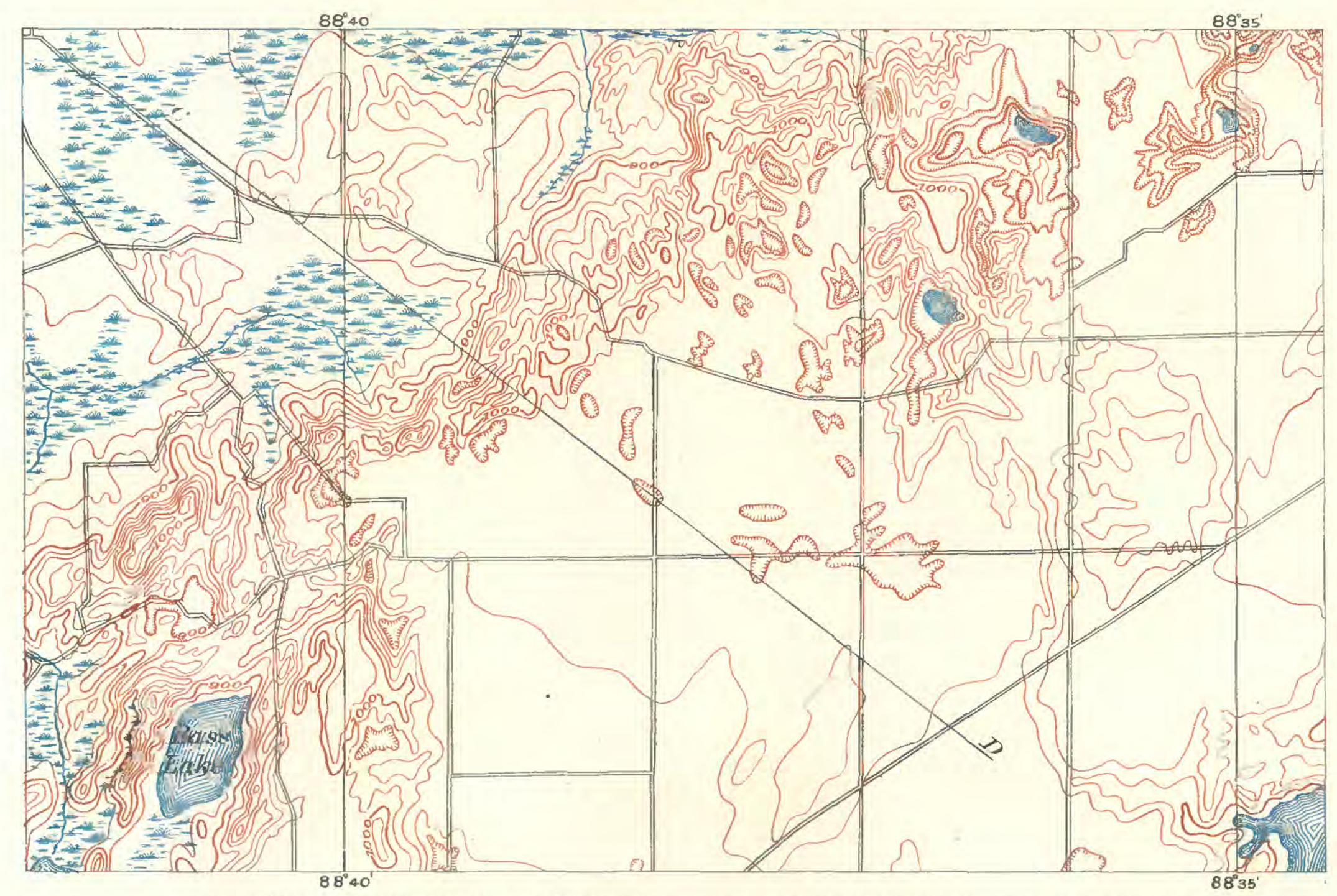

B. GLACIATION-TERMINAL MORAINES: PART OF WHITEWATER (WIS.) SHEET 


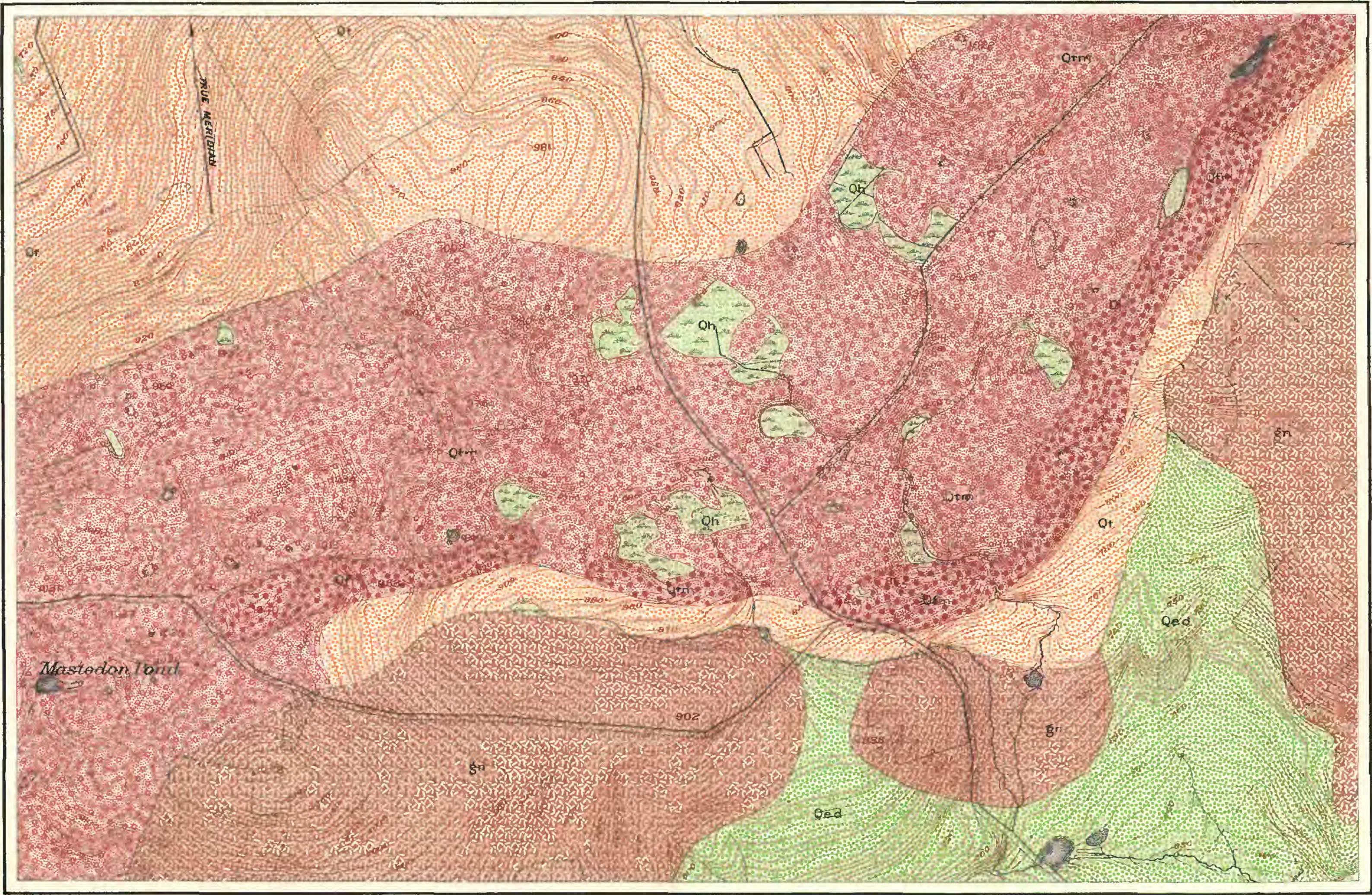

GLACIATION: MORAINE NORTHWEST OF HACKETTSTOWN, N.J.

1000 Scale in feet Contour interval 5 feet QUATERNARY

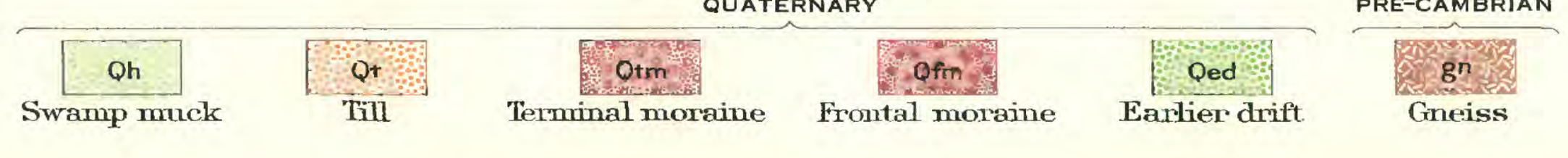




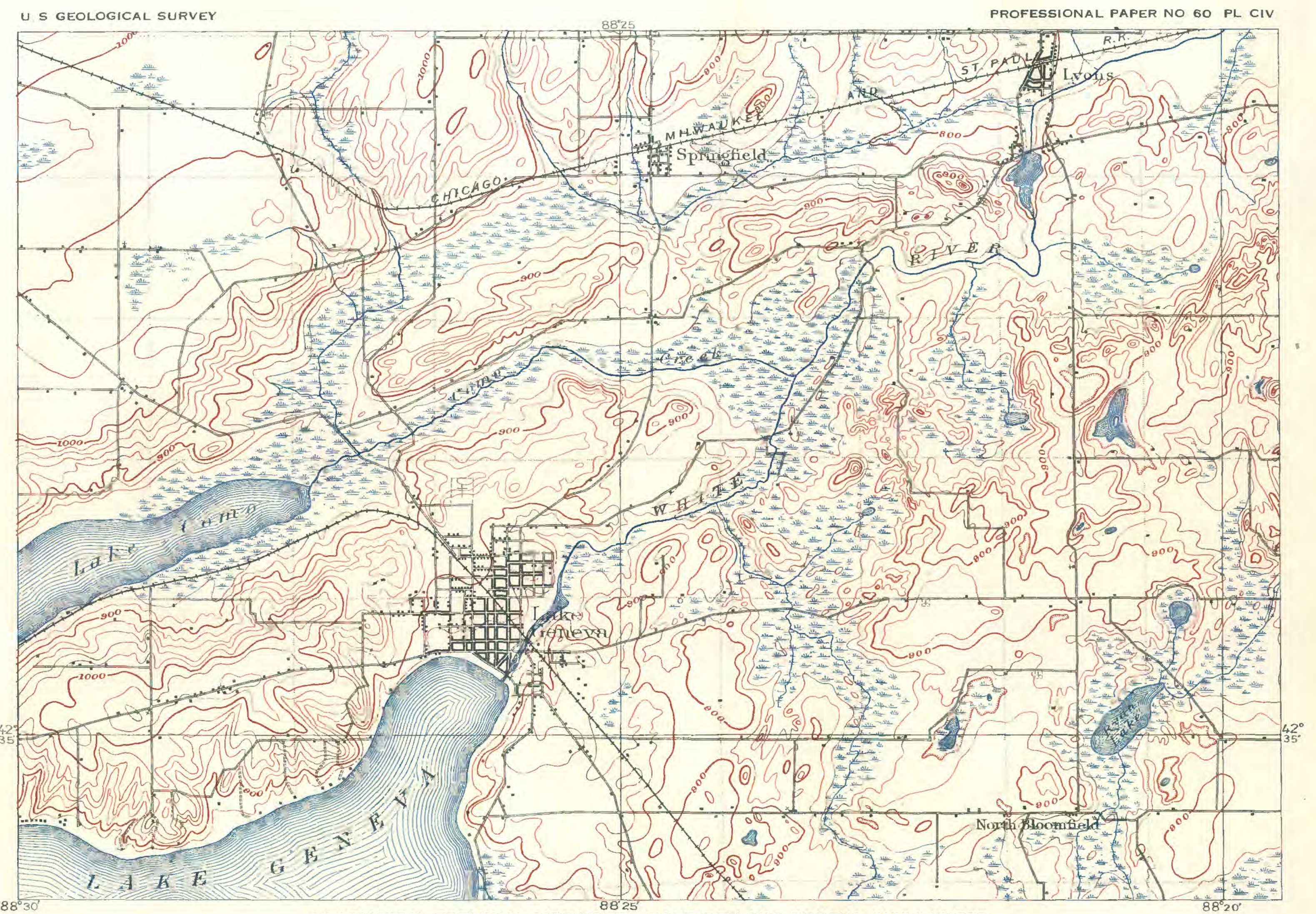

GLACIATION-TERMINAL MORAINES: PART OF LAKE GENEVA (WIS,) SHEET

$$
1 . \frac{1}{\begin{array}{c}
\text { Contorir interval } 20 \text { feet. } \\
\text { Dotam is mean sea level. }
\end{array} .}
$$




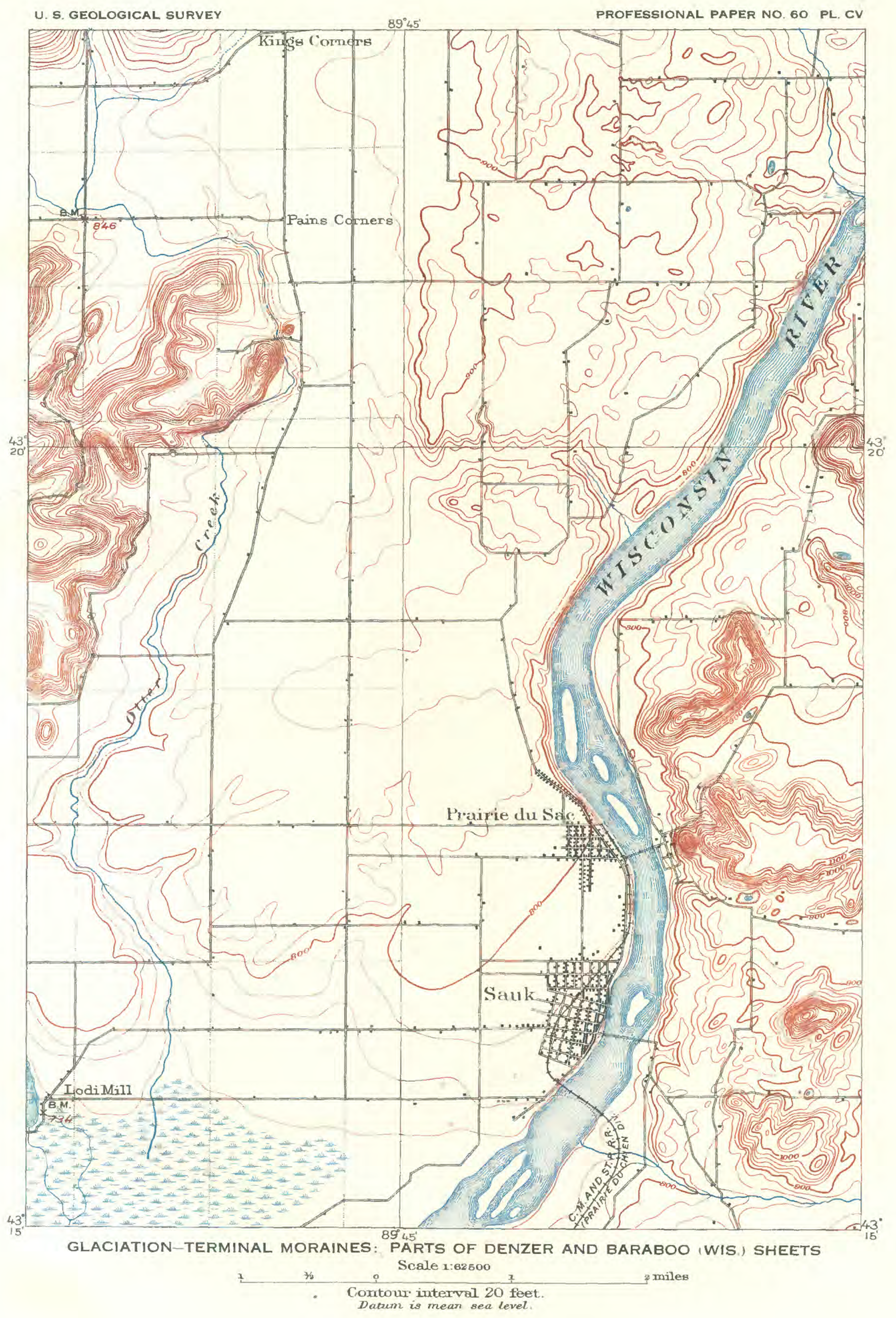




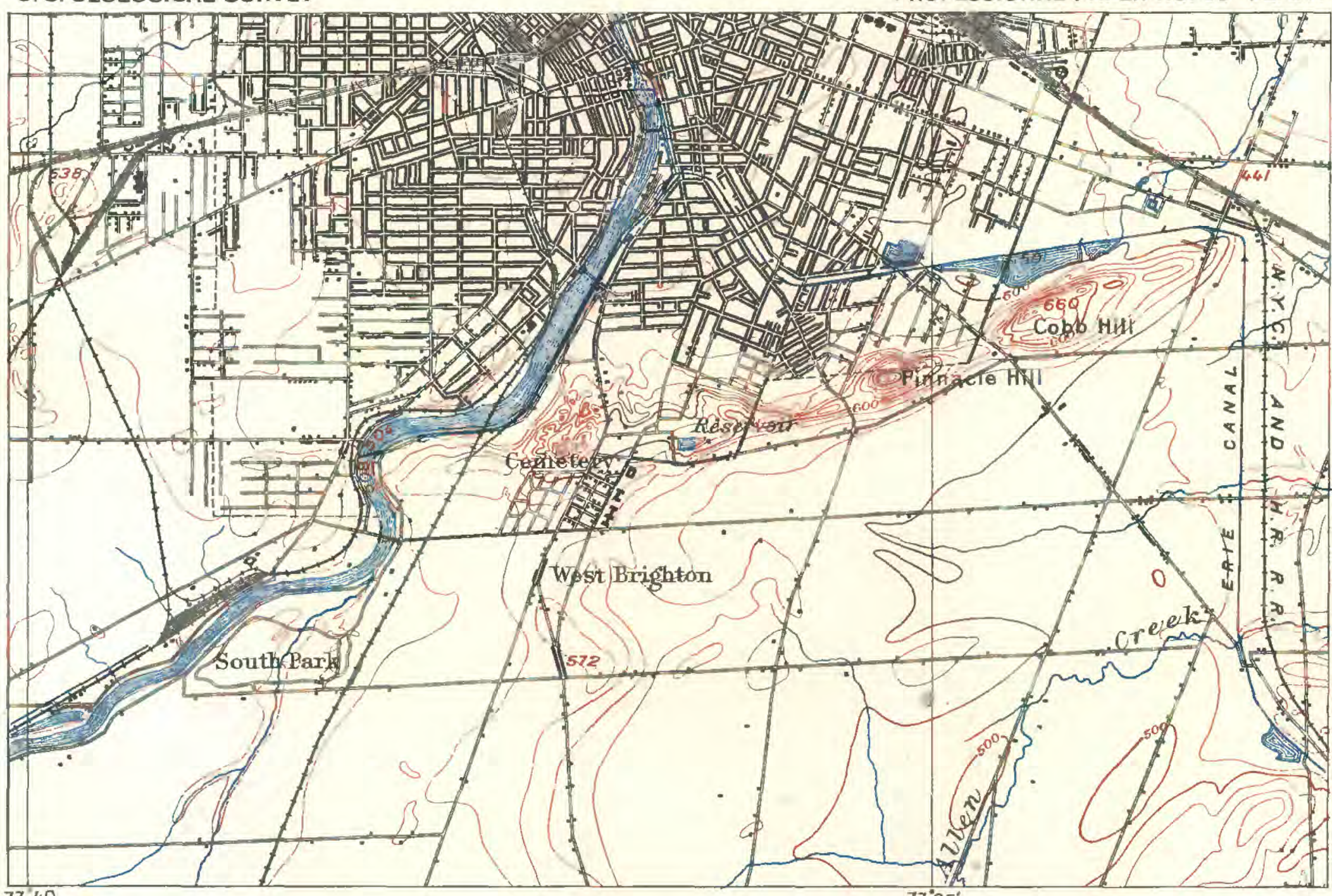

A. GLACIATION-KAMES: PART OF ROCHESTER (N. Y.) SHEET Scale 1:82500 $3 / 2$

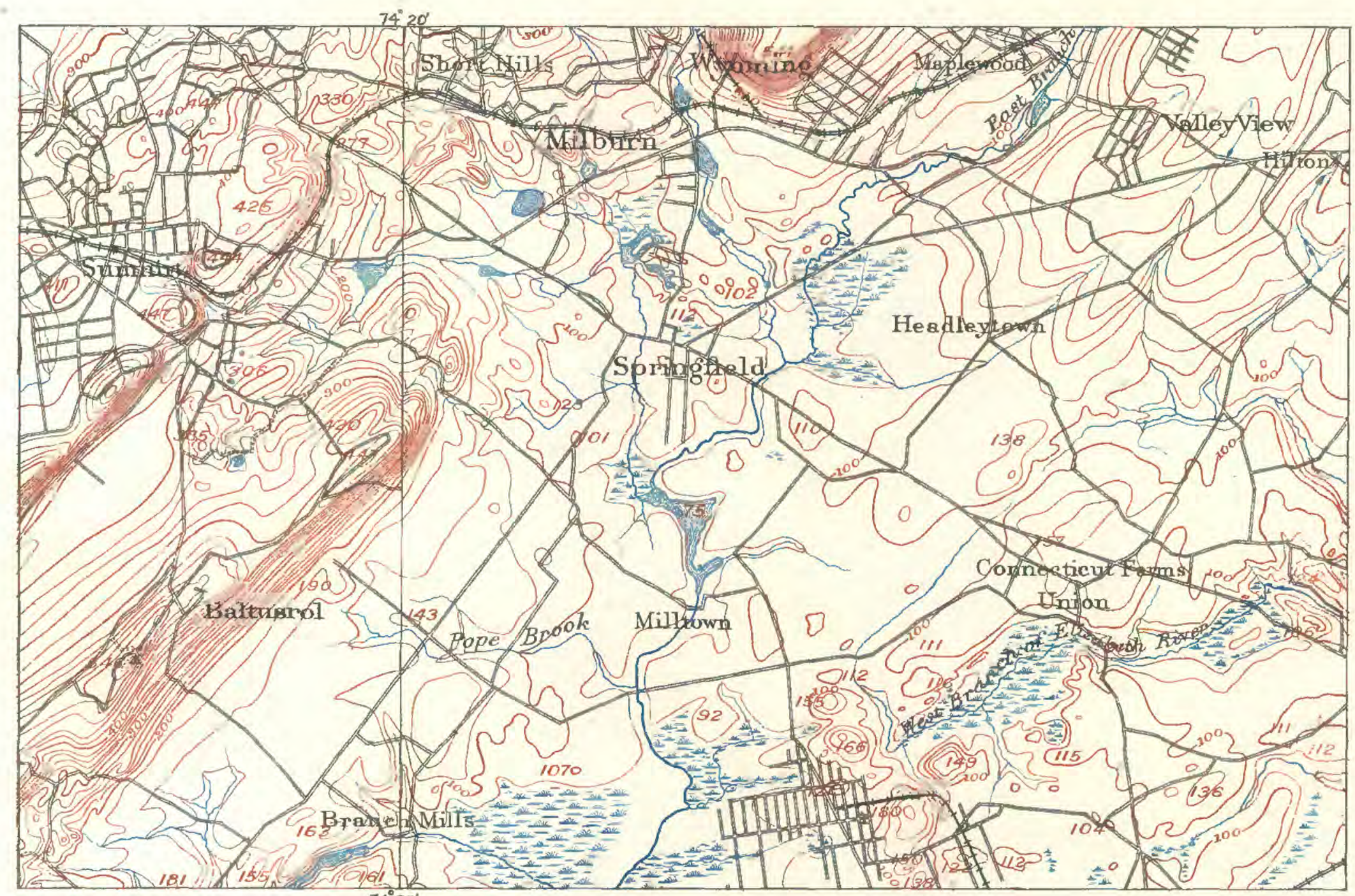

B. GLACIATION-KAMES: PART OF PLAINFIELD (N. J.-N. Y) SHEET 


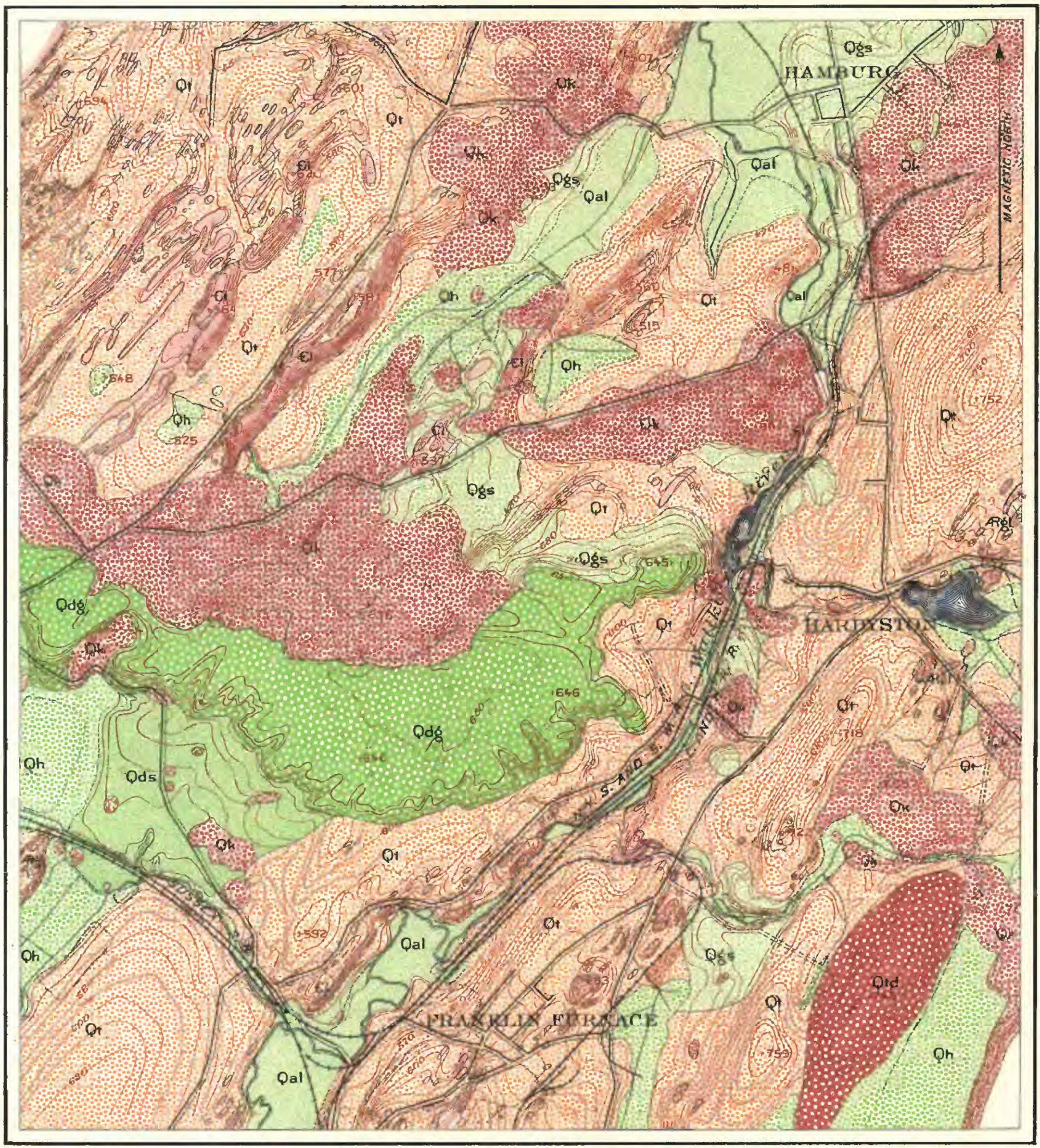

GLACIATION-KAMES: SURFACE GEOLOGY NEAR HAMBURG. N. J.

1000 . 1000 Scale in feet 3000 4000 sooo

Contour interval 10 feet

Datum is mean sea level

QUATERNARY

\begin{tabular}{|c|c|c|}
\hline $\mathrm{Qal}$ & Qh & Qt \\
\hline Alluvitima & $\begin{array}{l}\text { Swaunp } \\
\text { muck }\end{array}$ & Till \\
\hline
\end{tabular}

\begin{tabular}{|c|c|c|c|c|}
\hline Q Q & Qgs & Qdg & Qds & Pkg \\
\hline Drumlin & $\begin{array}{l}\text { Stratified } \\
\text { drift }\end{array}$ & $\begin{array}{l}\text { North Church } \\
\text { delta }\end{array}$ & $\begin{array}{l}\text { Delta } \\
\text { clay and } \\
\text { sand }\end{array}$ & $\begin{array}{l}\text { Kames and } \\
\text { kame-like areas }\end{array}$ \\
\hline
\end{tabular}

CAMBRIAN AND OLDER

$\begin{array}{cc}\text { SI } & \begin{array}{c}\text { Aigh } \\ \text { Chiefly } \\ \text { gneiss and } \\ \text { chystalline } \\ \text { limestone }\end{array}\end{array}$




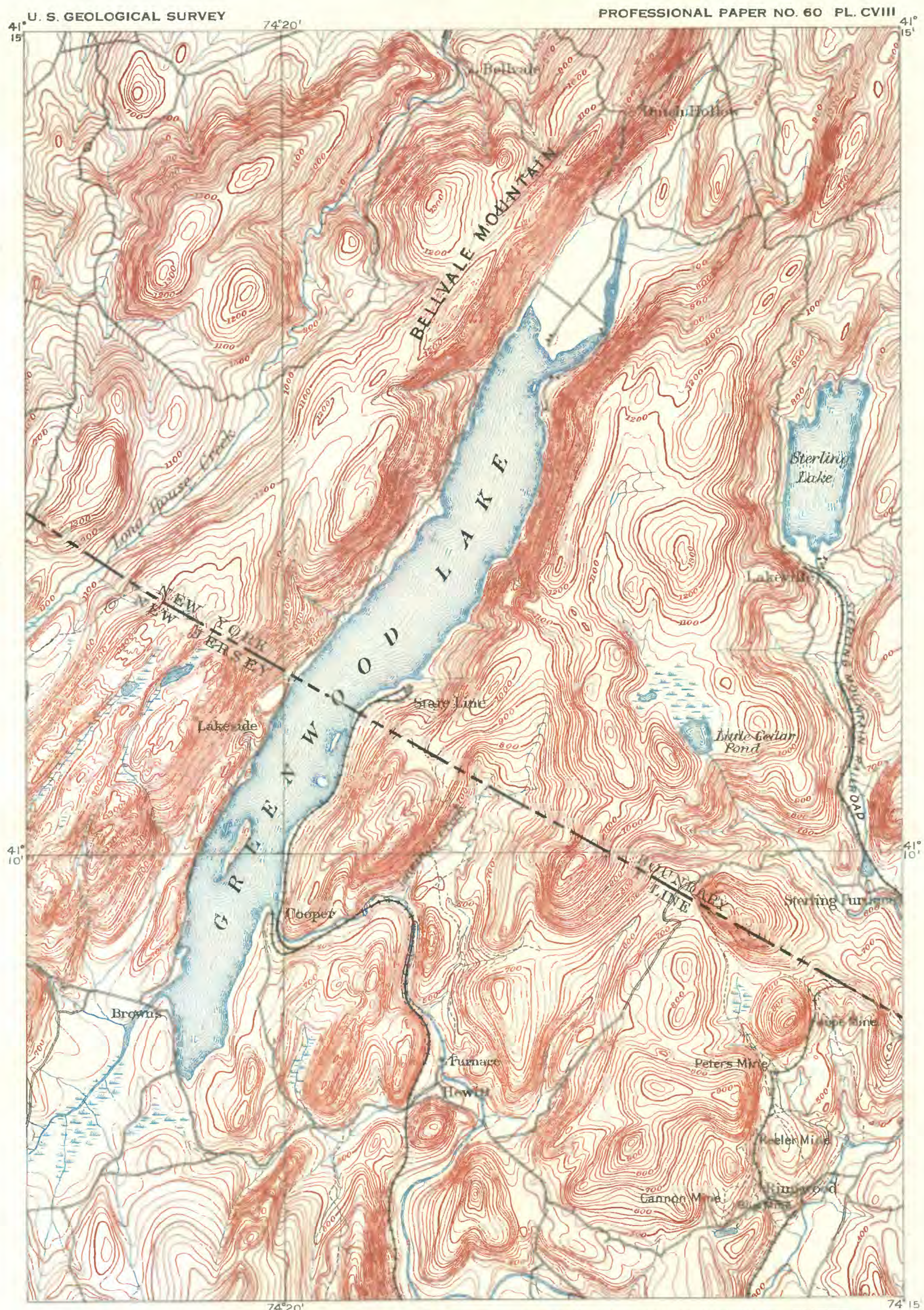

GLACIATION-DRAINAGE CHANGES: PART OF GREENWOOD LAKE (N. Y.-N. J.) SHEET Scale 1:6250 


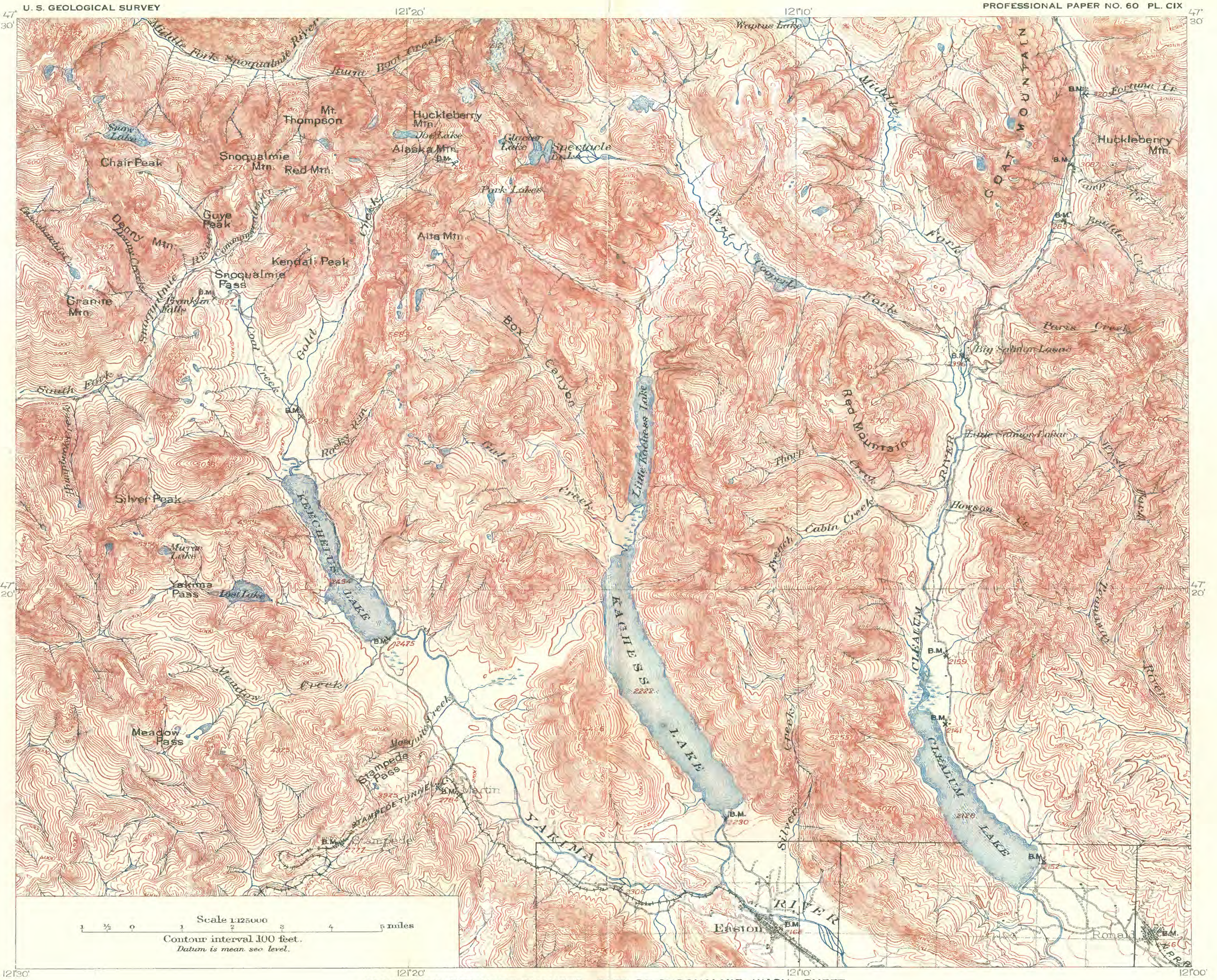




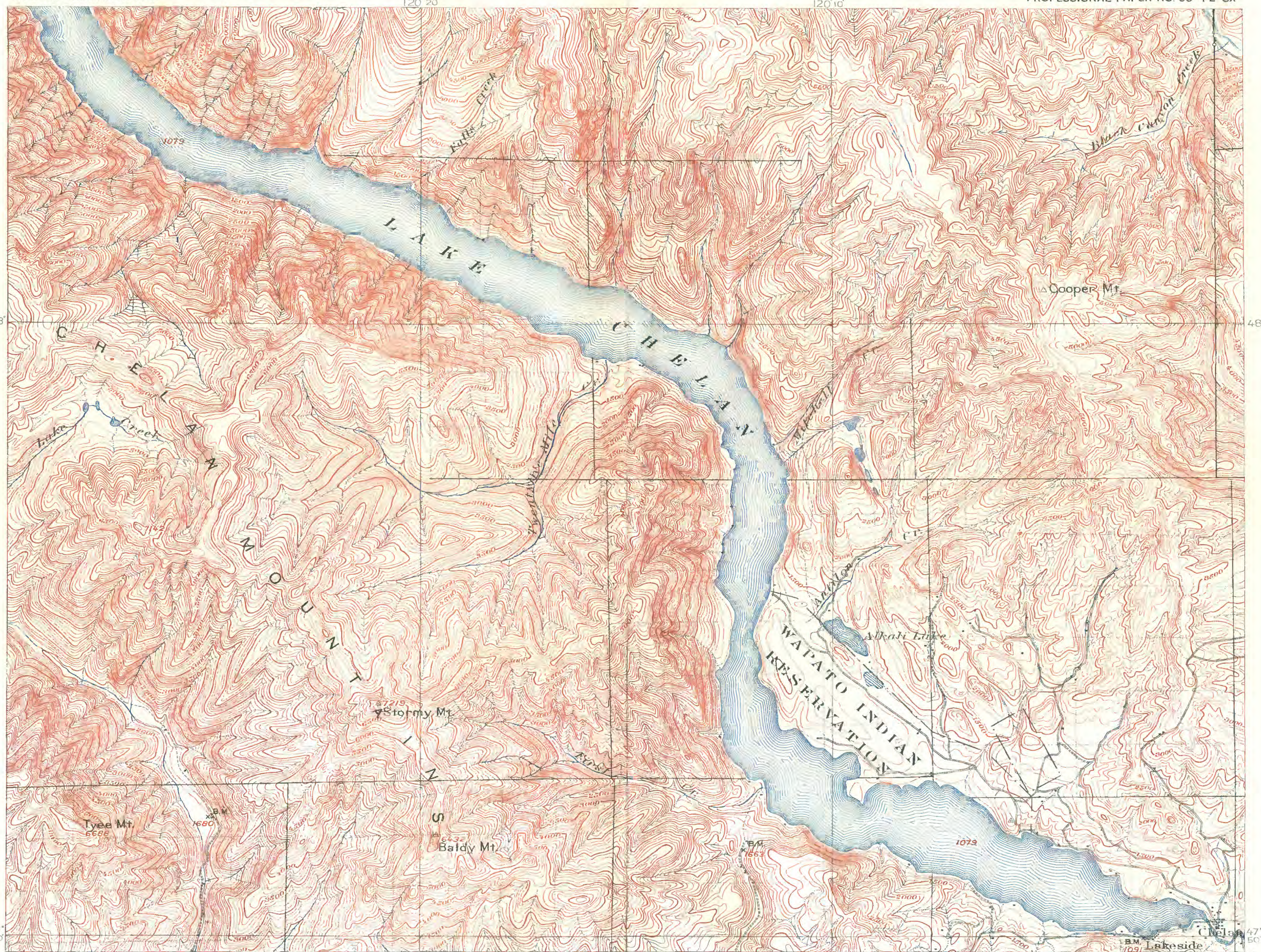




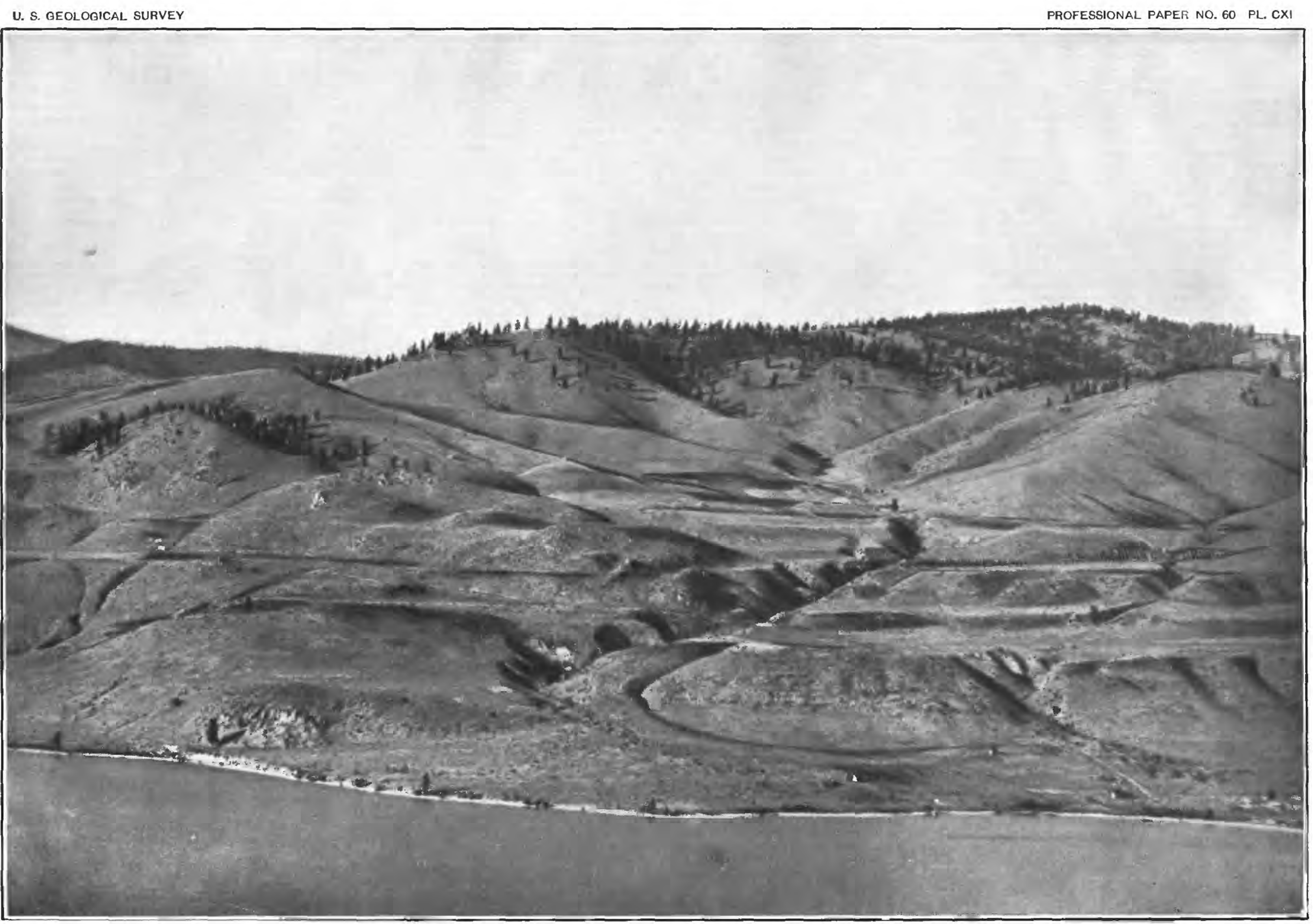

VIEW OF SLOPE ABOVE LAKE CHELAN, WASHINGTON. 


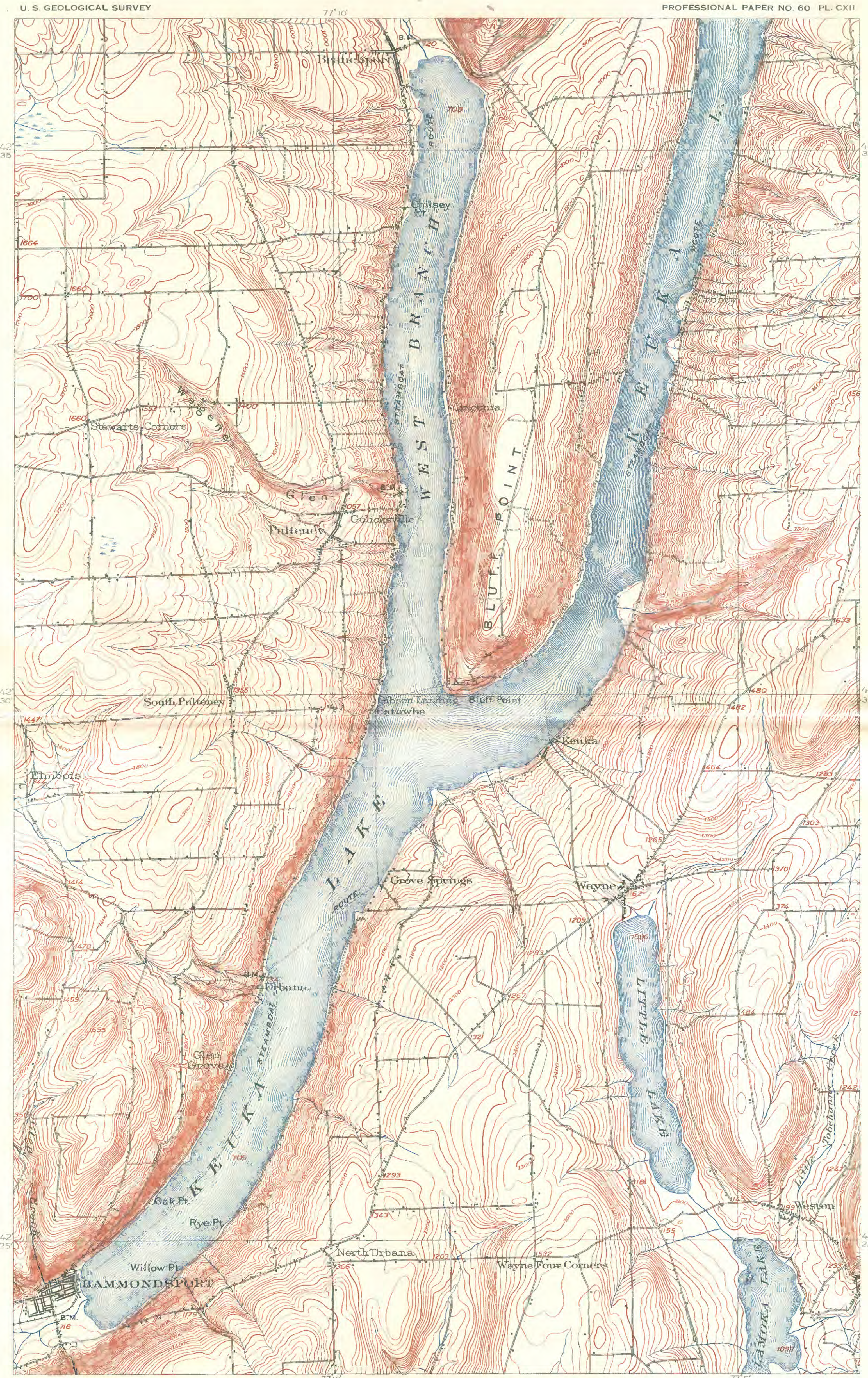




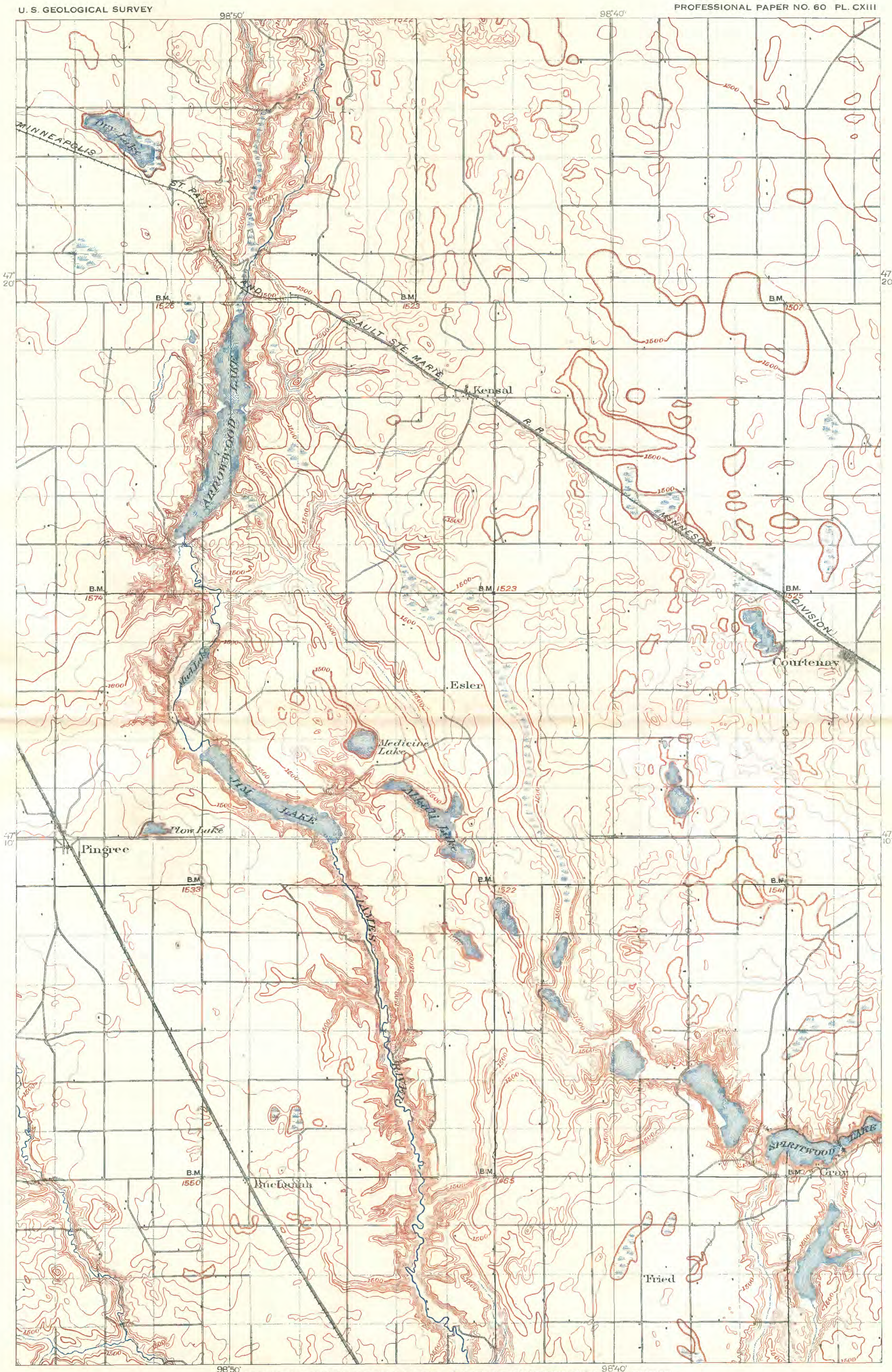

GLACIATION-DRAINAGE CHANGES: PART OF PINGREE (N. DAK.) SHEET 


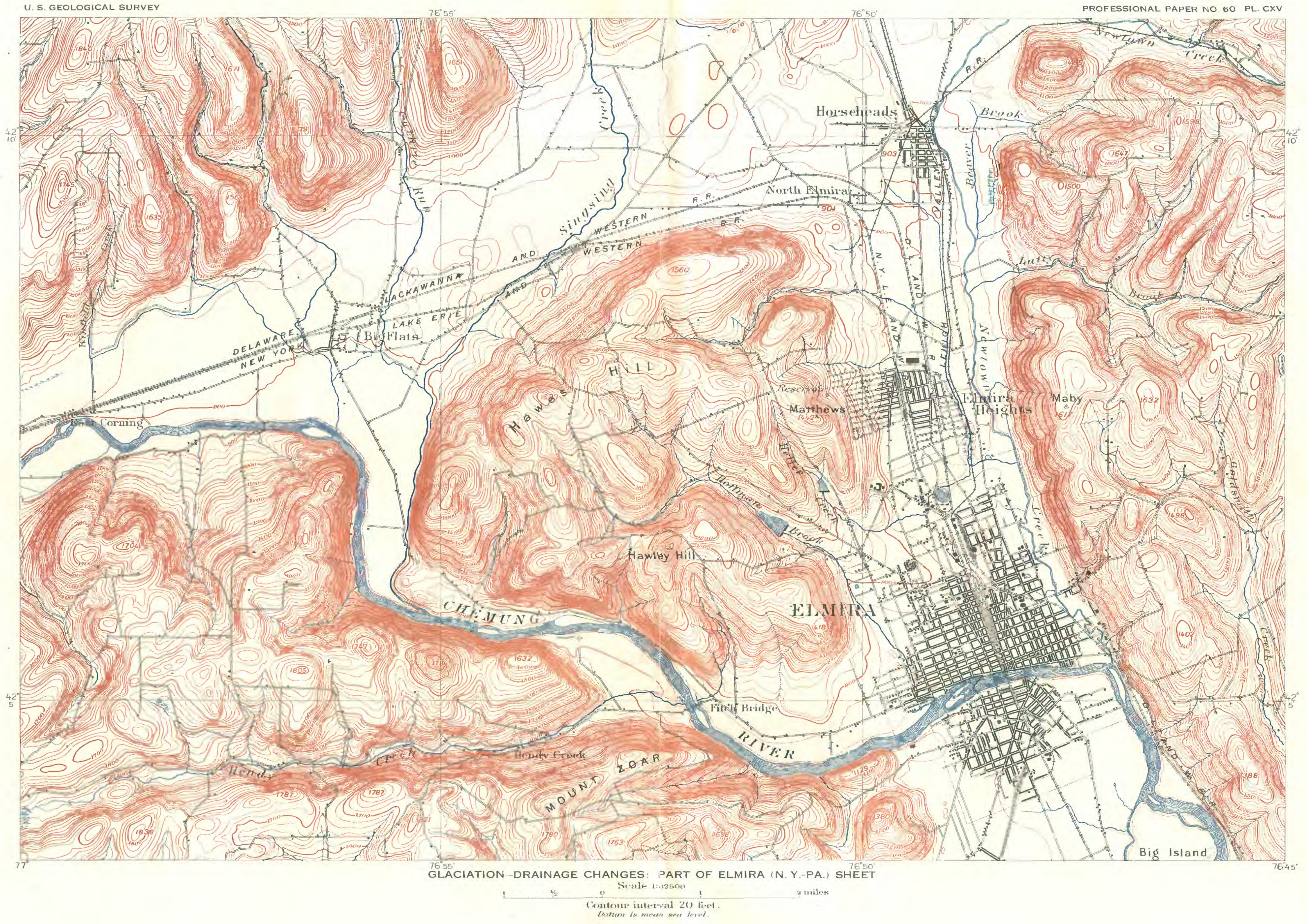




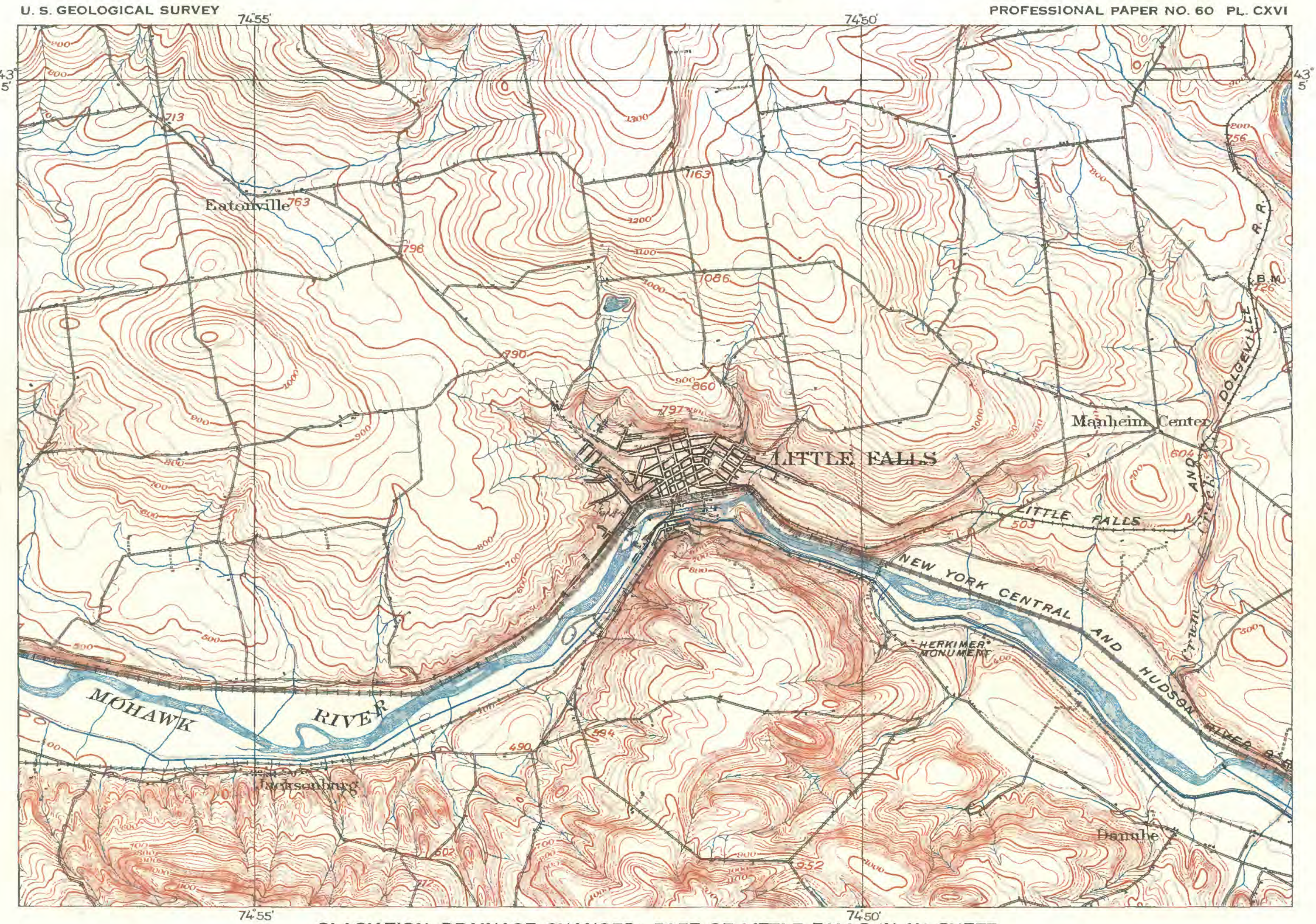

GLACIATION-DRAINAGE CHANGES: PART OF LITTLE FALLS (N. Y.) SHEET

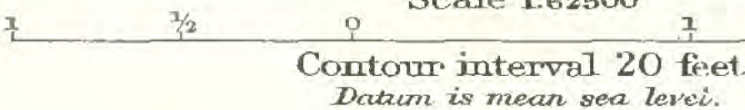




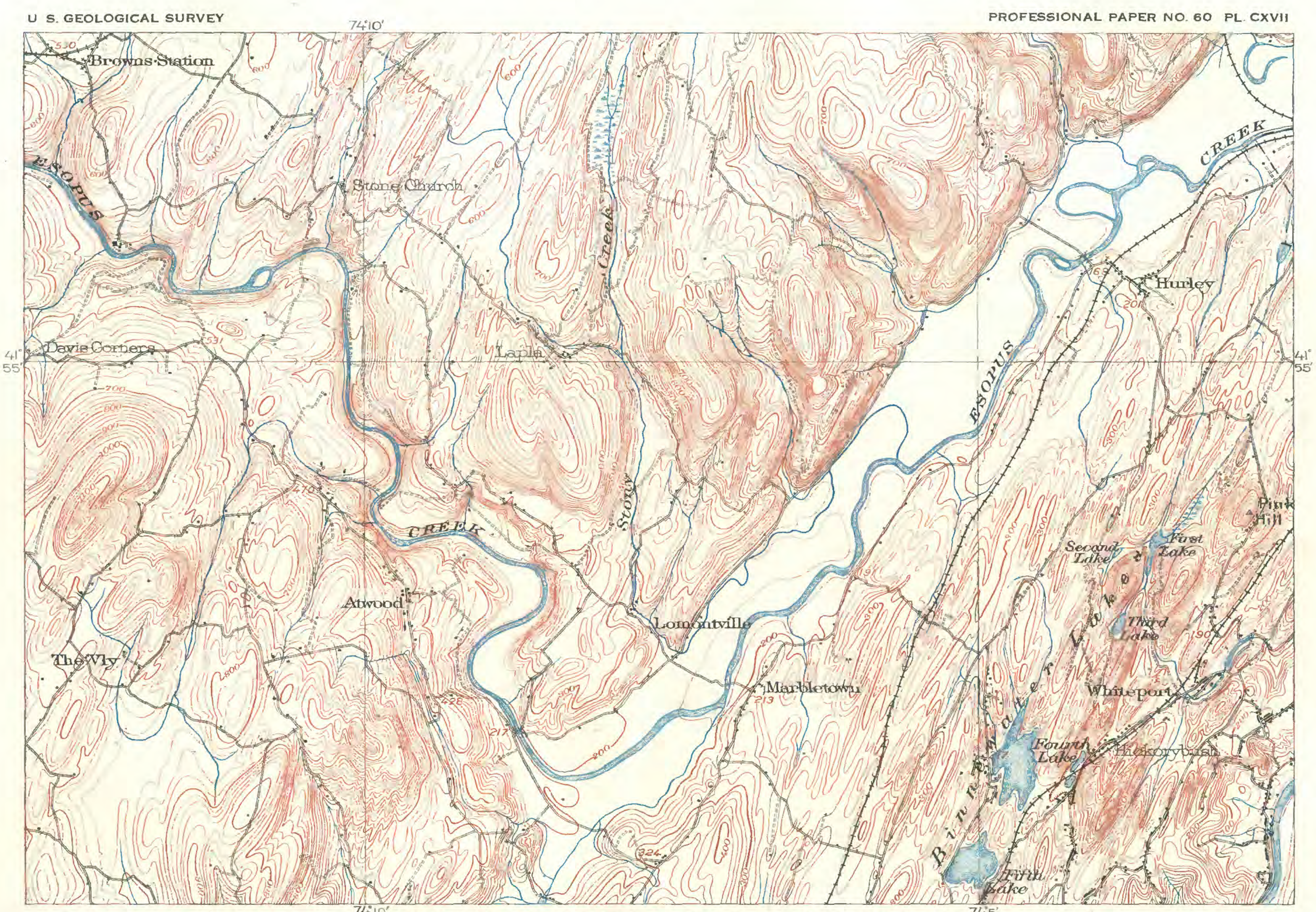

GLACIATION-DRAINAGE CHANGES: PART OF ROSENDALE (N. Y.) SHEET 


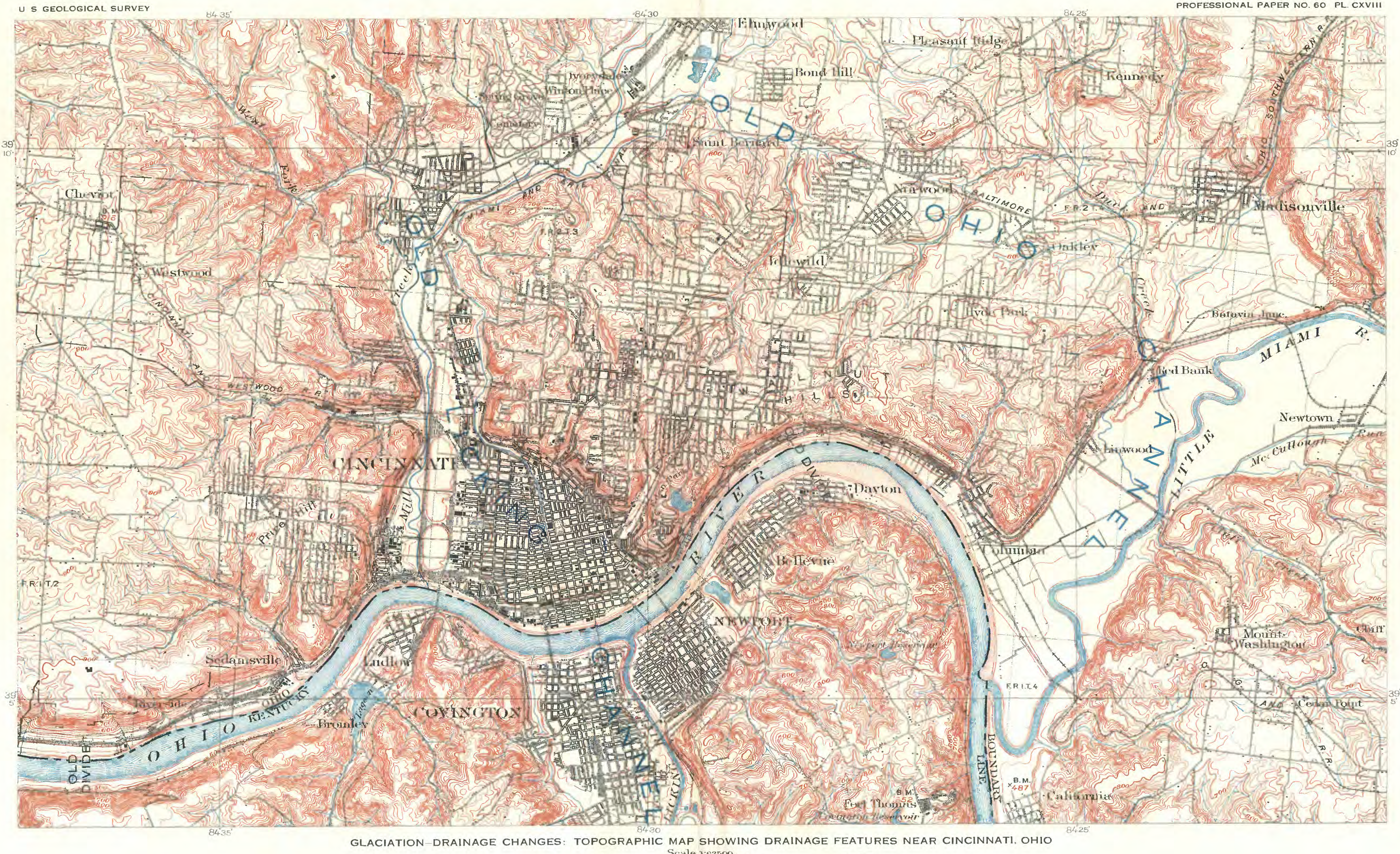
GLACIATION-DRAINAGE CHANGES: TOPOGRAPHIC MAP SHOWING DRAINAGE FEATURES NEAR CINCINNATI. OHIO 
U. S. GEOLOGICAL SURVEY

PROFESSIONAL PAPER NO. 60 PL. CXIX

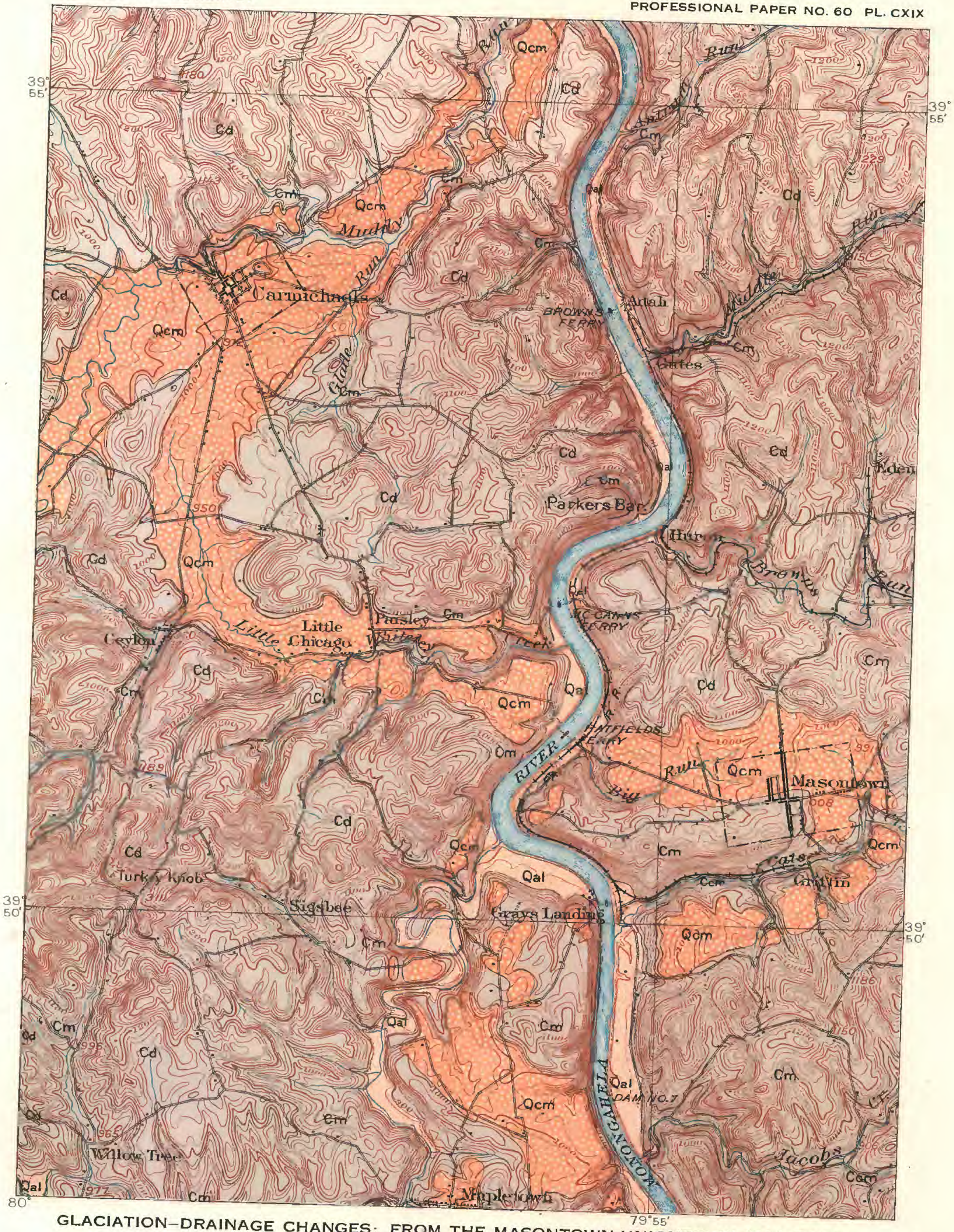

GLACIATION-DRAINAGE CHANGES: FROM THE MASONTOWN-UNIONTOWN (PA.) FOLIO

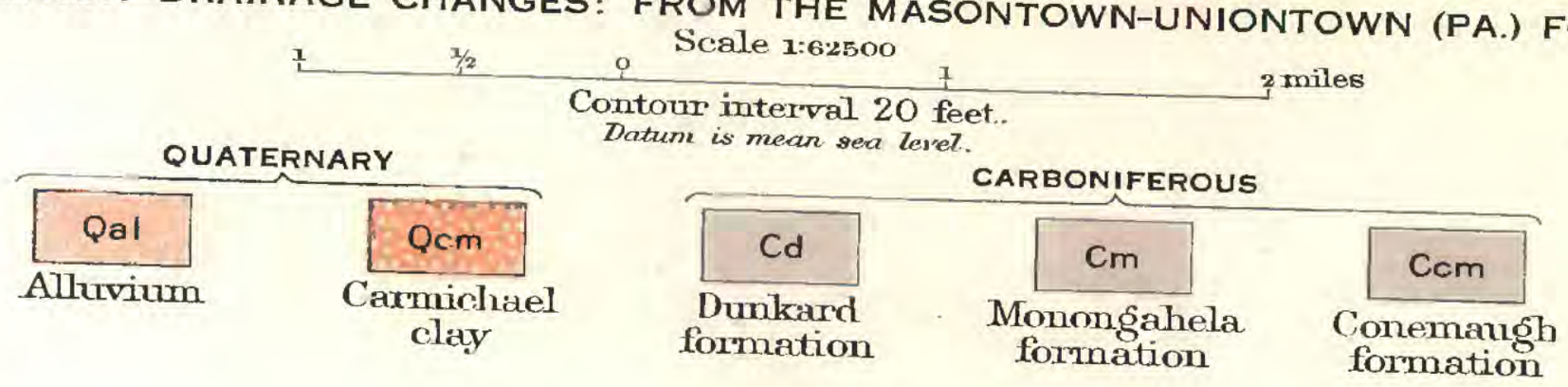




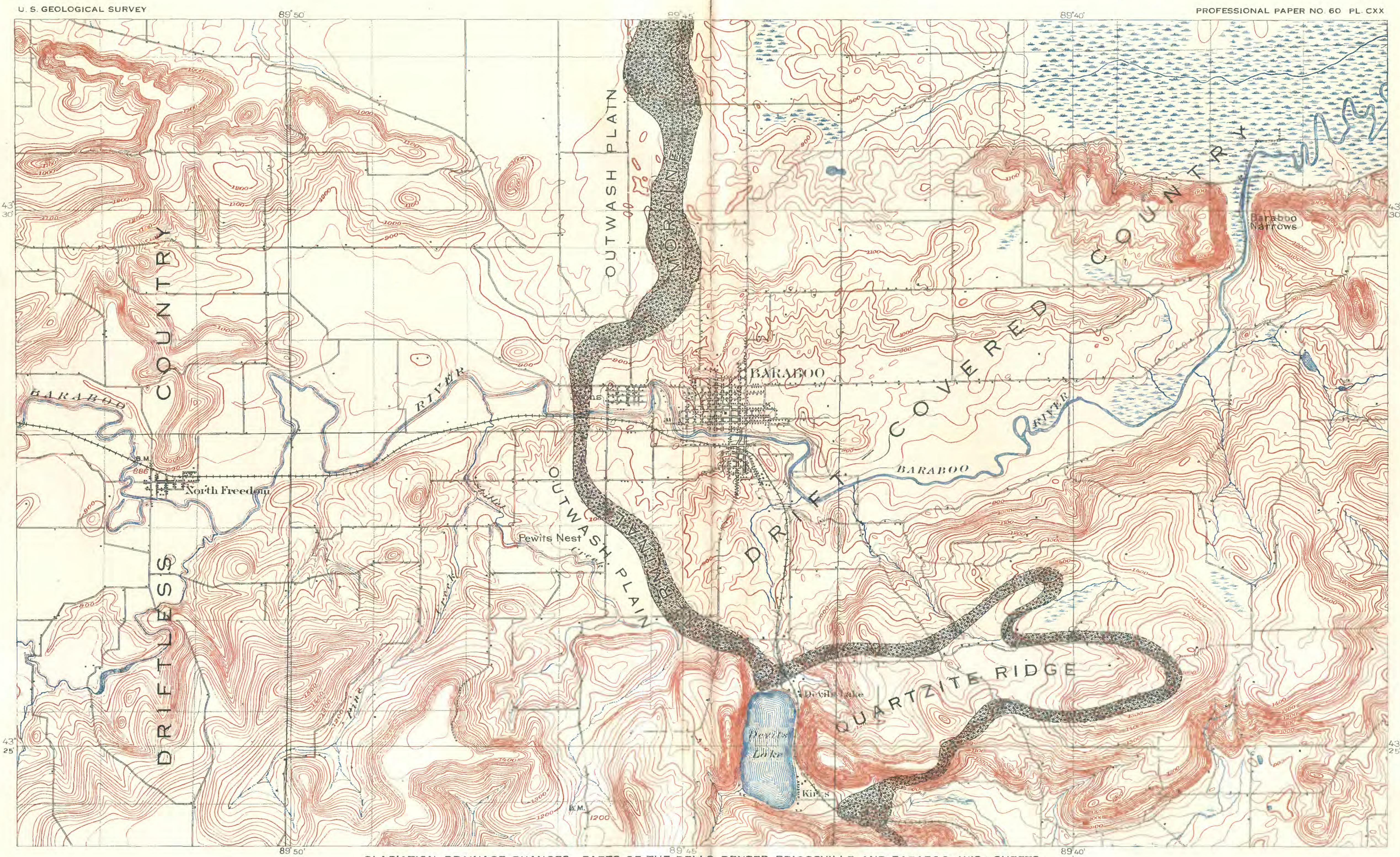

GLACIATION DRIINAGE CHANGES. PARTS OF THE DELLS. DENZER, BRIGGSVILLE AND BARABOO WIS, SHEETS 

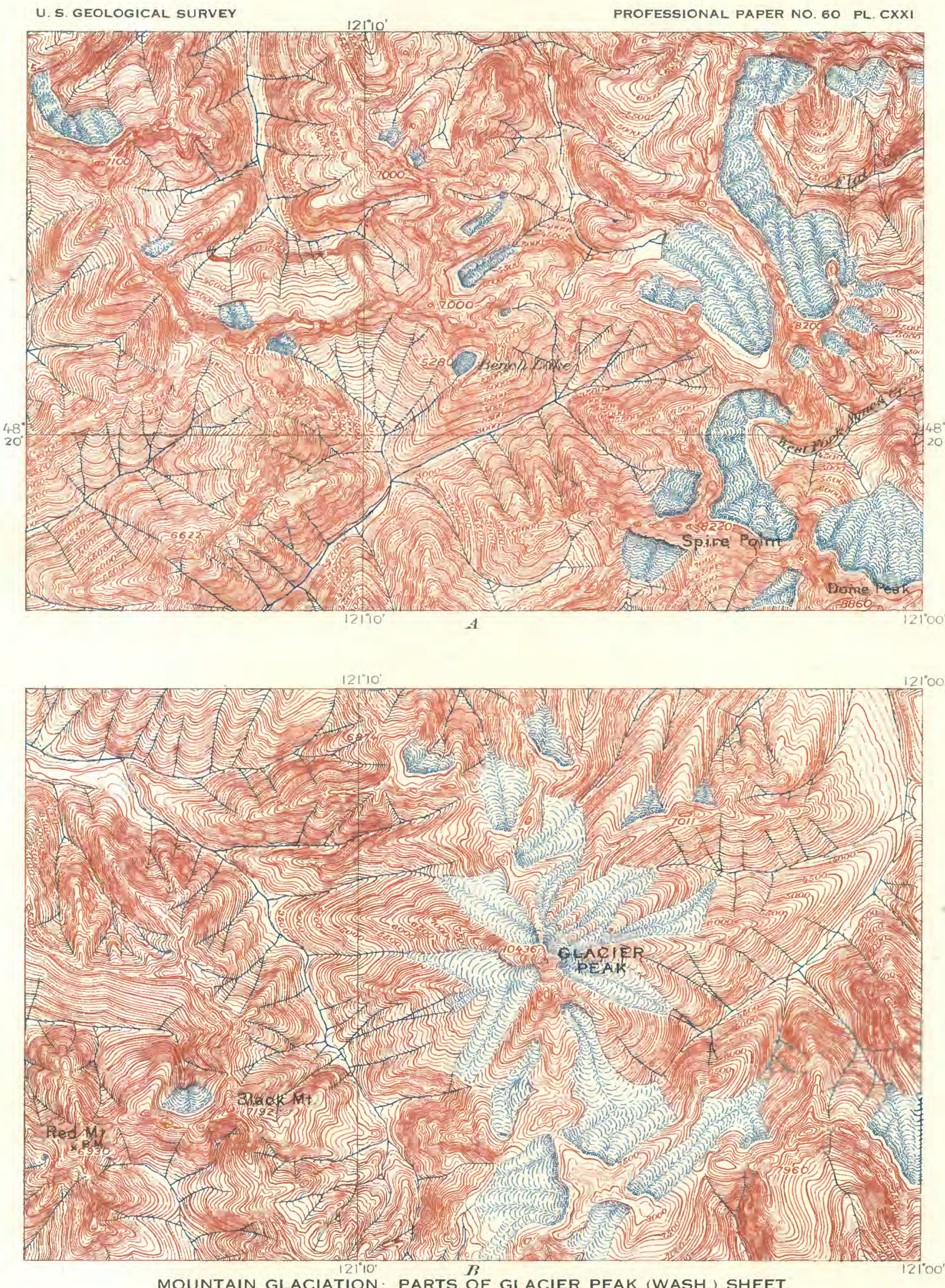

MOUNTAIN GLACIATION: PARTS OF GLACIER PEAK (WASH.) SHEET

$13 / 2 \quad 0 \quad 2$ Sorle $\frac{2}{2} 1250003$ 5 wiles 


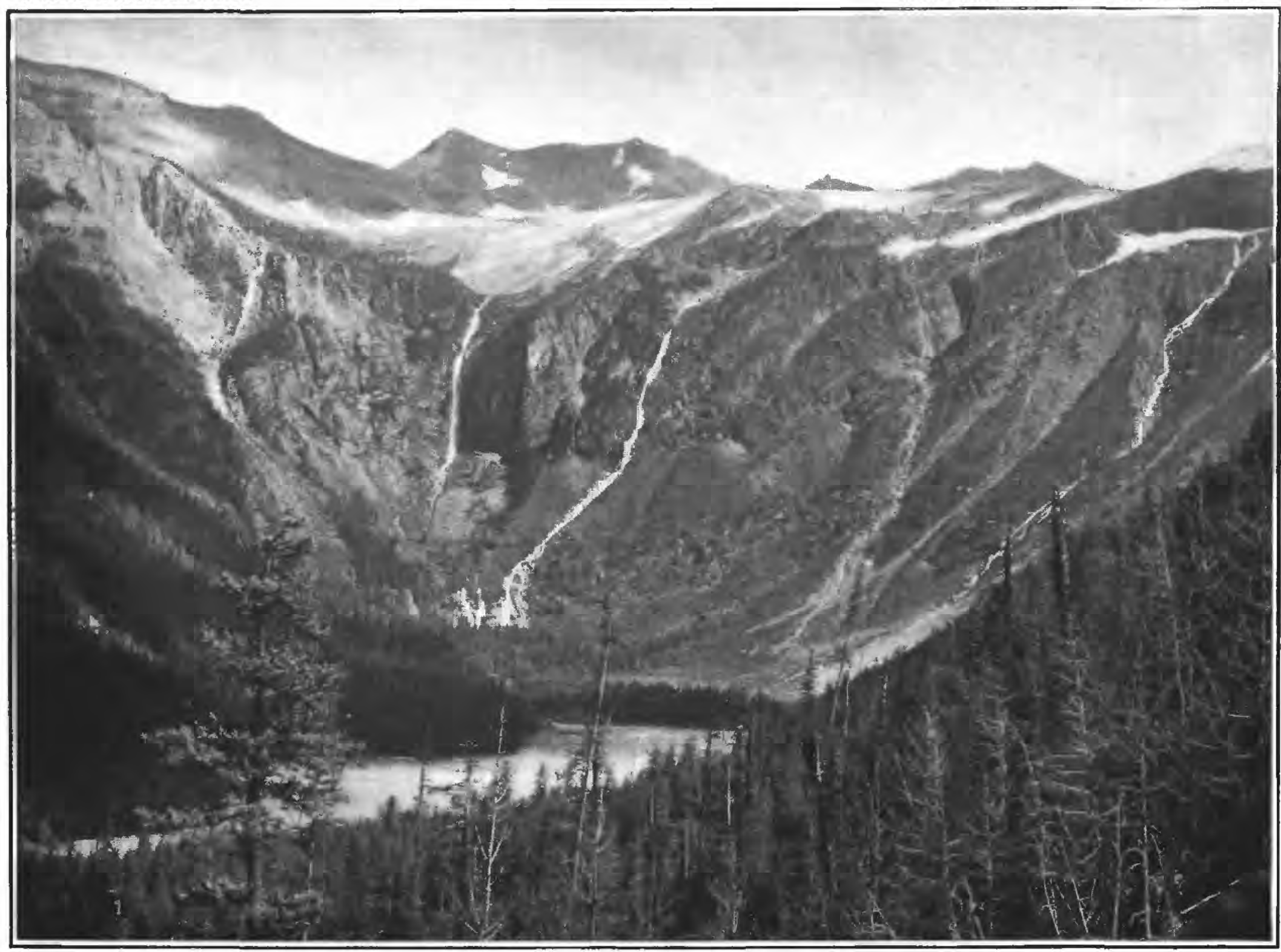

A.

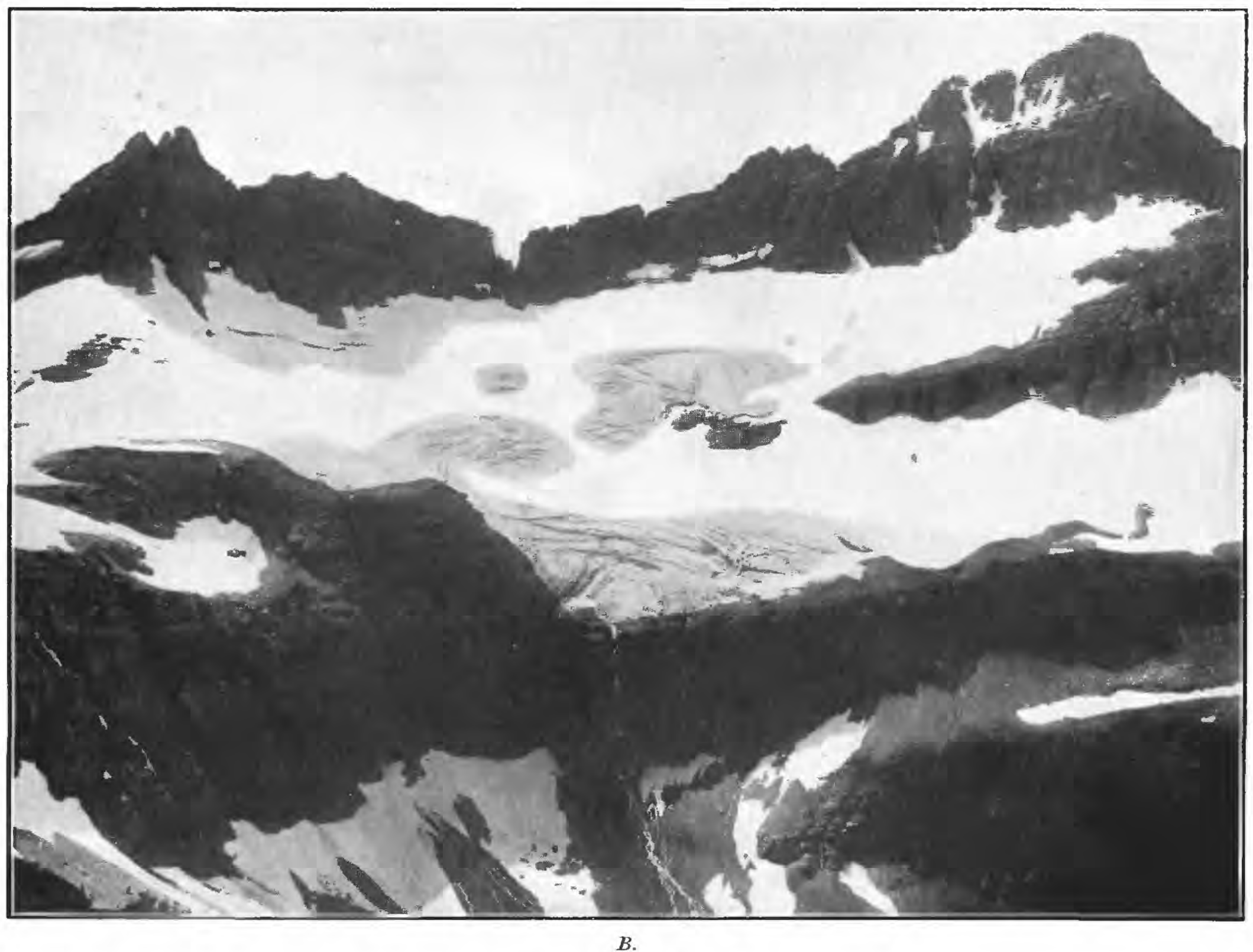

VIEWS OF GLACIERS. 


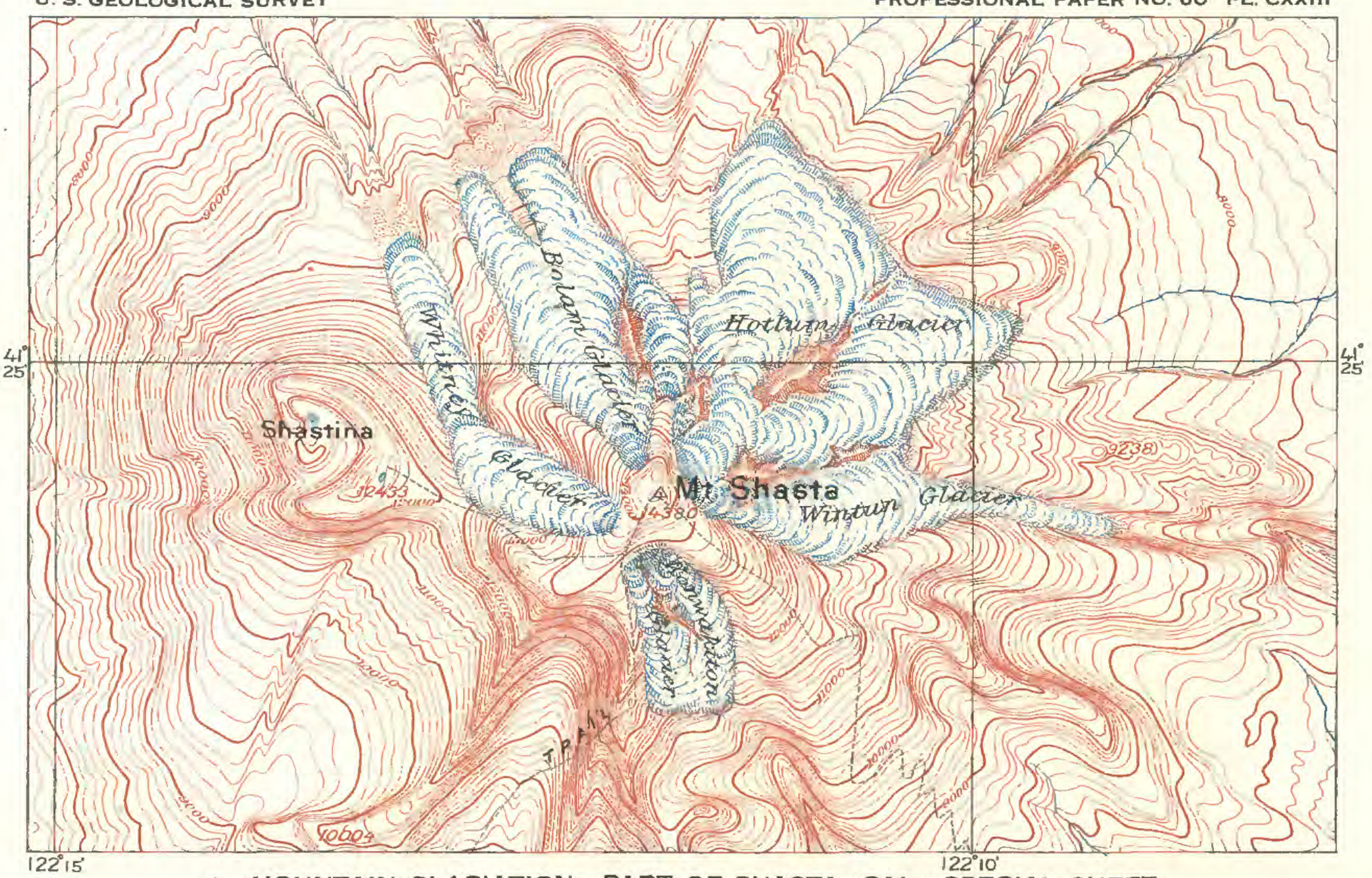

A. MOUNTAIN GLACIATION: PART OF SHASTA (CAL.) SPECIAL SHEET

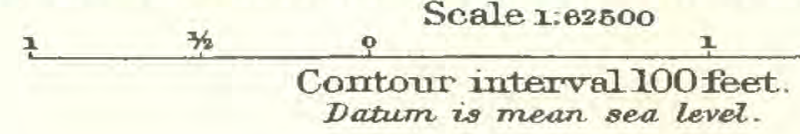

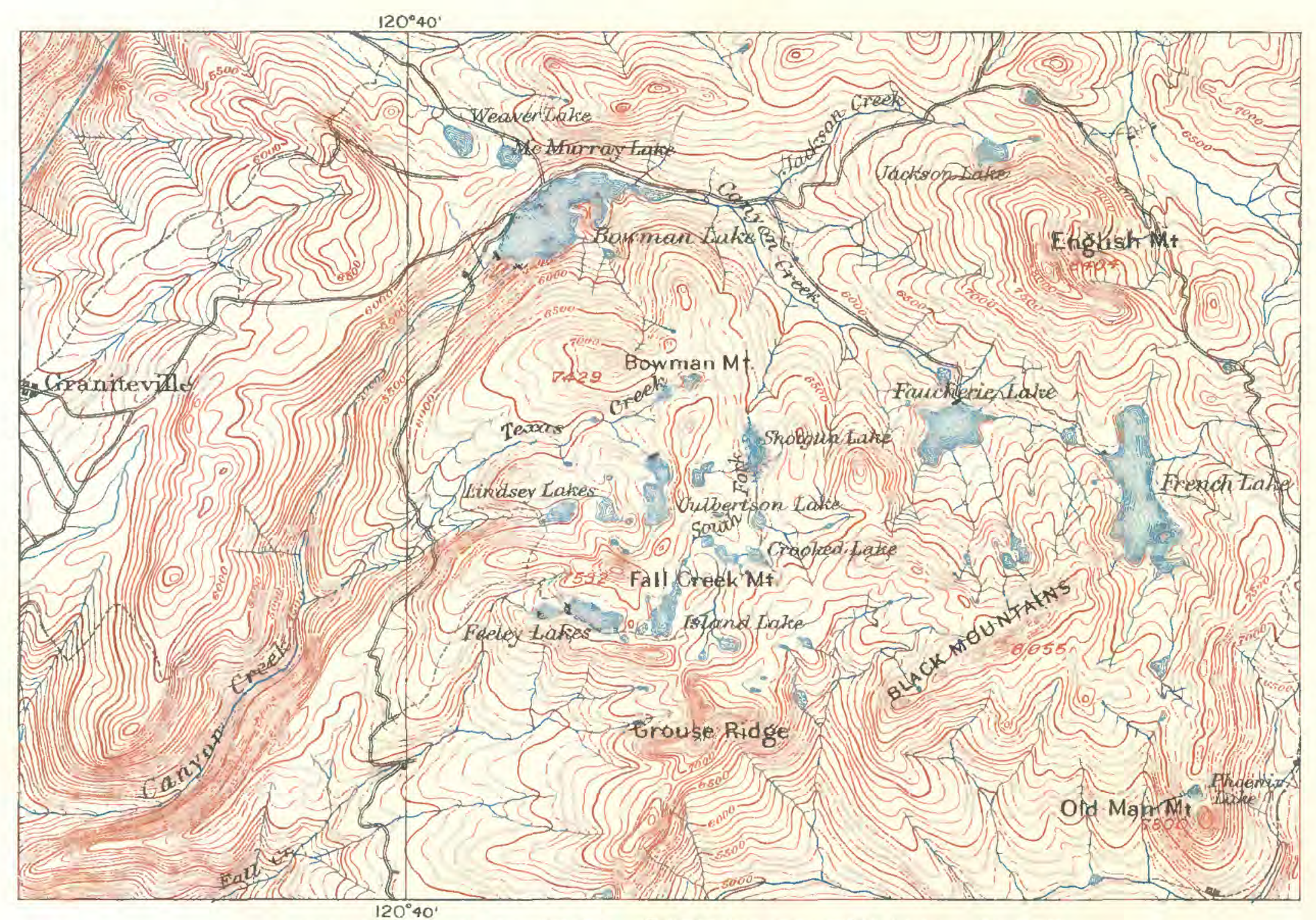

B. MOUNTAIN GLACIATION: PART OF COLFAX (CAL.) SHEET

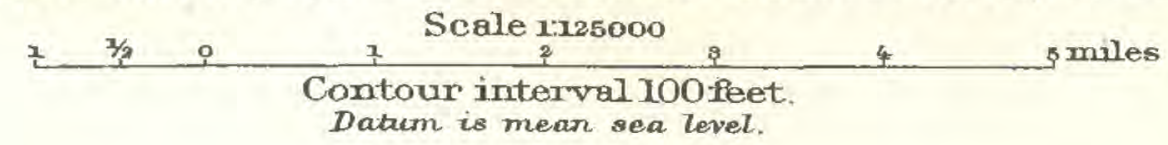




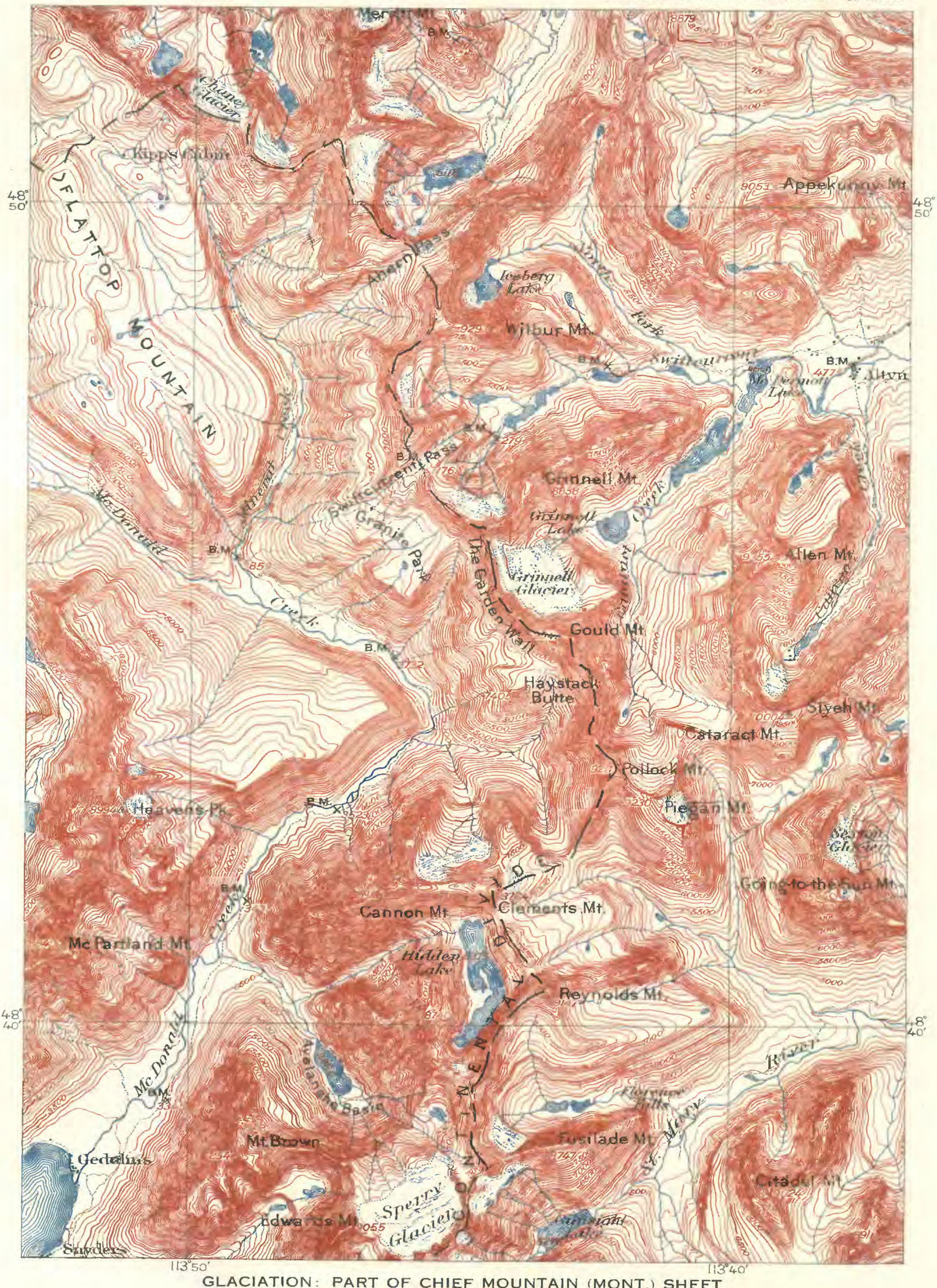

GLACIATION : PART OF CHIEF MOUNTAIN (MONT.) SHEET

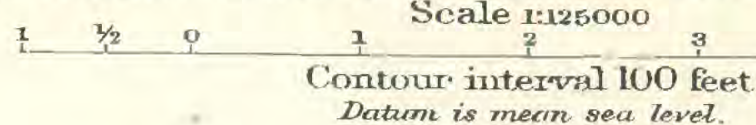




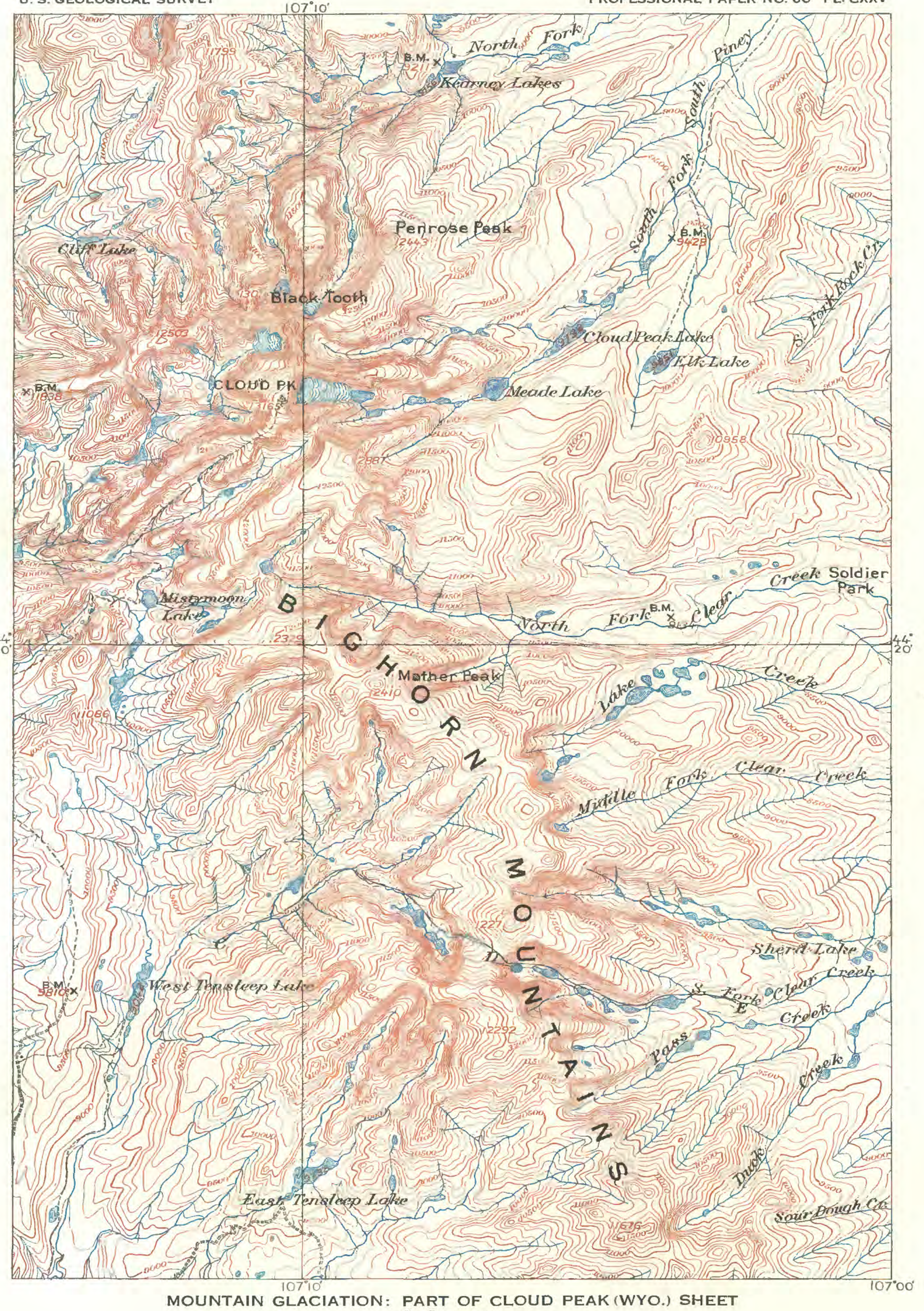

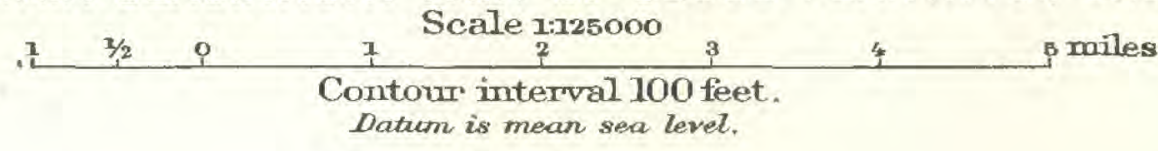




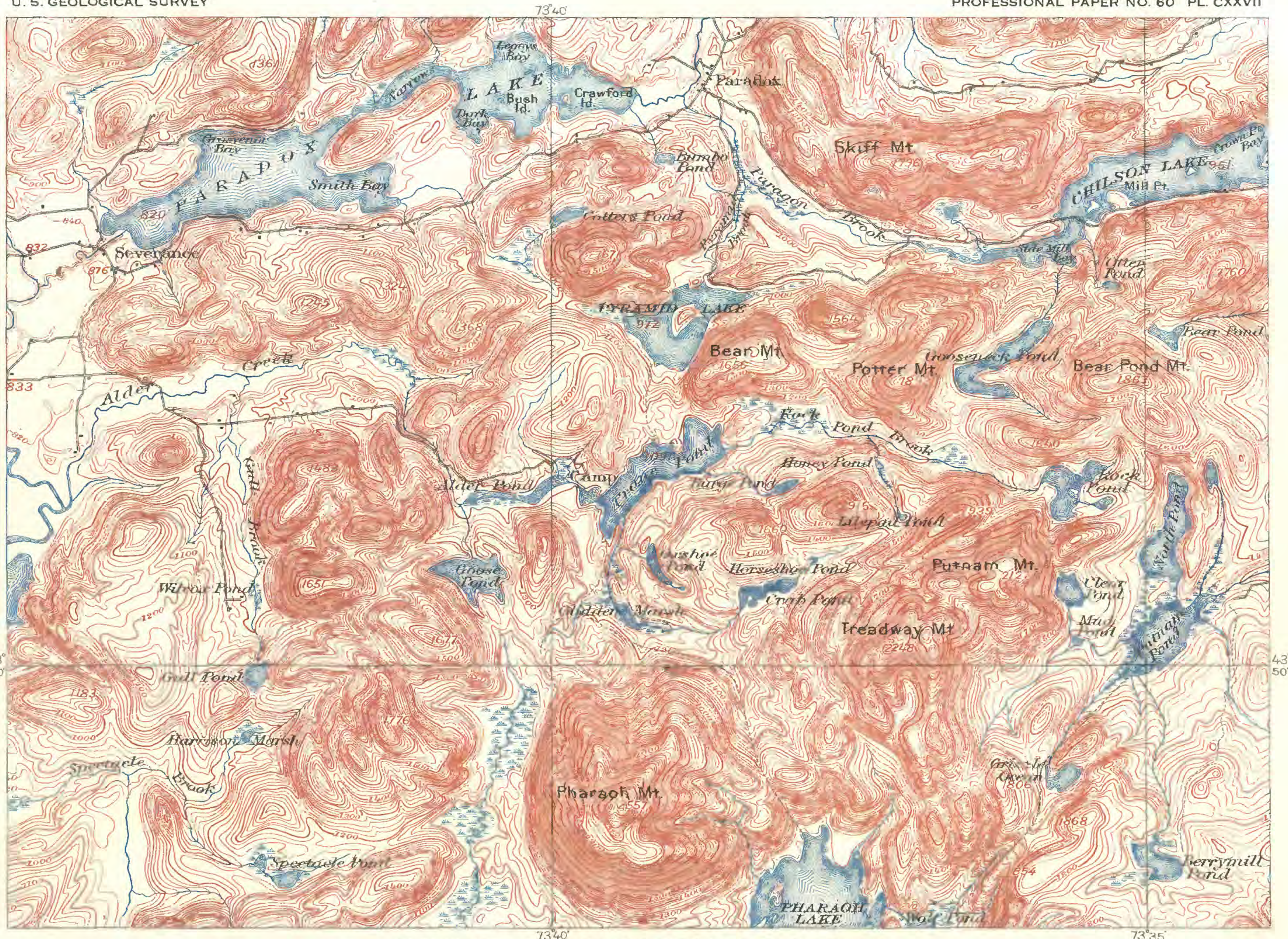

GLACIATION: PART OF PARADOX LAKE (N. Y.) SHEET

\% Scale 1:62500
Contour interval 20 feet.
Datum is mear sea level. 2 miles 


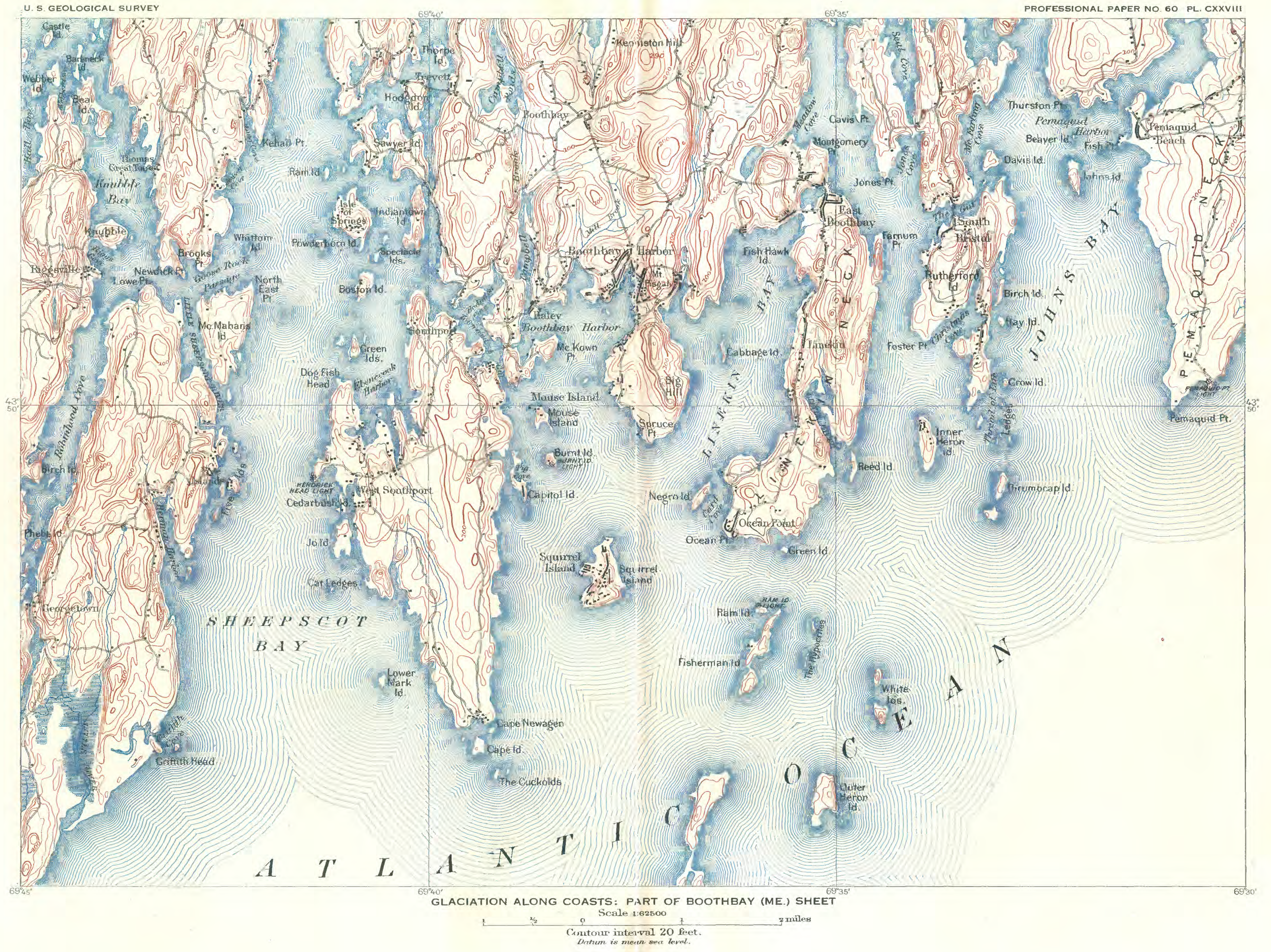




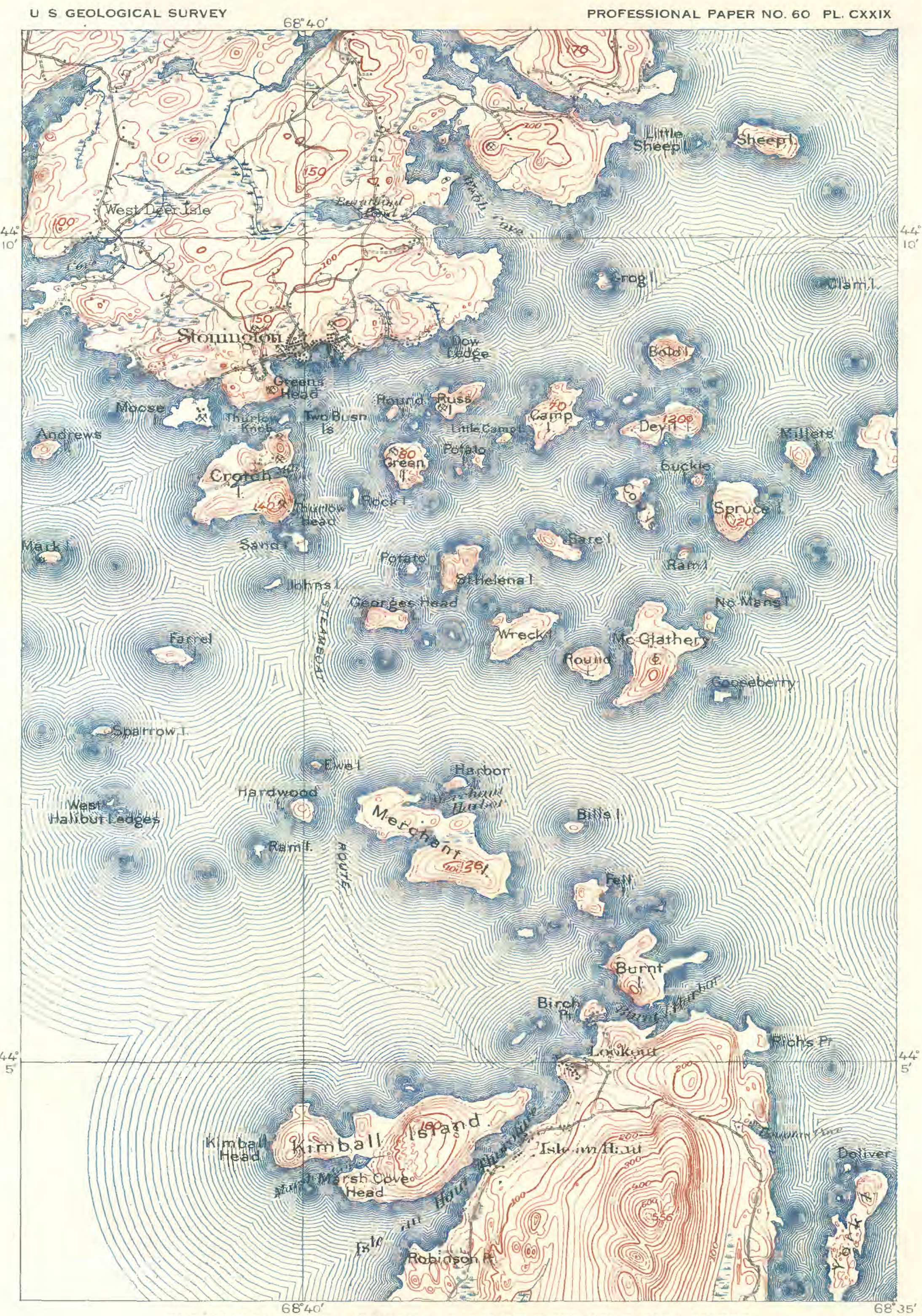

GLACIATION ALONG COASTS: PART OF DEER ISLE (ME.) SHEET

$1 / 2$ o Scale 1:62500

Contour inrerval 20 teet.

2 miles 


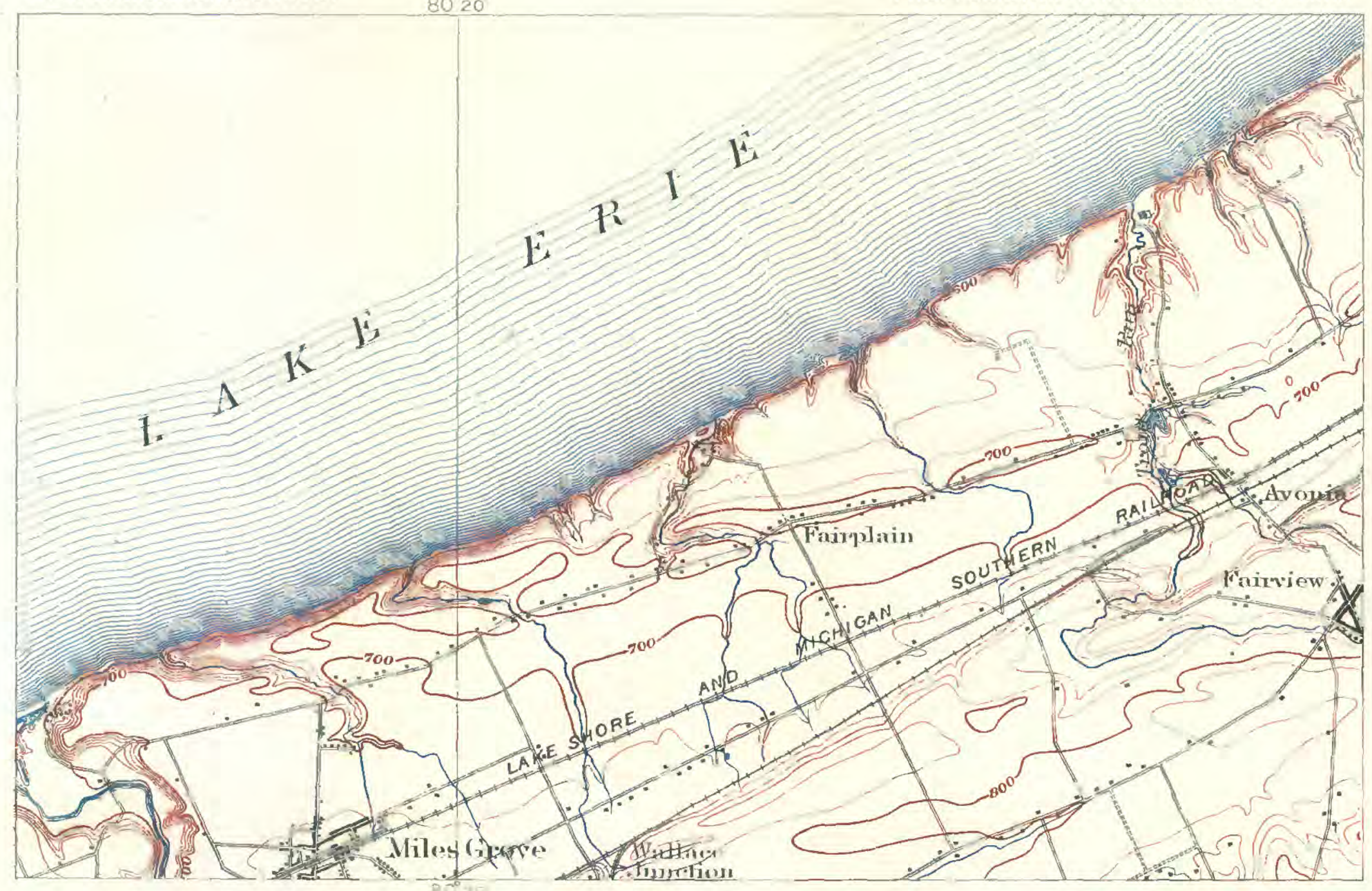

A. COAST LINE: PART OF FAIRVIEW (PA.) SHEET

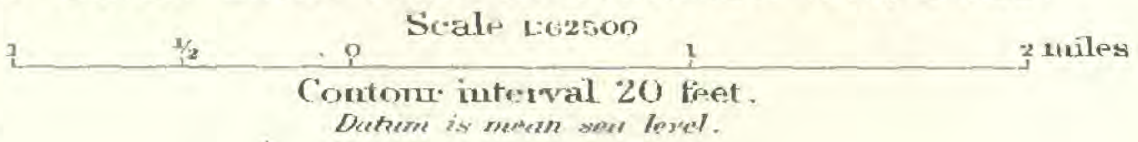

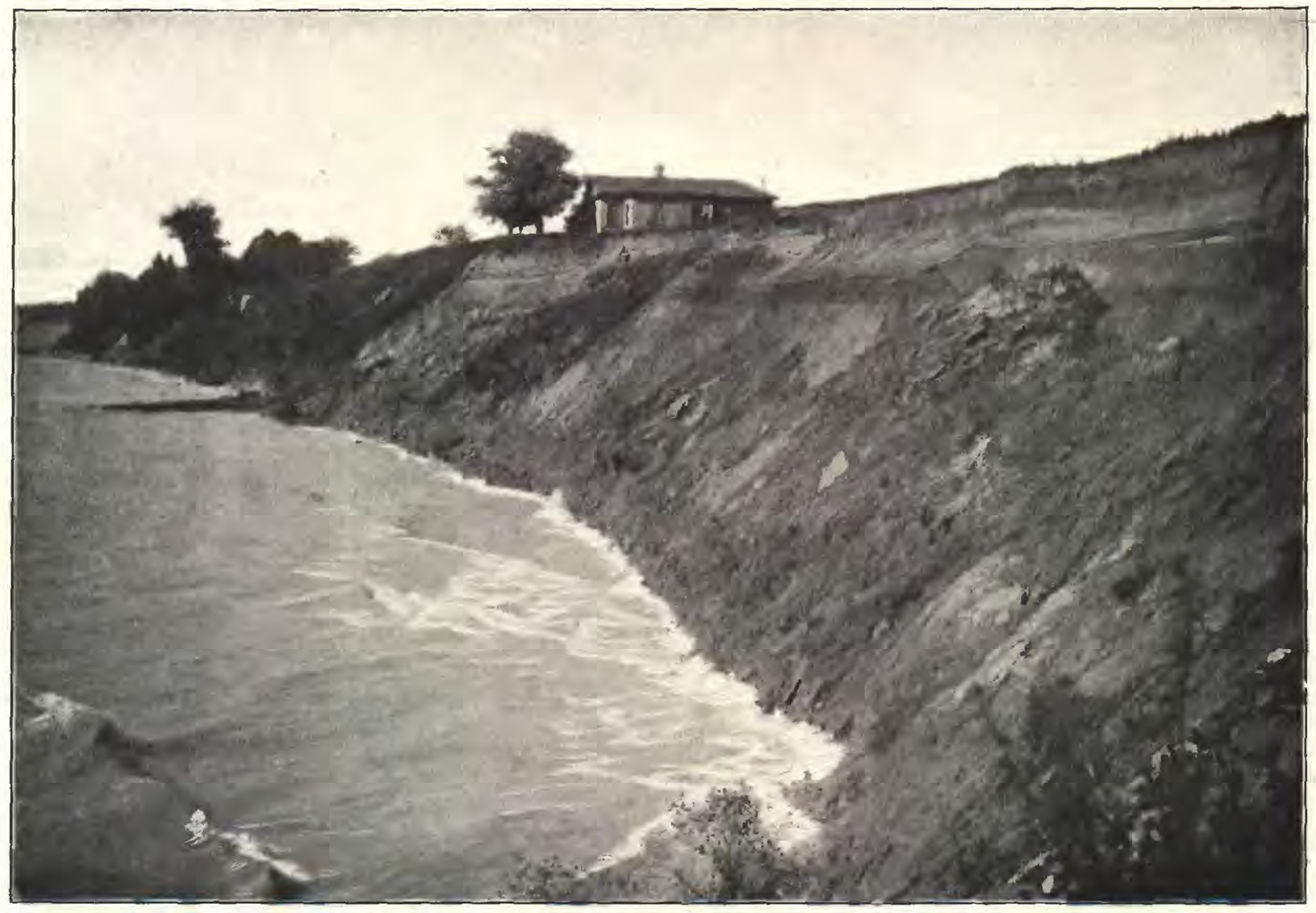

B. VIEW OF COAST LINE: LAKE CLIFF AT RACINE, WIS. 


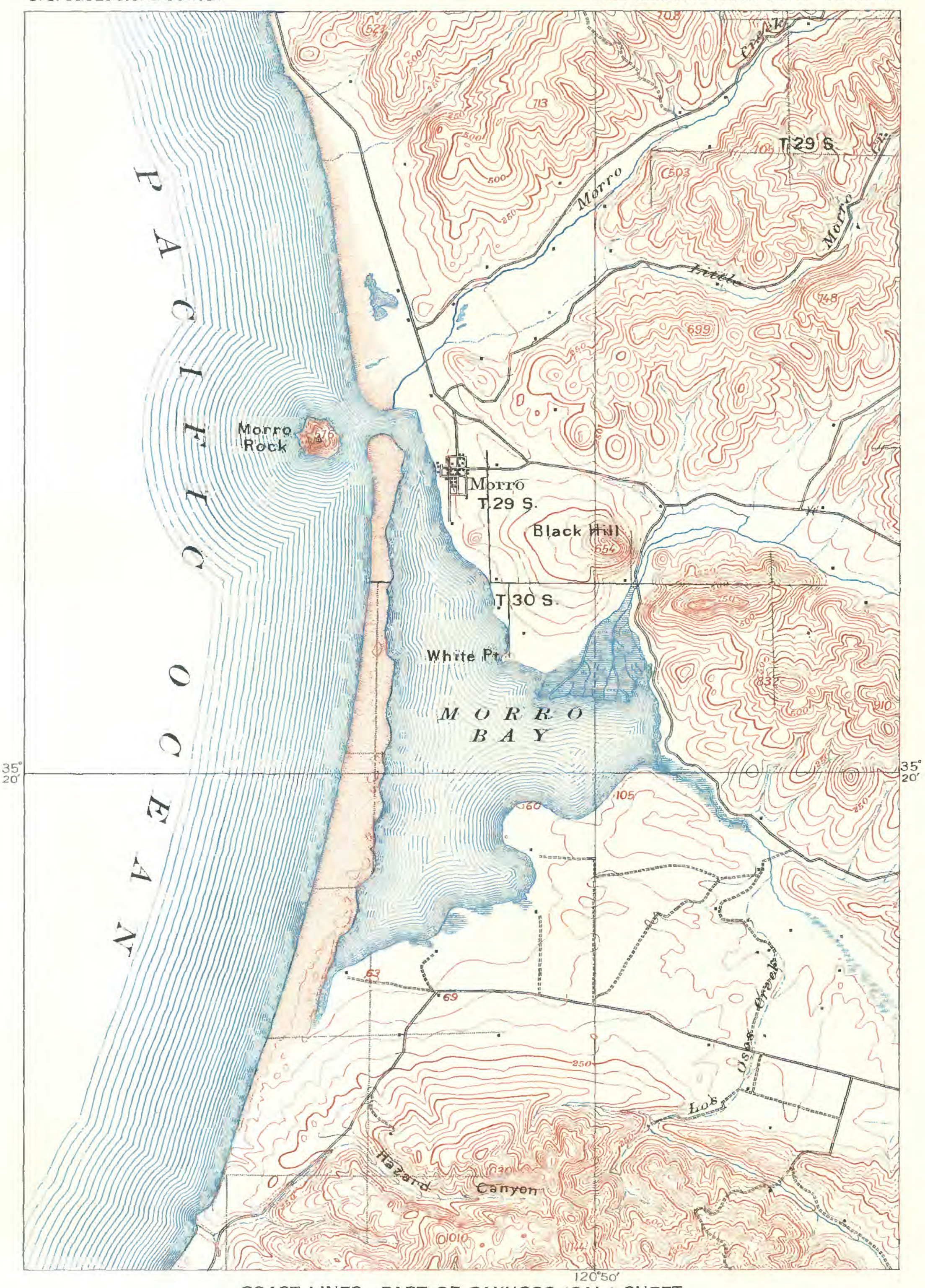

COAST LINES: PART OF CAYUCOS (CAL.) SHEET

ב

$1 / 2$ Scale 1:62500 


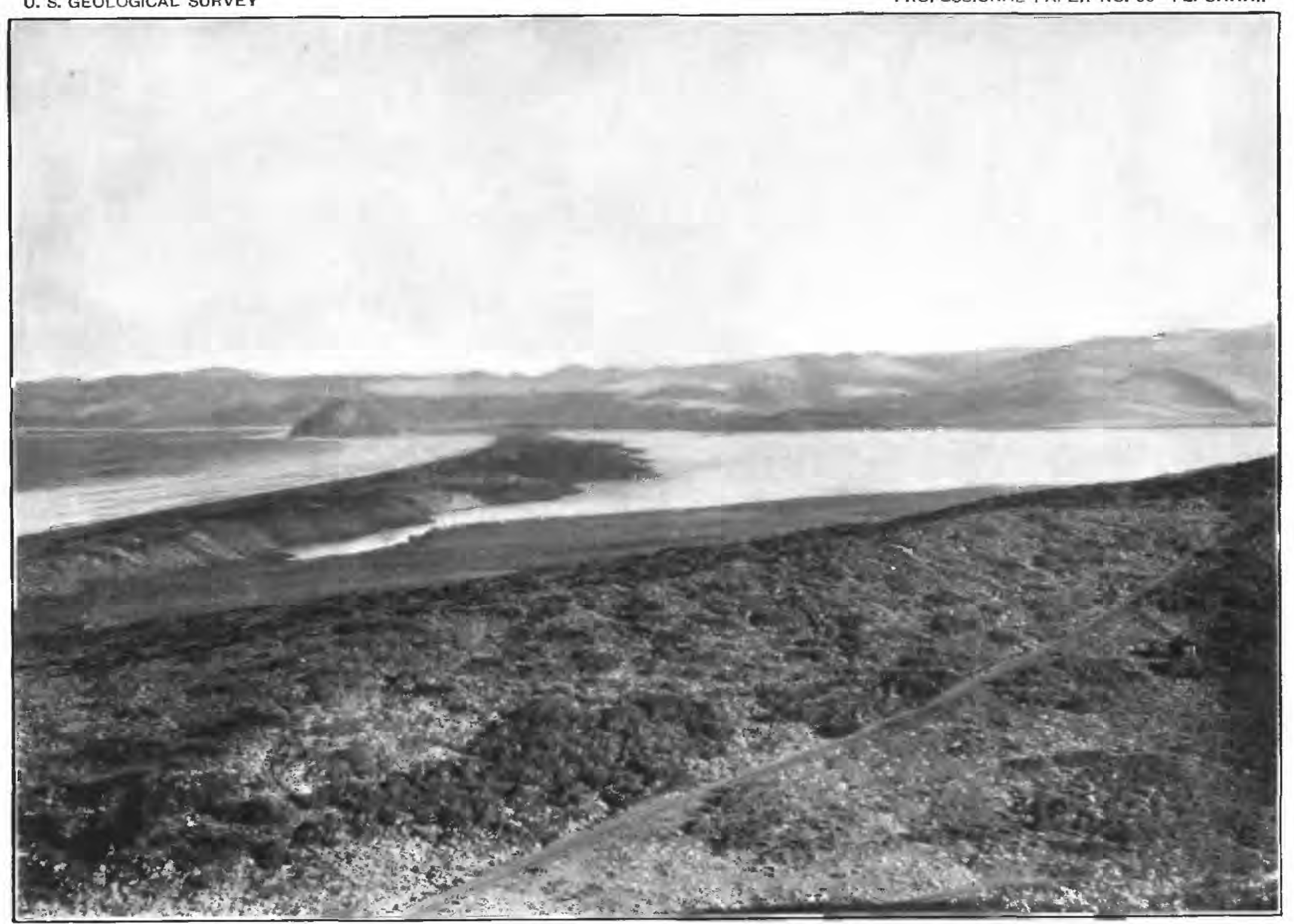

A. MORRO BAY, CALIFORNIA, FROM THE SOUTH.

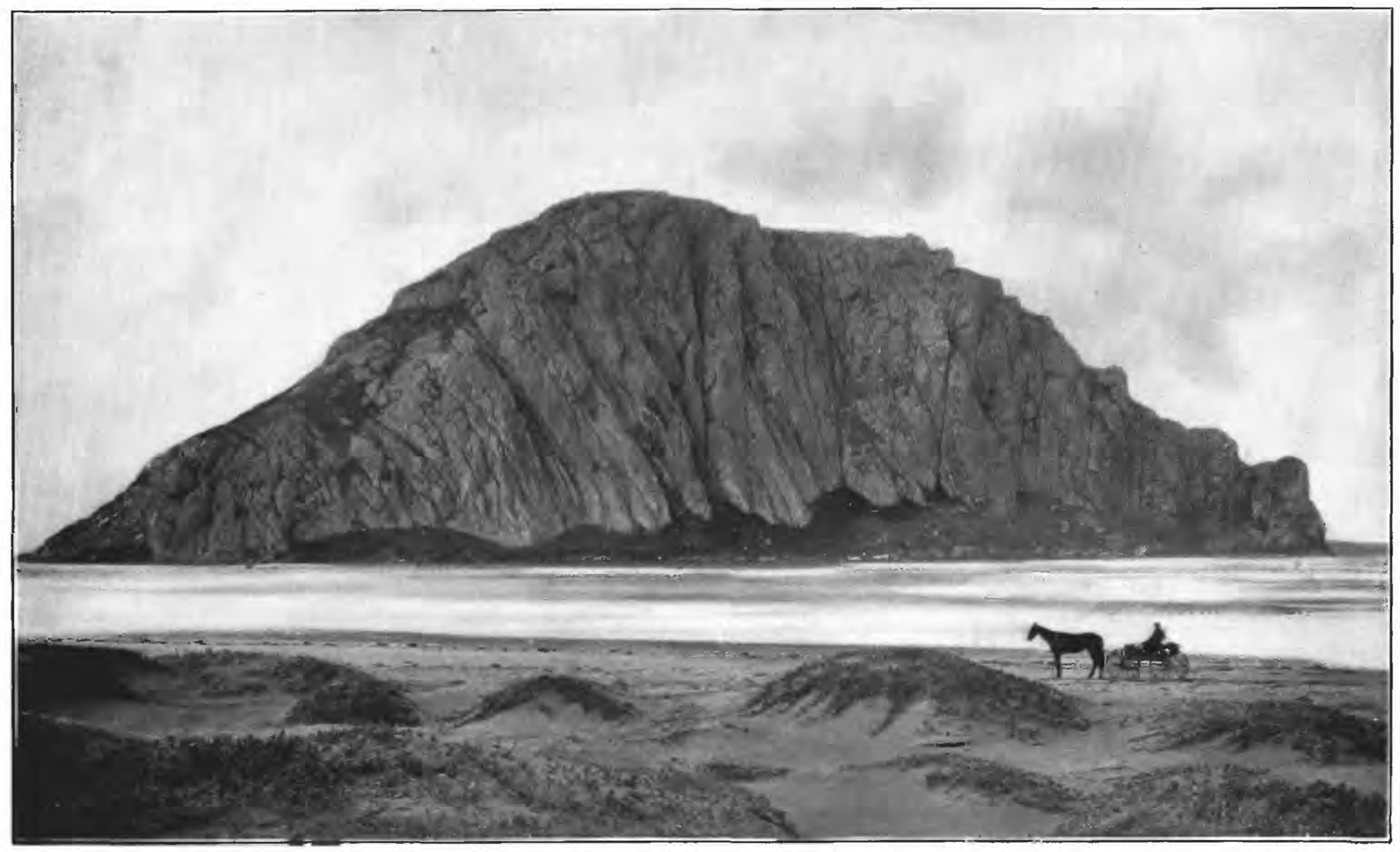

B. MORRO ROCK, CALIFORNIA, FROM THE EAST. 


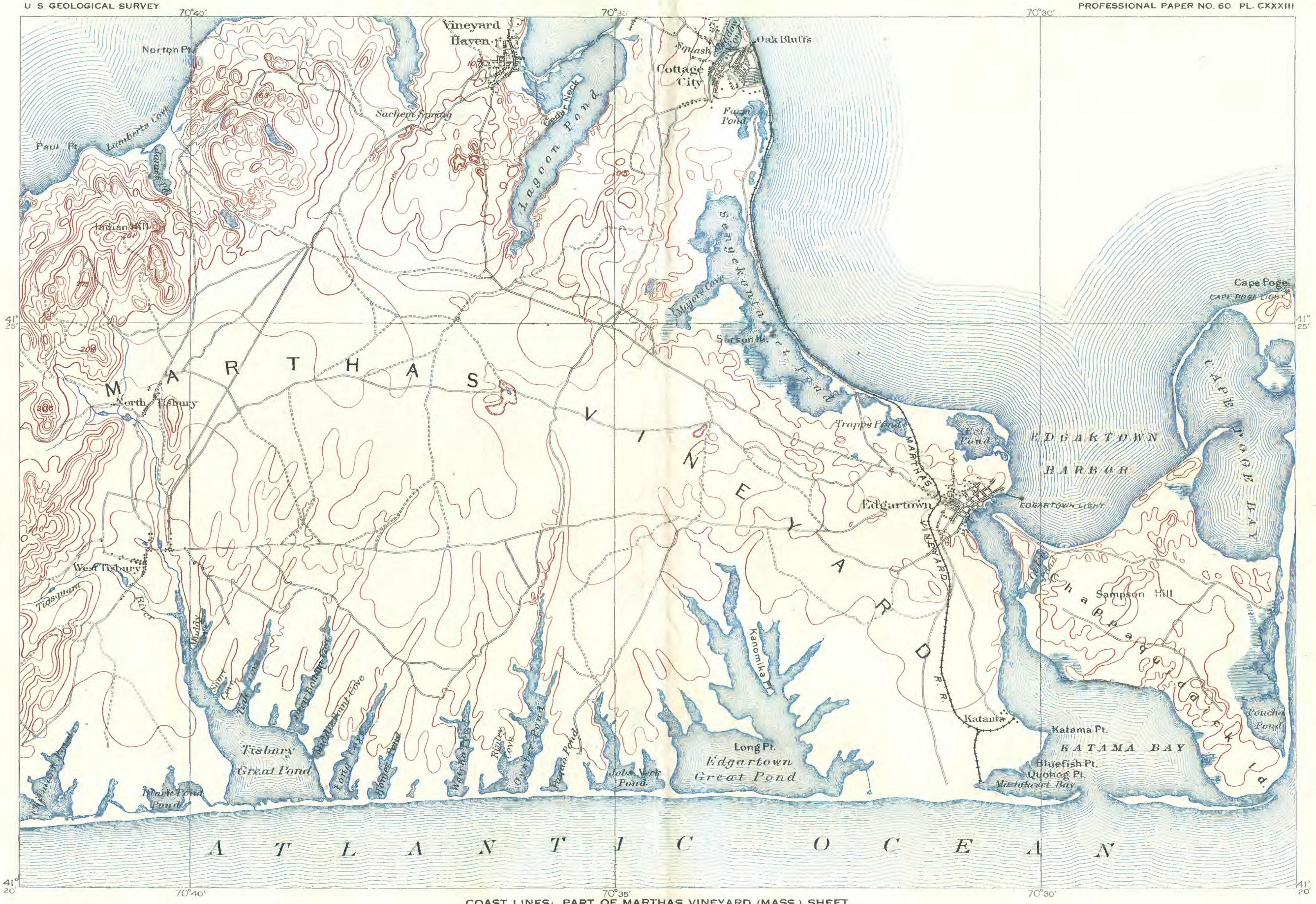

COAST LINES: PART OF MARTHAS VINEYARD (MASS.) SHEET 


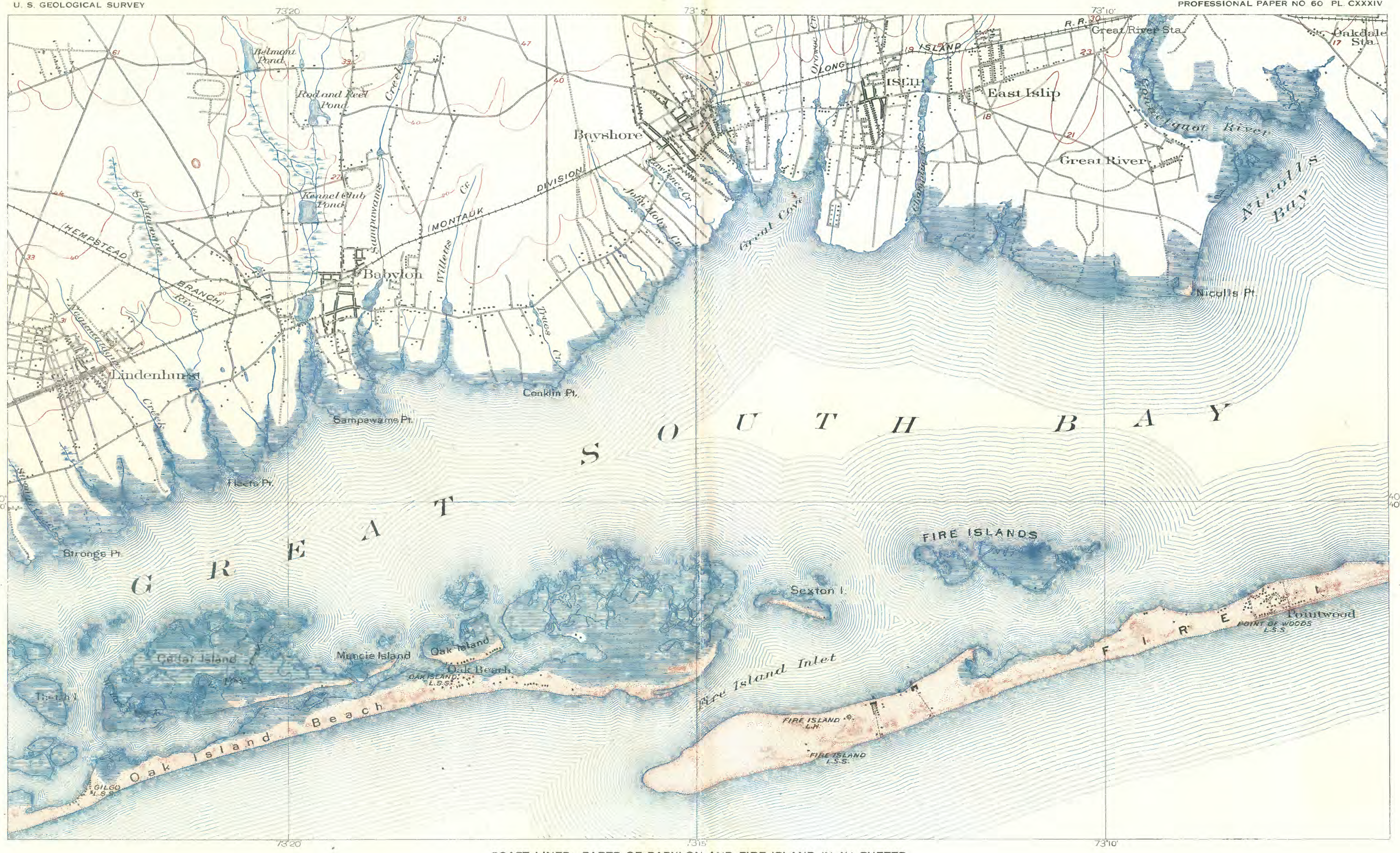

COAST LINES: PARTS OF BABYLON AND FIRE ISLAND IN Y I SHEETS 


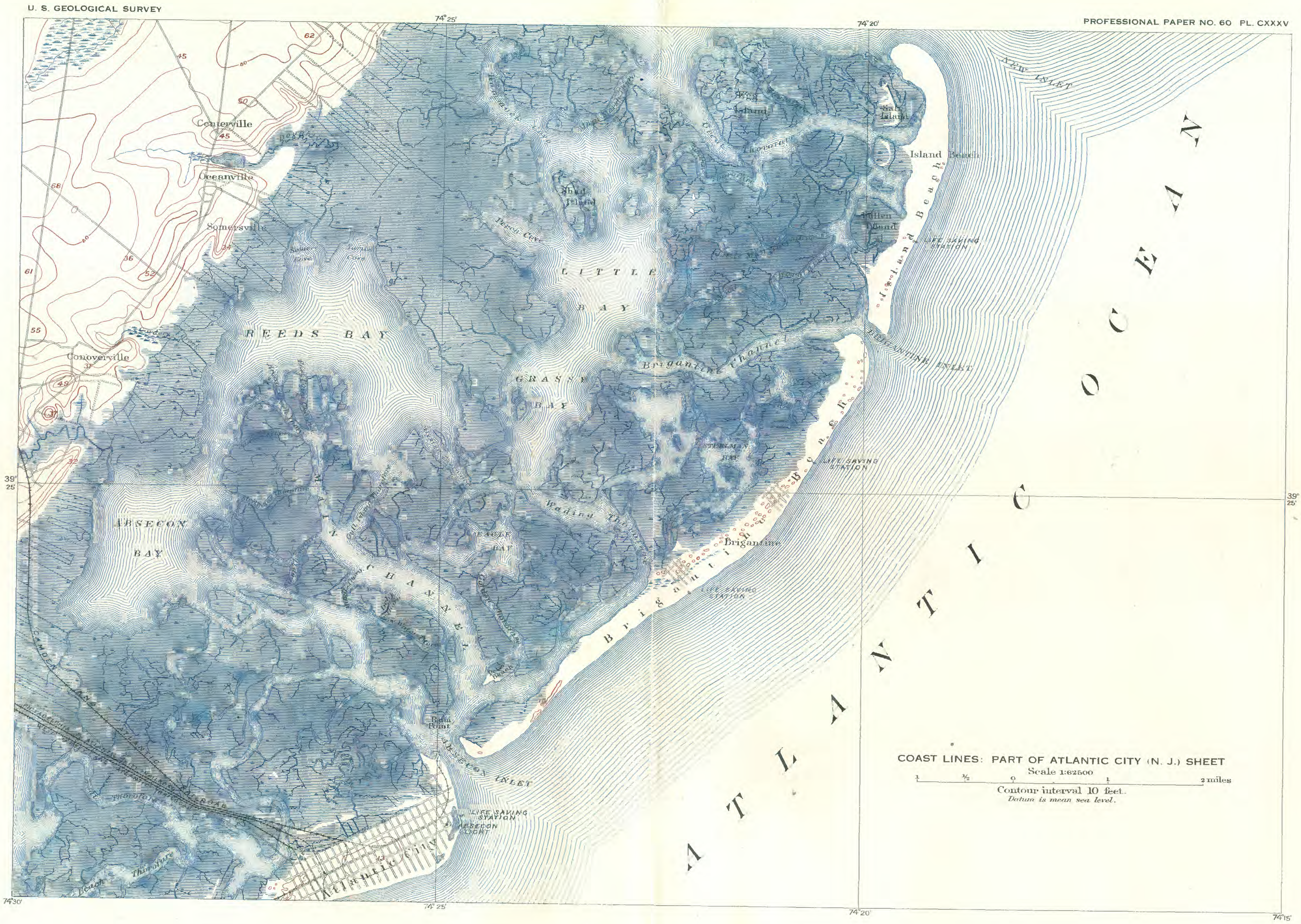




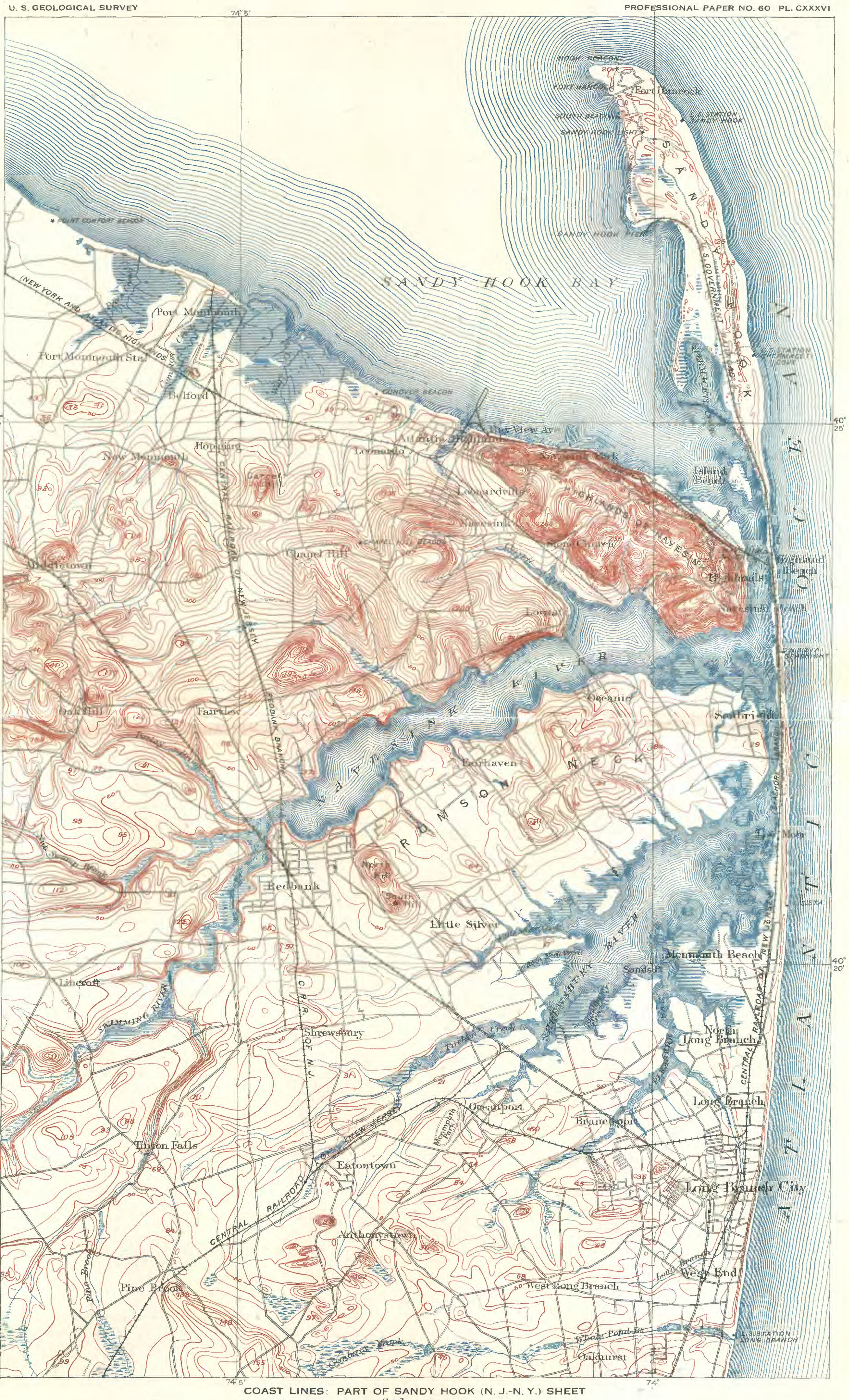




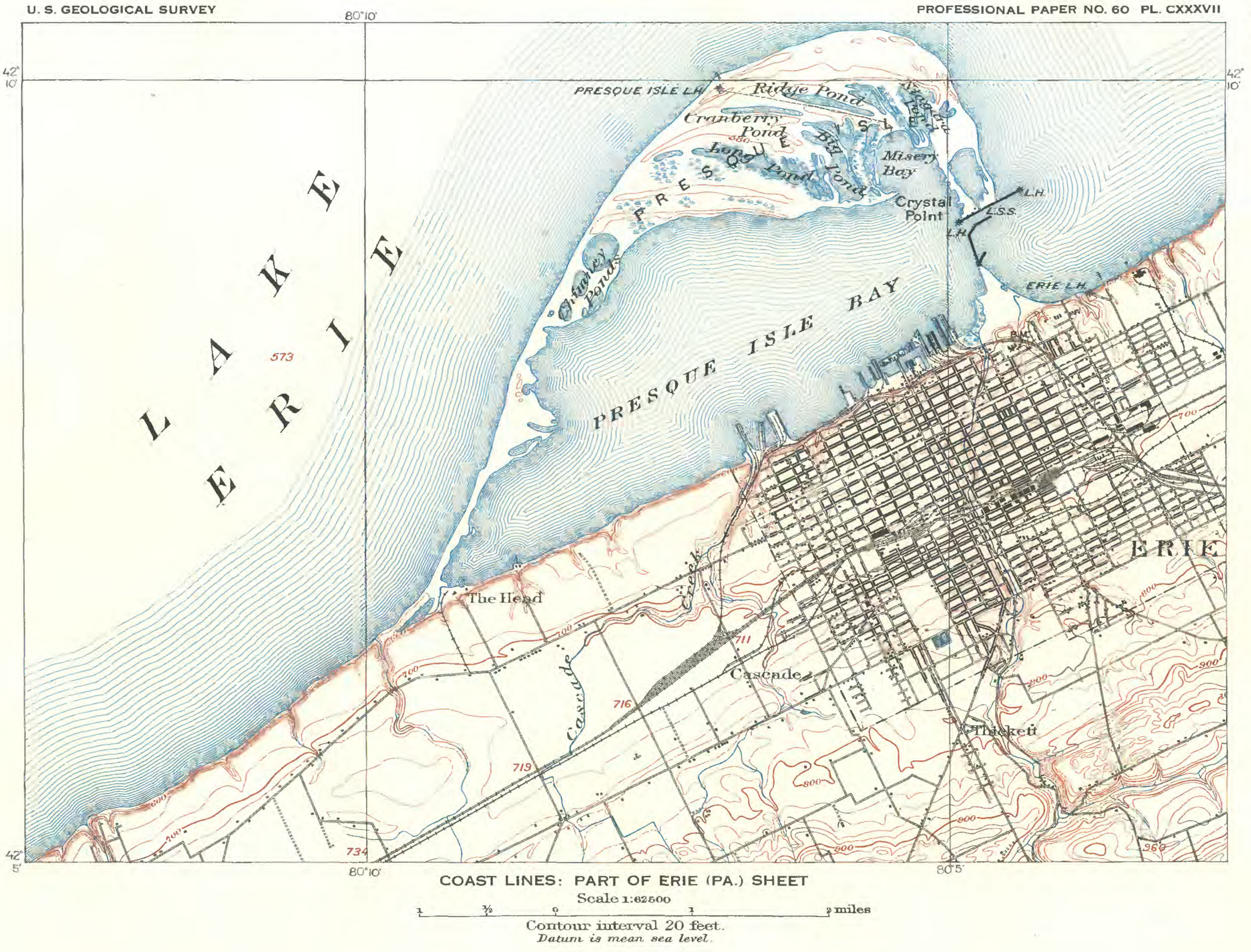




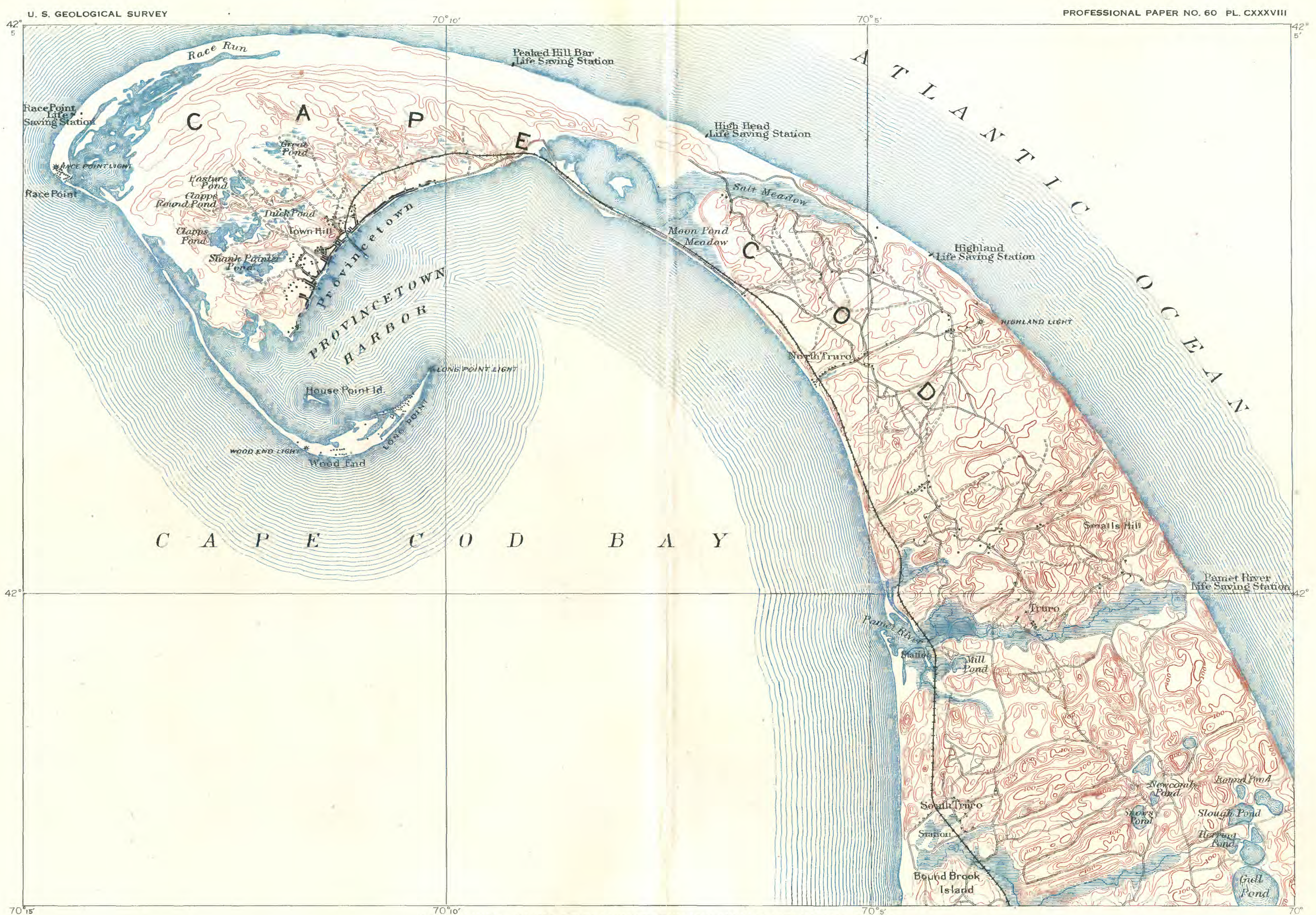

COAST LINES: PARTS OF PROVINCETOWN AND WELLFLEET (MASS.) SHEETS

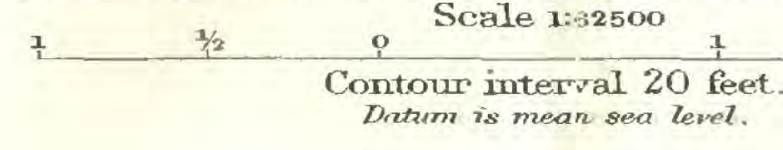




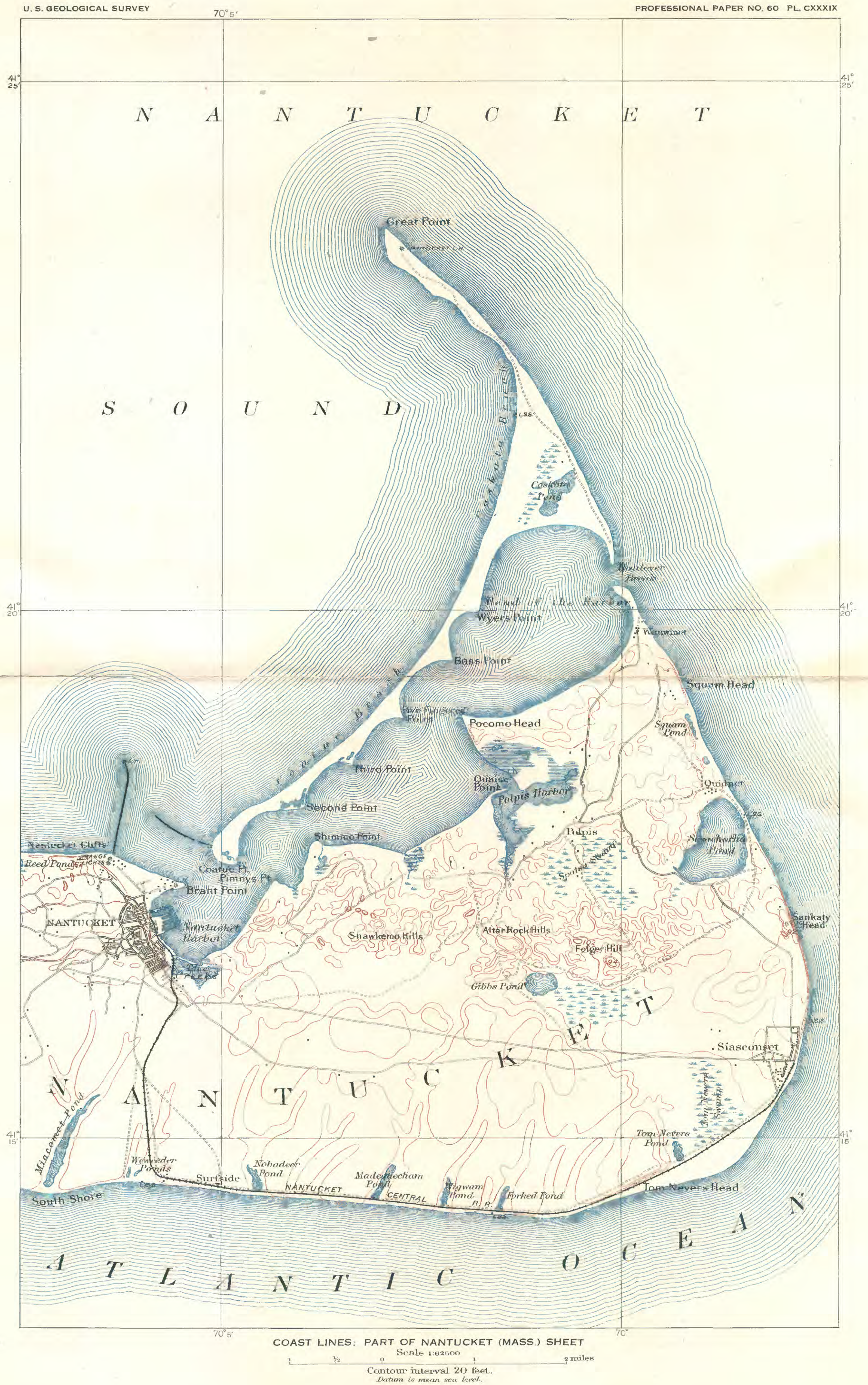




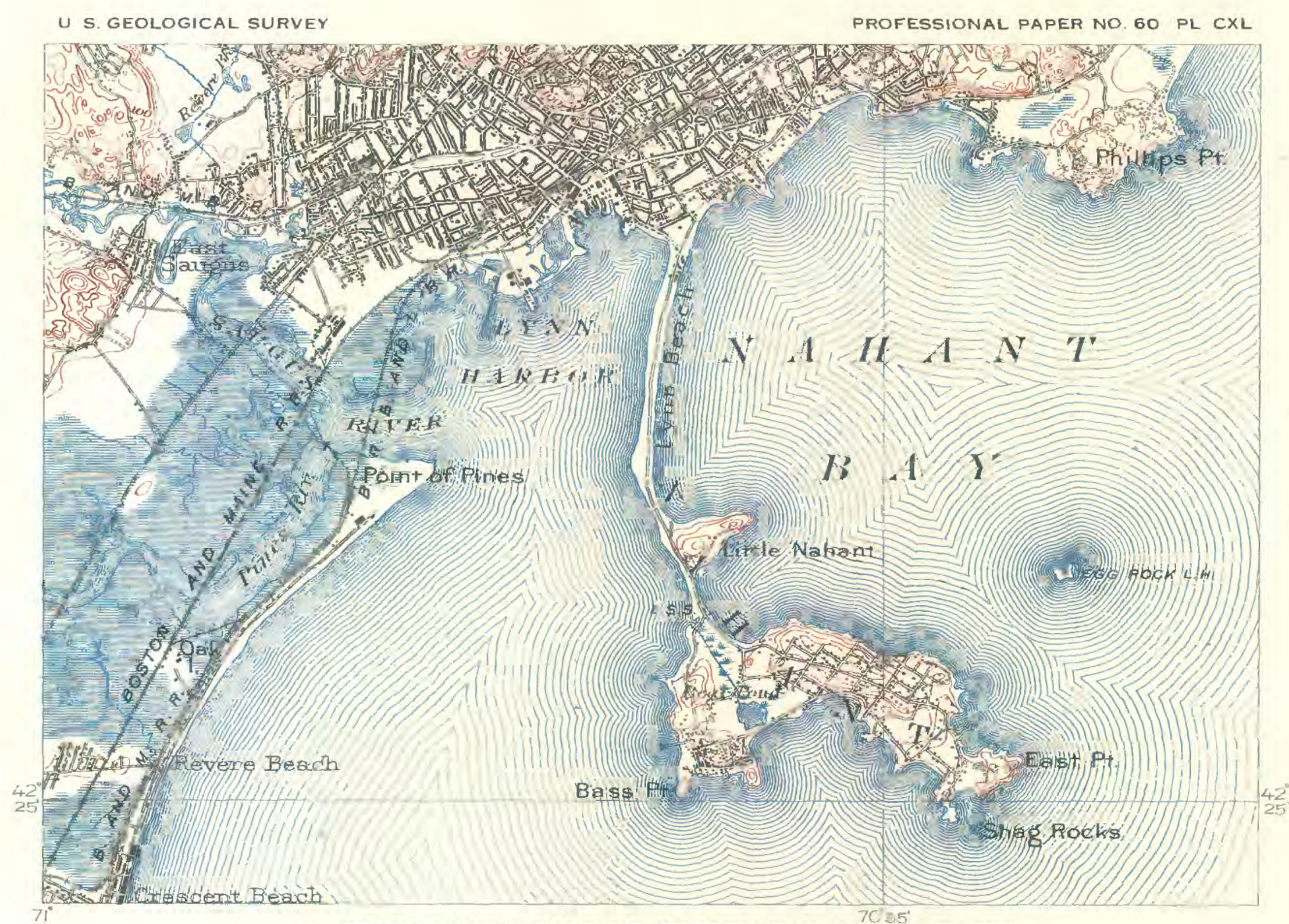

A. COAST LINES: PART OF BOSTON BAY (MASS.) SHEET

Contour interval 20 feet.
Datum is mean sen level.

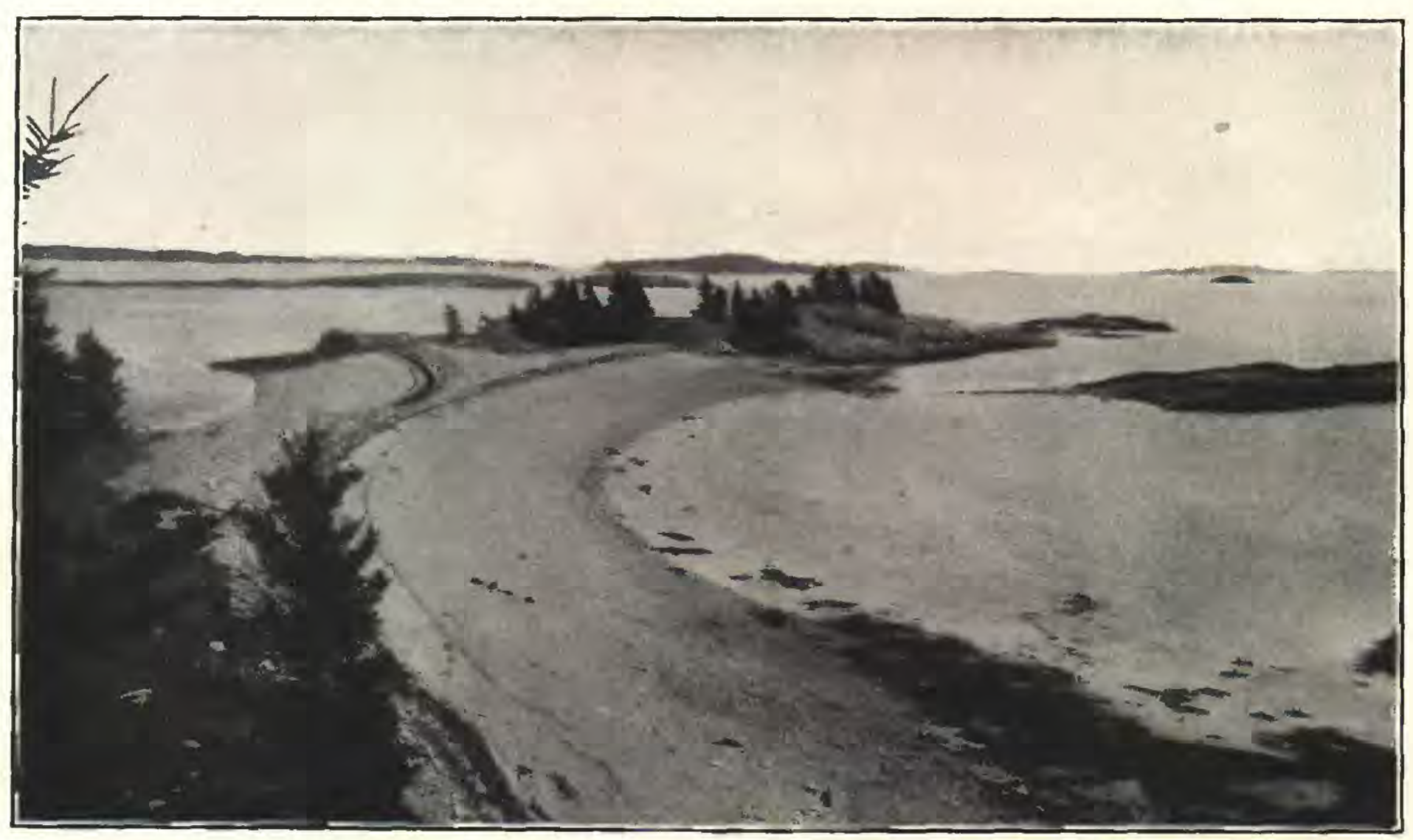

B. LAND-TIED ISLAND: SPRUCE HEAD ISLAND. PENOBSCOT BAY. ME. 


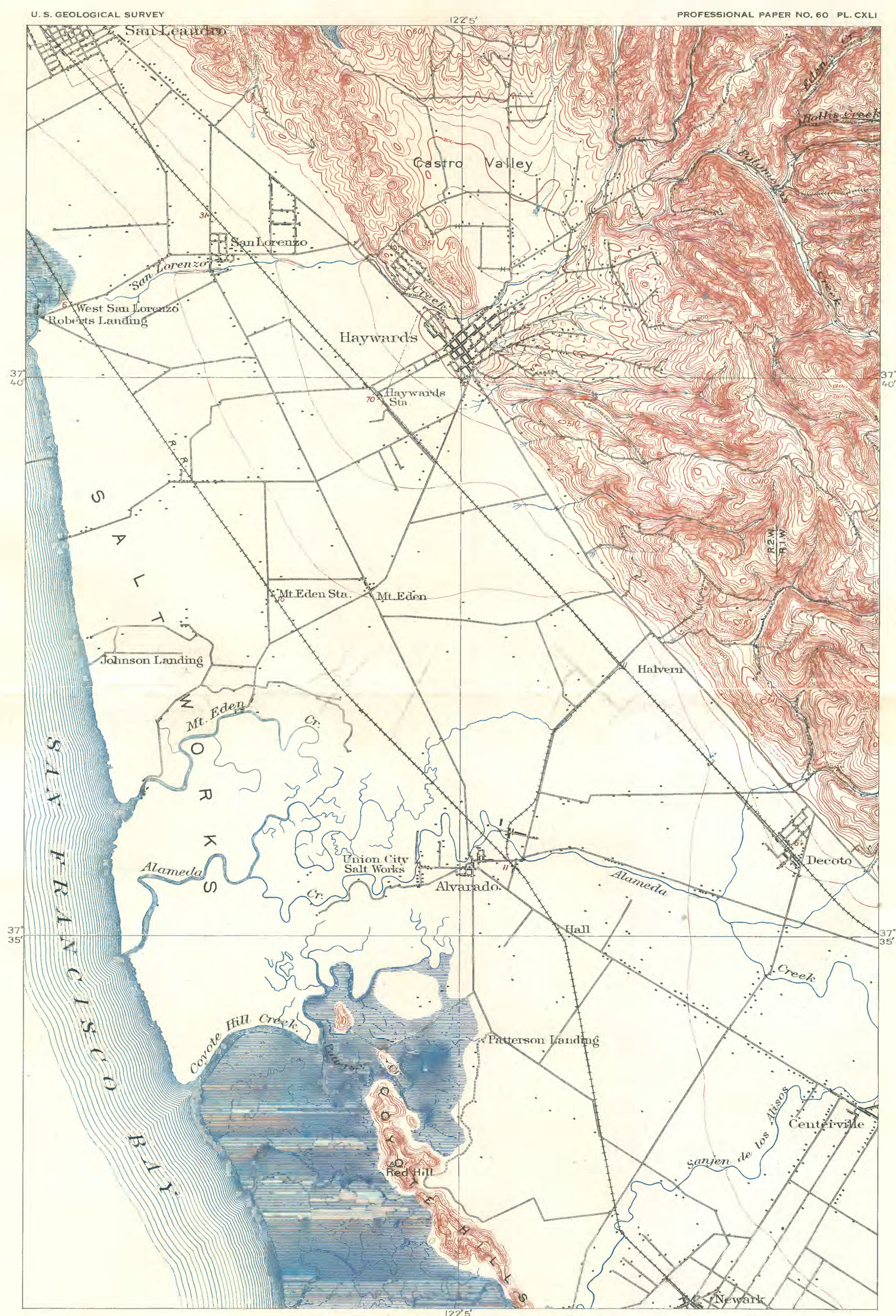

SHORE LINE: PART OF HAYWARDS (CAL.) SHEET

Contour interval 25 feet.
Datiom is mean sea level. 


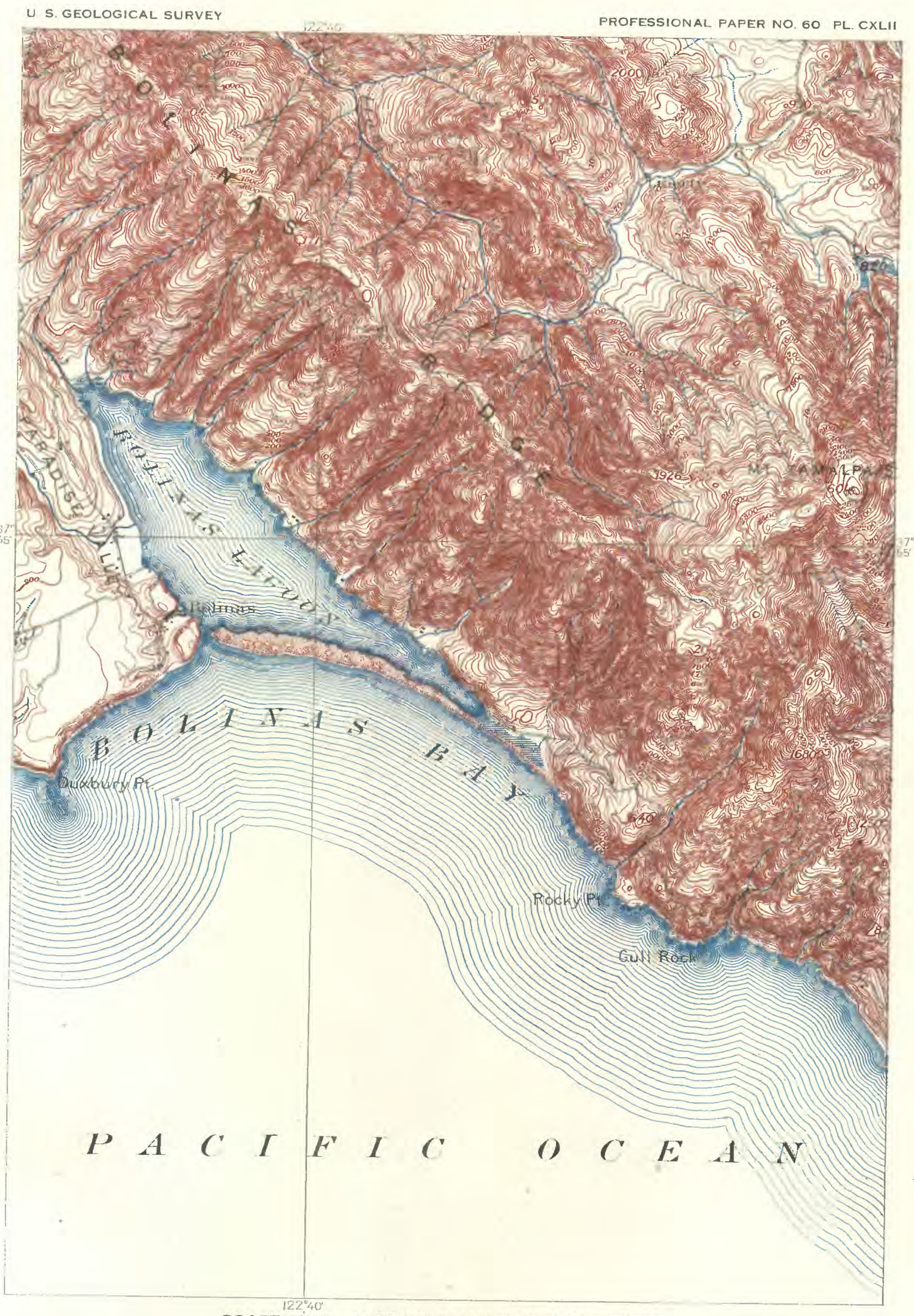

COAST LINE: PART OF TAMALPAIS (CAL.) SHEET

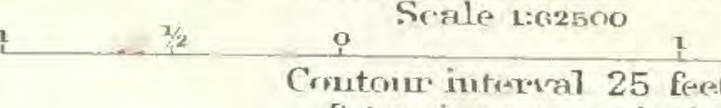
2 miless

Decturn is meen sers lavel. 


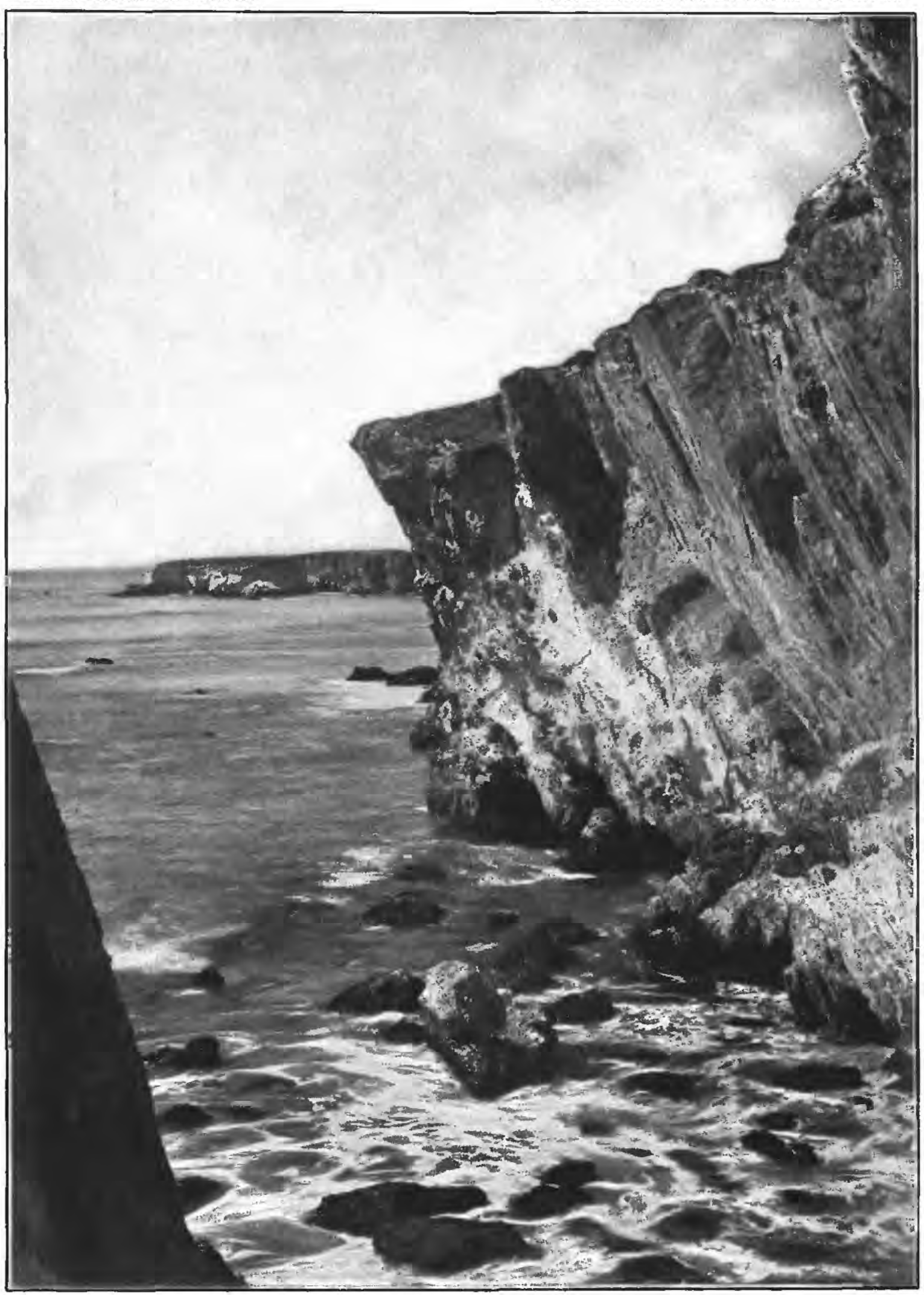

A. OVERHANGING CLIFFS ON THE CALIFORNIA COAST.

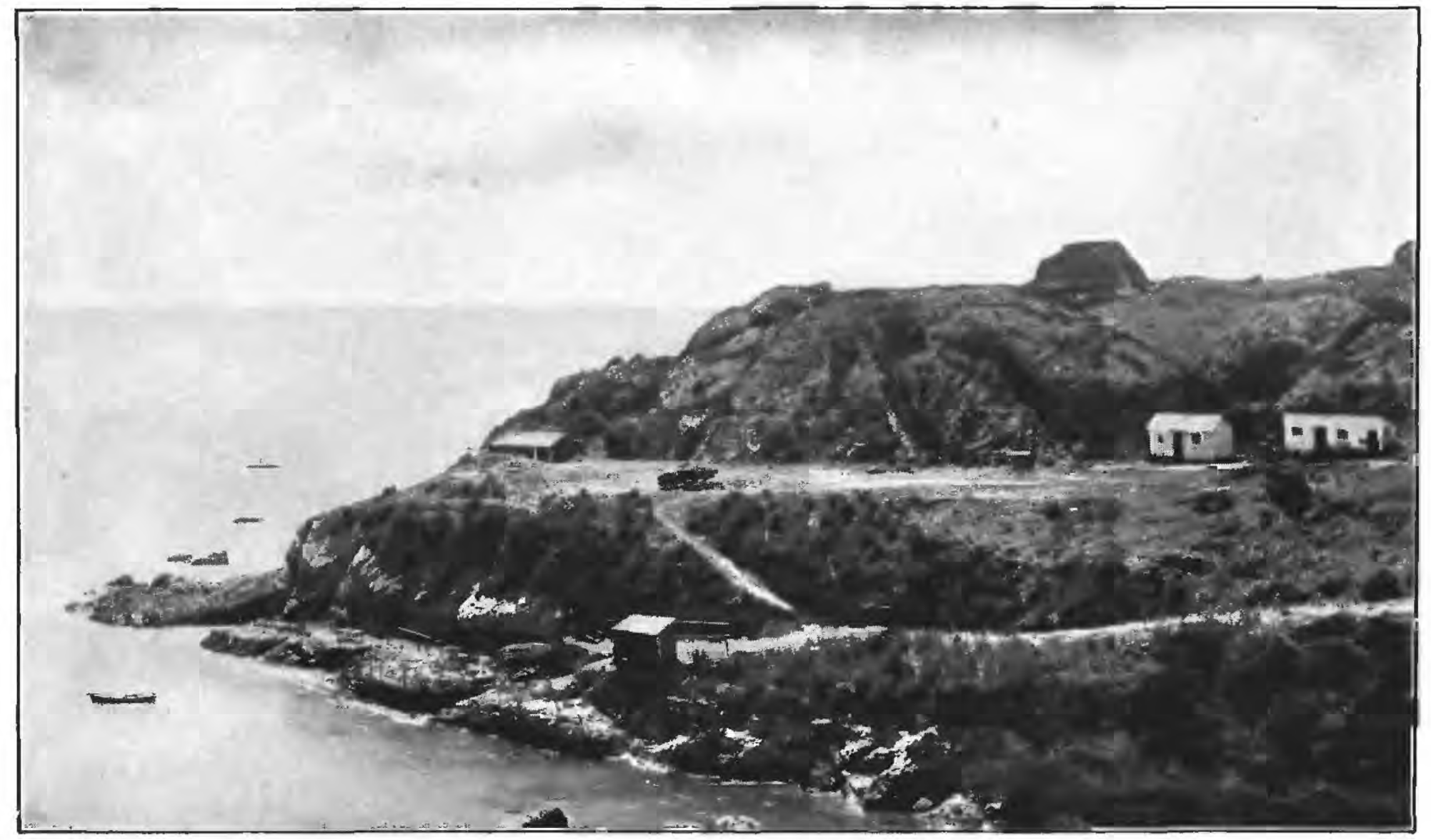

B. WAVE-CUT TERRACES ON THE CALIFORNIA COAST. 


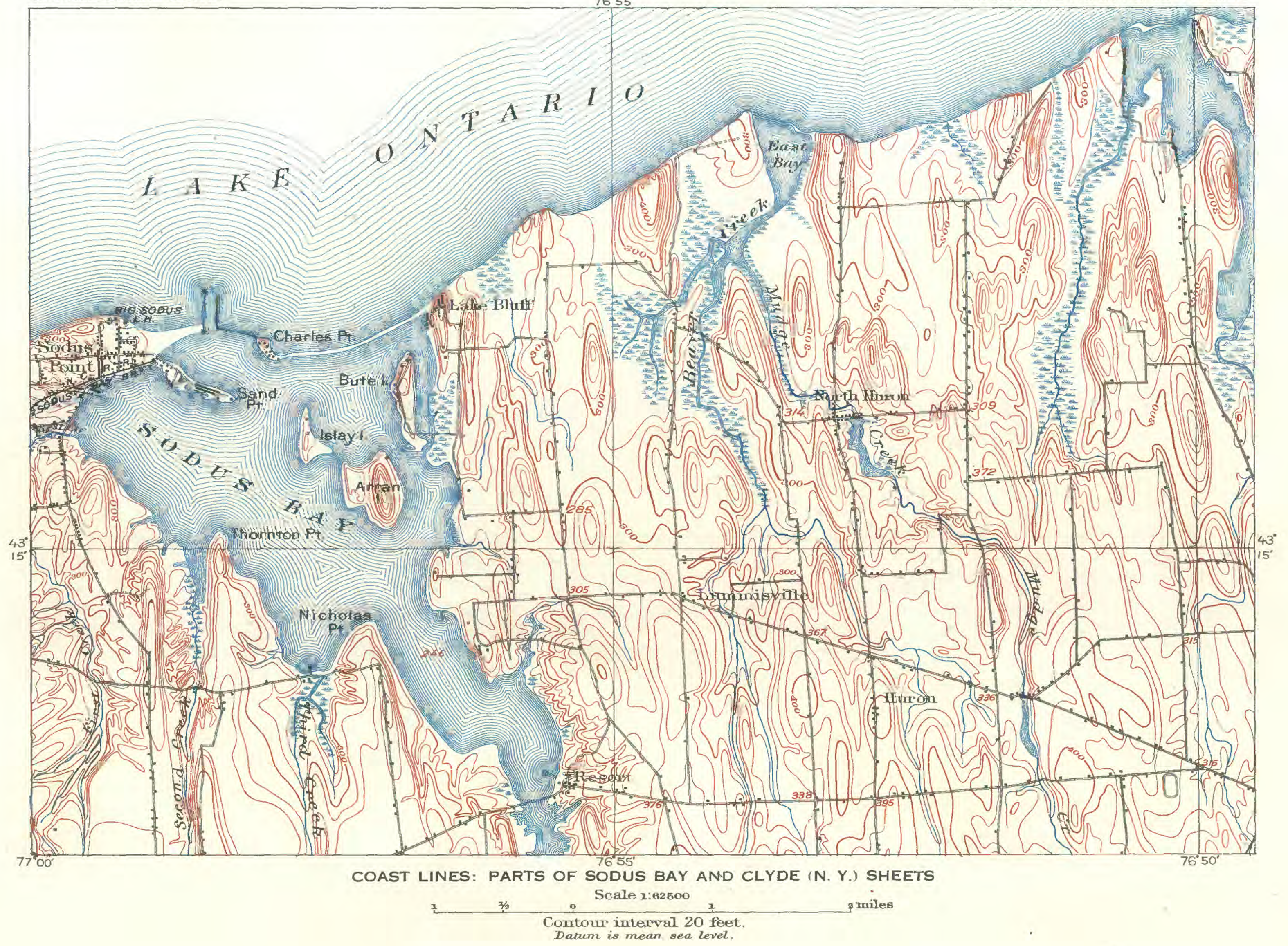




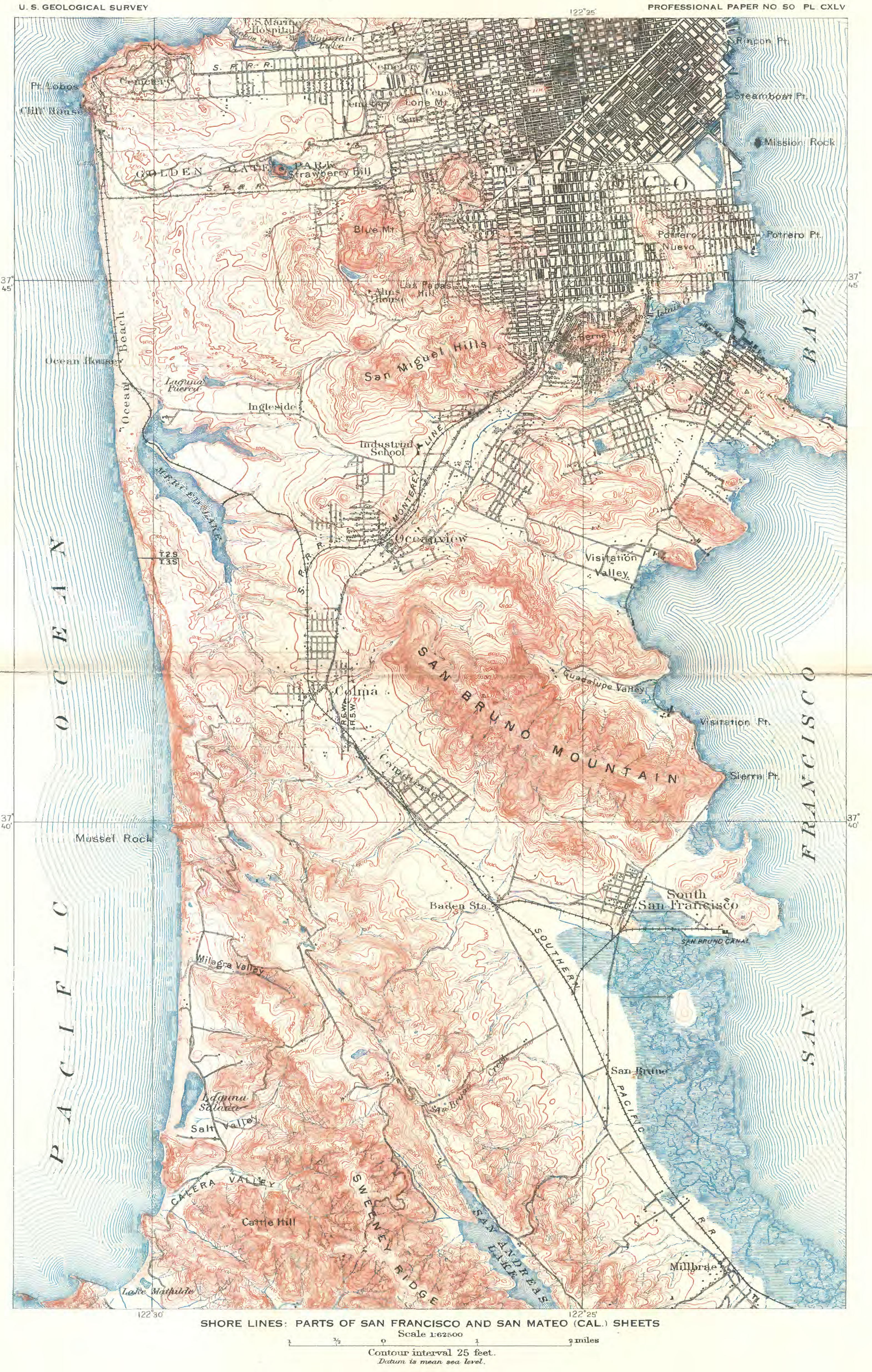




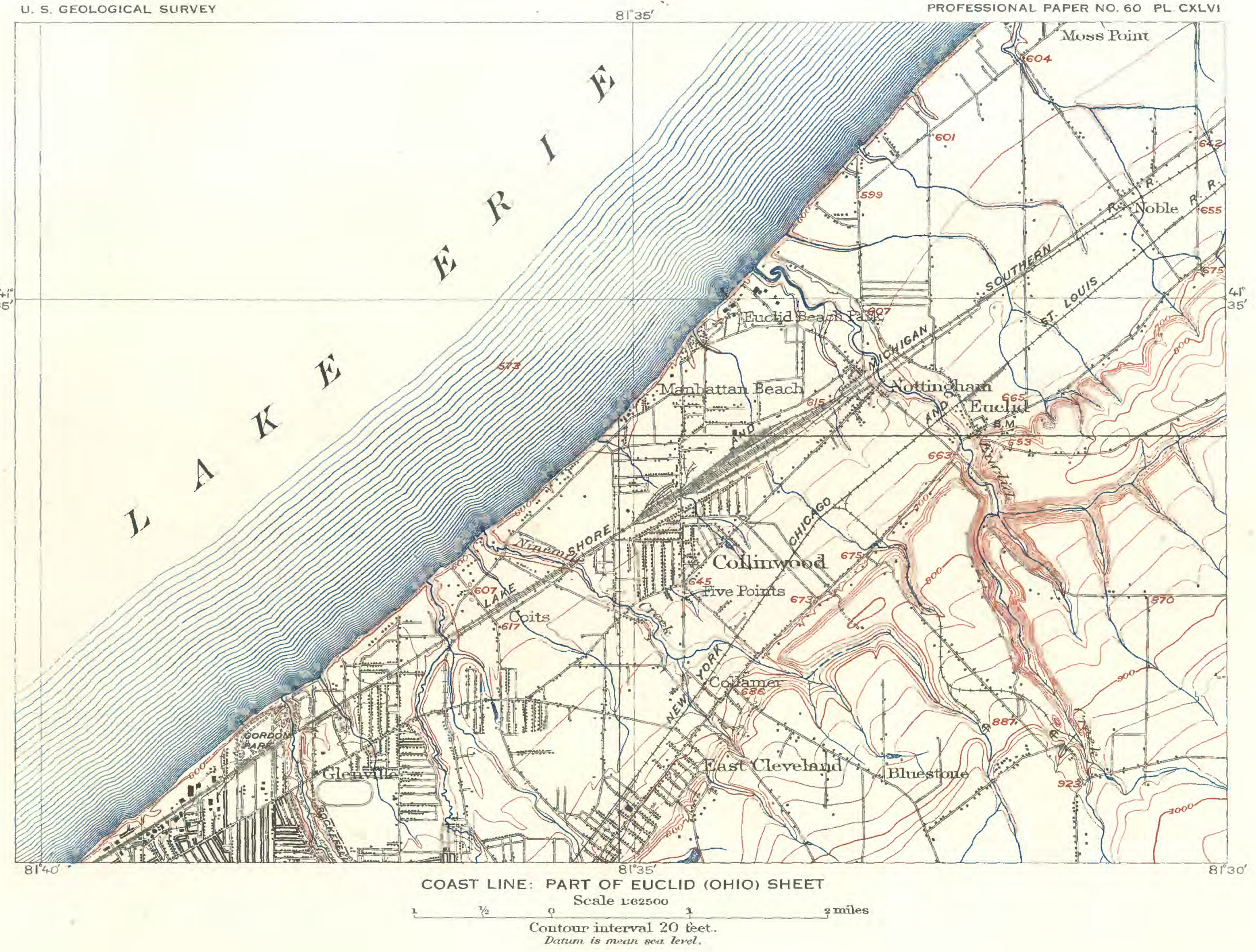




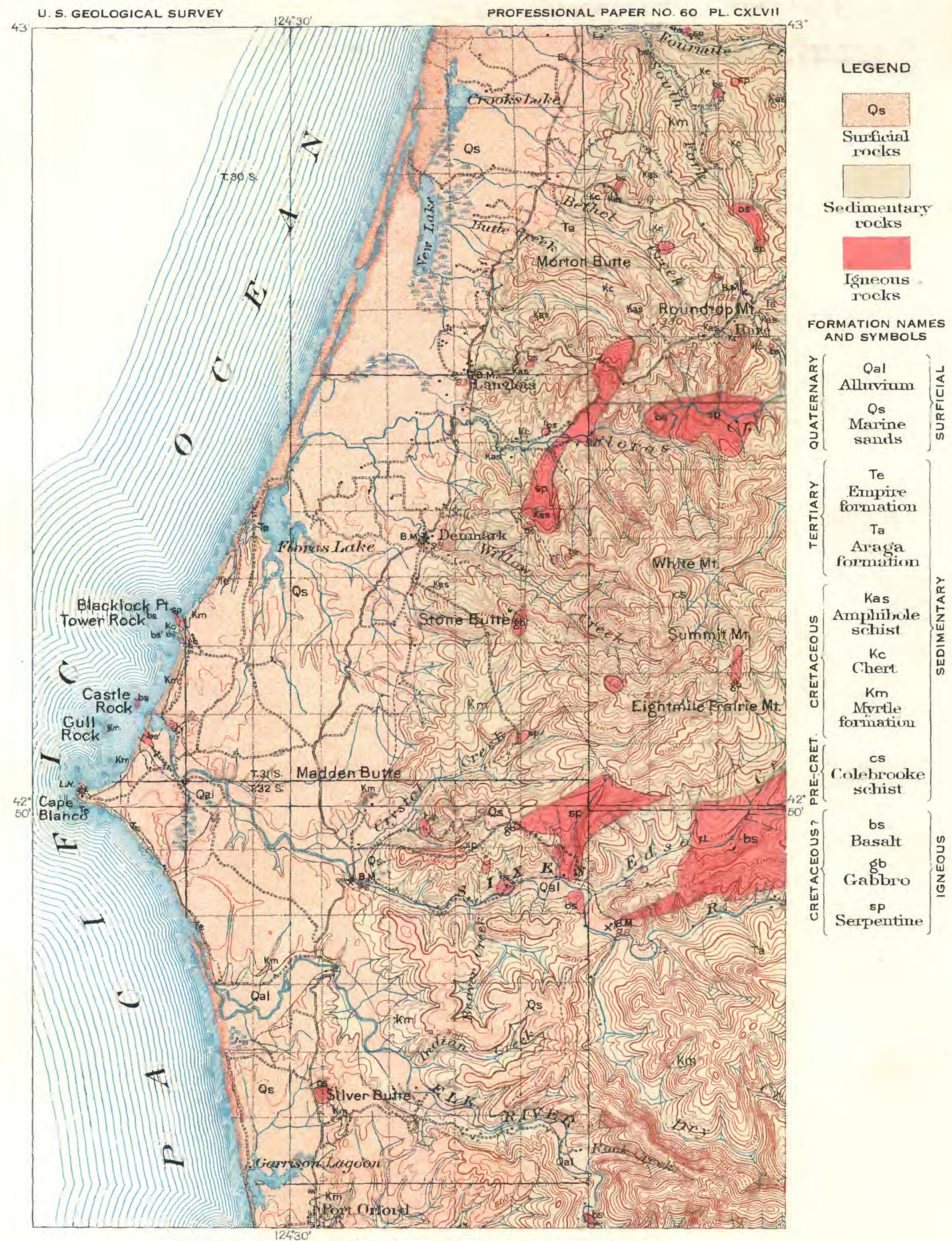

43

COAST LINE: FROM THE PORT ORFORD (OREG .) FOLIO

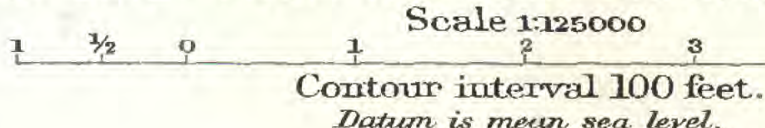
s miles 


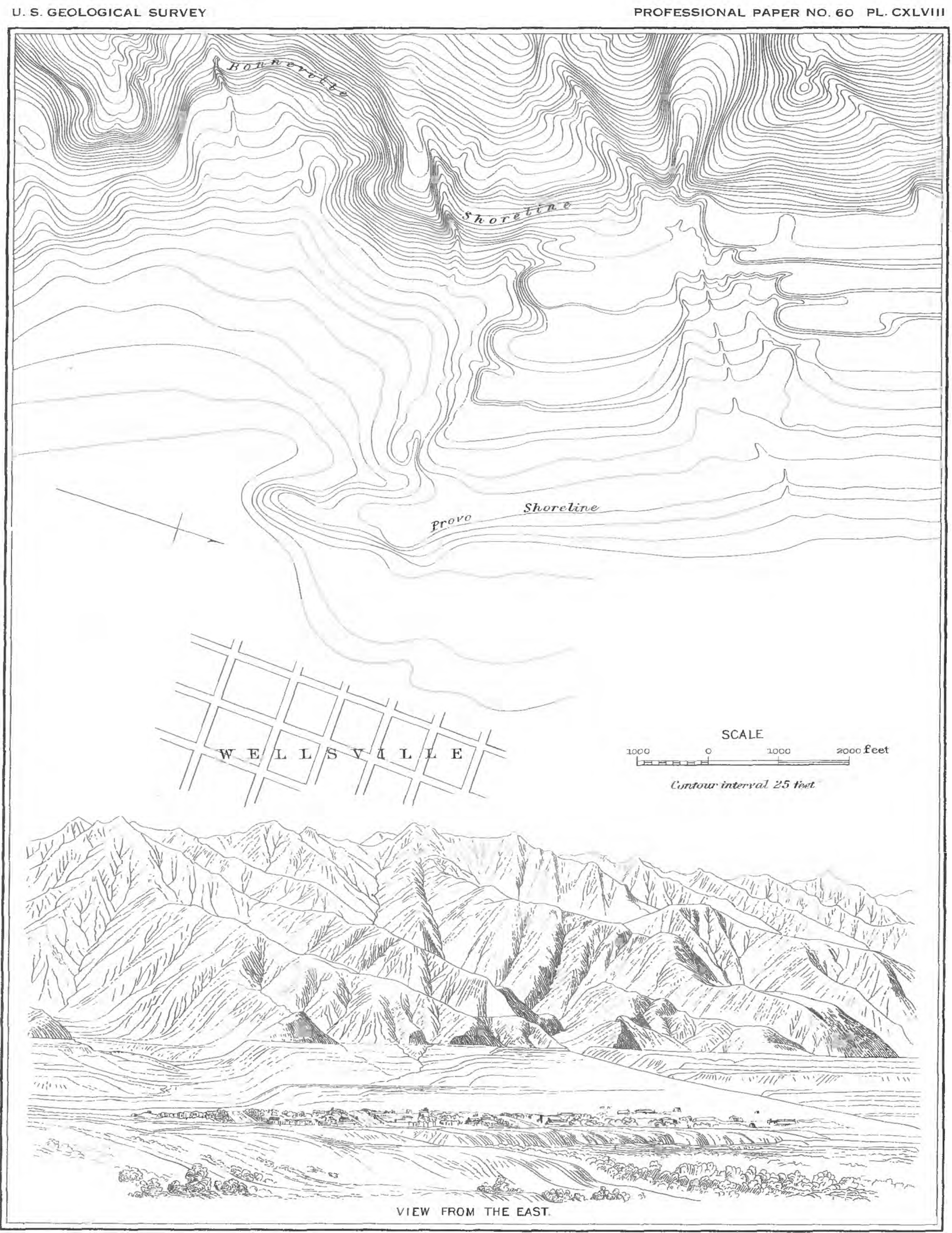

COAST LINES: SHORE TERRACES AND BARS OF ANCIENT LAKE

BY A. L, WEGSTER 


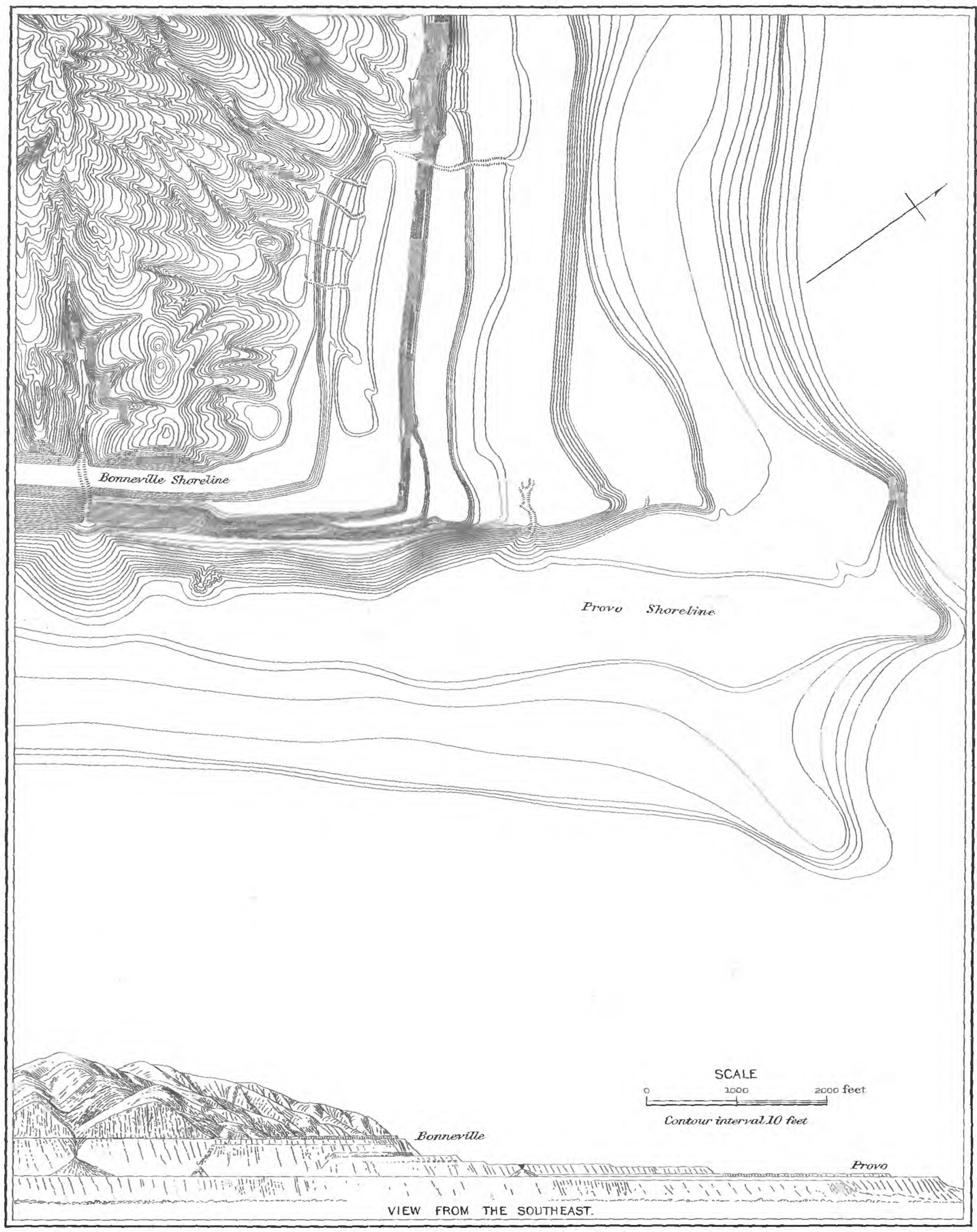

COAST LINES: SHORE TERRACES OF ANCIENT LAKES NEAR DOVE CREEK, UTAH BY GILBERT THOMPSON 
U. S. GEOLOGICAL SURVEY

PROFESSIONAL PAPER NO. 60 PL. CL

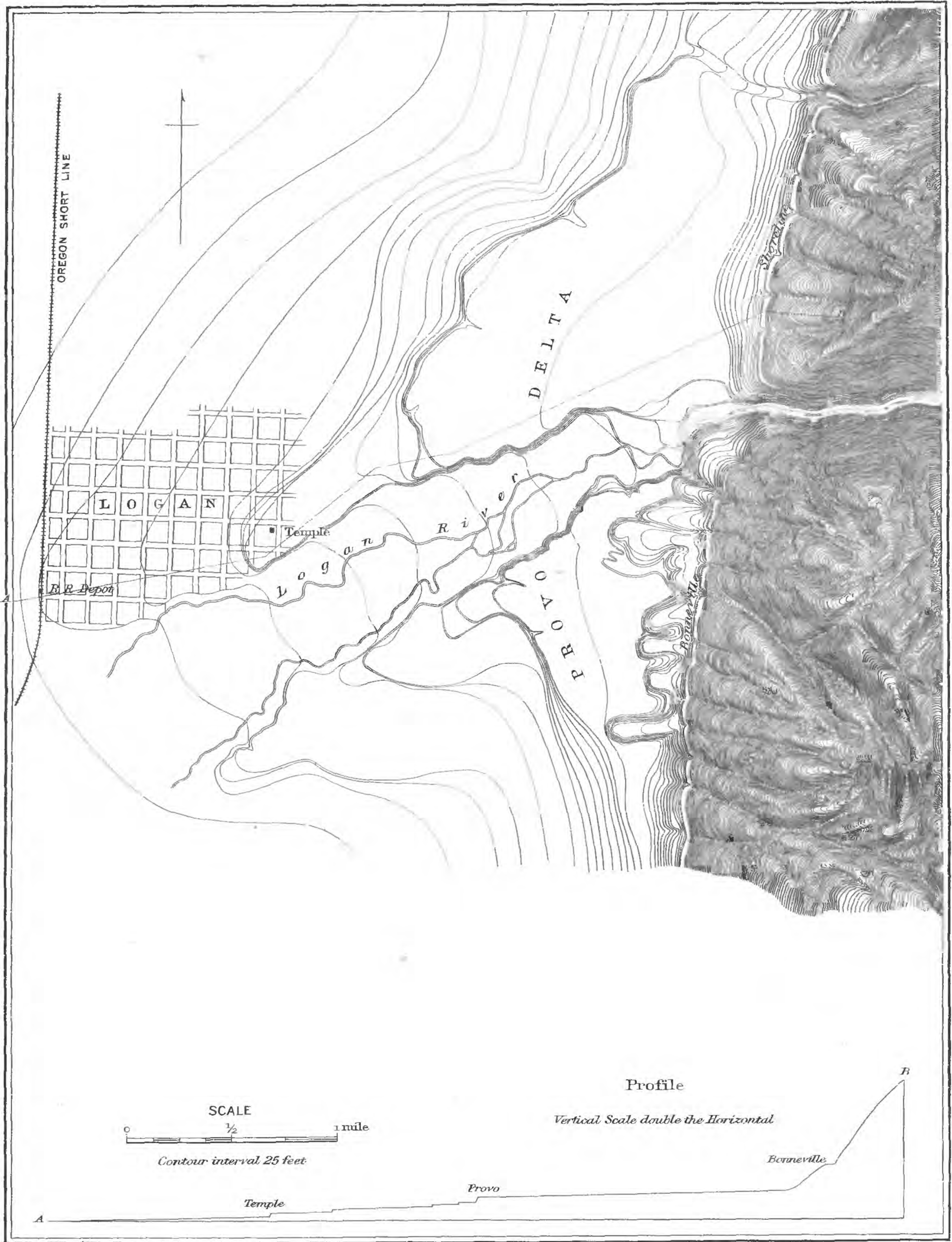

COAST LINES: DELTAS AND SHORE TERRACES OF ANCIENT LAKE.

BY W. D. JOHNSON 


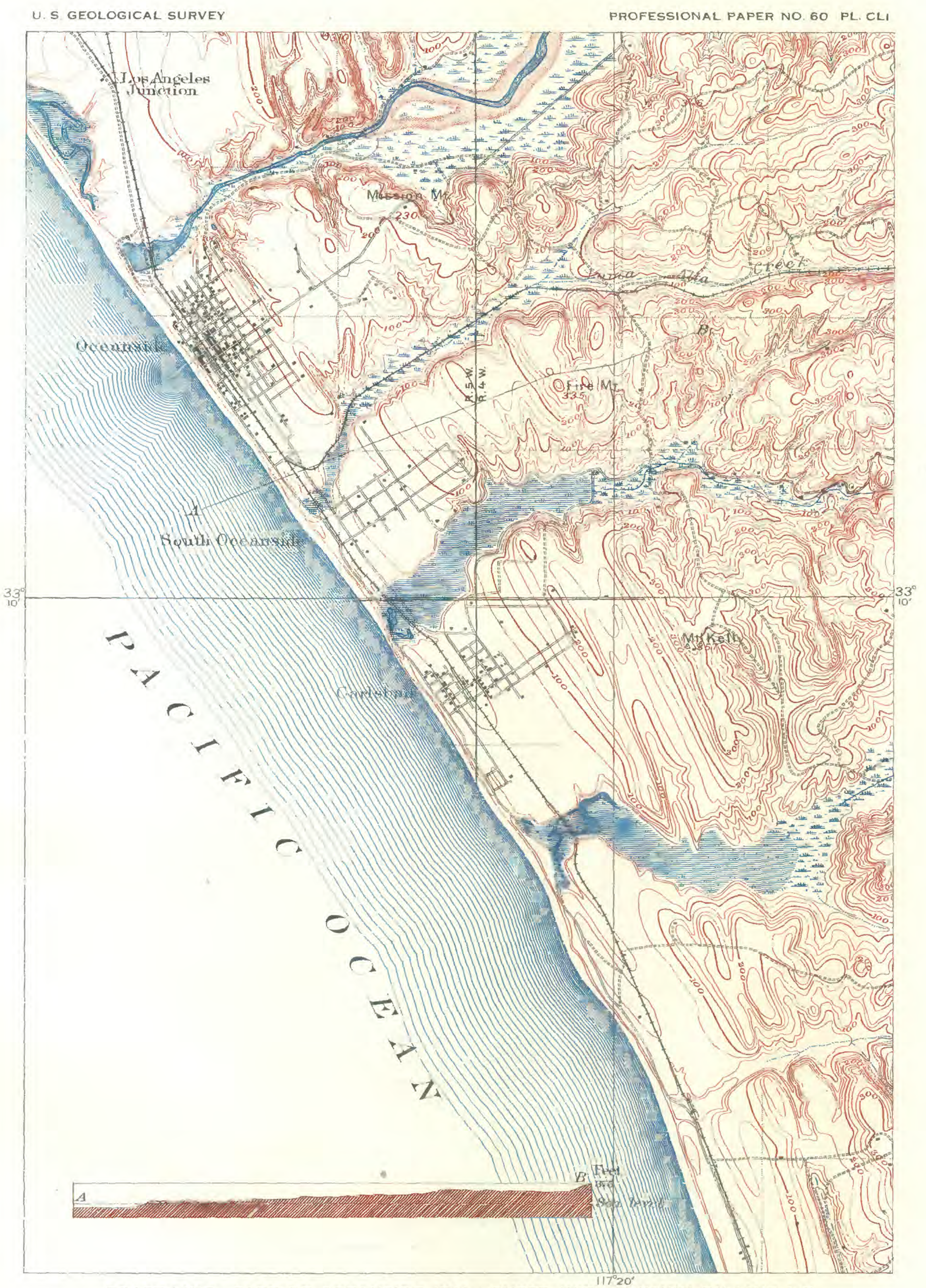

COAST LINE: PART OF OCEANSIDE (CAL.) SHEET. WITH SECTION ON LINE A-B o Scale 1:62500 


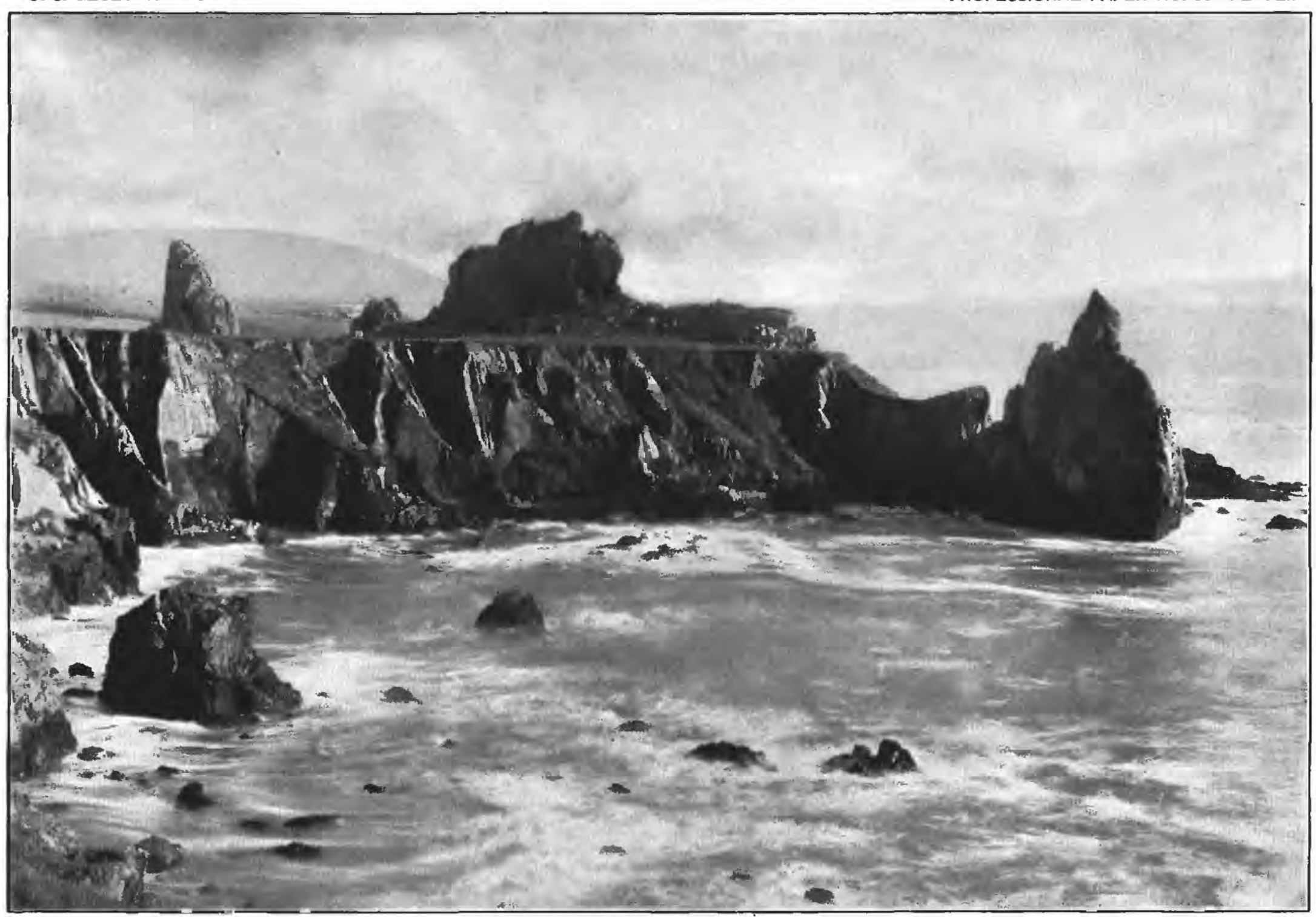

A. AN EleVATED WAVE-CUt TERRACE NORTH OF PORT HARFORD, CALIFORNIA.

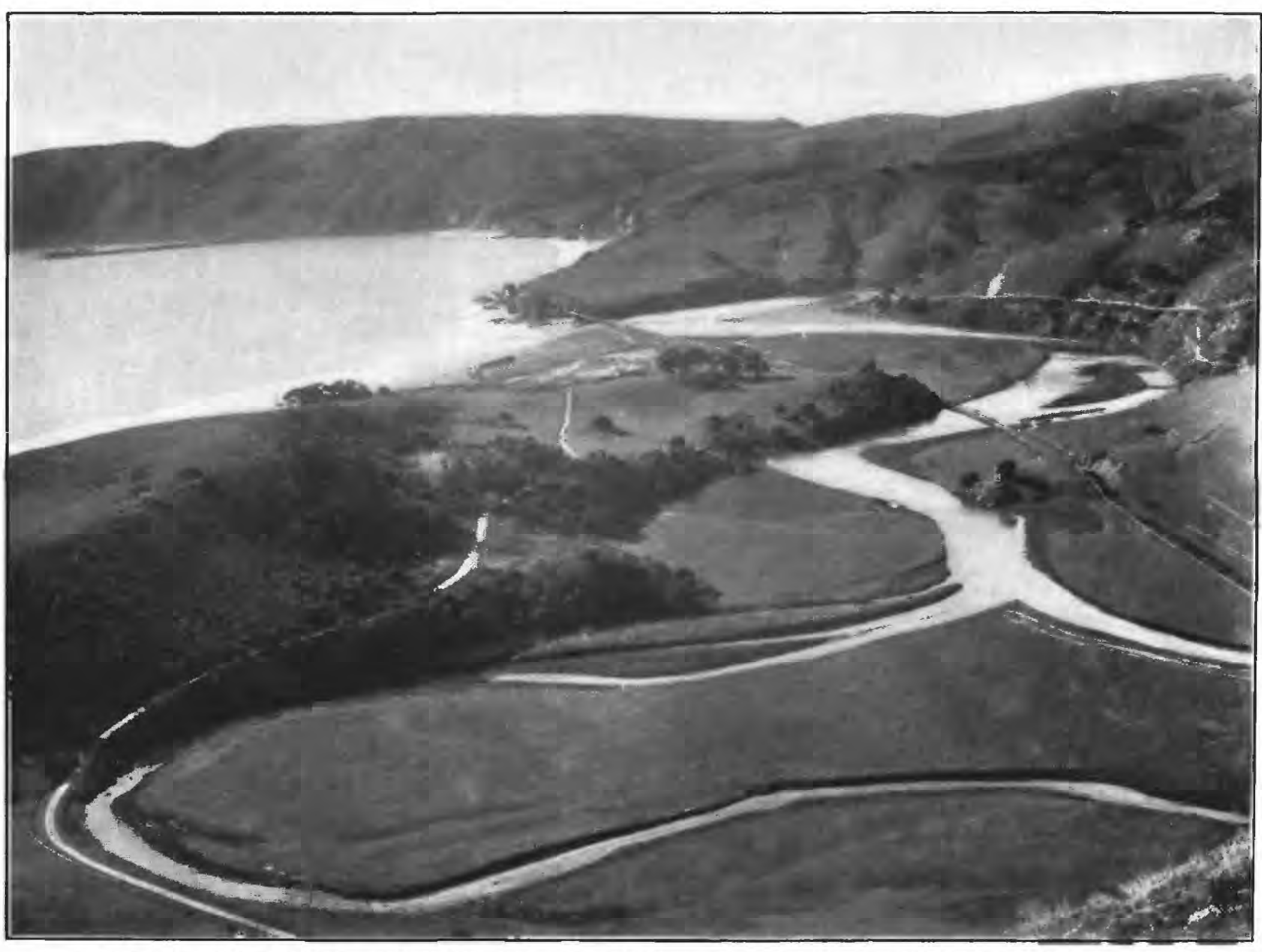

B. TIDAL LAGOON FORMED BY SAND SPIT AT MOUTH OF SAN LUIS OBISPO CREEK, CALIFORNIA. 
Imis:

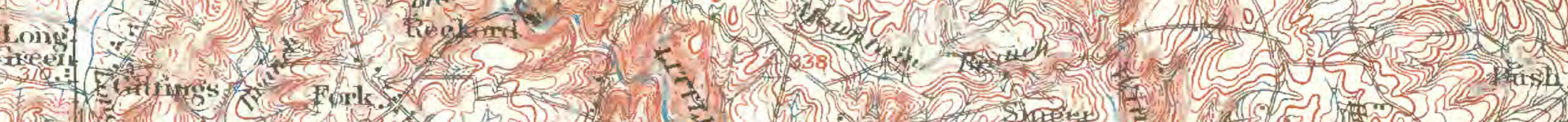
5.7.

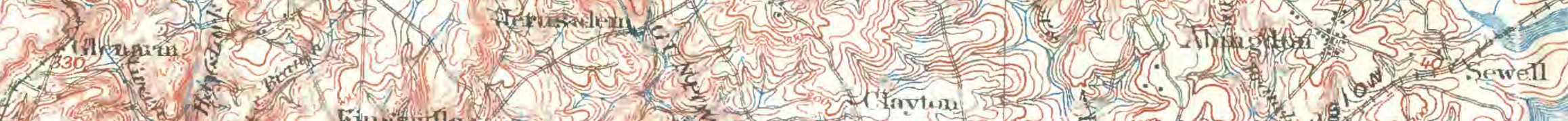

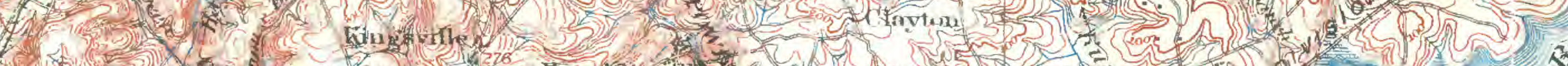

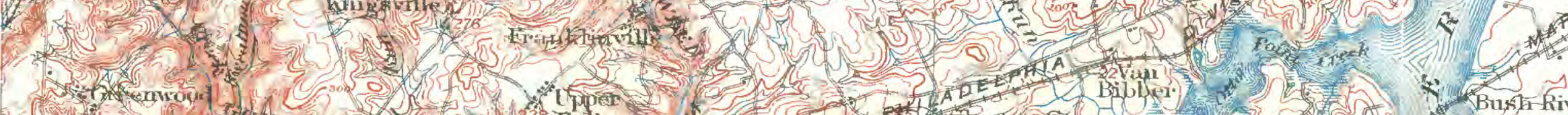
2.

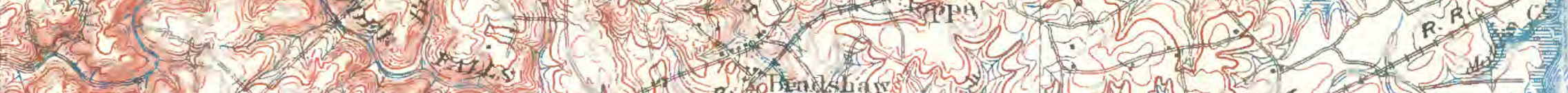
H.

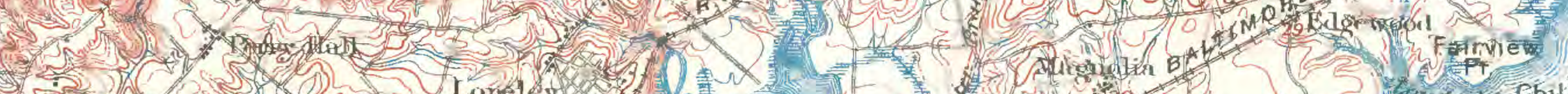

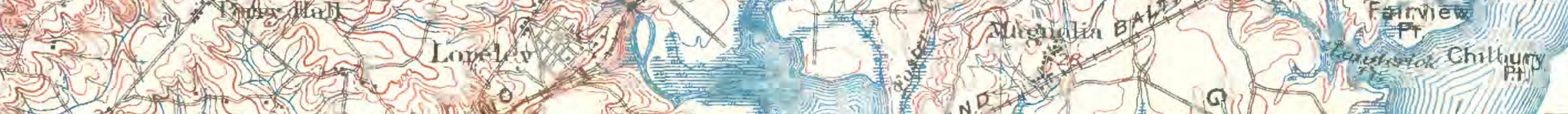

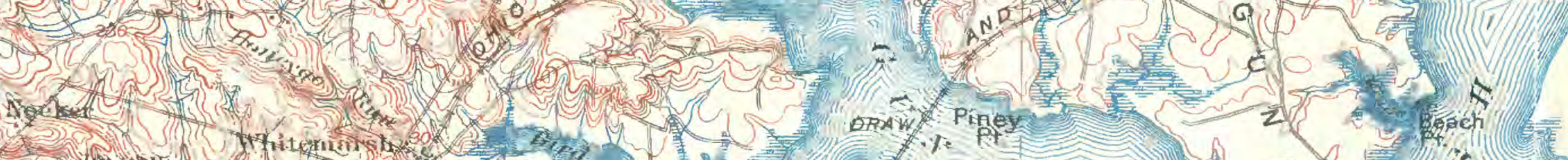

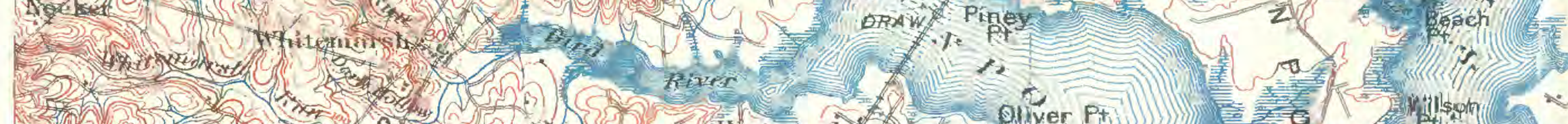
2.

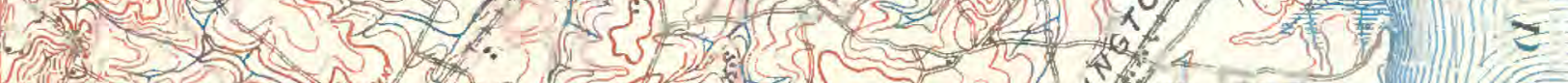
- = x.

icte 1.20.

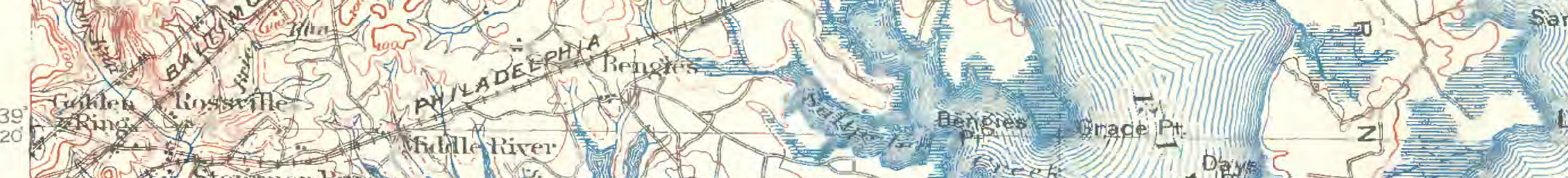

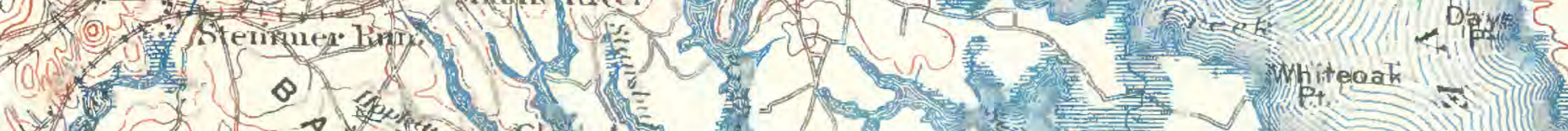

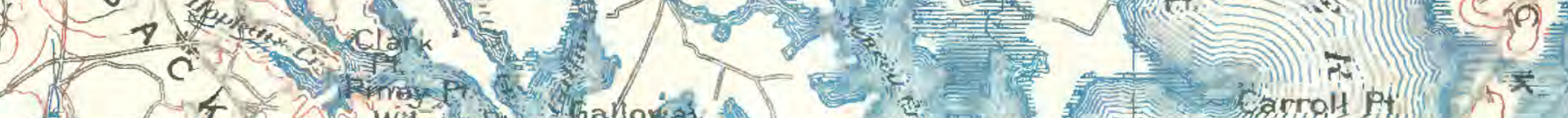

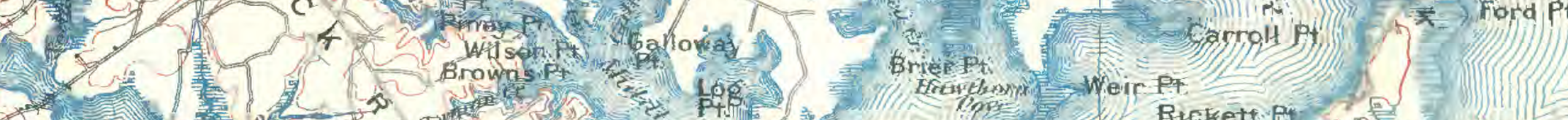

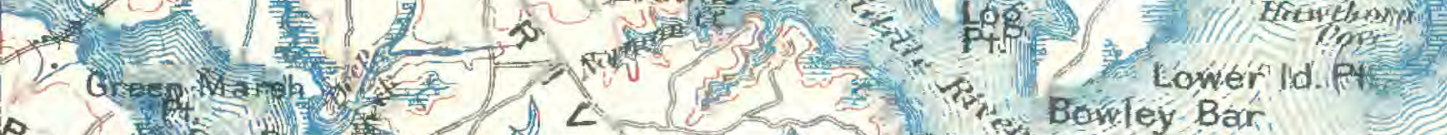

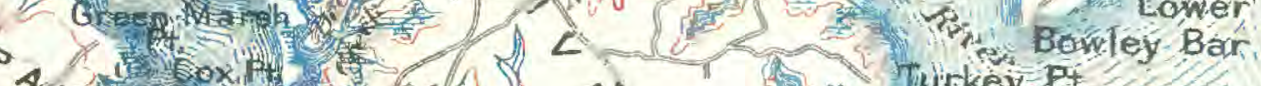

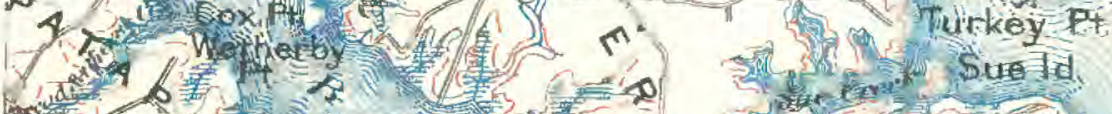

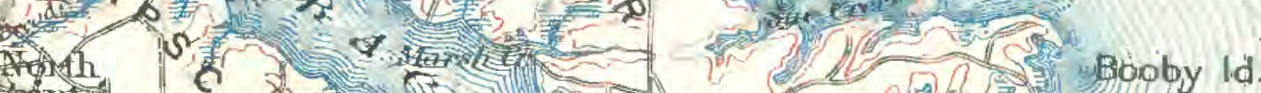

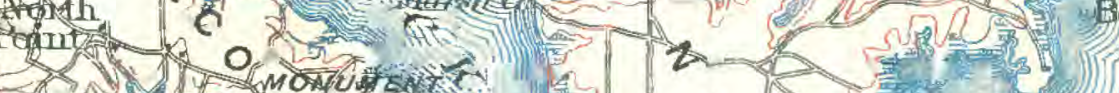

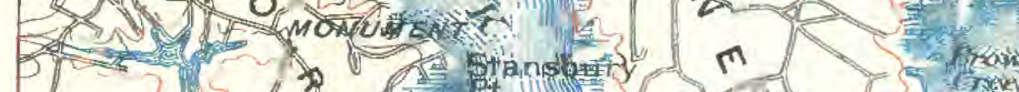

2.

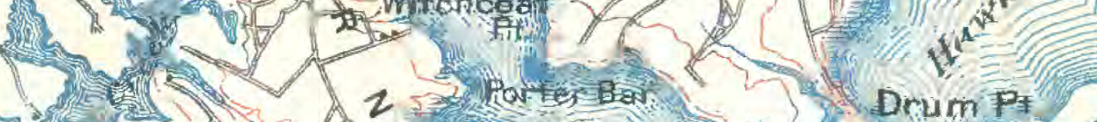

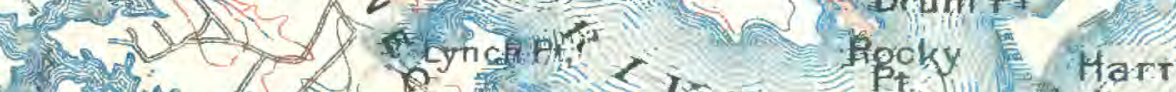

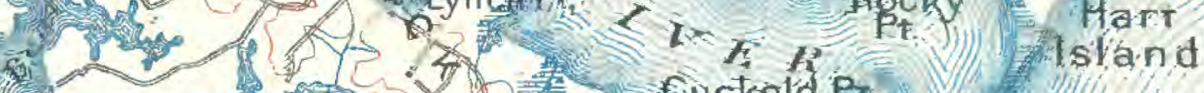

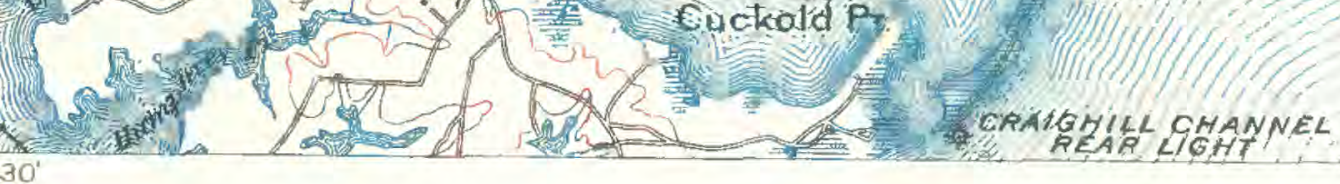

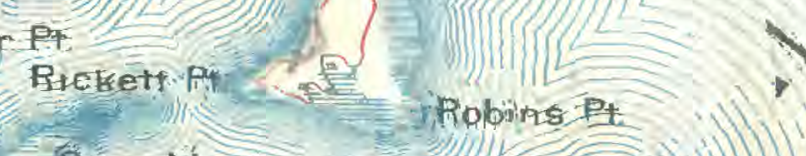

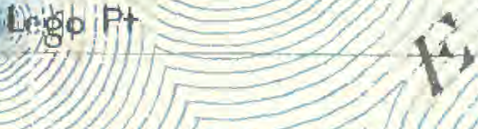

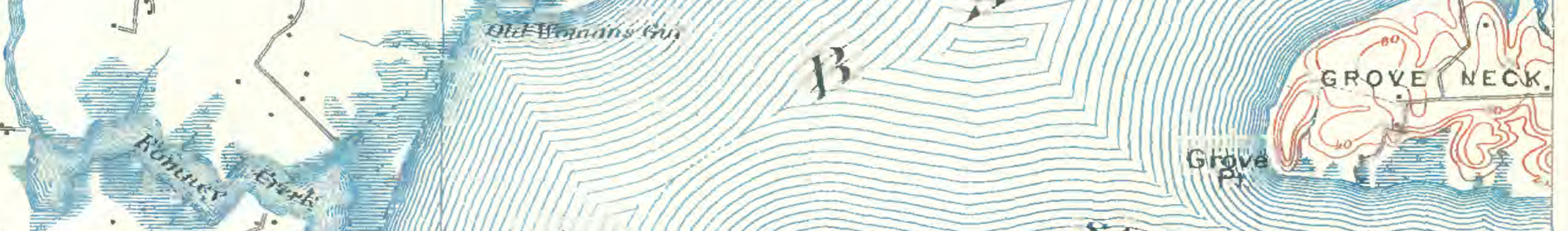

Hower $\mathrm{P}$ - W

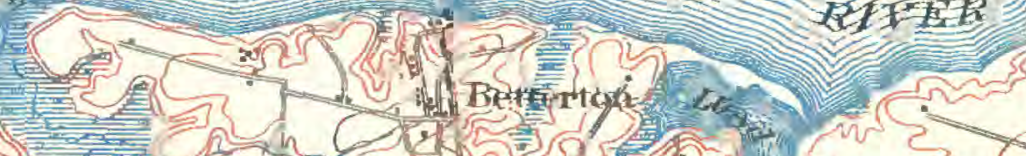

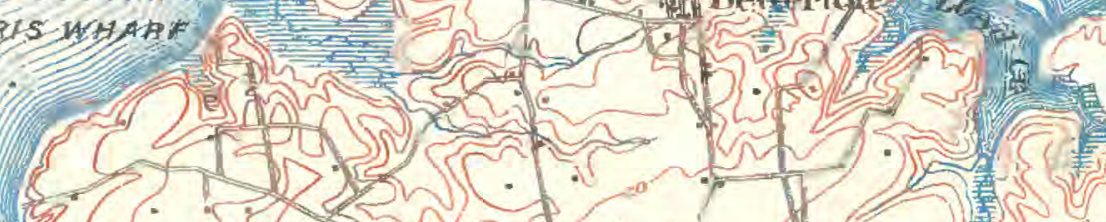

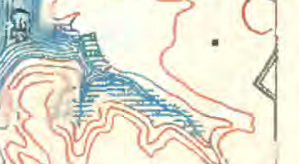

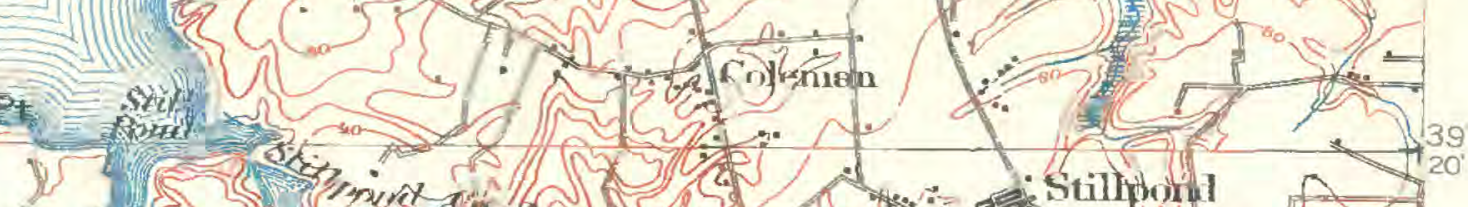

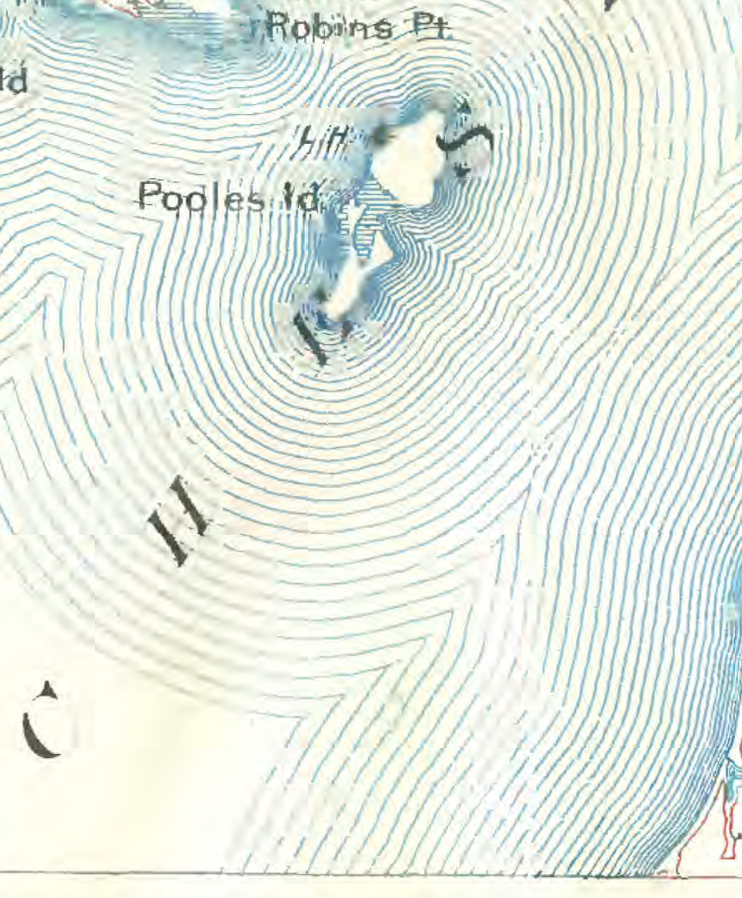

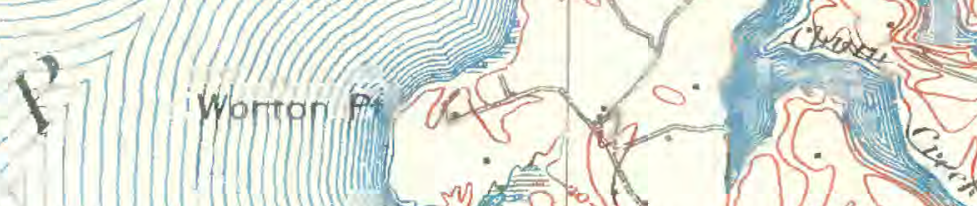

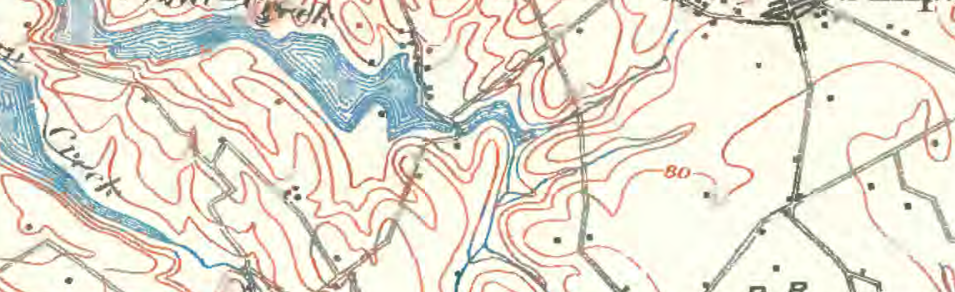

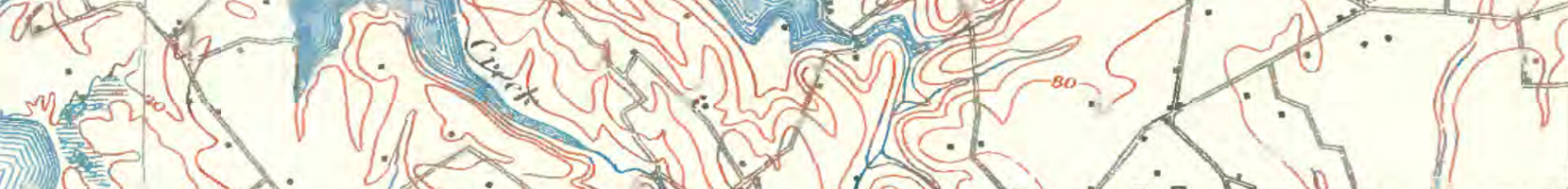
(5. cis

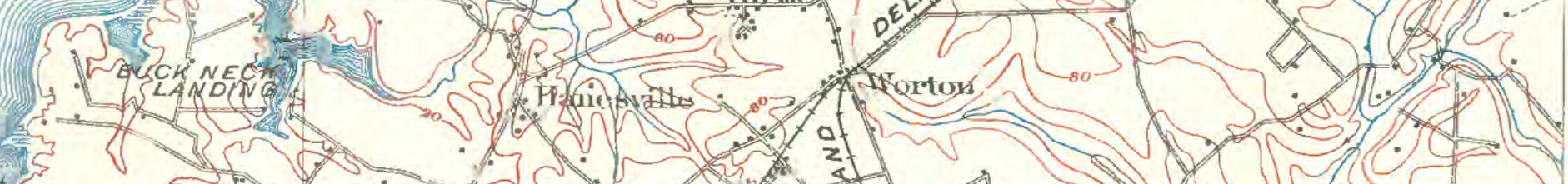

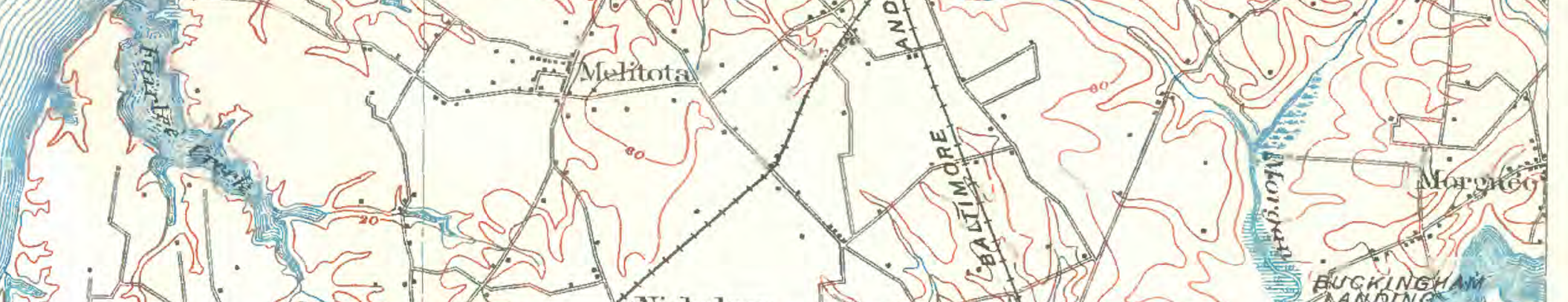

COAST LINES: PART OF T OLCHESTER IMD SHEET

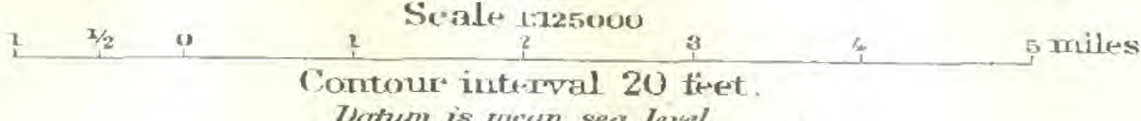




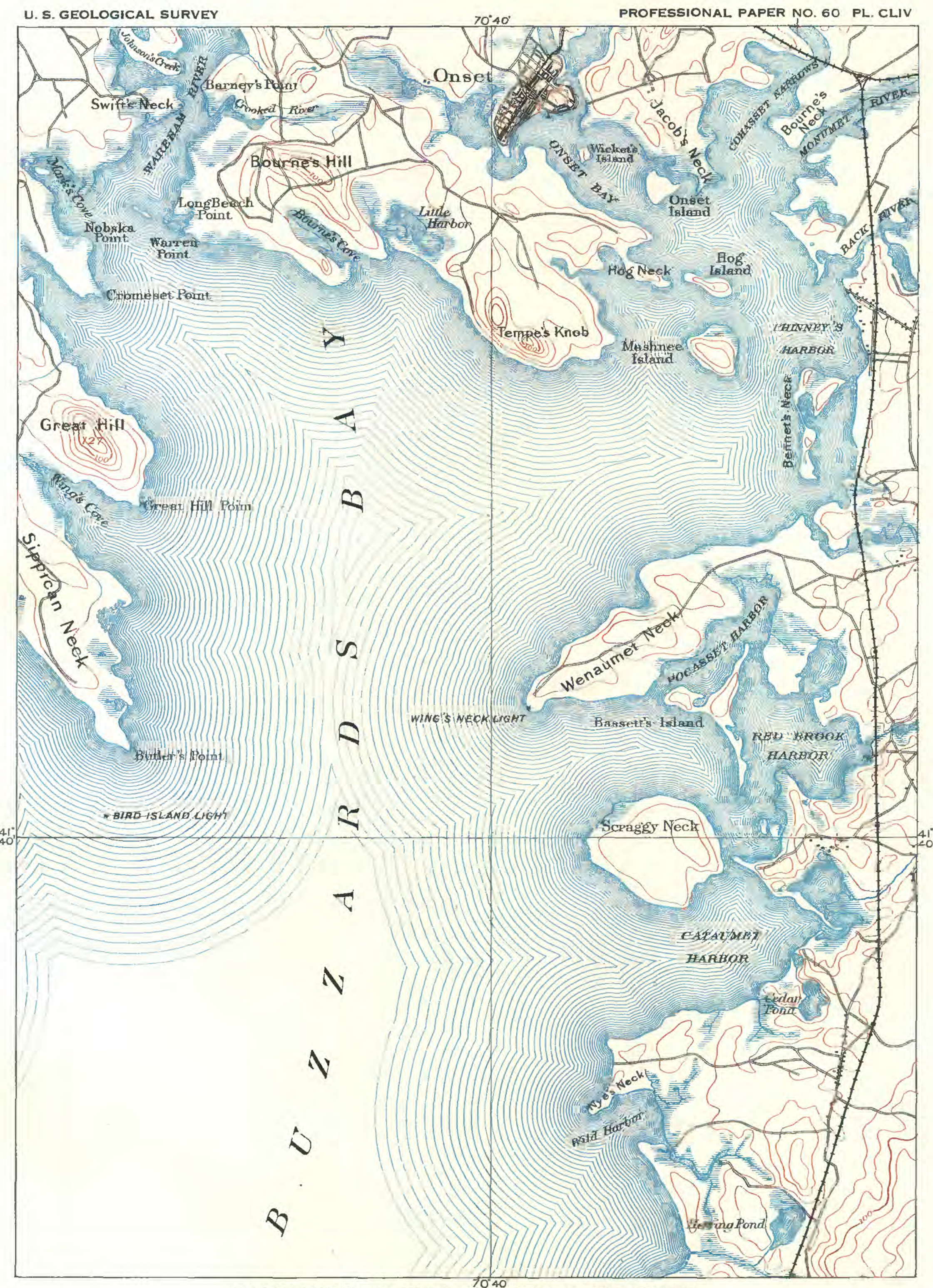

COAST LINES: PART OF FALMOUTH (MASS.) SHEET

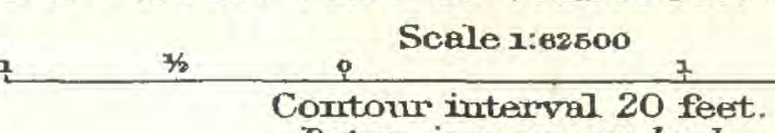




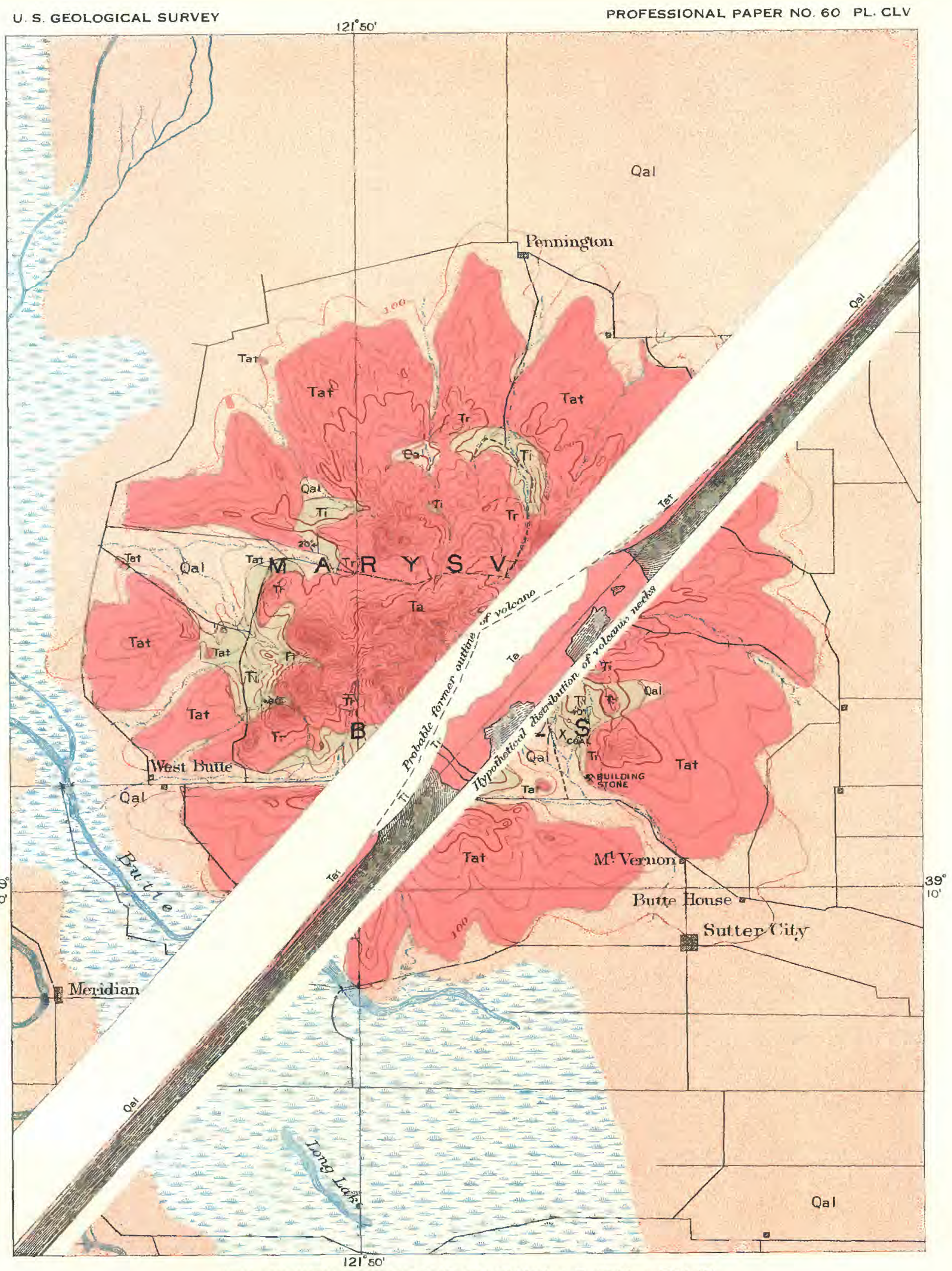

VOLCANISM: FROM THE MARYSVILLE (CAL.) FOLIO

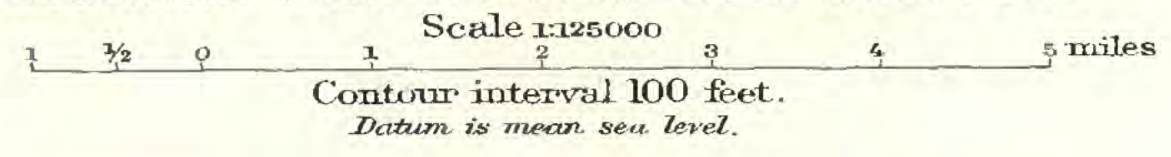

Datum is mean sea. level.

Surficial rocks Sedimentaxy rocks [gneuns rocks

Qa

$\mathrm{Ti}$

Tt

Alluvium

Ione formation

Tejon formation

Andesite

Andesitic tutits and brencias

Rhyolite 


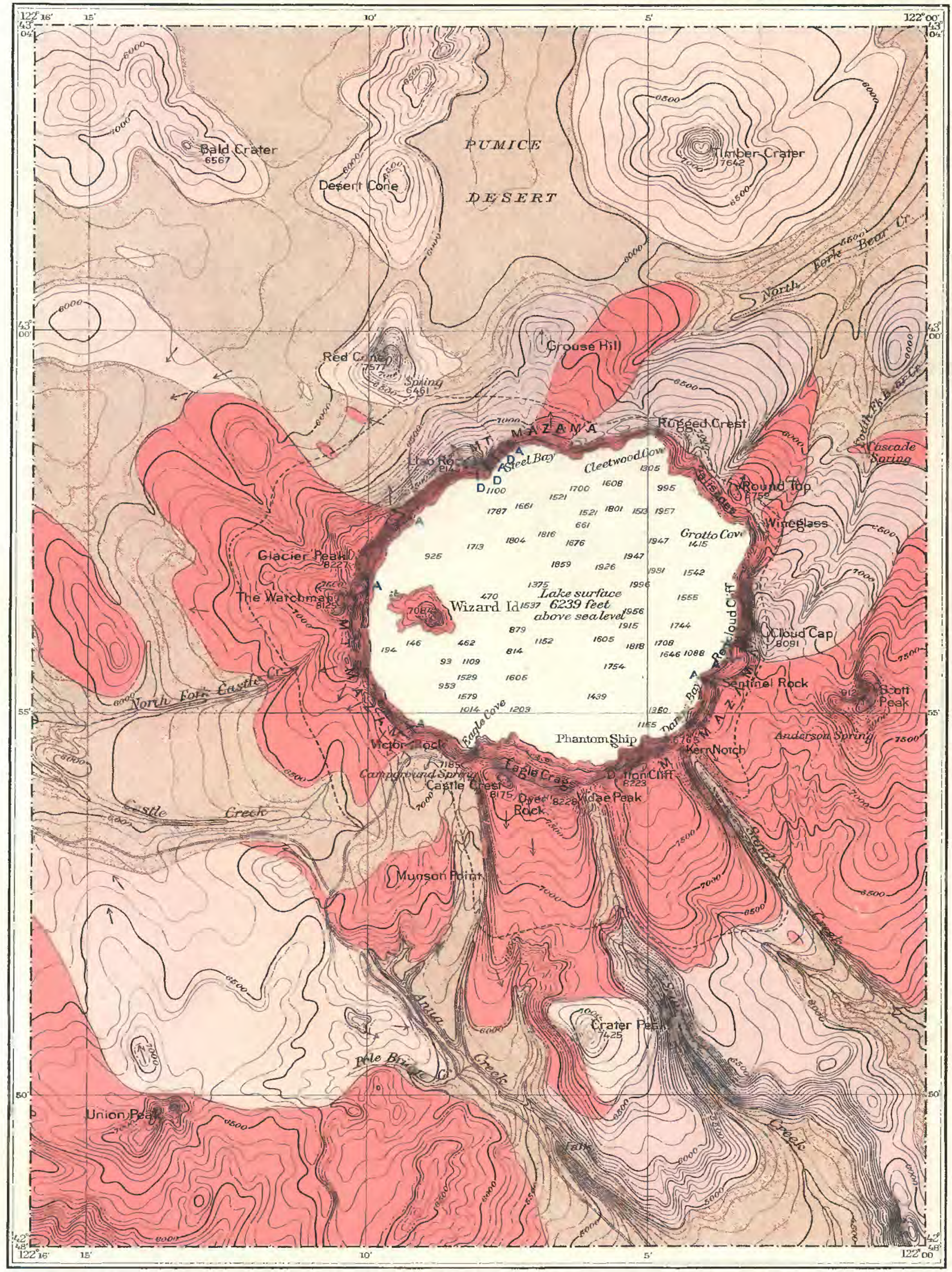

VOLCANISM: GEOLOGIC MAP OF MOUNT MAZAMA AND CRATER LAKE. NATIONAL PARK, OREGON

Triansuliation and topośra phy by Mark BKerr. BY J S. DILLER

Surveyed in 1886 . Scale

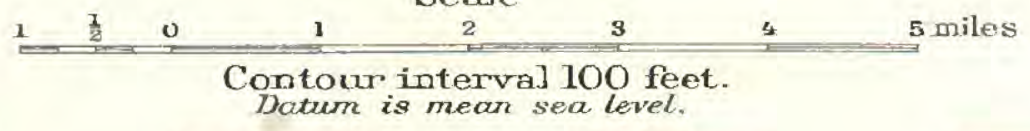

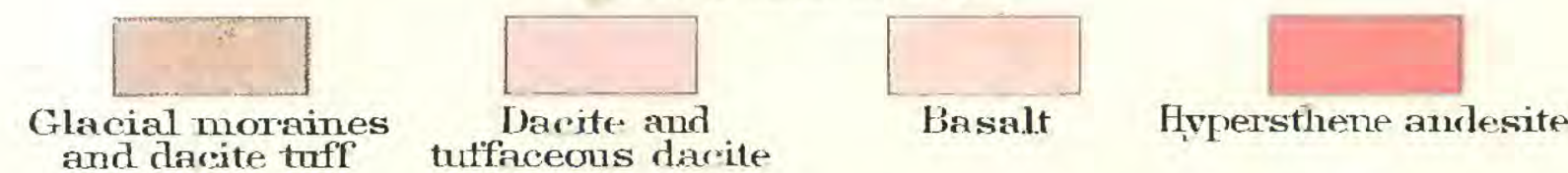

$\rightarrow$ Glacial striat - A Hypersthene — D Darite dikes 


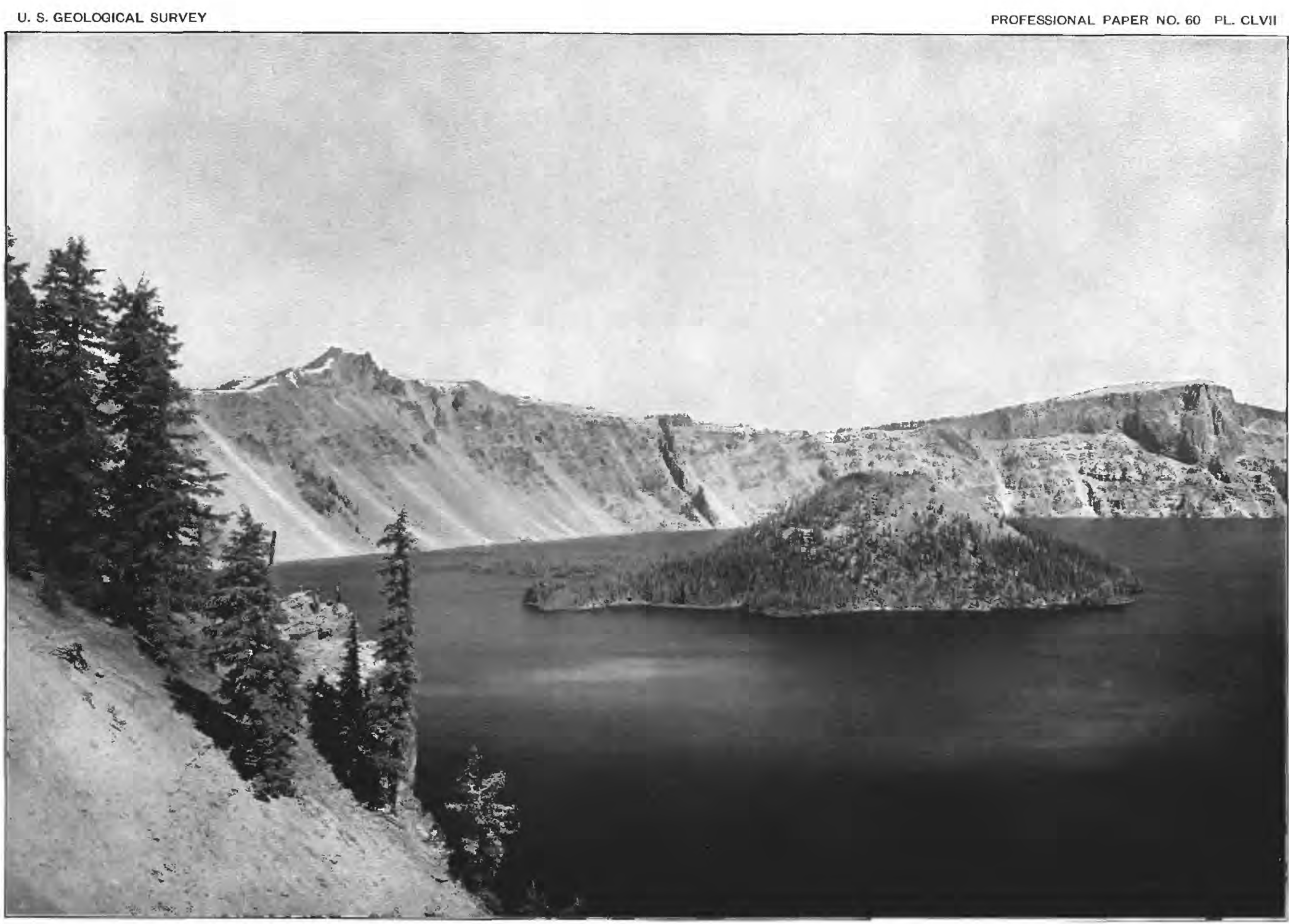

WESTERN BORDER OF CRATER LAKE, OREGON. 


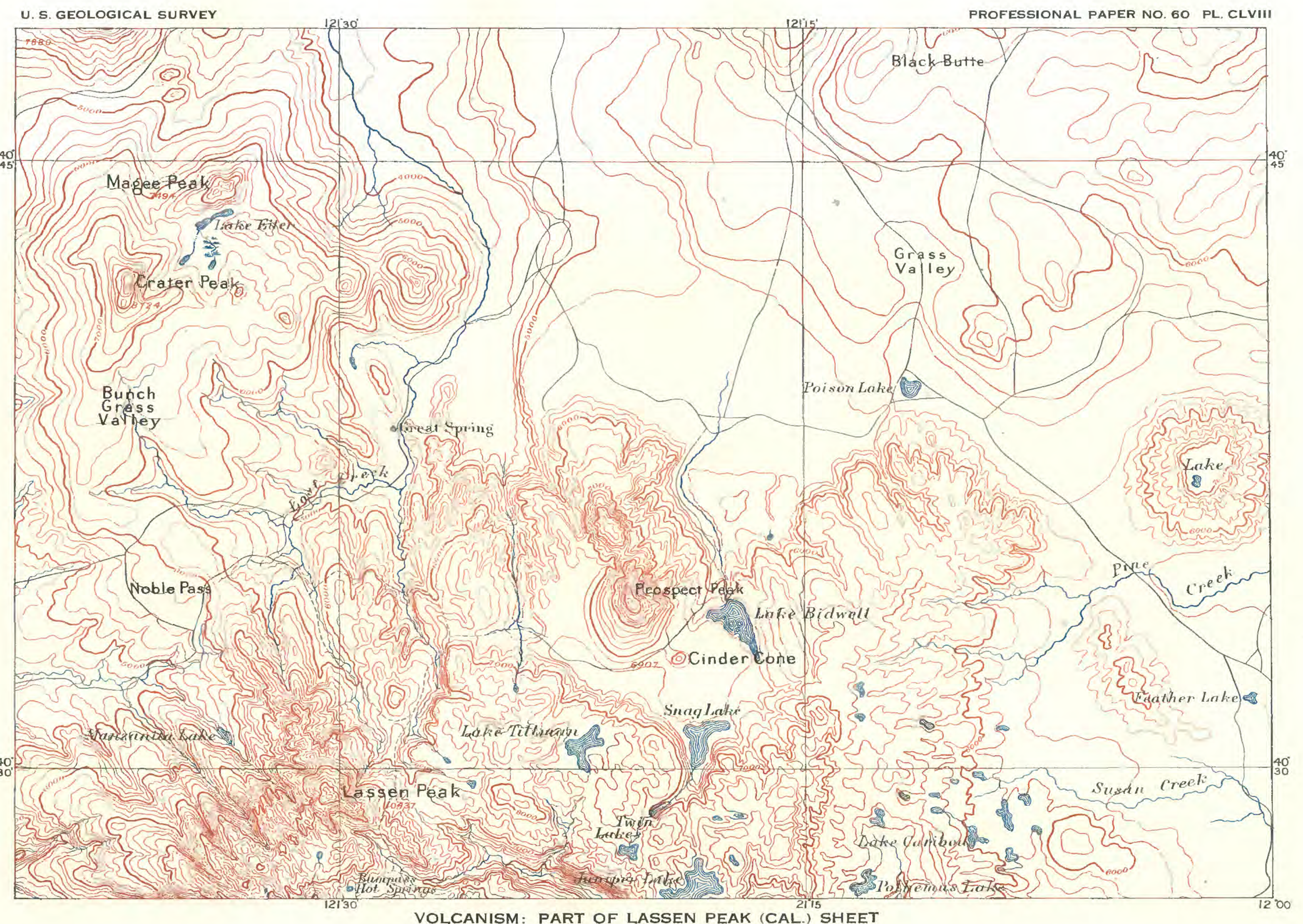

VOLCANISM: PART OF LASSEN PEAK (CAL) SHEET 4 Scale L:250000 


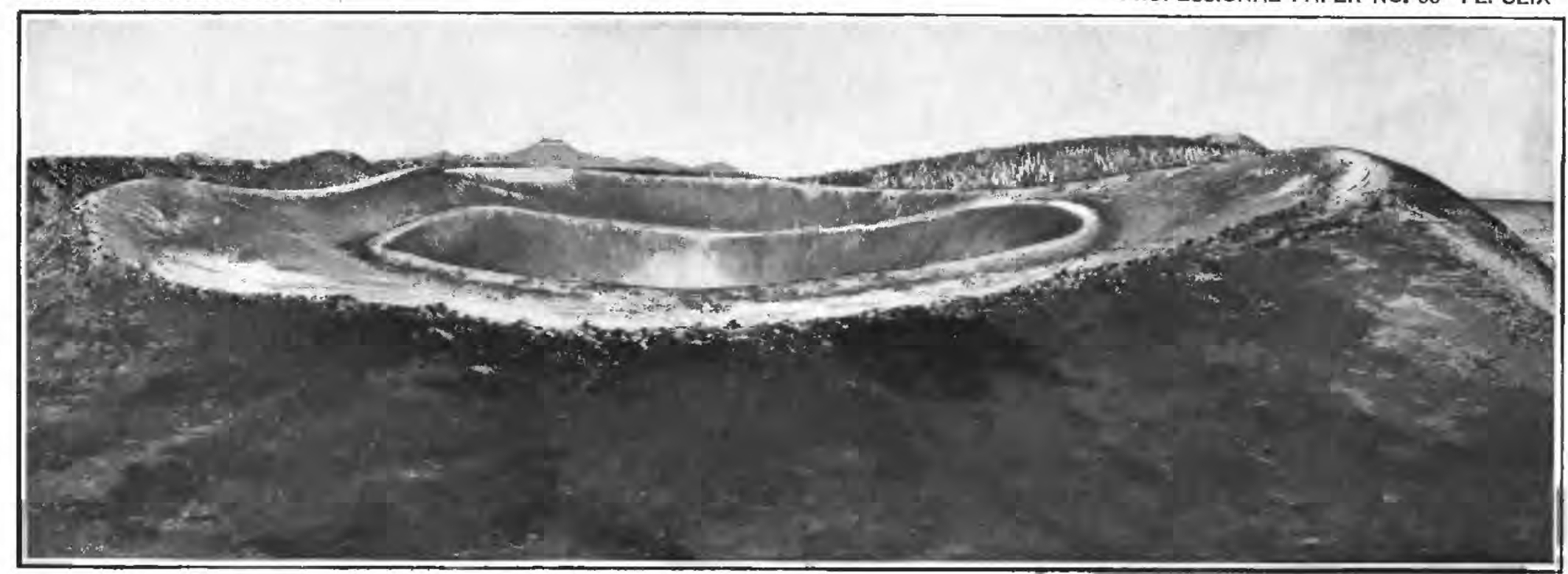

A.

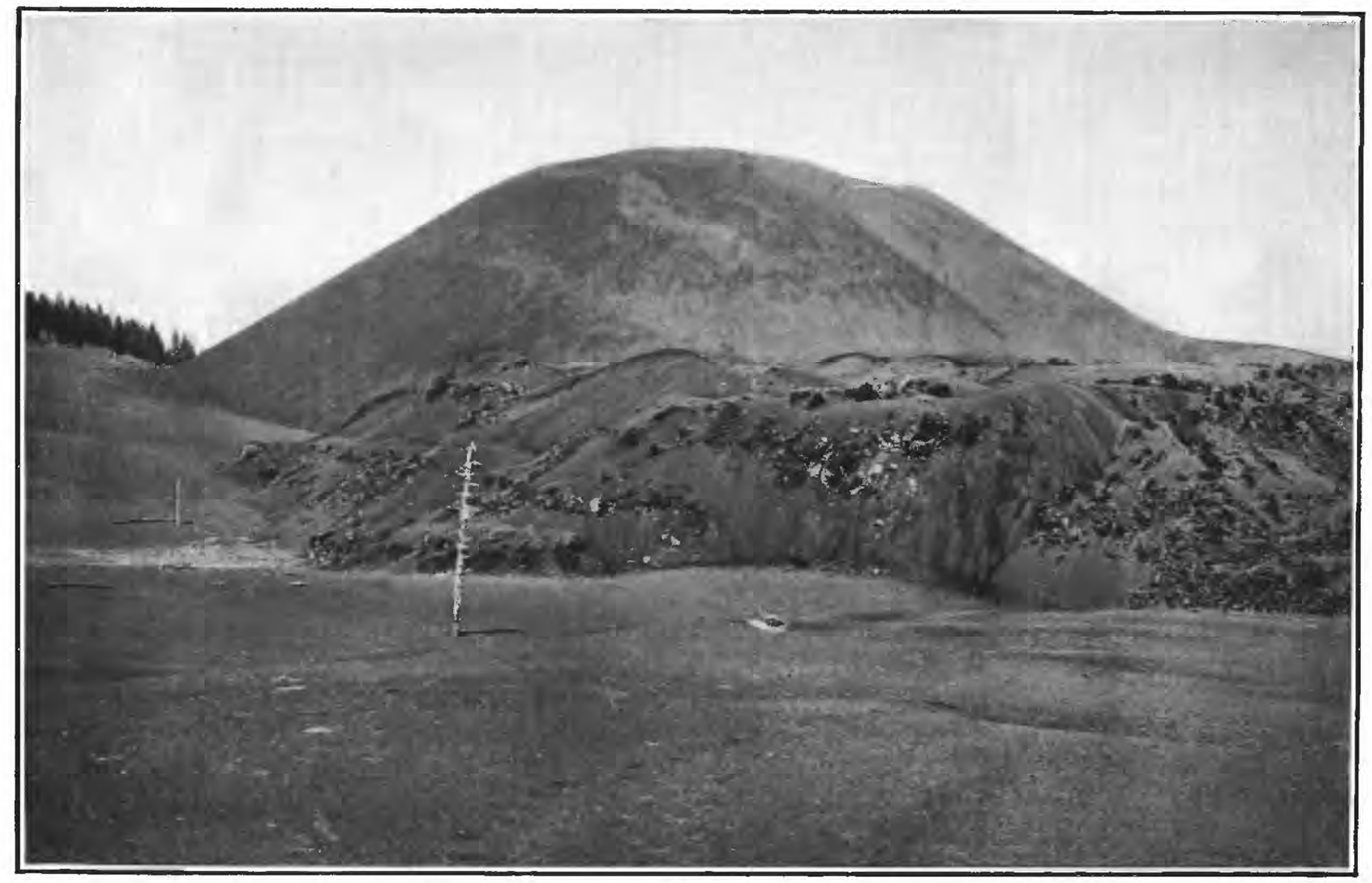

B.

VIEWS OF CINDER CONE, CALIFORNIA. 
38. U. S. GEOLOGICAL SURVEY

PROFESSIONAL PAPER NO. 60 PL. CLX

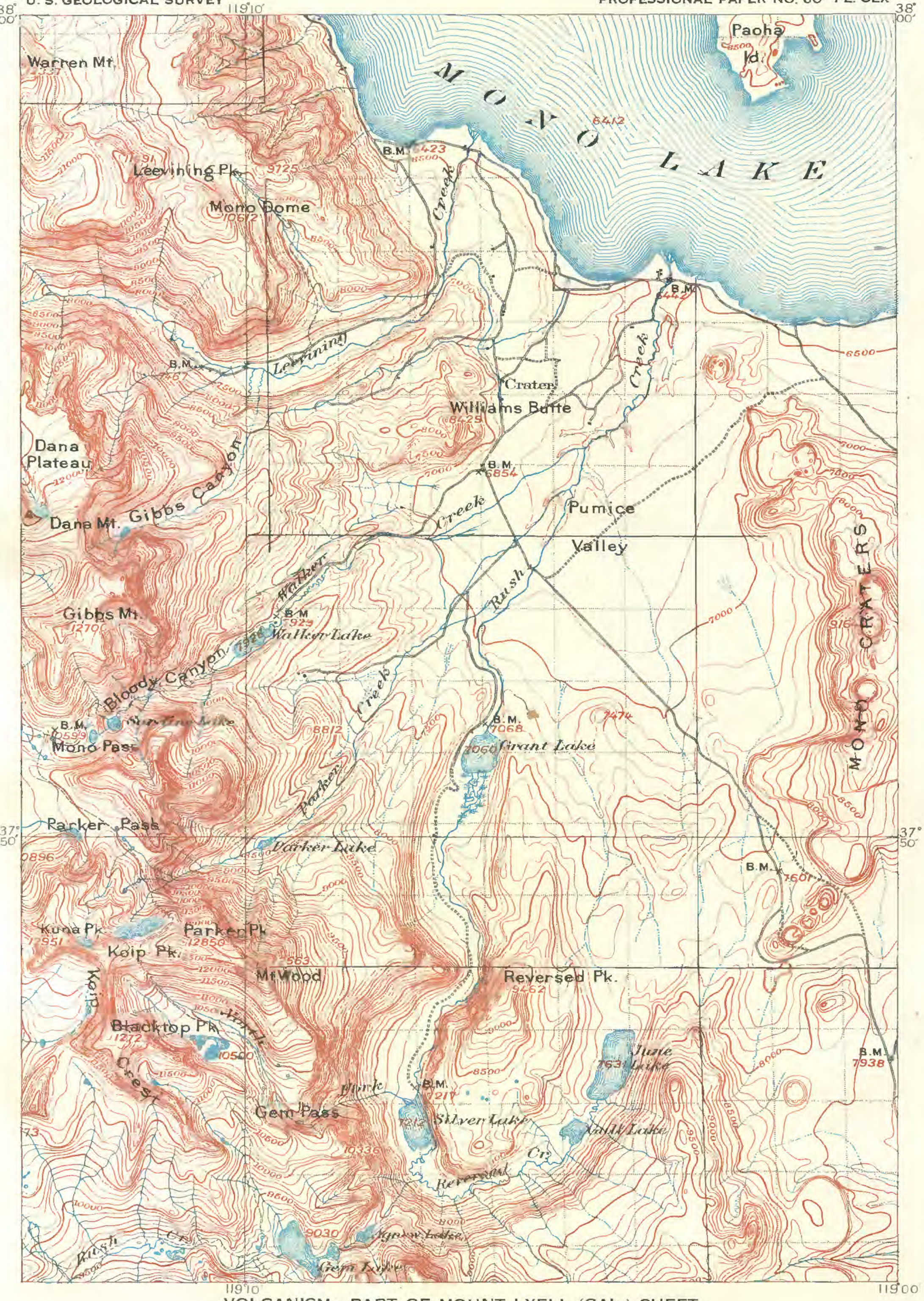

VOLCANISM: PART OF MOUNT LYELL (CAL.) SHEET

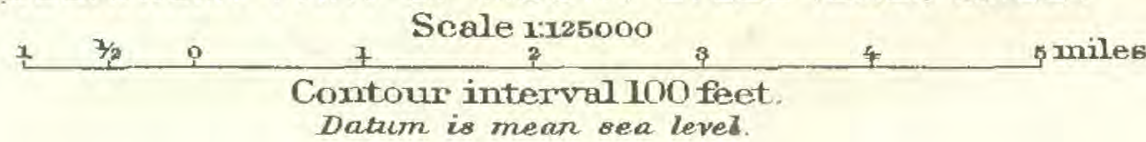




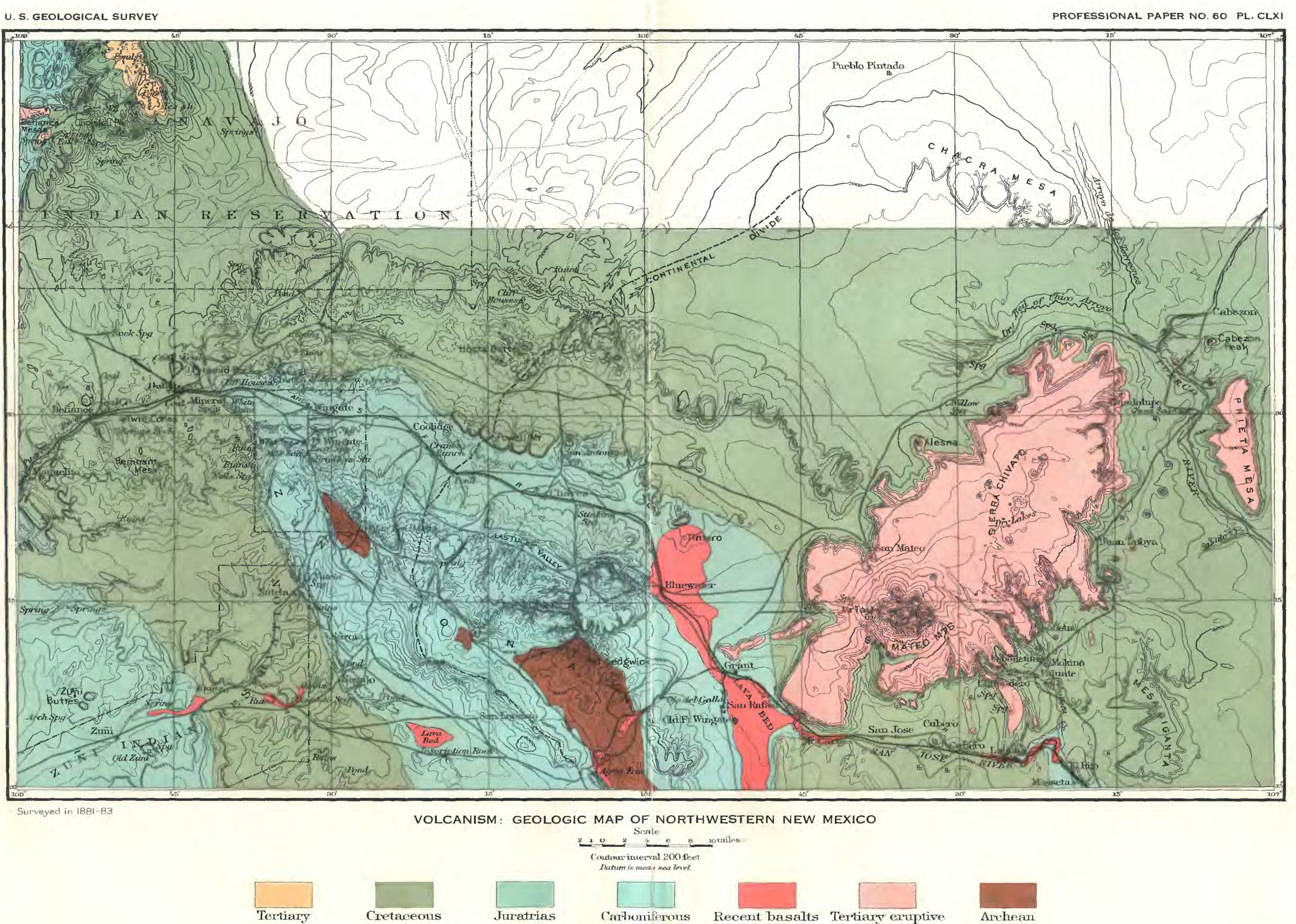




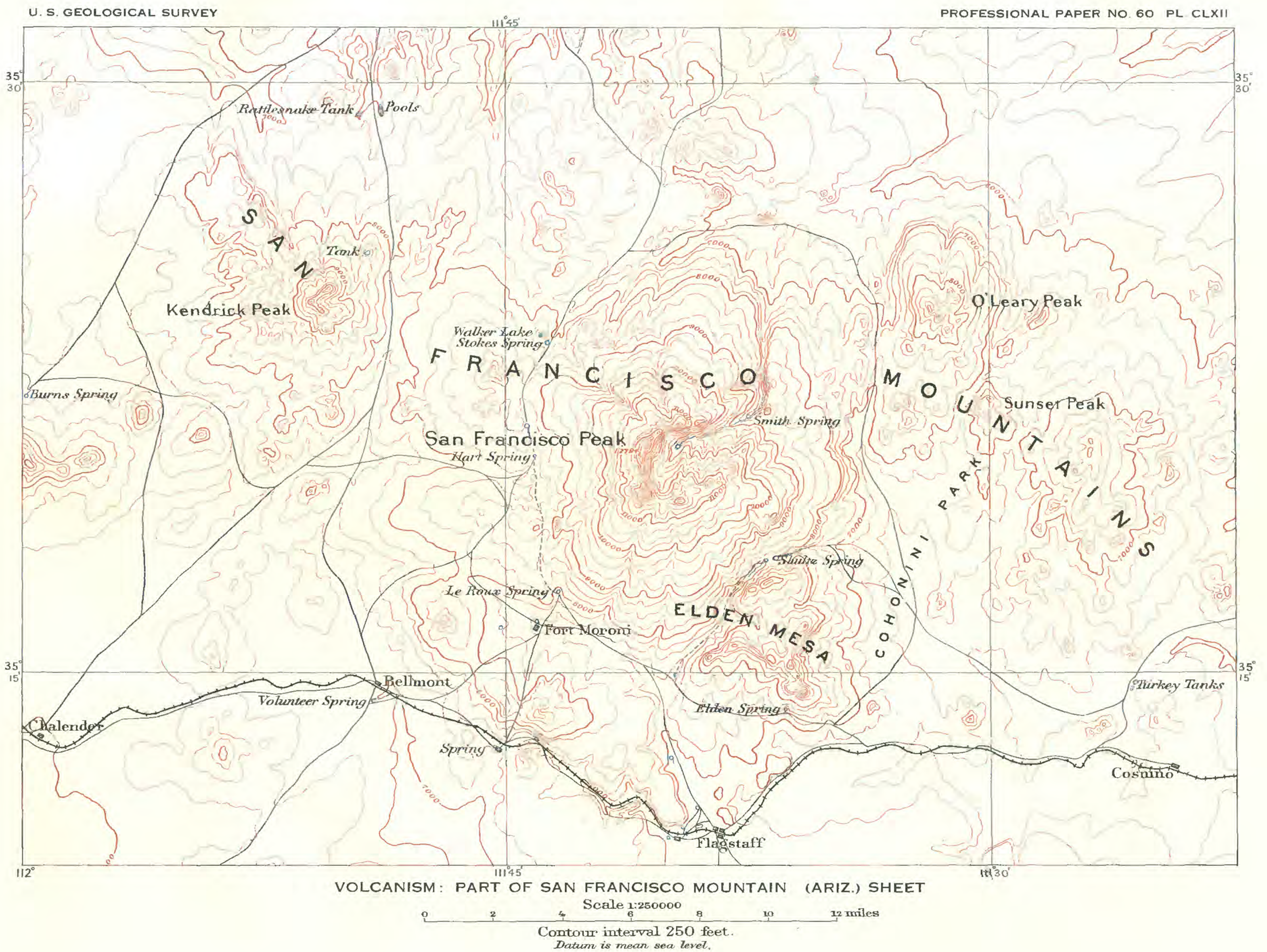



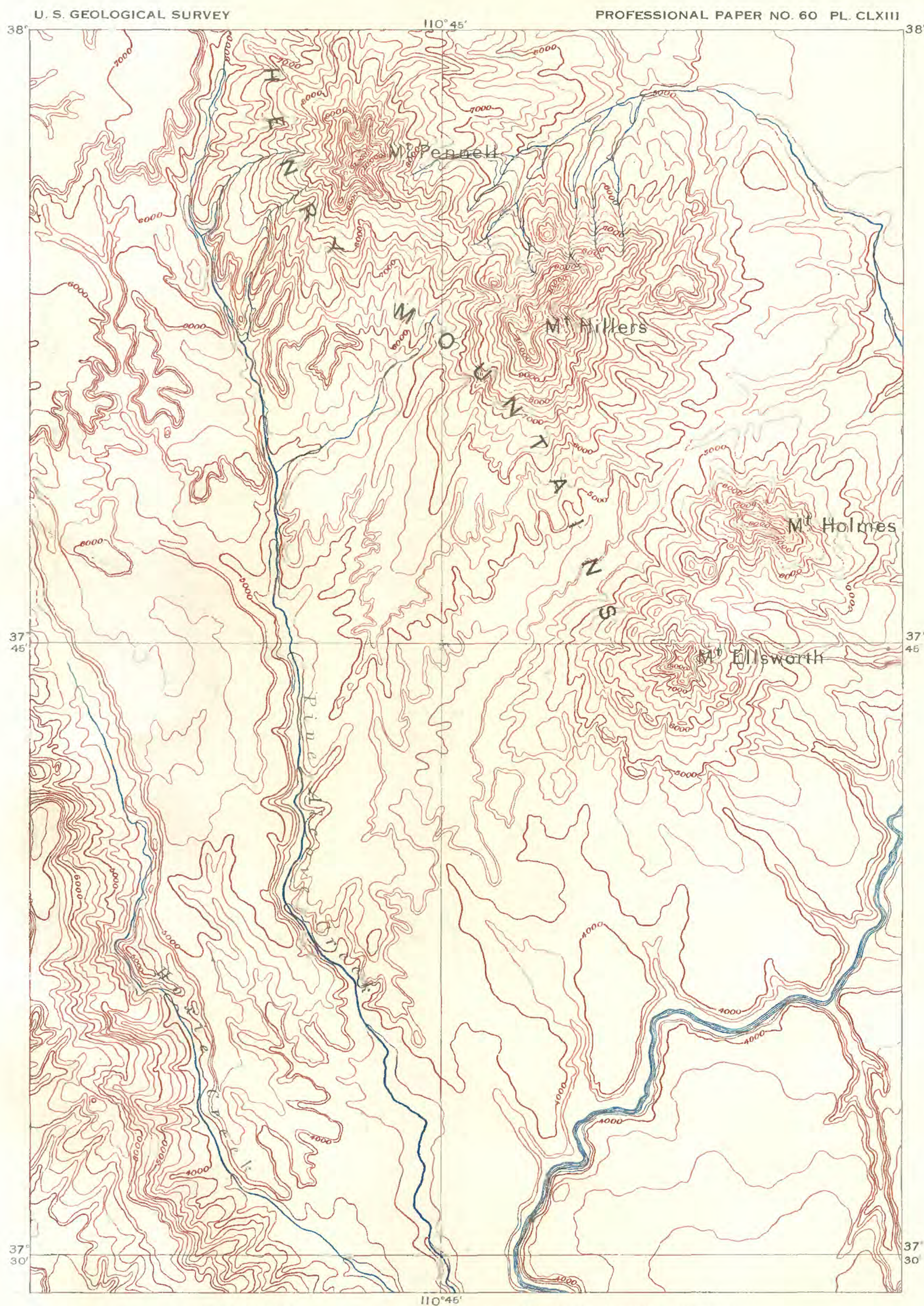

VOLCANISM: PART OF HENRY MOUNTAINS (UTAH) SHEET

i. 2 


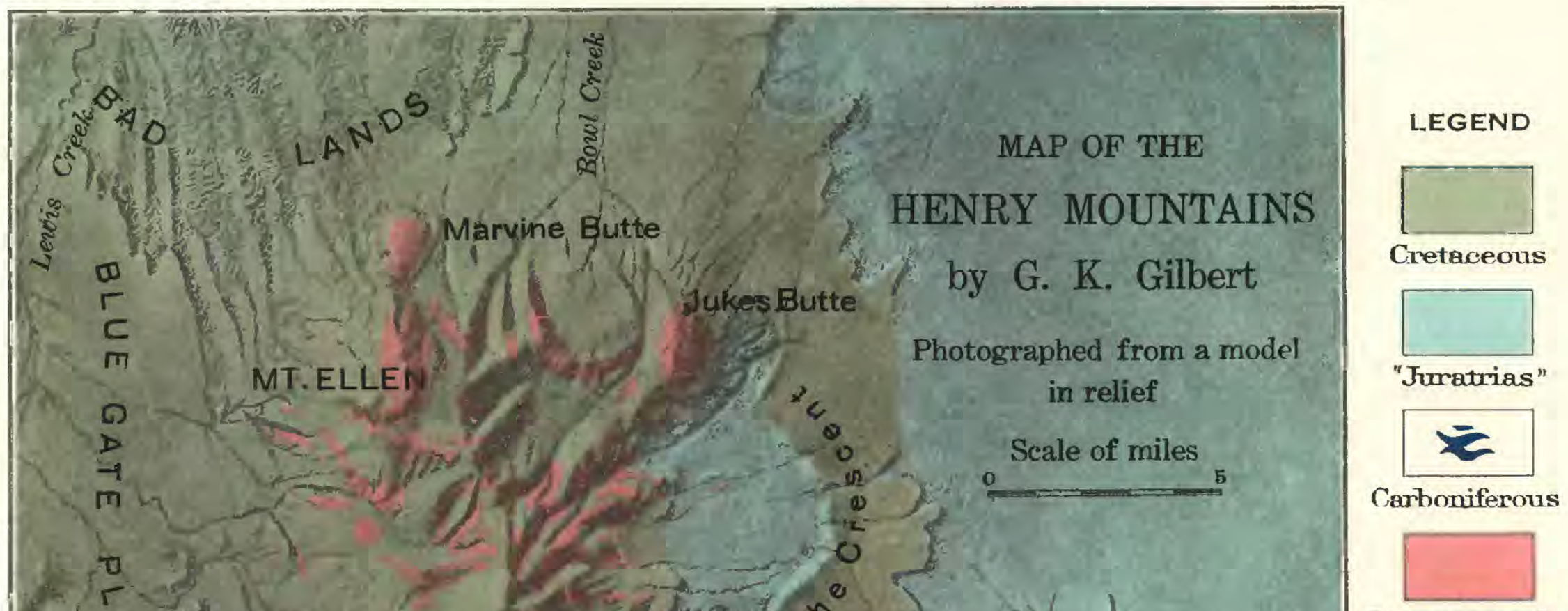

Igneous racks

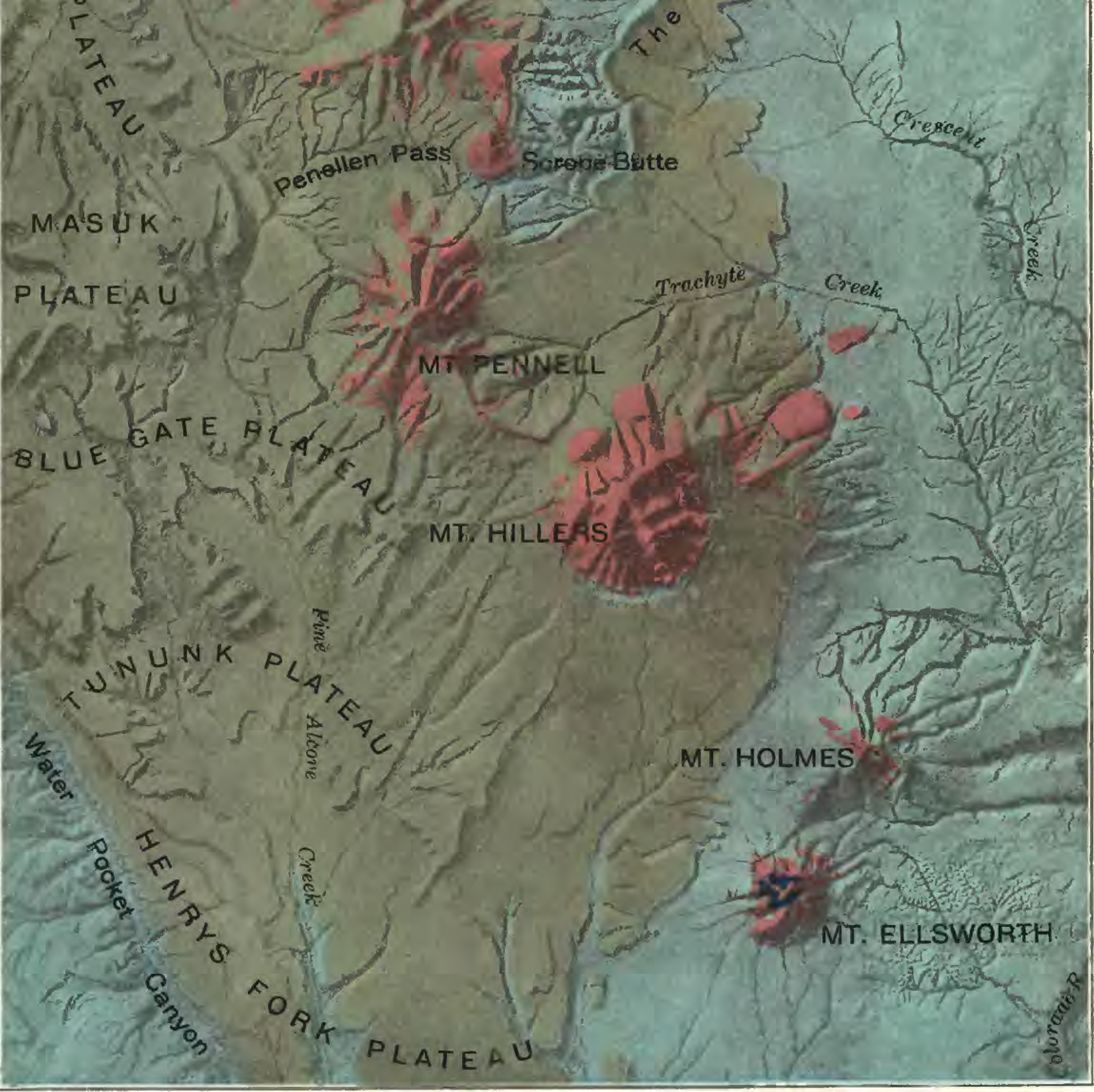

VOLCANISM : VIEW OF MODEL OF THE HENRY MOUNTAINS, UTAH

FROM "GEOLOGY OF THE HENRY MOUNTAINS" gY G. K. GILgert 


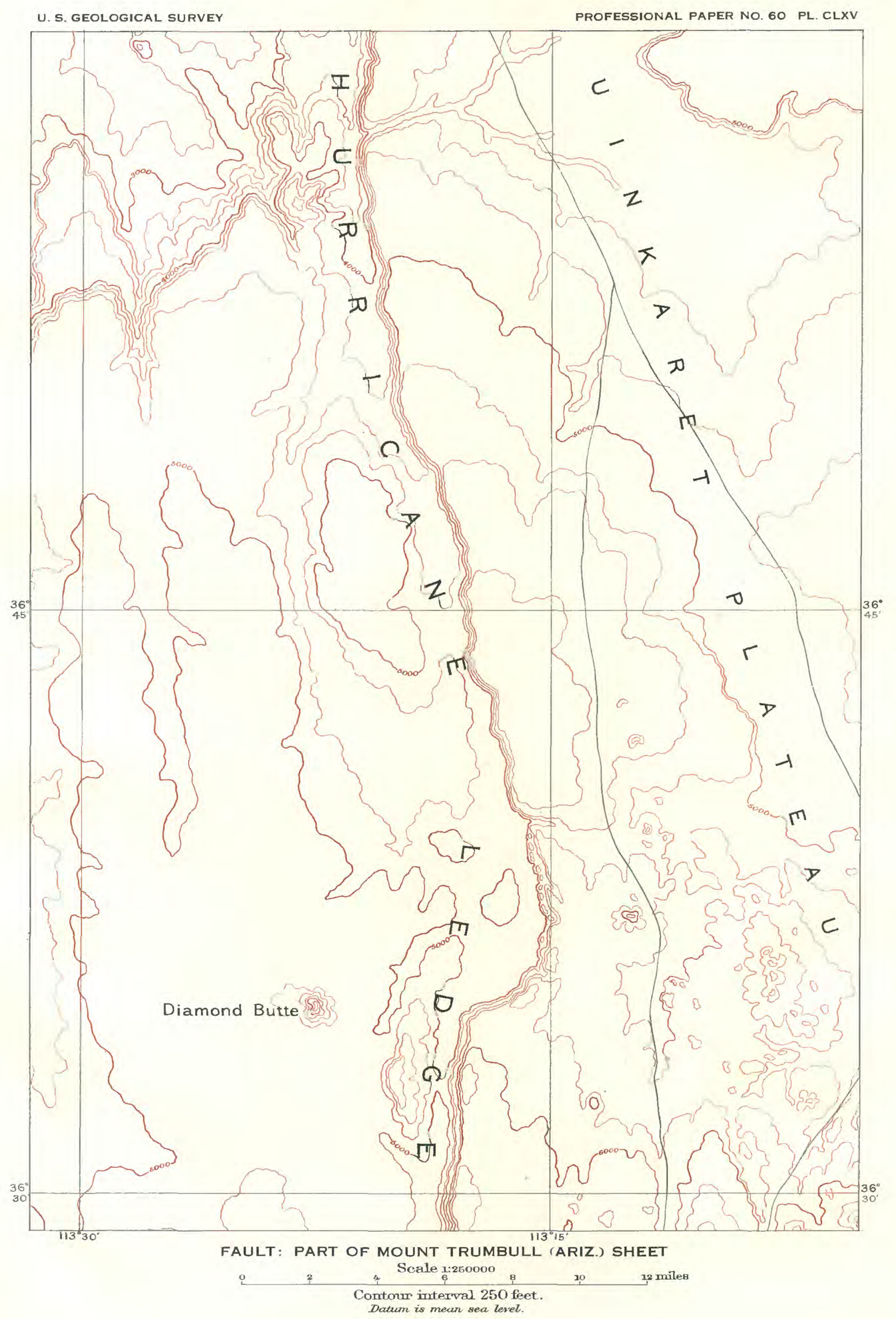




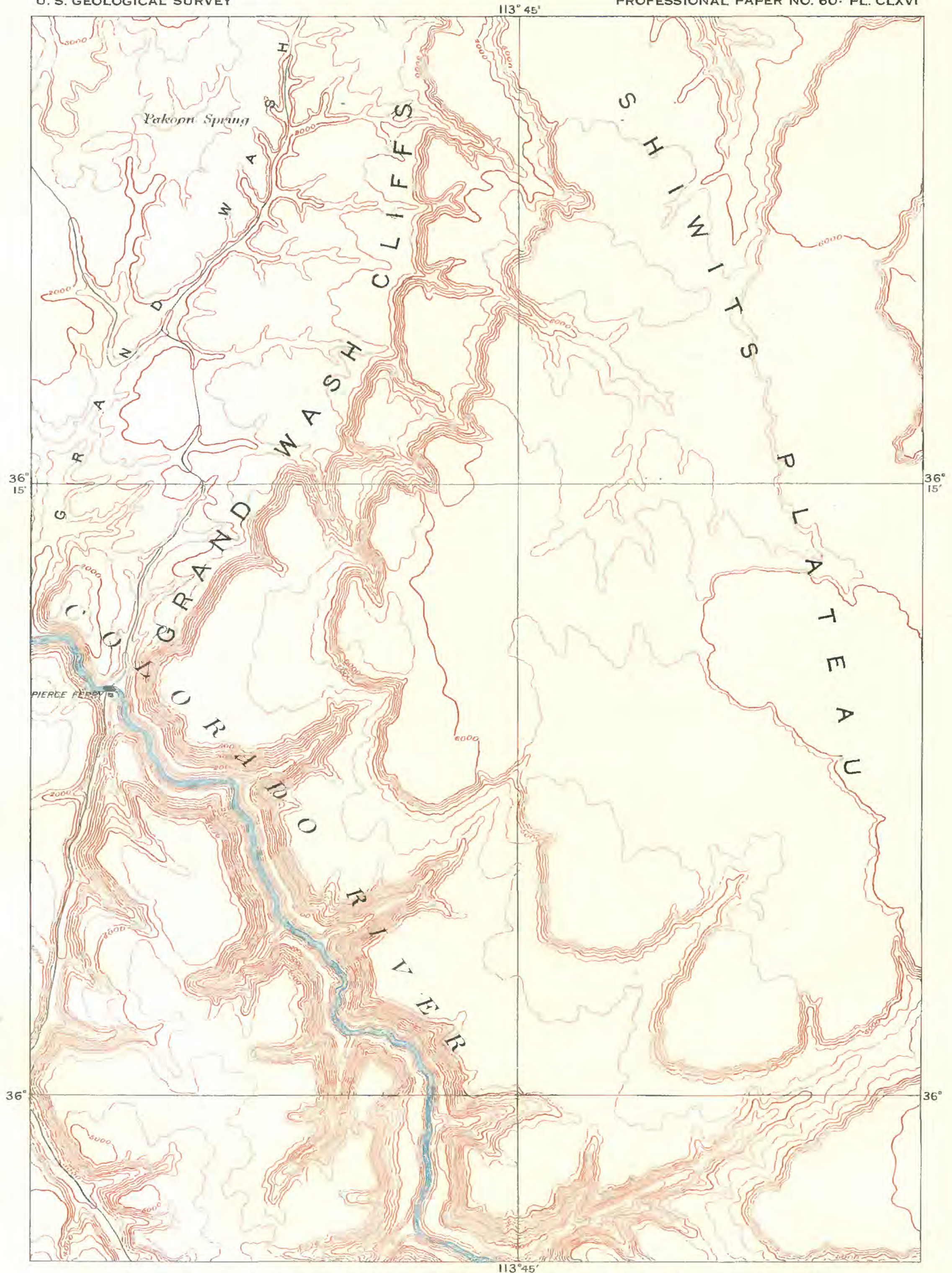

FAULT: PARTS OF MOUNT TRUMBULL AND DIAMOND CREEK (ARIZ.) SHEETS

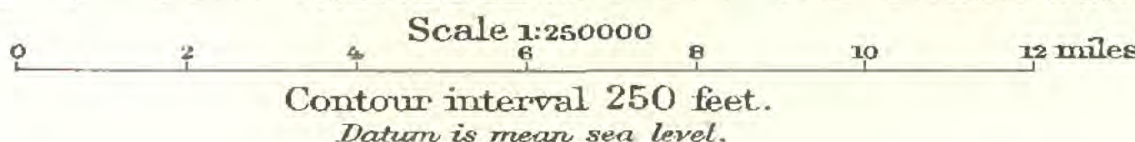




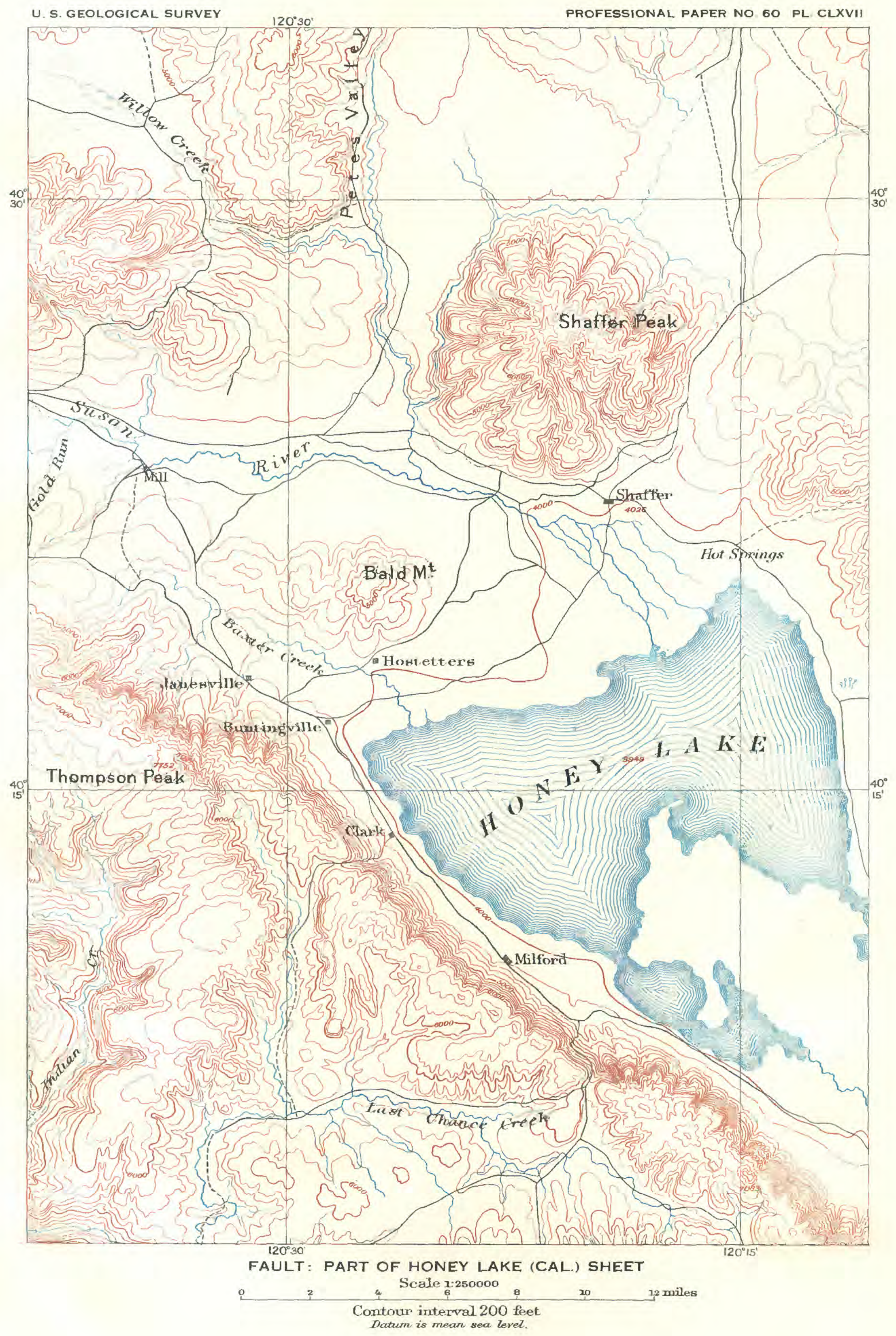




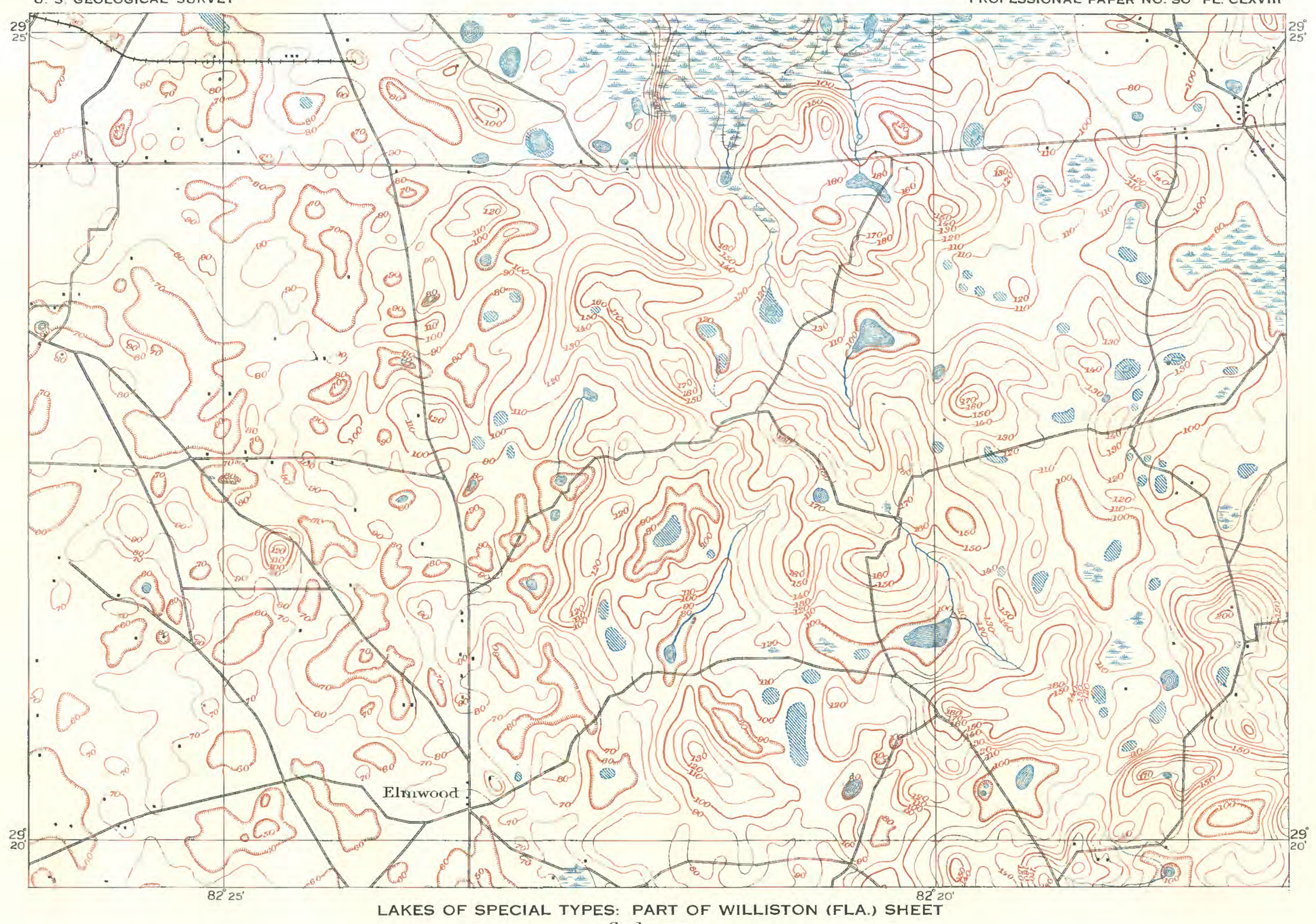
LAKES OF SPECIAL TYPES: PART OF WILLISTON (FLA.) SHEET 


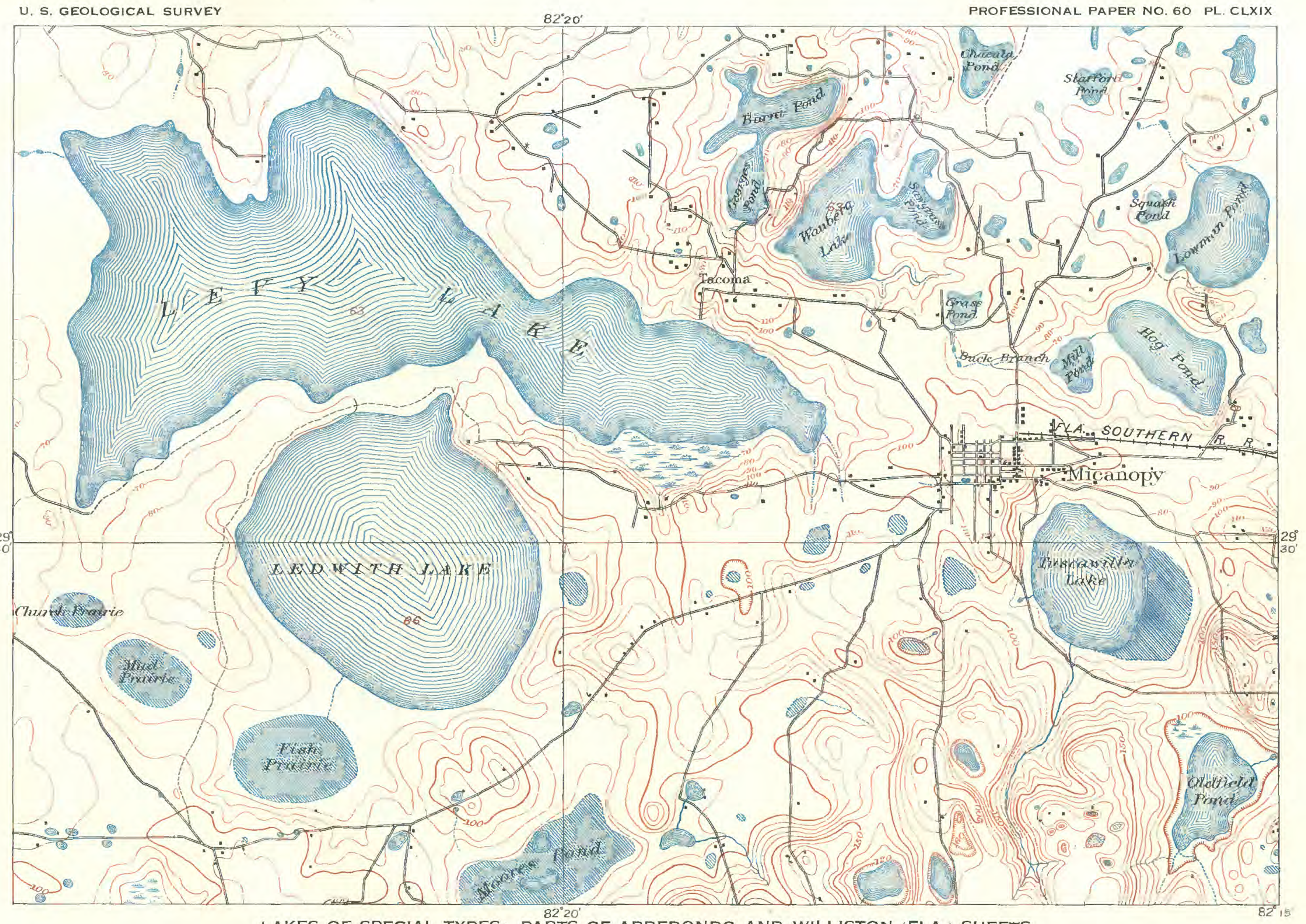

LAKES OF SPECIAL TYPES: PARTS OF ARREDONDO AND WILLISTON (FLA.) SHEETS 


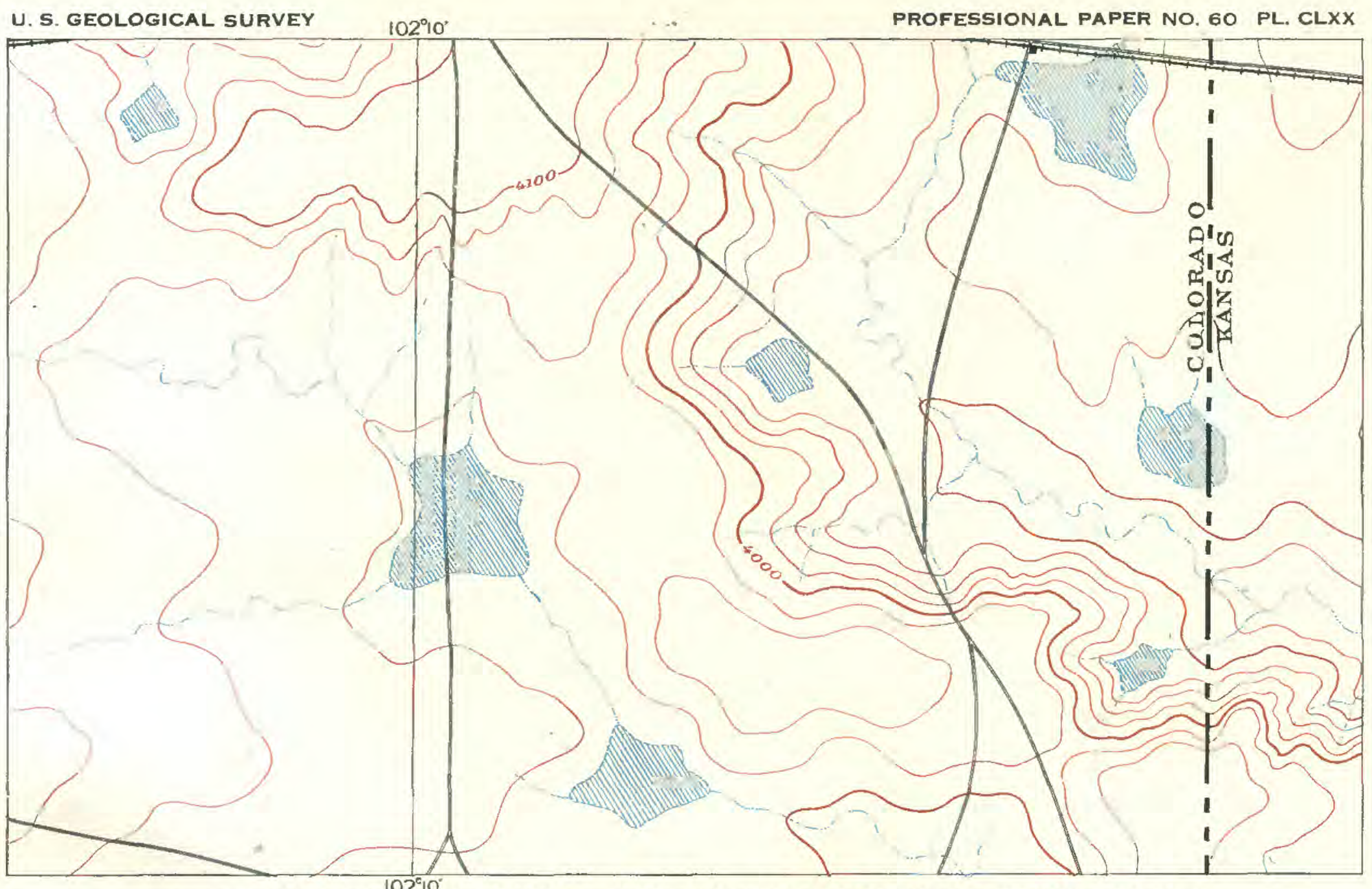

A. SPECIAL TYPES OF LAKES: PART OF GRANADA (COLO.-KANS.) SHEET

Serle 125000

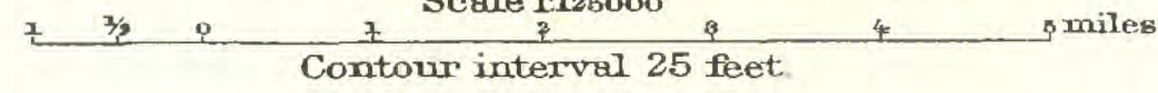

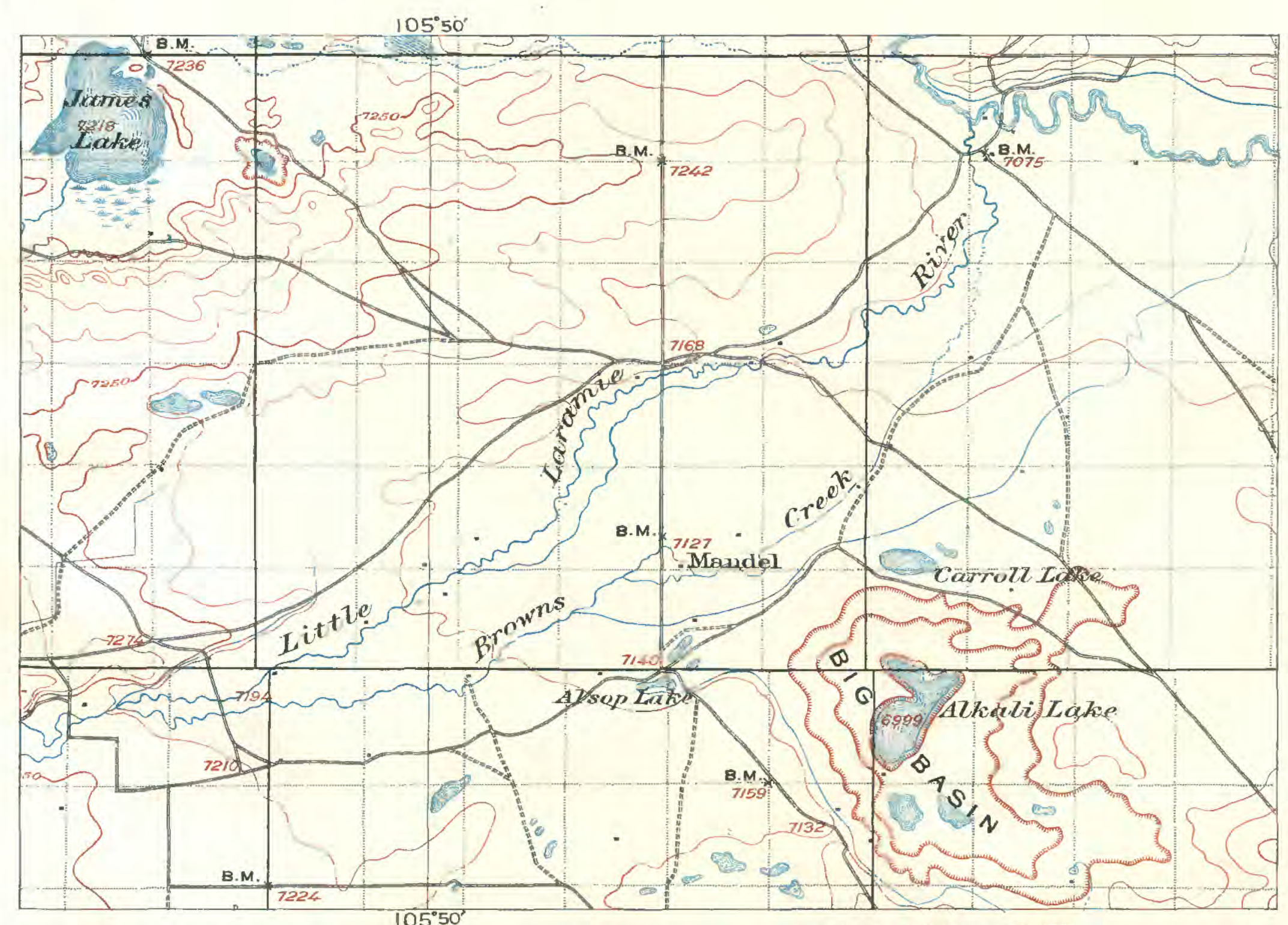

B. SPECIAL TYPES OF LAKES: PART OF LARAMIE (WYO.) SHEET

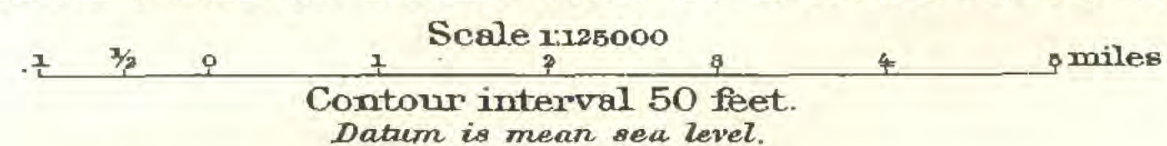

